\title{
Calculating air exchange rates from broiler
}

\section{livestock houses}

\author{
Dissertation \\ zur Erlangung des Doktorgrades \\ der Fakultät für Agrarwissenschaften \\ der Georg-August-Universität Göttingen
}

\author{
vorgelegt von \\ Luke Charles Formosa \\ geboren in Sydney/Australien
}

Göttingen, im Juli 2005 
1. Referentin/Referent: Prof. Dr. Herman Van den Weghe.

2. Korreferentin/Korreferent: Prof. Dr. Jörg Hartung....................

Tag der mündlichen Prüfung: 06. 07. 2005 


\section{ACKNOWLEDGEMENTS}

I would like to thank my supervisors Prof. Dr. Jörg Hartung and Prof. Dr. Herman Van den Weghe for help, encouragement and support to make this study possible during the last 3,5 years. I would also like to thank Dr. Jens Seedorf and Jochen Schulz both for their support and assistance, throughout the years.

I would also like to extend my gratitude to the Institut für Tierhygiene, Tierschütz und Nutztierethologie, Tierärtzliche Hochschule Hannover, Fakultät für Agrarwissenschaften Georg-August-Universität, Zentrum für Veredelungswirtschaft Weser-Ems and the Saxonomy government for financial support which has made this project possible. Furthermore, my collegues, and Bianca who kindly helped me get to the printers on time. Last but not least, my family on the other side of the world for their moral support. 


\section{CONTENTS}

ABREVIATIONS AND DEFINITIONS .......................................................................................... IX

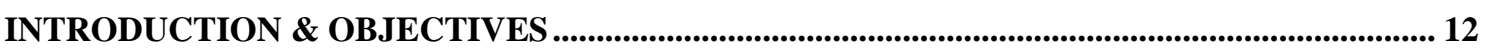

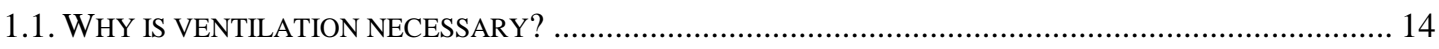

1.2. DISCUSSION OF UNITS TO EXPRESS AIR VOLUME DISCHARGES FROM LIVESTOCK BUILDINGS .......... 15

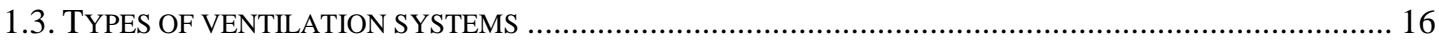

1.4. OUTLINE OF METHODS FOR MEASURING AIR VOLUME FLOWS ............................................... 18

1.5. VIOLATIONS OF COMPLETE AIR MIXING IN LIVESTOCK HOUSES ................................................ 19

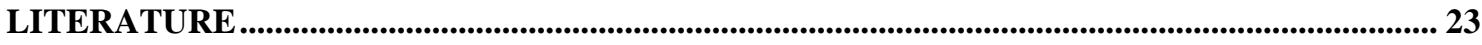

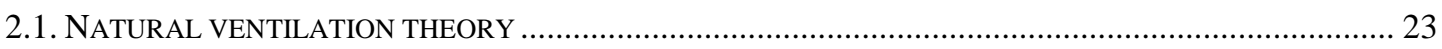

2.2. MASS BALANCE MODELS - NATURAL TRACER GASES ............................................................ 25

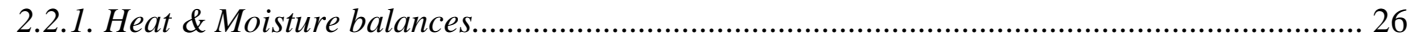

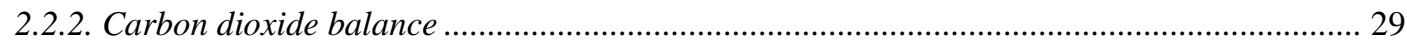

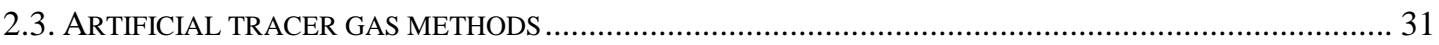

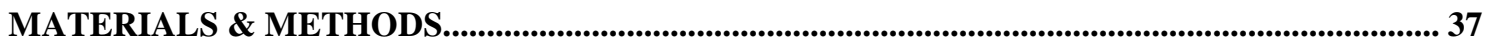

3.1. EXPERIMENTAL SITE 1 - NATURALLY VENTILATED BROILER HOUSE........................................ 37

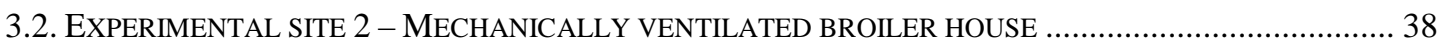

3.3. MASS BALANCE MODELS - NATURAL TRACER GASES .............................................................. 39

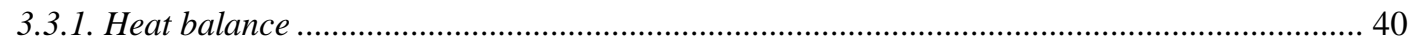

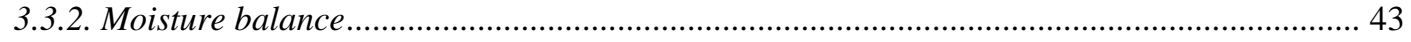

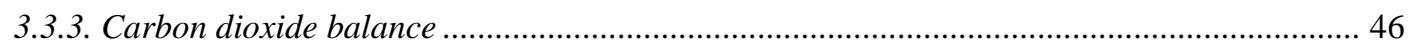

3.4. EXPERIMENT 1: MASS BALANCE MODELS TESTED IN LIVESTOCK HOUSE 1..................................... 48

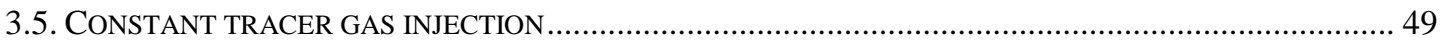

3.6. EXPERIMENT 2: NATURALLY VENTILATED BROILER HOUSE ..................................................... 50

3.7. EXPERIMENT 3: MECHANICALLY VENTILATED BROILER HOUSE .................................................. 54

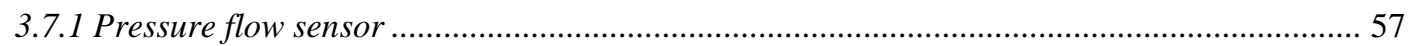

3.7.2 True air exchange rate measurement method ................................................................. 59

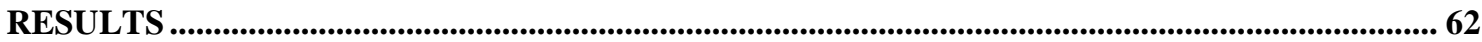

4.1. EXPERIMENT 1: $\mathrm{CO}_{2}$, HEAT AND MOISTURE MASS BALANCE RESULTS FROM LIVESTOCK HOUSE 1 .. 62 4.2. EXPERIMENT 2: HEAT AND MOISTURE MASS BALANCE RESULTS ................................................ 70

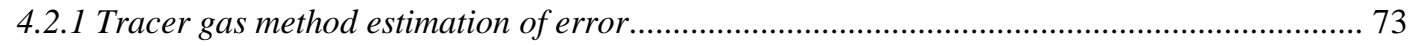

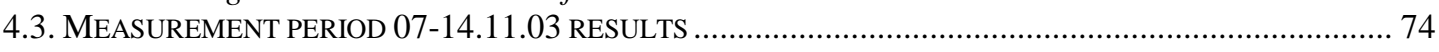

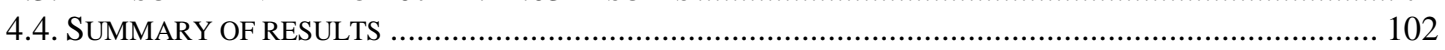

4.5. EXPERIMENT 3: MASS BALANCE MODELS (HEAT, MOISTURE \& $\mathrm{CO}_{2}$ ), TRACER GAS .................... 104

4.6. MASS BALANCE MODEL AND TRACER GAS MEASUREMENT RESULTS 14.07 .04 AND 28.07.04 ....... 106

4.7. MASS BALANCE MODEL, TRACER GAS AND EXTRAPOLATED TRUE AER MEASUREMENT .............. 117

4.8. PRESSURE FLOW SENSOR AERS AND MASS BALANCE MODEL RESULTS $08.09 .04 \& 14.09 .04 \ldots \ldots . .130$

4.9. COMPARISON OF TRUE AERS WITH MASS BALANCE MODELS .................................................... 139

DISCUSSION

5.1. DISCUSSION \& CONCLUSION OF EXPERIMENT 1 RESULTS ........................................................ 142

5.2. DISCUSSION \& CONCLUSION OF EXPERIMENT 2 RESULTS ....................................................... 145

5.3. DISCUSSION \& CONCLUSION OF EXPERIMENT 3 RESULTS ................................................... 155

GENERAL CONCLUSIONS AND FURTHER RESEARCH ....................................................... 165

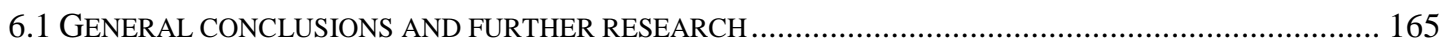

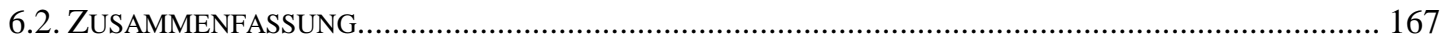

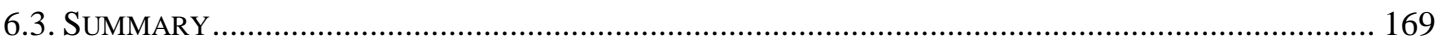

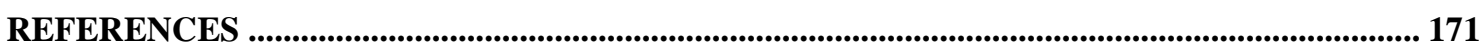




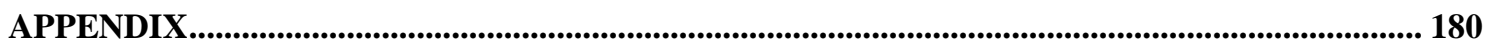

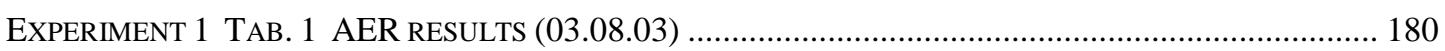

EXPERIMENT 1 TAB.2 CO CO $_{2}$ BALANCE RESULTS (3.08.03).......................................................... 181

EXPERIMENT 1 TAB.3 HEAT BALANCE RESULTS (3.08.03) …….................................................... 182

EXPERIMENT 1 TAB.4A MOISTURE BALANCE RESULTS (03.08.03) ..................................................... 183

EXPERIMENT 1 TAB.4B MOISTURE BALANCE RESULTS (03.08.03) ………………………................. 184

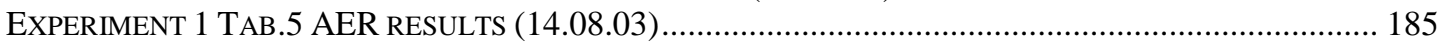

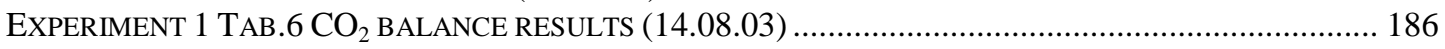

EXPERIMENT 1 TAB.7 HEAT BALANCE RESULTS (14.08.03) ............................................................ 187

EXPERIMENT 1 TAB.8A MOISTURE BALANCE RESULTS (14.08.03) ................................................... 188

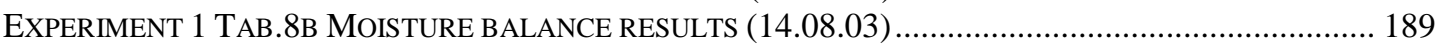

APPENDIX B. EXPERIMENT 2 TAB.1A AER RESULTS (07.11.03) ...................................................... 190

APPENDIX B. EXPERIMENT 2 TAB.1B U-VALUE CALCULATION FOR LIVESTOCK HOUSE 1 ...................... 191

APPENDIX B. EXPERIMENT 2 TAB.1C U-VALUE CALCULATION FOR LIVESTOCK HOUSE 1...................... 192

APPENDIX B. EXPERIMENT 2 TAB.2 TRACER GAS RESULTS (07.11.03) ............................................. 193

APPENDIX B. EXPERIMENT 2 TAB.3 HEAT BALANCE RESULTS (07.11.03) .......................................... 194

APPENDIX B. EXPERIMENT 2 TAB.4A MOISTURE BALANCE RESULTS (07.11.03) ………..................... 195

APPENDIX B. EXPERIMENT 2 TAB.4B MOISTURE BALANCE RESULTS (07.11.03) ………….................. 196

APPENDIX B. EXPERIMENT 2 TAB.5 AER RESULTS (08.11.03) ....................................................... 197

APPENDIX B. EXPERIMENT 2 TAB.6 TRACER GAS RESULTS (08.11.03) ….......................................... 198

APPENDIX B. EXPERIMENT 2 TAB.7 HEAT BALANCE RESULTS (08.11.03) ......................................... 199

APPENDIX B. EXPERIMENT 2 TAB.8A MOISTURE BALANCE RESULTS (08.11.03) ................................. 200

APPENDIX B. EXPERIMENT 2 TAB.8B MOISTURE BALANCE RESULTS (08.11.03) …….......................... 201

APPENDIX B. EXPERIMENT 2 TAB.9 AER RESULTS (09.11.03) ....................................................... 202

APPENDIX B. EXPERIMENT 2 TAB.10 TRACER GAS RESULTS (09.11.03) .............................................. 203

APPENDIX B. EXPERIMENT 2 TAB.11 HEAT BALANCE RESULTS (09.11.03) ...................................... 204

APPENDIX B. EXPERIMENT 2 TAB.12A MOISTURE BALANCE RESULTS (09.11.03) ................................ 205

APPENDIX B. EXPERIMENT 2 TAB.12B MOISTURE BALANCE RESULTS (09.11.03) ................................ 206

APPENDIX B. EXPERIMENT 2 TAB.13 AER RESULTS (12.11.03) ....................................................... 207

APPENDIX B. EXPERIMENT 2 TAB.14 TRACER GAS RESULTS (12.11.03) ........................................... 208

APPENDIX B. EXPERIMENT 2 TAB.15 HEAT BALANCE RESULTS (12.11.03) ...................................... 209

APPENDIX B. EXPERIMENT 2 TAB.16A MOISTURE BALANCE RESULTS (12.11.03) ............................... 210

APPENDIX B. EXPERIMENT 2 TAB.16B MOISTURE BALANCE RESULTS (12.11.03) ............................... 211

APPENDIX B. EXPERIMENT 2 TAB.17 AER RESULTS (13.11.03) ………...................................... 212

APPENDIX B. EXPERIMENT 2 TAB.18 TRACER GAS RESULTS (13.11.03) ............................................ 213

APPENDIX B. EXPERIMENT 2 TAB.19 HEAT BALANCE RESULTS (13.11.03) ......................................... 214

APPENDIX B. EXPERIMENT 2 TAB.20A MOISTURE BALANCE RESULTS (13.11.03) ............................... 215

APPENDIX B. EXPERIMENT 2 TAB.20B MOISTURE BALANCE RESULTS (13.11.03) ………................... 216

APPENDIX C. EXPERIMENT 3 TAB. 1A AER RESULTS (14.07.04) …………………………............. 217

APPENDIX C. EXPERIMENT 3 TAB. 1B U-VALUE CALCULATION FOR LIVESTOCK HOUSE 2 …................. 218

APPENDIX C. EXPERIMENT 3 TAB. 1C U-VALUE CALCULATION FOR LIVESTOCK HOUSE 2 …................ 219

APPENDIX C. EXPERIMENT 3 TAB. 2 TRACER CALCULATION RESULTS (14.07.04) ………................... 220

APPENDIX C. EXPERIMENT 3 TAB. $3 \mathrm{CO}_{2}$ BALANCE RESULTS (14.07.04) .......................................... 221

APPENDIX C. EXPERIMENT 3 TAB. 4 HEAT BALANCE RESULTS (14.07.04)......................................... 222

APPENDIX C. EXPERIMENT 3 TAB. 5A MOISTURE BALANCE RESUlTS (14.07.04) ................................ 223

APPENDIX C. EXPERIMENT 3 TAB. 5B MOISTURE BALANCE RESULTS (14.07.04)................................. 224

APPENDIX C. EXPERIMENT 3 TAB. 6 AER RESULTS (28.07.04) ………………………….............. 225

APPENDIX C. EXPERIMENT 3 TAB. 7 TRACER GAS RESULTS (28.07.04) ........................................... 226

APPENDIX C. EXPERIMENT 3 TAB. $8 \mathrm{CO}_{2}$ MASS BALANCE RESULTS (28.07.04) ………….................. 227

APPENDIX C. EXPERIMENT 3 TAB. 9 HEAT BALANCE RESULTS (28.07.04)........................................ 228

APPENDIX C. EXPERIMENT 3 TAB. 10A MOISTURE BALANCE RESULTS (28.07.04) .............................. 229

APPENDIX C. EXPERIMENT 3 TAB. 10B MOISTURE BALANCE RESULTS (28.07.04).............................. 230

APPENDIX C. EXPERIMENT 3 TAB. 11 AER RESULTS (18.08.04)..................................................... 231

APPENDIX C. EXPERIMENT 3 TAB. 12 TRACER GAS RESULTS (18.08.04) ………................................. 232

APPENDIX C. EXPERIMENT 3 TAB. $13 \mathrm{CO}_{2}$ BALANCE RESULTS (18.08.04) ....................................... 233

APPENDIX C. EXPERIMENT 3 TAB. 14 HEAT BALANCE RESUlTS (18.08.04).......................................... 234

APPENDIX C. EXPERIMENT 3 TAB. 15A MOISTURE BALANCE RESULTS (18.08.04) ………................... 235

APPENDIX C. EXPERIMENT 3 TAB. 15B MoISTURE BALANCE RESULTS (18.08.04)............................... 236

APPENDIX C. EXPERIMENT 3 TAB. 16 AER RESULTS (25.08.04)................................................... 237

APPENDIX C. EXPERIMENT 3 TAB. 17 TRACER GAS RESULTS (25.08.04) ………................................. 238

APPENDIX C. EXPERIMENT 3 TAB. 18 CO $_{2}$ BALANCE RESULTS (25.08.04) ......................................... 239 
APPENDIX C. EXPERIMENT 3 TAB. 19 HEAT BALANCE RESULTS (25.08.04)...................................2 240

APPENDIX C. EXPERIMENT 3 TAB. 20A MOISTURE BALANCE RESULTS (25.08.04) .......................... 241

APPENDIX C. EXPERIMENT 3 TAB. 20B MOISTURE BALANCE RESULTS (25.08.04)............................ 242

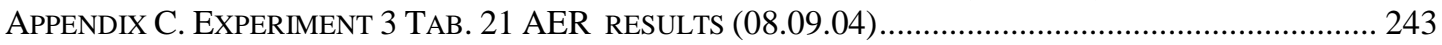

APPENDIX C. EXPERIMENT 3 TAB. $22 \mathrm{CO}_{2}$ MASS BALANCE RESULTS $(08.09 .04)$............................. 244

APPENDIX C. EXPERIMENT 3 TAB. 23 HEAT BALANCE RESULTS (08.09.04)...................................... 245

APPENDIX C. EXPERIMENT 3 TAB. 24A MOISTURE BALANCE RESULTS (08.09.04) ............................ 246

APPENDIX C. EXPERIMENT 3 TAB. 24B MOISTURE BALANCE RESULTS (08.09.04)........................... 247

APPENDIX C. EXPERIMENT 3 TAB. 25 AER RESULTS (14.09.04) ................................................ 248

APPENDIX C. EXPERIMENT 3 TAB. 26 CO CO $_{2}$ BALANCE RESULTS (14.09.04) ......................................... 249

APPENDIX C. EXPERIMENT 3 TAB. 27 HEAT BALANCE RESULTS (14.09.04)...................................... 250

APPENDIX C. EXPERIMENT 3 TAB. 28A MOISTURE BALANCE RESULTS $(14.09 .04)$........................... 251

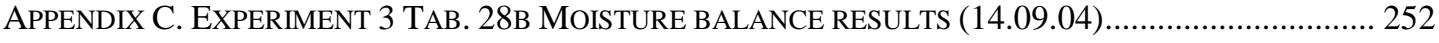




\section{FIGURES}

\section{Chapter 3}

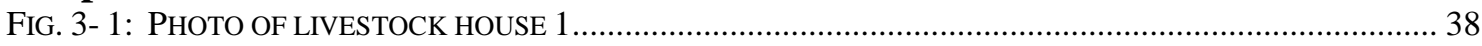

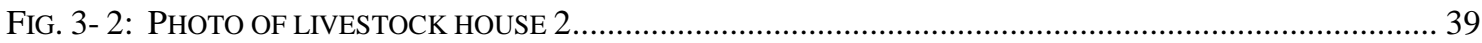

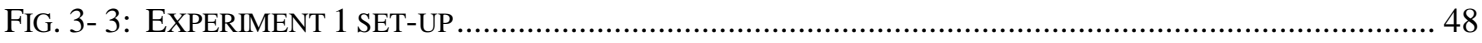

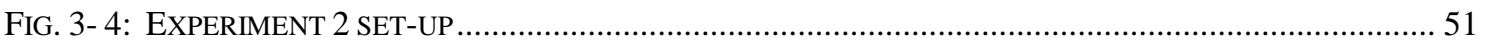

FIG. 3- 5: SMOKE TEST DISPLAYS AIR MIXING WITHIN THE BROILER HOUSE AND AIR MIXING.................... 52

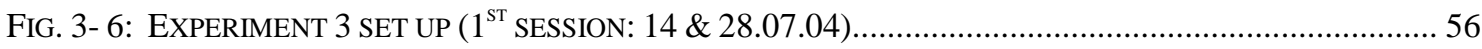

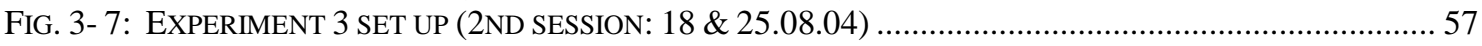

FIG. 3- 8: PRESSURE FLOW SENSOR AND FAN WHEEL ANEMOMETER CHECK CURVE ...................................5

FIG. 3- 9: EXHAUST FAN WITH FLOW RECTIFIER AND PRESSURE FLOW SENSOR .................................... 59

\section{CHAPTER 4}

FIG. 4- 1: HOURLY MASS BALANCE AER RESUlTS AND INFLUENCING WEATHER VARIABLES (03.08.03) ...64

FIG. 4- 2: HOURLY MASS BALANCE AER RESULTS AND INFLUENCING WEATHER VARIABLES (14.08.03) ... 68

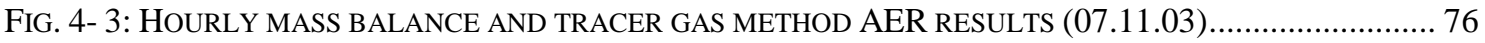

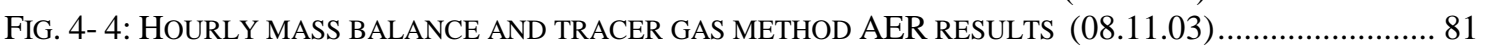

FIG. 4- 5: HOURLY MASS BALANCE AND TRACER GAS METHOD AER RESULTS (09.11.03).......................8 87

FIG. 4- 6: HOURLY MASS BALANCE AND TRACER GAS METHOD AER RESULTS (12.11.03)...................... 92

FIG. 4- 7: HOURLY MASS BALANCE AND TRACER GAS METHOD AER RESULTS (13.11.03) ...................... 98

FIG. 4- 8: DAILY AER VS MEDIAN WIND SPEEDS \& OUTSIDE TEMPERATURES IN EXPERIMENT 2 ............... 102

FIG. 4- 9: MEDIAN DAILY TRACER GAS \& MASS BALANCE MODEL AERS VS WIND SPEED IN EXPERIMENT 2

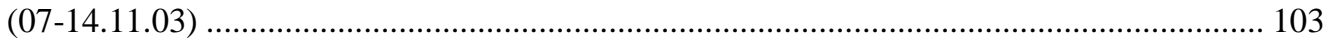

FIG. 4- 10: HOURLY TRACER GAS METHOD AND MASS BALANCE AER RESULTS ALONG WITH OUTSIDE

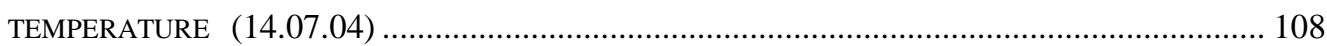

FIG. 4- 11: HOURLY TRACER GAS METHOD RESULTS (14.07.04) …...................................................... 108

FIG. 4- 12: HOURLY TRACER GAS METHOD AND MASS BALANCE AER RESULTS ALONG WITH OUTSIDE

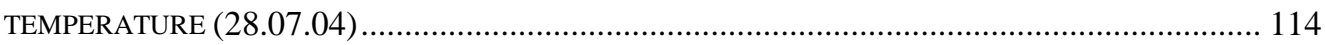

FIG. 4- 13: HOURLY TRACER GAS METHOD AER RESULTS (28.07.04) ................................................ 114

FIG. 4- 14: HOURLY PRESSURE FLOW SENSOR, TRACER GAS METHOD, MASS BALANCE AER RESULTS AND OUTSIDE TEMPERATURES (18.08.04) ...................................................................... 119

FIG. 4- 15: HOURLY PRESSURE FLOW SENSOR AND TRACER GAS METHOD AER RESULTS (18.08.04)........ 119

FIG. 4- 16: HOURLY PRESSURE FLOW SENSOR, TRACER GAS METHOD, MASS BALANCE AER RESULTS AND

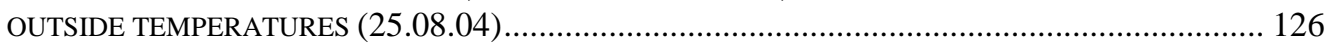

FIG. 4- 17: HOURLY PRESSURE FLOW SENSOR AND TRACER GAS METHOD RESULTS (25.08.04) ............... 127

FIG. 4- 18: HOURLY PRESSURE FLOW SENSOR, MASS BALANCE AER RESULTS AND OUTSIDE TEMPERATURES (08.09.04)

FIG. 4- 19 HOURLY PRESSURE FLOW SENSOR, MASS BALANCE AER RESULTS AND OUTSIDE TEMPERATURES (14.09.04) 


\section{TABLES}

\section{CHAPTER 3}

TAB. 3- 1 LIVESTOCK HOUSE 2 VENTILATION SYSTEM INFORMATION

\section{CHAPTER 4}

TAB. 4- 1 SUMMARISED MASS BALANCE RESULTS AND WEATHER CONDITIONS (03.08.03).......

TAB. 4- 2 SUMMARISED MASS BALANCE RESULTS AND WEATHER CONDITIONS (14.08.03) ......................67

TAB. 4- 3 SUMMARISED AER RESULTS AND WEATHER CONDITIONS $(07.11 .03)$............................... 74

TAB. 4- 4 TRACER GAS METHOD AND INFLUENCING VARIABLE CORRELATION TABLE $(07.11 .03) \ldots \ldots \ldots \ldots . . . .77$

TAB. 4- 5 DAY/NIGHT AND 24H AVERAGE RESULT COMPARISONS WITH TRACER GAS METHOD RESULTS

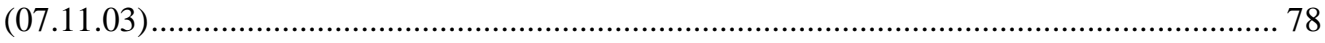

TAB. 4- 6 SUMMARISED AER RESULTS AND WEATHER CONDITIONS $(08.11 .03)$................................... 79

TAB. 4- 7 TRACER GAS METHOD AND INFLUENCING VARIABLE CORRELATION TABLE $(08.11 .03)$...............8. 82

TAB. 4- 8 DAY/NIGHT AND 24H AVERAGE RESULT COMPARISONS WITH TRACER GAS METHOD RESULTS (08.11.03).

TAB. 4- 9 SUMMARISED AER RESULTS AND WEATHER CONDITIONS (09.11.03) …........................... 85

TAB. 4- 10 TRACER GAS METHOD AND INFLUENCING VARIABLE CORRELATION TABLE $(09.11 .03)$.............8 88

TAB. 4- 11 DAY/NIGHT AND 24H AVERAGE RESULT COMPARISONS WITH TRACER GAS METHOD RESULTS

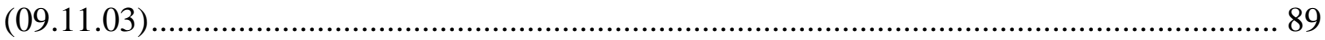

TAB. 4- 12 SUMMARISED AER RESULTS AND WEATHER CONDITIONS (12.11.03) .................................. 90

TAB. 4- 13 TRACER GAS METHOD AND INFLUENCING VARIABLE CORRELATION TABLE $(12.11 .03)$.............94

TAB. 4- 14 DAY/NIGHT AND 24H AVERAGE RESULT COMPARISONS WITH TRACER GAS METHOD RESULTS

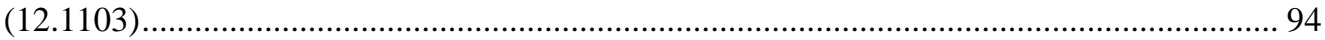

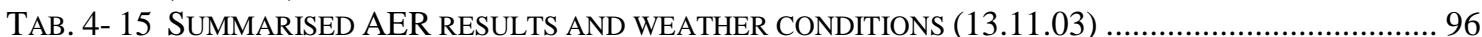

TAB. 4- 16 TRACER GAS METHOD AND INFLUENCING VARIABLE CORRELATION TABLE $(13.11 .03) \ldots \ldots \ldots . . .100$

TAB. 4- 17 DAY/NIGHT AND 24H AVERAGE RESULT COMPARISONS WITH TRACER GAS METHOD RESULTS

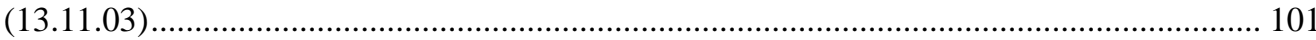

TAB. 4- 18 SUMMARISED AER RESULTS AND WEATHER CONDITIONS (14.07.04) ................................ 106

TAB. 4- 19 TRACER GAS METHOD AND INFLUENCING VARIABLE CORRELATION TABLE $(14.07 .04) \ldots \ldots \ldots . . .110$

TAB. 4- 20 SUMMARISED AER RESULTS AND WEATHER CONDITIONS (28.07.04) .................................. 111

TAB. 4- 21 AVERAGE 24H SF 6 SAMPLE LOCATION (1-6) CONCENTRATIONS ...................................... 112

TAB. 4- 22 TRACER GAS METHOD AND INFLUENCING VARIABLE CORRELATION TABLE (28.07.04) .......... 115

TAB. 4- 23 SUMMARISED AER RESULTS AND WEATHER CONDITIONS $(18.08 .04)$.................................. 117

TAB. 4- 24 TRACER GAS METHOD \& PRESSURE FLOW SENSOR INFLUENCING VARIABLE CORRELATION

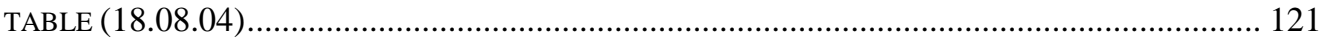

TAB. 4- 25 PRESSURE FLOW SENSOR AER, MBM DAY/NIGHT TIME AND 24H AVERAGES (18.08.04) ...... 122

TAB. 4- 26 SUMMARISED AER RESULTS AND WEATHER CONDITIONS (25.08.04) ................................. 123

TAB. 4- 27 AVERAGE 24H SF 6 SAMPLE LOCATION (1-6) CONCENTRATIONS .......................................... 125

TAB. 4- 28 TRACER GAS METHOD \& PRESSURE FLOW SENSOR AER INFLUENCING VARIABLE CORRELATION

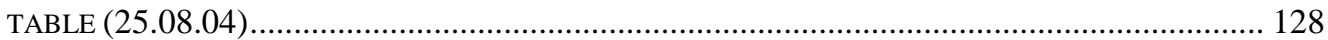

TAB. 4- 29 PRESSURE FLOW SENSOR AER, MBM DAY/NIGHT TIME AND 24H AVERAGES (25.08.04) ...... 129

TAB. 4- 30 SUMMARISED AIR EXCHANGE RATE RESULTS AND WEATHER CONDITIONS (08.09.04)............ 130

TAB. 4- 31 PRESSURE FLOW SENSOR AER AND INFLUENCING VARIABLE CORRELATION TABLE ............... 133

TAB. 4- 32 PRESSURE FlOW SENSOR AER, MBM DAY/NIGHT TIME AND 24H AVERAGES (08.09.04)...... 134

TAB. 4- 33 SUMMARISED AER RESULTS AND WEATHER CONDITIONS (14.09.04) ................................. 135

TAB. 4- 34 PRESSURE FLOW SENSOR AND INFLUENCING VARIABLE CORRELATION TABLE (14.09.04)...... 137

TAB. 4- 35 TRUE AER AND MBM DAY/NIGHT TIME AND 24H AVERAGES (14.09.04) .......................... 138

TAB. 4- 36 ACCURACY \& $\mathrm{R}^{2}$ VALUES BETWEEN ADJUSTED MBMS AND TRUE AERS (18.08.04)............. 139

TAB. 4- 37 ACCURACY \& $\mathrm{R}^{2}$ VALUES BETWEEN ADJUSTED MBMS AND TRUE AERS (25.08.04)............. 140

TAB. 4- 38 ACCURACY \& $\mathrm{R}^{2}$ VALUES BETWEEN ADJUSTED MBMS AND TRUE AERS (08.09.04)............. 140

TAB. 4- 39 ACCURACY \& R ${ }^{2}$ VALUES BETWEEN ADJUSTED MBMS AND TRUE AERS (14.09.04)............. 141 


\section{ABREVIATIONS AND DEFINITIONS}

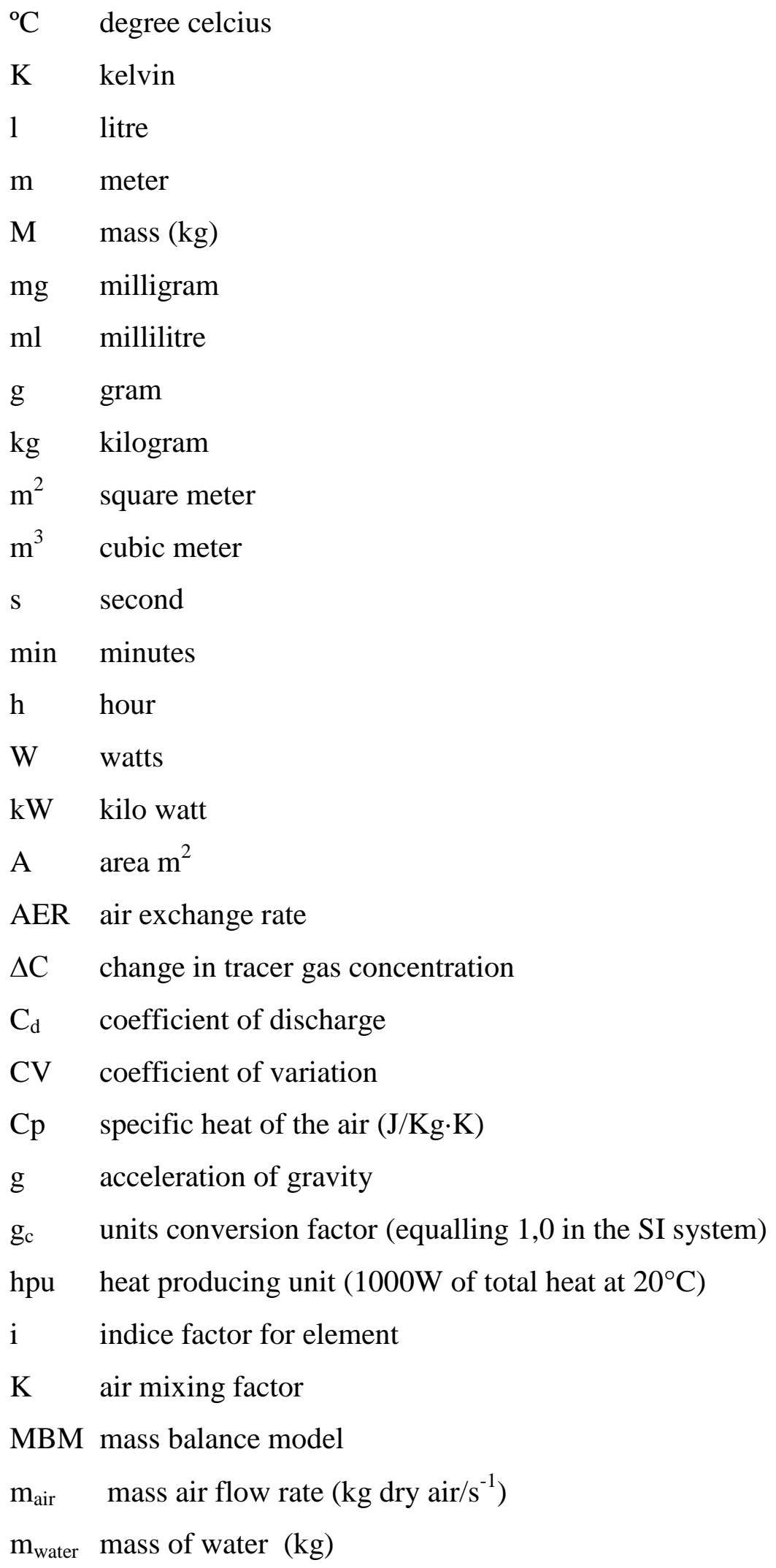


n number

$\mathrm{N} \quad$ air exchange rate $\left(\mathrm{h}^{-1}\right)$

$\Delta \mathrm{p} \quad$ pressure difference $(\mathrm{Pa})$

$\mathrm{P} \quad$ static pressure

$\mathrm{p}_{\mathrm{atm}}$ atmospheric pressure

$\mathrm{p}_{\mathrm{ws}} \quad$ water vapor saturation partial pressure

$\mathrm{p}_{w} \quad$ actual partial pressure of water vapor

Q air flow rate $\left(\mathrm{m}^{3} / \mathrm{s}^{-1}\right)$

$\mathrm{qb}$ sensible heat lost though building (W)

$\mathrm{qb}$ sensible heat loss though building (W)

qv sensible heat loss from Ventilation (W)

qs sensible heat from animals (W)

RQ respiratory quotient

SD standard deviation

$\mathrm{T}$ temperature $(\mathrm{K})$

$\mathrm{T}_{\mathrm{o}} \quad$ outside temperature $(\mathrm{K})$

$\mathrm{T}_{\mathrm{i}} \quad$ inside temperature $(\mathrm{K})$

Tc set point temperature

$\Delta \mathrm{t} \quad$ change in time

$\sigma_{\mathrm{t}=\mathrm{t} 0} \quad$ initial tracer gas content at time $\mathrm{t}=\mathrm{t}_{0}$ (start of injection)

$\sigma_{\mathrm{t}=\mathrm{t} 1} \quad$ tracer gas content at time $\mathrm{t}=\mathrm{t}_{1}$

$\sigma_{\mathrm{t}=\mathrm{t} 2} \quad$ tracer gas content at time $\mathrm{t}=\mathrm{t}_{2}$

$\mathrm{U}$ heat transmission coefficient for surface areas, $\mathrm{W} / \mathrm{m}^{2} \mathrm{~K}$

V velocity

$\mathrm{V}_{\mathrm{I}}$ constant volume flow of injected tracer gas $(1 / \mathrm{min})$

$V_{L} \quad$ supplied volume flow rate $\left(\mathrm{m}^{3} / \mathrm{h}^{-1}\right)$

$\mathrm{V}_{\mathrm{R}} \quad$ is room volume $\left(\mathrm{m}^{3}\right)$

$W \quad$ humidity ratio with stall and outside air (kg water vapor/kg dry air)

$\mathrm{W}_{\mathrm{i}}, \quad$ indoor humidity ratio

$\mathrm{w}_{\mathrm{O}} \quad$ outdoor humidity ratio (kg water/kg dry air)

$\mathrm{z} \quad$ elevation above an arbitrary fixed datum

$\rho \quad$ air density $\left(\mathrm{kg} / \mathrm{m}^{3}\right)$

$\sigma_{I}$ tracer gas content of injected tracer gas flow (\%) 
$\sigma_{t} \quad$ measured tracer gas content in the zone

$\Phi_{\text {tot }} \quad$ total heat (W)

$\Phi_{s} \quad$ sensible heat $(\mathrm{W})$

$\Phi_{l} \quad$ latent heat (W)

$\Phi_{L} \quad$ latent heat production $(\mathrm{kg} / \mathrm{s})$

$\phi \quad$ relative humidity 


\section{Introduction \& Objectives}

The need to accurately quantify livestock house emissions is increasingly becoming important as the effects of bioaerosols on local environments are recognised and pressure on industry and governments to reduce greenhouse gas emissions increases. Animals and/or their wastes in livestock buildings generate different forms of air pollution, including ammonia, carbon dioxide, methane and nitrous oxide gases, as well as odours, dusts microorganisms and endotoxins, collectively known as bioaerosols. Reasons for concern over these different air pollutants include animal and human health, forest die back and global warming (Phillips et al. 1998), and so improved methods of measuring these emissions are needed to guide research on abatement strategies (Phillips et al. 2000).

An international study from investigations undertaken in England, The Netherlands, Germany and Denmark found that $\mathrm{NH}_{3}$ emissions from cattle houses varied between 315 - 1798 and $649-3751 \mathrm{mg} / \mathrm{h}$ per $500 \mathrm{~kg}$ live weight from pig houses, whereas $\mathrm{NH}_{3}$ emissions from poultry houses (laying hens and broilers) varied between 602 and 10 $892 \mathrm{mg} / \mathrm{h}$ per $500 \mathrm{~kg}$ live weight (Koerkamp et al. 1998). Overall dust concentrations were also measured between the livestock houses and it was found that mean inhalable and respirable dust concentrations were 145 and $24 \mathrm{mg} / \mathrm{h}$ for cattle, 762 and 85 for pigs; and 3165 and 504 for poultry (Takai et al. 1998). Therefore, it is clear that poultry houses are a concentrated source of pollutants. 
For the quantification of emissions, the air volume flow and the gas concentrations in the exhaust air must be known. Emission is defined as the product of the ventilation flow rate and the concentration of the pollutant (Phillips et al. 1998). A detailed knowledge of these emissions is only possible with air volume calculations. The challenges of calculating air exchange rates (AERs) from broiler houses depends on a number of factors, the technical equipment at hand, the level of accuracy required and very importantly the type of ventilation system. Generally, there exists 2 types of ventilation systems, natural ventilation (Louisiana stalls) and mechanically ventilated livestock houses.

The ventilation rates in Louisiana stalls is based upon the physical principles of the stack and wind effects. The principle of the stack effect is based on the fact that the specific weight of the entering colder air is greater than that of the warmer foul air and therefore pushes the later upwards where it must be removed. The wind effect will create a pressure phenomenon on and in the livestock building, the pressure difference depending on the wind direction, wind intensity and the form and dimensions of the building (Maton et al. 1985). Such buildings have large open contact surfaces with their environment, which are difficult to define. Hence, the emissions directly depend on atmospheric influences with permanently changing conditions (Brehme \& Krause 2002; Snell et al. 2003). Therefore, it is still considered a challenge to record emissions from naturally ventilated buildings. For some housing types with natural ventilation, it can be very complicated or even impossible to measure the ventilation rate (Sousa \& Pedersen 2004).

On the other hand with mechanically ventilated systems, air volumes are released from fixed exhaust outlets, the number of ventilators is known and a high degree of accuracy can be obtained (Hinz \& Linke 1998; Li et al. 2005). However, the difficulties associated with quantifying air emissions from large livestock houses should not be underestimated. Methods used to measure air volume flows can either be direct, i.e. hot wire anemometers, fan wheel anemometers and pressure flow sensors and indirect, i.e. artificial $\left(\mathrm{SF}_{6}\right.$, Krypton 84$)$ and natural tracer gas methods $\left(\mathrm{CO}_{2}\right.$, heat and moisture mass balance models). Indirect methods can be applied to naturally and mechanically ventilated livestock houses, whereas direct techniques are usually applied to 
mechanically ventilated systems (Seedorf et al. 1998; Phillips et al. 2001 \& Li et al. 2005).

The objective of this study was to calculate the air exchange rates using direct and indirect techniques from 2 broiler houses, 1) a Louisiana stall and 2) a mechanically ventilated livestock house. In the naturally ventilated livestock house the very cheap and practical mass balance models (MBMs) along with a tracer gas method were tested. Because the ventilation rates from naturally ventilated livestock houses still can not be fully validated, an in depth analysis of the internal stall environment conditions along with external weather variables was conducted to ascertain the validity of the results. In the mechanically ventilated livestock house indirect methods (natural and artificial tracer gas methods) and a direct method (pressure flow sensor) were tested. The true AERs were calculated using a pressure flow sensor and by knowing the real time operation capacity of the ventilation system. With the true AERs, the accuracy of all other methods could be tested and compared.

\subsection{Why is ventilation necessary?}

The performance of farm animals is a result of the genotype of the animals and parameters like nutrition, hygiene, livestock management as well as the abiotic factors (light, temperature and atmosphere gases). An adequate physical environment for the animals should be provided by the livestock building and the ventilation system (Schauberger et al. 2000). This environment should fulfil the requirements of the animals to improve the performance of the livestock. (Hartung 1994).

The major purpose of a livestock house ventilation system is to provide an aerial environment in which animal health is maintained and productivity is satisfactory. The need for ventilation is governed by 2 requirements. The maximum ventilation rate is necessary in the summer to prevent hyperthermia, i.e. at high temperatures the heat stress imposed on the stock by the environment may depress production (Clark et al. 1994). While the minimum ventilation rate more important in winter, is set to provide an acceptable heat and aerial environment for animal performance, for e.g. if condensation occurs in the building this may facilitate the transmission of disease between animals, indirectly causing a loss of production, and condensation on or within 
the fabric of the building may result in damage to the structure (Schauberger et al. 2000). The performance of a ventilation system can be evaluated by its ability to control air temperature, relative humidity and air speed at animal height and to maintain tolerable concentrations of gases, dust and airborne microorganisms. Furthermore, this can also be seen as a contribution towards the reduction of the amount of drugs used to treat environmentally caused diseases (Straw 1992). The ventilation rate governs the emissions of aerial pollutants from the building and the design of the ventilation system is a major determinant of the environmental impact of a livestock building (Seedorf $e t$ al. 1998).

Extensive research and development over the past 20-30 yr has lead to a variety of systems of mechanical and natural ventilation that can satisfy the above conditions. The efficiency of ventilation in each zone depends on the airflow pattern, which in turn is influenced by the geometrical configuration of inlets and outlets, the air jet velocity and its spatial reach and the location of fixed equipment and the animals (Seedorf et al. 1998).

\subsection{Discussion of units to express air volume discharges from livestock buildings}

There are several different ways to describe air volume quantities expelled from livestock buildings. The air exchange rate (AER) which will be commonly referred to in this study is defined as the complete room volume exchange of old air with fresh air and may be regarded in air exchange per hour. This has the advantage of providing a clear picture of the quantity of air volume leaving a building in a point of time, but has the disadvantage in that it does not include animal mass and therefore can not be used as an air exchange standard, but only as an air exchange indicator. When measuring air volumes in livestock houses, because of the large air volume spaces being measured it is more useful to be expressing air volumes as AERs, as AERs quantify the whole system regarding the air space being quantified and ventilation rates only provide information on the air space requirement per animal unit.

Ventilation rates are more often used when considering the whole system, air exchange plus animals and there are several ways of expressing the ventilation rate. The least 
useful is the ventilation rate per animal, since this takes no account of an animals weight or any other index of physiological activity. A ventilation rate per "heat production unit" clearly accounts for metabolic heat production and is therefore appropriate when temperature control is the main objective. A heat producing unit (hpu) is $1 \mathrm{~kW}$ of metabolic heat produced by an animal at an ambient temperature of $20^{\circ} \mathrm{C}$. This unit is, in turn, related to an animals weight since basal metabolic weight is proportional to live weight raised to the 3 quarter power and to activity or any other physiological process that affects heat production, such as temperature. A ventilation rate per unit of live weight $(500 \mathrm{~kg})$ is widely accepted, though it too has limitations, e.g. the lack of equivalence for animals differing in body weight (Seedorf et al. 1998).

Generally, it depends on the level of information required and the aim of the measurement. When it is only necessary to know air volume emissions, and/or conducting air volume tests then air exchange rates are useful. However, when it is necessary to apply an air volume to a livestock house with a specific number of animals and a particular weight, such as with ventilation system designs and standards then ventilation rates are more useful.

\subsection{Types of ventilation systems}

Cattle generally require no control of temperature, hence are usually housed in naturally ventilated and un-insulated buildings. In contrast, pigs and poultry require close control of temperature and are invariably housed in well insulated buildings with control of ventilation rate. Although a significant proportion of pig houses are naturally ventilated, most poultry houses are fan ventilated. Poultry are very sensitive to temperature, light and air exchange rate, and the biological and cost consequences of suboptimal environments are severe.

Livestock housing ventilation systems are generally of 2 types, the more common natural ventilation (Louisiana) design and the internally regulated mechanical ventilation systems. The term natural ventilation refers to those systems not using mechanical power to produce air movement, the motive power being provided from two sources, wind and thermal buoyancy. With natural ventilation it is not usually possible to maintain close control over the ventilation rate but it is essential to be able to achieve 
the minimum required rate under any external conditions (Randall 1994). Ventilation systems in Louisiana livestock houses have no fixed inlets and outlets. Generally the building may contain a system of adjustable side wall openings, eaves and/or chimneys, with the ventilation rate dependent on heat buoyancy (heat produced by the animals) as well as external temperature, wind direction and wind speed. Therefore, the level of emissions will depend on these factors and because the weather is constantly changing then so are the air distribution patterns within the livestock house and the emission rates. For e.g. an exchange surface (window or other opening) could be an entry and in the next moment an exit.

The ventilation systems of mechanically ventilated livestock buildings are mainly designed as temperature-controlled variable volume flow systems, whereby fresh air is drawn in though fixed inlets and foul air is expelled via exhaust outlets. There are a wide range of mechanical ventilation systems, whether with negative, positive or neutral pressure, the system depending on the local climate and the needs of the livestock. In this study the broiler house utilised a negative pressure system, whereby an under pressure is created within the livestock house by the mechanical removal of foul air causing fresh air to be drawn in though the inlets. These buildings are more costly to set up, but do provide more stable air distribution patterns than naturally ventilated stalls.

The control unit uses the indoor air temperature as control value. The supply voltage of the fans and therefore the resulting volume flow is the output of the control unit. Idealised characteristics of the ventilation system control unit. Two parameters, the set point temperature, $\mathrm{T}_{\mathrm{C}}$, and bandwidth (P-band), $\Delta \mathrm{T}_{\mathrm{C}}$, describe the course of the volume flow depending on the indoor temperature $\mathrm{Ti}$ as a control value. For an indoor air temperature less than the set point temperature, the minimum volume flow is supplied. In the range of the P-band above the set point temperature, the volume flow is increased until the maximum ventilation rate is reached. Above this range, the livestock building is supplied by the maximum ventilation flow (Schauberger et al. 2000).

Although, naturally ventilated livestock buildings are generally less expensive to maintain, i.e. regarding less energy consumption. The emissions are released through side windows as well as chimneys, thus creating more odour/emission problems for 
neighbours and the surrounding environment, compared with mechanical ventilation systems where chimneys expel emissions into the upper air column.

\subsection{Outline of methods for measuring air volume flows}

Quantifying ventilation rates from full sized livestock houses is a complicated and expensive task and differs depending on the type of livestock house and the desired level of accuracy required. Calculating ventilation flow from naturally ventilated buildings is much more complicated than mechanically ventilated buildings because the inlets and outlets are not fixed, i.e. changing wind direction, wind speed and temperatures will influence directly how much the side wall curtains and chimney baffles will open/close permitting fresh air in, expelling stale air out or even interchanging between both functions simultaneously. Methods available for measuring ventilation rates in naturally ventilated livestock buildings include measuring air speed and the cross section of ventilation openings, however this not well documented. Models for livestock buildings with natural ventilation have been described by Bruce (1986) and Albright (1990), which predict ventilation rates as a function of pressure differences due to wind or heat buoyancy. These models assume a static pressure difference over an opening, however, the frequency and magnitude of fluctuations in pressure differences in and around agricultural buildings are high and set up costs in full scale measurements systems would be expensive and time consuming.

Other more researched techniques for quantifying ventilation flow from Louisiana type livestock buildings, maybe achieved using artificial tracer gas techniques (e.g. $\mathrm{SF}_{6}$, Freon $134 \mathrm{a}$ etc) which requires expensive state of the art technology multi-gas monitors, gas sampling and dosing equipment. Four tracer gas methods are available, constant tracer gas injection, variable tracer gas injection, concentration decay and fan duct constant flow, these will be discussed in detail in the next chapter. Alternatively, an estimate can be obtained by the MBMs, i.e. $\mathrm{CO}_{2}$, heat and moisture (Albright 1990; Van Ouwerkerk \& Pedersen 1994; Van`t Ooster, 1994 \& CIGR 2002). These methods are much cheaper but are only recommended to provide a $24 \mathrm{~h}$ estimate and will be further discussed in the following chapters. 
The ventilation rate of force ventilated houses can be measured either at their air inlets or outlets, because the equation of continuity must be fulfilled. However, in negative pressure systems, measurement at the outlets is preferred, because leakages in the building structures may complicate measurements at the air inlets (Hinz \& Linke 1998). Technical approaches include measuring the ventilation flow via the exhaust outlets with measuring fan wheels (Berckmans et al. 1991) and pressure flow sensors, such as the one used in this study. The standard method for testing air volume flows from ducts (British Standards Institution, 1980) involves inserting a flow rectifier into the duct and then sampling the air velocity across a grid this is averaged and then multiplied by the cross sectional area. Fan wheel anemometers are preferred for air velocity tests in ducts than are hot wire anemometers. Hot wire anemometers are more sensitive to turbulences then fan wheel anemometers and are also not as robust, more susceptible to interference from dusts (Phillips et al. 2001).

Artificial and natural tracer gas methods can be applied to mechanically ventilated livestock houses. The advantages with mechanical ventilation systems, is that it is possible to obtain a good estimation, whereas with natural ventilation the calculation errors are much higher. Criteria for choosing a method for use in a major experimental program depend on the aim of the measurements: accuracy of the measurements required, investment level, human labour demand and applicability throughout the year (Scholtens and Van’t Ooster 1994).

\subsection{Violations of complete air mixing in livestock houses}

One of the main causes of error when using natural and artificial tracer gas methods is incomplete mixing of tracer gas and air. The design of livestock building ventilation systems is based on the premise of complete mixing. The complete mixing assumption involves equating the thermodynamic properties of exhaust air to the average thermodynamic properties of the bulk air space so as to enable the calculation of steady state heat and moisture balances, as well as the assumption that the tracer gas concentration at the outlet is representative of the whole air space. Three examples of how the complete mixing assumption may be theoretically violated include, short circuiting, secondary flow regions and tanks in series flow regime (Barber \& Ogilvie 1982). 
Short circuiting: only a portion of the supply air enters the airspace and the remaining portion is short circuited directly to the exhaust outlet. The effect of short circuiting is to increase the humidity ratio and enthalpy of the airspace above the design values. The airspace is under-ventilated as a result of short-circuiting.

Secondary flow regions: The airspace is considered to consist of a primary airflow region (zone 1) plus an attached secondary airflow region (zone 2). As in the case of short circuiting, the total air space is under-ventilated, in a sense, as a result of the existence of the secondary flow region.

Tanks-in-series flow regime: The inlet and outlet are separated by 2 flow regions connected in series. All the supply air initially enters zone 2. As in the previous 2 compartment air space, a degree of back mixing between the 2 zones also occurs.

A more plausible description of ventilated air space depicts the existence of well mixed primary zones with one or more secondary flow regions, which rather than being completely isolated from the main airspace, interact slowly with the primary airflow regions. Thus the presence of tanks in series flow regime appears to offer a more logical explanation, than the concept of totally stagnant zones. The physical consequence of short circuiting is a reduction in the effective ventilation rate. The entire air space will be under ventilated, unless ventilation fans are oversized, resulting in a reduction in the efficiency of electrical energy usage by the ventilation system.

The presence of multiple flow regions establishes large moisture and temperature gradients within the ventilated airspace resulting in non-isothermal conditions. To prevent condensation and stale air build up in the under ventilated zones, other zones must be over ventilated correspondingly. Dependent on the arrangement of flow regions between the inlet and outlet, incomplete mixing caused by multiple flow zones can result either in under or over ventilation of the airspace and can be accompanied by substantial gradients of the thermodynamic properties of air within the incompletely mixed airspace (Barber \& Ogilvie 1982). These violations of incomplete mixing are often hard to determine, generally tracer gas measurements provide good information on the air distribution patterns within the air space. 
While the flow visualisation technique provides a good visual representation of airflow patterns, the technique is not readily amenable to the determination of the quantity of air flowing in particular regions of the airspace. The rate of back mixing between adjacent zones, or the amount of air which is short circuited, cannot be quantified by flow visualization techniques alone. Tracer gas techniques are also useful in understanding air flow patterns in air spaces.

The parameter $\mathrm{K}$, referred to as the mixing factor, is a quantitative estimate of the extent of departure from complete mixing. Secondary zones result in values of $\mathrm{K}$ which are less than unity, whereas tanks in series flow causes values of $\mathrm{K}$ to be greater than unity. In the real airspace, undoubtedly all 3 causes of incomplete mixing can exist simultaneously, thereby further complicating the interpretation of the $\mathrm{K}$ mixing factor. Reseachers using tracer gas techniques for quantification of ventilation rates should be cognizant of the possible modes of incomplete mixing and of the effects such mixing conditions may have on the interpretation of their data. Many authors, have contended that mixing factors greater than unity could be caused by the existence within the airspace of totally stagnant regions. However, in reality, totally stagnant regions seem highly unlikely in livestock buildings under non isothermal conditions. A more plausible description of the ventilated airspace depicts the existence of well-mixed primary zones with one or more secondary flow regions which, rather than being completely isolated from the main airspace, interact slowly with the primary airflow regions. As previously discussed, such flow conditions will result in mixing factors differing from unity. The presence of a tanks-in-series flow regime appears to offer a more logical explanation for mixing factors exceeding unity than does the concept of totally stagnant regions.

Kaul et al. (1975) showed K mixing factors between 0,8 and 1,8 for ventilated livestock buildings. They reasoned, but did not prove, that the values less than unity were due to short circuiting while the values greater than unity were caused by totally stagnant regions. Other causes of incomplete mixing appear to be at least as likely to explain variations in their data. A mixing factor of 0,8 means that the effective air exchange rate in the experimental airspace was $20 \%$ less than the predicted air exchange rate based on the measured airflow rate and the complete mixing assumption. A mixing factor of 1,1 means the effective air exchange rate was $10 \%$ higher than predicted for the complete 
mixing situation. This apparent increase in the effectiveness of ventilation is unlikely to be a real benefit, since the non uniformity of mixing resulted in substantial temperature gradients within the airspace. Under multiple rotary flow zones, large temperature and moisture gradients are established within the ventilated airspace. To prevent condensation and stale air build up in the under ventilated zones, other zones must be over ventilated correspondingly, with an attendant decrease in the efficiency of the ventilation system.

The opposite effects of secondary zones and tanks-in-series flow regimes draw attention to the perhaps underemphasized importance of the exhaust location. While it is accepted as truth that the exhaust location does not affect air motion within the ventilated room, the exhaust location can, theoretically, affect the extent of departure from complete mixing. Firstly, changing from one outlet location to another may affect the steady-state temperature and humidity for a particular ventilation rate without ever affecting the airflow pattern. Secondly, the effects of the outlet placement will be manifested as a change in the steady-state concentration of contaminants within the airspace rather than by a change in the rate of removal of contaminants in the exhaust air (Barber \& Ogilvie 1982). 


\section{Chapter}

\section{Literature}

\subsection{Natural ventilation theory}

The design of natural ventilation systems is based on the stack and wind effect. Whereby, convected heat from animals drives warmer, polluted air out at the top of the building and fresh cooler air is drawn in though low level openings. In windy conditions additional ventilation is caused by pressure differences around the building. The air pressure at the low level opening inside the building must be below atmospheric pressure since air is drawn in from the outside. As the air is heated, it expands, becomes more buoyant, its pressure increases and it is forced out of openings near the top of the building. There is a pressure gradient from inlet to outlet. However, at some level in the building the pressure must be equal to the atmospheric pressure. This level is known as the neutral plane. Any openings below it act as inlets and above act as outlets (Pearson \& Owen 1994).

There are some simple rules of thumb when designing naturally ventilated barns. For e.g. 1) it is recommended a naturally ventilated building have a roof slope no less than $14^{\mathrm{o}}$, this is necessary to promote ventilation by heat buoyancy during cold weather when there is little wind. Another rule of thumb 2) is that side wall openings should be large during warm weather ( 1 to $1.5 \mathrm{~m}$ wide, at least) to promote ventilation by the wind. With openings this wide, even slight breezes provide many air exchanges per hour within the building, and wind is rarely totally still (Albright 1990). 
Air flow calculations are based on 2 important relationships from fluid mechanics - the continuity equation and the Bernoulli equation. Flow continuity is a statement of mass conservation. When a fluid (air) with a density of $\rho$ flows though an opening of area A, and has an average velocity of $\mathrm{v}$, the mass flow $(\mathrm{Q})$ rate is

$\mathrm{Q}=\rho A \mathrm{v}$

When there exists $n$ openings in an air space, with air flowing in some openings and out others, continuity requires

$$
\sum_{n}(\rho A v)_{n}=0
$$

When air approaches an opening inlet, streamlines converge and that convergence will act to reduce the effective area of the flow. Turbulence effects and the resulting energy loss also act to reduce flow though the opening, the moving air undergoes a contraction and friction effect affecting the velocity. The combination of the contraction and friction effect is known as the discharge coefficient. Given the discharge coefficient $\left(\mathrm{C}_{\mathrm{d}}\right)$, the area of the inlet $(A)$ and the air velocity $(\mathrm{v})$, the actual airflow through an inlet can be calculated. Now with the coefficient of discharge considered, the flow continuity is more properly expressed as

$$
\sum_{n}\left(C_{d} \rho A v\right)_{n}=0
$$

Values for discharge must be determined empirically, as it depends on the geometry of the opening. Air velocity through an inlet is a function of the pressure difference across the opening and can be determined using the Bernoulli equation. Whereas the continuity equation is a statement of the conservation of mass, the Bernoulli equation is equivalent to a statement of the conservation of energy. Bernoullis equation written in terms of pressure is 


$$
\frac{\rho v^{2}}{2 g_{c}}+P+\frac{\rho g z}{g_{c}}=\text { constant }
$$

Where $\rho$ is density, $\mathrm{v}$ is velocity, $\mathrm{P}$ is static pressure, $\mathrm{z}$ is the elevation above an arbitrary fixed datum, $\mathrm{g}$ is the acceleration of gravity, and $\mathrm{g}_{\mathrm{c}}$ is a units conversion factor (equalling 1,0 in the SI system). The first term in equation (4), is kinetic energy the second and third are pressure and potential energy, respectively (Albright 1990). Each term in the equation has units pascals. The flow though any opening can be found by applying Bernoulli`s law, assuming the air to be incompressible. Equations for velocity through a vertical opening acting as an inlet, outlet, inlet and outlet and representing the combined effects from buoyancy and wind have been derived by Van't Ooster (1994), Demmers et al. (1997) and Demmers et al. (2001).

An investigation conducted in a simulated naturally ventilated livestock house cross section involved comparing a tracer gas method with a pressure difference method, using natural ventilation theory. The external and internal pressure flow coefficients balanced the flow through the building, but failed to estimate the actual emission rate correctly. The calculations did not agree with the tracer gas measurements and it was concluded that a better understanding of the discharge and total pressure coefficients is needed (Demmers et al. 2001). Van't Klooster (1994) obtained good agreement in a full scale cattle building between rates calculated from natural ventilation theory based on the combined effects of wind and buoyancy. However Van't Ooster (1994) did not measure the internal pressure coefficient but calculated it using the equation for conservation of mass, obscuring any errors in the discharge coefficient. A major benefit of these investigations is that information on the magnitude and direction of the air flow rate from any inlet or outlet is known, providing an in depth overview of the air flows within the whole system.

\subsection{Mass balance models - Natural tracer gases}

The three MBMs $\left(\mathrm{CO}_{2}\right.$, heat and moisture $)$ are based on steady state conditions within the livestock house, assuming the animal heat production is constant on a 24 hour basis, therefore the everyday diurnal variations of activity, feeding strategy etc are not considered. The models do not claim to provide accurate hourly results, but are more 
suited to providing a rough 24 hour estimate and are favourable because of their low cost and easy application. Also, the natural tracer gases $\left(\mathrm{CO}_{2}\right.$, heat and moisture $)$ are released from the animals so the tracer gas is released from the source and throughout the stall, so good mixing between the natural tracer gases and stall air is guaranteed. They also have other uses for engineers such as selecting building materials, designing ventilation systems and planning the location of surrounding neighbourhoods etc. The accuracy of these models was tested in these investigations and the background theory is described further.

\subsubsection{Heat \& Moisture balances}

During the last few decades comprehensive research has been carried out on the heat and moisture production of different types of livestock. Predictive equations for total heat and sensible heat production on cattle, pigs and poultry suited to Northern European conditions were developed from reviewed literature in 1978 by Stroem. The literature was further reviewed by CIGR working groups in 1984, 1992 and 2002 where the equations were refined and correction factors for interfering sources such as water evaporation arising from spilt water, wet feed and manure were integrated. The equations presented in detail in section 3.3. Although these equations were derived from climate controlled chambers, thus do not represent real conditions, they are the result from decades of research. Chepete \& Xin 2004 recently checked the heat and moisture production equations used for broilers as applied in this report and found they were in good agreement with laboratory results.

The total animal heat production will fundamentally depend on the fact that animals are homothermal and full heat producing, because their heat production due to maintenance and production must be dissipated from their bodies. Homothermal refers to an organism that maintains a constant internal body temperature. Consequently, their body weights, production levels, i.e. their feed intake (energy concentration in feed), will influence their total heat production directly. How the heat is dissipated will depend on the physiology of the animals and on the surroundings with respect to air temperature, radiation from cold/warm surfaces, air velocity and bedding conditions. Furthermore, 
animal heat production varies diurnally as a consequence of the animal activity influenced by feeding routines and photoperiod (light vs. darkness). Therefore, it is important to define for which condition the animal heat production is referred. In accordance with common practice, $20^{\circ} \mathrm{C}$ and normal production conditions on a 24 -hour basis are selected as benchmarks for all species, this temperature lies within the thermoneutral zone, this is where the temperature can vary without causing changes in heat dissipation from the animals (Pedersen \& Sällvik 2002).

Investigations by Pedersen et al. (1985) showed a reduction in total heat of $2.4 \%$ per ${ }^{\circ} \mathrm{C}$ increase (within the temperature range from 15 to $25^{\circ} \mathrm{C}$ ) for broilers of $1.5 \mathrm{~kg}$ and a higher reduction for smaller animals. On the basis of available literature, it can be concluded that total heat production with respect to ambient temperature can be described by a linear relation. For temperatures above $30^{\circ} \mathrm{C}$, no clear relation can be found between ambient temperature and total heat production. However, it is likely that the heat production will increase for animals that are exposed to sudden temperature changes, because of the metabolization of feed. On the other hand, for animals exposed to constant high temperatures, the feed intake is likely to be reduced, thus resulting in a lower heat production. It is therefore assumed that a linear relation will be acceptable also for ambient temperatures above $30^{\circ} \mathrm{C}$.

Total heat $\left(\Phi_{t o t}\right)$ is composed of sensible and latent heat. Sensible heat $\left(\Phi_{s}\right)$ is dissipated in accordance with the temperature gradient between the animal deep body temperature and the ambient environment. Latent heat $\left(\Phi_{l}\right)$ dissipates from the animal in the form of moisture from the respiratory track and the skin. Animal deep body temperature is an important index of the physiological status of an animal, physical, chemical and biological temperatures are affected by temperature. Consequently, $\Phi_{s}$ will therefore be zero when the ambient temperature is equal to the animal deep body temperature, depending on species, age, and ambient temperature level. At house level some of the sensible heat dissipated is used for evaporation of water from wet surfaces, feed, manure, spilt drinking water. This will result in changes in the partitioning between $\Phi_{s}$ and $\Phi_{l}$ at house level, fortunately these factors are theoretically accounted for in equation 3 (section 3.3.1). Factors affecting the $\Phi_{s}$ used 
for evaporation could be flooring system, stocking density, watering, moisture content of the feed, litter, feeding system, animal activity and relative humidity.

To maintain the animal heat balance and body temperature, $\Phi_{l}$ will increase with increasing temperature to substitute the decrease in $\Phi_{s}$. The partitioning between $\Phi_{s}$ and $\Phi_{l}$ is furthermore affected by factors such as type of animal, production stage, body surface area, fur type, dryness of skin, and sweating ability (Pedersen \& Sällvik 2002).

Part of the sensible heat produced is lost due to transmission through the building (qb). This is calculated by the mean value of the heat transmission coefficient (U) weighted by the areas of the different construction elements (walls, ceiling, doors, windows), the mean area of all these elements, A; and the temperature difference between outdoor $\left(\mathrm{T}_{\mathrm{O}}\right)$ and indoor air $\left(\mathrm{T}_{\mathrm{i}}\right)$ (Owen 1994; NBE-CT-79.1979 \& Schauberger et al. 2000), (refer equation 4 section 3.3.1). Buildings for all classes of stock, except adult cattle and most calves, are insulated to a high standard, with $U$ values of the order of $0.6 \mathrm{Wm}^{-}$ ${ }^{2} \mathrm{~K}^{-1}$ (Carpenter. 1974). In Europe and the US a heat conductance of $\mathrm{U}=0.4 \mathrm{Wm}^{-2 \circ} \mathrm{C}^{-1}$ or better is usually necessary. In all climates such standards are necessary, both for welfare and for performance, in order to minimize solar heat gain.

The heat and moisture balance methods were expected to have many uncertainties. Heat production of the animals, radiation input, the influence of the building and building materials. This method has more sinks and sources then the $\mathrm{CO}_{2}$ method and therefore more errors. The accuracy of the thermal and moisture balances is expected to be slightly less then the accuracy of the $\mathrm{CO}_{2}$ method (Scholtens and Van't Ooster 1994). This was tested in Experiment 3.

The moisture balance is a tool normally used to obtain a minimum ventilation rate, which guarantees acceptable humidity and $\mathrm{CO}_{2}$ levels within the barn. Latent heat dissipated from the animal in the form of moisture from the respiratory tract and the skin. To maintain the animal heat balance and the body temperature, latent heat will increase with increasing temperature to substitute the decrease in sensible heat. In the moisture balance method it is assumed that only ventilation can remove the moisture produced by the animals. 


\subsubsection{Carbon dioxide balance}

In 1984, the $\mathrm{CO}_{2}$ production average across all species (pigs, cattle and chickens) was estimated to be $0.163 \mathrm{~m}^{3} / \mathrm{h}$ per hpu (heat producing unit) at "normal" indoor temperatures $\left(20^{\circ} \mathrm{C}\right)$. The experience since 1984 has shown that the carbon dioxide production per hpu is above $0.163 \mathrm{~m}^{3} \mathrm{~h}^{-1}$. The respiratory carbon dioxide production depends on various factors, such as respiratory quotient $\left(\mathrm{RQ}=\right.$ volume of $\mathrm{CO}_{2}$ produced divided by volume of $\mathrm{O}_{2}$ consumed), feed intake, animal activity and species. According to Van Ouwerkerk and Pedersen (1994), the $\mathrm{CO}_{2}$ production $\left(\mathrm{m}^{3} \mathrm{~h}^{-1}\right.$ per hpu) for an RQ value from 0.8 to 1.2 increases from $0.142 \Phi_{t o t}$ to $0.195 \Phi_{t o t}$. A low RQ of 0.8 refers to a low feed intake and 1.2 to a high feed intake. Van Ouwerkerk and Pedersen concluded that the carbon dioxide production ranges from 0.17 to $0.20 \mathrm{~m}^{3} \mathrm{~h}^{-1}$ per hpu, assuming the RQ lies within 1.0 to 1.2 and the $\mathrm{CO}_{2}$ production from manure is $4 \%$ of the total production (Van Ouwerkerk \& Pedersen 1994). Thus, an investigation of surveys from the Netherlands, Germany, Great Britain and Denmark (Pedersen et al. 1998) has indicated that carbon dioxide production is about $0.185 \mathrm{~m}^{3} \mathrm{~h}^{-1}$, which corresponds to a medium feeding level for all three species over a $24 \mathrm{~h}$ period. Diurnal variations in the production of metabolic heat, moisture and $\mathrm{CO}_{2}$ will limit the accuracy for estimating the ventilation rate, hence averages over $24 \mathrm{~h}$ were estimated to eliminate this problem (Pedersen et al. 1998). The pattern of drinking water intake also affects diurnal heat and carbon dioxide production (Van Ouwerkerk \& Pedersen 1994). Therefore, by incorporating a function for the daily pattern of activity of animals into the of $\mathrm{CO}_{2}$ production model, perhaps the accuracy of the prediction can be improved.

Carbon dioxide is also produced during the breakdown of faeces and urine. The breakdown of urine is a fast process, but the anaerobic process of biogas production in manure is slower. Much of the biogas consists of carbon dioxide. Although respiration is always the main part of carbon dioxide production, about 0-4\% (Aarnink et al. 1992) and even up to $8.5 \%$ (Curtis 1983), depending on storage time, is from manure. If the bedding in the building ferments (this is common in broiler buildings) carbon dioxide release increases considerably, by up to $50 \%$ if the birds are young (Beek \& Van Beeking 1992; van Ouwerkerk \& Pedersen 1994). 
A difference between indoor and outdoor $\mathrm{CO}_{2}$ concentrations of 200ppm, 250ppm or 500ppm (Pedersen et al. 1998; Seedorf et al. 1998 \& Choiniere et al. 1992, respectively) is considered necessary for accurate calculation of the ventilation rate, hence this method is only applicable in livestock buildings with a considerable livestock density (Seedorf et al. 1998). The appropriate $\mathrm{CO}_{2}$ difference for accurate results was checked under hot summer conditions experienced in this study. It is considered important that the carbon dioxide concentrations be measured outside, especially if ventilation rates are high, because even small errors in assumptions or measurements of outside concentrations could lead to large errors in predicted ventilation rates. Pedersen et al. 1998 calculated when outside $\mathrm{CO}_{2}$ concentrations were $50 \mathrm{ppm}$ from the real value, ventilation rates could be under/over estimated in winter and summer by $2.3 \%$ $8.8 \%$, respectively. Corrections also need to be applied if the building is adjacent to other carbon dioxide releasing objects, livestock buildings or arable crops (Van Ouwerkerk \& Pedersen 1994).

It is important that representative locations for the measurement of $\mathrm{CO}_{2}$ concentration are selected. In an international study measurements were made each hour at 7 sampling points within the animal house and a reference sampling point outside the animal house. Three sampling points were located at animal level, 3 points at the height of the human breathing zone and one point was close to an air exhaust outlet. The concentration of this later point was taken as the indoor reference for the estimation of the ventilation rate (Seedorf et al. 1998).

To obtain estimates on an hourly basis, the carbon dioxide production would have to be adjusted for by including animal activity (Pedersen et al. 1998). If the animal activity is measured, the adjustment of the carbon dioxide concentration can be made directly. Part of the energy required by livestock is expended on activity, for e.g. the energy requirement for broilers fed ad lib is about $10 \%$ of total energy requirement and for restrictively fed broilers is about $20 \%$. When animal activity measurements are recorded the results undergo a variance reduction transformation before the relative activity is multiplied by the air exchange rate, to lower the impact of the activity measurements on the calculated air exchange rate. Generally, the best fit is achieved when the calculated ventilation rate is adjusted to $50 \%$ of the diurnal variation in animal activity. If for instance, the animal activity is $10 \%$ above the daily mean, the carbon 
dioxide will be increased by $5 \%$ and vice versa. With the relative activity adjusted for the exchange rate can be calculated, whether on half hourly or hourly basis (Pedersen $e t$ al. 1998). Real time monitoring of activity is preferred, if this is not possible, correcting the daily value by means of a sinusoidal dromedary model may improve the prediction (Van Ouwerkerk \& Pedersen 1994; Pedersen \& Sällvik 2002 ).

\subsection{Artificial tracer gas methods}

Tracer gases are used for a wide variety of diagnostic techniques including leak detection and atmospheric tracing (Sherman 1988). The theoretical basis for these methods is the equation for the mass balance between the tracer gas and air. If we consider the air volume in the stable being constant with time (constant temperature and pressure), and that the air at the outlet is representative of the mean stable air concentration and the stable is considered as a box with one way in and one way out, with this theoretical approach we can calculate the air volume exchange within the livestock house (Marik and Levin 1996), of course in reality it is not so simple. Tracer gases are often used because the tracer gas source within the envelope (e.g livestock house) is clearly defined and additional sources can be excluded (Seedorf et al. 1998). The tracer gas method is a stimulus response technique. The stimulus, a change in some measurable property of the incoming air, is imposed on the system, and the response to the stimulus is monitored within the control volume or at the outlet. Analysis of the response provides information on the system behaviour (Barber and Ogilvie 1982).

In order to measure air exchange, the tracer gas should meet the following criteria; should be chemically stable in the environment studied - should not be present in normal air - must not be hazardous to human or animal health at the concentrations analysed - must not be inflammable or explosive - must be possible to measure with a high degree of accuracy, even at low concentrations - should be readily available and inexpensive (Phillips et al. 2000). Very few gases fulfil these requirements, main gases are, $\mathrm{Ar}, \mathrm{NH}_{3}, \mathrm{CO}_{2}, \mathrm{He}, \mathrm{H}_{2}, \mathrm{~N}_{2} \mathrm{O}, \mathrm{Xe}$ and $\mathrm{SF}_{6}$ and more recently Freon 134a.

Generally an exact flow rate, or mass, of a tracer is introduced into a building and the ventilation rate is estimated from the resulting tracer concentration at the exhaust outlets, using the equation of conservation of mass, in which the production and 
extraction rates must be equal. Allowance must also be made for short term storage when the ventilation rate changes, and for natural sources or sinks of the tracer in the building. Strictly, tracer methods require complete mixing of the tracer within the ventilated space, such that the tracer concentration is uniform (Sherman 1988) however, this is very unlikely in livestock buildings, so it is more important that the tracer gas is distributed the same way as the air rather than obtaining complete mixing (Demmers $e t$ al. 2000). When the internal volume is imperfectly mixed, the methods become less accurate, owing to variations in the measurement of internal concentration. Barber and Ogilvie (1984) found incomplete mixing of air during tracer gas experiments in isoheat conditions. Several authors (Kaharabata et al. 2000; Dore et al. 2004; Scholtens et al. 2004) have successfully used the external tracer gas method, whereby the tracer gas is released within the livestock house and measured via a grid located downwind from the livestock house. However, the internal tracer ratio method is less susceptible in operation to changes of wind direction than is the external one. It also offers a better chance of characterising the emissions from individual sources in a close group, e.g. from different buildings or stores on the same site (Phillips et al. 2000).

The use of tracer gas methods for ventilation rate measurements in livestock buildings is well documented. Because livestock buildings generally contain a single zone, single tracer gas techniques are appropriate (Sherman 1988). Sulphur hexafluoride is probably the most widely used of gaseous tracers with livestock building measurements (Leonard et al., 1984; Marik \& Levin 1996; Seipelt et al., 1998; Kaharabata \& Scuepp 2000; Snell et al. 2003), because of its inert properties and ease of detection. However, $\mathrm{SF}_{6}$ is a very potent greenhouse gas with a global warming potential 25000 times greater than that of $\mathrm{CO}_{2}$, has a very long half life in the atmosphere and has a molecular weight approximately 5 times heavier than air. In Denmark, the use of $\mathrm{SF}_{6}$ as a tracer gas is now illegal and the preferred tracer gas is Freon 134a. Other artificial tracer gases used in livestock house ventilation rate measurements include CO and Krypton 84 (Demmers et al. 1998 \& Müller et al. 1995), however, CO is very toxic at high concentrations and Krypton 84 is radioactive.

Generally, as previously mentioned there are 4 known tracer gas methods used to estimate air exchange rates, descriptions of these will be provided below. 


\section{Constant tracer gas injection}

The tracer gas is injected continuously near the air inlets (to promote good tracer/air mixing) at a continuous rate during the whole measuring period. At the sampling points, which represent the probable points of the outgoing air, the gas concentration is analysed. Because of the different air change the sampling concentration varies over time. The measured values are considered as inverse proportional to the air change rate. This method enables measurement of the supplied volume flow rate $\left(V_{L}\right)$ in a zone (VDI 4300. 2001).

$V_{L}=\frac{\sigma_{I}}{\sigma_{t}} \times V_{I}$

$V_{L}$ is supplied volume flow rate $\left(\mathrm{m}^{3} / \mathrm{h}^{-1}\right)$

$\sigma_{I}$ is tracer gas content of injected tracer gas flow (ppm)

$\sigma_{t}$ is measured tracer gas content in the zone

$\mathrm{V}_{\mathrm{I}}$ is constant volume flow of injected tracer gas $(1 / \mathrm{min})$

$N=\frac{V_{L}}{V_{R}}$

$\mathrm{N}$ is air exchange rate $\left(\mathrm{h}^{-1}\right)$

$\mathrm{V}_{\mathrm{R}}$ is room volume $\left(\mathrm{m}^{3}\right)$

\section{Variable tracer gas injection}

The tracer gas is injected into the envelope at given injection points. The air exchange rate is determined by measuring the amount of tracer gas necessary for maintaining a constant concentration of tracer gas in the measured volume (NT VVS 048. 1985). Therefore a feed back control of the tracer gas flow at the injection points is needed, which requires high-level automation equipment. At present the application of the variable tracer gas injection is limited to the area of research and development, and there are no references of this method used in the quantification of air flows from agricultural buildings. 
$V_{R} \times \Delta C=V_{L} \times \Delta t+N \times V_{R} \times \sigma_{I} \times \Delta t-N \times V_{R} \times \sigma_{t} \times \Delta t$

$\Delta \mathrm{C}$ is change in tracer gas concentration

$\Delta \mathrm{t}$ is change in time

\section{Concentration decay}

This method contrasts the constant injection method, in that it allows the direct measurement of the air exchange rate (VDI 4300. 2001). The principle of this method is to dose a small quantity of tracer gas in the room until a stable concentration is reached, and then to record the decrease of the tracer gas concentration over time. For the airflow calculation, airflow and tracer gas concentration are considered to behave proportionally. The homogenous dosage of the tracer gas at the air inlet, and the gain of representative air samples at the air outlet are essential for the exactness of the procedure.

$$
N=\frac{1}{t_{2}-t_{1}} \times \ln \frac{\sigma_{t=t_{i}}}{\sigma_{t=t_{2}}}
$$

$\mathrm{t}$ is time of sampling the tracer gas

$\sigma_{\mathrm{t}=t 0}$ is the initial tracer gas content at time $\mathrm{t}=\mathrm{t}_{0}$ (start of injection)

$\sigma_{\mathrm{t}=\mathrm{t} 1}$ is the tracer gas content at time $\mathrm{t}=\mathrm{t}_{1}$

$\sigma_{\mathrm{t}=\mathrm{t} 2}$ is the tracer gas content at time $\mathrm{t}=\mathrm{t}_{2}$

\section{Fan duct constant flow}

Tracer gas is injected (via a 16 port manifold) into the duct upstream from the fan and the air is sampled from 1 location near the end of the duct. This method is performed inside the chimney envelope using the constant injection tracer gas theory and assumes very good tracer gas/ air mixing (Leonard et al. 1984). The flow rate though each chimney can be calculated.

Of the 4 tracer gas methods documented, constant tracer injection is most often used for continuous measurement of ventilation and emission rates in both naturally and 
mechanically ventilated livestock houses (Leonard et al. 1984; Scholtens et al. 1994 \& 2004; Marik \& Levin 1996; Sneath et al. 1997; Demmers et al. 1998, 2000, 2001; Kaharabata \& Scuepp 2000). The constant injection method avoids disturbing normal internal mixing and it allows the continuous measurement of instantaneous ventilation rate, but it, like the other methods, is liable to unknown errors in the calculation of the ventilation rate should there be incomplete air mixing as is likely in livestock buildings (Demmers et al. 2000). The concentration decay method has also been successfully used by the following authors with livestock house air quantification techniques (Leonard et al. 1984; Müller \& Möller 1998; Snell et al. 2003). An advantage with this method, is less tracer gas is required, however more advanced dosing and sampling equipment is required and the method does not provide continuous measurements over long periods of time. The fan duct constant flow method (Leonard et al. 1984) is able to achieve good tracer gas/ air mixing because of a 16 port dosing manifold and very small air volume within the duct compared with a whole livestock house building. An accuracy of within $5 \%$ of measured values was obtained. This appears to be a very useful method with potential, but considering injection and sampling lines need to be fitted to each individual fan this could prove costly. However, if one fan could be used which is representative of all emission points, than a good estimation could be obtained. At present the use of this technique in livestock houses is not well documented.

\section{Advanced tracer gas studies}

Air exchange rate estimations from complicated building structures using multiple tracer gas techniques and multizone tracer strategies are described by Sherman (1988), these techniques are much more advanced than the single tracer gas techniques reviewed in this paper and are capable of uniquely determining the entire matrix of air flows. Such techniques require expensive technical equipment and investigate complicated air flow distributions beyond the scope of this report.

Air flow simulation studies using compartmentalisation Brehme and Krause (2002) were able to simulate air flow in livestock houses with compartmentalisation. This technique considers not only the decay functions of tracer concentration but also the mass conservation in the whole system. This is done by dividing the stable air space into several virtual compartments, with a measuring point in the middle of each 
compartment. An air exchange of tracer gas can only occur through the exchange surfaces to the bordering compartments and the system environment. Balance equations are formulated for each compartment. The change of tracer gas in each compartment is measured over time as well as the exchange of tracer gas between neighbouring compartments. The transfer of tracer gas between each compartment is denoted with transfer coefficients. A negative transfer coefficient means a loss (air flow out of a compartment) and a positive a gain (air influx into a compartment) within a compartment and between compartments. Because the transfer coefficients between compartments are located in each compartment equation, a linear connected system of equations is established which can be solved by a suitable algorithm and then the average air exchange rate for the whole stable and whole time of the measurement can be interpreted. This technique is able to provide a real image of the probable air flow patterns and eddies within stalls, helping determine an air exchange surface as an entry or an exit for a specific time step. These highly advanced simulation and multi-method techniques go beyond the scope of this paper 


\section{Materials \& Methods}

\subsection{Experimental site 1 - Naturally ventilated broiler house}

The Louisiana (naturally ventilated) broiler house investigated in this study is situated in Eicklingen, northern Germany (Fig. 3-1). The livestock house runs from north to south and is relatively large $120 \mathrm{~m}$ length by $16 \mathrm{~m}$ width and $6.2 \mathrm{~m}$ height at the roof apex with an internal air volume of $\approx 8148 \mathrm{~m}^{3}$. The livestock house produces around 40000 broilers per grow out cycle and its internal climate is regulated naturally with the aid of automated side wall curtains and chimney baffles controlled by an internal climate computer (Fancom, Pannigen, Holland) based on internal temperature. Measurements were performed on 2 days in the summer $(03.08 .03 \& 14.08 .03)$ and over 1 week in the autumn (7-14.11.03).

The livestock house was constructed in 1994. It was assumed that the DIN 18910 (1998) guidelines would apply to this building design. These guidelines assume that under northern European winter conditions the install temperatures would remain $18^{\circ} \mathrm{C}$ above outside temperatures. These recommended ventilation rates were calculated and compared with the calculated ventilation rates. 


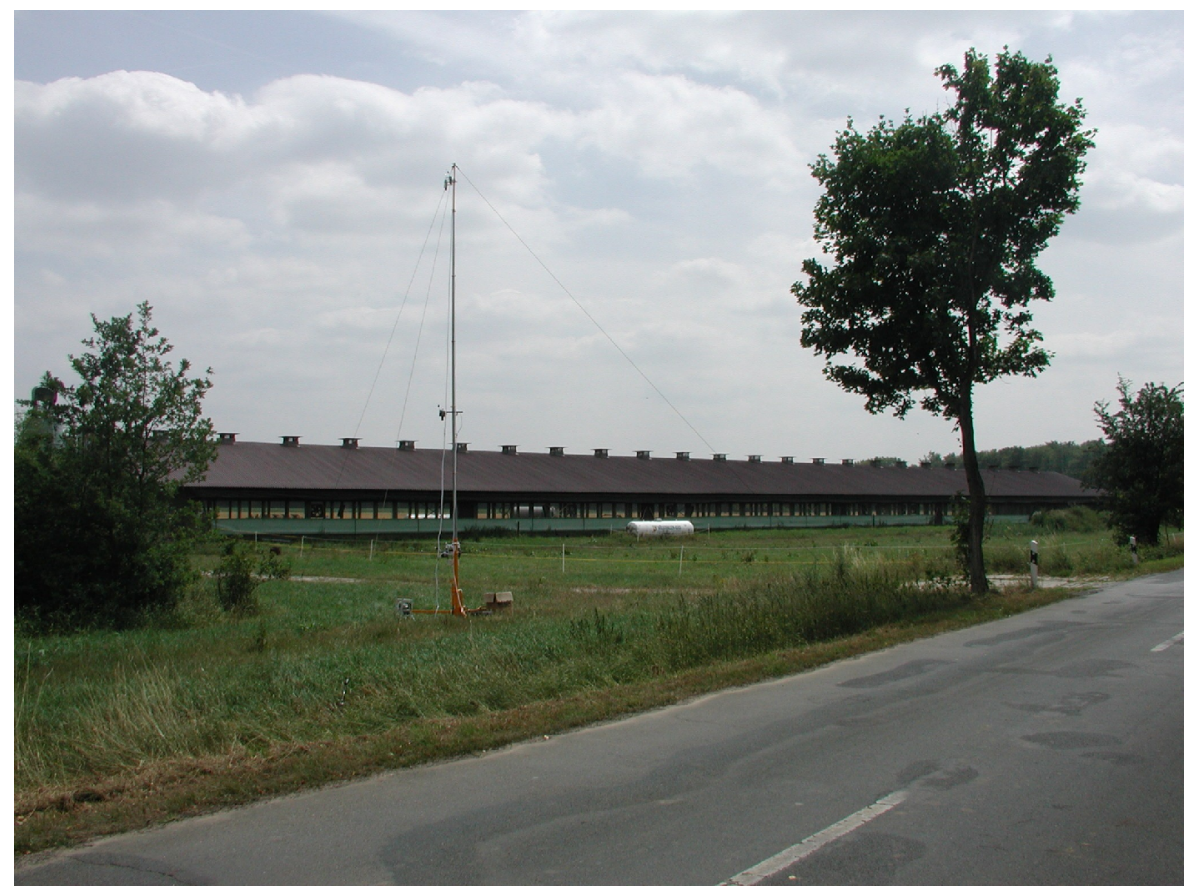

Fig. 3- 1: Photo of livestock house 1

\subsection{Experimental site 2 - Mechanically ventilated broiler house}

The AERs were calculated from a mechanically ventilated broiler house located in Brockzetel, northern Germany. The livestock house runs from north west to south east and is relatively large $70 \mathrm{~m}$ length by $18,3 \mathrm{~m}$ width and 5,4m height at the roof apex and an internal volume of $5206 \mathrm{~m}^{3}$ (Fig. 3-2). The livestock house produces around 30000 broilers per grow out cycle and its internal climate is controlled by a climate control system (SKOV, Glyngore, Denmark) which continuously measures internal temperature and operates a multi-step negative pressure air extraction system. A total of 36 fresh air wall inlets (heights $0.75 \mathrm{~m} \& 2.2 \mathrm{~m}$ ) are located on both side walls along with a 12 chimney foul air extraction system situated at the northern end (Fig. 3-2). The measurements were performed once every 2 weeks over a 2 month period JulySeptember 2004 (summer). 
The livestock house was constructed in 1998. Correspondance with the livestock farmer suggested the DIN 18910 (1998) guidelines had been applied to this building design, however data from DIN 18910 (2004) was used in this report. These guidelines assume that under northern European summer conditions if outside temperatures are $30^{\circ} \mathrm{C}$ then install temperatures would not rise over $33^{\circ} \mathrm{C}$.

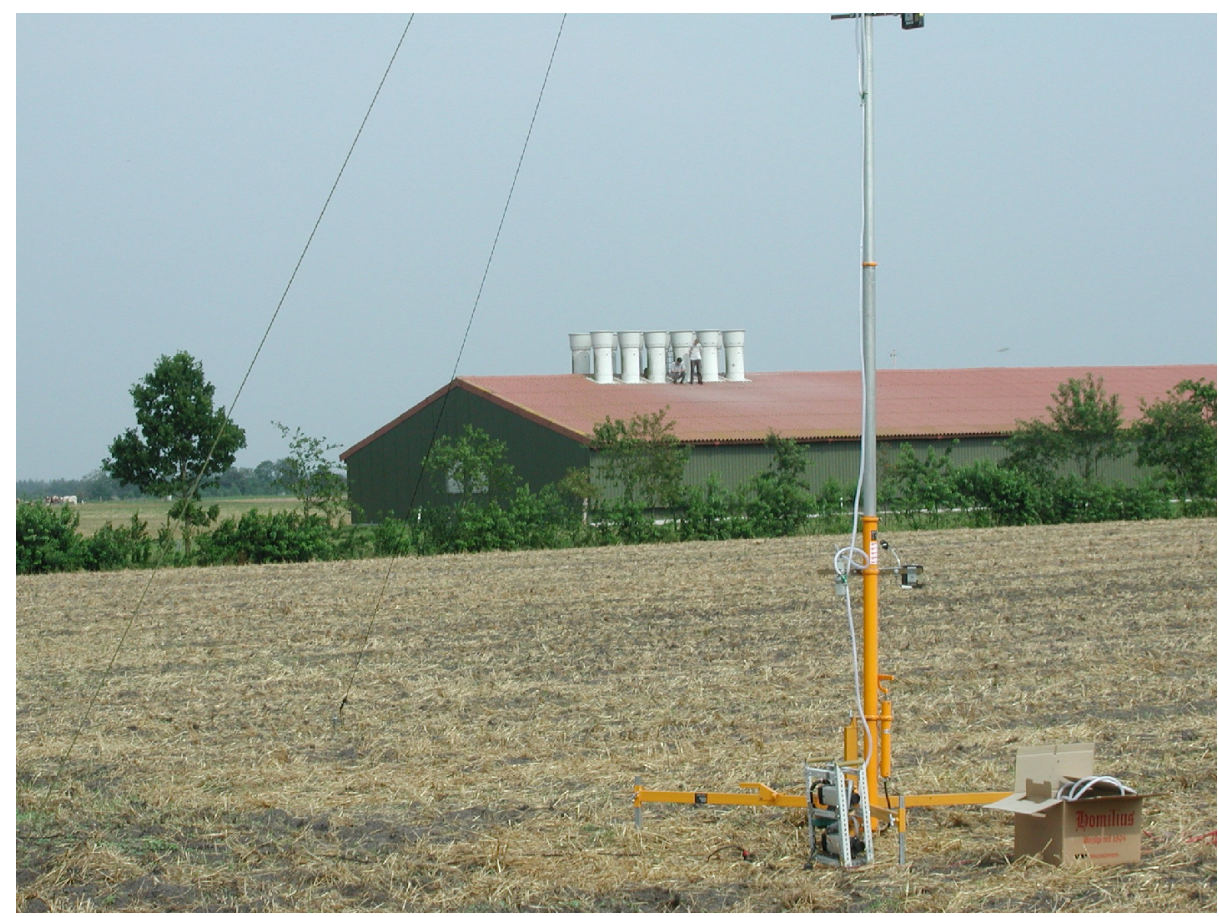

Fig. 3- 2: Photo of livestock house 2

\subsection{Mass balance models - natural tracer gases}

The models are based on steady state conditions within the livestock house, assuming the animal heat production is constant on a 24 hour basis, therefore a flaw in the MBMs is that everyday diurnal variations in animal activity, feeding strategy etc. are not considered. 


\subsubsection{Heat balance}

The equations for calculation of $\Phi_{t o t}$ refers to thermoneutral conditions $\left(20^{\circ} \mathrm{C}\right)$ for broilers and is a function of the metabolic body mass weight which gives the heat dissipation due to maintenance. At lower temperatures, the total heat production increases, and at higher temperatures it decreases on the basis of heat producing units (hpu), where one hpu corresponds to $1000 \mathrm{~W}$ of total heat at $20^{\circ} \mathrm{C}$.

$\Phi_{t o t}=10.62 \cdot M^{0.75}$

$\Phi_{t o t}$ is total heat production (W)

$\mathrm{M}$ is body mass $(\mathrm{kg})$

Experimental results on sensible and latent heat are rare because experiments are normally focused on total heat. When calculating ventilation demand/ventilation rate, and judging animal comfort, it is essential to distinguish between sensible and latent heat dissipation.

$\Phi_{t o t}=\Phi_{s}+\Phi_{l}$

$\Phi_{s}$ is sensible heat $(\mathrm{W})$

$\Phi_{l}$ is latent heat $(\mathrm{W})$

In the heat balance we are only interested in the sensible heat, and at temperature different from $20^{\circ} \mathrm{C}$, so we apply equation (11).

$\Phi_{s}=0.61 \times\left[1000+20 \times\left(20-T_{i}\right)\right]-0.228 \times T_{i}^{2}$

$\Phi_{s}$ is sensible heat production per animal (W)

$\Phi_{t o t}$ is total heat production per animal (W)

$\mathrm{T}_{\mathrm{i}}$ is indoor temperature $(\mathrm{K})$ 
The heat balance is calculated taking into account that the sources of heat are equal to the losses, assuming that the building is working under steady state conditions. The structure is similar to other balance equations, although the heat balance equation has an additional term for transmission heat loss, which is independent on the ventilation rate. Unless at the beginning of the grow out cycle, when the chickens are young and additional heating is required, the source of heat contribution is solely from the animals inside the building and the losses are compounded by heat transmission through the building structure and direct loss via ventilation.

The heat loss though the walls depends on the material type, its total area and the temperature difference between the two sides of the wall, to calculate this, the U value must be calculated.

\section{Calculating U values}

The construction materials separate the indoor and outdoor environments. Because both indoor and outdoor environments differ, heat transmission through building to a certain degree will always occur, with diffusion always from the highest temperature to the lowest.

Heat transmission through buildings is an important source of heat loss (or a source of heat gain under hot conditions). All construction elements such as walls, floor, roof, windows, doors etc. the material through which heat transmission take place conditioned by their heat properties and dimensions.

The rate of heat lost through a building is defined by:

$$
q b=\sum_{i=1}^{n}\left(T_{i}-T_{o}\right) \cdot U_{i} \cdot A_{i}
$$

$\mathrm{qb}$ is sensible heat lost through building (W)

$\mathrm{T}_{\mathrm{i}}$ is indoor temperature $(\mathrm{K})$

$\mathrm{T}_{\mathrm{o}}$ is outdoor temperature $(\mathrm{K})$

$\mathrm{U}_{\mathrm{i}}$ is $\mathrm{U}$-value of each element $\left(\mathrm{W} / \mathrm{m}^{2} \cdot \mathrm{K}\right)$

$A_{i}$ is area of each element $\left(\mathrm{m}^{2}\right)$ 
The calculations of the U-value for each element were done using Owen 1994 and the Spanish Norm (NBE-CT-79. Heat conditions in buildings). It takes into account the thickness and heat conductivity of each material and the situation of each element in respect to what kind of ambient is separating the materials. The calculated U-value for livestock buildings 1 and 2 are presented in Appendix B and C, Tab. 1b, respectively.

\section{Calculating ventilation rate}

The amount of heat transported by the air depends on the difference between the initial and final temperature of the air. So the sensible heat rate exhausted by the ventilation rate is obtained though the follow expression:

$q v=\rho \cdot C p \cdot Q \cdot\left(T_{i}-T_{o}\right)$

$\mathrm{qv}=$ sensible heat exhaust by the air $(\mathrm{W})$

$\rho=\operatorname{air}$ density $\left(\mathrm{Kg} / \mathrm{m}^{3}\right)$

$\mathrm{Cp}=$ specific heat of the air $(\mathrm{J} / \mathrm{Kg} \cdot \mathrm{K})$

$\mathrm{Q}=$ mass flow rate of air $\left(\mathrm{m}^{3} / \mathrm{s}^{-1}\right)$

$\mathrm{T}_{\mathrm{i}}=$ indoor temperature $(\mathrm{K})$

$\mathrm{T}_{\mathrm{o}}=$ outdoor temperature $(\mathrm{K})$

In this case we have considered the value $1210\left(\mathrm{~J} / \mathrm{m}^{3 \circ} \mathrm{C}\right)$ as the result of $\rho^{*} \mathrm{Cp}$.

Then with all parameters calculated the ventilation rate can be estimated with the equation below (all the terms are expressed in watts).

$q s=q b+q v$

$\mathrm{qs}=$ sensible heat from animals $(\mathrm{W})$

$\mathrm{qb}=$ sensible heat loss through building $(\mathrm{W})$

$\mathrm{qv}=$ sensible heat loss from ventilation $(\mathrm{W})$

Consequently, the animal heat transmission through the building envelope and ventilation heat losses is lower at night when the outdoor temperature is low, thus 
resulting in a lower ventilation rate and a higher indoor relative humidity than calculated. On the other hand, in order to keep the difference between the indoor and outdoor temperature low in the middle of the day, the ventilation rates will be higher than the calculated ventilation flow (Pedersen \& Sällvik 2002).

The minimum temperature difference between inside and outside conditions for reliable mass balance results is $2^{\circ} \mathrm{C}$. Therefore, when the temperature difference was below this level, it was corrected and assigned the minimum difference value $\left(2^{\circ} \mathrm{C}\right)$, so that model calculations remained realistic.

\subsubsection{Moisture balance}

The humidity balance is a tool normally used to obtain a minimum ventilation rate, which guarantees acceptable humidity and $\mathrm{CO}_{2}$ levels within the barn. To maintain the animal heat balance and the body temperature, latent heat will increase with increasing temperature to substitute the decrease in sensible heat. In the humidity balance method it is assumed that only ventilation can remove moisture produced by the animals.

To calculate the humidity ratio (Albright 1990), i.e. mass of water vapour evaporated into dry air $(\mathrm{kg} / \mathrm{kg})$ for the livestock house and outdoor air, several parameters must first be calculated. By knowing the dry-bulb temperature, the water vapour saturation partial pressure ( $\left.\mathrm{p}_{\mathrm{ws}}\right)$ was determined, as well as the actual partial pressure of water vapour $\left(p_{w}\right)$ and then the humidity ratio (kg water vapour/kg dry air) within the stall and outside air were calculated.

Psychometric equations

Temperature range from 0 to $200^{\circ} \mathrm{C}$, suited to the livestock house conditions.

$$
\operatorname{In}\left(p_{w s}\right)=\frac{A_{1}}{T+A_{2}+A_{3} T+A_{4} T^{2}+A_{5} T^{3}+A_{6} T^{4}+A_{7} \operatorname{In}(T)}
$$

Coefficients to calculate water vapour saturation partial pressure $\left(\mathrm{p}_{\mathrm{ws}}\right)$ are:

$\mathrm{A} 1=-5.8002206 \mathrm{E}+03$ 


$$
\begin{aligned}
& \mathrm{A} 2=1.3914993 \mathrm{E}+00 \\
& \mathrm{~A} 3=-48.640239 \mathrm{E}-03 \\
& \mathrm{~A} 4=41.764768 \mathrm{E}-06 \\
& \mathrm{~A} 5=-14.452093 \mathrm{E}-09 \\
& \mathrm{~A} 6=0.0 \\
& \mathrm{~A} 7=6.5459673 \mathrm{E}+00 \\
& \mathrm{~T}=\text { Temperature }(\mathrm{K})
\end{aligned}
$$

Then, with the $\mathrm{p}_{\mathrm{ws}}$ value and the relative humidity $(\phi)$, the actual partial pressure of water vapour $\left(p_{w}\right)$ in the measured air can be calculated.

$\phi=p_{w} / p_{w s}$

With these values it is now possible to calculate the humidity ratio ( $\mathrm{kg}$ water vapour $/ \mathrm{kg}$ dry air) with the stall and outside air.

$$
W=\frac{0.62198 \times p_{w}}{\left(p_{a t m}-p_{w}\right)}
$$

Latent heat from animals

The total heat production $\Phi_{t o t}$ from the broilers is derived below

$$
\Phi_{t o t}=1000+20 \times(20-t)
$$

Then, sensible heat (equation 11) is subtracted. The latent heat production from the broilers is thus

$$
\Phi_{l}=\Phi_{\text {tot }}-\Phi_{\mathrm{s}}
$$

$\Phi_{l}=$ latent heat from all animals (W)

$\Phi_{t o t}=$ total heat from all animals (W)

$\Phi_{s}=$ sensible heat from all animals (W) 
The latent heat production is described in terms of energy, so to get the amount of water produced by the broilers the latent heat production is divided with the latent heat of evaporation of water i.e.

$\frac{\Phi_{L}[\mathrm{~J} / \mathrm{s}]}{2410[\mathrm{~kJ} / \mathrm{kg}]}=\frac{\Phi_{L}}{2410 \cdot 10^{3}}\left[\mathrm{~kg} / \mathrm{S}^{-1}\right]$

Just like the heat balance the study is done under steady state conditions so the sources of water should be equal to the losses. The source of water is in this case only the animals, with sources from faeces, urine and feed included, and the loss the ventilation air.

In order to find the air flow rate $(\mathrm{Q})$ we simply divide with the amount of water removed by ventilation $\mathrm{w}_{\mathrm{i}}-\mathrm{w}_{\mathrm{o}}$ i.e:

$Q=\frac{\Phi_{L} / 2410 \cdot 10^{3}\left[\mathrm{~kg} / \mathrm{S}^{-1}\right]}{\left(w_{i}-w_{o}\right)\left[\mathrm{kg} / \mathrm{m}^{3}\right]}$

$\Phi_{L} \quad=$ latent heat production $(\mathrm{kg} / \mathrm{s})$

$\mathrm{w}_{\mathrm{i}}, \mathrm{w}_{\mathrm{o}}=$ indoor and outdoor humidity ratios ( $\mathrm{kg}$ water/kg dry air)

Mass Ventilation Rate

In this case it is assumed that the mass flow rates are assumed to be the same at the inlets and outlets (Albright 1990), calculated by the following psychometric equations:

$m_{\text {air }}=\frac{m_{\text {water }}}{\left(w_{i}-w_{o}\right)}\left(k_{\text {dry air }} / S^{-1}\right)$

$\mathrm{m}_{\text {air }}=$ mass air flow rate $\left(\mathrm{kg}\right.$ dry air $\left./ \mathrm{s}^{-1}\right)$

$\mathrm{m}_{\text {water }}=$ mass of water $(\mathrm{kg})$

$\mathrm{w}_{\mathrm{i}}, \mathrm{w}_{\mathrm{o}}=$ indoor and outdoor humidity ratios $\left(\mathrm{kg}_{\text {water }} / \mathrm{kg}\right.$ dry air $)$ 
Finally the air flow rate $\left(\mathrm{m}^{3} / \mathrm{s}^{-1}\right)$ is obtained by adding the water content of the air in ambient conditions and applying the density, with the following expression:

$$
Q=\frac{\left(m_{\text {air }}+w_{i}\right)}{\rho}
$$

$\mathrm{Q}=$ air flow rate rate $\left(\mathrm{m}^{3} / \mathrm{s}^{-1}\right)$

$\mathrm{m}_{\text {air }}=$ mass air flow rate $\left(\mathrm{kg}_{\text {dry air }} / \mathrm{s}^{-1}\right)$

$\mathrm{w}_{\mathrm{i}}=$ indoor humidity ratio $(\mathrm{kg}$ water $/ \mathrm{kg}$ dry air $)$

Once again, this model follows the assumption that the animal latent heat production is constant on a diurnal basis, in spite of the fact that the heat production varies diurnally. The diurnal variation will for instance be influenced by the feeding strategy, lighting and hygro-heat parameters. Both livestock houses tested in this study used ad lib feeding systems. The Louisiana stall combined the use of natural and artificial lighting, whereas the mechanically ventilated stall used artificial lighting. Animal activity can also be used with the heat and moisture balance models to try and improve the AER calculations.

The minimum moisture difference between inside and outside conditions to obtain reliable results is $0,5 \times 10^{-3} \mathrm{~kg}$ water $/ \mathrm{m}^{3}$ dry air (Pedersen et al. 1998), therefore if the moisture difference were below this level, then the value was corrected and the minimum difference value $\left(0,5 \times 10^{-3} \mathrm{~kg}\right.$ water $/ \mathrm{m}^{3}$ dry air $)$ was assigned for the calculation.

\subsubsection{Carbon dioxide balance}

The $\mathrm{CO}_{2}$ mass balance requires measuring actual carbon dioxide concentrations in combination with evaluating a model of carbon dioxide production. In the model, carbon dioxide production in livestock buildings is compared to the carbon dioxide release that escapes via the ventilation, therefore, the carbon dioxide terms have to be considered separately (Van Ouwerkerk \& Pedersen, 1994). Research since the last 2030 years has indicated that the average $\mathrm{CO}_{2}$ production from cattle, pigs and poultry over a $24 \mathrm{~h}$ period and corresponding to a medium feeding level amounts to $0,185 \mathrm{~m}^{3} \mathrm{~h}^{-1}$. 
To improve the accuracy of the calculation, i.e. incorporate diurnal variation into the model, it is recommended to include animal activity.

Ventilation flow per hpu $\left(\mathrm{m}^{3} / \mathrm{h}\right)=\frac{0.185 \times(\text { relative animal activity })}{\left(\mathrm{CO}_{2} \text { indoors }-\mathrm{CO}_{2} \text { outdoors }\right) \times 10^{-6}}$

Animal activity was measured according to authors Pedersen \& Pedersen 1995, with passive infrared detectors (PIDs) and a data logger. The activity signal is dependent on the temperature and velocity of a heated body, the distance to the sensor and for two simultaneously moving bodies. Two PID units were mounted $2 \mathrm{~m}$ above the ground in the centre of the stall at an angle of $45^{\circ}$, and activity data was accumulated every 5 minutes over 24 hour periods. The measurements were transformed and integrated into the calculations to account for the diurnal variation which is not accounted for with the balance models alone, as discussed in the $\mathrm{CO}_{2}$ theoretical section.

The accuracy of the $\mathrm{CO}_{2}$ technique is affected adversely by artificial $\mathrm{CO}_{2}$ sources, e.g. manure and depends on the estimate of metabolic $\mathrm{CO}_{2}$ production, which varies according to body weight, health status, etc (Seedorf et al. 1998). In the literature (Van Ouwerkerk and Pedersen 1994) it is stated that under farm house conditions with a medium to high feed intake $\mathrm{CO}_{2}$ production from manure is $4 \%$ of the total production, this was corrected for in all $\mathrm{CO}_{2}$ mass balance calculations. Furthermore, if direct-fired gas or oil-fuelled heaters are used at any time, particularly when the chicks are young, then additionally amounts of carbon dioxide will be produced, and must be corrected for. Numerous authors have stated that a minimum difference of 200ppm between inside and outside conditions is necessary for reliable results (Pedersen et al. 1998), in Experiment 4.1 because of the high air exchange rates under summer conditions a minimum difference of $150 \mathrm{ppm}$ was used.

Overall, it is often stated in the literature that the typical accuracy of the mass balance models in estimating ventilation rates falls with in the acceptable range of $\pm 20 \%$, this was checked, on three occasions under different conditions. The first round of measurements involved testing the three mass balance models in a full sized naturally ventilated livestock house under summer conditions (Experiment 1). 


\subsection{Experiment 1: Mass balance models tested in Livestock house 1}

Air samples were tested for $\mathrm{CO}_{2}, 10$ locations from inside the livestock house (refer to Fig. 3-3) and 2 control samples located outside. The Innova 1312 photo-acoustic multigas monitor (Innova Airtech Instruments, Denmark) was used in combination with the 1309 multipoint sampler and 7300 application software (Innova Airtech Instruments, Denmark). The 1312 gas monitor can measure almost any gas which absorbs infra-red light, can selectively measure up to 5 component gases (including water vapour) in any air sample simultaneously, whilst at the same time compensating for temperature fluctuations, water vapour interference and interference from other gases. Polytetrafluoroethylene (PTFE) tubing $(3 \mathrm{~mm}$ diameter and $0.5 \mathrm{~mm}$ wall thickness) was used and all tube lengths were less than 50m. Teflon tubing should not be used because $\mathrm{SF}_{6}$ is strongly adsorbed by Teflon and subsequently released when $\mathrm{SF}_{6}$ concentration drops (Dietz \& Cote 1973). All air was first drawn through fine Teflon dust filters at the beginning of each sampling line.

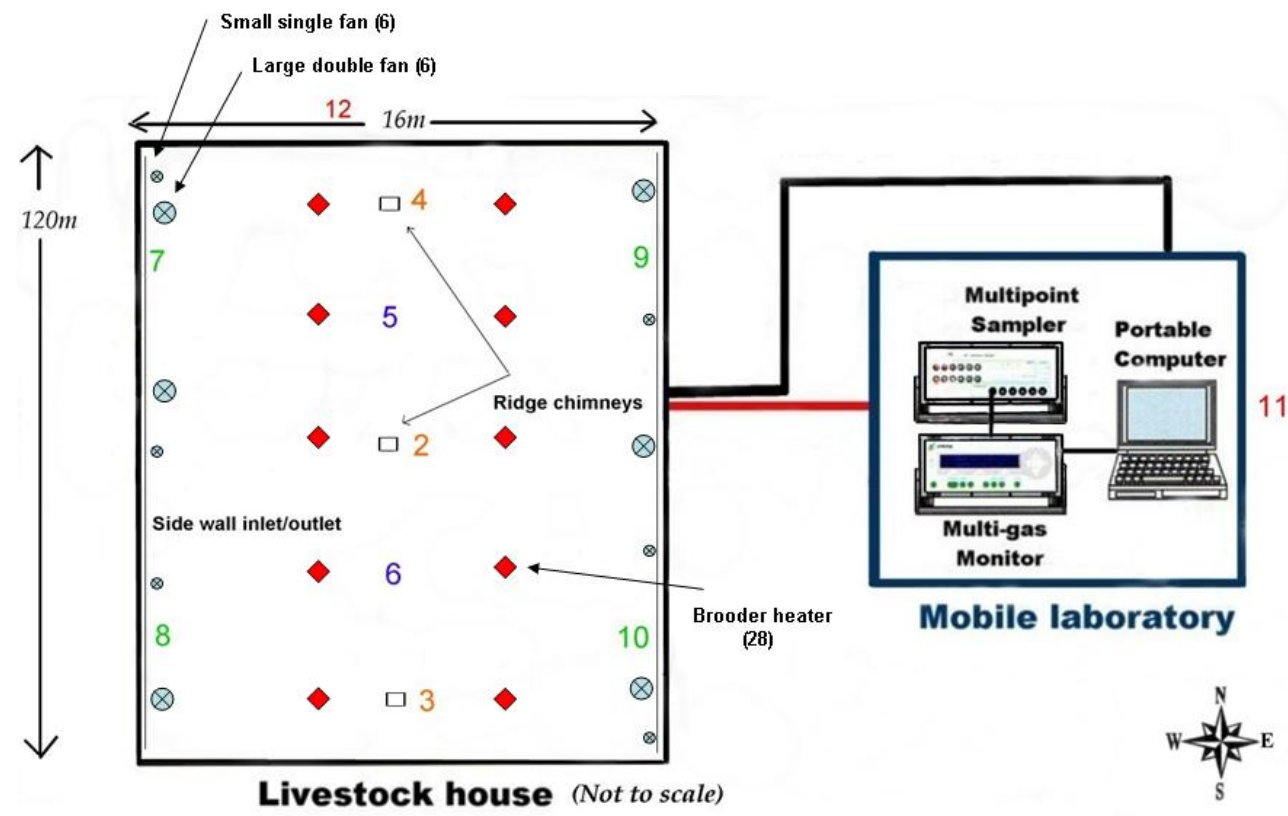

Fig. 3- 3: Experiment 1 set-up

Sample location numbers 2-4 (orange) located near chimney openings. Samples 5-6 (violet) located in middle of stall, height 1,5m. Samples 7-10 (green) located along wall, height 0,75m. Samples 11 \& 12 (control samples), located outside mobile laboratory and at far northern end of stall, respectively. 
During the measurement days (03.08.03 \& 14.08.03), weather conditions were very hot. The high temperatures damaged the activity sensor, so no bird activity results were obtained over this period. Because of the hot temperatures air circulation fans (Fig. 3-3) were operating and the times were noted down by the farmer. The control samples, 11 located next to the mobile laboratory and 12 at the northern end were not located far enough away from the livestock house, both were contaminated and recorded high $\mathrm{CO}_{2}$ concentrations throughout the measurement periods. Background concentrations measured away from the livestock house were $\sim 350 \mathrm{ppm}$, this value was used as the background concentration for calculations.

Temperature and humidity samples were measured from 2 rotronic sensors (Rotronic type HygroLog-D, Switzerland) located inside the stall, one in the middle of the stall at the northern end and the other at the southern end, both at a height of $1,5 \mathrm{~m}$ above the floor.

The external weather parameters (temperature, humidity, wind speed and wind direction) were measured hourly from a weather station (TOSS GmbH, Germany), which was located $300 \mathrm{~m}$ away from the livestock house in the upwind direction.

\subsection{Constant tracer gas injection}

The constant tracer injection method was found to be the best method for both livestock houses. The concentration decay method could have provided more accurate results but would have required more equipment, technical automation expertise and labour time which were not possible under the circumstances. The constant injection method (VDI 4300. 2001) was easy to set up and could provide good results over days at a time with minimal supervision. This method was tested in both the naturally and mechanically ventilated broiler houses with varying results. The basic theory behind the constant injection method was provided (section 2.3. equations 5-6).

This method does not enable direct measurement of the air exchange rate, but the measurement of the supplied volume flow rate $\mathrm{V}_{\mathrm{L}}$ in a zone. Each sampling point delivers a local air change rate. From these local values the overall air flow is usually 
calculated by taking the average of all measured values. However, the interpretation of the different air exchange rates can be difficult, especially cases of changing wind velocities, wind directions and high variation between sample locations, requiring a careful check of the results.

\subsection{Experiment 2: Naturally ventilated broiler house}

The Innova 1303 multipoint sampler and doser (Innova Airtech Instruments, Denmark) was used in combination with the Innova 1312 multi-gas monitor and 7620 tracer gas monitoring application software (Innova Airtech Instruments, Denmark). Both instruments were calibrated before the experiments. The Innova 1303 unit is normally used for office sized room measurements and can only analyse samples from a maximum of 6 locations and release a maximum dosing volume of $15 \mathrm{ml} / \mathrm{sec}$. The 7620 application software enables remote control from a personal computer of the gas monitor (1312) and sampler/doser unit (1303). All measurements were recorded in the 7620 program and later transferred to Excel for storage and processing. Pure $\mathrm{SF}_{6}$ tracer gas (100\% concentration) was injected in all tracer gas experiments.

The multi-gas monitor was set up to measure $\mathrm{SF}_{6}$ from each of the 6 sample locations, with a whole sampling cycle including sample analysis and cell flushing lasting $\approx 10$ minutes. Once again, PTFE tubing ( $3 \mathrm{~mm}$ diameter and $0.5 \mathrm{~mm}$ wall thickness) was used for all air sampling and tracer gas dosage tasks. The PTFE tubing at all locations was no longer than $50 \mathrm{~m}$ and consisted of a fine Teflon dust filter installed at the beginning of each sampling line. An external pump (Innova Airtech Instruments, type EB 6000, Denmark) was also connected to the 1303 unit to increase the air vacuum rate for sample tubes. 


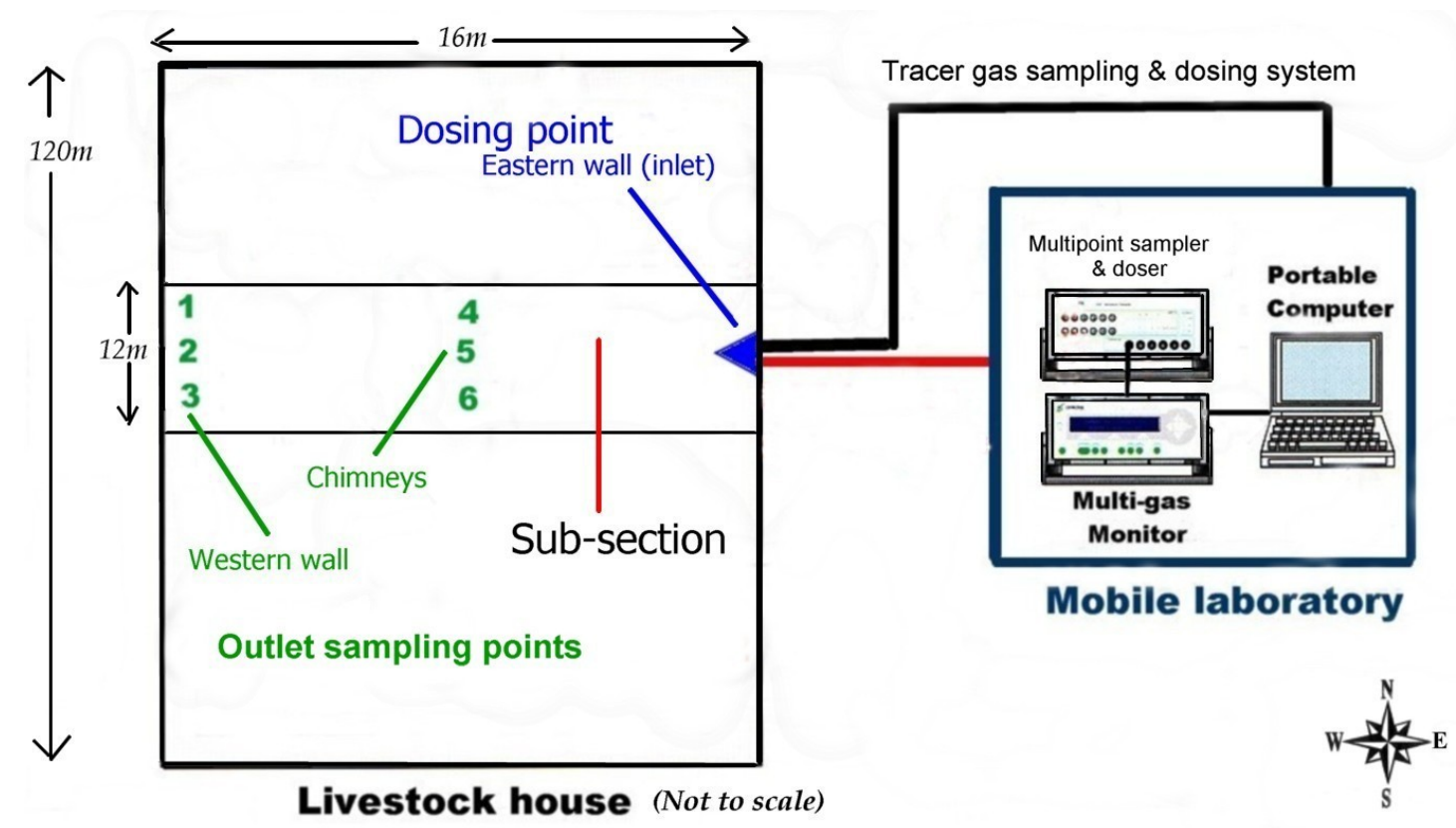

Fig. 3- 4: Experiment 2 set-up

The main problem when conducting tracer gas measurements in naturally ventilated livestock buildings is that inlets and outlets are constantly changing. With the equipment at hand in these experiments only 6 sampling locations were available and a maximum dosage volume $(15 \mathrm{ml} / \mathrm{sec})$. Because of the very large livestock house internal air volume $\approx 8148 \mathrm{~m}^{3}$, very expensive tracer gas costs, limitations of technical equipment and constantly changing air distribution patterns inside Louisiana stall environments. A section was created within the livestock house (Fig. 3-4) and was partially separated from the livestock house with tarpolines (internal volume $\approx 815 \mathrm{~m}^{3}$ ), here the gas sampling/dosing equipment were all installed. The tarpolines only very basic covered $\approx 47 \%$ of the internal transect area, were quickly installed and did not hamper farming operations. The aim of installing the tarpolines was to stabilise the air distribution patterns, reduce longitudinal flow/turbulences and increase air mixing within the livestock house so that air sampled within this section was representative of the whole internal environment. Several smoke tests were conducted to confirm sufficient mixing of livestock house air with the air mixing sub-section (Fig. 3-5). This sub-section will be referred to as the air mixing sub-section. Sampling was conducted within the air mixing sub-section from the openings of 3 chimneys (height $5.7 \mathrm{~m}$ ) and 3 lee side window locations (height $1.7 \mathrm{~m}$ ) (Fig. 3-4). The tracer gas was constantly injected from the prevailing windward side via a single point on 07-10.11.03 and via 
three points on the windward side wall 12-13.11.03. On the 13.11.03 the wind direction changed from easterly to westerly, the dosing and sampling equipment swapped sides with 3 point dosing being conducted from the opposite side wall within the air mixing sub-section at a height of $\approx 1,7 \mathrm{~m}$.

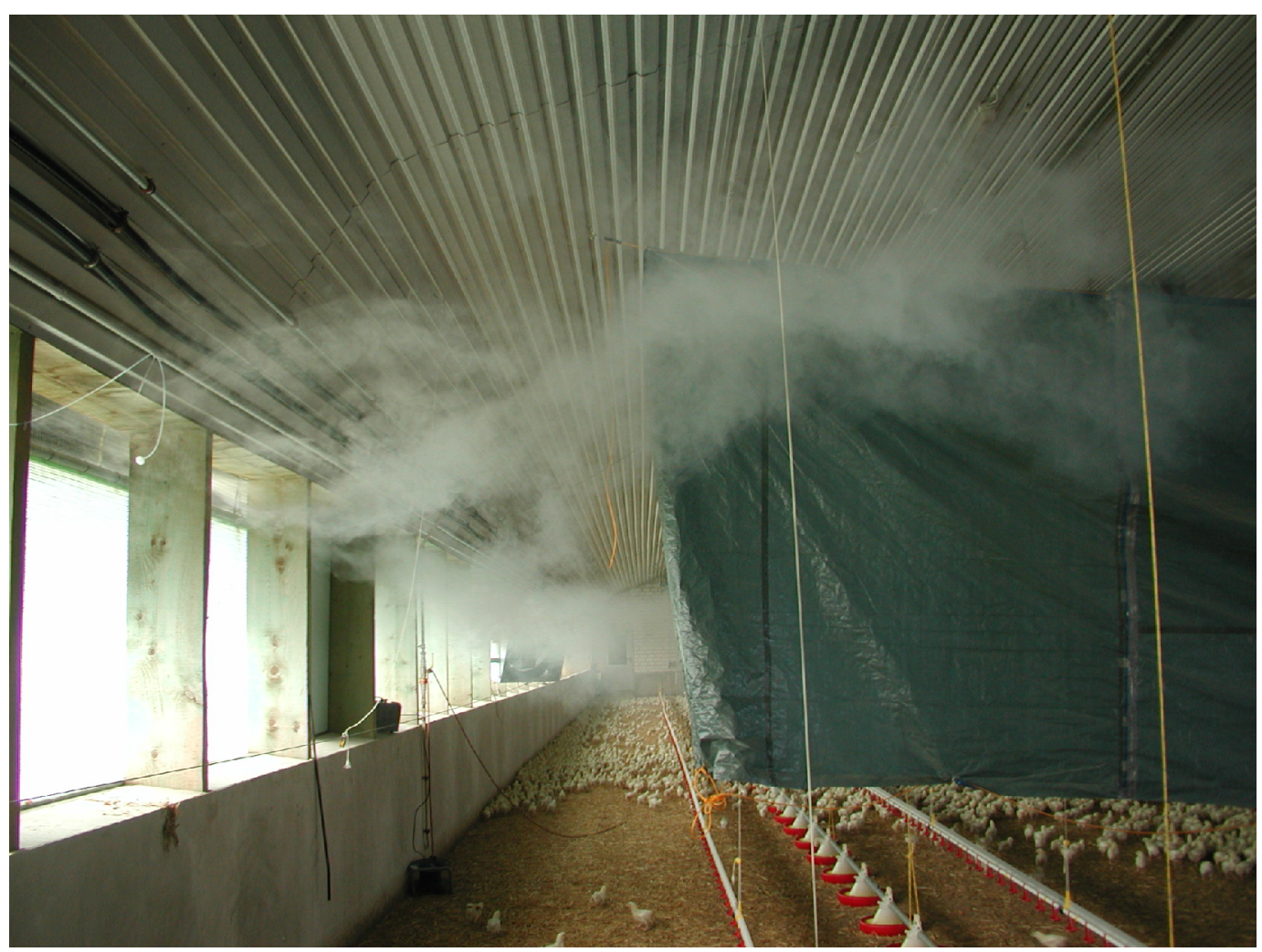

Fig. 3- 5: Smoke test displays air mixing within the broiler house and air mixing sub-section

Furthermore, because of the technical limitations in this experiment it was hoped that by performing the measurements under constant weather conditions, i.e. constant transverse winds $\left(90^{\circ}\right.$ wind angle of attack to the building) the inlets and outlets would remain relatively fixed and thus fresh air would mix with the injected tracer gas and outlet samples were assumed to be representative of outgoing air. It is believed that the best conditions for such measurements are in winter when air exchange rates are not too high in comparison to the high volume air exchanges occurring under summer conditions. Fortunately, the majority of measurements were conducted in autumn (0714.11.03) with relatively constant transverse wind directions and wind velocities generally $>2 \mathrm{~ms}^{-1}$, therefore conditions were optimal. 
When doing ventilation rate measurements in full sized naturally ventilated houses the actual ventilation rate is not known. A reference method giving the true value is not available, therefore it is difficult to determine the accuracy of each method. Under such circumstances a useful approach is to compare the methods with inside hygro-heat parameters and outside weather conditions, as was done in the results and discussion section.

In addition to the tracer gas method, the 2 mass balance models heat $\&$ moisture (CIGR 2002) were used for calculating the air exchange rates. In Experiment 1 (summer conditions) it was possible to test all 3 mass balance models $\left(\mathrm{CO}_{2}\right.$, heat and moisture), however due to time constraints in the autumn working in line with the farmers operations, the PFTE tubing was insulated but not heated, therefore condensation occurred in the gas sampling tubes resulting in false $\mathrm{CO}_{2}$ results, so only the heat and moisture mass balance models were tested along side the tracer gas method. Because of power problems it was only possible to conduct bird activity measurements from the 12 14.11.03. These results will not be included because there is no way of validating mass balance model result improvements in naturally ventilated stalls. The effect of including activity on the mass balance model results in the mechanically ventilated stall (Experiment 3) were included, because the true ventilation rates were measured and direct comparisons could be made.

Several temperature/humidity sensors (Rotronic type HygroLog-D, Switzerland) measuring temperature and humidity were installed throughout the livestock house. Three were positioned at the sampling locations along the wall and 1 at the dosing point, these values reflected the outside weather conditions so were not used. Normally it is recommended to use the values from sensors located in the centre of the stall (height $1,5 \mathrm{~m}$ ), but the sensor was damaged, so the 3 sensors located near the chimneys (height $\sim 5,7 \mathrm{~m}, 1$ inside the air mixing sub-section and the other 2 outside) were used in the calculations. There was no difference in temperature and humidity measurements between the sensors within and outside the air mixing section. The sensors for measuring temperature and relative humidity were all checked in a climate-controlled chamber before the measurements. The climate in the room was $20^{\circ} \mathrm{C}$ and $40 \%$ relative humidity, correction factors for each sensor were calculated and included in the calculations. 
Because it was autumn and the weather was cool, there were heaters operating at times throughout the measurement period. At the beginning of the measurement period (07.11.03) the birds were approximately 3 weeks old, so there was no need for the heaters to operate at full capacity. After discussion with the farmer and several inspections it was clear that the brooding heaters were set up in such a way, to minimize heat consumption and evenly distribute the heat. Of the total 28 heaters in the stall (Fig. 3.6.1), seven distributed throughout the stall were functioning at near full capacity and the remaining twenty one were operating at a much lower output $(\sim 10 \%)$. In order to improve the accuracy of the heat and moisture balance calculations the consumption of natural gas by the heaters was measured and the heat output calculated. Because it was ascertained that the heaters were generally operating at 2 different output levels, 2 gas meters were fitted to two heaters with different output levels. The gas consumption was metered and noted over time and an average heat output for all heaters was calculated, this additional heat source was included in the heat and moisture balance calculations.

The external weather parameters (temperature, humidity, wind speed and wind direction) were measured hourly from a weather station (TOSS GmbH, Germany), which was located $300 \mathrm{~m}$ away from the livestock house in the upwind direction.

\subsection{Experiment 3: Mechanically ventilated broiler house}

All three mass balance models carbon dioxide, heat and moisture (CIGR 2002) were compared with a constant injection tracer gas method (VDI 4300. 2001). Unfortunately, the pressure flow sensor (Micatrone, Solna, Sweden) and ventilation system true ventilation rate measurements could only be conducted at the end of the measurement period (08 \& 14.09.04). However, with the ventilation system data, a true ventilation rate extrapolation was performed on the $18 \& 25.08 .04$, the accuracy of this extrapolation will be discussed in the next section (refer to 3.7.2). The bird activity was also measured on some of the days $(18.08 .04,08.09 .04 \& 14.09 .04)$, along with the pressure flow sensor extrapolation and measurements. The results from the pressure flow sensor are assumed to be the true values so the accuracy of all other methods could be compared against the reference results. The pressure flow sensor was validated against a fan wheel anemometer to confirm its accuracy. 
Because the livestock house ventilation system is mechanically regulated, the inlets and outlets are fixed, thus one would assume the location of dosing and sampling points is rather straight forward, however with the equipment used, selecting a dosing location that encourages good tracer gas and air mixing as well as sampling locations that are representative of outgoing air was not so simple. Smoke tests were used to obtain a basic visualisation of the air flow patterns, however such tests induce extreme animal stress and must be conducted with care. After equipment re-calibration, the 1312 gas monitor, 1309 sampling/dosing units and temperature/humidity sensors (Rotronic type HygroLog-D, Switzerland) were set up.

The temperature/humidity sensors were set up along the walls at low and high heights $0,75 \mathrm{~m}$ and $2,2 \mathrm{~m}$, respectively. Sensors were also set up adjacent the tracer gas sampling locations near the exhaust chimney mouths and in the middle of the stall at a height of $1,5 \mathrm{~m}$ on the infra-red animal activity sensor stands. Once again, animal activity was measured from 2 locations, at the southern and northern ends in the middle of the stall at a height of $1,5 \mathrm{~m}$. Animal activity measurements could not be performed each day because the lab top was also used in field measurements.

The tracer gas was injected from the southern end of the stall, but the dosing set up underwent 3 different configurations to see which dosing arrangement functioned the best, and was the most cost effective. On the $14^{\text {th }}$ and the $28^{\text {th }}$ July 2004 the pure $\mathrm{SF}_{6}$ tracer gas was dosed from the southern end in the middle of the stall from 2 heights $0,75 \mathrm{~m}$ and $1,9 \mathrm{~m}$, simultaneously (Fig. 3-6). Because $\mathrm{SF}_{6}$ is expensive, a lower dosing rate of $3 \mathrm{ml} / \mathrm{sec}$ was selected. The sampling locations (1-6) were all located at the exhaust chimneys during the first tests.

On the $18^{\text {th }}$ and $25^{\text {th }}$ August 2004 the tracer gas dosing set up was changed from the middle of the stall to 2 points on opposite side walls adjacent to the low fresh air inlets height $\sim 0,5 \mathrm{~m}$ (Fig. 3-7). Dosing was injected at a rate of $3 \mathrm{ml} / \mathrm{sec}$ on the 18.08 .04 and then changed to $15 \mathrm{ml} / \mathrm{sec}$ on the 25.08.04. This time 4 sampling locations were positioned near the chimney mouths, sample location number 6 was positioned on the western wall not far from the middle length of the stall (height $0,5 \mathrm{~m}$ ) to check the degree of mixing between inside air and tracer gas away from the exhaust ducts. 
Sample location number 5 was situated beneath the exhaust chimneys and in front of the extra fans (height $1,5 \mathrm{~m}$ ).

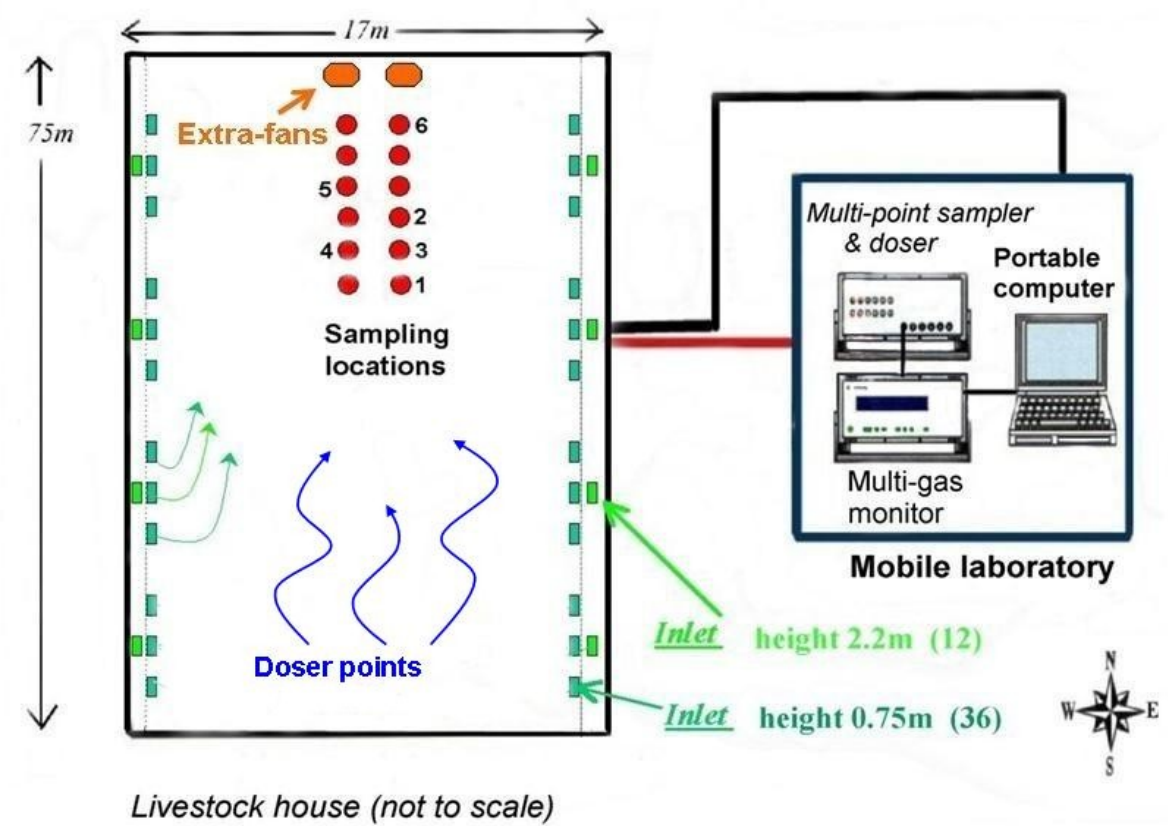

Fig. 3- 6: Experiment 3 set up ( $1^{\text {st }}$ session: $\left.14 \& 28.07 .04\right)$

On the $8^{\text {th }}$ and $14^{\text {th }}$ September, dosing was conducted from the same locations as previously, however because of little remaining $\mathrm{SF}_{6}$ tracer gas the constant injection dosing was changed to concentration decay configuration. Unfortunately the amount of dosed tracer gas was too small to yield reasonable results and therefore the results are not included.

The external weather parameters (temperature and humidity) were measured hourly from a weather station (TOSS GmbH, Germany), which was located 250m away from the livestock house in the upwind direction. 


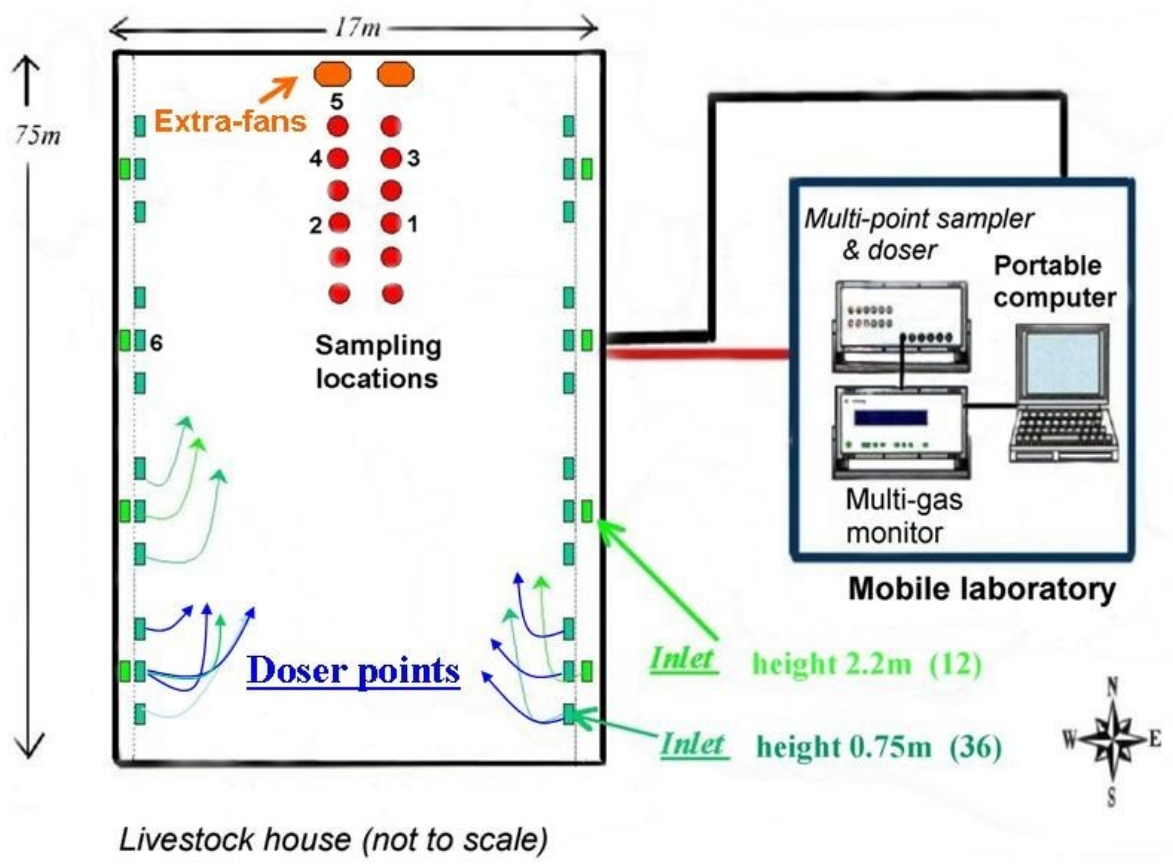

Fig. 3- 7: Experiment 3 set up (2nd session: 18 \& 25.08.04)

\subsubsection{Pressure flow sensor}

The pressure flow sensor (Micatrone, Sweden) consists of 2 bars arranged across the duct in cross formation. The pressure flow difference between the underside (facing the exhausted air) and upperside (background) is measured and an air flow $\left(\mathrm{m}^{3} / \mathrm{sec}\right)$ is calculated from the following formula. The accuracy of the pressure flow sensor is \pm $0,5 \%$ of the pressure range.

$Q=A \times \sqrt{\frac{2 \times \Delta p}{1,20}}$

$\mathrm{Q}=$ air flow rate $\left(\mathrm{m}^{3} / \mathrm{s}\right)$

$\mathrm{A}=$ area of the duct $\left(\mathrm{m}^{2}\right)$

$\Delta \mathrm{p}=$ pressure difference $(\mathrm{Pa})$ 
Unfortunately, the pressure flow sensor could not be validated with a measuring fan wheel because of time constraints, however it was checked with a fan wheel anemometer. The fan wheel anemometer is only a basic checking device, however this is a standard method for checking air flow rates (British Standards Institution, 1980).

A flow rectifier was placed inside a chimney piece and the air volume flow was controlled by a transformer. The fan wheel anemometer (Testo, Germany), tested two cross sections with a total of 18 measuring points. The average air velocity from the 18 measurements was calculated and then multiplied by the cross section area of the chimney. The results are presented below (Fig. 3-8)

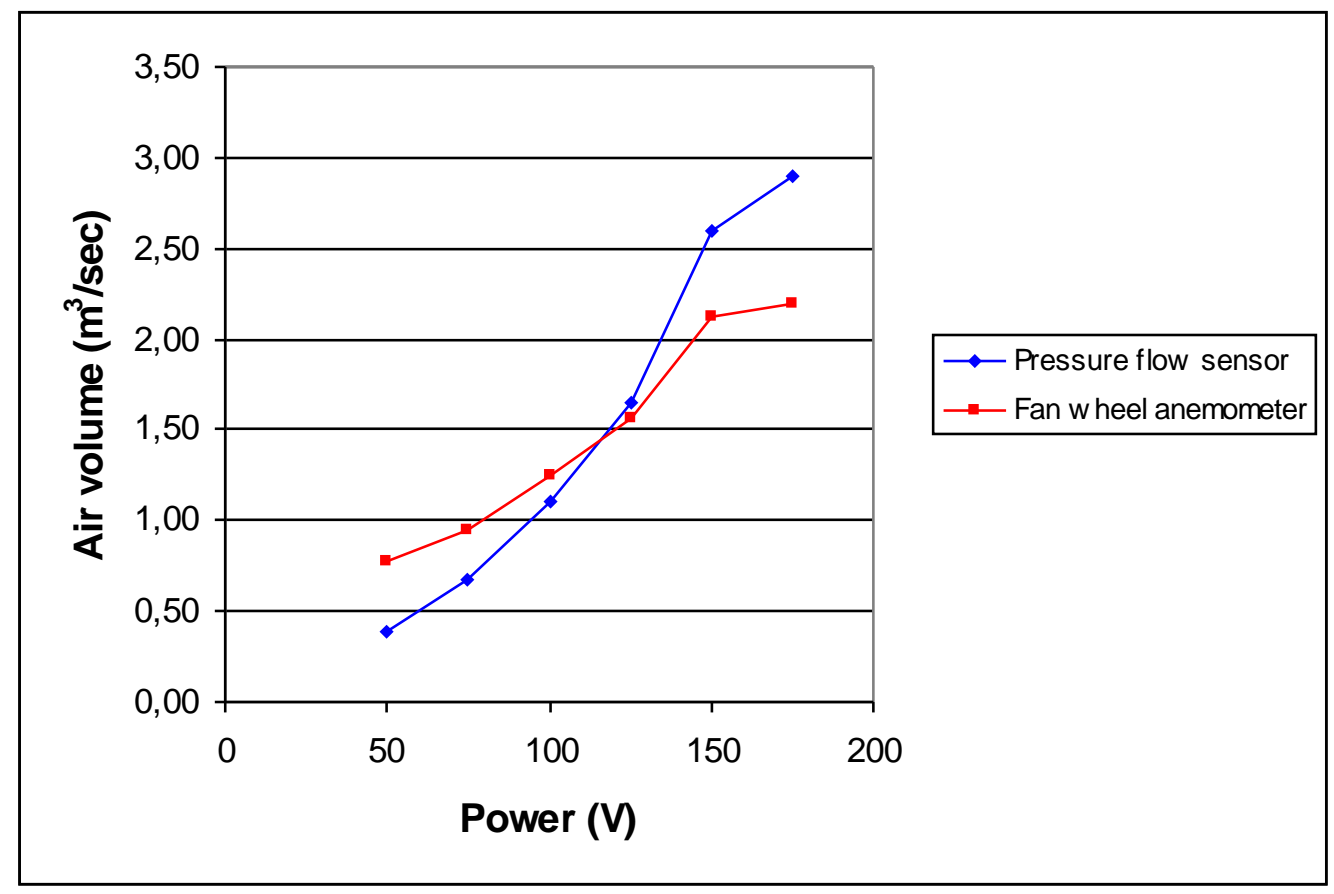

Fig. 3- 8: Pressure flow sensor and fan wheel anemometer check curve

The results (Fig. 3-8) indicate the pressure flow sensor results were closely aligned with the standard fan wheel anemometer method $\left(r^{2}=1,00\right)$, therefore the pressure flow sensor was calibrated correctly. 


\subsubsection{True air exchange rate measurement method}

The negative air extraction ventilation system is based on a multi-step principle. When the in house temperature reached a certain level extra fans are automatically switched on or off. A lab top computer was set up and continuously downloaded the ventilation system data, so that the operation capacity of the system and functioning exhaust fans at any time throughout the measurement period was known. The data was continuously down loaded and used together with the pressure flow sensor calculations, to determine the true air exchange rates.

The pressure flow sensor was installed inside the multi-step chimney approximately 70 $\mathrm{cm}$ above a flow rectifier (Fig. 3-9) and the air flow rates were calculated from the downloaded air pressure measurements. The multi-step exhaust fan is the only exhaust fan which operates continuously, and its purpose is to regulate the air discharge from the whole livestock house under the control of the climate control system. All 12 chimneys are divided into 4 groups (groups 1-4) and with the addition of the 2 large extra fans on the northern wall (Fig. 3-7) there are a total of 6 groups. The multi-step engages or disengages groups depending on the temperature inside the stall. Altogether there are 32 ventilation combinations e.g. chimneys from groups $1 \& 2$ and 1 extra fan operating simultaneously, or chimneys from groups $1 \& 3$ operating together etc.

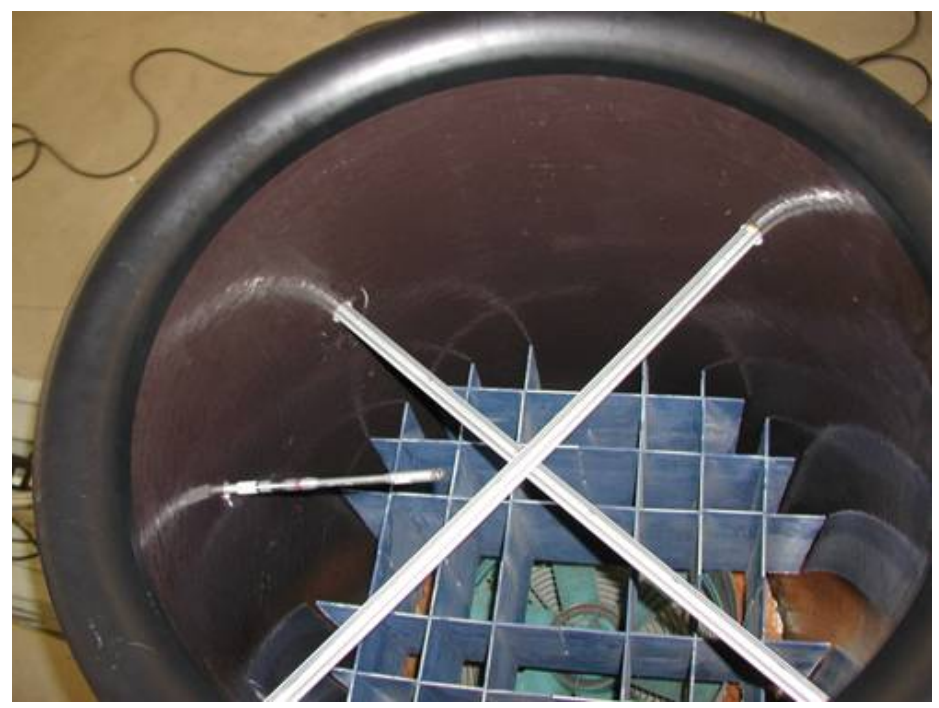

Fig. 3- 9: Exhaust fan with flow rectifier and pressure flow sensor 
The air flow rate of the multi-step exhaust fan varies continuously and when it peaks in a ventilation combination (1-32), then the recorded chimney volume flow rate represents the air flow rate of all exhaust fans activated in the ventilation combination. These values were calculated and used in the true air exchange rate calculations (Tab. 31). Each of the 12 exhaust fan flow rates were tested at constant conditions with the pressure flow sensor so that a correction factor for each fan could be calculated (Tab. 31). Because of the cost, a pressure flow sensor could not be installed in each chimney, so with the equipment at hand this was the most accurate way of obtaining the true ventilation rates.

Tab. 3- 1 Livestock house 2 ventilation system information

\begin{tabular}{ccccccc}
\hline $\begin{array}{c}\text { Multi-step } \\
\text { Groups }\end{array}$ & $\begin{array}{c}\text { Air } \\
\text { pressure } \\
\mathbf{( P a )}\end{array}$ & $\begin{array}{c}\text { Air volume } \\
\left(\mathbf{m}^{3} \mathbf{s e c}\right) \text { per } \\
\text { chimney }\end{array}$ & $\begin{array}{c}\text { Number of } \\
\text { exhaust fans } \\
\text { operating }\end{array}$ & $\begin{array}{c}\text { Extra } \\
\text { exhaust } \\
\text { fans } \\
\text { operating }\end{array}$ & $\begin{array}{c}\text { Exhaust } \\
\text { fan } \\
\text { Number }\end{array}$ & $\begin{array}{c}\text { Exhaust } \\
\text { fan } \\
\text { correction } \\
\text { factor }\end{array}$ \\
\hline 63 & 30,3 & 2,14 & 12 & 2 & 1 & 1,0 \\
31 & 43,3 & 2,56 & 12 & 1 & 2 & 1,2 \\
29 & 43,3 & 2,56 & 10 & 1 & 3 & 1,0 \\
15 & 25,0 & 1,94 & 12 & & 4 & 1,0 \\
14 & 18,2 & 1,66 & 11 & & 5 & 0,9 \\
13 & 21,4 & 1,80 & 10 & & 6 & 0,6 \\
12 & 22,4 & 1,84 & 9 & & 7 & 1,1 \\
7 & 24,4 & 1,92 & 8 & & 8 & 1,0 \\
6 & 29,1 & 2,10 & 7 & & 9 & 1,0 \\
5 & 37,1 & 2,42 & 6 & & 10 & 0,8 \\
4 & 53,2 & 2,84 & 5 & & 11 & 0,9 \\
3 & 59,9 & 3,01 & 4 & & 12 & 1,0 \\
2 & 61,9 & 3,06 & 3 & & & \\
\hline
\end{tabular}

Because the pressure flow sensor was not available on the measurement days 18 \& 25.08.04, an air exchange rate extrapolation was calculated from the measurements on the $08 \& 14.09 .04$ and the downloaded ventilation system data on the $18 \& 25.08 .04$. This extrapolation method was tested and then compared with the measured values on the 08.09.04 and 14.09.04, respectively. On the 08.09.04 the median ratio between extrapolated and measured hourly AER values was 1,01:1,00, with a minimum of $2,12 \%$ and a maximum of $+7,93 \%$. On the 14.09 .04 , the median ratio between extrapolated and measured hourly AER values was 1,00:1,00, with a minimum of - 
$3,92 \%$ and a maximum of $+5,97 \%$. Therefore, the extrapolated values were close to the true values.

The ventilator fan manufacturer states that each exhaust fan has a full capacity of 13 $000 \mathrm{~m}^{3} / \mathrm{h}$ (under laboratory conditions), however in the field, with influences from air pressure, dust etc. this was found to be otherwise. When all exhaust fans (12) plus the extra fans were operating (maximum ventilation system capacity), the multi-step exhaust fan functioned at $\sim 60 \%$ capacity. When only one fan group together with the multi-step was operating (minimum ventilation system capacity) the multi-step exhaust fan functioned at $86 \%$ capacity. According to the manufacturer, 1 large extra fan operating at full capacity has air flow rates of $35000 \mathrm{~m}^{3} / \mathrm{h}$ (under laboratory conditions), however, because this air flow could not be measured, it was assumed that each extra fan function at $60 \%$ capacity. 


\section{Chapter}

\section{Results}

\subsection{Experiment 1: $\mathrm{CO}_{2}$, heat and moisture mass balance results from livestock house 1}

The following measurements were performed under summer conditions, the year 2003 was the hottest summer to hit Europe in the last 100 years. The average $24 \mathrm{~h}$ temperatures on the 03.08.04 $\left(25.3^{\circ} \mathrm{C}\right)$ and $14.08 .03\left(19.5^{\circ} \mathrm{C}\right)$, were both above the summer average $\left(16.8^{\circ} \mathrm{C}\right)$ for this region. Because of the very hot conditions, air circulation fans situated on the side walls of the livestock house were operating during these periods to keep the environment suitable for the productivity and welfare of the broilers. There exists a total of 12 large fans (diameter $95 \mathrm{~cm}$ ) and 6 smaller fans (diameter $50 \mathrm{~cm}$ ), with 6 large fans and 3 small fans located along each side wall (refer Fig. 3.3).

Because there is no exact way to measure the air exchange rates from naturally ventilated livestock buildings, there is no way of determining which method is more accurate, however, by considering the age of the birds and comparing the calculated mass balance hourly AERs throughout the day and night with weather conditions it is possible to gain a realistic impression. Mass balance models only provide an estimate of the air exchange rate, often only useful in providing the $24 \mathrm{~h}$ average value. Therefore in this section the results are presented to only 1 decimal place. 
Tab. 4- 1 Summarised mass balance results and weather conditions $(03.08 .03)$

\begin{tabular}{|c|c|c|c|}
\hline $\begin{array}{l}\text { Bird weight: } 0,62 \mathrm{~kg} \\
\text { Age: } 17 \text { days }\end{array}$ & Mean \pm SD & Range & Median \\
\hline $\begin{array}{c}\mathrm{CO}_{2} \text { balance } \\
\text { (exchange rate/h) }\end{array}$ & $40,3 \pm 5,9$ & $27,8-44,9$ & 43,7 \\
\hline $\begin{array}{c}\text { Heat balance } \\
\text { (exchange rate/h) }\end{array}$ & $19,7 \pm 5,8$ & $9,3-23,6$ & 23,6 \\
\hline $\begin{array}{l}\text { Moisture balance } \\
\text { (exchange rate/h) }\end{array}$ & $39,8 \pm 15,3$ & $14,9-50,2$ & 50,2 \\
\hline Wind speed $\left(\mathrm{ms}^{-1}\right)$ & $0,7 \pm 0,6$ & $0,0-1,7$ & 0,9 \\
\hline Wind direction $\left(^{\circ}\right)$ & $175,5 \pm 152,7$ & $0,0-352,5$ & 172,8 \\
\hline Outside temperature $\left({ }^{\circ} \mathrm{C}\right)$ & $25,3 \pm 5,4$ & $17,4-31,6$ & 25,8 \\
\hline Inside temperature $\left({ }^{\circ} \mathrm{C}\right)$ & $26,3 \pm 2,1$ & $23,8-29,3$ & 25,4 \\
\hline $\begin{array}{c}\Delta \text { Temperature } \\
\text { (inside \& outside stall }{ }^{\circ} \mathrm{C} \text { ) }\end{array}$ & $1,0 \pm 3,5$ & $(-) 2,8-6,8$ & $-0,4$ \\
\hline Coefficient of variation betwe & & & \\
\hline $\begin{array}{l}\mathrm{CO}_{2} \text { sample location } \\
\text { concentrations }(\%)\end{array}$ & $5,2 \pm 4,4$ & $0,2-12,7$ & 4,2 \\
\hline
\end{tabular}

The bird age was 17 days (approximate weight $0,62 \mathrm{~kg}$ ). The temperature on the 03.08.03 was hot with a maximum of $31,6^{\circ} \mathrm{C}$ and a median of $25,8^{\circ} \mathrm{C}$, sometimes the temperature was hotter outside than inside the stall, as can be seen with a minimum temperature difference between inside and outside conditions ( $\Delta$ temperature) of $(-)$ $2,8^{\circ} \mathrm{C}$. The inside conditions were also rather hot with a median of $25,4^{\circ} \mathrm{C}$ (Tab. $4-1$ ). Because the heat mass balance model requires a temperature difference of $>2{ }^{\circ} \mathrm{C}$ to give reasonable results this led to errors in the calculations. Generally, when the temperature difference between inside and outside the stall is small it is reasonable to assume high ventilation rates occurred, under these circumstances a very low mean $\Delta$ temperature of $1^{\circ} \mathrm{C}$ and a median of $-0,4^{\circ} \mathrm{C}$ indicates high air exchange rates occurred as well as hot outside temperatures.

For good ventilation in naturally ventilated buildings to occur, transverse winds i.e. direction $90^{\circ}$ (direct easterly) or $270^{\circ}$ (direct westerly wind) would be ideal with wind speeds $>2 \mathrm{~ms}^{-1}$. The wind conditions were not optimal with a median of $0,9 \mathrm{~ms}^{-1}$, a 
range from $0-1,7 \mathrm{~ms}^{-1}$ and wind directions ranging from $0,0-352,5^{\circ}$. Therefore, it seems probable that the wind was not a strong contributor to the air exchange rates.

The small average coefficient of variation (CV) and standard deviation (SD) between $\mathrm{CO}_{2}$ concentrations throughout the stall sampling locations (9) of 5,2 $\pm 4,4 \%$ suggests the air was well mixed. The high mixing of the air would have been due to the large heat buoyancy and the air circulation fans. The CV values (Appendix A Tab.1) increased sharply from a low of $2,6 \%$ at $12 \mathrm{~h}$ to $11,6 \%$ at $13 \mathrm{~h}$ and then fluctuated between 12,7 and 6,5\% onwards. High turbulences caused by increased AERs as well as the increased $\mathrm{CO}_{2}$ production from the birds, may have caused the increased $\mathrm{CV}$ between the sample locations.

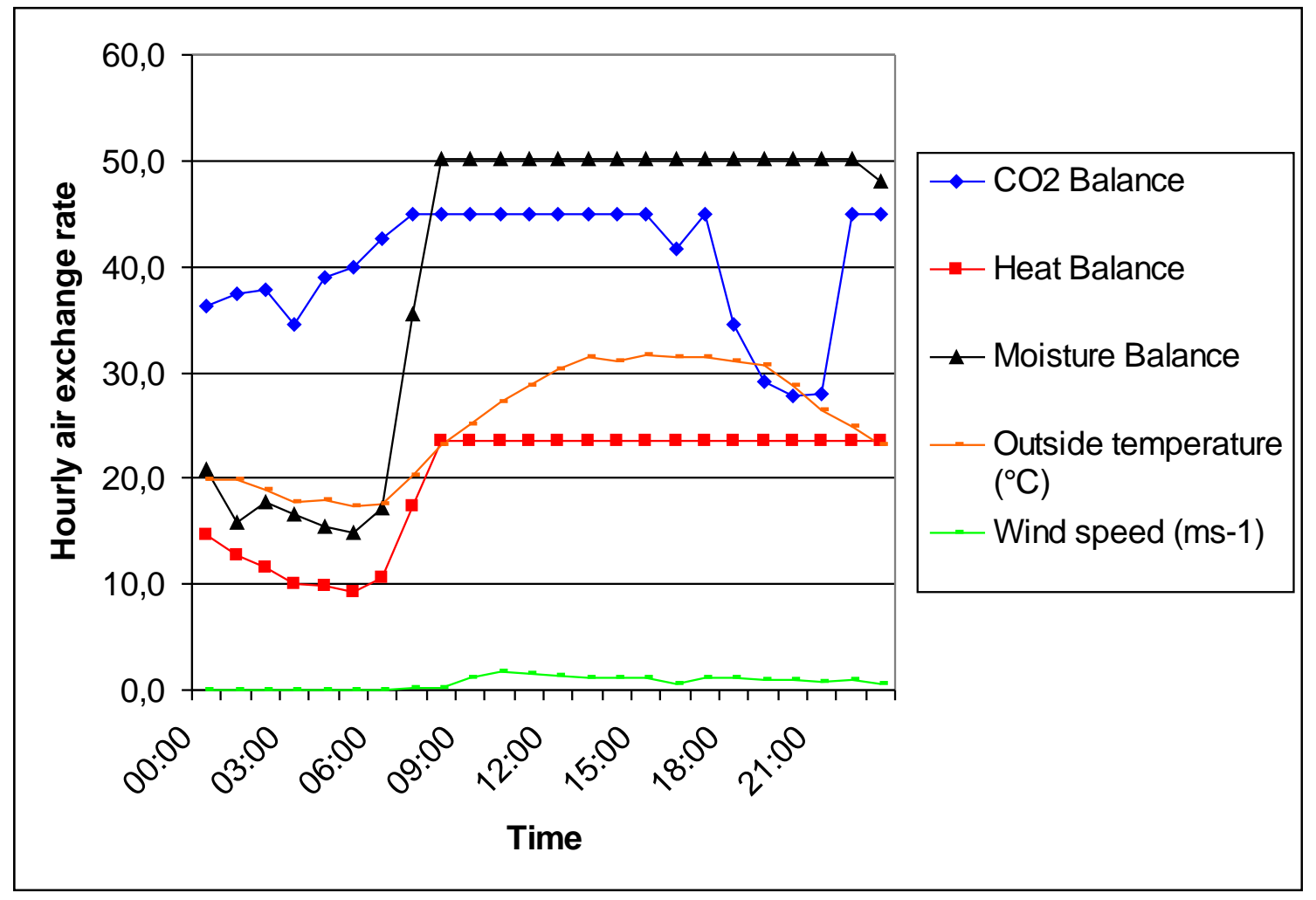

Fig. 4- 1: Hourly mass balance AER results and influencing weather variables (03.08.03)

From the mass balance results (Fig. 4-1) all MBMs exceeded the peak early in the day, the $\mathrm{CO}_{2}$ model at $07 \mathrm{~h}$, heat and moisture balance models at $09 \mathrm{~h}$. This is because the $\Delta$ $\mathrm{CO}_{2}$ concentration, $\Delta$ temperature and $\Delta$ moisture between inside and outside the stall were below the recommended minimum difference $\left(\Delta \mathrm{CO}_{2}>200 \mathrm{ppm}, \Delta\right.$ temperature $>$ $2{ }^{\circ} \mathrm{C}$ and $\Delta$ moisture $>0,0005 \mathrm{~kg} / \mathrm{m}^{3}$ ), resulting in absurd values throughout most of the 
day (Appendix A. Tab. 1). To correct these values, the results had to be modified by inserting the minimum difference for e.g. $\mathrm{CO}_{2}$ concentration of $150 \mathrm{ppm}$ into the model equation etc, thus resulting in the highest possible air exchange rate calculation, as shown with the plateau peaks in Fig. 4-1.

The $\mathrm{CO}_{2}$, heat and moisture mass balance models recorded mean hourly air exchange rates of 40,3, 19,7 and 39,8/h, respectively. The highest range was recorded by the moisture balance model 14,9-50,2, by viewing Fig. 4-1 it is clear the range is too wide. The model did not function because of the hot weather conditions, the outside air containing a higher water content than the inside air. This was the same with the temperature mass balance model, the outside temperatures were higher than inside temperatures causing absurd air exchange calculations, this was indicated with the median $\Delta$ temperature difference $(-) 0,4^{\circ} \mathrm{C}$. The heat and moisture balance results were both out of range from $09 \mathrm{~h}$ until $23 \mathrm{~h}$, thus, the models were incapable of providing results for over two thirds of the day. The $\mathrm{CO}_{2}$ model also recorded very high results from $07-15 \mathrm{~h}, 17 \mathrm{~h}$ and $22-00 \mathrm{~h}$, but at least this model provided some results in the morning and afternoon, and followed a realistic trend with higher air exchange rates occurring in the middle of the day. The high AER peaks from 22-00h are due to a flaw in the model, as the low $\mathrm{CO}_{2}$ concentrations at this time would have been due to reduced activity rather than high ventilation. These AERs would have been more in line with $21 \mathrm{~h}$.

From the results it appears that the temperatures were too high for the successful calculation of the heat and moisture balance models. However, it seems probable that the reason for the peaks early in the day with the $\mathrm{CO}_{2}$ results were due to the operation of fans. Interestingly, at $07 \mathrm{~h}$ the heat and moisture balance model results began to rise, due to the increased temperatures and decreasing difference between inside and outside temperature and moisture levels. However, this would have no effect on the $\mathrm{CO}_{2}$ mass balance results, which peaked at $07 \mathrm{~h}$, and because wind speeds were negligible $\left(0,1 \mathrm{~ms}^{-}\right.$ ${ }^{1}$ ), the peak is likely to be a response to the activation of the air circulation fans causing the dilution of the $\mathrm{CO}_{2}$ concentrations and thus the $\mathrm{CO}_{2}$ mass balance model peak results. 
Because of the very low wind speeds throughout the day between $0,1-1,7 \mathrm{~ms}^{-1}$ and the wind directions were very irregular (Appendix A. Tab. 1), it was probably necessary to operate extra fans during the day. Notes from the farmer indicate the small fans were operating consistently throughout this period, and it seems that between $09-12 \mathrm{~h}$ perhaps the large fans were switched on as the $\mathrm{CO}_{2}$ concentration difference between inside and outside the stall decreased below 50ppm (Appendix A. Tab. 1). The outdoor temperatures remained above $30^{\circ} \mathrm{C}$ until $19 \mathrm{~h}$, so the extra fans were probably operating at full capacity until $\sim 20 \mathrm{~h}$, when the inside and outside temperatures began to drop. The extra fans as well as the higher air exchange rates after midday may have caused the high CV increase at $13 \mathrm{~h}$, which stayed between 6,5 and $12,7 \%$ until midnight.

The $\mathrm{CO}_{2}$ balance results may have been exaggerated with the air circulation fans diluting the $\mathrm{CO}_{2}$ concentrations. Although the concentrations were diluted and the air circulation was increased in the stall, this increased circulation would not necessarily have increased the air exchange rates to the same extent as cross winds with high velocity. Also the circulation fans only operate at several locations and at different angles, rather than direct winds passing though the whole stall.

The $\mathrm{CO}_{2}$, heat and moisture balance mean hourly air exchange rates varied significantly, with $40,3 / \mathrm{h}, 19,7 / \mathrm{h}$ and $39,8 / \mathrm{h}$, respectively. Because of the hot temperatures and the operation of the fans, the side wall curtains were completely open, if there had been high wind speeds and in the transverse direction, perhaps a high air exchange rate of 50,2/h (moisture balance maximum) during the middle of the day could have been possible, but because of the low wind speeds it seems more likely that the real 24h AER would have been between 40,3/h $\left(\mathrm{CO}_{2}\right.$ balance mean) and 19,7/h (heat balance mean) therefore $\sim 30,0 / \mathrm{h}$.

The maximum recommended ventilation rate under these conditions is $2,97 \mathrm{~m}^{3} / \mathrm{bird} / \mathrm{h}$ (DIN 18910. 1998), this translates to an air exchange rate of $14,6 / \mathrm{h}$. 
Tab. 4- 2 Summarised mass balance results and weather conditions (14.08.03)

\begin{tabular}{|c|c|c|c|}
\hline $\begin{array}{l}\text { Bird weight: } 1,35 \mathrm{~kg} \\
\text { Age: } 28 \text { days }\end{array}$ & Mean \pm SD & Range & Median \\
\hline $\begin{array}{c}\mathrm{CO}_{2} \text { balance } \\
\text { (exchange rate/h) }\end{array}$ & $68,9 \pm 15,8$ & $35,4-79,5$ & 79,5 \\
\hline $\begin{array}{c}\text { Heat balance } \\
\text { (exchange rate/h) }\end{array}$ & $37,5 \pm 13,4$ & $20,5-52,6$ & 34,4 \\
\hline $\begin{array}{l}\text { Moisture balance } \\
\text { (exchange rate/h) }\end{array}$ & $51,9 \pm 26,9$ & $24,1-85,9$ & 34,6 \\
\hline Wind speed $\left(\mathrm{ms}^{-1}\right)$ & $1,9 \pm 2,0$ & $0,0-5,7$ & 1,2 \\
\hline Wind direction $\left({ }^{\circ}\right)$ & $297,2 \pm 30,3$ & $269,8-359,0$ & 284,0 \\
\hline Outside temperature $\left({ }^{\circ} \mathrm{C}\right)$ & $19,5 \pm 3,3$ & $14,9-24,8$ & 18,7 \\
\hline Inside temperature $\left({ }^{\circ} \mathrm{C}\right)$ & $22,6 \pm 0,7$ & $21,5-23,8$ & 22,7 \\
\hline $\begin{array}{c}\Delta \text { Temperature } \\
\text { (inside \& outside stall }{ }^{\circ} \mathrm{C} \text { ) }\end{array}$ & $3,1 \pm 2,7$ & $(-) 1,1-6,7$ & 3,9 \\
\hline Coefficient of variation between & & & \\
\hline $\begin{array}{c}\mathrm{CO}_{2} \text { sample location concentrations } \\
(\%)\end{array}$ & $6,3 \pm 3,5$ & $0,8-13$ & 6,8 \\
\hline
\end{tabular}

The birds were approximately 28 days old (weight $1,35 \mathrm{~kg}$ ), so the birds were approaching the final harvest weight of $1,5-2 \mathrm{~kg}$ (Tab. 4-2). The temperature on the 14.08.03 was warm with a range $14,9-24,8^{\circ} \mathrm{C}$ and a median of $18,7^{\circ} \mathrm{C}$ but not as hot as 03.08.03 with a median $25,8^{\circ} \mathrm{C}$ (range $17,4-31,6^{\circ} \mathrm{C}$ ). Once again, sometimes the temperature was hotter outside the stall than inside, as can be seen with a minimum $\Delta$ temperature $(-) 1,1^{\circ} \mathrm{C}$. A $\Delta$ temperature median of $3,9^{\circ} \mathrm{C}$ also suggests high air exchange rates. The median inside temperature $22,7^{\circ} \mathrm{C}$ (range $21,5-23,8^{\circ} \mathrm{C}$ ) was lower than $25,4^{\circ} \mathrm{C}$ (range $23,8-29,3^{\circ} \mathrm{C}$ ) recorded on the 03.08.03. The wind speed was reasonably low with a median of $1,2 \mathrm{~ms}^{-1}$, however high wind speeds were recorded with a maximum of $5,7 \mathrm{~ms}^{-1}$, compared to the previous period $(03.08 .03)$ median $=0,9 \mathrm{~ms}^{-1}$ and maximum $=1,7 \mathrm{~ms}^{-1}$. The wind direction was almost transverse with a median of $284^{\circ}\left(270^{\circ}\right.$ transverse westerly) and a standard deviation of $30,3^{\circ}$, compared with the irregular wind directions previously (03.08.03). Because the outside temperatures were 
not as hot as 03.08.03, the air circulation fans were not operating at full capacity, but with the effects from strong transverse winds, heavier birds (more heat production) and perhaps higher AERs, these factors may have caused the higher CV median 6,8\% compared to $4,2 \%$ on the 03.08.03. It also seems possible that the lower CVs on the 03.08.03 were due to the better mixed air because of the air circulation fans operating at full capacity to keep the temperatures down.

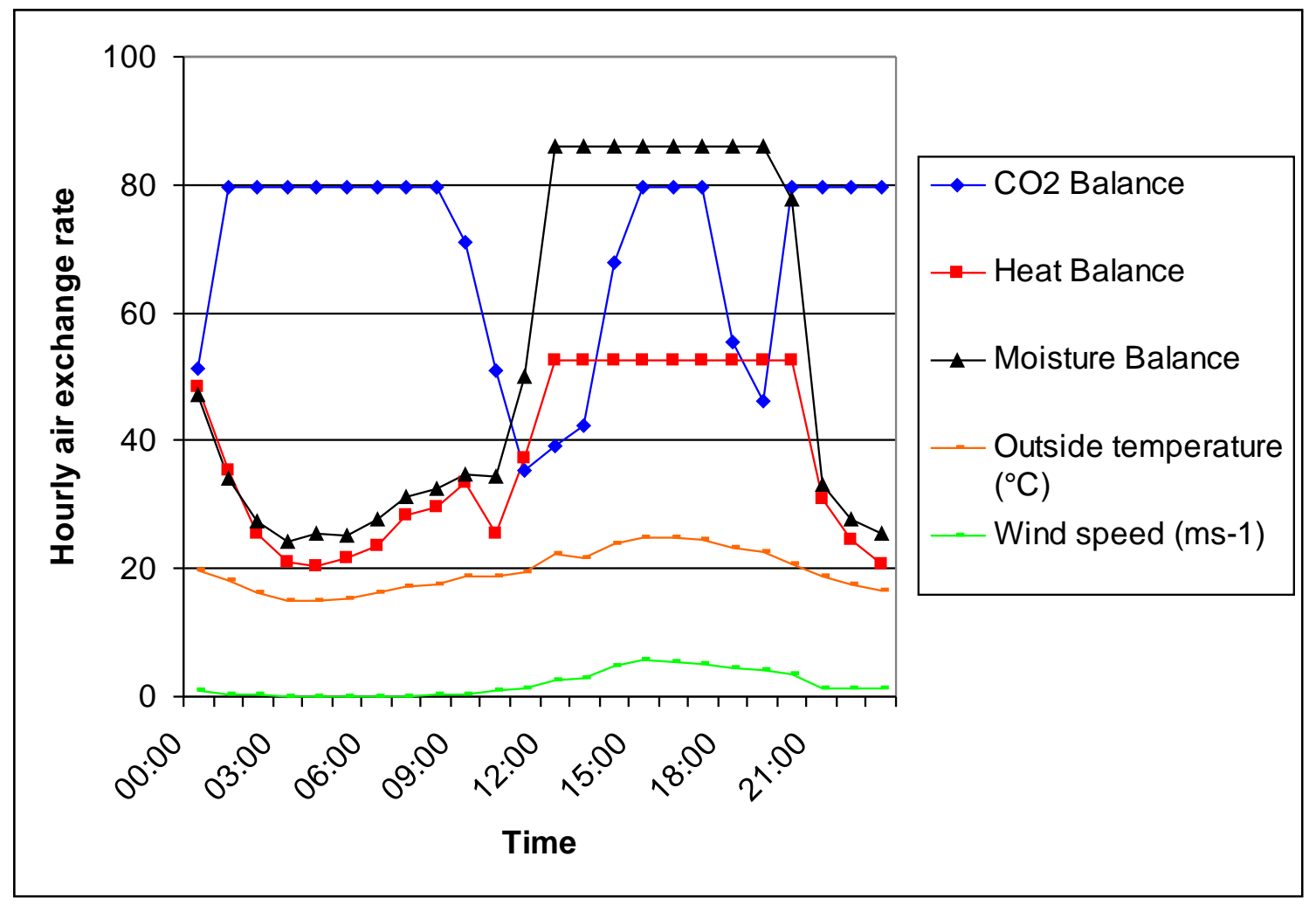

Fig. 4- 2: Hourly mass balance AER results and influencing weather variables (14.08.03)

Once again, because of the very warm conditions the difference between inside and outside $\mathrm{CO}_{2}$, temperature and moisture levels were at times below the minimum recommended levels, therefore the mass balance results had to be corrected (Appendix A Tab. 2) causing the peak plateaus throughout the period (Fig. 4-2). The moisture balance recorded a maximum air exchange rate of $85,9 / \mathrm{h}$, compared with the $\mathrm{CO}_{2}$ and heat balances, 79,5/h and 52,6/h, respectively. The heat and moisture balances followed a realistic diurnal trend with higher air exchange rates during the middle of the day, opposite to the $\mathrm{CO}_{2}$ balance and to the previous results (03.08.03), where the $\mathrm{CO}_{2}$ balance produced more reliable results. 
The heat and moisture balance peaks from $12-20 \mathrm{~h}$ were due to the reduced temperature/moisture difference between inside and outside conditions below the recommended minimum. Interestingly, the heat and moisture balance AERs both peaked at $12 \mathrm{~h}$, precisely when wind speeds increased above $2 \mathrm{~ms}^{-1}$ in the transverse direction (Appendix A Tab. 2). The wind speeds remained between 4-5,7 $\mathrm{ms}^{-1}$ from 1419h, also coinciding with the heat and moisture balance peak AERs. Both the heat and moisture balances recorded high correlation coefficients between hourly air exchange rate and wind speed $\left(r^{2}=0,85\right.$ and 0,92 , respectively). The high air exchange rates coincided with peak outside temperatures and wind speeds (Fig. 4-2).

The reasons for the incorrect $\mathrm{CO}_{2}$ mass balance model peaks were due to the very low $\mathrm{CO}_{2}$ concentrations during the early morning and late evening resulting in the air exchange rate peaks at these times. The lower $\mathrm{CO}_{2}$ concentrations during the morning and evening would be due to the reduced feeding, metabolism and animal activity at these times resulting in a reduced $\mathrm{CO}_{2}$ production, with the combined effect from high ventilation rates keeping the $\mathrm{CO}_{2}$ concentrations to a minimum. Furthermore, the higher $\mathrm{CO}_{2}$ concentrations during the day causing the lower AERs would be from the increased animal metabolism, activity etc, causing a rise in the $\mathrm{CO}_{2}$ production. This is a typical flaw in the model, whereby, increased $\mathrm{CO}_{2}$ concentrations caused by increased $\mathrm{CO}_{2}$ production calculates to lower AERs, even when in reality high ventilation rates are occurring simultaneously.

Once again, the air circulation fans were also operating during this period, from the farmers notes the large fans were on, the times are not clear. However, during the daytime from $12-20 \mathrm{~h}$ wind speeds were between $2,4-5,7 \mathrm{~ms}^{-1} / \mathrm{h}$ and in the transverse direction (mean $279,3^{\circ}$ ). Therefore, it seems likely that the farmer would have had the fans off during this period. Interestingly, the $\mathrm{CO}_{2}$ values sharply increase from 1,8$8,3 \%$ at $08 \mathrm{~h}$ (Appendix A Tab. 2) and at this time wind speeds were only $0,2 \mathrm{~ms}^{-1}$, probably a result from the farmer turning the fans on at this time the increased turbulences causing the $\mathrm{CO}_{2}$ values to rise, and then the fans were probably switched off around midday, whereby, the strong winds kept the CV values continuously high.

The mean $\mathrm{CO}_{2}$, heat and moisture balance air exchange rates were 68,9/h, 37,5/h and $51,9 / \mathrm{h}$, respectively. The $\mathrm{CO}_{2}$ balance $24 \mathrm{~h}$ average 68,9 seems high, and the heat 
balance $37,5 / \mathrm{h}$ too low, a realistic $24 \mathrm{~h}$ average would perhaps lie between the $\mathrm{CO}_{2}$ and moisture balance mean results $\sim 53,2 / \mathrm{h}$, above the estimated mean 30/h $(03.08 .03)$. The higher air exchange rate on the 14.08.03 seems realistic due to the increased heat buoyancy contributions from the heavier birds $(0,73 \mathrm{~kg}$ heavier $)$ and the relatively strong transverse winds during the middle of the day $\left(2,4-5,7 \mathrm{~ms}^{-1}\right)$. The high heat and moisture balance AERs during very early morning 00-03h $(25,6-48,4 / \mathrm{h})$ seem too high and are due to flaws in the model, whereby reduced activity causes the reduced temperature and moisture levels, not high AERs. Realistically, AERs at these times would lie between 15-20/h, considering the reduced bird activity, negligible wind speeds $\left(0,1 \mathrm{~ms}^{-1}\right)$ and mild temperatures $15-19,7^{\circ} \mathrm{C}$. The high air exchange rate peak recorded by the heat and moisture balance models from $12-20 \mathrm{~h}$, is realistic considering bird activity at this time, transverse wind directions $\left(280^{\circ}\right)$, high wind speeds $\left(4,2 \mathrm{~ms}^{-1}\right)$ and high outside temperatures $\left(20,8-24,8^{\circ} \mathrm{C}\right)$, these influences could have caused high AERs perhaps between the heat and moisture balance maximums $70 / \mathrm{h}$ or even up to $100 / \mathrm{h}$.

The maximum recommended ventilation rate under these conditions is $4,41 \mathrm{~m}^{3} / \mathrm{bird} / \mathrm{h}$ (DIN 18910. 1998), this translates to an air exchange rate of 21,7/h. The assumed AER $53,2 / \mathrm{h}$ was well above.

\subsection{Experiment 2: Heat and moisture mass balance results along with constant injection tracer gas method in Livestock house 1}

The following methods were performed under normal farm conditions on a full sized broiler farm so the level of error from farm management operations etc. could not be controlled, in comparison to studies performed in experimental buildings under controlled conditions. Because of the time constraints in keeping up with the farmers operations the gas tubes were insulated but not heated, therefore when the tubes passed from the warm stall environment though the cool outside air into the mobile laboratory moisture formed in the tubes and thus all $\mathrm{CO}_{2}$ results were discarded and hence the $\mathrm{CO}_{2}$ mass balance could not be performed.

Because there is no precise way to measure the air exchange rates from naturally ventilated livestock buildings, there is no way of determining which method is more 
accurate. All methods tested are subject to error, the variability of bird masses and therefore model calculations of heat and moisture production, heat emissions from the heaters, heat transmission loss and gain though the building structure, moisture contributions from the manure/litter, poor distribution and mixing of tracer gas with air, instrumental drift etc are all sources for inaccuracies with the methods tested. However, it was hoped that good equipment preparation and ideal conditions would yield informative results and that by comparing the air exchange rate calculations with influencing factors such as bird weight, wind speed, outdoor temperature and previous studies the accuracy of the results could be assessed.

The heat contributions from the brooder heaters were estimated by attaching a gas meter on to 2 brooder heaters both functioning at different outputs and from this the heat output from all heaters was estimated (discussed in materials and methods). Although this method of estimating was justified through discussion with the farmer and inspections, it is clear that because of the large number of heaters (28) there would be performance and gas consumption variability amongst different heaters, however it was hoped that a good estimation of heat and moisture contributions to the environment from the heaters could be provided.

From the 07.11.03 dosing was conducted from a single dosing point at a height of $1,7 \mathrm{~m}$ on the eastern wall in the centre of the air mixing sub-section. On the 12.11.03, the dosing point was altered, from 1 to 3 dosing points at the same height and evenly spaced within the air mixing sub-section. On the 13.11.03, dosing and sampling locations were changed, because of a change in wind direction the 3 point dosing system was set up on the western wall and sampling from the opposite side.

Because of the increased sensitivity of measurements gained with the tracer gas method, consistent conditions and the small differences between the results, all results are presented to 2 decimal places. In addition the influencing weather variables and inside hygro-thermal parameters have also been presented to 2 decimal places, because these were also very similar between the measured days. Although the differences between the results are small, there does appear to be very interesting relationships between the influencing variables and results. 
The mean AER calculations from the previous experiment (experiment 1) were compared because the mass balance models alone are only used for $24 \mathrm{~h}$ averages. In the following experiment the median results have been analysed and compared because of the increased level of accuracy gained with the tracer gas method results.

The weather conditions over the measuring period were very cool temperatures and rather constant wind direction and speeds, ideal for the intentions of the experimental set up. The first successful measuring day commenced on the 07.11 .03 (17h) and continued until $14.11 .03(10 \mathrm{~h})$, each measurement period analysed consisted of a $24 \mathrm{~h}$ period, except where a power failure occurred after 10h (14.11.03), reducing this measurement period to 22 hours.

The ventilation system (discussed in materials and methods) operates by the opening and closing of side wall curtains and chimney baffles, based on the temperature and humidity values recorded at a height of $0,7 \mathrm{~m}$ above the ground in the centre of the livestock house. The sensor was checked, although it was within an acceptable range it was not as accurate as the rotronic sensors and was placed at a height of $0,7 \mathrm{~m}$ compared to the rotronic sensor heights $\sim 5,7 \mathrm{~m}$.

Bird activity was successfully measured on the 12.11 .03 and 13.11 .03 and the activity coefficient for each hour was multiplied by the mass balance air exchange rate to obtain air exchange rate values. Because air exchange rates measured from naturally ventilated buildings can not be fully validated, the calculated air exchange rates with bird activity were not included.

Considering that pure $\mathrm{SF}_{6}$ was dosed and the molecular weight is 5 times heavier than air, concentrations at the lower sampling locations along the wall compared with the higher chimney locations, showed no significant differences throughout all measurement periods. Therefore, the dosed tracer gas mixed well within the livestock house. 


\subsubsection{Tracer gas method estimation of error}

Experimental errors play a role and reduce the accuracy of results in tracer gas experiments. The probable experimental error in tracer gas experiments can be estimated using partial differentiation of the ventilation rate $\theta$ (Van't Klooster \& Heitlager 1994), according to the continuity of flow equation 17, this can be expressed as equation 19.

$Q(t)=\frac{\varphi(t)}{c_{i}(t)-c_{e}(t)}$

$Q(t)=$ Ventilation rate $\mathrm{m}^{3} \mathrm{~s}^{-1}$

$\varphi(t)=$ Rate of tracer gas release $(\mathrm{mg})$

$c_{i \& e}(t)=$ Indoor tracer concentration $\left(\mathrm{c}_{\mathrm{i}}\right)$ and correction for background concentration $\left(c_{\mathrm{e}}\right)$

$$
\frac{\delta \theta}{\theta}=\left[\left(\frac{\delta Q}{Q}\right)^{2}+\left(\frac{\delta \varphi(0)}{\varphi(0)^{2}}\right)^{2}+\left(\frac{\delta C(0)}{C(0)^{2}}\right)\right]^{\frac{1}{2}}
$$

The relative overall error in the determination of the air exchange rate is given from the error propagation from the sum of the relative errors of the individual factors (VDI 4300. 2001). With relative errors in room volume, stability of injected flow, tracer gas content of injection stream to be $1,2,1 \%$ respectively this amounts to a probable error of $\theta$ of $2,4 \%$. Besides these errors the assumption of complete mixing is not met and adds to the error. The error in $\theta$ can be estimated from the standard deviations in the mean ventilation rates derived from 4 relevant measuring positions (Van't Klooster \& Heitlager 1994). This was calculated for all experimental days as, 07.11 .03 (22,9\%), $08.11 .03(12,3 \%), 09.11 .03(6,5 \%), 12.11 .03(7,5 \%)$ and $13.11 .03(3,6 \%)$.

The total probable error, as the square root of the sum of the squares was, $23 \%, 12 \%$, $7 \%, 8 \%$ and $4 \%$ for the measured days, respectively. The higher levels of error calculated from the periods partly correspond with the higher air exchange rates calculated. The highest air exchange rates were calculated on the 07.11 .03 (error 23\%) 
and the lowest error was calculated on the 13.11.03 (4\%). Indicating the error increased as the air exchange rates increased. However, this was a basic approach, a more detailed analysis of error should include a more accurate error associated with tracer gas escaping from the well mixed zone and or tracer gas remaining in possible sinks within and outside of the air mixing sub-section. Because of the small number of samples, good mixing within the stall is only a basic assumption and only a basic error analysis was performed.

\subsection{Measurement period $07-14.11 .03$ results}

Tab. 4- 3 Summarised AER results and weather conditions (07.11.03)

\begin{tabular}{|c|c|c|c|}
\hline $\begin{array}{l}\text { Bird weight: } 0,92 \mathrm{~kg} \\
\text { Age: } 21 \text { days }\end{array}$ & Mean \pm SD & Range & Median \\
\hline $\begin{array}{l}\text { Tracer gas method } \\
\text { (exchange rate/h) }\end{array}$ & $2,60 \pm 0,83$ & $1,04-4,49$ & 2,62 \\
\hline $\begin{array}{c}\text { Heat balance } \\
\text { (exchange rate/h) }\end{array}$ & $3,50 \pm 0,55$ & $2,99-4,57$ & 3,24 \\
\hline $\begin{array}{l}\text { Moisture balance } \\
\text { (exchange rate/h) }\end{array}$ & $5,44 \pm 0,62$ & $4,55-6,73$ & 5,22 \\
\hline Wind speed $\left(\mathrm{ms}^{-1}\right)$ & $3,9 \pm 0,85$ & $1,90-5,30$ & 3,75 \\
\hline Wind direction $\left(^{\circ}\right)$ & $87,61 \pm 3,43$ & $78,30-92,10$ & 88,25 \\
\hline Outside temperature $\left({ }^{\circ} \mathrm{C}\right)$ & $7,04 \pm 1,08$ & $6,20-9,20$ & 6,50 \\
\hline Inside temperature $\left({ }^{\circ} \mathrm{C}\right)$ & $23,29 \pm 0,49$ & $22,24-24,05$ & 23,44 \\
\hline Inside humidity (\%) & $56,65 \pm 1,56$ & $53,47-60,23$ & 56,71 \\
\hline $\begin{array}{c}\Delta \text { Temperature } \\
\text { (inside \& outside stall }{ }^{\circ} \mathrm{C} \text { ) }\end{array}$ & $16,26 \pm 1,52$ & $13,48-17,61$ & 16,99 \\
\hline $\begin{array}{c}\text { Coefficient of variation } \\
\text { between } \mathrm{SF}_{6} \text { sample location } \\
\text { concentrations (\%) }\end{array}$ & $18,16 \pm 4,26$ & $10,78-27,14$ & 18,25 \\
\hline
\end{tabular}

On the 07.11 .03 the birds weighed approximately $0,92 \mathrm{~kg}$ and were 3 weeks old, so therefore at this stage in the grow out cycle a significant driving force behind the natural 
ventilation forces originated from the thermal buoyancy produced by the birds. In reference to Tab. 4-3, the outdoor temperature results indicate the highest temperatures throughout the measurement period (07-14.11.03), the temperature conditions are cool and constant with a range from $6,20-9,20^{\circ} \mathrm{C}$ and a median of $6,50^{\circ} \mathrm{C}$. The $\Delta$ temperature (difference between inside and outside conditions) median $16,99^{\circ} \mathrm{C}$ (range $13,48-17,61^{\circ} \mathrm{C}$ ) was the lowest out of all days tested, as expected with the higher outside temperatures (Tab. 4-3). The median inside temperature was also the lowest out of the 5 measurement periods tested even with the higher outdoor conditions, these lower indoor temperatures could be due to the lower weight of the birds and/or higher air exchange rates. Of particular interest are the wind conditions, the wind speed remained reasonably high and relatively constant with a median $3,75 \mathrm{~ms}^{-1}$ (range 1,90 $5,30 \mathrm{~ms}^{-1}$ ) along with a constant transverse direction median $88,25^{\circ}$ (easterly transverse direction $90^{\circ}$ ) and range 78,30-92,10 . The highest median wind speed out of all days tested was recorded in this period. In agreement with the data, the median air exchange rate $2,62 / \mathrm{h}$ was slightly higher than all other days tested. The CV between the sampling locations also recorded the highest median $(18,25 \%)$ out of all measurement periods with a range $10,78-27,14 \%$, this maybe due to the higher air movements and turbulences created by higher air exchange rates. With the higher outside temperatures the side curtains may have been more open than the following days and with the high wind speeds and constant transverse wind directions, the higher fresh air influx causing greater turbulences and slightly higher air exchange rates.

The tracer gas fluctuations throughout the day are reasonable with a SD of $\pm 0,83$ air exchanges (32\%), this may be due to the constant wind direction (mean and SD) 87,61 $\pm 3,43^{\circ}$ and wind speed $3,9 \pm 0,85 \mathrm{~ms}^{-1}$. The heat and moisture balance fluctuations were even smoother with mean and standard deviations 3,50 $\pm 0,55$ and 5,44 $\pm 0,62$, respectively. The natural tracer gas hourly exchange rate curves were also much smoother than the tracer gas method, which is perhaps due to the better mixing the natural tracer gases (temperature and moisture) undergo inside the stall environment. A possible explanation could be because the natural tracer gases are released from the source (the birds) and throughout the whole stall, also the heat and moisture MBMs assume constant heat and moisture production over time. Whereas, the artificial tracer gas was released from a single point at a height of $1,7 \mathrm{~m}$ from the side wall, this method is obviously susceptible to more interference. 


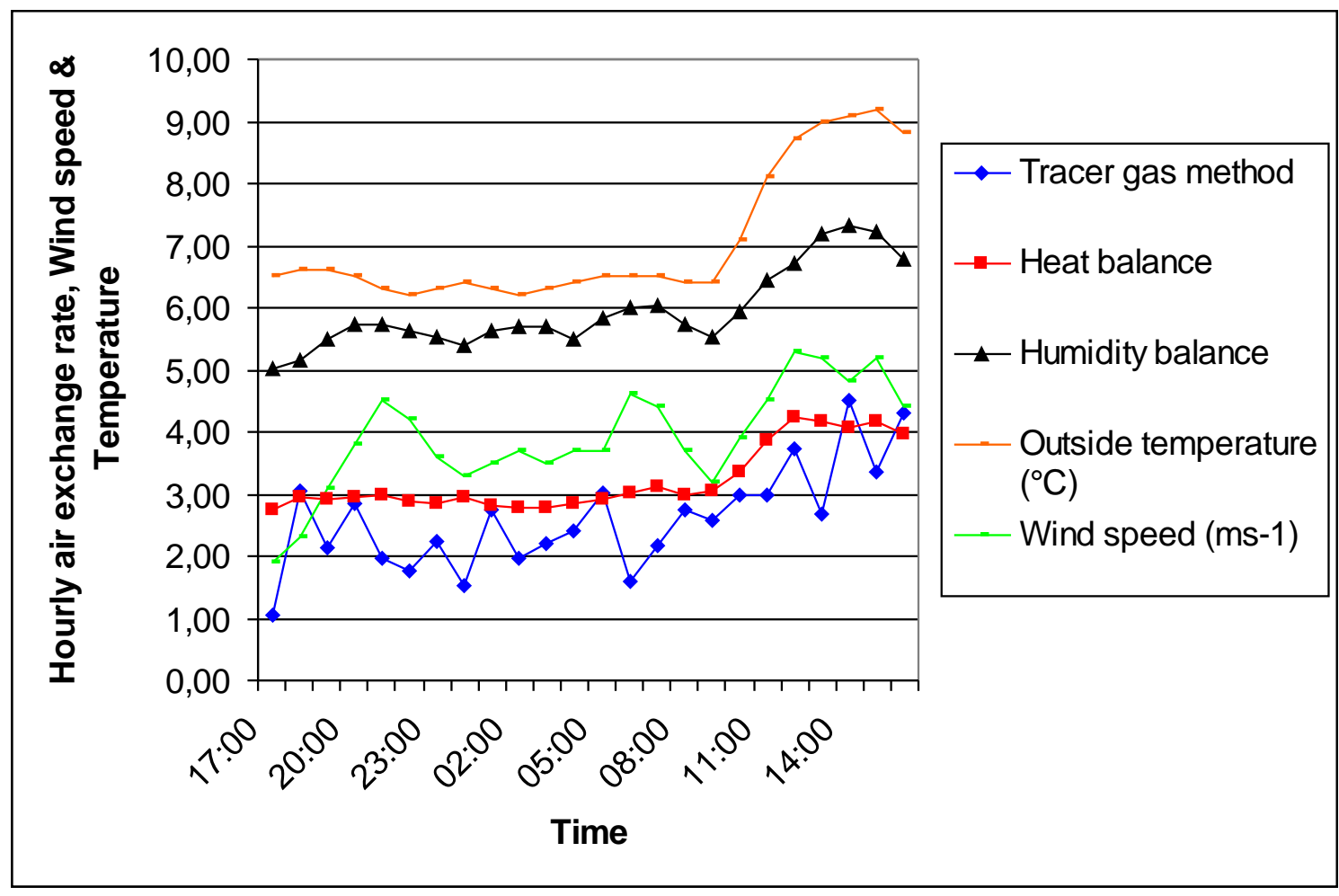

Fig. 4- 3: Hourly mass balance and tracer gas method AER results along with influencing weather variables $(\mathbf{0 7 . 1 1 . 0 3 )}$

The tracer gas method results (Fig. 4-3) indicate the low air exchange rates occurred at $17 \mathrm{~h}(1,04 / \mathrm{h}), 00 \mathrm{~h}(1,53 / \mathrm{h})$ and $06 \mathrm{~h}(1,61 / \mathrm{h})$. At these times temperatures were reasonably low (between $6-6,7^{\circ} \mathrm{C}$ ), as expected in the early morning hours (Appendix 4.2a). The lowest air exchange rate occurred at $17 \mathrm{~h}(1,04 / \mathrm{h})$, at this time the lowest wind speed was recorded $\left(1,9 \mathrm{~ms}^{-1}\right)$ and the highest inside temperature $\left(24,1^{\circ} \mathrm{C}\right)$. During the other early morning hours $(00 \mathrm{~h} \& 06 \mathrm{~h})$ the effects from wind speeds would be expected to be minimal because the side wall curtains would be nearly closed at these times.

After $11 \mathrm{~h}$, temperatures increased above $8^{\circ} \mathrm{C}$ and peaked at $9,2^{\circ} \mathrm{C}(15 \mathrm{~h})$, also wind speeds rose over $4 \mathrm{~ms}^{-1}$ at $11 \mathrm{~h}$ and peaked at $\sim 5,30 \mathrm{~ms}^{-1}$ at $13 \& 16 \mathrm{~h}$. Air exchange rates could be seen to increase above cerca $3 / \mathrm{h}$ after $12 \mathrm{~h}$ and peaked at $4,49 / \mathrm{h}$ at $14 \mathrm{~h}$. The higher AERs at these times are also in agreement with the lowest inside temperature $\left(22,2^{\circ} \mathrm{C}\right)$ recorded at $12 \mathrm{~h}$ (Appendix B. Tab.1). Inside temperatures dropped below $\left(23^{\circ} \mathrm{C}\right)$ at $10 \mathrm{~h}$, also corresponding with an air exchange rate increase from $2,57-2,98 / \mathrm{h}$ and then a further gradual increase (Fig. 4-3). Simultaneously, the heat and moisture 
balance AERs both began to increase around this time at $10 \mathrm{~h}$. The heat balance rose over $3,6 / \mathrm{h}$ to reach a peak of $4,6 / \mathrm{h}(12 \mathrm{~h})$ whilst the moisture balance peaked at $6,6 / \mathrm{h}(13$ $\& 15 h)$.

The AER plots (Fig. 4-3) are in good agreement with each other and all correspond with the temperature and wind speed fluctuations. The tracer gas method results are also correlated with the heat and moisture balances, $r^{2}=0,73$ and 0,71 , respectively. In particular, the heat balance results are quite closely aligned with the tracer gas method results. The heat and moisture balance AERs are partly derived from temperature in the calculations, therefore a correlation between mass balance air exchange rates and temperature is expected. However, both recorded a positive correlation with wind speed, $r^{2}=0,75$ and 0,86 , respectively. The high correlation coefficients between heat and moisture balance air exchange rates with wind speed was unexpected, but is clear as increased volumes of cool air enter the livestock house environment, ventilation will increase and the internal temperatures will simultaneously decrease.

Tab. 4- 4 Tracer gas method and influencing variable correlation table (07.11.03)

\begin{tabular}{|c|c|c|c|c|c|c|}
\hline & \multirow{2}{*}{$\begin{array}{l}\text { Average } \\
\text { hourly } \\
\text { wind } \\
\text { speeds }\end{array}$} & \multirow{2}{*}{$\begin{array}{c}\text { Average } \\
\text { maximum } \\
\text { hourly } \\
\text { wind } \\
\text { speeds }\end{array}$} & \multicolumn{3}{|c|}{ Temperature } & \multirow{2}{*}{$\begin{array}{c}\text { Inside } \\
\text { humidity }\end{array}$} \\
\hline & & & Outside & $\Delta$ & Inside & \\
\hline $\begin{array}{c}\text { Tracer gas } \\
\text { method }\end{array}$ & 0,47 & 0,67 & 0,73 & $-0,74$ & $-0,68$ & $-0,38$ \\
\hline
\end{tabular}

The tracer gas method recorded a correlation between hourly air exchange rates and wind speed $r^{2}=0,47$ and with maximum hourly wind speeds $r^{2}=0,67$ (Tab. 4-4). These correlations are not high, but are significant, no significance would be determined at $r^{2}=$ 0,40 (Myers \& Well 2003). Furthermore, a correlation coefficient $r^{2}=0,73$ was recorded between air exchange rates and outside temperature (Tab. 4-4). The $\Delta$ temperature difference between inside and outside stall temperatures was also negatively correlated with air exchange rates $r^{2}=-0,74$, indicating as air exchange rates increased the temperature difference decreased. A reasonably high negative correlation coefficient between inside temperatures and air exchange rates $r^{2}=-0,68$ was recorded (Tab. 4-4). This is in agreement with the natural ventilation system which involves the mechanical opening and closing of side wall curtains and chimney baffles based on inside 
temperature and humidity levels, i.e. as the ventilation rate increases the inside temperature level will drop. However, this is not always the case depending on the level of heat produced and the air volume exchange.

A comparison of the day time (07-19h), night time (19-07h) and $24 \mathrm{~h}$ average was made between the tracer gas and mass balance models results (Tab. 4-5).

Tab. 4- 5 Day/night and 24h average result comparisons with tracer gas method results (07.11.03)

\begin{tabular}{cccc}
\hline $\begin{array}{c}\text { Air exchange } \\
\text { calculation } \\
\text { method }\end{array}$ & $\begin{array}{c}\text { Day time } \\
\mathbf{0 7 - 1 9 h r}\end{array}$ & $\begin{array}{c}\text { Night time } \\
\mathbf{1 9 - 0 7 h r}\end{array}$ & $\mathbf{2 4 h r}$ \\
\hline $\begin{array}{c}\text { Tracer gas } \\
\text { method }\end{array}$ & 2,69 & 2,20 & 2,60 \\
Heat balance & $3,60(+33 \%)$ & $3,17(+45 \%)$ & $3,50(+35 \%)$ \\
Moisture balance & $5,38(+100 \%)$ & $5,19(+136 \%)$ & $5,44(+109 \%)$ \\
\hline
\end{tabular}

The results indicate the heat balance was closer aligned with the tracer gas method results than the moisture balance method. The tracer gas method was on average $35 \%$ lower than the heat balance model and 109\% lower than the moisture balance model.

The tracer gas median air exchange value $2,62 / \mathrm{h}$ translates to a ventilation rate of 0,53 $\mathrm{m}^{3} / \mathrm{h} /$ animal, above the recommended (DIN 18910. 1998) minimum $0,34 \mathrm{~m}^{3} / \mathrm{h} /$ animal. The heat and moisture balance ventilation rates were also above the recommended minimum, 0,66 and $1,06 \mathrm{~m}^{3} / \mathrm{h} /$ animal, respectively. 
Tab. 4- 6 Summarised AER results and weather conditions (08.11.03)

\begin{tabular}{|c|c|c|c|}
\hline $\begin{array}{c}\text { Bird weight: } 0,992 \mathrm{~kg} \\
\text { Age: } 22 \text { days }\end{array}$ & Mean \pm SD & Range & Median \\
\hline $\begin{array}{l}\text { Tracer gas method } \\
\text { (exchange rate/h) }\end{array}$ & $2,66 \pm 1,21$ & $0,92-5,67$ & 2,35 \\
\hline $\begin{array}{c}\text { Heat balance } \\
\text { (exchange rate/h) }\end{array}$ & $3,37 \pm 0,71$ & $2,65-4,64$ & 3,04 \\
\hline $\begin{array}{l}\text { Moisture balance } \\
\text { (exchange rate/h) }\end{array}$ & $5,20 \pm 0,82$ & $4,18-6,80$ & 4,83 \\
\hline Wind speed $\left(\mathrm{ms}^{-1}\right)$ & $3,56 \pm 1,15$ & $2,00-5,30$ & 3,35 \\
\hline Wind direction $\left(^{\circ}\right)$ & $90,62 \pm 3,95$ & $85,00-102,30$ & 89,70 \\
\hline Outside temperature $\left({ }^{\circ} \mathrm{C}\right)$ & $5,87 \pm 1,91$ & $4,10-9,20$ & 4,80 \\
\hline Inside temperature $\left({ }^{\circ} \mathrm{C}\right)$ & $23,50 \pm 0,47$ & $22,56-24,30$ & 23,50 \\
\hline Inside humidity (\%) & $57,67 \pm 2,51$ & $53,85-63,99$ & 57,42 \\
\hline $\begin{array}{c}\Delta \text { Temperature } \\
\text { (inside \& outside stall }{ }^{\circ} \mathrm{C} \text { ) }\end{array}$ & $17,63 \pm 2,32$ & $13,77-20,00$ & 18,66 \\
\hline $\begin{array}{l}\text { Coefficient of variation } \\
\text { between } \mathrm{SF}_{6} \text { sample location } \\
\text { concentrations }(\%)\end{array}$ & $15,47 \pm 3,43$ & $10,07-24,80$ & 15,42 \\
\hline
\end{tabular}

On the $08.11 .03(12 \mathrm{~h})-09.11 .03(12 \mathrm{~h})$ the birds weighed approximately $0,992 \mathrm{~kg}$. The weather results in Tab. 4-6 indicate similar conditions to the previous day, but slightly cooler temperatures with the temperatures recording a median of $4,80^{\circ} \mathrm{C}$ compared to $6,50^{\circ} \mathrm{C}$ on the 07.11 .03 . The temperature conditions were also quite constant, but with a larger range $\left(4,10-9,20^{\circ} \mathrm{C}\right)$, compared to $6,20-9,20^{\circ} \mathrm{C}$, as previously. Both these measurement periods recorded the same peak temperatures because the last period (07.11.03 17h-08.11.03 16h) overlapped into this period from 12-16h (08.11.03). A slightly higher $\Delta$ temperature median $18,66 \quad{ }^{\circ} \mathrm{C}$ (Tab. 4-6) compared to $16,99^{\circ} \mathrm{C}$ (07.11.03) is in agreement with the lower outside temperatures. The median inside temperature $23,50^{\circ} \mathrm{C}$ was slightly higher than $23,44^{\circ} \mathrm{C}$, this higher inside temperature could be due to increased sensible heat production from the cooler temperatures and/or lower ventilation rates, a lower temperature may have been also anticipated with the 
slightly lower outside temperatures. The wind direction was very similar with a median $89,70^{\circ}$ (range $85,00-102,30^{\circ}$ ) compared with $88,25^{\circ}$ (range $78,30-92,10^{\circ}$ ) on the 07.11.03, both with ranges $\pm \sim 12^{\circ}$ above and below the $90^{\circ}$ transverse. The wind speeds displayed similarities, on the 08.11 .03 the velocity decreased slightly with a median of $3,35 \mathrm{~ms}^{-1}$ (range 2,00-5,30 $\mathrm{ms}^{-1}$ ) compared with a median of $3,75 \mathrm{~ms}^{-1}$ (range $1,90-5,30 \mathrm{~ms}^{-1}$ ) on the 07.11 .03 , once again the higher wind speeds from the previous session overlapped into the beginning of this period. The median air exchange rate $2,35 / \mathrm{h}$ (range $0,92-5,67 / \mathrm{h}$ ) was very similar but slightly lower that the previous period median 2,62/h (range 1,04-4,49/h), in agreement with the lower wind speeds and outside temperatures. The $\mathrm{SF}_{6} \mathrm{CV}$ median on 08.11 .03 decreased to $15,42 \%$ compared to $18,25 \%$ (07.11.03). The slightly lower $\mathrm{SF}_{6} \mathrm{CV}(08.11 .03)$ may be due to a slightly lower air exchange rate generating less turbulences and better air/tracer gas mixing. There were no significant relationships found between $\mathrm{SF}_{6} \mathrm{CV}$ and air exchange rates or uneven distribution of tracer gas between the ceiling (chimney) and side wall (curtain) samples.

The tracer gas method air exchange rate fluctuations throughout the day are slightly higher than the previous period with a $\mathrm{SD} \pm 1,21$ compared with $\pm 0,83$, this maybe explained by the slightly higher wind speed and wind direction standard deviations over this period $\pm 1,15 \mathrm{~ms}^{-1}, 3,95^{\circ}(08.11 .03)$ and $\pm 0,74 \mathrm{~ms}^{-1}, 3,43^{\circ}(07.11 .03)$. The heat and moisture balance models also followed the same trend as the tracer gas method recording standard deviations of $\pm 0,71$ and $\pm 0,82$, respectively, also an increase from the previous period (07.11.03) of 0,55 and 62 , respectively. 


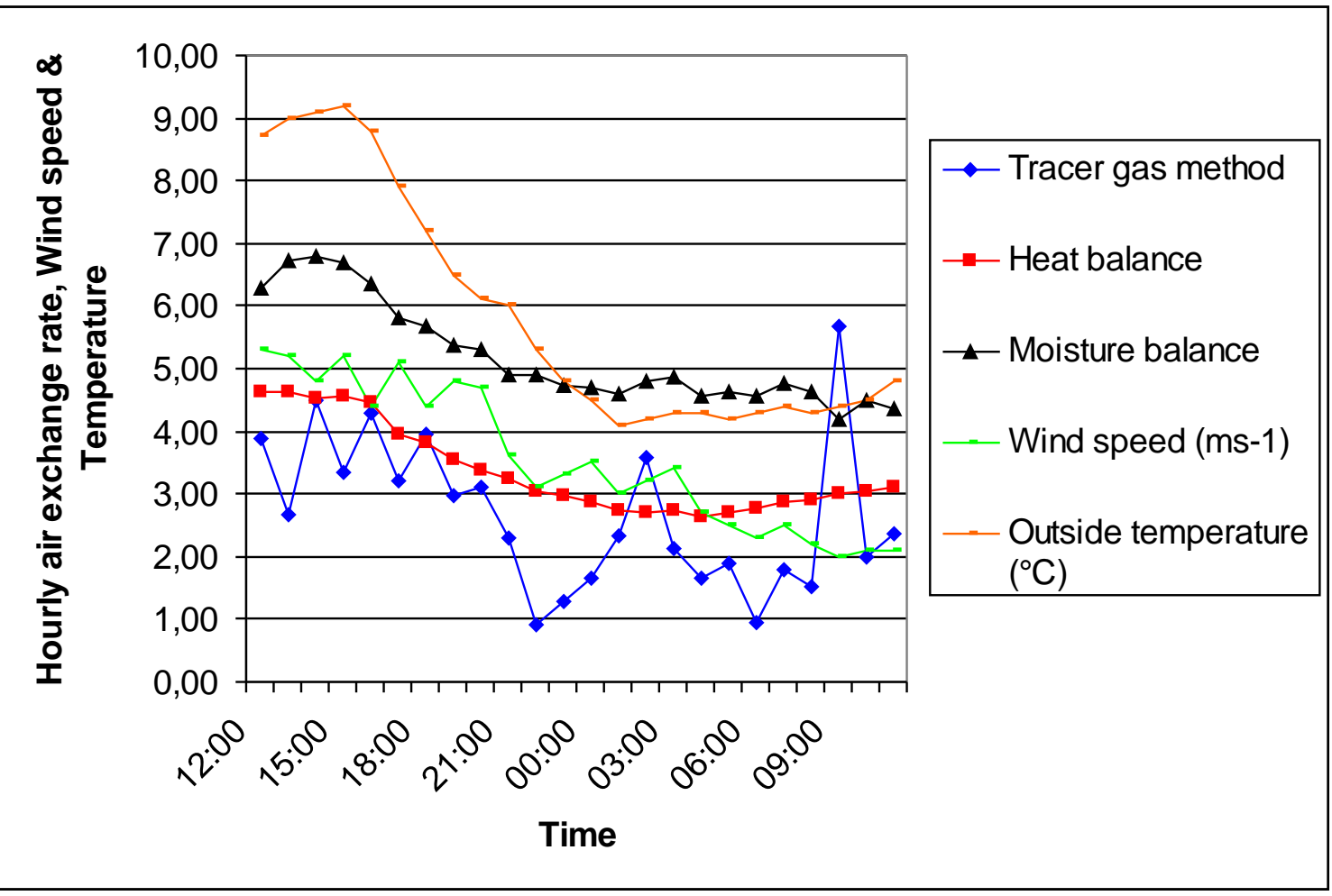

Fig. 4- 4 Hourly mass balance and tracer gas method AER results along with influencing weather variables $(\mathbf{0 8 . 1 1 . 0 3 )}$

The tracer gas method results (Fig. 4-4) indicate the lowest air exchange rates occurred at $22 \mathrm{~h}(0,92 / \mathrm{h})$ and $06 \mathrm{~h}(0,96 / \mathrm{h})$. Wind speed decreased from $3,6 \mathrm{~ms}^{-1}$ at $21 \mathrm{~h}$ to $3.1 \mathrm{~ms}^{-1}$ (22h), simultaneously outside temperature steadily decreased (Fig. 4-4), and at 06h wind speed had also dropped from $2,5 \mathrm{~ms}^{-1}(05 \mathrm{~h})$ to $2,1 \mathrm{~ms}^{-1}(06 \mathrm{~h})$, wind directions at these times were in the transverse direction. Even though the decreased wind speeds at these times were still reasonably high, the effects would therefore not be large. Furthermore, autumn temperatures late at night and very early in the morning are cool and animal activity would be reduced, the side wall curtains would be perhaps slightly open, thus impacts from winds would be minimal. However, straight after the air exchange rate depression at $22 \mathrm{~h}$ the hourly air exchange rate steadily increased reaching a peak of $3,57 / \mathrm{h}$ at $02 \mathrm{~h}$. The lowest temperature was reached at $01 \mathrm{~h}\left(4,10^{\circ} \mathrm{C}\right)$ and the wind speed at $02 \mathrm{~h}$ was still quite high $\left(3,2 \mathrm{~ms}^{-1}\right)$, therefore this higher air exchange rate could be a response to the low ventilation rate at $22 \mathrm{~h}$, thus resulting in an increased air exchange due to thermal buoyancy and external wind pressure effects. The internal temperatures (Appendix B Tab.5) from 02-06h were around $24^{\circ} \mathrm{C}$ with a peak of $24,3^{\circ} \mathrm{C}$ at $04 \mathrm{~h}$, also corresponding with a reduced air exchange rate 1,67/h at $04 \mathrm{~h}$ (Fig. 4-4). 
From the measurements, it appears that the air exchange rate patterns with this ventilation system undergo a cycle of ventilation accessions followed by depressions.

The high air exchange rates occurred between 14-18h $(\sim 3,90 / \mathrm{h})$, corresponding with the peak temperature at $15 \mathrm{~h}\left(9,2^{\circ} \mathrm{C}\right)$ and wind speeds were also between 4,40-5,20 $\mathrm{ms}^{-1}$ (14-18h). At the very beginning of the period (12h) an air exchange rate 3,88/h was recorded corresponding with the peak wind speed $\left(5,3 \mathrm{~ms}^{-1}\right)$ and the lowest inside temperature $22,6^{\circ} \mathrm{C}$, also at this time the outside temperatures were approaching $9^{\circ} \mathrm{C}$. The heat and moisture balances are both in agreement with the tracer gas method recording air exchange rate peaks at the beginning of the period, with the heat balance peaking $(4,64 / \mathrm{h})$ at $12 \mathrm{~h}$ and the moisture balance reaching $6,80 / \mathrm{h}$ at $14 \mathrm{~h}$. The highest air exchange rate $(5,67 / \mathrm{h})$ occurred at $09 \mathrm{~h}(09.11 .03)$, the wind speeds $\left(2 \mathrm{~ms}^{-1} / \mathrm{h}\right)$ and outside temperatures $\left(4,4^{\circ} \mathrm{C}\right)$ were not particularly high. This peak may simply be due to the previously low air exchange rates resulting in the need for a fresh air purge, however inside temperatures did not show an increase. Perhaps poor tracer gas/air mixing resulted in tracer gas escaping from the mixing sub-section without properly mixing with the livestock house air. The moisture balance also displayed a peak at $03 \mathrm{~h}$ $(4,81 / \mathrm{h})$, nearby with the small tracer gas peak at $02 \mathrm{~h}(3,57 / \mathrm{h})$.

All 3 air exchange rate plots (Fig. 4-4) are within range of each other, and all correspondingly decrease with outside temperatures and wind speeds. The wind speed was positively correlated with the heat and moisture balances $\left(r^{2}=0,84\right.$ and 0,89$)$ and the MBM results were correlated with the tracer gas results $r^{2}=0,57$ and 0,48 , respectively, not as high as $07.11 .03\left(\mathrm{r}^{2}=0,73\right.$ and 0,71 , respectively). These results indicate all methods were correlated with the wind speeds and were also correlated with each other.

Tab. 4- 7 Tracer gas method and influencing variable correlation table (08.11.03)

\begin{tabular}{|c|c|c|c|c|c|c|}
\hline & \multirow{2}{*}{$\begin{array}{l}\text { Average } \\
\text { hourly } \\
\text { wind } \\
\text { speeds }\end{array}$} & \multirow{2}{*}{$\begin{array}{c}\text { Average } \\
\text { maximum } \\
\text { hourly } \\
\text { wind } \\
\text { speeds }\end{array}$} & \multicolumn{3}{|c|}{ Temperature } & \multirow{2}{*}{$\begin{array}{c}\text { Inside } \\
\text { humidity }\end{array}$} \\
\hline & & & Outside & $\Delta$ & Inside & \\
\hline $\begin{array}{c}\text { Tracer gas } \\
\text { method }\end{array}$ & 0,43 & 0,50 & 0,54 & $-0,56$ & $-0,59$ & $-0,05$ \\
\hline
\end{tabular}


The tracer gas method results were correlated with wind speeds and maximum hourly wind speeds $r^{2}=0,43$ and $r^{2}=0,50$, respectively (Tab. 4-7), from the results (Appendix B Tab.5) the higher AERs at the beginning 12-17h corresponded with high wind gusts blowing between $9-12,1 \mathrm{~ms}^{-1}$. Furthermore, a correlation coefficient $\mathrm{r}^{2}=0,54$ was recorded between air exchange rates and outside temperature (Tab. 4-7) and the $\Delta$ temperature difference between inside and outside stall temperatures was also negatively correlated with air exchange rates $r^{2}=-0,56$. Interestingly, these correlation coefficient values are considerably lower than the $07.11 .03 \quad\left(r^{2}=0,73\right.$ and $-0,74$, respectively), which may be due to the slightly lower outdoor temperatures on the 08.11.03 median $=4,8^{\circ} \mathrm{C}$, compared with $6,5^{\circ} \mathrm{C}$ on the 07.11 .03 . A negative correlation coefficient $r^{2}=-0,59$ was recorded between inside temperatures and air exchange rates once again perhaps in agreement with the ventilation system thermostat and lower than the previous $r^{2}=.-0,68(07.11 .03)$.

A comparison of the day time (07-19h), night time (19-07h) and $24 \mathrm{~h}$ average was made between the tracer gas and mass balance models results (Tab. 4-8).

Tab. 4- 8 Day/night and 24h average result comparisons with tracer gas method results $(08.11 .03)$

\begin{tabular}{cccc}
\hline $\begin{array}{c}\text { Air exchange } \\
\text { calculation } \\
\text { method }\end{array}$ & $\begin{array}{c}\text { Day time } \\
\mathbf{0 7 - 1 9 h r}\end{array}$ & $\begin{array}{c}\text { Night time } \\
\mathbf{1 9 - 0 7 h r}\end{array}$ & $\mathbf{2 4 h r}$ \\
\cline { 2 - 4 } & 3,24 & 1,97 & 2,66 \\
\hline Tracer gas method & $3,64(+12 \%)$ & $2,89(+47 \%)$ & $3,37(+27 \%)$ \\
Heat balance & $5,31(+64 \%)$ & $4,78(+140 \%)$ & $5,20(+95 \%)$ \\
\hline
\end{tabular}

The results indicate the heat balance was better aligned with the tracer gas method results than the moisture balance method. The tracer gas method was on average $27 \%$ lower than the heat balance model and 95\% lower than the moisture balance model. The closer alignment during the day time maybe due to the MBMs overestimating night time AERs.

The tracer gas ventilation rate $=0,48 \mathrm{~m}^{3} / \mathrm{h} /$ bird was slightly above the recommended minimum $0,36 \mathrm{~m}^{3} / \mathrm{h} / \mathrm{bird}$ (DIN 18910. 1998). The heat and moisture balance ventilation rates were also above the recommended minimum, 0,62 and $0,98 \mathrm{~m}^{3} / \mathrm{h} / \mathrm{animal}$, 
respectively. All methods recorded decreased AERs compared with the previous period. 
Tab. 4- 9 Summarised AER results and weather conditions (09.11.03)

\begin{tabular}{|c|c|c|c|}
\hline $\begin{array}{l}\text { Bird weight: } 1,06 \mathrm{~kg} \\
\text { Age: } 23 \text { days }\end{array}$ & Mean \pm SD & Range & Median \\
\hline $\begin{array}{l}\text { Tracer gas method } \\
\text { (exchange rate/h) }\end{array}$ & $2,50 \pm 0,65$ & $1,59-4,22$ & 2,37 \\
\hline $\begin{array}{c}\text { Heat balance } \\
\text { (exchange rate/h) }\end{array}$ & $3,11 \pm 0,32$ & $2,71-3,60$ & 2,99 \\
\hline $\begin{array}{l}\text { Moisture balance } \\
\text { (exchange rate/h) }\end{array}$ & $5,16 \pm 0,23$ & $4,81-5,63$ & 5,12 \\
\hline Wind speed $\left(\mathrm{ms}^{-1}\right)$ & $2,73 \pm 0,73$ & $1,90-3,50$ & 2,70 \\
\hline Wind direction $\left(^{\circ}\right)$ & $93,6 \pm 1,99$ & $90,60-97,70$ & 93,40 \\
\hline Outside temperature $\left({ }^{\circ} \mathrm{C}\right)$ & $4,13 \pm 1,17$ & $2,10-5,70$ & 4,20 \\
\hline Inside temperature $\left({ }^{\circ} \mathrm{C}\right)$ & $23,49 \pm 0,32$ & $23,04-24,05$ & 23,39 \\
\hline Inside humidity (\%) & $59,11 \pm 3,06$ & $54,16-64,75$ & 59,10 \\
\hline $\begin{array}{c}\Delta \text { Temperature } \\
\text { (inside \& outside stall }{ }^{\circ} \mathrm{C} \text { ) }\end{array}$ & $19,36 \pm 1,35$ & $17,50-21,24$ & 19,60 \\
\hline $\begin{array}{c}\text { Coefficient of variation } \\
\text { between } \mathrm{SF}_{6} \text { sample location } \\
\text { concentrations (\%) }\end{array}$ & $16,04 \pm 4,24$ & $10,74-25,33$ & 15,14 \\
\hline
\end{tabular}

On the $09.11 .03(12 \mathrm{~h})-10.11 .03(12 \mathrm{~h})$ the birds weighed approximately $1,06 \mathrm{~kg}$. The weather results in Tab. 4-9 indicate temperatures were slightly cooler with a median of $4,20^{\circ} \mathrm{C}$ compared to $4,80^{\circ} \mathrm{C}$ on the previous period 08.11 .03 . However, the temperature range on the $09.11 .03\left(2,10-5,70^{\circ} \mathrm{C}\right)$ was slightly lower than $4,10-9,20^{\circ} \mathrm{C}$ on the 08.11.03. A higher $\Delta$ temperature median $19,60^{\circ} \mathrm{C}$ (Tab. 4-9) compared to $18,66^{\circ} \mathrm{C}$ (08.11.03 12h) may be due to the reduced outside temperatures, also resulting in a slightly lower median inside temperature $23,39^{\circ} \mathrm{C}$ compared with $23,50^{\circ} \mathrm{C}(08.11 .03)$. However, the inside temperature range $23,04-24,05^{\circ} \mathrm{C}$ was smaller than the previous period $22,56-24,30^{\circ} \mathrm{C}(08.11 .03)$, indicating less indoor temperature fluctuations, perhaps due to less air exchanges. The wind direction on both days were also in the transverse direction and similar, 90,62 $\pm 3,95^{\circ}$ (mean and SD) on the 08.11.03 compared with $93,6 \pm 1,99^{\circ}$ on the $09.11 .03(12 \mathrm{~h})$, therefore less wind direction 
deviations occurred on the 09.11 .03 (range 90,60-97,70 ${ }^{\circ}$ ) than on the 08.11 .03 (range $\left.85,00-102,30^{\circ}\right)$. The median wind speed on the 09.11 .03 decreased slightly from $3,35 \mathrm{~ms}^{-1}$ on the 08.11 .03 to $2,70 \mathrm{~ms}^{-1}(09.11 .03)$. It appears that the wind speed and temperature had both decreased from the previous day, however the median air exchange rate (median 2,37/h) compared with $2,35 / \mathrm{h}$ on the 08.11 .03 , is slightly higher. The average on the other hand is lower $2,50 / \mathrm{h}$ compared with $2,66 / \mathrm{h}$ on the 08.11 .03 . It seems that the air exchange rates are very similar and perhaps the slightly higher median on the 09.11.03 is due to the more consistent transverse winds and increased heat production from the birds due to the cooler temperatures. The $\mathrm{SF}_{6} \mathrm{CV}$ were both quite similar with a median of $15,14 \%$ compared to $15,42 \%$ (08.11.03 $12 \mathrm{~h})$, the slightly lower CV (09.11.03) may be explained by the more consistent conditions with constant wind directions (range 90,60-97,70 ${ }^{\circ}$ ) and lower wind speeds 1,90-3,50 $\mathrm{ms}^{-1}$ compared with wind speeds ranging from 2,00-5,30 $\mathrm{ms}^{-1}$ and wind directions from 85,00-102,30 on the 08.11.03, perhaps generating more turbulences on the 08.11.03, and thus higher $\mathrm{CV}$ values.

The AER standard deviation on the 08.11 .03 was $\pm 1,21 / \mathrm{h}$ compared to $0,65 / \mathrm{h}$ on the 09.11.03, the smaller fluctuations also in agreement with the more stable weather conditions on the 09.11.03. The heat and moisture balance models also followed the same trend as the tracer gas method recording standard deviations of $\pm 0,32$ and 0,23 , respectively, also a decrease from the previous period $(08.11 .0300 \mathrm{~h})$ of $\pm 0,71$ and 82 , respectively. 


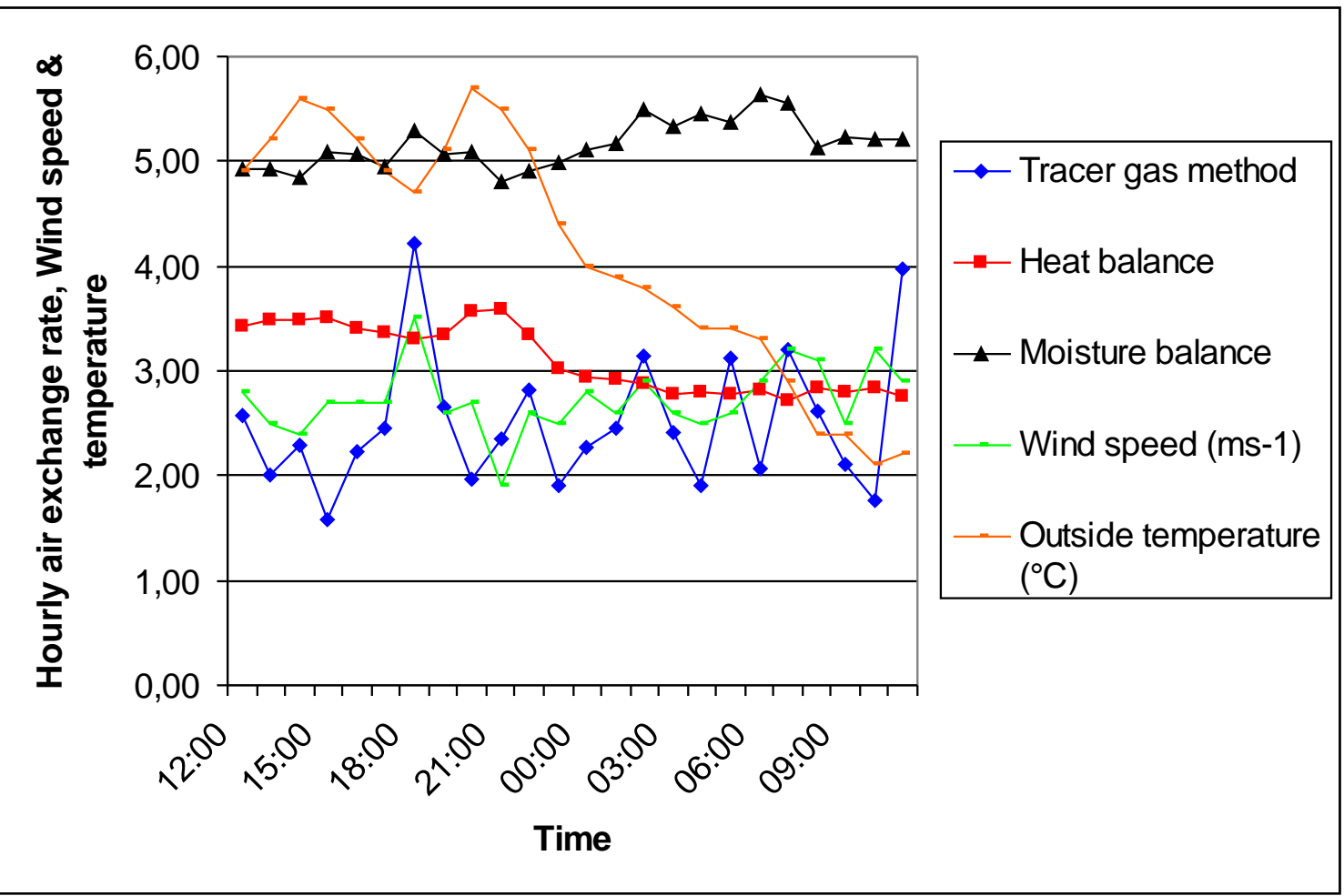

Fig. 4- 5: Hourly mass balance and tracer gas method AER results along with influencing weather variables (09.11.03)

The tracer gas method results (Fig. 4-5) indicate the low air exchange rates occurred at 15h (1,59/h), 20h (1,96/h), 23h (1,91/h), 04h (1,90/h) and 10h (1,76/h). The lowest air exchange rate at $15 \mathrm{~h}$ seems unlikely with direct transverse wind speeds $2,7 \mathrm{~ms}^{-1}$ and an outside temperature of $5,5^{\circ} \mathrm{C}$. The other depressions also could not be explained, except for the outdoor temperature drop of $2,1^{\circ} \mathrm{C}$ (minimum temperature) at $10 \mathrm{~h}$ perhaps contributing to the depression at this time.

The highest air exchange rate occurred at $18 \mathrm{~h}(4,22 / \mathrm{h})$ corresponding with the highest wind speed peak $\left(3,5 \mathrm{~ms}^{-1}\right)$ in the transverse direction. Other AER peaks $>3 / \mathrm{h}$ can be observed at $02 \mathrm{~h}(3,15 / \mathrm{h}), 05 \mathrm{~h}(3,13 / \mathrm{h}), 07 \mathrm{~h}(3,20 / \mathrm{h})$ and $11 \mathrm{~h}(3,97 / \mathrm{h})$. The peaks at $02 \mathrm{~h}$ and $07 \mathrm{~h}$ corresponded with slight wind speed accessions (Fig. 4-5). However, in general the tracer gas results remain relatively constant fluctuating between 1,59-4,22 air exchanges/h. For e.g. the air exchange rate peak at $11 \mathrm{~h}$ (Fig. 4-5) does not correspond with a wind speed or temperature peak but seems to be an accession directly after a depression. The AER accessions and depressions could represent minimum air exchange rates followed by fresh air purges resulting in a ventilation rate increase, as would be imagined with the natural ventilation system design. These conditions could 
be due to the cooler temperatures requiring that the window inlets remained nearly shut for most of the time, reducing the effects from the wind speeds, the air exchanges being more dependent on thermal buoyancy forces produced from the growing birds.

The air exchange rate plots (Fig. 4-5) are not as closely aligned as the last 2 periods but are however, within range of each other. Once again the tracer gas method results are substantially lower than the mass balance results, particularly the moisture balance. Only the moisture balance correlated with the wind speed recording a correlation coefficient $r^{2}=0,51$. Although the heat balance is slightly better aligned with the tracer gas method results, it did not correspond with the moisture balance or tracer gas method peaks and troughs. The moisture balance peaks at $18 \mathrm{~h}, 02 \mathrm{~h}$ and $07 \mathrm{~h}$ corresponding with the tracer gas method peaks (Fig. 4-5), however no significant correlations were recorded between the tracer gas method and mass balance models.

Tab. 4- 10 Tracer gas method and influencing variable correlation table (09.11.03)

\begin{tabular}{|c|c|c|c|c|c|c|}
\hline & \multirow{2}{*}{$\begin{array}{l}\text { Average } \\
\text { hourly } \\
\text { wind } \\
\text { speeds }\end{array}$} & \multirow{2}{*}{$\begin{array}{c}\text { Average } \\
\text { maximum } \\
\text { hourly wind } \\
\text { speeds }\end{array}$} & \multicolumn{3}{|c|}{ Temperature } & \multirow{2}{*}{$\begin{array}{c}\text { Inside } \\
\text { humidity }\end{array}$} \\
\hline & & & Outside & $\Delta$ & Inside & \\
\hline $\begin{array}{c}\text { Tracer gas } \\
\text { method }\end{array}$ & 0,46 & 0,58 & $-0,21$ & 0,21 & 0,12 & $-0,24$ \\
\hline
\end{tabular}

The tracer gas method hourly air exchange rates recorded a correlation coefficient $r^{2}=0,46$ with hourly wind speed and $r^{2}=0,58$ with maximum wind speeds (Tab. 4-10). Only the wind speeds were correlated with hourly air exchange rates. There were no correlations between tracer gas air exchange rates and inside temperature. No significant correlations between the tracer gas method AERs, outside temperatures and $\Delta$ temperature maybe due to the low outside temperatures. The highest correlation coefficient between AERs and outside temperatures occurred on the $07.11 .03\left(\mathrm{r}^{2}=0,73\right)$ median outside temperature $6,5^{\circ} \mathrm{C}$, followed by $08.11 .03\left(\mathrm{r}^{2}=0,54\right)$ median outside temperature $4,8^{\circ} \mathrm{C}$. The median outside temperature on the 09.11 .03 was $4,2^{\circ} \mathrm{C}$, perhaps this decreased temperature was too low to record a significant $\mathrm{r} 2$ between outside temperature and AERs. 
It appears that the lower temperatures may have inhibited the effects temperature had on air exchange rate, because of the low temperatures it seems that hourly air exchange rates were at the absolute minimum being driven by thermal buoyancy and wind speeds. However, even though there are minimal significant correlations the mass balance results are within range of the tracer gas method results and the tracer gas method results are in agreement with the previous results.

A comparison of the day time (07-19h), night time (19-07h) and $24 \mathrm{~h}$ average was made between the tracer gas and mass balance models results (Tab. 4-11).

Tab. 4- 11 Day/night and 24h average result comparisons with tracer gas method results $(09.11 .03)$

\begin{tabular}{cccc}
\hline $\begin{array}{c}\text { Air exchange } \\
\text { calculation } \\
\text { method }\end{array}$ & $\begin{array}{c}\text { Day time } \\
\mathbf{0 7 - 1 9 h r}\end{array}$ & $\begin{array}{c}\text { Night time } \\
\mathbf{1 9 - 0 7 h r}\end{array}$ & $\mathbf{2 4 h r}$ \\
\cline { 2 - 4 } & 2,56 & 2,47 & 2,50 \\
Tracer gas method & $3,11(+21 \%)$ & $3,02(+22 \%)$ & $3,11(+24 \%)$ \\
Heat balance & $5,11(+100 \%)$ & $5,24(+112 \%)$ & $5,16(+106 \%)$ \\
Moisture balance & &
\end{tabular}

The results indicate the heat balance was better aligned with the tracer gas method results than the moisture balance method. The tracer gas method was on average $24 \%$ lower than the heat balance model and $106 \%$ lower than the moisture balance model.

The tracer gas median air exchange rate $2,37 / \mathrm{h}$ was above the minimum recommended air exchange rate for this day 1,84/h (DIN 18910. 1998). The air exchange rate translates to a ventilation rate of $0,50 \mathrm{~m}^{3} / \mathrm{h} / \mathrm{bird}$, just above the minimum guideline value $0,37 \mathrm{~m}^{3} / \mathrm{h} / \mathrm{bird}$. The heat and moisture balance ventilation rates were 0,61 and $1,04 \mathrm{~m}^{3} / \mathrm{h} /$ bird, respectively. 
Tab. 4- 12 Summarised AER results and weather conditions (12.11.03)

\begin{tabular}{|c|c|c|c|}
\hline $\begin{array}{l}\text { Bird weight: } 1,28 \mathrm{~kg} \\
\text { Age: } 26 \text { days }\end{array}$ & Mean \pm SD & Range & Median \\
\hline $\begin{array}{l}\text { Tracer gas method } \\
\text { (exchange rate/h) }\end{array}$ & $2,57 \pm 1,54$ & $0,43-5,81$ & 2,50 \\
\hline $\begin{array}{c}\text { Heat balance } \\
\text { (exchange rate/h) }\end{array}$ & $3,37 \pm 0,62$ & $2,65-4,55$ & 3,17 \\
\hline $\begin{array}{l}\text { Moisture balance } \\
\text { (exchange rate/h) }\end{array}$ & $5,52 \pm 0,75$ & $4,30-7,27$ & 5,62 \\
\hline Wind speed $\left(\mathrm{ms}^{-1}\right)$ & $2,27 \pm 1,07$ & $0,50-3,70$ & 2,65 \\
\hline Wind direction $\left(^{\circ}\right)$ & $88,33 \pm 10,73$ & $56,80-103,30$ & 90,85 \\
\hline Outside temperature $\left({ }^{\circ} \mathrm{C}\right)$ & $2,06 \pm 2,17$ & $(-) 1,00-6,00$ & 1,45 \\
\hline Inside temperature $\left({ }^{\circ} \mathrm{C}\right)$ & $23,13 \pm 0,43$ & $22,41-23,87$ & 23,09 \\
\hline Inside humidity (\%) & $59,02 \pm 4,31$ & $51,86-67,49$ & 58,12 \\
\hline $\begin{array}{c}\Delta \text { Temperature } \\
\text { (inside \& outside stall }{ }^{\circ} \mathrm{C} \text { ) }\end{array}$ & $21,07 \pm 2,49$ & $16,61-24,53$ & 21,72 \\
\hline $\begin{array}{c}\text { Coefficient of variation } \\
\text { between } \mathrm{SF}_{6} \text { sample location } \\
\text { concentrations (\%) }\end{array}$ & $11,04 \pm 7,91$ & $2,68-31,55$ & 8,61 \\
\hline
\end{tabular}

On the $12.11 .03(00 \mathrm{~h})-13.11 .03(00 \mathrm{~h})$ the birds weighed approximately $1,28 \mathrm{~kg}$ and were nearly 4 weeks old. The weather results in Tab. 4-12 indicate a further temperature drop with a median of $1,45^{\circ} \mathrm{C}$ (range $(-) 1,00-6,00^{\circ} \mathrm{C}$ ) compared to $4,20^{\circ} \mathrm{C}$ (range $2,10-5,70^{\circ} \mathrm{C}$ ) on the previous period 09.11.03. Therefore, this larger temperature range corresponds with the higher $\Delta$ temperature median recorded $21,72^{\circ} \mathrm{C}$ (Tab. 4-12) compared to $19,60^{\circ} \mathrm{C}$ on the 09.11 .03 . The $\Delta$ temperature ranges were also slightly larger on the 12.11 .03 (range $16,61-24,53^{\circ} \mathrm{C}$ ) compared with range $17,50-21,24^{\circ} \mathrm{C}$ on the 09.11.03. The median temperature within the stall $\left(23,09^{\circ} \mathrm{C}\right)$ was the lowest recorded, slightly lower than the previous day $(09.11 .03)$ median $23,39^{\circ} \mathrm{C}$. This could be indicative of the lower outside temperatures and/or higher air exchange rates. The wind direction on the 09.11 .03 was $93,6 \pm 1,99^{\circ}$ (mean and SD) compared with $88,33 \pm$ $10,73^{\circ}$ on the 12.11 .03 , so there were more direction fluctuations away from transverse on the 12.11.03. The wind speeds between both days were similar with a slight 
decrease on the 12.11.03 median $=2,65 \mathrm{~ms}^{-1}$ (range $\left.0,50-3,70 \mathrm{~ms}^{-1}\right)$ compared with a median of $2,70 \mathrm{~ms}^{-1}$ (range $1,90-3,50 \mathrm{~ms}^{-1}$ ) on 09.11 .03 , so the wind speeds also underwent larger fluctuations on the 12.11.03. The median AER of 2,50/h (range 0,43$5,81 / \mathrm{h}$ ) on the 12.11 .03 was slightly higher than median $=2,37 / \mathrm{h}$ (range $1,59-4,22 / \mathrm{h}$ ) on the 09.11.03. Even though the difference is small, on the 09.11.03 the wind directions were more transverse, median wind speeds were slightly higher and higher outside temperatures were higher, these factors would indicate a higher air exchange rate on the 09.11.03, rather than the 12.11.03. However, perhaps the slightly higher air exchange rates on the 12.11 .03 were due to more sensible heat production from the heavier birds induced by the cooler temperatures and/or the higher maximum wind speeds recorded on the $12.1103\left(\right.$ median $=5,85 \mathrm{~ms}^{-1}$ ) compared with $5,70 \mathrm{~ms}^{-1}(09.11 .03)$ playing a contributing role.

Interestingly, the CV value median of $8,61 \%$ (12.11.03) was significantly lower than $15,14 \%$ (09.11.03). This lower CV, usually assumed to be due to better air mixing from a lower air exchange rate, may have resulted from better air mixing with a change in the dosing procedure, whereby dosing was conducted from 3 points instead of 1 as on previous days tested, and/or the larger weight of the birds contributing more heat and heat buoyancy to the internal environment, thus inducing better air/tracer mixing conditions. It should also be pointed out that dosing from 3 points instead of 1 did not result in a big difference between results, indicating that with 1 point the tracer gas was mixing sufficiently with the stall air and with 3 points the system behaved similarly. Furthermore, the $\mathrm{CV}$ range on the 12.11 .03 (2,68-31,55\%) is significantly larger than $10,74-25,33 \%$ (09.11.03). The CV values recorded a positive correlation $r^{2}=0,59$ with maximum wind speeds. It is therefore possible that the higher maximum wind speeds on the 12.11.03, were a contributing factor in raising the $\mathrm{CV}$ values and the air exchange rates above the level recorded on the 09.11.03.

The tracer gas method air exchange rate fluctuations on the 12.11 .03 are higher than the previous period with a $\mathrm{SD} \pm 1,54$ compared with $\pm 0,65$ (09.11.03), this maybe explained by the lower temperatures and larger range of wind speeds on the 12.11.03, causing a larger array of values, not to mention the more constant wind direction and wind speeds on the 09.11.03 resulting in a lower standard deviation. The heat and moisture balance models also followed the same trend as the tracer gas method 
recording increased air exchange rate standard deviations of $\pm 0,62$ and $\pm 0,75$, respectively, an increase from the previous period (09.11.03) of 0,30 and 0,52 , respectively.

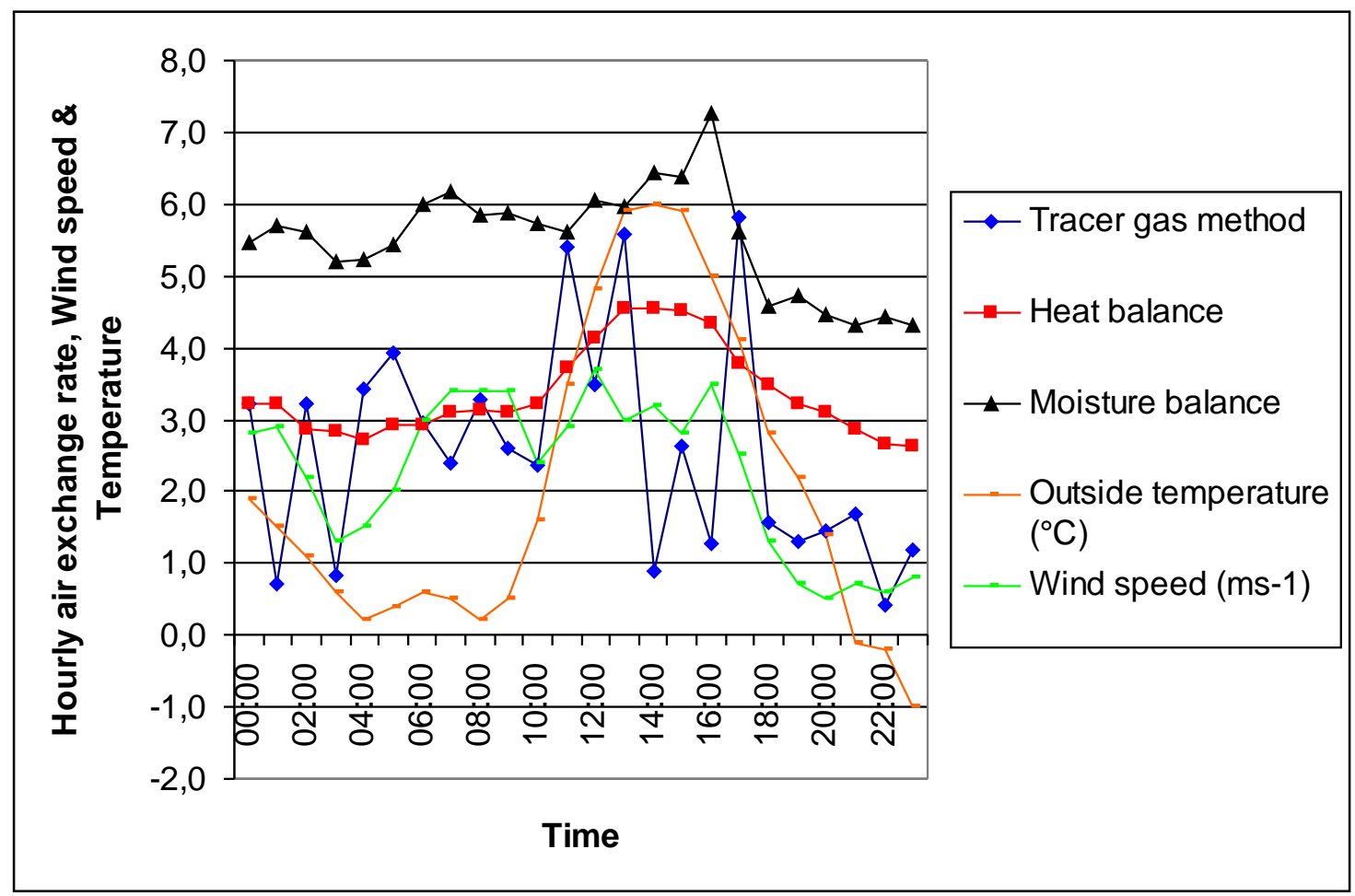

Fig. 4- 6: Hourly mass balance and tracer gas method AER results along with influencing weather variables (12.11.03)

The tracer gas method results (Fig. 4-6) indicate the lowest air exchange rates occurred at $01 \mathrm{~h}(0,7 / \mathrm{h}), 03 \mathrm{~h}(0,8 / \mathrm{h}), 14 \mathrm{~h}(0,9 / \mathrm{h})$ and $22 \mathrm{~h}(0,4 / \mathrm{h})$. Except for the low air exchange rate at $14 \mathrm{~h}$, low hourly air exchange rates at the other times seem likely considering the times of the day very early morning and late evening when outside temperatures were low and the effects from wind speeds reduced (Fig. 4-6). Particularly at $22 \mathrm{~h}$ the wind speed was only $0,6 \mathrm{~ms}^{-1}$ and the highest inside temperature $23,87^{\circ} \mathrm{C}$ was also recorded. The low air exchange rates recorded at 14 and 16h (Fig. 4-6) could be experimental error because at these times the indoor temperatures were lowest (Appendix B Tab.13), therefore this combined with higher wind speeds and outside temperatures would tend to higher air exchange rates at these times. These low air exchange rates may be due to incomplete mixing of tracer gas or back mixing, whereby after leaving the stall and/or re-circulating within the stall, tracer gas re-entered the air mixing sub-section. 
However, these depressions are preceded and followed by accessions in agreement with previous results.

The highest air exchange rates occurred in between $11-17 \mathrm{~h}$, the maximum hourly wind speeds were recorded at $12 \mathrm{~h}\left(3,70 \mathrm{~ms}^{-1}\right)$ and $16 \mathrm{~h}\left(3,50 \mathrm{~ms}^{-1}\right)$ and the lowest inside temperatures were recorded from 13-16h (Appendix B Tab.13). In addition between 11-16h maximum wind speeds ranged from $6,9-8,0 \mathrm{~ms}^{-1}$ with wind directions close to the transverse $\left(96,2-103,3^{\circ}\right)$. The air exchange rate peaks at $11 \mathrm{~h}(5,41 / \mathrm{h})$ and $13 \mathrm{~h}$ $(5,57 / \mathrm{h})$ correspond with the rise in outside temperatures, and wind speeds were $\sim 3 \mathrm{~ms}^{-1}$ (Fig. 4-6). However, these peaks were followed by a sharp decline between 14-16h. Animal activity peaked from $07-10 \mathrm{~h}$ and 14-16h, AER peaks were recorded directly after these peaks at 11 and $17 \mathrm{~h}$ (maximum 5,81/h). Interestingly animal activity was negatively correlated with inside temperature $r^{2}=-0,68$ and the inside temperatures decreased from $22,82^{\circ} \mathrm{C}$ at $11 \mathrm{~h}$ to the minimum $22,41{ }^{\circ} \mathrm{C}$ at $16 \mathrm{~h}$. However, the highest peak at $17 \mathrm{~h}$ may be due to the previously low ventilation rates and build up of heat and stale air requiring a fresh air purge.

Wind speeds dropped from $3,5 \mathrm{~ms}^{-1} / \mathrm{h}$ (16h) to $0,5 \mathrm{~ms}^{-1}$ (20h) with air exchange rates also correspondingly decreasing in the evening hours (Fig. 4-6). Although there are significant deviations between the hourly air exchange rates, it seems reasonable to assume that the tracer gas method results peaked during the middle of the day with outside temperatures, wind speeds and animal activity. The typical pattern of depressions followed straight after by accessions and vice versa seems to follow the same trend as the previous periods.

The moisture balance air exchange rates fluctuated between 4,30-7,27/h ( $\mathrm{SD}=0,75)$, but also recorded a peak at $16 \mathrm{~h}, 1$ hour before the tracer gas method peak, and then after 16h the air exchange rate continuously decreased. A notable trough was recorded at 03h similar to the tracer gas depression and a peak at $07 \mathrm{~h}$, the tracer gas method recording a small peak at $08 \mathrm{~h}$. The heat balance results fluctuated between $2,65-4,55 / \mathrm{h}$ $(\mathrm{SD}=0,62)$ and recorded a clear peak at 13-16h, corresponding with the moisture balance and tracer gas methods. The heat balance method air exchange rates also began to decrease after $16 \mathrm{~h}$ in agreement with the temperature, wind speeds, moisture balance and tracer gas methods. The air exchange rate plots (Fig. 4-6) are all within range of 
each other and are all correlated with wind speed. The heat and moisture balances recorded positive correlations with wind speed, $r^{2}=0,57$ and 0,90 , respectively. However no significant correlations were found between the methods.

Tab. 4- 13 Tracer gas method and influencing variable correlation table (12.11.03)

\begin{tabular}{cccccccc}
\hline & $\begin{array}{c}\text { Average } \\
\text { hourly } \\
\text { wind } \\
\text { speeds }\end{array}$ & $\begin{array}{c}\text { Average } \\
\text { maximum } \\
\text { hourly wind } \\
\text { speeds }\end{array}$ & Outside & $\boldsymbol{\Delta}$ & Inside & $\begin{array}{c}\text { Inside } \\
\text { humidity }\end{array}$ \\
\hline $\begin{array}{c}\text { Tracer gas } \\
\text { method }\end{array}$ & 0,41 & 0,47 & 0,30 & $-0,30$ & $-0,26$ & $-0,30$ \\
\hline
\end{tabular}

The tracer gas method air exchange rates recorded a very low correlation coefficient $r^{2}=0,41$ with hourly wind speed and $r^{2}=0,47$ with maximum wind speeds (Tab. 4-13), lower than $r^{2}=0,46$ and 0,58 , recorded on the 09.11.03. The correlation coefficients must be over $r^{2}>0,40$ to be significant (Myers \& Well 2003), so the significance is low. Also, once again there were no significant correlations between the tracer gas method and other install and outside hygro-heat variables. Only the wind speeds were correlated with hourly air exchange rate methods. It appears that once again the lower outside temperatures may have inhibited the effects temperature had on air exchange rate as well as reducing the effects from wind on the air exchange rates, by lower temperatures keeping the side wall curtains closed for most of the time. It appears that the hourly air exchange rates were driven mainly by thermal buoyancy with contributions from wind forces.

A comparison of the day time (07-19h), night time (19-07h) and $24 \mathrm{~h}$ average was made between the tracer gas and mass balance models results (Tab. 4-14).

Tab. 4- 14 Day/night and 24h average result comparisons with tracer gas method results (12.1103)

\begin{tabular}{cccc}
\hline & \multicolumn{3}{c}{ Average } \\
\cline { 2 - 4 } $\begin{array}{c}\text { Air exchange } \\
\text { calculation method }\end{array}$ & $\begin{array}{c}\text { Day time } \\
\mathbf{0 7 - 1 9 h r}\end{array}$ & $\begin{array}{c}\text { Night time } \\
\mathbf{1 9 - 0 7 h r}\end{array}$ & $\mathbf{2 4 h r}$ \\
\hline Tracer gas method & 3,02 & 1,89 & 2,57 \\
Heat balance & $3,81(+26 \%)$ & $2,90(+53 \%)$ & $3,37(+31 \%)$ \\
Moisture balance & $4,07(+35 \%)$ & $4,99(+164 \%)$ & $5,52(+115 \%)$ \\
\hline
\end{tabular}


The results indicate the heat balance was better aligned with the tracer gas method results than the moisture balance method. The tracer gas method was on average $31 \%$ lower than the heat balance model and $115 \%$ lower than the moisture balance model.

The tracer gas median air exchange rate $2,50 / \mathrm{h}$ was above the minimum recommended air exchange rate for this day 2,10/h (DIN 18910. 1998). The tracer gas air exchange rate translates to a ventilation rate of $0,51 \mathrm{~m}^{3} / \mathrm{h} / \mathrm{bird}$, higher than the minimum guideline value $0,43 \mathrm{~m}^{3} / \mathrm{h} / \mathrm{bird}$. The heat and moisture balance ventilation rates were 0,65 and $1,15 \mathrm{~m}^{3} / \mathrm{h} /$ bird, respectively, both above the recommended minimum. 
Tab. 4- 15 Summarised AER results and weather conditions (13.11.03)

\begin{tabular}{|c|c|c|c|}
\hline $\begin{array}{l}\text { Bird weight: } 1,35 \mathrm{~kg} \\
\text { Age: } 27 \text { days }\end{array}$ & Mean \pm SD & Range & Median \\
\hline $\begin{array}{l}\text { Tracer gas method } \\
\text { (exchange rate/h) }\end{array}$ & $0,86 \pm 0,54$ & $0,29-2,77$ & 0,71 \\
\hline $\begin{array}{c}\text { Heat balance } \\
\text { (exchange rate/h) }\end{array}$ & $3,05 \pm 0,15$ & $2,88-3,46$ & 3,00 \\
\hline $\begin{array}{l}\text { Moisture balance } \\
\text { (exchange rate/h) }\end{array}$ & $3,99 \pm 0,37$ & $3,61-4,90$ & 3,87 \\
\hline Wind speed $\left(\mathrm{ms}^{-1}\right)$ & $0,30 \pm 0,35$ & $0,00-1,30$ & 0,2 \\
\hline Wind direction $\left({ }^{\circ}\right)$ & $81,40 \pm 116,48$ & $0,00-359,00$ & 50,3 \\
\hline Outside temperature $\left({ }^{\circ} \mathrm{C}\right)$ & $3,77 \pm 0,59$ & $3,00-4,60$ & 3,8 \\
\hline Inside temperature $\left({ }^{\circ} \mathrm{C}\right)$ & $24,99 \pm 0,27$ & $24,35-25,66$ & 24,95 \\
\hline Inside humidity (\%) & $72,23 \pm 3,38$ & $62,36-76,68$ & 72,26 \\
\hline $\begin{array}{c}\Delta \text { Temperature } \\
\text { (inside \& outside stall }{ }^{\circ} \mathrm{C} \text { ) }\end{array}$ & $21,22 \pm 0,62$ & $19,85-22,01$ & 21,4 \\
\hline $\begin{array}{c}\text { Coefficient of variation } \\
\text { between } \mathrm{SF}_{6} \text { sample location } \\
\text { concentrations (\%) }\end{array}$ & $3,05 \pm 2,93$ & $0,70-11,53$ & 1,71 \\
\hline
\end{tabular}

On the $13.11 .03(12 \mathrm{~h})-14.11 .03(10 \mathrm{~h})$ the birds weighed approximately $1,35 \mathrm{~kg}$ and were nearly 1 month old, approaching the end of the fattening period. The tracer gas was dosed from the opposite side throughout this period, also from a 3 point dosing tube. The weather results in Tab. 4-15 indicate a slight increase in temperature with a median of $3,80^{\circ} \mathrm{C}$ (range $3,00-4,60^{\circ} \mathrm{C}$ ) compared to $1,45^{\circ} \mathrm{C}$ (range $-1,00-6,00^{\circ} \mathrm{C}$ ) on the previous period 12.11.03. The temperature conditions are reasonably constant with a range of only $1,6^{\circ} \mathrm{C}$. A lower $\Delta$ temperature median $21,40^{\circ} \mathrm{C}$ (range $19,85 \quad-22,01^{\circ} \mathrm{C}$ ) compared to $21,72^{\circ} \mathrm{C}$ (range $16,61-24,5^{\circ} \mathrm{C}$ ) indicates the slightly higher temperatures, and the very small range on the 13.11 .03 may be explained by stable in house conditions. The internal temperatures on this day were the highest out of all days tested, median $24,95^{\circ} \mathrm{C}$ (range $24,35-25,66^{\circ} \mathrm{C}$ ) compared with median 23,08 (range 22,41- 
$23,87^{\circ} \mathrm{C}$ ) on the $12 \cdot 11.03$. The high indoor temperatures could also be due to the larger bird mass, slightly warmer outside temperatures and /or lower air exchange rates. The wind direction on both days were different, $90,85^{\circ}\left(56,80-103,30^{\circ}\right)$ on the 12.11 .03 compared with $50,30^{\circ}\left(0-359^{\circ}\right)$ on the 13.11 .03 , there were clearly much more fluctuations in wind direction on the 13.11 .03 and transverse directions were seldom. The wind speeds on both days were different with a large decrease on the 13.11.03 median $=0,20 \mathrm{~ms}^{-1}\left(\right.$ range $\left.0,00-1,30 \mathrm{~ms}^{-1}\right)$ compared with a median of $2,65 \mathrm{~ms}^{-1}$ (range $\left.0,50-3,70 \mathrm{~ms}^{-1}\right)$, so the wind speeds were clearly very low almost negligible on the 13.11.03 and the wind directions were random. Therefore, it seems likely that the effect from wind forces on the 13.11.03 had only a minor influence on the air exchange rates. The median air exchange rates on the 13.11 .03 were $0,71 / \mathrm{h}$ (range $0,29-2,77 / \mathrm{h}$ ) compared with 2,50/h (range $0,43-5,81 / \mathrm{h}$ ), therefore the calculated air exchange rates on the 13.11 .03 were very low.

The CV values between both days differed with a median of $0,45 \%$ (13.11.03) compared to $8,61 \%$ (12.11.03), the lower CV (13.11.03) may be explained by better air mixing due to very low air exchange rates, both periods had tracer gas dosing from 3 points within the air mixing sub-section. Furthermore, the $\mathrm{CV}$ range on the 12.11.03 $(2,68-31,55 \%)$ is much larger than $0,14-2,85 \%$ (13.11.03), also suggesting the higher air exchange rates perhaps led to a higher degree of variation between sample locations because of higher turbulences etc. A high correlation coefficient $r^{2}=0,73$ was recorded on the 13.11 .03 between air exchange rates and $\mathrm{CV}$, confirming that when the air exchange rates increased then so did the $\mathrm{CV}$ values.

The very low air exchange rates recorded by the tracer gas method appear to be too low, such air exchange rates would not provide a sufficient environment for the birds, however it is interesting that very low results can be observed, as would be expected with the wind and inside temperature conditions observed. The tracer gas result fluctuations on the 13.11 .03 are lower than the previous period with a $\mathrm{SD} \pm 0,54$ compared with $\pm 1,54$ (12.11.03), this can be simply explained by the lower air exchange rates on the 13.11.03. The heat and moisture balance models also followed a similar trend, recording decreased standard deviations of $\pm 0,15$ and $\pm 0,37$, respectively, a decrease from the previous period (12.11.03) of 0,62 and 0,75 . 


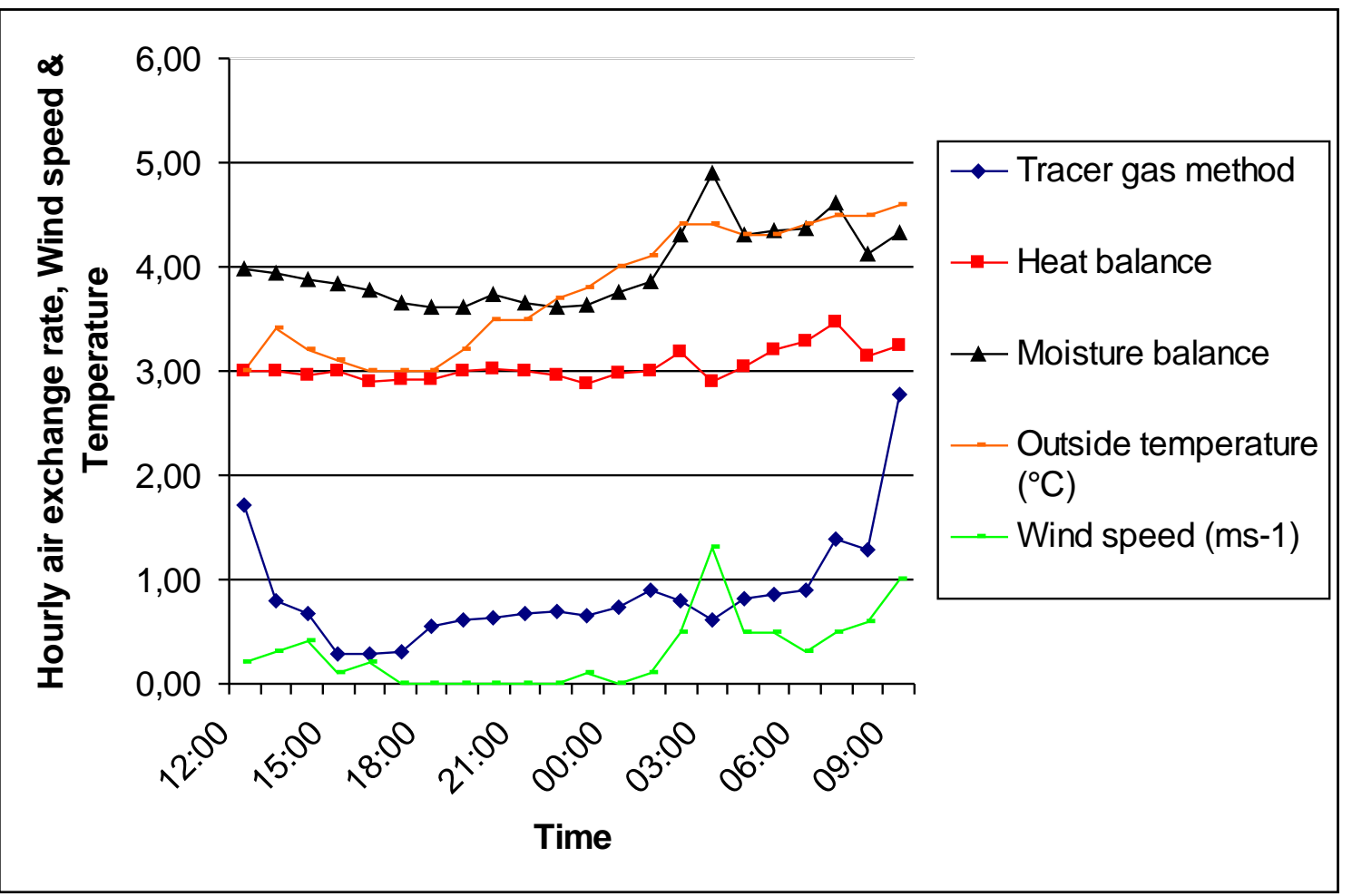

Fig. 4- 7: Hourly mass balance and tracer gas method AER results along with influencing weather variables $(13.11 .03)$

The tracer gas method results (Fig. 4-7) indicate the lowest air exchange rates occurred between $15-17 \mathrm{~h}(0,29-0,30 / \mathrm{h})$. The outside temperatures were lowest at $16-18 \mathrm{~h}\left(3^{\circ} \mathrm{C}\right)$ and wind speeds were negligible $\left(0-0,20 \mathrm{~ms}^{-1}\right)$ with directions at varying angles, the inside temperatures were slightly higher than neighbouring values (Appendix B Tab.17) possibly the result from lower air exchange rates and/or slightly higher bird activity at this time (Appendix B Tab.17). Although, low air exchange rates do seem unlikely at this time of the day, it nearly coincides with slight air exchange rate depressions recorded by the heat balance (16-18h) and moisture balance (17-19h). Interestingly, a ventilation rate depression at $03 \mathrm{~h}(0,62 / \mathrm{h})$ was recorded (Fig. 4-7) corresponding with a temperature of $4,4^{\circ} \mathrm{C}$ (temperature peak was $4,6^{\circ} \mathrm{C}$ ) and the highest wind speed $1,3 \mathrm{~ms}^{-1}$ in the transverse direction $\left(90^{\circ}\right)$. However, as observed in this study outside temperatures below $4,5^{\circ} \mathrm{C}$ seemed to have a reduced effect on air exchange rates as well as wind speeds below $2 \mathrm{~ms}^{-1}$, not to mention the very early morning hours where ventilation patterns under winter conditions seemed to be more controlled by thermal buoyancy forces. 
The highest air exchange rate with the tracer gas method occurred at $09 \mathrm{~h}(2,77 / \mathrm{h})$ and $12 \mathrm{~h}(1,71 / \mathrm{h})$, the first and last results of the measurement period. In addition 2 smaller peaks at $01 \mathrm{~h}(0,90 / \mathrm{h})$ and $07 \mathrm{~h}(1,39 / \mathrm{h})$ occurred. At $02 \mathrm{~h}$ the inside temperatures dropped slightly and at $07 \mathrm{~h}$ as well, however animal activity recorded the lowest values between 02-07h. The tracer gas method peaks in the middle of the day (13.11.03) and the mid morning (09h) on the 14.11.03, seem to be from increased thermal buoyancy produced from the birds rather than influencing weather variables and animal activity was at its highest during these times (Appendix B Tab.17).

Interestingly, the tracer gas peaks at $07 \mathrm{~h}$ and $09 \mathrm{~h}$ correspond with slight peaks recorded by both mass balance models. The slight peak recorded by the tracer gas method at $01 \mathrm{~h}$, is nearly aligned with the heat balance peak at $02 \mathrm{~h}$ and moisture balance peak at 03h. The tracer gas method results seem to be too low, low air exchange rates over this period were expected but a minimum of $0,29 / \mathrm{h}$ seems too low considering the age of the birds (27 days). It could be possible that the released tracer gas was not mixing properly with the rest of the livestock house air, because of the very low AERs and low turbulences perhaps the tracer gas may have settled in the air mixing sub-section and not dispersed throughout the broiler house, resulting in high tracer gas concentrations in this zone, thus the very low AER results.

The air exchange rate plots (Fig. 4-7), are not as closely aligned as previous days, but do correspond with each other at times especially the heat and moisture balance models. Both the heat and moisture balances were correlated $r^{2}=0,59$. The tracer gas method results also follow the similar trend as previous results with depressions followed sharply by accessions. The tracer gas method results are positively correlated with the heat balance results $r^{2}=0,57$. The heat balance results recorded minor fluctuations with a range $2,88-3,46 / \mathrm{h}(\mathrm{SD}=0,15)$. The moisture balance results followed a similar trend, range 3,61-4,90/h $(\mathrm{SD}=0,37)$. The heat and moisture balance hourly air exchange rates were quite similar median $3,00 / \mathrm{h}$ and $3,87 / \mathrm{h}$, respectively. 
Tab. 4- 16 Tracer gas method and influencing variable correlation table (13.11.03)

\begin{tabular}{ccccccc}
\hline & $\begin{array}{c}\text { Average } \\
\text { hourly } \\
\text { wind } \\
\text { speeds }\end{array}$ & $\begin{array}{c}\text { Average } \\
\text { maximum } \\
\text { hourly } \\
\text { wind } \\
\text { speeds }\end{array}$ & Outside & $\Delta$ & Inside & $\begin{array}{c}\text { Tnside } \\
\text { humidity }\end{array}$ \\
\hline $\begin{array}{c}\text { Tracer gas } \\
\text { method }\end{array}$ & 0,49 & 0,58 & 0,48 & $-0,58$ & $-0,27$ & $-0,27$ \\
\hline
\end{tabular}

The tracer gas method hourly air exchange rates recorded a positive correlation coefficient $r^{2}=0,49$ with hourly wind speed and $r^{2}=0,58$ with maximum wind speeds (Tab. 4-16). This could be due to a pressure build up outside the livestock house from winds at the end of the period (between 05-10h) whereby air exchange rates increased from $0,85-2,77 / \mathrm{h}$ with wind speeds simultaneously increasing from $0,3-1 \mathrm{~ms}^{-1}$. Although these wind speeds seem too low to have an effect, maximum wind speeds between $1,3-3,2 \mathrm{~ms}^{-1}$ at these times (05-10h) were also measured (Appendix B Tab.17) and the wind directions were increasingly becoming transverse between $59-87^{\circ}$. The tracer gas method was correlated with outside temperatures $r^{2}=0,48$, and negatively correlated with $\Delta$ temperature difference $\mathrm{r}^{2}=-0,58$. The median outside temperature was $3,80^{\circ} \mathrm{C}(13.11 .03)$, which is lower than the median $4,20^{\circ} \mathrm{C}(09.11 .03)$ and no significant correlation coefficient was recorded on this date. This correlation could be coincidental, however, the air exchange rate does slowly increase as the outside temperature rises (Fig. 4-7), perhaps because of the reduced effect wind speeds had on AERs the outside temperature played more of an influencing role. There was a significant negative correlation between the tracer gas method and $\Delta$ temperature, this maybe due to the increased role thermal buoyancy played driving the ventilation rates under these conditions in combination with outside temperatures.

It seems likely that the tracer gas method results were inaccurate in this period because of the very low air exchange rates. Under these weather conditions with cool temperatures, almost negligible wind speeds and sporadic wind directions ventilation rates would have been quite low as expected, but with the weight of the birds, the main driving force would have been thermal buoyancy. Although the air exchange rates were too low, the air exchange rate trend may be quite representative of the actual ventilation rate. 
A comparison of the day time (07-19h), night time (19-07h) and $24 \mathrm{~h}$ average was made between the tracer gas and mass balance models results (Tab. 4-17).

Tab. 4- 17 Day/night and 24h average result comparisons with tracer gas method results (13.11.03)

\begin{tabular}{cccc}
\hline $\begin{array}{c}\text { Air exchange } \\
\text { calculation method }\end{array}$ & $\begin{array}{c}\text { Day time } \\
\mathbf{0 7 - 1 9 h r}\end{array}$ & $\begin{array}{c}\text { Night time } \\
\mathbf{1 9 - 0 7 h r}\end{array}$ & $\mathbf{2 4 h r}$ \\
\cline { 2 - 4 } & 1,34 & 0,80 & 0,86 \\
Tracer gas method & $3,08(+130 \%)$ & $3,08(+285 \%)$ & $3,05(+255 \%)$ \\
Heat balance & $4,01(+199 \%)$ & $4,09(+411 \%)$ & $3,99(+364 \%)$ \\
\hline
\end{tabular}

The results indicate the tracer gas method results were much lower than the mass balance model results. The tracer gas method was on average $255 \%$ lower than the heat balance model and $364 \%$ lower than the moisture balance model.

The tracer gas median air exchange rate, converts to a ventilation rate of $0,15 \mathrm{~m}^{3} / \mathrm{h} / \mathrm{bird}$ which is substantially less than the recommended minimum of $0,44 \mathrm{~m}^{3} / \mathrm{h} / \mathrm{bird}$. The heat and moisture balance ventilation rates were 0,61 and $0,78 \mathrm{~m}^{3} / \mathrm{h} / \mathrm{bird}$, respectively. 


\subsection{Summary of results}

The median air exchange rate results measured from the 07-14.11.03, were graphed together with the median wind speeds and median outside temperatures from the days tested (Fig. 4-8).

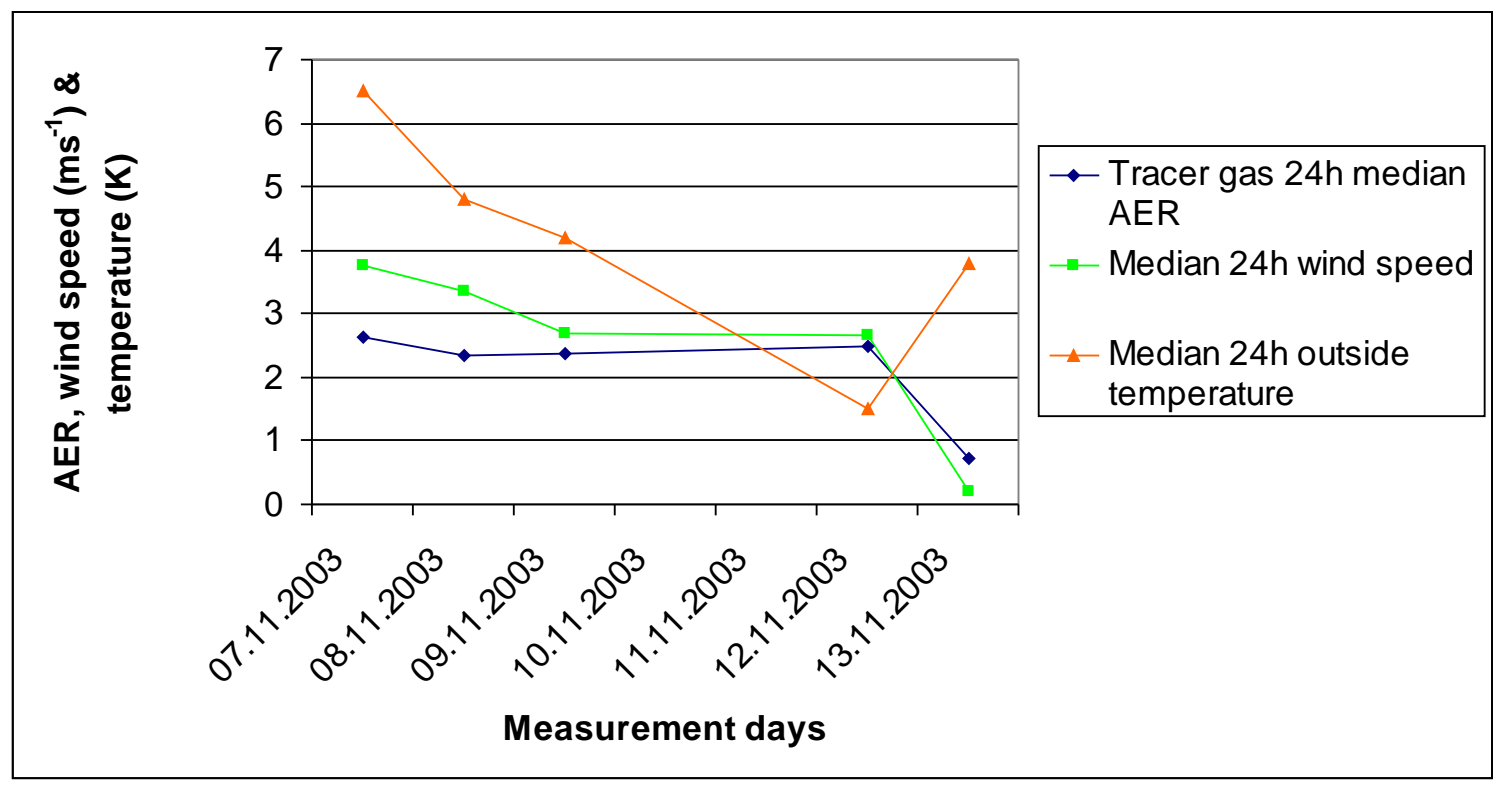

Fig. 4- 8: Daily AER vs median wind speeds \& outside temperatures in Experiment 2 (07-14.11.03)

The results indicate a linear relationship, higher median air exchange rates corresponded with higher median wind speeds, except for the 12.11 .03 where a higher air exchange rate was recorded with a slightly lower wind speed (as previously discussed). These 2 variables were highly correlated $\mathrm{r}^{2}=0,96$, confirming the sensitivity of the method with the wind speeds and the calculated results. The outside temperatures also follow a similar trend except for the 13.11.03, whereby temperatures were slightly higher and air exchange rates were lower. However, the 13-14.11.03 period conditions were rather different to the very consistent conditions on the previous days, i.e. wind speeds were very low and wind directions were random. Thus, illustrating the effect wind speed and wind direction has on air exchange rates. Median inside temperatures on the days tested were negatively correlated $r^{2}=-0,97$ with air exchange rates, indicating lower inside temperatures were correlated with higher AERs. Although, inside temperatures are affected by a number of factors, i.e. bird mass, bird activity, outside temperatures the ventilation rate also plays a crucial role in reducing and increasing inside temperatures, especially under winter conditions. 


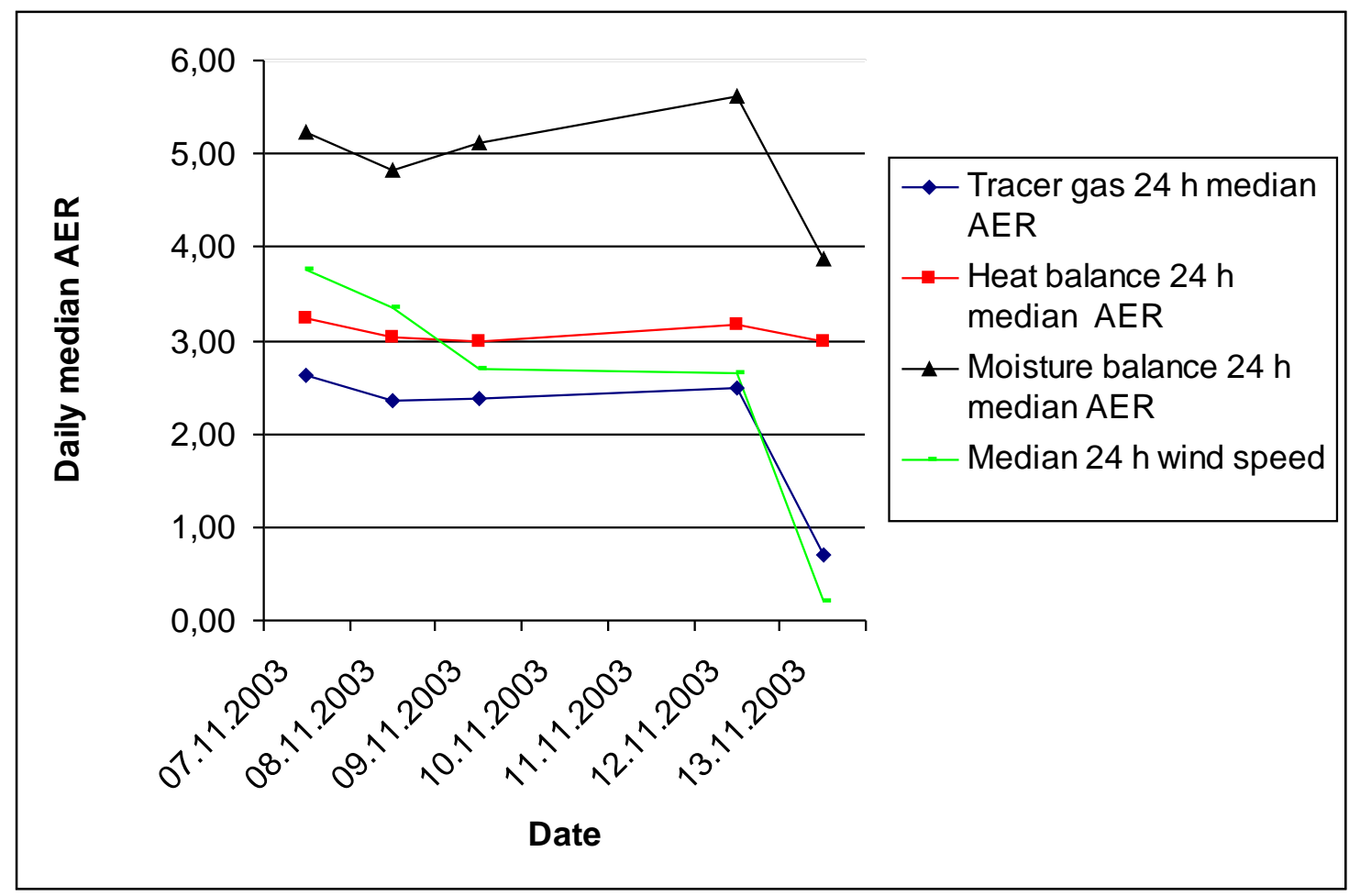

Fig. 4- 9: Median daily tracer gas \& mass balance model AERs vs wind speed in Experiment 2 (0714.11.03)

The heat and moisture balance models also recorded highly significant correlations with wind speeds (Fig. 4-9). On the 07.11.03 wind speeds correlated with the heat and moisture balances, $\mathrm{r}^{2}=0,75$ and 0,86 , respectively. The moisture balance recorded a positive correlation coefficient on all measurement periods (range $r^{2}=0,51-0,90$ ). The heat balance was not significantly correlated on 2 periods, but recorded significant correlation coefficient (range $\left.r^{2}=0,57-0,84\right)$. However, when the daily medians were tested against the daily median wind speeds the heat and moisture balance correlated $r^{2}=0,56$ and 0,79 , respectively. The tracer gas method recorded a positive $r^{2}=0,96$, indicating the tracer gas method was overall, more sensitive to the fluctuations in wind speeds throughout the measurement period. 


\subsection{Experiment 3: Mass balance models (heat, moisture \& $\mathrm{CO}_{2}$ ), tracer gas and pressure flow sensor validation technique in Livestock house 2}

All methods were once again tested on a commercially operated full sized broiler house so the work had to correspond with farm management operations and influences from farmer activities could not be controlled.

Because there are fixed inlet and outlet points in this livestock house, it was possible to obtain through calculation and extrapolation the near exact air exchange rate values. All methods tested in this section are subject to error, the variability of bird masses and therefore model calculations of heat, moisture and $\mathrm{CO}_{2}$ production, heat transmission loss and gain though the building structure, moisture contributions from the manure/litter, poor distribution and mixing of tracer gas with air, exhaust fan variability, instrumental drift etc are all sources for inaccuracies with the methods tested.

Two different tracer gas dosing set ups were tested in this experiment (as described in the materials and methods chapter). On the $14^{\text {th }}$ and $28^{\text {th }}$ July 2004 dosing was conducted from the middle of the stall, at 2 heights $0,75 \mathrm{~m}$ and $1,9 \mathrm{~m}$ and a flow rate of $3 \mathrm{ml} / \mathrm{s}$ (refer to schematic Fig. 3-6).

On the $18^{\text {th }}$ and $25^{\text {th }}$ August 2004, dosing was conducted from 2 points on opposite side walls adjacent to the low fresh air inlets at $0,5 \mathrm{~m}$ height (refer to Fig. 3-7). It was hoped better tracer gas/air mixing would occur from the side wall dosing points. Furthermore, tracer gas was dosed at $3 \mathrm{ml} / \mathrm{s}$ on the 18.08 .04 and then this was increased to $15 \mathrm{ml} / \mathrm{s}$ on the 25.08.04.

Normally gas fired heaters are turned on from between 1-7 or 1- 9 days in the summer depending on the weather in order to maintain high inside temperatures when the chicks are young. On the 18.08.04, the chickens were $\sim 8$ days old and the outside temperatures were warm (median $21,1^{\circ} \mathrm{C}$ ). Because the heater information was not recorded by the SKOV climate computer system it is unsure whether the heaters were switched on for short periods of time in the early morning hours on the 19.08.04. However, if they were switched on it is assumed that the extra heat from the heaters and 
carbon dioxide additions from the burnt natural gas would have effects on the mass balance model results. Although the heat balance recorded large fluctuations, no significant change in the $\mathrm{CO}_{2}$ or moisture balance models can be observed at these times, therefore, it is assumed if the heaters were temporarily switched on the effects were negligible.

The ventilation system (detail in section 3-7) operates by an air extraction system removing air and creating a negative under pressure in the stall, which then draws fresh air in though the stall inlets. The livestock house inlets are covered by wind breakers, therefore the effects from winds on the ventilation rate are negligible and were therefore not considered important. The weather conditions over the measurement period were generally warm.

The tracer gas dosing and sampling equipment is suited to measurements in office buildings, so the system with only 6 sampling locations and a maximum dosage rate of $15 \mathrm{ml} / \mathrm{s}$ was used to the best of its capability.

The following experiments were divided into 5 sections chapters 4.6-4.10. 


\subsection{Mass balance model and tracer gas measurement results 14.07.04 and 28.07.04}

Tab. 4- 18 Summarised AER results and weather conditions (14.07.04)

\begin{tabular}{|c|c|c|c|}
\hline $\begin{array}{l}\text { Bird weight: } 1,02 \mathrm{~kg} \\
\text { Age: } 21 \text { days }\end{array}$ & Mean \pm SD & Range & Median \\
\hline Tracer gas method & $2,38 \pm 0,31$ & $1,64-2,86$ & 2,44 \\
\hline $\begin{array}{c}\mathrm{CO}_{2} \text { balance } \\
\text { (exchange rate/h) }\end{array}$ & $19,36 \pm 4,00$ & $14,92-28,42$ & 17,42 \\
\hline $\begin{array}{c}\text { Heat balance } \\
\text { (exchange rate/h) }\end{array}$ & $13,91 \pm 2,12$ & $11,13-18,63$ & 13,61 \\
\hline $\begin{array}{l}\text { Moisture balance } \\
\text { (exchange rate/h) }\end{array}$ & $14,64 \pm 2,16$ & $11,25-18,65$ & 14,25 \\
\hline Outside temperature $\left({ }^{\circ} \mathrm{C}\right)$ & $16,1 \pm 2,0$ & $13,9-19,9$ & 15,60 \\
\hline Inside temperature $\left({ }^{\circ} \mathrm{C}\right)$ & $22,4 \pm 1,0$ & $21,1-24,2$ & 21,90 \\
\hline $\begin{array}{c}\Delta \text { Temperature } \\
\text { (inside \& outside stall }{ }^{\circ} \mathrm{C} \text { ) }\end{array}$ & $6,2 \pm 1,1$ & $4,2-7,8$ & 6,40 \\
\hline $\begin{array}{c}\text { Coefficient of variation } \\
\text { between } \mathrm{SF}_{6} \text { sample location } \\
\text { concentrations (\%) }\end{array}$ & $13,72 \pm 0,96$ & $12,06-15,23$ & 13,47 \\
\hline
\end{tabular}

On the 14.07.04 the birds weighed approximately $1,02 \mathrm{~kg}$ and were 3 weeks old. In reference to Tab. 4-18, the outdoor temperature results indicate the temperatures were mild with a median of $15,6^{\circ} \mathrm{C}$ (range $13,9-19,9 \mathrm{C}^{\circ} \mathrm{C}$ ). The $\Delta$ temperature (difference between inside and outside conditions) median was $6,4^{\circ} \mathrm{C}$ (range $4,2-7,8^{\circ} \mathrm{C}$ ). The median inside temperature $21,9^{\circ} \mathrm{C}$ with a small range $\left(21,1-24,2^{\circ} \mathrm{C}\right)$, indicates reasonably stable in house conditions. The tracer gas method median air exchange rate $2,44 / \mathrm{h}$ was much lower than the $\mathrm{CO}_{2}$, heat and moisture mass balance calculations, $16,38 / \mathrm{h}, 13,61 / \mathrm{h}$ and $14,25 / \mathrm{h}$, respectively. 
The tracer gas method results remained relatively constant with a small air exchange rate range of $1,64-2,86 / \mathrm{h}$, whereas, the $\mathrm{CO}_{2}$, heat and moisture balance ranges fluctuated considerably, 14,92-28,42/h, 11,13-18,63/h \& 11,25-18,65/h, respectively.

The median CV between the sampling locations was $13,47 \%$ with a small range 12,06 $15,23 \%$. This small CV range is perhaps due to relatively constant air exchange rates.

The tracer gas fluctuations throughout the day are low with a mean and SD of 2,38 \pm 0,31 air exchanges/h compared with the $\mathrm{CO}_{2}$, heat and moisture balances 19,36 $\pm 4,00$, $13,91 \pm 2,12$ and 14,64 $\pm 2,16$, respectively. Interestingly, all mass balance models also recorded relatively low standard deviations indicating the air exchange rates were relatively constant.

Considering the birds were 3 weeks old, outside temperatures were warm and the ventilation system the tracer gas method results are too low.

The natural tracer gas hourly exchange rate curves were all well aligned with each other and the outside temperatures, however the tracer gas results were very low and did not correspond with either the natural tracer gas results or outside temperatures (Fig. 4-10). The heat and moisture balances were correlated with each other $\left(r^{2}=0,97\right)$ and with the $\mathrm{CO}_{2}$ balance, $\mathrm{r}^{2}=0,95$ and $\mathrm{r}^{2}=0,93$, respectively. Confirming the close relationship between the production of these 3 variables from the birds (Fig. 4-10). 


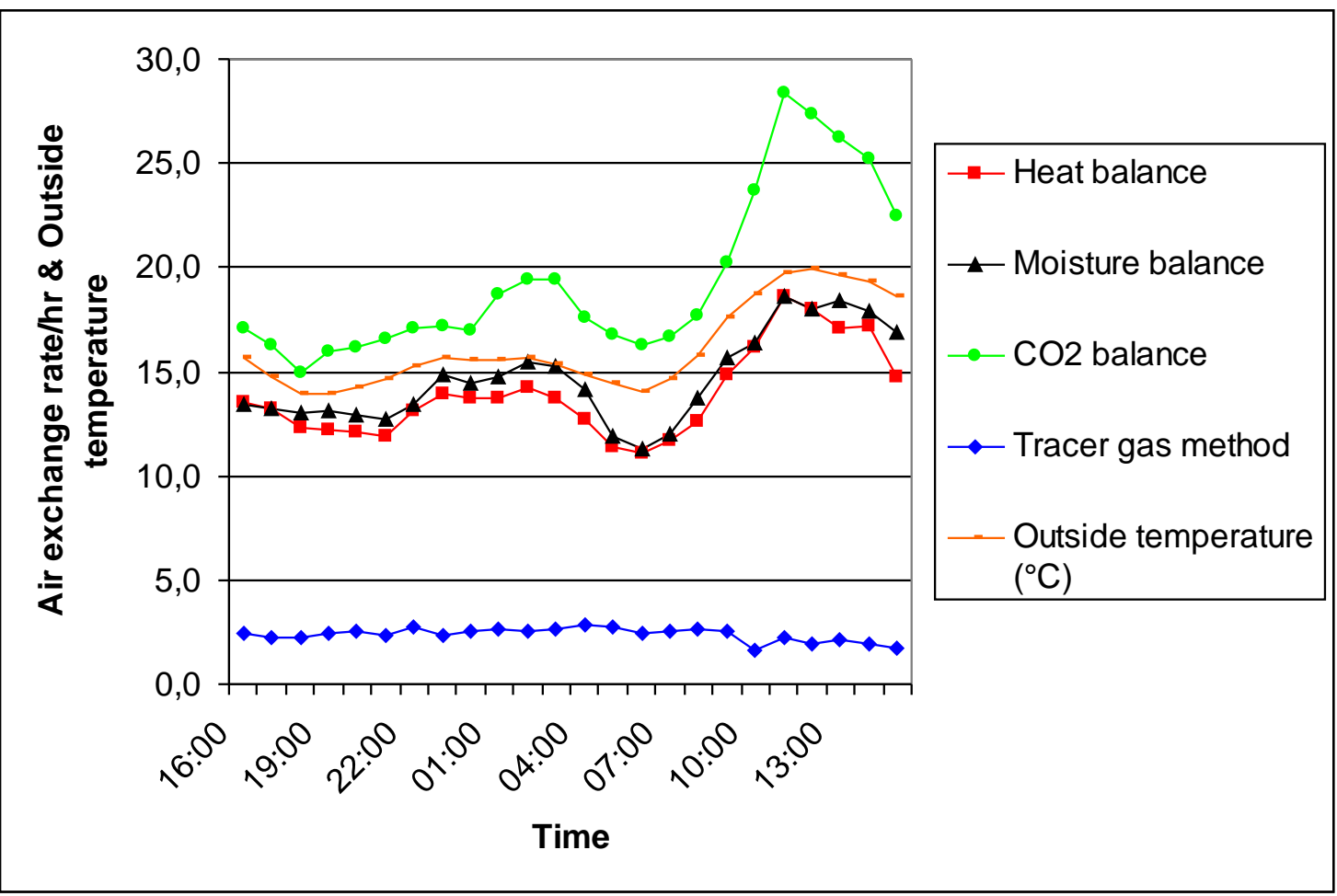

Fig. 4- 10: Hourly tracer gas method and mass balance AER results along with outside temperature (14.07.04)

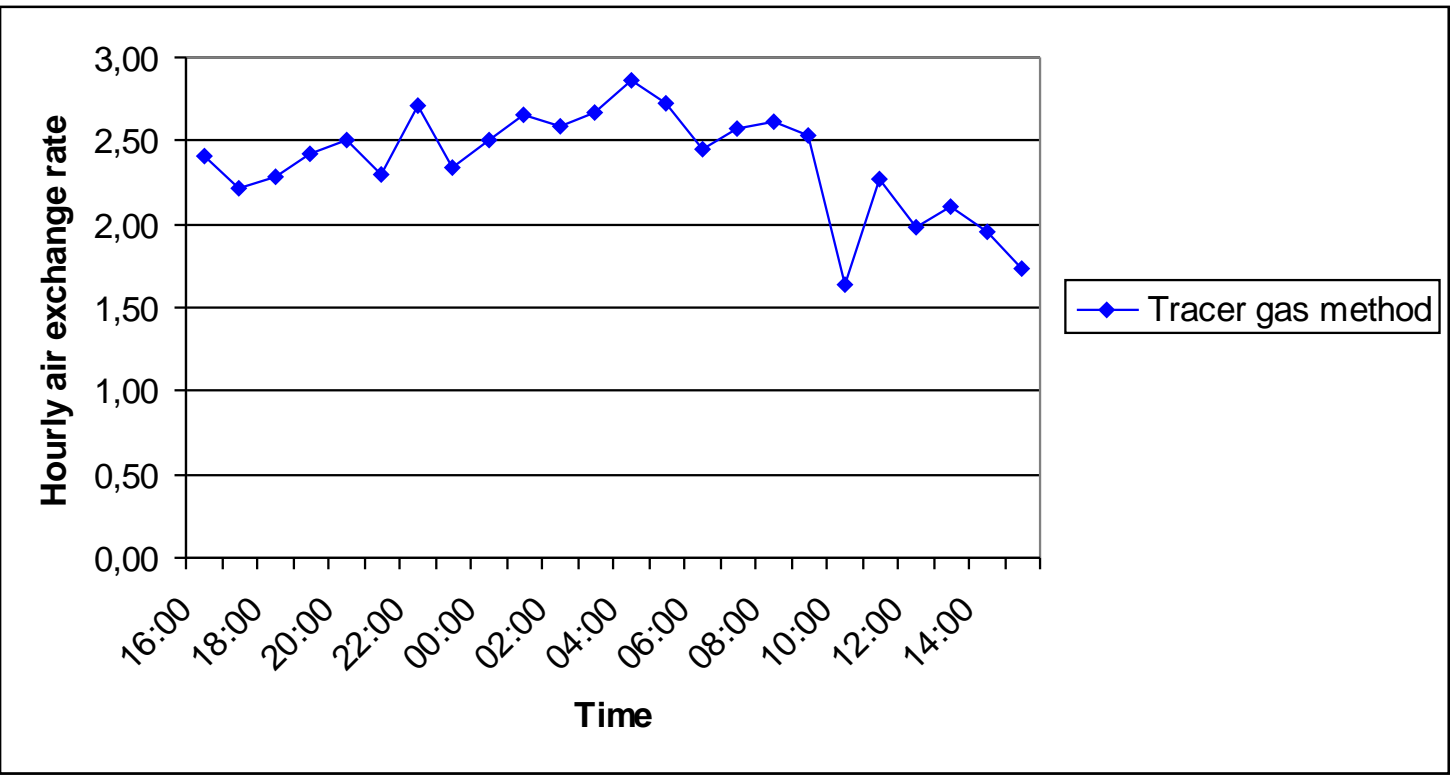

Fig. 4- 11: Hourly tracer gas method results (14.07.04) 
The tracer gas method results (Fig. 4-11.) recorded peak AERs at $04 \mathrm{~h}(2,86 / \mathrm{h})$ and 0006h (2,51-2,86/h). The mass balance models $\left(\mathrm{CO}_{2}\right.$, heat and moisture) also recorded AER peaks from 00-04h (19,5, 14,3 \& 15,7/h). However, it seems more likely that low AERs would have occurred at these times, rather than the higher air exchanges. The reason for the high air exchanges recorded by the mass balance models is a basic flaw in the MBMs as the animal activity would be at a minimum around these times resulting in lower $\mathrm{CO}_{2}$ concentrations, heat and moisture production levels, the models calculate higher exchange rates assuming the excess levels are being removed by the ventilation system rather than reduced production from the animals.

On the other hand the increased tracer gas method air exchange rates at these times are also from a fault in the method, perhaps due to the dosing location and/or dosage volume, resulting in poor tracer gas/air mixing. The tracer gas method recorded higher air exchange rates at these early morning times because the tracer gas underwent better mixing with the lower air exchange rates resulting in lower tracer gas concentrations and thus higher air exchange rate calculations (tracer gas constant injection equation inverse relationship).

The mass balance results all simultaneously recorded a depression at 06h when the minimum outside temperatures were recorded $\left(14^{\circ} \mathrm{C}\right)$ and then began to increase from $10 \mathrm{~h}$ as the outside temperatures began to approach $20^{\circ} \mathrm{C}$. The $\mathrm{CO}_{2}$ mass balance recorded the highest peak $(28,4 / \mathrm{h})$ at $11 \mathrm{~h}$, the heat balance $(18,6 / \mathrm{h})$ and moisture balance $(18,7 / \mathrm{h})$ also coinciding at $11 \mathrm{~h}$, and then all simultaneously decreased towards the end of the period. The mass balance models $\left(\mathrm{CO}_{2}\right.$, heat and moisture $)$ all recorded minimum values at $06 \mathrm{~h}(16,3,11,1 \& 11,3 / \mathrm{h}$, respectively). The tracer gas method recorded the lowest AER at $10 \mathrm{~h}(1,64 / \mathrm{h})$ and the AERs remained low from between 10$16 \mathrm{~h}(1,64-2,27 / \mathrm{h})$. It seems more likely that the minimum ventilation rates would have occurred very early in the morning, more likely at $06 \mathrm{~h}$, rather than $10 \mathrm{~h}$ as recorded with the tracer gas method, once again a problem due to insufficient tracer gas/air mixing.

The tracer gas method results were negatively correlated with the $\mathrm{CO}_{2}$, heat and moisture mass balance models, $r^{2}=-0,59,-0,59$ and $-0,57$, respectively. Confirming that the higher air exchange rates caused higher tracer gas concentrations at the outlets 
due to a direct pull effect from the negative pressure ventilation system, and the lower air exchange rates induced better mixing, causing lower $\mathrm{SF}_{6}$ concentrations at the outlets and thus higher air exchange rate calculations. This may explain why the tracer gas method did not function properly.

Tab. 4- 19 Tracer gas method and influencing variable correlation table (14.07.04)

\begin{tabular}{ccccc}
\hline & \multicolumn{3}{c}{ Temperature } & \\
\cline { 2 - 4 } & Outside & $\boldsymbol{\Delta}$ & Inside & Inside humidity \\
\hline Tracer gas method & $-0,66$ & 0,62 & $-0,67$ & 0,77 \\
\hline
\end{tabular}

The tracer gas method results (Tab. 4-19) recorded a negative correlation with outside temperature $\left(r^{2}=-0,66\right)$, therefore as the outside temperature increased the tracer gas air exchange rate results decreased. Contrary to what would be expected. Furthermore, another disagreement with the general ventilation assumption as the temperature difference between outside and inside stall conditions increased so did the AER $\left(\mathrm{r}^{2}=\right.$ 0,62 between $\Delta$ temperature and tracer gas method results), meaning the highest AERs occurred at night time and not during the day. Because of the summer conditions a positive correlation between inside temperature and air exchange rates would have been expected, as the outside temperatures increase, so does the bird activity and inside temperatures, with the ventilation rate simultaneously increasing to keep the inside temperatures from climbing too high. Instead a negative correlation $\left(r^{2}=-0,67\right)$ between tracer gas method results and inside temperature was recorded. If the tracer gas method functioned properly, a negative correlation between AER and inside humidity would have been expected, the high positive correlation $\left(r^{2}=0,77\right)$ indicates as the inside humidity levels increased (usually during the night) then the AER increased, which was the case with the tracer gas method results, however the true AER values would not have followed these trends.

The tracer gas median air exchange rate value $2,44 / \mathrm{h}$ translates to a ventilation rate of $0,42 \mathrm{~m}^{3} / \mathrm{h} /$ animal, well below the recommended level $3,35 \mathrm{~m}^{3} / \mathrm{h} /$ animal (DIN 18910 . 2004). The mass balance results $\left(\mathrm{CO}_{2}\right.$, heat and moisture), recorded median hourly ventilation rates of $3,02 / \mathrm{h}, 2,36 / \mathrm{h}$ and $2,48 / \mathrm{h}$, all below the recommended level. 
Tab. 4- 20 Summarised AER results and weather conditions (28.07.04)

\begin{tabular}{|c|c|c|c|}
\hline $\begin{array}{l}\text { Bird weight: } 1,26 \mathrm{~kg} \\
\text { Age: } 28 \text { days }\end{array}$ & Mean \pm SD & Range & Median \\
\hline Tracer gas method & $1,89 \pm 0,32$ & $1,30-2,76$ & 1,83 \\
\hline $\begin{array}{c}\mathrm{CO}_{2} \text { balance } \\
\text { (exchange rate/h) }\end{array}$ & $29,02 \pm 7,15$ & $17,76-36,76$ & 31,63 \\
\hline $\begin{array}{c}\text { Heat balance } \\
\text { (exchange rate/h) }\end{array}$ & $27,91 \pm 13,55$ & $13,11-69,54$ & 26,49 \\
\hline $\begin{array}{l}\text { Moisture balance } \\
\text { (exchange rate/h) }\end{array}$ & $24,31 \pm 10,27$ & $11,15-43,97$ & 22,15 \\
\hline Outside temperature $\left({ }^{\circ} \mathrm{C}\right)$ & $17,0 \pm 3,7$ & $11,7-23,9$ & 17,50 \\
\hline Inside temperature $\left({ }^{\circ} \mathrm{C}\right)$ & $21,6 \pm 1,6$ & $19,6-25,2$ & 21,50 \\
\hline $\begin{array}{c}\Delta \text { Temperature } \\
\text { (inside \& outside stall }{ }^{\circ} \mathrm{C} \text { ) }\end{array}$ & $4,6 \pm 2,2$ & $1,3-8,3$ & 4,00 \\
\hline Coefficient of variation betwee & & & \\
\hline $\begin{array}{l}\mathrm{SF}_{6} \text { sample location } \\
\text { concentrations (\%) }\end{array}$ & $11,34 \pm 2,57$ & $7,08-19,84$ & 11,54 \\
\hline
\end{tabular}

On the 28.07.04 the birds weighed approximately $1,26 \mathrm{~kg}$ and were 4 weeks old. In reference to Tab. 4-20, the outdoor temperature results indicate the temperatures were warmer than the previous period with a median of $17,5^{\circ} \mathrm{C}$ (range $11,7-23,9 \mathrm{C}^{\circ} \mathrm{C}$ ) compared with median $15,6^{\circ} \mathrm{C}$ (range $13,9-19,9^{\circ} \mathrm{C}$ ) on the 14.07 .04 . The $\Delta$ temperature was less than the previous period median $4,0^{\circ} \mathrm{C}$ (compared to $6,4^{\circ} \mathrm{C}$ ) and a larger range $1,3-8,3^{\circ} \mathrm{C}$ (compared with $4,2-7,8^{\circ} \mathrm{C}$ ). The lower $\Delta$ temperature and larger range may be effects from the larger outdoor temperature range and/or the combined effect from larger air exchange rates. The median inside temperature $21,5^{\circ} \mathrm{C}$ was slightly lower than the previous period with a range $\left(19,6-25,2^{\circ} \mathrm{C}\right)$, compared to the previous results $21,9^{\circ} \mathrm{C}$ (range $21,1-24,2^{\circ} \mathrm{C}$ ). Assuming lower inside temperatures combined with higher outside temperatures this should correspond with higher AERs, however this is not in agreement with the tracer gas method results recording a median air exchange rate $1,89 / \mathrm{h}$, lower than $2,44 / \mathrm{h}$ from the previous period. 
The median $\mathrm{SF}_{6}$ concentration $\mathrm{CV}$ between the sampling locations was $11,54 \%$ with a range $7,08-19,84 \%$, lower than the 14.07 .04 median value $13,47 \%$ but a higher range than $12,06-15,23 \%$ on the 14.07 .04 .

The lower $\mathrm{SF}_{6} \mathrm{CV}$ on the 28.07.04 maybe due to better mixing induced by larger and more variable air exchange rates. The mass balance results $\left(\mathrm{CO}_{2}\right.$, heat and moisture $)$ tend to agree with this assumption, with mean and $\mathrm{SD}$ values $27,00 \pm 6,48,27,91 \pm$ 13,55 and $24,31 \pm 10,27$ on the 28.07 .04 compared with $18,14 \pm 3,64,13,91 \pm 2,12$ and $14,64 \pm 2,16$ (14.07.04). Interestingly the high $\mathrm{SF}_{6} \mathrm{CV}$ values on the 14.07 .04 and $28.07 .04,15,23 \%$ and 19,84\%, respectively occurred before and after mass balance AER peaks on both days. Although, the MBMs at best are only good indications of when air exchange rate peaks occurred, it is possible at these times the true air exchange rate underwent a significant fluctuation from low to high or high to low, resulting in increased $\mathrm{SF}_{6}$ variation in the stall.

The $\mathrm{SF}_{6} \mathrm{CV}$ was taken from 4 sample locations near the exhaust chimney mouths for both measurements, these were the samples used in calculations. The sample locations $5 \& 6$ were situated at the northern end adjacent to the exhaust chimneys (refer to Fig. 3-6) and recorded consistently higher $\mathrm{SF}_{6}$ concentrations throughout both periods (Tab. 4-21). During both periods the extra fans were at times in operation.

Tab. 4- 21 Average 24h $\mathrm{SF}_{6}$ sample location (1-6) concentrations

\begin{tabular}{ccccccc}
\hline Date & $\mathbf{1}$ & $\mathbf{2}$ & $\mathbf{3}$ & $\mathbf{4}$ & $\mathbf{5}$ & $\mathbf{6}$ \\
\hline 14.07 .2004 & 1,90 & 1,57 & 1,71 & 2,15 & 6,47 & 4,57 \\
28.07 .2004 & 2,90 & 2,24 & 2,72 & 2,83 & 6,27 & 4,26 \\
\hline
\end{tabular}

The consistently higher $\mathrm{SF}_{6}$ concentrations at the northern end of the building indicate the presence of a $\mathrm{SF}_{6}$ sink. This could be due to the low negative air pressure located beneath the fans creating a still zone, whereby the $\mathrm{SF}_{6}$ was constantly re-circulated, also a result from the heavier density of $\mathrm{SF}_{6}$ compared with normal air. This kept the $\mathrm{SF}_{6}$ concentrations high at the exhaust outlets, causing the very low AER calculations on both periods ( $14 \& 28.07 .04)$. 
The tracer gas fluctuations throughout the day are low, similar to the previous period with a mean and SD of 1,89 $\pm 0,32$ air exchanges/h compared with a mean and SD 2,38 $\pm 0,31$ on the 14.07.04. Both sessions indicate small fluctuations. The lower tracer gas method air exchange rates recorded on the 28.07.04 appear to be the result of less tracer gas/air mixing induced by the higher air exchange rates. It appears that the dosed tracer gas was drawn directly though the middle of the stall to the outlets rather than undergoing mixture with livestock house air. This effect would have been exacerbated by the heavier mass of $\mathrm{SF}_{6}$, perhaps the $\mathrm{SF}_{6}$ gas was too heavy to follow the air patterns under the high negative pressure within the stall.

Considering the birds were 4 weeks old, the warm weather conditions, and the mechanical ventilation system, the tracer gas method results are unrealistic. The MBM results seem to be too high but better correspond with the expected AERs under these conditions.

The heat and moisture balance were positively correlated with the $\mathrm{CO}_{2}$ balance, $\mathrm{r}^{2}=0,94$ and 0,83, respectively (Fig. 4-12). The natural tracer gas hourly exchange rate curves were all reasonably well aligned with each other and the outside temperatures. 


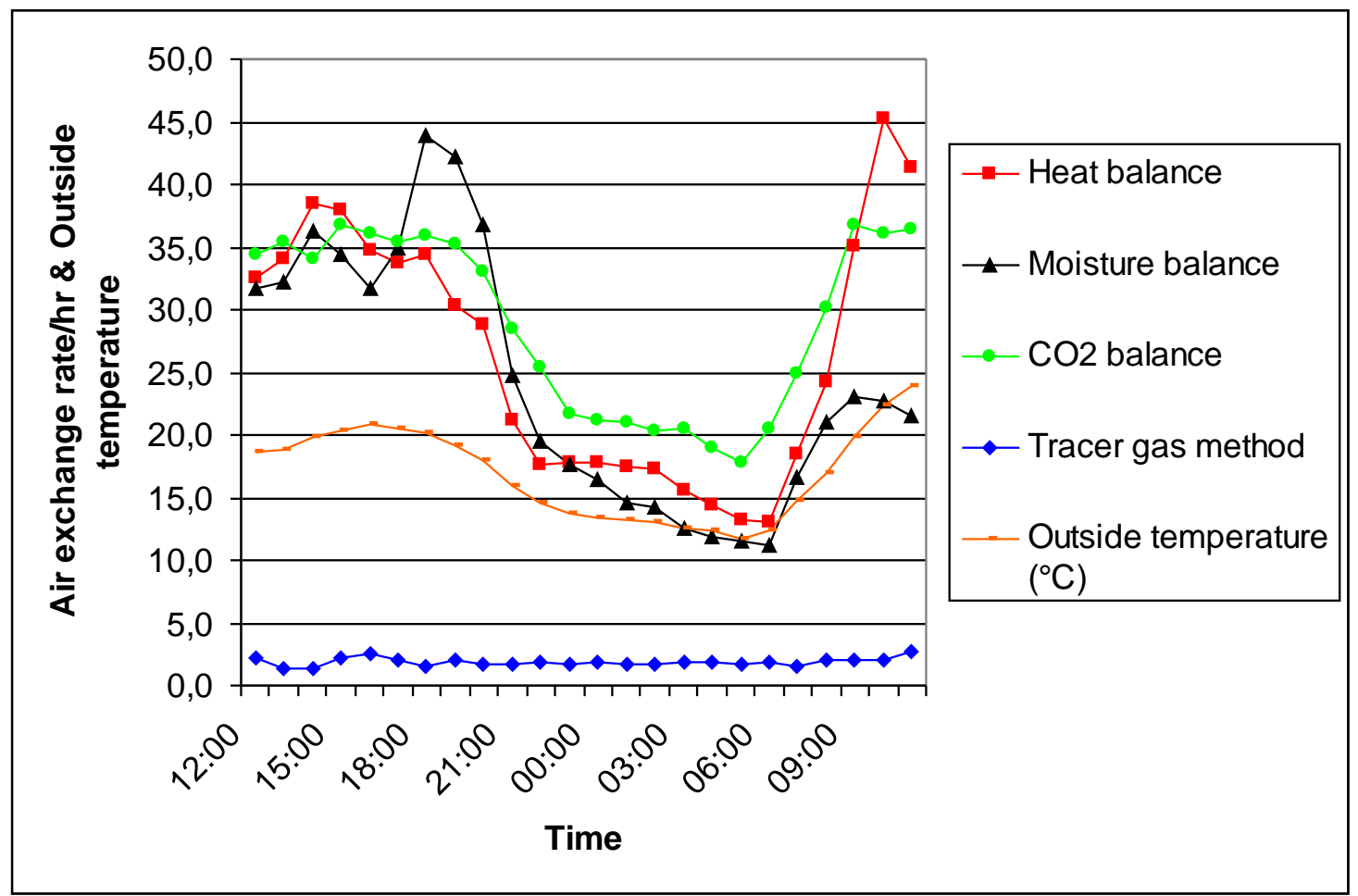

Fig. 4- 12: Hourly tracer gas method and mass balance AER results along with outside temperature (28.07.04)

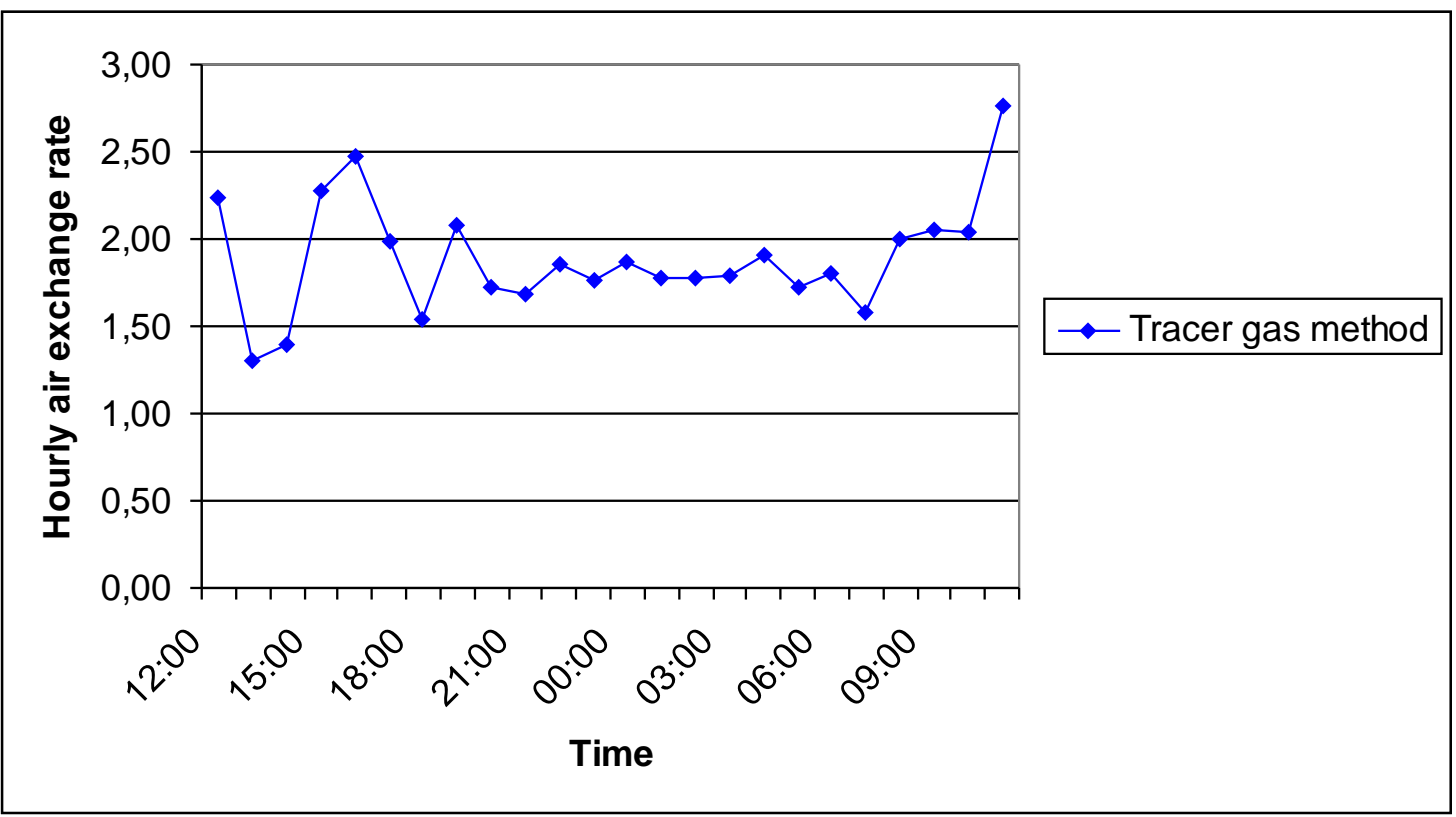

Fig. 4- 13: Hourly tracer gas method AER results (28.07.04) 
The tracer gas method results (Fig. 4-13) recorded an initial air exchange rate peak at $12 \mathrm{~h}(2,23 / \mathrm{h})$ followed by $15-18 \mathrm{~h}(1,98-2,47 / \mathrm{h})$ and then the maximum peak at $11 \mathrm{~h}$ $(2,76 / \mathrm{h})$ on the following day. Although these results are very low, at least peaks occurred at realistic times unlike the previous results. The moisture balance recorded the highest initial peak $(44 / \mathrm{h})$ between $17-21 \mathrm{~h}$, followed by the heat balance $(38,5 / \mathrm{h})$ and the $\mathrm{CO}_{2}$ balance (36,7/h) between 15-19h (Fig. 4-12). After this late afternoon peak all MBM results began to decrease, with the heat and moisture balances recording minimum values $13,1 / \mathrm{h}$ and $11,1 / \mathrm{h}$, respectively, in the early morning (06h) on the 29.07.04. The $\mathrm{CO}_{2}$ mass balance recorded a minimum of $17,8 / \mathrm{h}$ at $05 \mathrm{~h}(29.07 .04)$. At $07 \mathrm{~h}$ the tracer gas method also recorded an air exchange rate descent $(1,58 / \mathrm{h})$, coinciding with the mass balance models. However the tracer gas method minimum AER of $1,30-1,40 / \mathrm{h}$ from $13-15 \mathrm{~h}$ on the 28.07 .04 , is highly unlikely and in contrast to the MBMs and what would be expected.

Soon after the low AERs on the 29.07.04, the mass balance results all simultaneously began to increase from $10 \mathrm{~h}$ onwards, as the outside temperatures began to approach $20^{\circ} \mathrm{C}$. The heat balance recorded a peak value of $45,3 / \mathrm{h}$ at $10 \mathrm{~h}-12 \mathrm{~h}$, when there was a $2{ }^{\circ} \mathrm{C}$ temperature difference (the minimum recommended level) between inside and outside conditions. The tracer gas method recorded a maximum peak at $11 \mathrm{~h}(2,76 / \mathrm{h})$, once again coinciding with the mass balance models.

Although the tracer gas method results coincided with the mass balance models at times, no significant correlation coefficients between the methods were recorded.

Tab. 4- 22 Tracer gas method and influencing variable correlation table (28.07.04)

\begin{tabular}{ccccc}
\hline & \multicolumn{3}{c}{ Temperature } & \\
\cline { 2 - 4 } & Outside & $\boldsymbol{\Delta}$ & Inside & Inside humidity \\
\hline Tracer gas method & 0,45 & 0,62 & 0,53 & 0,68 \\
\hline
\end{tabular}


As with the previous results the tracer gas method recorded significant correlation coefficients (Tab. 4-22), however all are in disagreement with expectations under these conditions and what would be expected if the tracer gas method functioned correctly.

The tracer gas method median air exchange value $1,83 / \mathrm{h}$ translates to a ventilation rate of $0,32 \mathrm{~m}^{3} / \mathrm{h} /$ animal, well below the recommended level $3,92 \mathrm{~m}^{3} / \mathrm{h} /$ animal or $\sim 22,6$ air exchanges/h (DIN 18910. 2004). The mass balance results $\left(\mathrm{CO}_{2}\right.$, heat and moisture), recorded median hourly ventilation rates of 5,49, 4,60 and 3,85 $\mathrm{m}^{3} / \mathrm{h} /$ animal, except for the moisture balance all are above the recommended level. 


\subsection{Mass balance model, tracer gas and extrapolated true AER measurement results $18.08 .04 \& 25.08 .04$}

In the next 2 tests the dosing set up was changed from the middle of the stall, to dose at the side walls adjacent to the inlets, also tracer gas was dosed at $3 \mathrm{ml} / \mathrm{sec}$ on the 18.08 .04 and $15 \mathrm{ml} / \mathrm{sec}$ on the 25.08 .04 (refer to section 3.7.2).

Furthermore, the pressure flow sensor (true AERs) were extrapolated on the 18.08.04 and 25.08.04.

Tab. 4- 23 Summarised AER results and weather conditions (18.08.04)

\begin{tabular}{|c|c|c|c|}
\hline $\begin{array}{l}\text { Bird weight: } 0,36 \mathrm{~kg} \\
\text { Age: } 7 \text { days }\end{array}$ & Mean \pm SD & Range & Median \\
\hline Pressure flow sensor & $9,65 \pm 0,66$ & $6,83-10,13$ & 9,82 \\
\hline Tracer gas method & $1,93 \pm 0,06$ & $1,78-2,04$ & 1,93 \\
\hline $\begin{array}{c}\mathrm{CO}_{2} \text { balance } \\
\text { (exchange rate/h) }\end{array}$ & $14,94 \pm 3,34$ & $9,38-21,44$ & 13,88 \\
\hline $\begin{array}{c}\text { Heat balance } \\
\text { (exchange rate/h) }\end{array}$ & $7,87 \pm 5,61$ & $2,87-20,17$ & 5,96 \\
\hline $\begin{array}{l}\text { Moisture balance } \\
\text { (exchange rate/h) }\end{array}$ & $10,17 \pm 1,21$ & $7,24-13,00$ & 10,20 \\
\hline Outside temperature $\left({ }^{\circ} \mathrm{C}\right)$ & $21,4 \pm 2,8$ & $18,0-26,0$ & 21,10 \\
\hline Inside temperature $\left({ }^{\circ} \mathrm{C}\right)$ & $27,0 \pm 0,6$ & $25,9-27,8$ & 27,10 \\
\hline $\begin{array}{c}\Delta \text { Temperature } \\
\text { (inside \& outside stall }{ }^{\circ} \mathrm{C} \text { ) }\end{array}$ & $5,6 \pm 3,0$ & $1,4-9,3$ & 5,20 \\
\hline \multicolumn{4}{|l|}{ Coefficient of variation between } \\
\hline $\begin{array}{l}\mathrm{SF}_{6} \text { sample location } \\
\text { concentrations (\%) }\end{array}$ & $7,40 \pm 1,41$ & $6,03-10,82$ & 6,82 \\
\hline
\end{tabular}

On the 18.08 .04 the birds weighed approximately $0,36 \mathrm{~kg}$ and were a little over 1 week old. In reference to Tab. 4-23, the outdoor temperature results indicate warm to hot 
conditions with a median of $21,1^{\circ} \mathrm{C}$ (range $18,0-26,0^{\circ} \mathrm{C}$ ). The $\Delta$ temperature was $5,2^{\circ} \mathrm{C}$ (range $1,4-9,3^{\circ} \mathrm{C}$ ). The high median inside temperature $27,1^{\circ} \mathrm{C}$ (range $25,9-27,8^{\circ} \mathrm{C}$ ) is necessary when the chickens are young and also a result from the very warm outside conditions.

The median $\mathrm{CV}$ between $\mathrm{SF}_{6}$ concentration at sampling locations was $6,82 \%$ with a range $6,03-10,82 \%$. The maximum $\mathrm{SF}_{6} \mathrm{CV}(10,82 \%)$ occurred at $17 \mathrm{~h}$, which corresponds with the pressure flow sensor air exchange rate peak $(10,13 / \mathrm{h})$. Perhaps the increased air exchange rate caused excess $\mathrm{SF}_{6}$ from sinks within the stall to be removed resulting in this increased $\mathrm{CV}$ value. Once again, the $\mathrm{CV}$ was calculated between sample locations $1-4$, the locations used in air exchange rate calculations.

The tracer gas fluctuations throughout the day are very low with a mean and SD of 1,93 $\pm 0,06$ air exchanges/h compared with the $\mathrm{CO}_{2}$, heat and moisture balances $14,94 \pm$ 3,34, 7,87 $\pm 5,61$ and 10,17 \pm 1,21 air exchanges/h, respectively. The extrapolated pressure flow sensor AER mean and standard deviation results $(9,65 \pm 0,66 / \mathrm{h})$ were much higher than the tracer gas results, and closer to the mass balance model results, particularly the moisture balance. Interestingly, all methods recorded reasonably low standard deviations. Considering the birds were only 1 week old, the extrapolated results seem quite high, however the outside temperatures were the highest recorded (median $21,1^{\circ} \mathrm{C}$ ) during the experiment period (14.07.04-15.09.04) and the farmer was under the belief that over ventilating is better than under ventilating.

The heat and moisture balances were positively correlated with the $\mathrm{CO}_{2}$ balance, $\mathrm{r}^{2}=$ 0,91 and 0,64, respectively (Fig. 4- 14). 


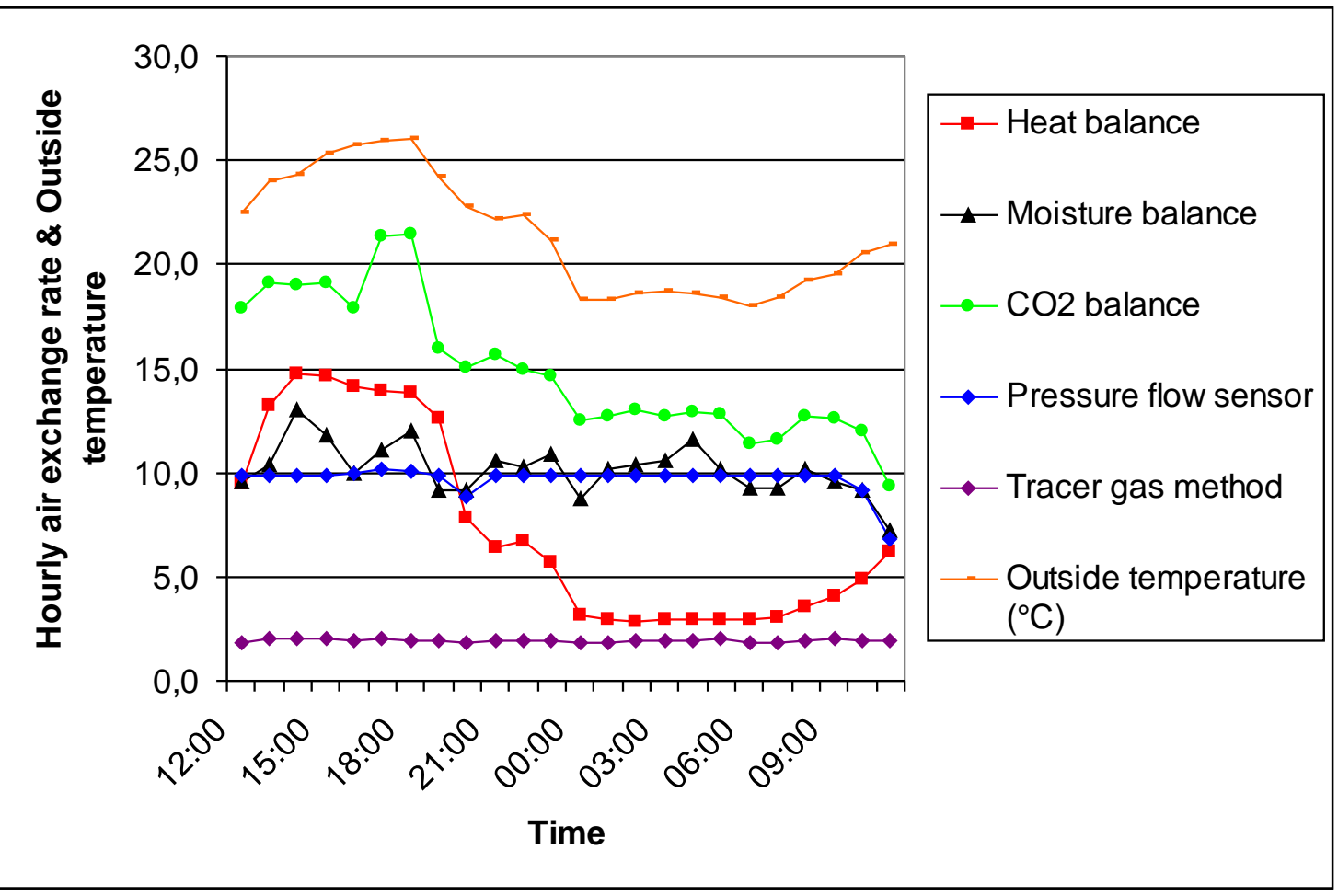

Fig. 4- 14: Hourly pressure flow sensor, tracer gas method, mass balance AER results and outside temperatures (18.08.04)

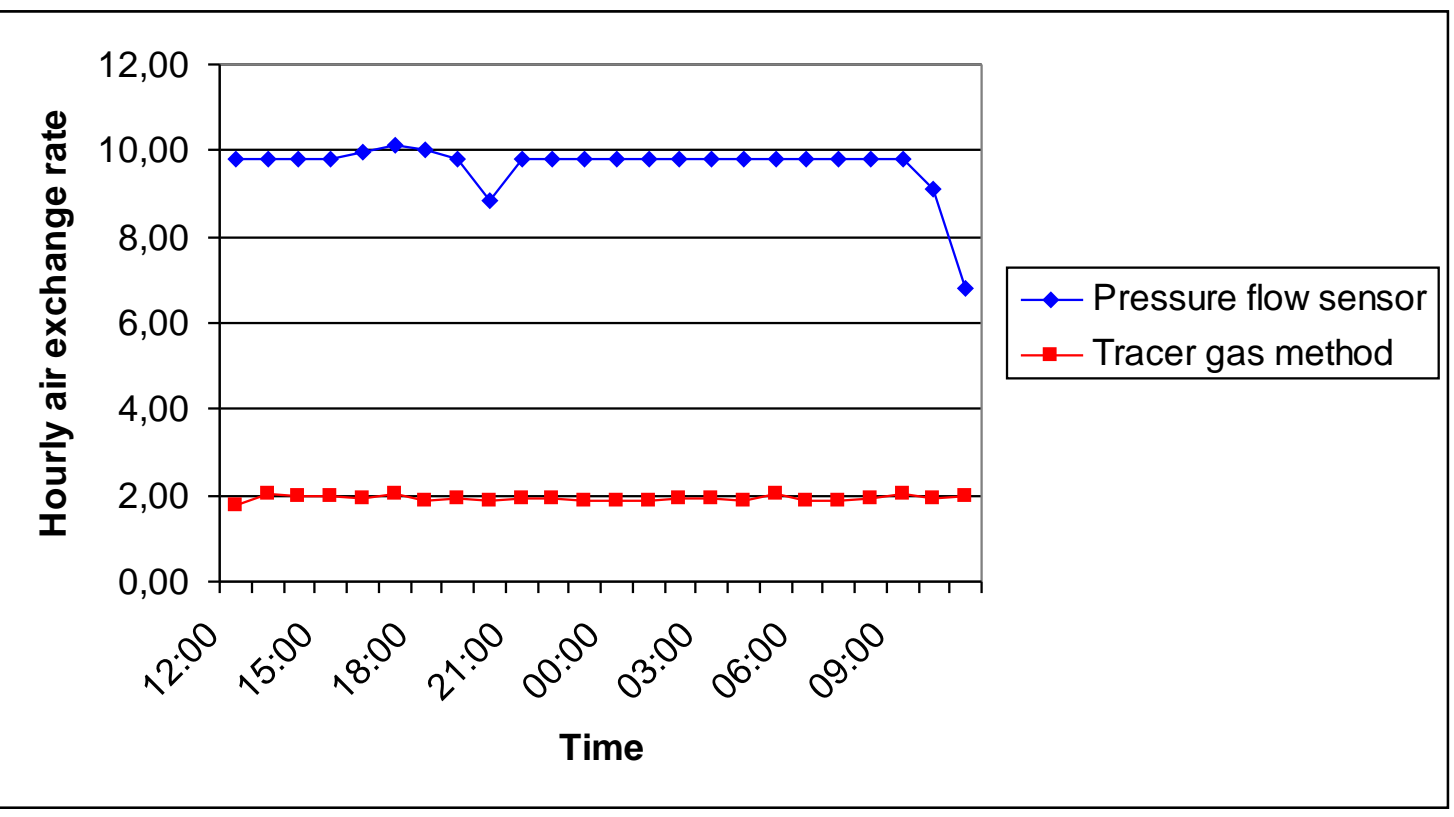

Fig. 4- 15: Hourly pressure flow sensor and tracer gas method AER results (18.08.04)

The results in Fig. 4- 14, display a wide range of AER values over the $24 \mathrm{~h}$ period, for e.g. at $18 \mathrm{~h}$ the tracer gas method recorded a result of $1,88 / \mathrm{h}$ whilst the $\mathrm{CO}_{2}$ mass balance recorded a maximum of $21,40 / \mathrm{h}$. The heat mass balance curve exhibits large 
variability, whereas, the $\mathrm{CO}_{2}$ and moisture balance curves are within range of each other. The moisture balance is also closely aligned with the extrapolated pressure flow sensor results.

The large heat balance variability seems to be due to a flaw in the model, for e.g. when the temperature difference between inside and outside conditions increases a larger portion of the sensible heat is transmitted though the livestock house heat insulation and because the bird heat production is small (due to age) this had a large effect on the results. In reality this loss would not be so large because the outside temperatures were quite high (between $18-20^{\circ} \mathrm{C}$ ), and the calculated $\mathrm{U}$ value 0,245 is also low (Appendix C Tab.1a).

The tracer gas method recorded a very small range 1,78-2,04 air exchanges/h (Fig. 415). Basically the air exchange rates remained constant over the measurement period, with minimal fluctuations and no noticeable peaks and/or troughs. The true AER results also remained constant throughout the period except for the very slight peak at 17-19h (10,13 air exchanges/h), the tracer gas method also recorded a maximum peak $2,04 / \mathrm{h}$ at $17 \mathrm{~h}$. These peaks corresponded with the outside temperature peak $\left(25,7-26^{\circ} \mathrm{C}\right)$ at $17-19 \mathrm{~h}$. The pressure flow sensor recorded a median of $9,82 / \mathrm{h}$ and the tracer gas $1,93 / \mathrm{h}$. The tracer gas method results do not correlate with the true AER results $\left(\mathrm{r}^{2}=\right.$ $0,00)$, and they are not within range of each other. On the other hand, the $\mathrm{CO}_{2}$, heat and moisture mass balance models recorded median values of $13,88 / \mathrm{h}, 5,96 / \mathrm{h} \& 10,20 / \mathrm{h}$, respectively. The moisture balance median is the closest to the extrapolated AER.

The extrapolated true AER results indicate a rather steady air exchange rate with 2 noticeable depressions at $20 \mathrm{~h}(8,84 / \mathrm{h})$ and the minimum at $11 \mathrm{~h}(6,83 / \mathrm{h})$. The moisture balance also recorded a depression at $20 \mathrm{~h}(9,2$ air exchanges/h), quite close to the pressure flow sensor result. At $11 \mathrm{~h}$ both the $\mathrm{CO}_{2}$ and moisture balance methods recorded decreased air exchanges $(9,4$ and $8,8 / \mathrm{h})$, once again the moisture balance results corresponded with the pressure flow sensor results.

The tracer gas method recorded no significant correlation coefficients with any of the mass balance models, however the true AER results were positively correlated with the moisture and $\mathrm{CO}_{2}$ balances $\left(\mathrm{r}^{2}=0,61 \& 0,45\right.$, respectively). 
Tab. 4- 24 Tracer gas method \& pressure flow sensor influencing variable correlation table (18.08.04)

\begin{tabular}{lcccc}
\hline & \multicolumn{3}{c}{ Temperature } & \\
\cline { 2 - 3 } & Outside & $\boldsymbol{\Delta}$ & Inside & Inside humidity \\
\hline Tracer gas method & 0,30 & $-0,27$ & 0,04 & $-0,15$ \\
Pressure flow sensor & 0,09 & 0,01 & 0,49 & $-0,01$ \\
\hline
\end{tabular}

The tracer gas method recorded no significant correlations with inside or outside hygrothermal variables (Tab. 4- 24). The pressure flow sensor did not record high significance with the hygro-thermal variables either, probably because the ventilation rate remained very constant over the period. The positive correlation coefficient $\left(r^{2}=0,49\right)$ between air exchange rates and inside temperature, although not a high correlation confirms that as the temperatures inside the stall decreased such as would occur at night time then so did the ventilation rate and vice versa.

The tracer gas method $24 \mathrm{~h}$ average result was $80 \%$ below the extrapolated true air exchange rates. The $24 \mathrm{~h}$ average of the heat balance results were $24 \%$ below the extrapolated 24h average (Tab. 4- 25). Whereas the $\mathrm{CO}_{2}$ and moisture balance results were $55 \%$ and $5 \%$, respectively, above the assumed true values. The moisture balance method results fitted the extrapolated results best. The variation between the extrapolated day time and night time air exchange rates were compared with the mass balance averages (Tab. 4- 25). 
Tab. 4- 25 Pressure flow sensor AER, MBM day/night time and 24h averages (18.08.04)

\begin{tabular}{cccc}
\hline & \multicolumn{3}{c}{ Average } \\
\cline { 2 - 4 } $\begin{array}{c}\text { Air exchange } \\
\text { calculation method }\end{array}$ & $\begin{array}{c}\text { Day time } \\
\mathbf{0 7 - 1 9 h r}\end{array}$ & $\begin{array}{c}\text { Night time } \\
\mathbf{1 9 - 0 7 h r}\end{array}$ & $\mathbf{2 4 h r}$ \\
\hline Pressure flow sensor & 9,50 & 9,74 & 9,65 \\
$\mathrm{CO}_{2}$ balance & $15,54(+64 \%)$ & $13,70(+41 \%)$ & $14,94(+55 \%)$ \\
Heat balance & $8,89(-6 \%)$ & $5,00(-49 \%)$ & $7,32(-24 \%)$ \\
Moisture balance & $10,09(+6 \%)$ & $10,08(+4 \%)$ & $10,17(+5 \%)$ \\
\hline
\end{tabular}

The results (Tab. 4- 25) indicate the night time variation was slightly lower with the $\mathrm{CO}_{2}$ and moisture balances, $23 \%$ and $2 \%$ increase in accuracy from the day time averages, respectively. Whereas, the accuracy of the heat balance results during the night time was reduced by $43 \%$ from the day time average.

The true AER and tracer gas median air exchange values translate to ventilation rates of $1,70 \mathrm{~m}^{3} / \mathrm{h} /$ animal and $0,33 \mathrm{~m}^{3} / \mathrm{h} /$ animal, respectively, the true AER result was above the recommended ventilation rate level $1,51 \mathrm{~m}^{3} / \mathrm{h} /$ animal (DIN 18910. 2004), however, the tracer gas method results are too low.

The mass balance results $\left(\mathrm{CO}_{2}\right.$, heat and moisture), recorded median hourly ventilation rates of 2,41, 1,03 and $1,77 \mathrm{~m}^{3} / \mathrm{h} /$ animal, except for the heat balance, all are above the recommended ventilation rate $\left(1,51 \mathrm{~m}^{3} / \mathrm{h} / \mathrm{animal}\right)$. The average of all 3 mass balance medians would be $1,68 \mathrm{~m}^{3} / \mathrm{h} /$ animal, which is close to the extrapolated true AER median value $\left(1,70 \mathrm{~m}^{3} / \mathrm{h} /\right.$ animal $)$. 
Tab. 4- 26 Summarised AER results and weather conditions (25.08.04)

\begin{tabular}{|c|c|c|c|}
\hline $\begin{array}{l}\text { Bird weight: } 0,78 \mathrm{~kg} \\
\text { Age: } 14 \text { days }\end{array}$ & Mean \pm SD & Range & Median \\
\hline Pressure flow sensor & $8,27 \pm 1,48$ & $6,45-10,68$ & 8,33 \\
\hline Tracer gas method & $4,05 \pm 0,40$ & $2,76-4,84$ & 4,11 \\
\hline $\begin{array}{c}\mathrm{CO}_{2} \text { balance } \\
\text { (exchange rate/h) }\end{array}$ & $12,77 \pm 1,65$ & $10,52-16,32$ & 12,27 \\
\hline $\begin{array}{c}\text { Heat balance } \\
\text { (exchange rate/h) }\end{array}$ & $7,15 \pm 1,95$ & $5,61-13,45$ & 6,28 \\
\hline $\begin{array}{l}\text { Moisture balance } \\
\text { (exchange rate/h) }\end{array}$ & $5,30 \pm 1,22$ & $3,94-9,26$ & 5,22 \\
\hline Outside temperature $\left({ }^{\circ} \mathrm{C}\right)$ & $16,12 \pm 1,65$ & $14,2-19,7$ & 16,00 \\
\hline Inside temperature $\left({ }^{\circ} \mathrm{C}\right)$ & $23,9 \pm 0,4$ & $23,3-24,6$ & 23,90 \\
\hline $\begin{array}{c}\Delta \text { Temperature } \\
\text { (inside \& outside stall }{ }^{\circ} \mathrm{C} \text { ) }\end{array}$ & $7,8 \pm 1,4$ & $4,6-9,5$ & 8,00 \\
\hline Coefficient of variation betwe & & & \\
\hline $\begin{array}{l}\mathrm{SF}_{6} \text { sample location } \\
\text { concentrations (\%) }\end{array}$ & $8,30 \pm 11,26$ & $3,46-56,99$ & 5,54 \\
\hline
\end{tabular}

On the 25.08.04 the birds weighed approximately $0,78 \mathrm{~kg}$ and were 2 weeks old. In reference to Tab. 4- 26, the outdoor temperature results indicate warm conditions median of $16,0^{\circ} \mathrm{C}$ (range $14,2-19,7^{\circ} \mathrm{C}$ ) but substantially cooler than the previous period median $21,1^{\circ} \mathrm{C}$ (range $\left.18,0-26,0^{\circ} \mathrm{C}\right)$. The median $\Delta$ temperature was $8,0^{\circ} \mathrm{C}(\mathrm{r}$ ange $4,6-$ $9,5^{\circ} \mathrm{C}$ ), greater than $5,2^{\circ} \mathrm{C}$ (range $1,4-9,3^{\circ} \mathrm{C}$ ), in agreement with the cooler outside conditions. The median inside temperature $23,9^{\circ} \mathrm{C}$ and range $23,3-24,6^{\circ} \mathrm{C}$, indicates steady conditions, also a decrease from the previous period median $27,1^{\circ} \mathrm{C}(25,9$ $27,8^{\circ} \mathrm{C}$ ). These cooler conditions would have been expected considering the drop in outside temperature and the increased age of the birds. 
The true AER extrapolation recorded a median value drop from 8,33/h compared with $9,82 / \mathrm{h}$ on the 18.08 .04 . The range on the $18.08 .04(6,83-10,13 / \mathrm{h})$ was similar with $6,45-10,68 / \mathrm{h}$ on the 25.08 .04 , however the exchange rate fluctuations were greater on the 25.08.04 with a mean and SD 8,27 $\pm 1,48 / \mathrm{h}$ compared with 9,65 $\pm 0,66 / \mathrm{h}(18.08 .04)$. The slightly lower air exchange rates on the 25.08 .04 are probably due to the lower outside temperatures.

The $\mathrm{CO}_{2}$ and moisture balance also recorded decreased median air exchange rates, from $13,88-12,27 / \mathrm{h}$ and $10,20-5,22 / \mathrm{h}$, respectively. The large decrease in the moisture balance results may be due to the difference in $\Delta$ mass of $\mathrm{kg}$ of water $/ \mathrm{m} \quad{ }^{3}$ of dry air between inside and outside conditions effecting the calculation. On the 18.08.04 the water mass was 3,4 times above the minimum recommended level $0,5 \times 10^{-3} \mathrm{~kg} / \mathrm{m}^{3}$ compared with 7,4 times over on the 25.08.04, this caused the lower AER model calculations.

Interestingly, the tracer gas method recorded an increased median on the 25.08.04 (median 4,11/h compared with $1,93 / \mathrm{h}$, previously). The tracer gas method may have undergone better mixing with the increased dosage rate $(15 \mathrm{ml} / \mathrm{s})$ on this date compared with $3 \mathrm{ml} / \mathrm{s}$ on the 18.08.04. The more variable and slightly lower air exchange rates may have induced better tracer gas/air mixing, whereas the constant conditions in the previous period may have had to much pull effect continuously drawing the tracer gas directly to the ducts, without adequate mixing. The median $\mathrm{CV}$ between the tracer gas sampling locations on the 25.08 .04 was $5,54 \%$ with a range $3,46-56,99 \%$, the previous period recorded a range of $6,03-10,82 \%$ and a median of $6,82 \%$. This lower median is in agreement with the assumed better mixing occurring on the 25.08.04.

Although the median values are similar, the maximum CV value on the 25.08.04 $(56,99 \%)$ is much higher than $10,82 \%$ on the 18.08.04. The high $\mathrm{SF}_{6} \mathrm{CV}$ values on the 18.08.04 $(10,82 \%)$ occurred as the AER increase from 9,95 to the maximum10,13/h at 17h (mentioned previously). Whereas, on the 25.08.04 the air exchange rates were at the minimum $6,45 / \mathrm{h}$ until $05 \mathrm{~h}$ and then increased to $9,82 / \mathrm{h}$ at $09 \mathrm{~h}$ with the tracer gas $\mathrm{CV}$ increasing from 6,1 to $26,4 \%$ at $08 \mathrm{~h}$ and then to $57 \%$ at $09 \mathrm{~h}$ (Appendix C Tab.16). Therefore, it appears that at low AERs the tracer gas volume was building up in the sinks and later released as the AER increased. These higher $\mathrm{SF}_{6}$ concentrations released 
from the sinks were responsible for the decreased AER results calculated via the tracer gas method and the higher variability between sample locations.

On the 18.08.04 and 25.08.04, there were 6 tracer gas sampling locations (refer to Fig 37), the $24 \mathrm{~h} \mathrm{SF}_{6}$ concentration averages are presented below (Tab. 4- 27). Location 6 was situated near the middle length of the western wall at a height of $0,5 \mathrm{~m}$ to check tracer gas/air mixing away from the exhaust ducts. Location 5 was situated at a height of $1,5 \mathrm{~m}$ beneath the exhaust ducts and in front of the extra fans. The extra fans were not operating throughout either of these periods.

Tab. 4- 27 Average 24h $\mathrm{SF}_{6}$ sample location (1-6) concentrations

\begin{tabular}{ccccccc}
\hline Date & $\mathbf{1}$ & $\mathbf{2}$ & $\mathbf{3}$ & $\mathbf{4}$ & $\mathbf{5}$ & $\mathbf{6}$ \\
\hline 18.08 .2004 & 2,49 & 2,59 & 2,73 & 2,93 & 6,94 & 2,03 \\
25.08 .2004 & 3,84 & 3,75 & 4,04 & 3,64 & 7,66 & 4,19 \\
\hline
\end{tabular}

On the 18.08.04, the average $\mathrm{SF}_{6}$ concentration at location 6 was lower than the exhaust chimney concentrations (channels 1-4), and vice versa on the 25.08.04. Although the difference is not large, it is however apparent. The lower average $\mathrm{SF}_{6}$ concentration at channel 6, maybe due to the higher AERs on the 18.08.04 (median 9,82/h) compared with $8,33 / \mathrm{h}$ on the 25.08 .04 , causing the majority of dosed tracer gas to pass directly though the middle of the stall towards the exhaust chimneys. Whereas, the higher concentration on the 25.08.04 maybe due to less bypass flow at lower air exchange rates and the higher tracer gas dosage rates masking the effects from the $\mathrm{SF}_{6}$ sink.

On the 18.08.04 and 25.08.04, location 5 consistently recorded higher $\mathrm{SF}_{6}$ concentrations then the other 5 locations (Tab. 4- 27). It appears that the location at the northern end of the stall beneath the ducts and at the ducts as previously mentioned (14 \& 25 07.04), was a $\mathrm{SF}_{6}$ sink zone which depressed air exchange rate calculations and led to fluctuations in air exchange rate calculations out of synchonisation with the assumed true AERs.

The tracer gas fluctuations throughout the day were low with a mean and SD of 4,05 \pm 0,40 air exchanges/h compared with the $\mathrm{CO}_{2}$, heat and moisture balances $14,94 \pm 3,34$, $7,15 \pm 1,95$ and $5,30 \pm 1,22$ air exchanges/h, respectively. The true AER mean and 
standard deviation results were within range of the mass balance results $8,27 \pm 1,48 / \mathrm{h}$, particularly the heat balance.

The heat and moisture balances were positively correlated with the $\mathrm{CO}_{2}$ balance, $\mathrm{r}^{2}=$ 0,73 and 0,43 , respectively (Fig. $4-16$ ). These correlations are not as highly significant as previous periods.

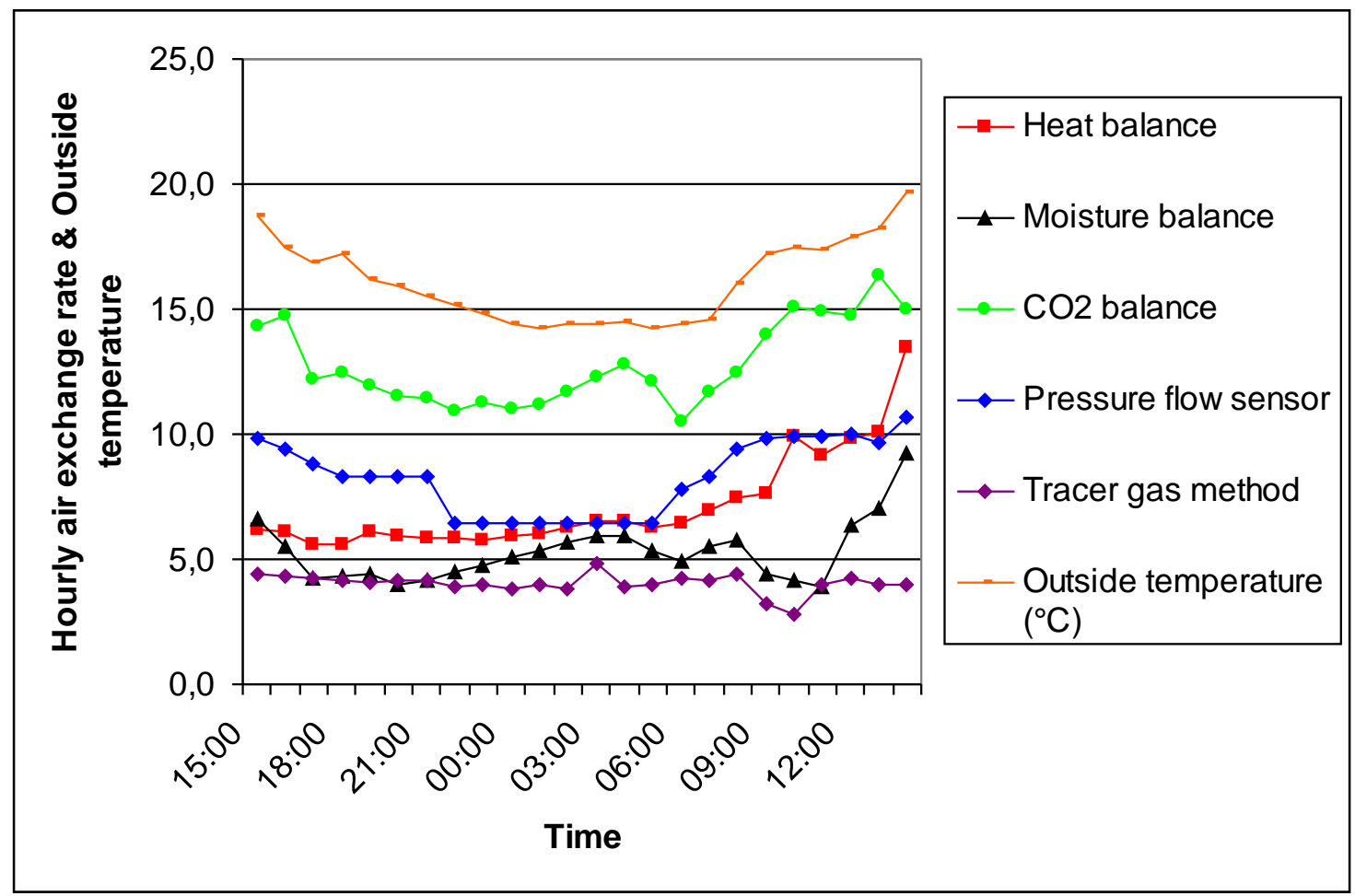

Fig. 4- 16: Hourly pressure flow sensor, tracer gas method, mass balance AER results and outside temperatures (25.08.04) 


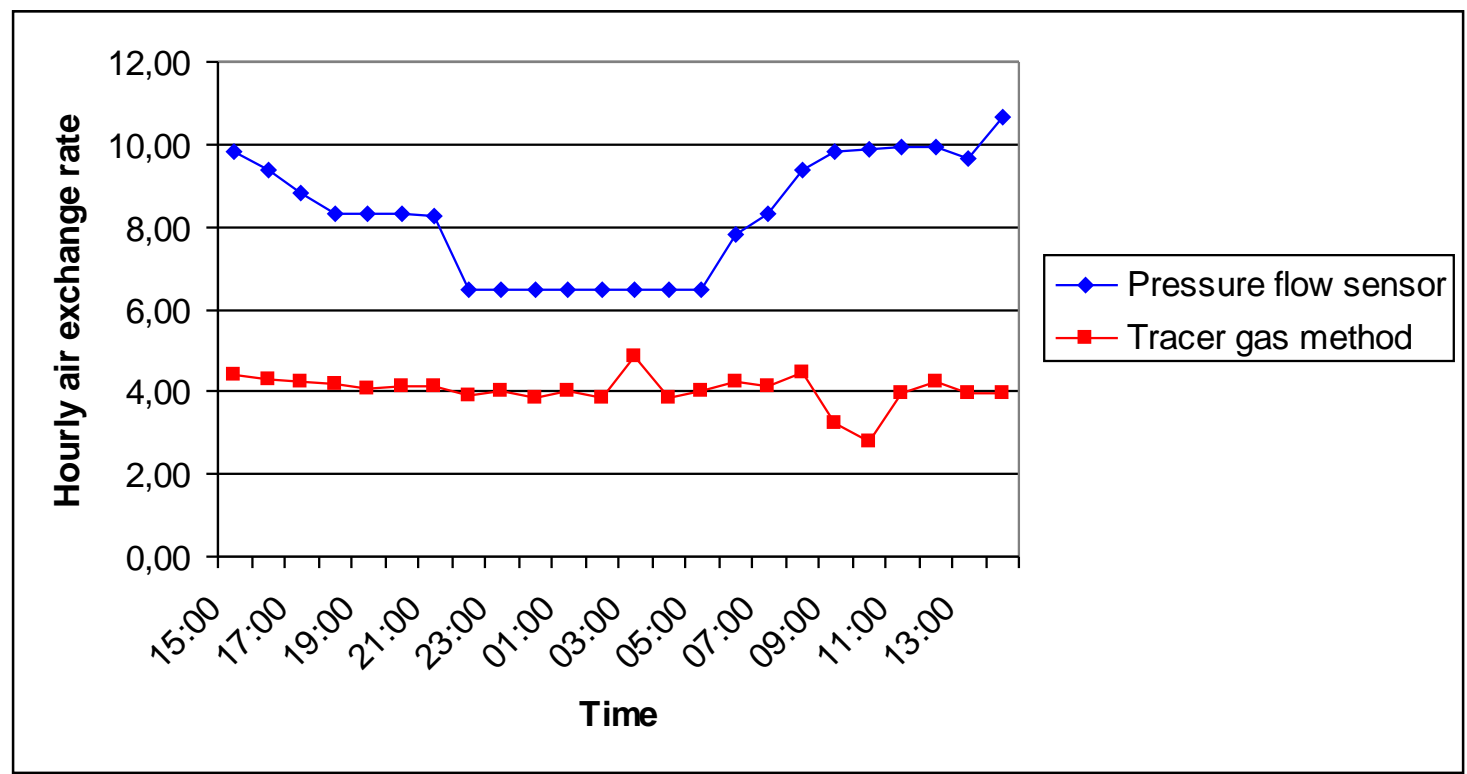

Fig. 4- 17: Hourly pressure flow sensor and tracer gas method results (25.08.04)

The results in Fig. 4-16, once again display a wide range of air exchange rate values over the $24 \mathrm{~h}$ period, with a maximum $\mathrm{CO}_{2}$ mass balance air exchange rate of $16,30 / \mathrm{h}$ and a corresponding tracer gas method result of $3,98 / \mathrm{h}$ at $13 \mathrm{~h}$. The heat balance curve is within range of the true AER results, and the moisture balance curve is nearer to the tracer gas method curve The $\mathrm{CO}_{2}$ method air exchange rates are substantially larger than all other method results. The tracer gas method results were closer aligned with the true AER results than the previous period, but nevertheless are too low.

The tracer gas method recorded air exchange rates ranging from 2,76-4,84 air exchanges/h. The tracer gas method results once again remain relatively constant except for the noticeable peak (4,84 air exchanges/h) at $03 \mathrm{~h}$ and trough $(2,76 / \mathrm{h})$ at $10 \mathrm{~h}$. The peak at $03 \mathrm{~h}$ is also followed by a slight peak at $08 \mathrm{~h}(4,44 / \mathrm{h})$ and then a sharp trough at $09-11 \mathrm{~h}(3,25-2,76 / \mathrm{h})$. Once again, the peak at $03 \mathrm{~h}$ is probably due to better tracer gas/air mixing from lower AERs (Fig. 4- 17). The trough at 09-11h, would have been a response to the high air exchange rates directly drawing the dosed $\mathrm{SF}_{6}$ to the outlets and excess $\mathrm{SF}_{6}$ concentrations from sinks within the stall. The tracer gas method trough recorded from $09-11 \mathrm{~h}$ was also mirrored by the moisture balance method $(4,4-3,9 / \mathrm{h})$ from 09-11h, however all other methods recorded an AER ascent at this time (Fig. 416). 
The mass balance models also recorded a slight accession at 03h (Fig. 4- 16), however this would be due to decreased $\mathrm{CO}_{2}$, heat and moisture production when the animals are resting. The extrapolated results recorded a constant trough from $22-06 \mathrm{~h}(6,45 / \mathrm{h})$, which seems realistic. Directly after this trough AERs began a steady ascent from 0614h (7,83-10,68/h), in agreement with higher inside and outside temperatures. The mass balance AERs also climbed from 06-14h, $\mathrm{CO}_{2}(10,5-16,3 / \mathrm{h})$, heat $(6,5-13,5 / \mathrm{h})$ and moisture (4,9-9,3/h), respectively.

The true AER recorded a median of $8,33 / \mathrm{h}$ and the tracer gas $4,11 / \mathrm{h}$. So the tracer gas results were less than half the true air exchange rates. On the other hand, the $\mathrm{CO}_{2}$, heat and moisture mass balance models recorded median values of 12,27/h, 6,28/h \& 5,22/h, respectively.

The tracer gas method recorded no significant correlation coefficients with any of the mass balance models, however the pressure flow sensor results were positively correlated with the $\mathrm{CO}_{2}$ and heat balances $\left(\mathrm{r}^{2}=0,78 \& 0,66\right.$, respectively).

Tab. 4- 28 Tracer gas method \& pressure flow sensor AER influencing variable correlation table (25.08.04)

\begin{tabular}{ccccc}
\hline & \multicolumn{3}{c}{ Temperature } & \\
\cline { 2 - 3 } & Outside & $\boldsymbol{\Delta}$ & Inside & Inside humidity \\
\hline Tracer gas method & $-0,01$ & 0,02 & 0,03 & $-0,33$ \\
Pressure flow sensor & 0,90 & $-0,93$ & 0,65 & 0,13 \\
\hline
\end{tabular}

The tracer gas method recorded no significant correlations with inside or outside hygroheat variables (Tab. 4- 28). This absence of significant correlation coefficients indicates the method did not function correctly.

On the other hand, the extrapolated true ventilation rate results recorded highly significant correlation coefficients with the hygro-thermal variables (Tab. 4- 28), unlike the previous period, this may be explained by the larger outside temperature range and AER fluctuations in this period compared with the 18.08.04. A high positive correlation $\left(\mathrm{r}^{2}=0,90\right)$ between outside temperature and AERs, indicates as the 
temperatures outside increased or decreased the ventilation rate coincided. The high negative correlation coefficient $\left(r^{2}=-0,93\right)$ between air exchange rates and $\Delta$ temperature and positive correlation $\left(\mathrm{r}^{2}=0,65\right)$ between inside temperature, both confirm the higher air exchange rates occurred during the day time, when the temperatures were warmer and decreased in the evenings when the conditions became cooler and the animals rested.

The tracer gas method $24 \mathrm{~h}$ average result was $51 \%$ below the extrapolated true AERs. The heat and moisture balance were also $14 \%$ and $36 \%$ below (Tab. 4- 29) and the $\mathrm{CO}_{2}$ balance was $54 \%$ above the extrapolated AERs. The heat balance performed best. The variation between the extrapolated air exchange rates and mass balance averages during the day time and night time periods were also compared (Tab. 4- 29).

Tab. 4- 29 Pressure flow sensor AER, MBM day/night time and 24h averages (25.08.04)

\begin{tabular}{cccc}
\hline $\begin{array}{c}\text { Air exchange calculation } \\
\text { method }\end{array}$ & $\begin{array}{c}\text { Day time } \\
\mathbf{0 7 - 1 9 h r}\end{array}$ & $\begin{array}{c}\text { Night time } \\
\mathbf{1 9 - 0 7 h r}\end{array}$ & $\mathbf{2 4 h r}$ \\
\cline { 2 - 4 } & 9,40 & 7,03 & 8,27 \\
$\mathrm{CO}_{2}$ balance & $13,85(+47 \%)$ & $11,56(+64 \%)$ & $12,77(+54 \%)$ \\
Heat balance & $7,59(-19 \%)$ & $6,14(-13 \%)$ & $7,15(-14 \%)$ \\
Moisture balance & $5,49(-42 \%)$ & $5,00(-29 \%)$ & $5,30(-36 \%)$ \\
\hline
\end{tabular}

The results (Tab 4-29) indicate the night time variation was lower with the heat and moisture balances, $6 \%$ and 13\% increase in accuracy compared with the day time averages, respectively. Whereas, the accuracy of the $\mathrm{CO}_{2}$ balance results during the night time were reduced by $17 \%$ from the day time average. The results show no corresponding pattern with the previous period (18.08.04), whereby the $\mathrm{CO}_{2}$ and moisture balance night time results increased in accuracy by 23 and $2 \%$ compared with the day time averages, respectively, and the night time heat balance results decreased in accuracy by $43 \%$ compared with the day average. The day and night time averages were further tested in the next periods. 
The true AER and tracer gas median air exchange values translate to ventilation rates of $1,45 \mathrm{~m}^{3} / \mathrm{h} /$ animal and $0,71 \mathrm{~m}^{3} / \mathrm{h} /$ animal, respectively, both below the recommended $2,73 \mathrm{~m}^{3} / \mathrm{h}$ /animal (DIN 18910. 2004). The mass balance results $\left(\mathrm{CO}_{2}\right.$, heat and moisture), recorded median hourly ventilation rates of 2,13, 1,09 and $0,91 \mathrm{~m}^{3} / \mathrm{h} / \mathrm{animal}$, all were below the recommended level.

\subsection{Pressure flow sensor AERs and mass balance model results 08.09.04 \& 14.09.04}

No tracer gas measurements were conducted in this section. Also, the pressure flow sensor (true AERs) were measured and not extrapolated, as in the previous section.

Tab. 4- 30 Summarised air exchange rate results and weather conditions (08.09.04)

\begin{tabular}{|c|c|c|c|}
\hline $\begin{array}{l}\text { Bird weight: } 1,30 \mathrm{~kg} \\
\text { Age: } 28 \text { days }\end{array}$ & Mean \pm SD & Range & Median \\
\hline Pressure flow sensor & $15,65 \pm 7,10$ & $9,40-25,86$ & 10,80 \\
\hline $\begin{array}{c}\mathrm{CO}_{2} \text { balance } \\
\text { (exchange rate/h) }\end{array}$ & $22,31 \pm 5,70$ & $13,45-32,07$ & 20,27 \\
\hline $\begin{array}{c}\text { Heat balance } \\
\text { (exchange rate/h) }\end{array}$ & $18,69 \pm 7,33$ & $10,57-33,89$ & 14,43 \\
\hline $\begin{array}{l}\text { Moisture balance } \\
\text { (exchange rate/h) }\end{array}$ & $17,85 \pm 6,12$ & $10,73-30,35$ & 15,41 \\
\hline Outside temperature $\left({ }^{\circ} \mathrm{C}\right)$ & $15,0 \pm 4,3$ & $8,7-20,9$ & 14,10 \\
\hline Inside temperature $\left({ }^{\circ} \mathrm{C}\right)$ & $21,6 \pm 1,8$ & $19,0-24,5$ & 21,40 \\
\hline $\begin{array}{c}\Delta \text { Temperature } \\
\text { (inside \& outside stall }{ }^{\circ} \mathrm{C} \text { ) }\end{array}$ & $6,6 \pm 2,6$ & $2,9-10.8$ & 7,40 \\
\hline
\end{tabular}

On the 08.09 .04 the birds weighed approximately $1,30 \mathrm{~kg}$ and were 4 weeks old. The outdoor temperature results (Tab. 4- 30) indicate mild conditions median of $14,1^{\circ} \mathrm{C}$ (range $8,7-20,9^{\circ} \mathrm{C}$ ). The $\Delta$ temperature was $7,4^{\circ} \mathrm{C}$ (range $2,9-10,8^{\circ} \mathrm{C}$ ). The median inside temperature $21,4^{\circ} \mathrm{C}$ (range $19,0-24,5^{\circ} \mathrm{C}$ ), indicates reasonable fluctuations, possibly due to the large outside temperature range and/or high air exchange rates. 
The pressure flow sensor fluctuations (true air exchange rates) throughout the day were quite high with a mean and $\mathrm{SD}$ of 15,65 \pm 7,10 air exchanges/h along with the $\mathrm{CO}_{2}$, heat and moisture balances $22,31 \pm 5,70,18,69 \pm 7,33$ and 17,85 \pm 6,12 air exchanges/h, respectively. The true AER results recorded minimum and maximum AERs of 9,40 and $25,86 / \mathrm{h}$, the maximum representing the highest AER recorded with the ventilation system running at full capacity. The $\mathrm{CO}_{2}$, heat and moisture balance maximum air exchange rates were, $32,07 / \mathrm{h}, 33,89 / \mathrm{h}$ and $30,35 / \mathrm{h}$, all higher but within the range of the true maximum AER.

The heat and moisture balance were not significantly correlated with the $\mathrm{CO}_{2}$ mass balance model, $\mathrm{r}^{2}=0,15$ and 0,08 , respectively (Fig. 4- 18).

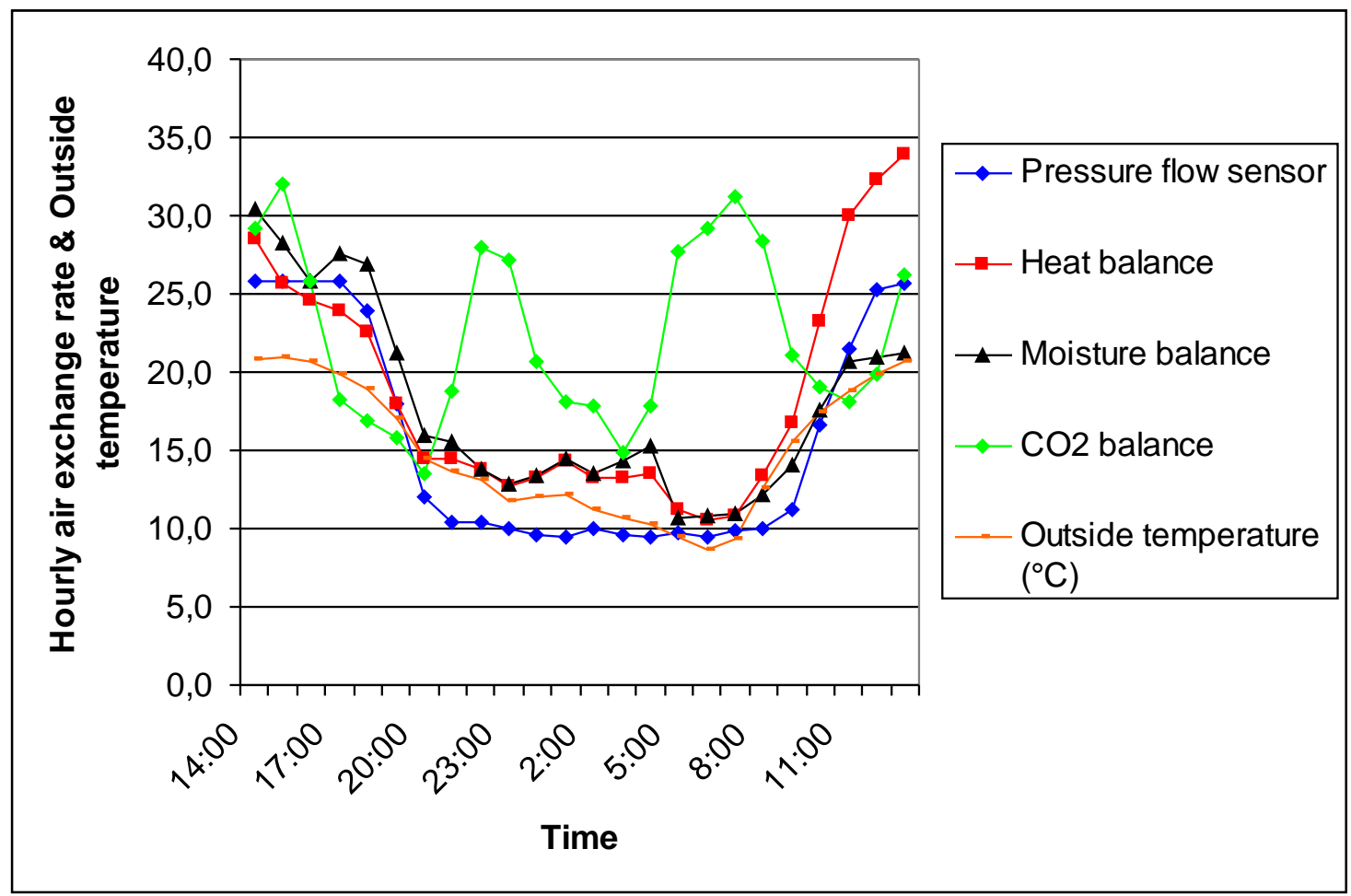

Fig. 4- 18: Hourly pressure flow sensor, mass balance AER results and outside temperatures (08.09.04)

The results in Fig. 4-18, display the estimated and measured air exchange rate values over the $24 \mathrm{~h}$ period. The heat and moisture balance curves are within range of each other and follow the same trend as the true AER measurements. The $\mathrm{CO}_{2}$ method results are not so smoothly aligned. 
The heat and moisture balance results recorded peak air exchange rates at the beginning and the end of the measurement period, and a general trough in the early morning hours, in close agreement with the true air exchange rate measurements. The moisture balance peaked $>25$ air exchanges/h from 14-19h, whereas the true AER recorded measurements $>25$ air exchanges/h from 14-18h. The heat and moisture balance peaked at $14 \mathrm{~h} 28,6 / \mathrm{h}$ and $30,35 / \mathrm{h}$, respectively and the true AER peaked at $15 \mathrm{~h}(25,86 / \mathrm{h})$. The heat and moisture balance results both remained within range of the true AER measurements and both followed the same trend with a drop in AERs in the early morning and then a further increase from $07 \mathrm{~h}$ onwards on the following day (Fig. 4$18)$.

The heat and moisture balances recorded minimum air exchange rates ranging from 10,5-11,5/h, both simultaneously occurring at $05-08 \mathrm{~h}$. The true AER measurements were low between $03-07 \mathrm{~h}(9,5-9,8 / \mathrm{h})$, with a minimum $9,4 / \mathrm{h}$ occurring at $01 \mathrm{~h}$, occurring when animal activity was reduced (Appendix C Tab.21).

The $\mathrm{CO}_{2}$ method also began like the other methods with high air exchange rates followed by a decline but later recorded AER peaks above 25/h at 22h and between 0609h, when the true AERs and other models recorded depressions. These fluctuations in $\mathrm{CO}_{2}$ concentration seem to be exacerbated by the $\mathrm{CO}_{2}$ production from the animals decreasing and the ventilation rate remaining relatively constant, a typical flaw in the mass balance models. For e.g. at $03 \mathrm{~h}$ the ventilation system is operating at a reduced capacity 9,5 air exchanges/h and $\mathrm{CO}_{2}$ concentration is $1327,2 \mathrm{ppm}$, the ventilation rate slightly increases to $9,8 / \mathrm{h}$ at $05 \mathrm{~h}$ and the $\mathrm{CO}_{2}$ concentration decreases to $882,1 \mathrm{ppm}$ causing the $\mathrm{CO}_{2}$ model to calculate an increase from $17,8 / \mathrm{h}$ to $27,7 / \mathrm{h}$ (an increase of $56 \%$ ). The bird activity recorded minimum values from 02-06h (Appendix C Tab.21), it seems likely that the reduced $\mathrm{CO}_{2}$ production from the animals caused the low $\mathrm{CO}_{2}$ levels from $05-09 \mathrm{~h}$ leading to the high model calculations. So the reduced $\mathrm{CO}_{2}$ concentration is due to reduced $\mathrm{CO}_{2}$ production from the animals rather than an increased ventilation rate, something which the model cannot distinguish between. Furthermore, the reduced $\mathrm{CO}_{2}$ concentrations $(812,2-857,4 \mathrm{ppm})$ at the beginning of the period $14-16 \mathrm{~h}$, are clearly the result from the high true AERs $(\approx 25,85 \mathrm{~h})$, the $\mathrm{CO}_{2}$ model calculated air exchange rates from 25,9-32,1/h. 
The true AER results were highly correlated with the heat and moisture balance results, $r^{2}=0,85$ and 0,91 , respectively.

Tab. 4- 31 Pressure flow sensor AER and influencing variable correlation table (08.09.04)

\begin{tabular}{lcccc}
\hline & \multicolumn{3}{c}{ Temperature } & \\
\cline { 2 - 4 } & Outside & $\boldsymbol{\Delta}$ & Inside & \\
\hline Pressure flow sensor & 0,95 & $-0,92$ & 0,93 & $-0,97$ \\
\hline
\end{tabular}

The pressure flow sensor measurements recorded high significance with the inside and outside hygro-heat variables (Tab. 4- 31). A high positive correlation $\left(r^{2}=0,95\right)$ between outside temperature and air exchange rates. The high negative correlation coefficient $\left(r^{2}=-0,92\right)$ between air exchange rates and $\Delta$ temperature and positive correlation $\left(r^{2}=\right.$ 0,93 ) between inside temperature, once again follow expectations. The pressure flow sensor measurements were correlated with bird activity $\left(r^{2}=0,43\right)$ and bird activity was positively correlated with inside temperature $\left(r^{2}=0,53\right)$, confirming as activity increased during the daytime so did inside temperatures and correspondingly air exchange rates to keep the stall environmental conditions optimal. Furthermore, a negative correlation between the pressure flow sensor measurements and inside humidity $\left(r^{2}=-0,92\right)$, also reinforces the relationships, between the influencing variables which control and are controlled by ventilation rates.

The $\mathrm{CO}_{2}$, heat and moisture balance $24 \mathrm{~h}$ average results were $43 \%, 19 \%$ and $14 \%$ above the true AER results. All mass balance models over estimated AERs, with the moisture balance method results best fitting the true AER results. The variation between the true AERs and mass balance averages during the day and night time periods, are presented below (Table 4-32). 
Tab. 4- 32 Pressure flow sensor AER, MBM day/night time and 24h averages (08.09.04)

\begin{tabular}{cccc}
\hline \multirow{2}{*}{$\begin{array}{c}\text { Air exchange calculation } \\
\text { method }\end{array}$} & $\begin{array}{c}\text { Day time } \\
\mathbf{0 7 - 1 9 h r}\end{array}$ & $\begin{array}{c}\text { Night time } \\
\mathbf{1 9 - 0 7 h r}\end{array}$ & $\mathbf{2 4 h r}$ \\
\cline { 2 - 4 } & 21,32 & 10,67 & 15,65 \\
Pressure flow sensor & $23,92(+12 \%)$ & $20,79(+95 \%)$ & $20,78(+33 \%)$ \\
$\mathrm{CO}_{2}$ balance & $23,99(+13 \%)$ & $13,56(+27 \%)$ & $18,69(+19 \%)$ \\
Meat balance & $22,31(+5 \%)$ & $14,3(+34 \%)$ & $17,85(+14 \%)$ \\
\hline
\end{tabular}

The results (Tab. 4- 32) indicate the mass balance night time variation was higher with all models the $\mathrm{CO}_{2}$, heat and moisture balances accuracy reduced by $83 \%, 14 \%$ and $29 \%$ from the day time averages, respectively. The moisture balance recorded the best day time fit $(+5 \%)$, whereas the heat balance recorded the closest night time fit $(+27 \%)$.

The true air exchange rate median translates to a ventilation rate of $1,87 \mathrm{~m}^{3} / \mathrm{h} / \mathrm{animal}$, well below the recommended level $4,02 \mathrm{~m}^{3} / \mathrm{h} /$ animal (DIN 18910. 2004). The mass balance results $\left(\mathrm{CO}_{2}\right.$, heat and moisture), recorded median hourly ventilation rates of $3,52,2,50$ and $2,67 \mathrm{~m}^{3} / \mathrm{h} /$ animal, all below the recommended level. 
Tab. 4- 33 Summarised AER results and weather conditions (14.09.04)

\begin{tabular}{|c|c|c|c|}
\hline $\begin{array}{c}\text { Bird weight: } 1,75 \mathrm{~kg} \\
\text { Age: } 34 \text { days }\end{array}$ & Mean \pm SD & Range & Median \\
\hline Pressure flow sensor & $13,98 \pm 4,42$ & $10,11-22,85$ & 11,61 \\
\hline $\begin{array}{c}\mathrm{CO}_{2} \text { balance } \\
\text { (exchange rate/h) }\end{array}$ & $30,50 \pm 3,07$ & $25,27-35,52$ & 29,96 \\
\hline $\begin{array}{c}\text { Heat balance } \\
\text { (exchange rate/h) }\end{array}$ & $31,99 \pm 4,33$ & $26,03-45,10$ & 30,88 \\
\hline $\begin{array}{l}\text { Moisture balance } \\
\text { (exchange rate/h) }\end{array}$ & $31,76 \pm 3,35$ & $22,94-38,54$ & 31,89 \\
\hline Outside temperature $\left({ }^{\circ} \mathrm{C}\right)$ & $14,4 \pm 1,6$ & $12,1-18,0$ & 14,20 \\
\hline Inside temperature $\left({ }^{\circ} \mathrm{C}\right)$ & $19,1 \pm 0,9$ & $17,8-21,0$ & 18,90 \\
\hline $\begin{array}{c}\Delta \text { Temperature } \\
\text { (inside \& outside stall }{ }^{\circ} \mathrm{C} \text { ) }\end{array}$ & $4,7 \pm 0,7$ & $3,0-5,9$ & 4,80 \\
\hline
\end{tabular}

On the 14.09.04 the birds weighed approximately $1,75 \mathrm{~kg}$ and were 5 weeks old, approaching harvest weight. The outdoor temperature results (Tab. 4-33) median of $14,2^{\circ} \mathrm{C}$ (range $12,1-18,0^{\circ} \mathrm{C}$ ) were similar with the 08.09 .04 median $14,1^{\circ} \mathrm{C}$ (range 8,7$20,9^{\circ} \mathrm{C}$ ). The $\Delta$ temperature was $4,8^{\circ} \mathrm{C}$ (range $3,0-5,9^{\circ} \mathrm{C}$ ) less than $7,40^{\circ} \mathrm{C}$ (range $2,9-$ $10,8^{\circ} \mathrm{C}$ ) on the 08.09 .04 , probably due to the smaller temperature range. The median inside temperature $18,9^{\circ} \mathrm{C}$ (range $17,8-21,0^{\circ} \mathrm{C}$ ), compared with median $21,4^{\circ} \mathrm{C}$ (range $19,0-24,5^{\circ} \mathrm{C}$ ) on the 08.09.04 indicates more stable conditions than the previous period, and perhaps higher and more constant air exchange rates. The age difference between the birds was only 1 week, and outside temperatures on both days were similar, therefore the air exchange rates were alike with a slightly higher median $11,61 / \mathrm{h}$ on the 14.09.04 (range 10,11-22,85/h) compared with median 10,80 (range 9,40-25,86/h) on the 08.09.04.

The air exchange rate fluctuations on the 14.09.04 were lower than the 08.09.04 with a mean and SD of $13,98 \pm 4,42$ air exchanges/h compared with $15,65 \pm 7,10 / \mathrm{h}$. The 
higher AER fluctuations on the 08.09.04 seem to be in agreement with the larger outside temperature range.

The $\mathrm{CO}_{2}$, heat and moisture balance mean and SD results (14.09.04) 30,50 $\pm 3,07$, $31,99 \pm 4,33$ and $31,76 \pm 3,35$ air exchanges/h, respectively, were substantially higher than the previous period $22,31 \pm 5,70,18,69 \pm 7,33$ and 17,85 $\pm 6,12$ air exchanges $/ \mathrm{h}$, respectively. Interestingly, even with the higher mean AERs on the 14.09.04, the standard deviations were still lower on the 14.09.04, perhaps due to more constant AERs. This is in agreement with the true AER results (Fig. 4-19).

The heat and moisture balance were positively correlated with the $\mathrm{CO}_{2}$ balance, $\mathrm{r}^{2}=0,79$ and 0,56 , respectively.

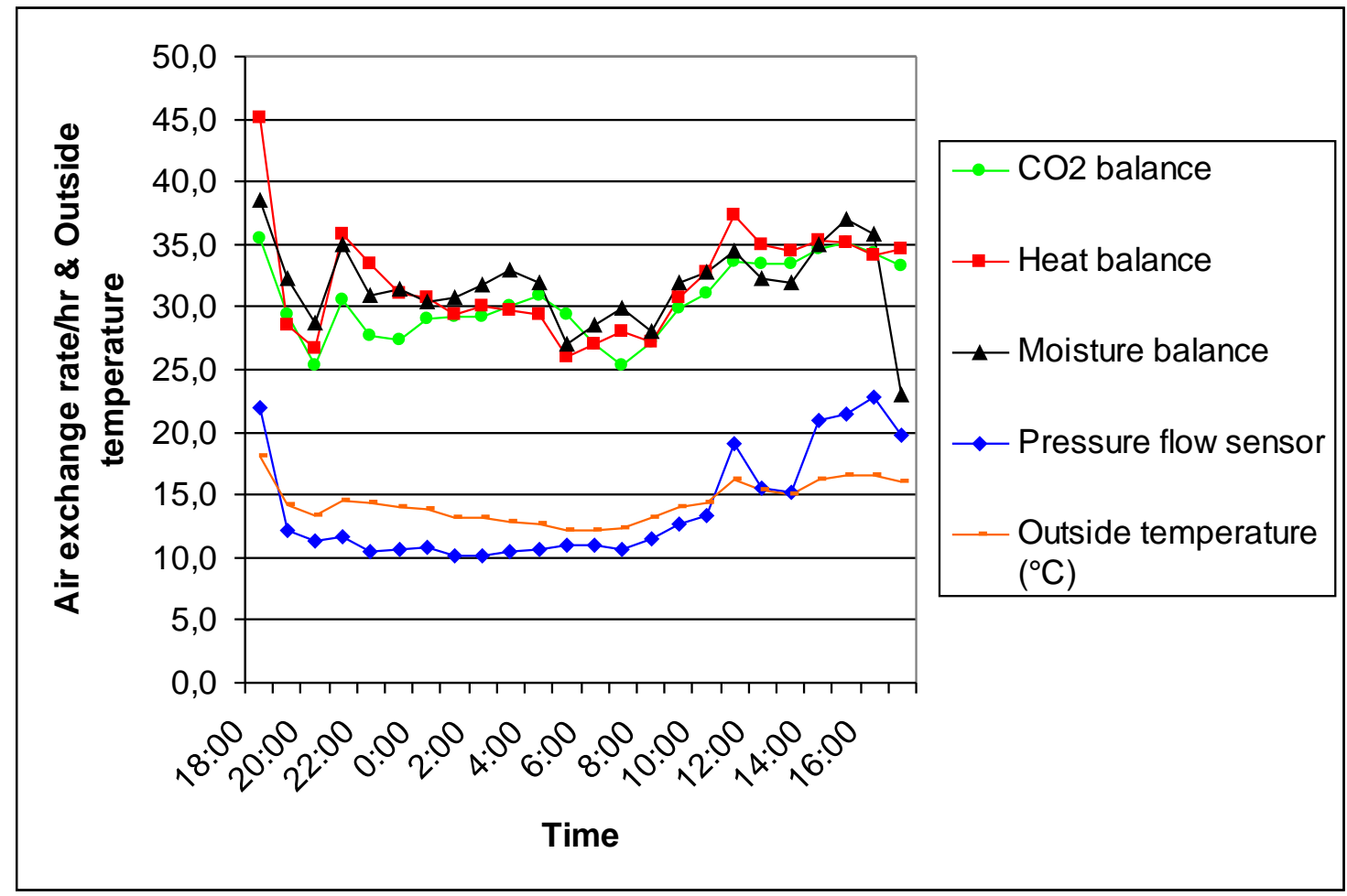

Fig. 4- 19 Hourly pressure flow sensor, mass balance AER results and outside temperatures (14.09.04)

The results in Fig. 4-19, display the estimated and measured air exchange rate values over the $24 \mathrm{~h}$ period. The mass balance curves are all closely aligned with each other but the air exchange rate results are much higher than the true values. The pressure flow sensor measurement results followed a similar pattern to the previous period 
recording accessions during the day time and depressions at night and early morning hours.

An AER peak of 22/h was recorded at $18 \mathrm{~h}$, simultaneously all $\mathrm{MBMs}\left(\mathrm{CO}_{2}\right.$, heat and moisture) recorded peaks at this time, 35,5/h, 45,1/h and 38,5/h, respectively. The second AER peak $(19,1 / \mathrm{h})$ at $11 \mathrm{~h}$, was mirrored by the mass balance models $\left(\mathrm{CO}_{2}\right.$, heat and moisture) 33,7/h, 37,4/h and 34,4/h, respectively (Fig. 4-19). Furthermore, the moisture and $\mathrm{CO}_{2}$ mass balances recorded a final peak at $15 \mathrm{~h}(37,0 / \mathrm{h}$ and $35,1 / \mathrm{h}$, respectively) whereas the third AER peak occurred at $16 \mathrm{~h}(22,9 / \mathrm{h})$. Therefore, the mass balance models grossly over estimated AERs but their peaks coincided with the actual AER peaks. The true AERs between 01-05h (10,1-10,6/h) did not coincide with the heat and moisture balance depression between 05-09h $(26-29,9 / \mathrm{h})$ and the $\mathrm{CO}_{2}$ model trough between 06-09h $(25,4-27,2 / \mathrm{h})$, once again the common flaw of the MBMs at these times.

The $\mathrm{CO}_{2}$, heat and moisture mass balance model results were all correlated with the true AERs, $r^{2}=0,86,0,74$ and 0,47 , respectively.

Tab. 4- 34 Pressure flow sensor and influencing variable correlation table (14.09.04)

\begin{tabular}{lcccc}
\hline & \multicolumn{3}{c}{ Temperature } & Inside humidity \\
\cline { 2 - 4 } & Outside & $\boldsymbol{\Delta}$ & Inside & \\
\hline $\begin{array}{c}\text { Pressure flow } \\
\text { sensor }\end{array}$ & 0,91 & $-0,80$ & 0,94 & $-0,78$ \\
\hline
\end{tabular}

Once again, measured AER results corresponded well with the internal and external hygro-thermal variables (Tab. 4-34). The correlation coefficient between measured air exchange rate and outside temperature $\left(\mathrm{r}^{2}=0,91\right)$ was not as high as the previous period $\left(r^{2}=0,95\right)$, probably because the temperatures were relatively stable and underwent less fluctuations than in the previous period. This may also explain the reduced negative correlation coefficient between measured AER and $\Delta$ temperature $\left(r^{2}=-0,80\right.$ compared with $-0,92$, previously). 
The positive correlation coefficient between AER and inside temperature $\left(r^{2}=0,94\right)$ is similar to $r^{2}=0,93$, recorded previously (08.09.04). Because inside temperature is the determining factor with the ventilation system, this correlation would be expected to be high. The inside humidity correlation factor between measured air exchange rate $\left(r^{2}=-\right.$ 0,78 ) was substantially lower than $r^{2}=-0,97$ from the 08.09.04.

The $\Delta$ in water content $\left(\mathrm{kg}\right.$ water $/ \mathrm{m}^{3}$ dry air) between inside and outside conditions used to calculate the moisture balance results, was 1,7 times higher on the 08.08 .04 than on the 14.09.04, this could have led to the reduced correlation coefficient $r^{2}=-0,78$ on the 14.09.04 compared with $\mathrm{r}^{2}=-0,97$ on the 08.09.04.

The median $24 \mathrm{~h} \mathrm{CO}_{2}$, heat and moisture balance air exchange rates were $118 \%, 128 \%$ and $127 \%$ higher than the measured AERs throughout this period (Tab. 4-35).

Tab. 4- 35 True AER and MBM day/night time and 24h averages (14.09.04)

\begin{tabular}{cccc}
\hline $\begin{array}{c}\text { Air exchange } \\
\text { calculation method }\end{array}$ & $\begin{array}{c}\text { Day time } \\
\mathbf{0 7 - 1 9 h r} \\
\mathbf{( \pm \% )}\end{array}$ & $\begin{array}{c}\text { Night time } \\
\mathbf{1 9 - 0 7 h r} \\
\mathbf{( \pm \% )}\end{array}$ & $\begin{array}{c}\mathbf{2 4 h r} \\
\mathbf{( \pm \% )}\end{array}$ \\
\hline Pressure flow sensor & 19,32 & 10,89 & 13,98 \\
$\mathrm{CO}_{2}$ balance & $33,73(+75 \%)$ & $28,75(+164 \%)$ & $30,50(+118 \%)$ \\
Heat balance & $39,12(+102 \%)$ & $29,84(+174 \%)$ & $31,99(+128 \%)$ \\
Moisture balance & $35,27(+83 \%)$ & $31,0(+185 \%)$ & $31,76(+127 \%)$ \\
\hline
\end{tabular}

The day and night time average AERs followed the same trend as the previous period with all MBMs accuracy decreasing at night time (Tab. 4-35). The $\mathrm{CO}_{2}$, heat and moisture balance results accuracy decreased by, 89\%, 72\% and 102\%, respectively. The day time averages were also very high, with the $\mathrm{CO}_{2}$, heat and moisture balances, $75 \%, 102 \%$ and $83 \%$ above the true day time AER.

The true AER median value translates to a ventilation rate of $2,01 \mathrm{~m}^{3} / \mathrm{h} / \mathrm{animal}$, this is below the recommended level $5,05 \mathrm{~m}^{3} / \mathrm{h} /$ animal (DIN 18910. 2004). The mass balance results $\left(\mathrm{CO}_{2}\right.$, heat and moisture), recorded median hourly ventilation rates of 5,20, 5,36 and $5,53 \mathrm{~m}^{3} / \mathrm{h} /$ animal, all above the recommended level. 


\subsection{Comparison of true AERs with mass balance models $\left(\mathrm{CO}_{2}\right.$, heat \& moisture) utilising $1 \mathrm{~h}$ and $2 \mathrm{~h}$ intervals along with animal activity, attempting to increase the accuracy of mass balance model results}

Animal activity measurements were conducted on the 18.08.04, 08.09.04 and 14.09.04. The effect of including animal activity and increasing the interval from 1 to 2 hours in the MBM calculations was analysed to ascertain whether the mass balance results could be improved by these simple measures. The MBM results were all tested for a significant correlation against the true AER results and an accuracy test was performed by dividing the mass balance results by the true air exchange rate and calculating a average variation value for the whole $24 \mathrm{~h}$ period. Each mass balance model was divided into 4 groups; a) 1 hour interval (standard) b) 1 hour interval with activity c) 2 hour interval and d) 2 hour interval with activity. The most desirable result from each group was highlighted i.e. high correlation and small \% variation with the true ventilation rate.

Tab. 4- 36 Accuracy \& $\mathbf{r}^{2}$ values between adjusted MBMs and true AERs (18.08.04)

\begin{tabular}{|c|c|c|c|c|c|c|c|c|}
\hline $\begin{array}{c}\text { Mass } \\
\text { balance } \\
\text { model }\end{array}$ & $\begin{array}{c}\mathrm{r}^{2} \\
1 \mathrm{~h} \\
\text { interval }\end{array}$ & $\begin{array}{c}\text { Av. 24h } \\
\text { deviation } \\
\text { from true } \\
\text { AER } \\
( \pm \%)\end{array}$ & $\begin{array}{c}\mathrm{r}^{2} \\
1 \mathrm{~h} \\
\text { interval } \\
\text { with } \\
\text { activity }\end{array}$ & $\begin{array}{c}\text { Av. 24h } \\
\text { deviation } \\
\text { from true } \\
\text { AER } \\
( \pm \%)\end{array}$ & $\begin{array}{c}\mathrm{r}^{2} \\
2 \mathrm{~h} \\
\text { interval }\end{array}$ & $\begin{array}{c}\text { Av. 24h } \\
\text { deviation } \\
\text { from true } \\
\text { AER } \\
( \pm \%)\end{array}$ & $\begin{array}{c}\mathrm{r}^{2} \\
2 \mathrm{~h} \\
\text { interval } \\
\text { with } \\
\text { activity }\end{array}$ & $\begin{array}{c}\text { Av. 24h } \\
\text { deviation } \\
\text { from true } \\
\text { AER } \\
\text { ( } \% \text { ) }\end{array}$ \\
\hline $\mathrm{CO}_{2}$ & 0,44 & 54 & 0,23 & 56 & 0,43 & 53 & 0,28 & 56 \\
\hline Heat & 0,13 & -24 & 0,12 & -17 & 0,18 & -25 & 0,17 & -18 \\
\hline Moisture & 0,61 & 5 & 0,24 & 5 & 0,28 & 7 & 0,06 & 5 \\
\hline
\end{tabular}

From the results above (Tab. 4- 36) the standard $\mathrm{CO}_{2}$ model (1h interval) recorded a significant correlation coefficient with the extrapolated true ventilation rates $\left(r^{2}=0,44\right)$ and a average variation of 54\% above the true air exchange rates, this was not significantly improved with adjustments. The heat balance model recorded results 17$25 \%$ below the true values and no significant correlations were recorded with any of the 4 groups, however the accuracy was improved by $7 \%$. The standard moisture balance 
was very closely aligned 5\% above the true ventilation rate and a significant correlation $\left(r^{2}=0,61\right)$. This result could not be improved with any of the group adjustments.

Tab. 4- 37 Accuracy \& $\mathbf{r}^{2}$ values between adjusted MBMs and true AERs (25.08.04)

\begin{tabular}{ccccc}
\hline $\begin{array}{c}\text { Mass balance } \\
\text { model }\end{array}$ & $\begin{array}{c}\mathbf{r}^{2} \\
\mathbf{1 ~ h} \text { interval }\end{array}$ & $\begin{array}{c}\text { Avh } \\
\text { deviation from } \\
\text { true AER } \\
( \pm \%)\end{array}$ & $\begin{array}{c}\mathbf{r}^{2} \\
\mathbf{2 h} \text { interval }\end{array}$ & $\begin{array}{c}\text { Av. 24h } \\
\text { deviation from } \\
\text { true AER } \\
( \pm \%)\end{array}$ \\
\hline $\mathrm{CO}_{2}$ & 0,78 & 57 & $\mathbf{0 , 8 0}$ & $\mathbf{5 6}$ \\
Heat & 0,66 & -13 & $\mathbf{0 , 6 5}$ & $\mathbf{- 1 0}$ \\
Moisture & 0,24 & -34 & 0,31 & -33 \\
\hline
\end{tabular}

No activity measurements were possible during this period (Tab. 4- 37). The $\mathrm{CO}_{2}$ balance correlation coefficient $\left(\mathrm{r}^{2}\right)$ was increased from $0,78-0,80$ and the accuracy slightly improved by using a $2 \mathrm{~h}$ interval in the calculations. The accuracy of the heat balance model was slightly improved by $3 \%$ with the $2 \mathrm{~h}$ adjustment, however, the correlation coefficient decreased marginally from $0,66-0,65$. The moisture balance was not significantly correlated with the true ventilation rates.

Tab. 4- 38 Accuracy \& $\mathbf{r}^{2}$ values between adjusted MBMs and true AERs (08.09.04)

\begin{tabular}{|c|c|c|c|c|c|c|c|c|}
\hline $\begin{array}{c}\text { Mass } \\
\text { balance } \\
\text { model }\end{array}$ & $\begin{array}{c}r^{2} \\
1 \mathrm{~h} \\
\text { interval }\end{array}$ & $\begin{array}{c}\text { Av. 24h } \\
\text { deviation } \\
\text { from true } \\
\text { AER } \\
( \pm \%)\end{array}$ & $\begin{array}{c}\mathrm{r}^{2} \\
1 \mathrm{~h} \\
\text { interval } \\
\text { with } \\
\text { activity }\end{array}$ & $\begin{array}{c}\text { Av. 24h } \\
\text { deviation } \\
\text { from true } \\
\text { AER } \\
( \pm \%)\end{array}$ & $\begin{array}{c}r^{2} \\
2 h \\
\text { interval }\end{array}$ & $\begin{array}{c}\text { Av. 24h } \\
\text { deviation } \\
\text { from true } \\
\text { AER } \\
( \pm \%)\end{array}$ & $\begin{array}{c}\mathrm{r}^{2} \\
2 \mathrm{~h} \\
\text { interval } \\
\text { with } \\
\text { activity }\end{array}$ & $\begin{array}{c}\text { Av. 24h } \\
\text { deviation } \\
\text { from true } \\
\text { AER } \\
( \pm \%)\end{array}$ \\
\hline $\mathrm{CO}_{2}$ & 0,07 & 70 & 0,20 & 66 & 0,05 & 72 & 0,18 & 67 \\
\hline Heat & 0,92 & 24 & 0,90 & 23 & 0,95 & 24 & 0,94 & 22 \\
\hline Moisture & 0,93 & 21 & 0,95 & 19 & 0,88 & 22 & 0,91 & 21 \\
\hline
\end{tabular}

The $\mathrm{CO}_{2}$ method recorded no significant correlations with any of the groups (Tab. 438). The standard heat balance recorded a high correlation $\left(r^{2}=0,92\right)$ and a reasonably good accuracy, 24\% above the true AERs. This was marginally improved with the $2 \mathrm{~h}$ interval $\left(r^{2}=0,95\right)$ accuracy remaining at $+24 \%$, and this was once again further improved with the $2 \mathrm{~h}$ interval and activity adjustment $\left(\mathrm{r}^{2}=0,94\right)$ and accuracy increasing to $+22 \%$ above the true AERs. The humidity balance was also highly 
correlated with the true AERs $\left(r^{2}=0,93\right)$ and accuracy level $21 \%$ above the true values. This correlation factor was increased $\left(\mathrm{r}^{2}=0,95\right)$ by including activity with $1 \mathrm{~h}$ interval, and the values became nearer to the true AERs by $2 \%$.

Tab. 4- 39 Accuracy \& $\mathbf{r}^{2}$ values between adjusted MBMs and true AERs (14.09.04)

\begin{tabular}{|c|c|c|c|c|c|c|c|c|}
\hline $\begin{array}{c}\text { Mass } \\
\text { balance } \\
\text { model }\end{array}$ & $\begin{array}{c}r^{2} \\
1 \mathrm{~h} \\
\text { interval }\end{array}$ & $\begin{array}{c}\text { Av. 24h } \\
\text { deviation } \\
\text { from true } \\
\text { AER } \\
( \pm \%)\end{array}$ & $\begin{array}{c}r^{2} \\
1 \mathrm{~h} \\
\text { interval } \\
\text { with } \\
\text { activity }\end{array}$ & $\begin{array}{c}\text { Av. 24h } \\
\text { deviation } \\
\text { from true } \\
\text { AER } \\
( \pm \%)\end{array}$ & $\begin{array}{c}\mathbf{r}^{2} \\
2 \mathrm{~h} \\
\text { interval }\end{array}$ & $\begin{array}{c}\text { Av. 24h } \\
\text { deviation } \\
\text { from true } \\
\text { AER } \\
( \pm \%)\end{array}$ & $\begin{array}{c}r^{2} \\
2 h \\
\text { interval } \\
\text { with } \\
\text { activity }\end{array}$ & $\begin{array}{c}\text { Av. 24h } \\
\text { deviation } \\
\text { from true } \\
\text { AER } \\
( \pm \%)\end{array}$ \\
\hline $\mathrm{CO}_{2}$ & 0,86 & 131 & 0,79 & 129 & 0,70 & 133 & 0,61 & 131 \\
\hline Heat & 0,74 & 142 & 0,79 & 139 & 0,55 & 144 & 0,67 & 141 \\
\hline Moisture & 0,47 & 143 & 0,57 & 140 & 0,70 & 144 & 0,76 & 141 \\
\hline
\end{tabular}

The standard $\mathrm{CO}_{2}$ model recorded a high correlation $\left(\mathrm{r}^{2}=0,86\right)$, however the mass balance results were well above the true AERs (+131\%) and this could not be improved (Tab. 4- 39). The standard heat balance was also quite highly correlated with the true AER $\left(r^{2}=0,74\right)$ and with low accuracy, $140 \%$ above the true values. The correlation coefficient was improved with the $1 \mathrm{~h}$ interval inclusion of activity $\left(\mathrm{r}^{2}=0,79\right)$, and the accuracy slightly increased from 142-139\% above the true AERs. The standard moisture balance model correlated with the true AER to a lesser extent as the other models $\left(r^{2}=0,47\right)$ and with even less accuracy $143 \%$ above the true ventilation rates. However, this was improved with the $2 \mathrm{~h}$ interval and activity adjustment $\left(\mathrm{r}^{2}=0,76\right)$, and the model deviations away from the true AERs was reduced by $2 \%$. 


\section{Discussion}

\subsection{Discussion \& conclusion of Experiment 1 results}

Realistically, it is not yet certain how to accurately measure air exchange rates from naturally ventilated livestock houses especially under summer conditions, with changing wind speeds/directions and the identification of inlets and outlets a very complicated task indeed (Demmers et al. 2001). Clearly, the models which have been calculated to perform under northern European conditions were pushed to their limits under the hot summer conditions experienced on the 03.08.04 and 14.08.04. Under summer conditions high air exchange rates up to 100/h were estimated by Müller \& Möller (1998). A tracer gas monitoring system capable of measuring the high air exchange rates in summer has been developed by Müller \& Möller (1998). This involves measurements from 40 sampling points running simultaneously with a maximum sampling rate of one second, air change rates of up to $1000 \mathrm{~h}^{-1}$ are measurable. However, the mass balance models $\left(\mathrm{CO}_{2}\right.$, heat and moisture) were the only practical methods available for gaining an estimation of the air exchange rates in this project.

Diurnal variation in the production of metabolic heat, water and $\mathrm{CO}_{2}$ will limit the accuracy of these methods for estimating the ventilation rate. However there are no widely accepted formulae for predicting this diurnal variation and, in consequence, averages over 24h were estimated to eliminate this problem (Pedersen et al. 1998). Pedersen et al. (1998) found the models gave comparable results except when the internal and external differences between $\mathrm{CO}_{2}$, temperature and moisture were too 
small. This was often the case during this experiment, but it was found that by correcting for this, reasonable results were still obtained.

In the literature (Pedersen et al. 1998), it is stated that the mass balance models will not give reliable results when the $\mathrm{CO}_{2}$, temperature and moisture difference between the stall and outside environment are $<200 \mathrm{ppm},<2^{\circ} \mathrm{C}$ and $<0,5 \times 10^{-3} \mathrm{~kg}$ water $/ \mathrm{m}^{3}$ dry air, respectively (Pedersen et al. 1998). On the 03.08.03, the heat and moisture balance models were unable to calculate reliable results for $67 \%$ of the time due to the hot outside temperatures (median $25,8^{\circ} \mathrm{C}$ ) particularly because the difference between inside and outside conditions were less than the recommended minimum and the outside temperatures and moisture levels were higher than inside the stall, resulting in negative AER results. This is because the heat and moisture balance models rely on the concept that heat and moisture is produced solely from within the stall and emitted to the outside environment, not gained from outside conditions, as was the case during these measurements. On the 14.08 .04 the $\mathrm{CO}_{2}$ mass balance was unable to obtain realistic results throughout most of the period because of the air circulation fans and very high AERs causing very low inside $\mathrm{CO}_{2}$ concentrations and thus very high AERs. On both days it was found that by incorporating the minimum difference values (i.e. $200 \mathrm{ppm}$ for $\mathrm{CO}_{2}$ differences $<200 \mathrm{ppm}$ ) into the models a good $24 \mathrm{~h}$ average was obtained and in some instances realistic hourly AERs. However, a problem with incorporating the recommended minimum values into the equations is that the true values and conditions are not considered and the diurnal variations which happen under real conditions are lost and replaced with a peak AER.

When no corrections were applied to the $\mathrm{CO}_{2}$ model, the AERs were at times too high, but they always remained positive, because the background $\mathrm{CO}_{2}$ concentrations are never higher than stall concentrations. On the 03.08 .03 when no corrections were made the calculated AERs ranged from 27,8-390,4 and with corrections the range was, 27,844,9/h. Without corrections the heat and moisture balance AERs on the 14.08.03 ranged from (-)240,9 $-1057,4 / \mathrm{h}$ and (-)16132,8-343,3/h, respectively, and with corrections the ranges were improved, from $20,5-52,6 / \mathrm{h}$ and $24,1-85,9 / \mathrm{h}$, respectively.

The $\mathrm{CO}_{2}$ model is not sensitive to temperature fluctuations and was able to perform sufficiently under the hot conditions on 03.08.03. In the literature, concentration 
differences of $200 \mathrm{ppm}, 250 \mathrm{ppm}$ and $500 \mathrm{ppm}$ are recommended for reliable results (Pedersen et al. 1998, Seedorf et al. 1998 and Choiniere et al. 1992). However, on the 03.08.03, only $13 \%$ of the $\mathrm{CO}_{2}$ concentration differences were above $200 \mathrm{ppm}$, the majority were between 150 and 200 ppm. Because of the high AERs, the $\mathrm{CO}_{2}$ level was consistently below $200 \mathrm{ppm}$, therefore, a $\Delta \mathrm{CO}_{2}$ concentration limit of $150 \mathrm{ppm}$ was used and was sufficient. However, because of the even higher AERs on the 14.08.03 than the 03.08.03 with the increased thermal buoyancy, air circulation fans and direct transverse winds, the $\mathrm{CO}_{2}$ concentrations were too low, and the calculated hourly AERs were inconsistent with real conditions i.e. peaks in the morning and troughs after midday. Even though the hourly AERs were inaccurate, the $24 \mathrm{~h}$ mean 30/h would be possible during the afternoon times with high temperatures and direct transverse winds.

The temperatures on the 14.08 .03 (median $18,7^{\circ} \mathrm{C}$ ) were low enough for reliable heat and moisture balance results throughout, most of the period, except when the temperature difference was too small (33\% of the time), however this occurred during the middle of the day when temperatures and wind speeds were high (transverse winds speeds $>5 \mathrm{~ms}^{-1}$ occurred in the afternoon), thus peak AERs would have been expected. During the winter/spring season AERs of $29.4 / \mathrm{h}$ and 55/h were calculated by Demmers et al. (1998). Kaharabata et al. (2000) used an external tracer gas method to measure AERs in a naturally ventilated dairy barn under summer conditions, a maximum air exchange rate of $48 / \mathrm{h}$ was calculated. On the 14.08 .03 the highest and lowest $24 \mathrm{~h}$ means (moisture balance $85,9 / \mathrm{h}$ and heat balance $52,6 / \mathrm{h}$ ) were averaged to give a $24 \mathrm{~h}$ AER mean of 53,2/h. This seems realistic considering Demmers et al. (1998) and Kaharabata et al. (2000) AER results..

In conclusion, because of the inaccuracy of the models under summer conditions it appears that it is more useful to do an in depth analysis on all 3 models to obtain an estimated AER rather than using only 1 model, as this provided a better $24 \mathrm{~h}$ mean value and at the same time provides some insight into the influencing variables, as well as providing a back up if:

1) The outside temperatures are too high (heat and moisture balances results will be inaccurate). 
2) The $\mathrm{CO}_{2}$ concentrations between inside and outside environments are too low $\left(\mathrm{CO}_{2}\right.$ balance results will be too high).

Although the calculated AERs can not be validated, it is concluded that when the driving forces behind natural ventilation are analysed i.e. bird age (mass), weather conditions (outside temperatures, wind speeds and directions) are known, and the small differences between inside and outside conditions are corrected for (if necessary), a realistic impression of the hourly diurnal air exchange rates and $24 \mathrm{~h}$ means were obtained. With this information the mass balance model results can be analysed and then an informed decision can be made regarding which mass balance models provided a realistic mean for the time period.

The assumed 24h mean AERs on the 03.08.03 and 14.08.03, 30,0/h and 53,2/h under the conditions do seem realistic, as was shown with comparative research which used more accurate AER calculation techniques.

\subsection{Discussion \& conclusion of Experiment 2 results}

The challenge of calculating air exchange rates from naturally ventilated livestock buildings has been attempted by numerous authors, the quality of the result can only be verified by the accuracy of the validation technique. The most accurate validation technique is with true air flow rate measurement comparisons, such as with measuring fan wheels (Berckmans 1991), however this can only be conducted in a simulated livestock house, which does not represent the real conditions inside a full sized naturally ventilated livestock building. Other validation techniques include intensive $\mathrm{CO}_{2}\left(\operatorname{Van}^{\prime} \mathrm{t}\right.$ Klooster \& Heitlager 1994; Scholtens \& Van`t Ooster 1994; Sneath et al. 1997), $\mathrm{NH}_{3}$ (Scholtens et al. 2004) and $\mathrm{CH}_{4}$ (Marik \& Levin 1996) mass balance model calculations along side tracer gas measurements (also known as tracer ratio methods), obviously the more influencing variables incorporated into the equations such as daily animal weight gain, feed intake etc the more accurate the mass balance calculation result. Other mass balance validations have also been done with the heat balance, whereby thermocouple measurements have been set up around the whole livestock building measuring heat influx and outflux from the building structure and solar radiation (Scholtens \& Van't Ooster 1994), however the $\mathrm{CO}_{2}$ method is generally preferred because there are less 
sources and sinks for interference. Attempts have been made to validate AERs with natural ventilation theory (Demmers et al. 2000), however, this was less accurate in comparison to tracer gas methods. Recently, validation has been attempted with correlating the weather conditions (Snell et al. 2003), this is logical, considering AERs from naturally ventilated stalls are directly controlled by heat buoyancy and wind speeds and is directly related to this project.

Müller \& Möller (1998) have been able to quantify emissions with a highly advanced sampling and dosing system, measuring up to 40 sampling points simultaneously, with a sampling rate of 1 per second using the concentration decay method. This method shows much promise, because a high source of error in tracer gas measurements is from the long sampling times in between gas measurements and not enough sample location measurements. Demmers et al. (2000), was able to validate a constant injection tracer gas method against fan wheel anemometers and achieved a range from 93 to $119 \%$ of the true ventilation rate. However, samples were measured from a total of 124 locations over 2 transverse planes, tracer gas was dosed at 200-800 1/min and the experiments were conducted in an experimental building section with an internal air volume of only $91 \mathrm{~m}^{3}$. Scholtens et al. (2004), also validated a constant release tracer gas experiment against a known release rate of $\mathrm{NH}_{3}$ in the same simulated animal house and was able to achieve an accuracy of 78 and $101 \%$ recovery at high and low wind speeds, the accuracy was reduced at high wind speeds.

Van't Klooster and Heitlager (1994) validated a tracer gas decay experiment against a $\mathrm{CO}_{2}$ mass balance model for pigs in a naturally ventilated stall. The $\mathrm{CO}_{2}$ model was intensively implemented, daily weight gain, daily feed intake and feed content analyses test results were included into the equations. The pig house stall was small (internal volume $\sim 1500 \mathrm{~m}^{3}$ ) and only contained 1 inlet and outlet. The tracer gas method utilised 5 sample locations. Results showed a mean discrepancy of $13 \%$ from the $\mathrm{CO}_{2}$ balance results. Dore et al. (2004) tested a constant injection tracer gas method inside a dairy cubicle house. The system utilised 44 tracer release points and 5 sampling points below the ridge to provide an integrated sample. The method was validated against $\mathrm{NH}_{3}$ production calculations from a dairy house, which involved the removal of manure twice daily and monitoring with several passive flux samplers. 
Demmers et al. (1998) successfully measured air exchange rates from a naturally ventilated dairy house (estimated internal air volume $3200 \mathrm{~m}^{3}$ ) with only 10 sampling locations in winter/spring conditions. In this study the location of inlets and outlets were also identified with tracer gas concentrations $<2 \mathrm{ppm}$ threshold indicating an inlet and above this value an outlet. It was found that the accuracy of the method was lowest at high wind speeds because of short circuiting. Scholtens \& Van't Ooster (1994) measured the AERs of a large naturally ventilated dairy and cattle house (internal volume $7500 \mathrm{~m}^{3}$ ), whereby tracer gas was dosed at $3000 \mathrm{~m}^{3} / \mathrm{h}$ and samples were measured from a total of 48 locations. The tracer gas method was validated by a comparison with the $\mathrm{CO}_{2}$ balance, heat balance and natural ventilation theory, the true ventilation rate was assumed to be the mean of all methods. The tracer gas method accuracy was found to be $\sim 10 \%$.

Snell et al. (2003) successfully measured ventilation rates in 4 naturally ventilated dairy houses with the tracer gas decay method, the tracer gas was evenly dosed throughout the entire building next to the inlets with critical glass capillaries, sampling locations were also set up along the air outlets with evenly spaced critical capillaries drawing in air samples obtaining an average integrated sample for the whole livestock house. The AERs were also validated against the weather conditions i.e. wind speeds, whereby higher AERs occurred with increased wind speeds etc.

The tracer gas method employed in this study supplied a small maximum dosage volume of $0,9 \mathrm{l} / \mathrm{min}$, utilised 6 sampling locations with a total measurement cycle lasting $\sim 10$ mins and the internal livestock house volume was $8148 \mathrm{~m}^{3}$. Because of this low number of sampling locations and large internal air space volume the air mixing sub-section was constructed, as previously discussed. The sampling locations were distributed within the air mixing sub-section, 3 were at the mouth of three chimneys and 3 at a height of $1,7 \mathrm{~m}$ at the side window on the lee side of the building. The dosing was conducted from the windward side of the building at 1 central point on the 07-09.11.03 and 3 equally divided points on the 12.11.03. Because of the minimum number of sampling locations and long gas measurement sample cycle, there was no means to establish which opening acted as an inlet or outlet, this of course depending mainly on the wind conditions. 
The weather was typical autumn conditions, which were ideal for the tracer gas measurements. It was important that the weather conditions were constant, i.e. cool temperatures encouraging low AERs and good tracer gas/air mixing as well as reasonably strong wind speeds with directions normal to the building. Snell et al. (2003) conducted successful tracer gas experiments by reducing the problem of climatic influences on the airflow affecting the tracer gas/air mixing by carrying out all measurements during winter. During the winter there are relatively big temperature differences between inside and outside air. Therefore, the amount of air that flows directly to the ridge and side wall outlets after entering the building (short circuiting) is relatively small. During the 8 day testing period (07-14.11.03), the temperatures were relatively constant and gradually decreased throughout the measurement period, temperatures ranged from $-1-9^{\circ} \mathrm{C}$ during the whole period. The $24 \mathrm{~h}$ wind speed averages were rather constant between $2,3-3,9 \mathrm{~ms}^{-1}$ on 4 of the days (07-12.11.03) and $0,3 \mathrm{~ms}^{-1}$ on the last day measured (13.11.03). The wind speeds were of medium strength, Demmers et al. (2001) reported low wind speeds $2 \pm 0,4 \mathrm{~ms}^{-1}$ and high wind speeds $6 \pm 0,4 \mathrm{~ms}^{-1}$. Very importantly were the wind directions, they also remained constant and near the transverse direction $\left(90^{\circ}\right)$ with $24 \mathrm{~h}$ averages ranging from $88-94^{\circ}$ on 4 of the days (07-12.11.03), the wind directions were random on the 13.11.03.

The highest air exchange rate (median $2,62 / \mathrm{h}$ ) occurred on the 07.11 .03 , this $24 \mathrm{~h}$ period also recorded the highest $\mathrm{SF}_{6} \mathrm{CV} 18,3 \%$ between sampling locations. The lowest median air exchange rate $0,71 / \mathrm{h}$ measured on the 13.11 .03 also recording the lowest $\mathrm{SF}_{6}$ CV $(1,71 \%)$. Therefore, it appears that the air was better mixed with low AERs (lower $\mathrm{CV} \%$ ) and the resulting higher turbulences caused by the higher air exchange rates caused higher tracer gas variation between the sample locations. Uniform spatial distribution of tracer gas within the house is probably caused by heat production of the animals, creating enough thermal buoyancy within the house to prevent serious problems with stagnant air (Van`t Klooster \& Heitlager 1994). Furthermore, Demmers et al. (2000) recorded CV values $<3 \%$ between tracer gas sampling locations. However, samples were measured from a total of 124 locations over 2 transverse planes, tracer gas was dosed at 200-800 1/min and the experiments were conducted in an experimental building section with an internal air volume of only $91 \mathrm{~m}^{3}$. Therefore, the higher CV values recorded in this experiment were expected. Interestingly, there was no significant difference between the tracer gas concentrations measured at the side 
windows $(1,7 \mathrm{~m}$ height $)$ and the chimneys $(5,7 \mathrm{~m}$ height $)$. Because of the heavier density of $\mathrm{SF}_{6}$, higher concentrations would have been expected at the side windows, if the internal air was not sufficiently mixed. This maybe explained by the strong thermal buoyancy forces in effect at low ventilation rates, this was in agreement with Demmers et al. (2000), the airflow pattern at the low ventilation rate showed strong buoyancydriven upward flows in the centre area of the building section.

The AERs were correlated with the outside temperatures on the 07.11.03, 08.11.03 and 13.11.03, with $\mathrm{r}^{2}=0,73,0,54$ and 0,48. Also on these dates, AERs were negatively correlated with $\Delta$ temperature (temperature difference between inside and outside) $\mathrm{r}^{2}=-$ $0,74,-0,56$ and $-0,58$, indicating AERs were highest during day time when outside temperatures were highest and when the $\Delta$ temperature was lowest, as would be expected. Similar research conducted by Snell et al. (2003), calculated no significant correlation coefficients between AERs and outside temperature and $\Delta$ temperature. On the 07.11.03 and 08.11.03, the inside temperatures were also negatively correlated with AERs $\left(r^{2}=-0,68\right.$ and $\left.-0,59\right)$, the effects from the increased AERs having an apparent cooling effect on inside air temperatures. Interestingly, as the outside temperatures decreased throughout the measurement period, then a corresponding decreased $r^{2}$ value between the AERs and outside temperatures was recorded. On the 07.11 .03 the average outside temperature was $6,5^{\circ} \mathrm{C}$ and $r^{2}=0,73$, compared with $4,8^{\circ} \mathrm{C}$ on the 08.11 .03 and $\mathrm{r}^{2}=0,54$.

The AER results from the naturally ventilated broiler house were in agreement with the influencing weather variables, air exchange rates on all measurement periods (07.11.03, 08.11.03, 09.11.03, 12.11.03 \& 13.11.03) were significantly correlated with wind speeds $r^{2}=0,47,0,43,0,46,0,41$ and 0,49 , respectively. The lowest correlation coefficient on the 12.11.03 $\left(r^{2}=0,41\right)$, also coincides with the lowest outdoor temperatures, mean outside temperature $1,45^{\circ} \mathrm{C}$ compared with $\left(r^{2}=0,46\right)$ and $4,20^{\circ} \mathrm{C}$ on the 09.11.03. Perhaps the reduced temperatures caused the inlet dimensions to be reduced, thus reducing the effect from wind speeds. The highest $r^{2}$ value $\left(r^{2}=0,49\right)$ on the 13.11.03 is not regarded because of the very random wind speeds and directions recorded during this period. Although the correlation coefficients were low they were in agreement with a similar study. 
Snell et al. (2003) measured ventilation rates in 4 Louisana dairy stalls with a novel tracer gas decay method, (previously described). All buildings had eave to ridge ventilation and measurements were conducted in winter, the building internal volumes are as follows 1) $3100 \mathrm{~m}^{3}$, 2) $4200 \mathrm{~m}^{3}$, 3) $5800 \mathrm{~m}^{3}$ \& 4) $2500 \mathrm{~m}^{3}$. The following correlation coefficients between AERs and wind speed were recorded from each house, as well as wind speed ranges, respectively; $r^{2}=0.47$ (house 3 ) wind speed range 0.2$2.3 \mathrm{~ms}^{-1}, \mathrm{r}^{2}=0.55$ (house 2) wind speeds range $0.2-3 \mathrm{~ms}^{-1}, \mathrm{r}^{2}=0.69$ (house 1) wind velocity range $0.2-1.8 \mathrm{~ms}^{-1}$ and $\mathrm{r}^{2}=0.92$ (house 4) $0.5-10.5 \mathrm{~ms}^{-1}$. The results indicate a decrease in significance with increased building air volume. The lowest correlation coefficient $\left(\mathrm{r}^{2}=0,47\right)$ was recorded in the largest building (building 3$)$ and the highest $r^{2}=0,92$ recorded in the smallest building (house 4), this could be due to the reduced effect wind velocity will have on larger volume air spaces. In addition, the highest wind speeds $\left(0,5-10,5 \mathrm{~ms}^{-1}\right)$ also occurred when the house 4 AERs correlated highly with the wind speeds $\left(r^{2}=0,92\right)$. Also, the low $r^{2}=0.47$ value recorded in the largest dairy house $\left(5800 \mathrm{~m}^{3}\right)$ wind speed range $0,2-2,3 \mathrm{~ms}^{-1}$ by Snell et al. (2003), coincided with the highest $\mathrm{r}^{2}=0,47$ recorded in this study (air volume $8148 \mathrm{~m}^{3}$ ) on the 07.11 .03 (wind speed range $\left.1,9-5,3 \mathrm{~ms}^{-1}\right)$.

The $24 \mathrm{~h}$ median heat and moisture mass balance AERs were also correlated with the $24 \mathrm{~h}$ wind speed medians $\left(\mathrm{r}^{2}=0,56\right.$ and 0,79 , respectively) over the measurement period (07-14.11.03), but not as highly correlated as the tracer gas method $\left(r^{2}=0,96\right)$. However, at times the heat and moisture mass balance models were very highly correlated with the wind speeds. The moisture balance AERs were significantly correlated with wind speeds on every day with a range from $r^{2}=0,51-0,90$. The heat balance was not significantly correlated on 2 days, but nevertheless recorded a highly significant range of $r^{2}=0,57-0,84$. The heat and moisture mass balance AERs were also correlated with the tracer gas method AERs on numerous occasions. On the 07.11.03, 08.11.03 and 13.11.03, the heat and moisture balance AERs correlated with the tracer gas AERs. The highest $r^{2}$ values occurred on the $07.11 .03\left(r^{2}=0,75\right.$ and 0,86 , respectively), followed by the 08.11.03 $\left(\mathrm{r}^{2}=0,57\right.$ and 0,48, respectively) and the lowest on the 13.11.03 $\left(\mathrm{r}^{2}=0,57\right.$ and 0,40, respectively). Interestingly, these days recorded the highest AER $\mathrm{r}^{2}$ values with wind speeds and outside temperatures. This may be indicative of the slightly warmer temperatures on these days resulting in an increased opening of the side wall 
curtains, thus increased effect from the wind speeds on the AERs was measured with the tracer gas and mass balance models.

The average 24h AER calculations between the methods (tracer gas, heat and moisture balance models) were within range of each other, the deviations between the method results are acceptable but the differences are nevertheless quite large. The heat balance results were always closer aligned with the tracer gas method results than the moisture balance results. The heat balance $24 \mathrm{~h}$ mean ranged from $24-35 \%$ greater than the tracer gas method results from the 07-12.11.03. The closest daytime average (07-19h) was $+12 \%$ on the 08.11 .03 and closest night time average $(19-07 \mathrm{~h})+22 \%$ on the 09.11.03 On the other hand the moisture balance results were not so closely aligned with $24 \mathrm{~h}$ average tracer gas AERs ranging from $+95-115 \%$ above the mean. A low daytime difference of $+26 \%$ was measured on the 12.11 .03 and the lowest night time mean difference of $+112 \%$ was recorded on the 09.11 .03 . Both the heat and moisture balance results were well above the tracer gas method results on the $13.11 .03,+255 \%$ and $+364 \%$, respectively. However, the tracer gas method results were too low on this day, correspondingly, the heat and moisture balance methods also recorded the lowest AERs on the 13.11.03.

The temperature and humidity measurements were taken from the locations near the chimney mouth, because heat rises these would have recorded higher results in both temperature and humidity resulting in slightly depressed AERs, however this effect would have been minimal, considering these were also outlets and not stagnant zones.

Also, because of the ease of the mass balance model application and lack of time due to the tracer gas system maintenance, the mass balance models were neglected. Information on the bird weights were collected from the farmer, daily weight gain, feed consumption and feed content analyses were not performed, this information would have added confidence to the MBM results.

The calculated tracer gas method AERs through out the measurement period ranged from a minimum AER 0,29/h (13.11.03) to a maximum of 5,8/h measured (12.11.03). The moisture balance recorded a maximum on the $12.11 .03(7,3 / \mathrm{h})$ and a minimum on the $13.11 .03(3,6 / \mathrm{h})$. The heat balance also recorded a corresponding maximum on the 
$12.11 .03(4,6 / \mathrm{h})$ and a minimum on the $08.11 .03(2,7 / \mathrm{h})$. Therefore, all methods recorded maximum AERs on the 12.11.03. The maximum tracer gas method, heat and moisture balance AERs all occurred after midday at, 17h, 13h and 16h, respectively. The outside temperatures were the lowest on this day $\left(\right.$ mean $\left.=1,45^{\circ} \mathrm{C}\right)$, wind speeds were lower than the previous periods ( median $=2,65 \mathrm{~ms}^{-1}$ ) and wind directions were constant $\left(88,3 \pm 10,7^{\circ}\right)$, but more variable than previous days. The higher AERs may have been due to increased sensible heat production from the broilers due to the cooler outside temperatures, also because of the rapid weight gain over a short period of time, heat production from the birds would have been greater at the end of the measurement period compared with the beginning. This combined with increased sensible heat production and reasonably consistent wind speeds and directions may be the combination of reasons explaining the highest AERs calculated throughout this period. The minimum AERs recorded by the tracer gas method and moisture balance on the 13.11.03, are in agreement with the weather conditions, on this day wind speeds were at times negligible, and directions were random. The minimum heat balance result on the 08.11.03, corresponds with the second lowest $24 \mathrm{~h}$ median tracer gas method and moisture balance results.

The tracer gas AERs calculated in this study ranged from 0,3-5,8/h. Comparative studies have also recorded similar AER results within range to this study. In a study conducted by Demmers et al. (2000), a low ventilation rate was calculated as approximately 6 air changes/h and a high ventilation rate at about 20 air changes $/ \mathrm{h}$ inside an experimental livestock building. Demmers et al. (1998), calculated quite high AERs from a naturally ventilated cattle building under calm conditions (wind speeds $<0.2 \mathrm{~ms}^{-1}$ ) at $10-20 / \mathrm{h}$, compared to $2-16 / \mathrm{h}$ for a dairy building described by Van't Ooster (1994). Snell et al. (2003) calculated AERs from 4 naturally ventilated dairy houses in the winter, wind speeds throughout the measurement period ranged from $0,2-10,5 \mathrm{~ms}^{-1}$ and measured AERs were between 4,3-14,4/h. The AER of a livestock building with all ventilation openings closed was calculated to be 0.48 /h (Van't Ooster 1994), which is above the minimum AER measured in this experiment $(0,29 / \mathrm{h})$ on the 13.11 .03 and the building was not completely closed, also confirming that the calculated results for this period were too low. Even though, the AERs calculated in this project are lower than the comparative studies, they are within range, the calculations in other studies were also conducted in buildings with different architectural designs and in different climatic 
zones. Also this study was performed on a large livestock house (internal volume $8148 \mathrm{~m}^{3}$ ), with basic technical equipment and only 6 sampling locations. It is possible that the lower AERs recorded in this study were due to tracer gas at times remaining in the mixing sub-section, especially with the very low AERs recorded on the 13.11.03, the lower turbulences may have caused tracer gas to settle in this location and depress the AER results. Smoke tests confirmed there was sufficient mixing between the air mixing section and the stall, but because of the low number of samples, no sampling locations could be located outside the air mixing section to confirm this theory.

The propagation of errors was calculated for each measurement period (07.11.03, 08.11.03, 09.11.03, 12.11 .02 and 13.11.03) an estimated error of 23\%, 12\%, 7\%, 8\% and $4 \%$, respectively. The higher error on the 07.11 .03 coincides with the overall higher AERs and the lowest on the 13.11.03 with the low AERs. The error does seem rather low, however, Kaharabata et al. (2000) conducted measurements with an external tracer gas method, which is open to much more influences and error, the overall uncertainty in the estimate was around 30\%. Therefore, the calculated error seems appropriate. Other sources of error not included in the calculation would be from tracer gas escaping from the building or remaining idle in sinks/stagnant zones and or the air mixing section. Furthermore, changing conditions inside the building during the sampling cycle of 10 min needed to sample all locations would also contribute to inaccuracies (Demmers et al. 2001). Also, the low number of sampling locations for the large air space, Müller and Möller (1998) found 40 sampling points to be a sufficient quantity for measuring the ventilation rate in naturally ventilated livestock buildings, and that due to the non-uniform air flow rate in livestock buildings only 6 sampling points leads to large measuring errors. These additional factors may mean that the true errors would have been higher than those calculated. Furthermore, because the heat and moisture balances assume heat and moisture production is fixed throughout the whole $24 \mathrm{~h}$ period, which is never the case, not to mention variable bird weights and performance, the heat and moisture balance models are also open to large errors, so it can not be concluded which method is more accurate.

A better understanding of the tracer gas method would have been obtained if more sampling locations were available, some samples located outside the air mixing section would have provided information on the level of air/tracer gas mixing outside the air 
mixing section. Furthermore, measurements of the opening and closing levels of the inlets and outlets would have also contributed more important information on the functioning of the ventilation system as well as another very important factor, inlet and outlet surface area, which would be useful in assessing and comparing the effects weather has on the calculated AERs.

In conclusion, although the measured tracer gas method AERs seemed low, they were closely aligned with the weather variables, were in agreement with previous research results and were generally above the minimum recommended ventilation rates necessary under winter conditions. The tracer gas method is much more expensive to set-up, but costs were kept to a minimum with the construction of the air mixing subsection and minimum sampling locations and dosage volumes. The results indicate that it is possible to measure AERs from large livestock houses using tracer gas methods with a minimum number of sampling locations and an air mixing section to improve tracer gas/stable air mixing. However, it is important that the outside weather conditions are stable. Because of the low air exchange rates under these weather conditions and the constant wind conditions keeping the inlets and outlets relatively fixed, it was possible to obtain reasonable results. The significant correlations coefficients between the AERs and weather variables, is logical and adds credibility to the results.

The mass balance models are recommended only as a $24 \mathrm{~h}$ estimate, however they proved to be accurate and sensitive enough to calculate rather accurate results. The methods proved their ability to estimate AERs very easily under the weather conditions in this experiment and recorded highly significant correlations with wind speeds. The methods were very cheap, easy and effective.

Because both the tracer gas method and mass balance models are all indirect techniques with the potential for quite high levels of error and no validation technique is presently available to determine which method gave more accurate results. Comparing the results with influencing weather variables and previous research can give enough information to ascertain whether the calculated air exchange rates are realistic, which they were in these experiments. Because all method results were in agreement with the weather 
conditions and previous research results, the assumed true AERs in this experiment would have been an average from all 3 methods.

\subsection{Discussion \& conclusion of Experiment 3 results}

Measuring AERs from mechanically ventilated livestock buildings can be very difficult when considering the number of air exhaust locations, uncontrollable variations in fan and system performance, fan belt slippage, dust accumulation in the fan blades and the variation in negative pressures at which the exhaust fans are operating (Feddes et al. 1984; Li et al. 2005). To determine AERs accurately the exhaust flow must be determined from each exhaust fan (Feddes et al. 1984), however sometimes livestock houses can contain a large number of exhaust fans making such an operation very expensive and impractical. Measuring air flow rates from the chimneys with measuring fan wheels, fan wheel anemometers, pressure flow sensors etc are the most accurate methods and are direct techniques. In this study the true AER was calculated (refer to section 3.7), by continuously monitoring the air flow rates via the multi-step chimney. Air flow rates for all chimneys were estimated for each ventilation combination (cerca 20 different levels of ventilation) operated throughout the measurement period. Air flow rates from all 12 exhaust fans were measured under constant conditions and numerical factors for each fan where calculated. With this information combined with continuous downloading of the operating times of each ventilation combination during the measurement periods the air exchange rates were calculated, because this is a direct technique and the most accurate out of all other methods tested (artificial and natural tracer gas techniques) this is referred to as the true air exchange rate.

Indirect techniques include natural $\left(\mathrm{CO}_{2}\right.$, heat and moisture) and artificial $\left(\mathrm{SF}_{6}, \mathrm{CO}\right.$ etc) tracer gases. Artificial tracer gas techniques are an acceptable alternative to anemometer techniques, the accuracy is however, highly dependent on how well the tracer gas mixes with the air, which is very unlikely in animal houses (Leonard et al. 1984). Complete mixing of tracer gas with air in livestock houses is not possible, because the air does not under go complete mixing, important is that the tracer gas is distributed the same way as the air (Demmers et al. 2000). The distribution of aerial pollutants and tracer gases inside a livestock building, and therefore the estimate of pollutant concentrations and emissions rates, depends on the ventilation rate, airflow 
patterns inside the building, floor construction, waste storage system, animal activity, level and type of feed. The airflow pattern is the most important factor in the distribution of a pollutant inside a building, it is influenced by building geometry and construction, size and distribution of ventilation inlets and outlets and heat production (Demmers et al. 2000).

Because of the option of using accurate direct techniques with mechanically ventilated livestock houses, there is not much available literature on measuring AERs in mechanically ventilated livestock buildings using tracer gas techniques.

An earlier study conducted by Leonard et al. (1984) successfully measured AERs from very small pig cubicles $\left(25 \mathrm{~m}^{3}\right)$ using various tracer gas techniques (constant injection, concentration decay and fan duct constant flow method). Air was injected at the inlet at a rate of $6 \mathrm{ml} / \mathrm{min}$ and sampled at the outlet. Each room also had a air circulation fan to increase mixing. The constant injection and concentration decay methods were within $20 \%$ of the true AER results obtained from fan wheel anemometer measurements. The most accurate method was the fan duct constant flow method achieving results within $5 \%$ of the true AERs. The higher accuracy was gained because of the small area within the duct reducing error which is encountered with large sized rooms. This method is only documented in this paper, however if this method could be successfully applied in the field, it would save a lot of time and expense, considering gas measurements only need to be set up inside a chimney space, rather than a whole livestock house building.

Scholtens and Van't Ooster (1994) conducted tracer gas measurements in a mechanically ventilated dairy house. The true ventilation rates were measured with fan wheel anemometers. A total of 20 sampling points were set up throughout the livestock house and 10 injection points were located on each side of the building. The injection points were precise glass orifices. The tracer gas method was found to have an accuracy of $\pm 10 \%$ with the true AERs. Marik and Levin (1996) measured the ventilation rates from a mechanically ventilated cattle house using a constant release tracer gas method. The livestock house was rather small with an internal volume of $1799 \mathrm{~m}^{3}$ and contained only 1 fresh air inlet and 3 exhaust chimney shafts. The highest AER measured was quite low, only 5,8/h. This method was validated against $\mathrm{CH}_{4}$ and $\mathrm{CO}_{2}$ mass balance models. 
The broiler house in this study had an internal volume of $5206 \mathrm{~m}^{3}$, with a total of 36 fresh air inlets (18 along each side) at heights of 0,7 and 2,2m (Fig. 3-6). The exhaust system consisted of 12 chimneys at the northern end, with 2 extra fans located at the far northern end of the building. It is the general assumption that with fixed inlets and outlets the setting up of dosing and sampling equipment is easy, however, this was not the case. The first dosing point was located in the centre of the stall, dosing from 2 heights $(0,75$ and $1,9 \mathrm{~m})$. The injected tracer gas was pure $100 \% \mathrm{SF}_{6}$. All 6 sampling locations were at the chimneys. The tracer gas AER results were very low on both the 14.07.04 and 28.07.04, median 24h AERs 2.44 and 1.83/h, respectively. On the 14.07.04 and 28.07.04, the birds were 3 and 4 weeks old, respectively and the $24 \mathrm{~h}$ median outside temperatures were warm, 15.6 and $17.5^{\circ} \mathrm{C}$. An average of the highest and lowest median mass balance model AER results for these days were 15.5 (14.07.04) and 26.9 (28.07.04) AERs/h. The estimated mass balance AERs seem high but are more realistic than the very low tracer gas method results on these days. It was assumed that the reason for the very low AERs was that not enough tracer gas was dosed into the stall to cover the interference from 1 several possible sinks. A $\mathrm{SF}_{6}$ sink was identified at the far northern end of the stall. The average $24 \mathrm{~h} \mathrm{SF}_{6}$ concentrations at the northern end of the chimney stack (locations $5 \& 6$ ) were $254 \%$ and $150 \%$ higher on the 14.07 .04 than locations 1-4 (positioned at the southern end of the chimney stack), and $135 \%$ and $59 \%$ higher on the 28.07.04. The highest $\mathrm{SF}_{6}$ concentration was consistently recorded at location 5 (middle of the chimneys). It appears that beneath the chimneys existed a sink which continuously recirculated $\mathrm{SF}_{6}$ tracer gas, thus the high concentrations at this location. The higher $\mathrm{SF}_{6}$ concentrations at locations $5 \& 6$ on the 14.07 .04 compared with the 28.07.04 may have been due to the lower AERs, as calculated with the mass balance model estimation, resulting in higher $\mathrm{SF}_{6}$ concentrations in this sink zone. This agrees with the higher $24 \mathrm{~h}$ AER median $(2,44 / \mathrm{h})$ on the 14.07 .04 compared with $1,83 / \mathrm{h}$ on the 28.07.04. The higher tracer gas method AERs recorded on the 14.07.04 may be explained by better tracer gas and air mixing occurring at the lower AERs.

The change over of dosing from the centre of the stall to the side walls on the 18 and 25.08.04, did not greatly improve the results, however, the increased dosing on the 25.08.04 did result in a higher median 4,11/h compared with 1,93/h on the 18.08.04, indicating an improvement with the increased dosing. The sample location changes on 
these periods confirmed the presence of a $\mathrm{SF}_{6}$ sink beneath the northern end of the chimneys and in front of the extra fans. The $24 \mathrm{~h}$ average concentration at location 5 (beneath the chimneys) was $167 \%$ higher than the other 5 locations on the 18.08 .04 and 99\% higher on the 25.08.04. This reduced difference on the 25.08.04 indicates the effect from the sink was reduced as the tracer gas dosage volume was increased. Also, the $24 \mathrm{~h}$ concentration at location $6(0,5 \mathrm{~m}$ high, western wall, middle length of stall) was $25 \%$ lower than channels $1-4$ on the 18.08 .04 and $10 \%$ higher on the 25.08.04. The lower concentration on the 18.08.04 due to the lower dosage rate and the higher AERs (median 9,82/h), the higher concentration on the 25.08.04 better tracer gas/ air mixing with the higher tracer gas volumes and lower AERs (median 8,33/h).

The extra fans were not operating throughout either of these periods, so it seems likely that tracer gas was stored at the far northern end of the livestock building and circulated continuously, but released when the ventilation rates increased. This was noticed on the 18.08.04 and 25.08.04, the $\mathrm{SF}_{6} \mathrm{CVs}$ increased to maximum levels $10,82 \%$ and 57\%, respectively, when the extrapolated true AERs also recorded corresponding peak ventilation rates. The higher $\mathrm{SF}_{6} \mathrm{CV}$ on the 25.08 .04 (57\%) probably due to a higher lock up of $\mathrm{SF}_{6}$ with the increased dosage rates in this period.

The dosage volume on the $14 \& 28.07 .04$ and 18.08 .04 was only $180 \mathrm{ml} / \mathrm{min}$ and then increased to the system maximum of $900 \mathrm{ml} / \mathrm{min}$ on the 25.08.04. Marik and Levin (1996) also used a low dosage volume of only $582 \mathrm{ml} / \mathrm{min}$, however the livestock house internal volume was only $1799 \mathrm{~m}^{3}$ compared $5206 \mathrm{~m}^{3}$ in this study. Also, the highest AER of 5,8/h is quite low, compared to the maximum 25,9 AERs recorded on the 08.09.04. Furthermore, Scholtens and Van't Ooster (1994), recorded an accuracy of within $10 \%$ of the true AERs using a dosage volume of $151 / \mathrm{min}$ (livestock house internal volume not given). Therefore, it seems quite clear that the real problem was with the dosage volume and not so much the location of the dosing points, the dosage volume was too low, and unable to mask the interference effects from the $\mathrm{SF}_{6}$ sink.

Smoke tests were performed at this sink zone beneath the ducts and did not indicate this zone under went higher turbulences than other locations in the stall. However, the smoke accelerated as it reached a range of about $1 \mathrm{~m}$ from the chimney mouth. Because of the high number of exhaust fans located in such close proximity, this may have 
created a slight vacuum at this sink zone and with the heavier density of pure $\mathrm{SF}_{6}(\sim 5$ times heavier than air) the tracer gas settled in this zone, out of range from the pull of the chimneys and slowly rising upwards as displacement occurred with additional $\mathrm{SF}_{6}$. Perhaps if the concentration of the $\mathrm{SF}_{6}$ was diluted to create a tracer gas mixture more similar with the density to air this would have reduced the effects from the sink zone. Marik and Levin (1996) used a tracer gas air mixture with only $5 \%$ pure $\mathrm{SF}_{6}$, and Demmers et al. (1998); (2000), Scholtens \& Van't Ooster (1994); Scholtens et al. (2004); have all used diluted forms of $\mathrm{CH}_{4}$ and $\mathrm{CO}$, both gases also having a lower density than $\mathrm{SF}_{6}$. Kaharabata et al. (2000) conducted tracer gas measurements in a naturally ventilated livestock house and used pure $\mathrm{SF}_{6}$, it was claimed that turbulent diffusion dominates molecular diffusion in the atmospheric transport of tracer gases so that density differences between $\mathrm{SF}_{6}\left(6.25 \mathrm{~kg} \mathrm{~m}^{-3}\right)$ and $\mathrm{CH}_{4}\left(0.68 \mathrm{~kg} \mathrm{~m}^{-3}\right)$ are negligible in the dispersion of the 2 gases in air. This maybe the case in naturally ventilated stalls as was found in experiment 2, when low ventilation rates were measured from the Louisiana stall the $\mathrm{SF}_{6} \mathrm{CV}$ values between chimney and wall samples were correspondingly low, because of the role heat buoyancy forces play in ventilating naturally ventilated livestock buildings. It is clear that the air flow patterns inside negative pressure mechanically ventilated livestock houses are indeed very different to naturally ventilated stalls, the different air pressures and air flow patterns playing a major part in the distribution of the tracer gas, thus the successful operation of tracer gas experiments requiring different planning in both cases.

The true ventilation rates were extrapolated from stall data on 2 days (18.08.04 \& 25.08.04) and measured with the pressure flow sensor on 2 days (08.09.04 \& 14.09.04) from the mechanically ventilated stall. The true air exchange rate results also recorded high correlation coefficients with outside temperature on the 25.08.04, 08.09.04 and 14.09.04 $\left(\mathrm{r}^{2}=0,90,0,95 \& 0,91\right)$, correspondingly high negative correlation coefficients were recorded between AERs and $\Delta$ temperature $\left(r^{2}=-0,93,-0,92 \&-0,80\right)$ on these days, indicating the AERs were highly correlated with outside temperatures, as would be expected. This relationship was also observed with the naturally ventilated livestock house. Furthermore, the mechanically ventilated AERs were positively correlated with the inside temperatures $\left(\mathrm{r}^{2}=0,63,0,93\right.$ and 0,94$)$, indicating inside stall temperatures were highest when ventilation rates were at maximum levels, obviously the higher temperatures during the day, combined with bird activity would have resulted in higher 
inside temperatures requiring higher AERs to keep the temperature level within the desired range. This was opposite to the naturally ventilated stall in the winter, recording significant negative correlation coefficients between AERs and inside temperatures. This can be explained by the increased AERs resulting in increased cold air influxes causing a reduction of the inside temperatures, this temperature drop would be registered by the ventilation system thermostat and inlet dimensions would be reduced, causing decreased AERs and a corresponding rise in internal temperatures.

The true AERs recorded a minimum of $6,45 / \mathrm{h}$ on the 25.08 .04 and a maximum of 25,86/h on the 08.09.04. This was in agreement with Demmers et al. (2000), measured low AERs of 6/h and high AERs 20/h. However, the measured ventilation rate was only above the recommended minimum level (DIN 18910. 2004) on one occasion. On the 18.08.04, the birds were only 7 days old, the AERs were high (median 9,82/h), this was $13 \%$ above the recommended minimum $8,65 / \mathrm{h}$. On the 25.08 .04 , the birds were 2 weeks old, the median AER was 8,33/h, a decrease due to cooler outside temperatures, the recommended ventilation rate level for the bird mass was $15,73 / \mathrm{h}$, this means the AER needed to increase by $82 \%$ from the previous week. This is a large increase considering the birds were only 1 week older, not to mention the true AERs on the 18.08.04 were already very high. On the 08.09.04 and 14.09.04, median AERs of 10,80 and 11,61 were measured, respectively, the recommended level of ventilation on these periods was 23,17 and 29,10 AERs/h. The true AERs on the 08.09.04 and 14.09.04 were -114 and $-151 \%$, respectively below the recommended levels. Once again, the recommended ventilation rates are too high and not necessary. Such high AERs were measured from naturally ventilated livestock houses, however the very large air exchange surfaces make these high AERs possible with these systems. Hinz and Linke (1998), accurately quantified AERs from a piggery, whereby the airflow was measured using fan wheel anemometers. The ventilation system was similar to the mechanically ventilated broiler house in this study, involving the aim of the ventilation control i.e. constant indoor temperature. Measured AERs ranged from 4-22/h and it was found that the piggery was over ventilated and energy consumption was too high. This is in agreement with the findings in this study. The very large increases in recommended ventilation rates over short periods of time in the grow out cycle seem to be out of range for practical purposes and energy costs. Part of the problem with the recommended levels seems to be that they do not consider the weather conditions. However, the 
recommended levels are only a guideline and because of the level of investment in animal livestock industry and the potential catastrophic effect if AERs are too low, it is safer to have AERs that are too high rather than too low.

The mass balance models $\left(\mathrm{CO}_{2}\right.$, heat and moisture) recorded high correlation coefficients with the true AERs. The importance of correlating estimated air flow rate measurements with measured results is to confirm that the methods correspondingly recorded high and low AERs etc, however a highly significant correlation coefficient does not deliver any information about the accuracy of the results. The accuracy of the calculated mass balance results were averaged over 12h blocks, day time (07-19h), night time (19h-07h) and $24 \mathrm{~h}$ to test the accuracy of the model results during day and night periods, as well as an overall average. Due to the small number of comparative tests in this study, only 4, it is not possible to draw solid conclusions from the results.

The lowest correlation coefficients were recorded on the 18.08.04. On the 18.08.04, the true AERs were positively correlated with the heat and moisture balance results $\left(r^{2}=0,61\right.$ and 0,44 , respectively). The moisture balance model recorded the highest level of accuracy ( $24 \mathrm{~h}$ mean) only $+5 \%$ above the true AERs. The moisture balance model also recorded the highest correlation coefficient on the 08.09.04 $\left(r^{2}=0,91\right)$ with a corresponding accuracy $+14 \%$, the heat balance correspondingly recorded a high correlation $\left(\mathrm{r}^{2}=0,85\right)$ and accuracy $+19 \%$. The most accurate result recorded by the $\mathrm{CO}_{2}$ method was $+54 \%\left(r^{2}=0,78\right)$. The least accurate results occurred on the 14.09.04, all mass balance models $\left(\mathrm{CO}_{2}\right.$, heat and moisture balance) were significantly correlated $\left(r^{2}=0,74,0,47\right.$ and 0,86), however the accuracy levels were low, $+118,+128$ and $+127 \%$ above the true $24 \mathrm{~h}$ mean AERs. The highest air exchange rates occurred during this period, this may be the reason for these inaccurate results $\mathrm{Li}$ et al. 2005 found the $\mathrm{CO}_{2}$ mass balance models were least accurate at high AERs. Scholtens and van't Ooster (1994) assumed that due to the greater number of sinks and sources for interference the heat and moisture balances would be slightly less accurate then the $\mathrm{CO}_{2}$ method. In this study, the moisture and heat balance results were more accurate than the $\mathrm{CO}_{2}$ mass balance model. Hinz and Linke (1998) performed $\mathrm{CO}_{2}$ mass balance estimation with pigs and found the $\mathrm{CO}_{2}$ method underestimated the true AERs by $\sim 6,5 \%$ over $24 \mathrm{~h}$ periods. The results in this study showed the $\mathrm{CO}_{2}$ method consistently over estimated $24 \mathrm{~h}$ periods ranging from 43-118\%, however Hinz and Linke (1998) analysed a total of 
$1924 \mathrm{~h}$ periods. The increased accuracy could also be due to the model for pigs being more accurate than for broilers. Phillips et al. (1998) and Sneath et al. (1997) achieved within $15 \%$ agreement between the measured ventilation rate and $\mathrm{CO}_{2}$ method in controlled tests, however this was conducted under controlled conditions. Hinz and Linke (1998) also found the best agreement with $\mathrm{CO}_{2}$ method was between $12 \mathrm{~h}$ night time averages and true AERs. This was only the case on one out of the three periods (18.08.04), where the accuracy was increased by $23 \%$ from the day time average.

The mass balance model results were variable. The heat and moisture balance models performed better than the $\mathrm{CO}_{2}$ mass balance model. The lowest true AER occurred on the 25.08 .04 (median $8,33 / \mathrm{h}$ ) on this period, the heat balance $24 \mathrm{~h}$ estimation was $-14 \%$ below the true 24h AER. The second lowest true AER was measured on the 18.08.04 (median 9,82/h), the moisture balance $24 \mathrm{~h}$ median was $+5 \%$ the true $24 \mathrm{~h}$ median AER. The moisture balance $24 \mathrm{~h}$ median was also only $+14 \%$ true AER median on the 08.09.04 (true AER median 10,80/h). Therefore, the 14.09.04 recorded the lowest level of accuracy between the mass balance AERs and the true AERs, where all 24h median mass balance AERs were $>+100 \%$ the true AER. The true AER on the 14.09 .04 was only $7,5 \%$ higher than the 08.09 .04 , therefore the difference was not so large. It appears that the small increase in ventilation on the 14.09.04, may have been too much for the mass balance models, as they all were too high. Overall, the moisture balance performed the best throughout the period. This could be due to the environmental conditions within the stall. Because of the high negative pressure within the stall, the litter was always dry, therefore minimal moisture contributions from the litter may have improved the accuracy of the models. Perhaps these conditions were ideal for the moisture balance model. The heat balance was also favoured by these conditions, the results were overall not as accurate as the moisture balance, but on 3 of the days recorded accuracy values ranging from $-24-19 \%$. This could also be due to a good U value calculation, accounting well for the heat transmission from the building. The heat and moisture production equations were recently tested by Chepete (2004), it was found that the equations were in good agreement with the true values, these results confirm this. The $\mathrm{CO}_{2}$ method did not perform so well, recording a range from $+43-55 \%$.on 3 of the measurement days, the lower inaccuracy of the $\mathrm{CO}_{2}$ method results may indicate that the production equations are in need of up dating. 
Because the $\mathrm{CO}_{2}$ production is varying diurnally, it can be concluded that calculation of ventilation flow based on $\mathrm{CO}_{2}$ production can only be done on a $24 \mathrm{~h}$ basis, unless the diurnal variation of $\mathrm{CO}_{2}$ is taken into account, by correcting daily mean values for the animal activity (Van Ouwerkerk \& Pedersen 1994). It was proposed by Li et al. 2005 that by using bi-hourly and longer averaging integration times with the $\mathrm{CO}_{2}$ mass balance calculations the results could be improved by a dampening down of the dynamic effects of the system on the derived ventilation rate. Both of these measures were implemented into the mass balance models in this study. Once again, only the 4 measurement periods with the validation technique were used. On the 25.08.04, the $\mathrm{CO}_{2}$ and heat balance model results were slightly improved with the $2 \mathrm{~h}$ intervals. The correlation coefficient of $\mathrm{CO}_{2}$ model results against the true AERs increased $\left(\mathrm{r}^{2}=0,78\right.$ 0,80 ), and the accuracy increased by $1 \%$. The heat balance correlation coefficient decreased marginally $\left(r^{2}=0,66-0,65\right)$, but the accuracy increased by $3 \%$. Furthermore, the accuracy and $\mathrm{r}^{2}$ value of the heat balance with $2 \mathrm{~h}$ interval and activity also increased $\left(\mathrm{r}^{2}=0,92-0,94\right)$ and accuracy increased by $2 \%$. The moisture balance on the 14.09 .04 recorded the largest improvement with $2 \mathrm{~h}$ interval and activity, the correlation coefficient increased $\left(r^{2}=0,47-0,76\right)$ and the accuracy slightly by only $2 \%$. Although, these improvements are minor, relationships could be observed with all models, particularly the heat and moisture balance models.

In conclusion, the tracer gas method did not record realistic results throughout the measurement periods due to insufficient dosing volumes, and perhaps because of the high density of pure $\mathrm{SF}_{6}$ tracer gas. However, the tracer gas method was able to provide some interesting information regarding the air flow distribution beneath the exhaust chimney stack, and provided some insight into the need of using larger tracer gas volumes in experiments to reduce the error effects from sinks within the air space. Because of the large air exchange rates which occurred in the mechanically ventilated livestock house, larger tracer gas dosage volumes are necessary to obtain realistic results. Pressure measurements undertaken in the $\mathrm{SF}_{6}$ sink zone and within the stall would be interesting, as well as more sample locations to check the air distribution patterns within the stall.

The heat and moisture mass balance models performed better than the $\mathrm{CO}_{2}$ mass balance model, and were generally within range of the true ventilation rates except for 
the last day when the highest AER results were measured. The dry litter conditions caused by the high under pressure may have been the cause for the good heat and moisture balance results. Slight improvements were evident with the incorporation of animal activity and $2 \mathrm{~h}$ intervals into the mass balance models, but more measurement periods would be necessary to confirm this.

The true AERs recorded high correlation coefficients with the outside temperatures indicating the highest measured AERs occurred during the day, as would be expected. Furthermore, the true AERs were within range of other studies and indicated that the recommended ventilation rates are too high. 


\section{Chapter}

\section{General conclusions and further research}

\subsection{General conclusions and further research}

The mass balance results were able to provide a basic $24 \mathrm{~h}$ estimate in the hot summer conditions when corrections were applied, weather conditions were assessed and only when all 3 mass balance models were calculated. Under hot conditions the $\mathrm{CO}_{2}$ method was more reliable and under conditions of high ventilation rates the heat and moisture mass balances performed better.

The constant injection tracer gas method calculated AERs using a minimum of 6 samples located within a section which promoted air/tracer gas mixing. Because of the constant weather conditions, low AERs in winter, transverse wind directions and heat buoyancy forces the tracer gas mixed well with the livestock house air and reasonable results were obtained, within range of comparative studies.

The calculated tracer gas AERs were in agreement with weather conditions and correlated with wind speeds $\left(r^{2}=0,47\right)$ and outside temperatures $\left(r^{2}=0,73\right)$.

The heat and moisture mass balance models were also correlated with tracer gas method results $\left(r^{2}=0,73,0,71\right.$, respectively) and wind speeds $\left(r^{2}=0,84\right.$ and 0,86 , respectively). The mass balance AERs were higher, but within range of the tracer gas method.

The true AERs measured from the mechanically ventilated broiler house were highly correlated with outside temperatures $\left(r^{2}=0,95\right)$ and were within range of other studies. 
The mass balance models recorded high $\mathrm{r}^{2}$ values with the true AERs, however more important was the accuracy. The moisture and heat balances were more accurate than the $\mathrm{CO}_{2}$ mass balance model, $+5 \%,-19 \%$ and $+43 \%$, of the $24 \mathrm{~h}$ true AER means, respectively.

Implementing $2 \mathrm{~h}$ intervals and activity improved the calculations, however not enough measurement periods were tested.

The tracer gas method did not function in the mechanically ventilated broiler house because the dosage volumes were too low.

More research should be conducted with the use of tracer gas methods and the air mixing section in naturally ventilated livestock buildings, to further investigate whether tracer gas and air mixing was improved, i.e. with more sample locations within and outside this section.

Furthermore, the degree of inlet and outlet dimension opening should be continuously measured throughout experiments, to correlate better the effects from wind speed and air inlet surface area with calculated AERs.

More research, is necessary involving tracer gas techniques in negative pressure mechanically ventilated livestock houses. To determine what concentration of tracer gas provides ideal tracer/air mixing and even distribution.

Larger studies need to be conducted on the mass balance models, more information is needed for the sometimes highly accurate and inaccurate results calculated by these models.

The use of animal activity and $2 \mathrm{~h}$ interval with the mass balance models showed some promise, these should be both further investigated. 


\subsection{Zusammenfassung}

Es wurden die Luftwechselraten von zwei Masthühnerställen üblicher Betriebsgröße kalkuliert. Bei dem ersten Stall handelte es sich um einen freigelüfteten Louisiana Stall und der zweite untersuchte Stall war ein zwangsbelüfteter Stall. Am freigelüfteten Stall wurden unter warmen Sommerbedingungen die $\mathrm{CO}_{2^{-}}$, Wärme- und LuftfeuchteMassenbilanzmodelle eingesetzt und bewertet. Die aufgrund hoher Temperaturen und hoher Luftwechselraten korrigierten Massenbilanzmodelle ergaben nachvollziehbare Luftwechselraten. Die Massenbilanzmodelle wurden im darauf folgenden Herbst neben einer Tracergas-Methode, die nur mit sechs Messpunkten im Stall durchgefüht wurde, erneut eingesetzt. Die gemessenen Ventilationsraten waren niedrig, zeigten aber eine signifikante Korrelation mit den Außentemperaturen $\left(\mathrm{r}^{2}=0,73\right)$ und den Windgeschwindigkeiten $\left(\mathrm{r}^{2}=0,47\right)$. Die Ventilationsraten lagen mit nur einer Ausnahme über den Mindestanforderungen für Wintersituationen. An dem Tag an dem die Anforderungen nicht erfüllt wurden herrschten niedrige Windgeschwindigkeiten und wechselnde Windrichtungen.

Die Ergebnisse der Tracergas-Methode korrelierten mit der Wärme- und LuftfeuchteMassenbilanzmethode $\left(\mathrm{r}^{2}=0,73\right.$ bzw. 0,71) und die sich daraus ergebenden Luftwechselraten lagen in der gleichen Größenordnung.

Im zwangsbelüfteten Stall wurden die Luftwechselraten mittels Differenzdruckmessung, konstanter Tracergas-Injektion und der Massenbilanzmethode ermittelt. Die mit dem Differenzdrucksensor gemessenen Abluftraten korrelierten hoch $\left(\mathrm{r}^{2}=0,95\right)$ mit den Luftwechselraten und den Außentemperaturen. Die Ergebnisse wurden validiert und als tatsächliche Luftwechselraten $\mathrm{zu}$ Grunde gelegt. Die Ergebnisse aus den $\mathrm{CO}_{2-}$, Wärme- und Luftfeuchte- Massenbilanzmodellen wurden mit den tatsächlichen Luftwechselraten verglichen. Die Ergebnisse der $\mathrm{CO}_{2}$ Massenbilanz korrelierte gut mit der Wärme- und

Luftfeuchte- Massenbilanz $\left(\mathrm{r}^{2}=0,91\right.$ bzw. 0,64). Die geringsten Abweichungen von der tatsächlichen Luftrate lagen für die $\mathrm{CO}_{2}$-Massenbilanz bei $54 \%$, für die WärmeMassenbilanz bei -14\% und für die Luftfeuchte-Massenbilanz bei 5\%. Die Genauigkeit der Massenbilanzmethode wurde durch die Betrachtung der Tages- und Nachtmittelwerte der tatsächlichen Luftwechselraten geprüft. Es konnten keine besseren Übereinstimmungen festgestellt werden. Weiterhin wurde geprüft, inwieweit die Einbeziehung der Aktivität der Tiere und Messungen im Zweistundenintervall die 
Ergebnisse der Massenbilanzmethode beeinflussen. In einigen Fällen konnten bessere Übereinstimmungen mit den tatsächlichen Luftwechselraten gefunden werden.

Die im zwangsbelüfteten Stall eingesetzte Tracergas-Methode ergab keine nachvollziehbaren Ergebnisse. Die geringe Vermischung des Tracergases mit der Luft und ein starker Abfall der $\mathrm{SF}_{6}$ Konzentration direkt unter den Abluftkaminen fühten zu einer Unterschätzung der Luftwechselraten. 


\subsection{Summary}

Air exchange rates (AERs) were calculated from 2 full sized broiler houses. The first broiler house was a Louisiana stall (natural ventilation) and the second a mechanically ventilated stall. The following methods were tested in the naturally ventilated livestock house. Under hot summer conditions the $\mathrm{CO}_{2}$, heat and moisture mass balance models were assessed. Because of the hot temperatures and high AERs, mass balance model results were corrected, reasonable AER estimates were obtained. In the autumn, a tracer gas method was set up with only 6 sampling locations, mass balance models were also tested. The measured ventilation rates were low, but recorded significant correlation coefficients with outside temperatures $\left(r^{2}=0,73\right)$, wind speeds $\left(r^{2}=0,47\right)$ and were above the minimum recommended winter ventilation rates, except on 1 day when the wind speeds were very low and wind directions random. The tracer gas method results were correlated with the heat and moisture mass balance model results $\left(r^{2}=0,73\right.$ and 0,71 , respectively) and the calculated AERs were within range of each other.

The following methods were tested in a mechanically ventilated broiler house; pressure flow sensor, constant tracer gas injection and the mass balance models. Air volume discharges were accurately quantified with the pressure flow sensor, a high correlation $\left(r^{2}=0,95\right)$ between AERs and outside temperatures was recorded. These measured results were validated and considered to be the true AERs. The $\mathrm{CO}_{2}$, heat and moisture mass balance models were validated against the true AERs. The mass balance results were unpredictable, sometimes very accurate and other times out of range. The $\mathrm{CO}_{2}$ mass balance results at times correlated well with the heat and moisture balance results $\left(\mathrm{r}^{2}=0,91\right.$ and 0,64 , respectively). At best, the average $24 \mathrm{~h} \mathrm{CO}_{2}$ mass balance results were $+54 \%$ above the true AERs $\left(r^{2}=0,78\right)$, the heat balance results $-14 \%$ below $\left(r^{2}=0,66\right)$ and moisture balance $+5 \%$ above $\left(r^{2}=0,61\right)$. To compare the accuracy of the mass balance models on a finer scale, day and night time averages from the true AERs were compared with the mass balance model results, no trends were observed. Methods of improving the mass balance results by incorporating bird activity into the model to account for diurnal variation, and using $2 \mathrm{~h}$ intervals instead of $1 \mathrm{~h}$ were tested. The mass balance results improved only sometimes with these amendments. Due to poor tracer gas/air mixing the tracer gas method did not obtain reasonable results. $\mathrm{A} \mathrm{SF}_{6}$ sink 
was identified, located directly beneath the exhaust chimneys this depressed the air exchange rate results. 


\section{Chapter}

\section{References}

Albright, L. D. (1990) Environment control for animals and plants. The American Society of Agricultural Engineers, De Vore-Hansen (Ed), Michigan

Aarnink, A. J. A., Van Ouwerkerk, E. N. J. and Verstegen, M. W. A. (1992) A mathematical model for estimating the amount and composition of slurry from fattening pigs. Livestock production science $\underline{31}, 133-147$

Barber, E. M. and Ogilvie, J. R. (1982) Incomplete mixing in ventilated airspaces. Part 1. Theoretical considerations. Canadian agricultural engineering $\underline{24}, 25-29$

Barber, E. M. and Ogilvie, J. R. (1984) Interpretation of tracer gas experiments in ventilation research. Journal of Agricultural Engineering Research 30, 57-63

Beek, G. and Van Beeking, F. F. E. (1992) Carbon dioxide emissions of litter in poultry houses. Proceedings World Poultry Congress, Amsterdam, 20-24 September 1992, p. $277-281$

Berckmans, D., Vandenbroeck, Ph. and Goedseels, V. (1991) Sensor for continuous measurements of the ventilation rate in livestock buildings. Indoor air, 3, 323-336 
Brehme, G. and Krause, K. H. (2002) Compartmental airflow simulation in stables with natural ventilation.

http://www.dspace.library.cornell.edu/bitstream/1813/121/46/BC+01+003b.pdf

Bruce, J. M. (1986) Theory of natural ventilation due to heat buoyancy and wind. In:

Proceedings of C.I.G.R. seminar on pig, rabbit and small birds species housing, Rennes, France, 8-11 September 1986, Vol. I I, CIGR, Merelbeke, p 1-9

Carpenter, G. A. (1974) Ventilation of buildings for intensively housed livestock. In: Monteith, J. L. and Mount, L. E. Heat loss from animals and Man London, Butterworths, pp. 389-403

Chepete, H. J. and Xin, H. (2004) Heat and moisture production of poultry and their housing systems: Literature review. Trans. ASHAE 110 (2): 448-466.

Choiniere, Y., Munroe, J. A. and Suchorski-Tremblay, A. (1992) "Natvent" software predictions versus full-scale estimates of wind induced natural ventilation in a swine barn. CSAE Canada, paper 92-202

CIGR, (1984) Climatization of animal houses. Working group on climatization of animal houses, CIGR and SFBI, Aberdeen, Scotland GB, 72 p

CIGR, EurAgEng. (2002). Fourth Report of Working Group on: Climatization of Animal Houses - Heat and moisture production at animal and housing levels. Pedersen, S. and Sällvik, K. (Eds). Research Centre Bygholm, Danish Institute Agricultural Sciences, Horsens, $45 \mathrm{p}$ www.agrsci.dk/jbt/spe/CIGRreport

Clark, J. A. and McArthur, A. J. (1994) Heat exchanges. In: Wathes C.M. and Charles D.R. (Eds): Livestock Housing. Wallingford, CAB International, p97-122

Curtis, S. E. (1983) Environment management in animal agriculture. Iowa State University Press, Ames, Iowa, 409 p 
Demmers, T. G. M (1997). Ventilation of livestock buildings and ammonia emissions. $\mathrm{PhD}$ Thesis, University of Nottingham, United Kingdom.

Demmers, T. G. M., Burgess, L. R., Phillips, V. R., Clark, J. A. and Wathes, C. M. (2000) Assessment of techniques for measuring the ventilation rate, using an experimental building section. Journal of Agricultural Engineering Research 76, 71-81

Demmers, T. G. M., Burgess, L. R., Short, J. L., Phillips, V. R., Clark, J. A. and Wathes, C. M. The use of pressure difference measurements in determining ammonia emissions from a naturally ventilated UK beef building. Internal document. Silsoe research institute, Bedford, England

Demmers, T. G. M., Burgess, L. R., Short, J. L., Phillips, V. R., Clark, J. A., and Wathes, C. M. (1998) First experiences with methods to measure ammonia emissions from naturally ventilated cattle buildings in the U.K. Atmospheric Environment $\underline{32}$ (3), 285-293

Demmers, T. G. M., Phillips, V. R., Short, L. S., Burgess, L. R., Hoxey, R. P. and Wathes, C. M. (2001) Validation of ventilation rate measurement methods and the ammonia emission from naturally ventilated dairy and beef buildings in the United Kingdom. Journal of Agricultural Engineering Research 79 (1), 107-116

Dietz, R. N., Cote, E. A. (1973) Tracing atmospheric pollutants by gas chromatographic determination of gas air tracers. Environmental Science and Technology 7, 338-342

DIN 18910 (1998). Wärmeschutz geschlossener Ställe. Berlin-Köln, Beuth DIN 18910 (2004). Wärmeschutz geschlossener Ställe. Berlin-Köln, Beuth Dore, C. J., Jones, B. M. R., Scholtens R., Huis in`t Veld, J. W. H., Burgess, L. R. and Phillips, V. R. (2004) Measuring ammonia emission from livestock buildings and manure stores-part 2: Comparative demonstrations of three methods on the farm. Atmospheric Environment $\underline{38}, 3017-3024$ 
Hartung, J. (1994) Environment and animal health. In: Wathes C.M. and Charles D.R. (Eds): Livestock Housing. Wallingford, CAB International, p25-48

Hinz, T. and Linke, S. (1998) A comprehensive experimental study of aerial pollutants in and emissions from livestock buildings. Part 1: Methods. Journal of Agricultural Engineering Research 70, 111-118

Hinz, T. and Linke, S. (1998) A comprehensive experimental study of aerial pollutants in and emissions from livestock buildings. Part 2: Methods. Journal of Agricultural Engineering Research 70, 119-129

Kaharabata, S., Schuepp, P. and Desjardins, R. L. (2000) Estimating methane emissions from dairy cattle housed in a barn and feedlot using an atmospheric tracer.

Environmental science technology $\underline{34}$, 3296-3302

Kaul, P., Maltry, W., Muller, H. J. and Winter (1975) Scientific technical principles for the control of the environment in livestock houses and stores. Translation 430, Br. Soc. Res. Agric. Eng., Nat. Inst. Agric. Eng., Silsoe.

Leonard, J. J., Feddes, J. J. R. and McQuitty, J. B. (1984) Measurement of ventilation rates using a tracer gas. Canadian agricultural engineering, 26 (1), 49-51

Li, H., Xin, H., Liang, Y., Gates, R.S., Wheeler, E. F. and Heber, A. J. (2005) Comparison of direct and indirect ventilation rate determinations in layer barns using manure belts. Trans. ASAE, $\underline{48}$ (1), 367-372

Maton, A., Daelemans, J. and Lambrecht, J. (1985). Some fundamentals concerning the construction of animal houses and the building materials to be used. In: Developments in Agricultural Engineering 6, Housing of animals. Amsterdam, Elsevier p 27-85

Marik, T. and Levin, I. (1996) A new tracer experiment to estimate the methane emissions from a dairy cow shed using sulphur hexafluoride $\left(\mathrm{SF}_{6}\right)$. Global biochemical cycles $\underline{10}(3), 413-418$ 
Müller, H. J. and Möller, B. (1998) The determination of emission streams at different animal houses. In: AgEng Oslo 98, EurAgEng, p.1-7

Myers, J. L and Well, A. Research design and statistical analysis. Lawrence Erlbaum Associates (eds). Manwah, 2003

NBCE-CT-79. Spannish norm 1979. Construction basic standards. Heat conditions of buildings. Ministerio de Obras Publicas y Urbanismo.

NT VVS 048 (1985): Total flow rate of air - continuous measurement in buildings Nordtest method. http://www.nordicinnovation.net/nordtestfiler/vvs048.pdf

Owen, J. E. Structures and materials. In: Livestock Housing (Wathes C M; Charles D R eds) pp. 183-246. Wallingford: CAB International, 1994

Pearson, C. C. and Owen, J. E. (1994). The resistanace to air flow of farm building ventilation components. Journal of agricultural engineering research, 57, 53-65

Pedersen, J., Chwalibog, A. and Eggum, B.O. 1985. Measurement of broiler latent and sensible heat production. Dannish Institute of Animal Science. Report No. 573

Pedersen, S. and Pedersen, C. B. (1995) Animal activity measured by infrared detectors. Journal of Agricultural Engineering Research 61, 239-246

Pedersen, S., Takai, H., Johnsen, J. O., Metz, J. H. M., Groot Koerkamp, P. W. G., Uenk, G. H., Phillips, V. R., Holden, M. R., Sneath, R. W., Short, J. L., White, R. P., Hartung, J., Seedorf, J., Schöder, M., Linkert, K. H. and Wathes, C. M. (1998) A comparison of three balance methods for calculating ventilation rates in livestock buildings. Journal of Agricultural Engineering Research 므, 25-37

Pedersen, S. and Takai, H. 2001. Diurnal variation in animal heat production in relation to animal activity. Internal publication. Department of agricultural engineering, Danish institute of agricultural sciences, Horsens, Denmark 
Phillips, V. R., Holden, M. R., Sneath, R. W., Short, J. L., White, R. P., Hartung, J., Seedorf, J., Schöder, M., Linkert, K. H., Pedersen, S., Takai, H., Johnsen, J. O., Koerkamp, P. W. G., Uenk, G. H., Scholtens, R., Metz, J. H. M. and Wathes, C. M. (1998) The development of robust methods for measuring concentrations and emission rates of gaseous and particulate air pollutants in livestock buildings. Journal of Agricultural Engineering Research 무, 11-24

Phillips, V. R., Lee, D. S., Scholtens, R., Garland, J. A. and Sneath, R. W. (2000) A review of methods for measuring emission rates of ammonia from livestock buildings and slurry or manure stores, Part 2: monitoring flux rates, concentrations and airflow rates. Journal of Agricultural Engineering Research $\underline{78}$ (1), 1-14

Randall, J. M. (1981) Ventilation system design. In: Clark, J. A., Environmental Aspects of housing for animal productions, London, Butterworths, p. 351-369 Randall, J. M. and Boon, C. R. (1994) Ventilation and control systems. In: Wathes C.M. and Charles D.R. (Eds): Livestock Housing. Wallingford, CAB International, p149-182

Schauberger, G., Piringer, M. and Petz, E. (2000) Steady state balance model to calculate the indoor climate of livestock buildings demonstrated for finnishing pigs. Bio-meteorology, 43 154-162

Scholtens, R., Dore, C. J., Jones, B. M. R., Lee, D. S. and Phillips, V. R. (2004) Measuring ammonia emission rates from livestock buildings and manure stores-part 1: development and validation of external tracer ratio, internal tracer ratio and passive flux sampling methods. Atmospheric Environment 38, 3003-3015

Scholtens, R. and van’t Ooster, A. (1994) Performance and accuracy of methods for measuring natural ventilation rates and ammonia emissions from naturally ventilated livestock houses. In: Ag. Eng. '94 Conference. Agricultural engineering Milano, p. 1-13

Seedorf, J., Hartung, J., Schöder, M., Linkert, K. H., Pedersen, S., Takai, H., Johnsen, J. O., Metz, J. H. M., Koerkamp, P. W. G., Uenk, G. H., Phillips, V. R., Holden, M. R., Sneath, R. W., Short, J. L., White, R. P., and Wathes, C. M. (1998) Concentrations and 
emissions of airborne endotoxins and microorganisms in livestock buildings in northern europe. Journal of Agricultural Engineering Research $\underline{70}$, 97-109

Seedorf, J., Hartung, J., Schöder, M., Linkert, K. H., Pedersen, S., Takai, H., Johnsen, J. O., Metz, J. H. M., Koerkamp, P. W. G., Uenk, G. H., Phillips, V. R., Holden, M. R., Sneath, R. W., Short, J. L., White, R. P., and Wathes, C. M. (1998) A survey of ventilation rates in livestock buildings in northern europe. Journal of Agricultural Engineering Research $\underline{70}$, 39-47

Seipelt, F., Ross, A., Steffens, G. and Van den Weghe, H. (1998) Monitoring of gaseous from naturally ventilated dairy houses using the tracer gas technique using the rate of decay method. In: International conference: construction, engineering and environment in livestock farming, Freising-Weihenstephan, p. 69-74

Sherman, M. H. (1988) Uncertainty in air flow calculations using tracer gas measurements. Submitted to Building and Environment. Internet PDF document.

Sherman, M. H. (1988) On estimation of multizone ventilation rates from tracer-gas measurements. Submitted to Building and Environment. Internet PDF document.

Sneath, R. W., Phillips, V. R., Demmers, T. G. M., Burgess, L. R., Short J. L. and Welch, S. K. (1997) Long term measurements of greenhouse gas emissions from UK livestock buildings. In: Livestock Environment V, Proceedings of the fifth international symposium, Bloomongton, Minnesta, p. 146-153

Snell, H. G. J., Seipelt, F. and Van den Weghe, H. F. A. (2003) Ventilation rates and gaseous emissions from naturally ventilated dairy houses. Biosystems Engineering $\underline{86}$ (1), 67-73

Sousa, P. and Pedersen, S. (2004) Ammonia emission from fattening pigs in relation to animal activity and carbon dioxide production. Internal publication. Department of agricultural engineering, Danish institute of agricultural sciences, Horsens, Denmark

Straw, B. (1992) Controlling pneumonia in swine herds. Veterinary-Medicine $\underline{87}$, 78-86 
Stroem, J. S. (1978) Heat loss from cattle, swine and poultry as basis for design of environmental control systems in livestock buildings (in Danish). SBILandbrugsbyggeri 55, Danish Building Research Institute, Denmark

Takai, H., Pedersen, S., Johnsen, J. O., Metz, J. H. M., Koerkamp, P. W. G., Uenk, G. H., Phillips, V. R., Holden, M. R., Sneath, R. W., Short, J. L., White, R. P., Seedorf, J., Hartung, J., Schöder, M., Linkert, K. H. and Wathes, C. M. (1998) Concentrations and emissions of airborne dust in livestock buildings in Northern Europe 70, 59-77

Van't Klooster, C. E. and Heitlager, B. P. (1994) Determination of minimum ventilation rate in pig houses with natural ventilation based on carbon dioxide balance. Journal of Agricultural Engineering Research 57, 279-287

VDI 4300 (2001): Indoor air pollution measurement, Measurement of the indoor air exchange rate. Verein Deutscher Ingenieure, Part 7 July 2001, Published by Beuth, Berlin.

Van't Ooster, A. (1994) Using natural ventilation theory and dynamic heat balance modelling for real time prediction of ventilation rates in naturally ventilated livestock houses. In: XII CIGR World Congress and Conference on Agricultural Engineering, Milan

Van Ouwerkerk, E.N.J. (1989) Modelling the heat balance of pigs at animal and housing levels. In: Second report of the CIGR working group on Climatization of Animal Houses, St. Univ. of Ghent, p. 1-17

Van Ouwerkerk, E. N. J. and Pedersen, S. (1994) Application of $\mathrm{CO}_{2}$ mass balance method to evaluate ventilation rates in livestock buildings. In: Proceedings XII World Congress on Agricultural Engineering, Milano, p. 516-529 


\section{Appendix}

\section{Experiment 1 Tab. 1 AER results (03.08.03)}

\begin{tabular}{|c|c|c|c|c|c|c|c|c|c|c|c|c|c|c|c|c|c|}
\hline Date & Time & $\begin{array}{c}\mathrm{CO}_{2} \\
\text { Balance } \\
\text { (corrected) }\end{array}$ & $\begin{array}{c}\mathrm{CO}_{2} \text { Balance } \\
\text { (uncorrected) }\end{array}$ & $\begin{array}{l}\mathrm{CO}_{2} \\
\mathrm{CV} \\
(\%)\end{array}$ & $\begin{array}{l}\Delta \mathrm{CO} 2 \\
(\mathrm{ppm})\end{array}$ & $\begin{array}{c}\text { Heat } \\
\text { Balance } \\
\text { (corrected) }\end{array}$ & $\begin{array}{l}\text { Heat Balance } \\
\text { (uncorrected) }\end{array}$ & $\begin{array}{c}\Delta \\
\text { Temp } \\
\left({ }^{\circ} \mathrm{C}\right)\end{array}$ & $\begin{array}{c}\text { Moisture } \\
\text { Balance }\end{array}$ & $\begin{array}{c}\text { Moisture } \\
\text { Balance } \\
\text { (uncorrected) }\end{array}$ & $\begin{array}{c}\Delta \text { water } \\
\text { content } \\
(\mathbf{k g} \\
\text { water } / \mathrm{m}^{3} \\
\text { dry air }\end{array}$ & $\begin{array}{l}\text { O.Temp } \\
\left({ }^{\circ} \mathrm{C}\right)\end{array}$ & $\begin{array}{l}\text { I.Temp } \\
\left({ }^{\circ} \mathrm{C}\right)\end{array}$ & $\begin{array}{c}\text { O.Humid } \\
(\%)\end{array}$ & $\begin{array}{l}\text { I. Humid } \\
(\%)\end{array}$ & $\begin{array}{l}\text { Wind } \\
\text { speed } \\
\left(\mathrm{mS}^{-1}\right)\end{array}$ & $\begin{array}{c}\text { Wind } \\
\text { Direction } \\
\left(^{\circ}\right)\end{array}$ \\
\hline 03.08 .03 & 00:00 & 36,27 & 36,27 & 0,7 & 186,0 & 14,75 & 14,75 & 4,5 & 20,81 & 20,81 & 0,00166 & 19,9 & 24,4 & 77,7 & 67,8 & 0 & 0 \\
\hline 03.08 .03 & 01:00 & 37,35 & 37,35 & 0,7 & 180,6 & 12,72 & 12,72 & 5,0 & 15,89 & 15,89 & 0,00219 & 19,8 & 24,8 & 77,1 & 67,9 & 0 & 0 \\
\hline 03.08 .03 & 02:00 & 37,84 & 37,84 & 1,1 & 178,3 & 11,52 & 11,52 & 5,6 & 17,76 & 17,76 & 0,00195 & 18,9 & 24,5 & 81,6 & 68,1 & 0 & 1 \\
\hline 03.08 .03 & 03:00 & 34,57 & 34,57 & 0,5 & 195,2 & 9,94 & 9,94 & 6,4 & 16,52 & 16,52 & 0,00209 & 17,8 & 24,2 & 86,7 & 69,3 & 0 & 0 \\
\hline 03.08 .03 & 04:00 & 39,03 & 39,03 & 0,9 & 172,9 & 9,81 & 9,81 & 6,4 & 15,41 & 15,41 & 0,00225 & 17,9 & 24,3 & 87,4 & 70,4 & 0 & 0 \\
\hline 03.08 .03 & 05:00 & 39,86 & 39,86 & 1,4 & 169,3 & 9,29 & 9,29 & 6,8 & 14,90 & 14,90 & 0,00232 & 17,4 & 24,2 & 89,7 & 71,0 & 0 & 352,5 \\
\hline 03.08.03 & 06:00 & 42,57 & 42,57 & 1,7 & 158,5 & 10,56 & 10,56 & 6,2 & 17,12 & 17,12 & 0,00202 & 17,6 & 23,8 & 89,8 & 71,9 & 0 & 0 \\
\hline 03.08 .03 & 07:00 & 44,90 & 78,93 & 1,0 & 85,5 & 17,28 & 17,28 & 3,9 & 35,41 & 35,41 & 0,00098 & 20,3 & 24,2 & 82,2 & 69,9 & 0,1 & 340,7 \\
\hline 03.08 .03 & 08:00 & 44,90 & 130,03 & 3,8 & 51,9 & 23,60 & 11,98 & 1,7 & 50,20 & 177,70 & 0,00020 & 23,1 & 24,8 & 73,3 & 67,3 & 0,2 & 28,6 \\
\hline 03.08 .03 & 09:00 & 44,90 & 253,68 & 1,0 & 26,6 & 23,60 & 2,80 & 0,1 & 50,20 & $-74,75$ & $-0,00047$ & 25,1 & 25,2 & 65,2 & 62,5 & 1,1 & 60,4 \\
\hline 03.08 .03 & $10: 00$ & 44,90 & 390,37 & 0,2 & 17,3 & 23,60 & $-46,80$ & $-1,5$ & 50,20 & $-33,13$ & $-0,00106$ & 27,2 & 25,7 & 54,1 & 53,9 & 1,7 & 77,3 \\
\hline 03.08 .03 & $11: 00$ & 44,90 & 246,47 & 4,5 & 27,4 & 23,60 & $-32,75$ & $-2,0$ & 50,20 & $-32,86$ & $-0,00107$ & 28,8 & 26,8 & 50,6 & 52,0 & 1,5 & 73,3 \\
\hline 03.08 .03 & $12: 00$ & 44,90 & 352,37 & 2,6 & 19,1 & 23,60 & $-25,60$ & $-2,3$ & 50,20 & $-32,23$ & $-0,00111$ & 30,3 & 28,0 & 46,0 & 48,1 & 1,4 & 82 \\
\hline 03.08 .03 & $13: 00$ & 44,90 & 107,66 & 11,6 & 62,7 & 23,60 & $-20,74$ & $-2,8$ & 50,20 & $-30,42$ & $-0,00118$ & 31,4 & 28,6 & 43,1 & 45,8 & 1,2 & 26,2 \\
\hline 03.08 .03 & $14: 00$ & 44,90 & 58,20 & 10,6 & 115,9 & 23,60 & $-23,58$ & $-2,4$ & 50,20 & $-56,09$ & $-0,00064$ & 31,0 & 28,6 & 43,0 & 46,9 & 1,1 & 344,7 \\
\hline 03.08 .03 & $15: 00$ & 44,90 & 55,06 & 12,7 & 122,5 & 23,60 & $-23,27$ & $-2,3$ & 50,20 & $-65,13$ & $-0,00055$ & 31,6 & 29,3 & 41,3 & 45,1 & 1,1 & 319,5 \\
\hline 03.08 .03 & $16: 00$ & 41,67 & 41,67 & 12,3 & 161,9 & 23,60 & $-24,14$ & $-2,2$ & 50,20 & $-78,25$ & $-0,00046$ & 31,5 & 29,3 & 39,3 & 42,9 & 0,6 & 279,4 \\
\hline 03.08 .03 & $17: 00$ & 44,90 & 44,93 & 10,4 & 150,0 & 23,60 & $-23,73$ & $-2,3$ & 50,20 & $-49,12$ & $-0,00074$ & 31,5 & 29,2 & 38,9 & 41,5 & 1,1 & 263,5 \\
\hline 03.08 .03 & $18: 00$ & 34,63 & 34,63 & 8,1 & 194,8 & 23,60 & $-25,72$ & $-2,2$ & 50,20 & $-116,97$ & $-0,00031$ & 31,0 & 28,8 & 38,2 & 42,1 & 1,2 & 313,8 \\
\hline 03.08 .03 & 19:00 & 29,20 & 29,20 & 8,2 & 231,0 & 23,60 & $-34,66$ & $-1,6$ & 50,20 & $-153,25$ & $-0,00024$ & 30,7 & 29,1 & 39,1 & 41,8 & 0,9 & 308,4 \\
\hline 03.08 .03 & $20: 00$ & 27,84 & 27,84 & 7,3 & 242,3 & 23,60 & $-56,15$ & $-1,1$ & 50,20 & $-83,41$ & $-0,00043$ & 28,7 & 27,6 & 44,7 & 45,7 & 1 & 316,8 \\
\hline 03.08 .03 & $21: 00$ & 27,88 & 27,88 & 6,5 & 242,0 & 23,60 & $-73,55$ & $-0,9$ & 50,20 & $-87,39$ & $-0,00040$ & 26,5 & 25,6 & 51,3 & 52,3 & 0,8 & 335,4 \\
\hline 03.08 .03 & $22: 00$ & 44,90 & 46,21 & 10,4 & 146,0 & 23,60 & 51,46 & 0,3 & 50,20 & 162,01 & 0,00021 & 24,8 & 25,1 & 57,1 & 57,1 & 0,9 & 344,1 \\
\hline 03.08.03 & 23:00 & 44,90 & 58,75 & 6,6 & 114,8 & 23,60 & 53,13 & 1,6 & 48,10 & 48,10 & 0,00072 & 23,2 & 24,8 & 62,8 & 60,6 & 0,5 & 344,6 \\
\hline
\end{tabular}




\section{Experiment $1 \mathrm{Tab} .2 \mathrm{CO}_{2}$ balance results (3.08.03)}

\begin{tabular}{|c|c|c|c|c|c|c|c|c|}
\hline Date & Time & $\begin{array}{c}\text { Inside } \mathrm{CO}_{2} \\
\text { concentration }\end{array}$ & $\begin{array}{l}\text { Corrected } \\
\text { for manure }\end{array}$ & $\Delta \mathrm{CO}_{2}$ & $\begin{array}{c}\mathrm{CO}_{2} \\
\text { productn / } \\
\Delta \mathrm{CO}_{2}\end{array}$ & $\begin{array}{c}\text { Air volume } \\
\text { displacement } \\
\text { m3/h }\end{array}$ & AER /h & $\begin{array}{c}\text { AER } \\
\text { (corrected) }\end{array}$ \\
\hline 3.8 .2003 & 00:00 & 558,3 & 536,0 & 186,0 & 994,59 & 295544,37 & 36,27 & 36,27 \\
\hline 03.08 .03 & 01:00 & 552,7 & 530,6 & 180,6 & 1024,27 & 304362,18 & 37,35 & 37,35 \\
\hline 03.08 .03 & 02:00 & 550,3 & 528,3 & 178,3 & 1037,64 & 308336,54 & 37,84 & 37,84 \\
\hline 03.08 .03 & 03:00 & 567,9 & 545,2 & 195,2 & 947,86 & 281658,38 & 34,57 & 34,57 \\
\hline 03.08 .03 & 04:00 & 544,7 & 522,9 & 172,9 & 1070,15 & 317996,92 & 39,03 & 39,03 \\
\hline 03.08 .03 & 05:00 & 540,9 & 519,3 & 169,3 & 1092,97 & 324777,35 & 39,86 & 39,86 \\
\hline 03.08 .03 & 06:00 & 529,7 & 508,5 & 158,5 & 1167,39 & 346890,17 & 42,57 & 42,57 \\
\hline 03.08 .03 & 07:00 & 453,6 & 435,5 & 85,5 & 2164,18 & 643088,45 & 78,93 & 44,90 \\
\hline 03.08 .03 & 08:00 & 418,6 & 401,9 & 51,9 & 3565,53 & 1059501,41 & 130,03 & 44,90 \\
\hline 03.08 .03 & 09:00 & 392,3 & 376,6 & 26,6 & 6955,97 & 2066973,54 & 253,68 & 44,90 \\
\hline 03.08 .03 & $10: 00$ & 382,6 & 367,3 & 17,3 & 10704,11 & 3180736,05 & 390,37 & 44,90 \\
\hline 03.08 .03 & 11:00 & 393,1 & 377,4 & 27,4 & 6758,41 & 2008268,43 & 246,47 & 44,90 \\
\hline 03.08 .03 & $12: 00$ & 384,5 & 369,1 & 19,1 & 9662,03 & 2871082,42 & 352,37 & 44,90 \\
\hline 03.08 .03 & $13: 00$ & 429,9 & 412,7 & 62,7 & 2952,17 & 877239,60 & 107,66 & 44,90 \\
\hline 03.08 .03 & $14: 00$ & 485,3 & 465,9 & 115,9 & 1595,80 & 474195,01 & 58,20 & 44,90 \\
\hline 03.08 .03 & $15: 00$ & 492,2 & 472,5 & 122,5 & 1509,67 & 448599,41 & 55,06 & 44,90 \\
\hline 03.08.03 & $16: 00$ & 533,2 & 511,9 & 161,9 & 1142,63 & 339535,13 & 41,67 & 41,67 \\
\hline 03.08 .03 & $17: 00$ & 521,0 & 500,2 & 150,2 & 1231,97 & 366080,31 & 44,93 & 44,93 \\
\hline 03.08 .03 & $18: 00$ & 567,5 & 544,8 & 194,8 & 949,51 & 282149,19 & 34,63 & 34,63 \\
\hline 03.08 .03 & $19: 00$ & 605,2 & 581,0 & 231,0 & 800,81 & 237962,14 & 29,20 & 29,20 \\
\hline 03.08 .03 & 20:00 & 617,0 & 592,3 & 242,3 & 763,52 & 226880,62 & 27,84 & 27,84 \\
\hline 03.08 .03 & 21:00 & 616,7 & 592,0 & 242,0 & 764,50 & 227171,20 & 27,88 & 27,88 \\
\hline 03.08 .03 & 22:00 & 516,7 & 496,0 & 146,0 & 1267,11 & 376522,70 & 46,21 & 44,90 \\
\hline 03.08 .03 & 23:00 & 484,2 & 464,8 & 114,8 & 1611,02 & 478716,51 & 58,75 & 44,90 \\
\hline
\end{tabular}




\section{Experiment 1 Tab.3 Heat balance results (3.08.03)}

\begin{tabular}{|c|c|c|c|c|c|c|c|c|c|c|}
\hline Date & Time & $\begin{array}{c}\text { Total } \\
\text { heat } \\
\text { /animal } \\
\left(20^{\circ} \mathrm{C}\right) \mathrm{W}\end{array}$ & $\begin{array}{l}\text { hpu/all } \\
\text { animals }\end{array}$ & $\begin{array}{c}\text { Sensible } \\
\text { heat and } \\
\text { temperature } \\
\text { factors }\end{array}$ & $\begin{array}{l}\text { Sensible } \\
\text { Heat/ all } \\
\text { animals } \\
\text { (W) }\end{array}$ & $\begin{array}{l}\text { Heat loss } \\
\text { Thought } \\
\text { Building } \\
\text { (W) }\end{array}$ & $\begin{array}{c}\text { Calculated } \\
\text { AER } \\
\left(\mathrm{m}^{3} / \mathrm{s}\right)\end{array}$ & $\begin{array}{l}\text { Calculated } \\
\text { AER }\left(\mathrm{m}^{3} / \mathrm{h}\right)\end{array}$ & $\begin{array}{c}\text { Heat balance } \\
\text { AER/h } \\
\text { (uncorrected) }\end{array}$ & $\begin{array}{c}\text { Heat } \\
\text { balance } \\
\text { AER/h } \\
\text { (corrected) }\end{array}$ \\
\hline 3.8 .2003 & 00:00 & 7,45 & 297,15 & 415,51 & 123468,40 & $-10783,54$ & 19,74 & 71076,50 & 13,65 & 14,75 \\
\hline 3.8.2003 & 01:00 & 7,45 & 297,15 & 414,83 & 123265,55 & $-11078,76$ & 19,13 & 68876,72 & 13,23 & 12,72 \\
\hline 3.8.2003 & 02:00 & 7,45 & 297,15 & 417,64 & 124102,90 & $-12861,12$ & 16,34 & 58831,66 & 11,30 & 11,52 \\
\hline 3.8 .2003 & 03:00 & 7,45 & 297,15 & 423,01 & 125697,47 & $-14850,07$ & 14,10 & 50771,37 & 9,75 & 9,94 \\
\hline 3.8 .2003 & 04:00 & 7,45 & 297,15 & 426,04 & 126597,87 & $-14323,49$ & 14,81 & 53315,52 & 10,24 & 9,81 \\
\hline 3.8.2003 & 05:00 & 7,45 & 297,15 & 423,79 & 125930,73 & $-15687,41$ & 13,28 & 47799,46 & 9,18 & 9,29 \\
\hline 3.8 .2003 & 06:00 & 7,45 & 297,15 & 426,91 & 126856,98 & $-14923,45$ & 14,17 & 51016,74 & 9,80 & 10,56 \\
\hline 3.8 .2003 & 07:00 & 7,45 & 297,15 & 415,76 & 123543,11 & $-9844,54$ & 21,82 & 78556,35 & 15,09 & 17,28 \\
\hline 3.8 .2003 & 08:00 & 7,45 & 297,15 & 406,84 & 120892,26 & $-4310,92$ & 51,10 & 183942,16 & 35,33 & 23,60 \\
\hline 3.8 .2003 & 09:00 & 7,45 & 297,15 & 408,00 & 121236,10 & 373,56 & $-615,08$ & $\begin{array}{c}- \\
2214283,01\end{array}$ & $-425,33$ & 23,60 \\
\hline 3.8.2003 & $10: 00$ & 7,45 & 297,15 & 397,52 & 118124,43 & 4163,15 & $-55,50$ & $-199793,61$ & $-38,38$ & 23,60 \\
\hline 3.8.2003 & 11:00 & 7,45 & 297,15 & 369,42 & 109772,70 & 5148,10 & $-42,18$ & $-151835,43$ & $-29,17$ & 23,60 \\
\hline 3.8.2003 & $12: 00$ & 7,45 & 297,15 & 347,03 & 103121,32 & 6489,85 & $-31,91$ & $-114879,42$ & $-22,07$ & 23,60 \\
\hline 3.8 .2003 & $13: 00$ & 7,45 & 297,15 & 327,33 & 97266,55 & 7195,81 & $-27,43$ & $-98742,02$ & $-18,97$ & 23,60 \\
\hline 3.8 .2003 & $14: 00$ & 7,45 & 297,15 & 327,29 & 97255,12 & 6277,84 & $-31,16$ & $-112173,42$ & $-21,55$ & 23,60 \\
\hline 3.8 .2003 & $15: 00$ & 7,45 & 297,15 & 311,84 & 92663,83 & 6249,11 & $-29,91$ & $-107660,52$ & $-20,68$ & 23,60 \\
\hline 3.8.2003 & $16: 00$ & 7,45 & 297,15 & 312,21 & 92773,60 & 6053,80 & $-30,84$ & $-111037,85$ & $-21,33$ & 23,60 \\
\hline 3.8 .2003 & $17: 00$ & 7,45 & 297,15 & 312,11 & 92744,72 & 6045,04 & $-30,88$ & $-111156,46$ & $-21,35$ & 23,60 \\
\hline 3.8.2003 & 18:00 & 7,45 & 297,15 & 316,95 & 94180,72 & 5338,39 & $-35,22$ & $-126799,67$ & $-24,36$ & 23,60 \\
\hline 3.8 .2003 & 19:00 & 7,45 & 297,15 & 311,61 & 92594,49 & 4170,55 & $-43,84$ & $-157814,63$ & $-30,31$ & 23,60 \\
\hline 3.8.2003 & $20: 00$ & 7,45 & 297,15 & 347,58 & 103284,62 & 2882,83 & $-69,58$ & $-250491,76$ & $-48,12$ & 23,60 \\
\hline 3.8 .2003 & 21:00 & 7,45 & 297,15 & 384,85 & 114357,62 & 1349,97 & $-161,94$ & $-582987,26$ & $-111,98$ & 23,60 \\
\hline 3.8 .2003 & $22: 00$ & 7,45 & 297,15 & 404,92 & 120322,07 & $-610,25$ & 370,64 & 1334293,44 & $-32,09$ & 23,60 \\
\hline 3.8.2003 & 23:00 & 7,45 & 297,15 & 416,96 & 123900,41 & $-3097,28$ & 73,69 & 265289,55 & $-34,17$ & 23,60 \\
\hline
\end{tabular}




\section{Experiment 1 Tab.4a Moisture balance results (03.08.03)}

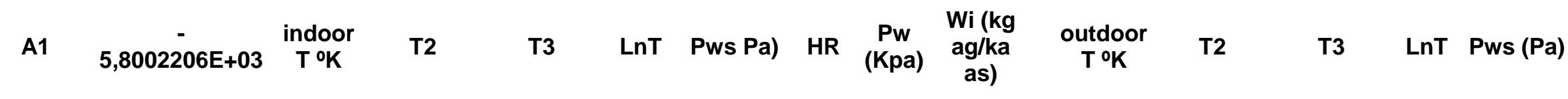

\begin{tabular}{|c|c|c|c|c|c|c|c|c|c|c|c|c|c|c|}
\hline A2 & 1,39 & 297,51 & 88511,33 & 26332875,20 & 5,70 & 3050,03 & 0,69 & 2,10 & 0,01 & 293,05 & 85878,30 & 25166636,55 & 5,68 & 2324,36 \\
\hline A3 & $-0,05$ & 297,93 & 88764,60 & 26445981,63 & 5,70 & 3128,61 & 0,67 & 2,11 & 0,01 & 292,95 & 85819,70 & 25140881,85 & 5,68 & 2309,99 \\
\hline A4 & 0,00 & 297,60 & 88566,34 & 26357427,02 & 5,70 & 3066,96 & 0,67 & 2,06 & 0,01 & 292,05 & 85293,20 & 24909879,79 & 5,68 & 2184,11 \\
\hline A5 & 0,00 & 297,37 & 88426,52 & 26295037,04 & 5,69 & 3024,07 & 0,69 & 2,08 & 0,01 & 290,95 & 84651,90 & 24629471,03 & 5,67 & 2038,46 \\
\hline A6 & 0,00 & 297,49 & 88502,47 & 26328923,37 & 5,70 & 3047,31 & 0,69 & 2,10 & 0,01 & 291,05 & 84710,10 & 24654875,33 & 5,67 & 2051,34 \\
\hline \multirow[t]{2}{*}{ A7 } & 6,55 & 297,36 & 88424,19 & 26293998,05 & 5,69 & 3023,36 & 0,71 & 2,14 & 0,01 & 290,55 & 84419,30 & 24528028,34 & 5,67 & 1987,65 \\
\hline & & 296,96 & 88187,69 & 26188578,45 & 5,69 & 2951,96 & 0,71 & 2,11 & 0,01 & 290,75 & 84535,56 & 24578714,80 & 5,67 & 2012,91 \\
\hline patm (Pa) & 101325,00 & 297,34 & 88409,28 & 26287349,11 & 5,69 & 3018,82 & 0,70 & 2,11 & 0,01 & 293,45 & 86112,90 & 25269831,24 & 5,68 & 2382,62 \\
\hline \multirow[t]{16}{*}{$\mathrm{Ra}$} & 287,06 & 297,91 & 88752,93 & 26440767,06 & 5,70 & 3124,96 & 0,67 & 2,09 & 0,01 & 296,25 & 87764,06 & 26000103,52 & 5,69 & 2827,50 \\
\hline & & 298,37 & 89022,44 & 26561294,27 & 5,70 & 3210,31 & 0,62 & 1,99 & 0,01 & 298,25 & 88953,06 & 26530250,89 & 5,70 & 3188,16 \\
\hline & & 298,90 & 89340,58 & 26703806,25 & 5,70 & 3313,50 & 0,55 & 1,83 & 0,01 & 300,35 & 90210,12 & 27094610,29 & 5,70 & 3609,42 \\
\hline & & 299,99 & 89996,43 & 26998393,53 & 5,70 & 3534,78 & 0,53 & 1,88 & 0,01 & 301,95 & 91173,80 & 27529929,66 & 5,71 & 3962,15 \\
\hline & & 301,11 & 90667,41 & 27300891,86 & 5,71 & 3773,47 & 0,50 & 1,87 & 0,01 & 303,45 & 92081,90 & 27942253,31 & 5,72 & 4319,70 \\
\hline & & 301,77 & 91066,00 & 27481116,74 & 5,71 & 3921,35 & 0,48 & 1,88 & 0,01 & 304,55 & 92750,70 & 28247226,45 & 5,72 & 4599,43 \\
\hline & & 301,71 & 91031,02 & 27465283,40 & 5,71 & 3908,19 & 0,48 & 1,89 & 0,01 & 304,15 & 92507,22 & 28136071,72 & 5,72 & 4495,94 \\
\hline & & 302,42 & 91456,46 & 27658049,31 & 5,71 & 4070,76 & 0,47 & 1,92 & 0,01 & 304,75 & 92872,56 & 28302913,42 & 5,72 & 4651,94 \\
\hline & & 302,40 & 91448,40 & 27654395,78 & 5,71 & 4067,63 & 0,45 & 1,83 & 0,01 & 304,65 & 92811,62 & 28275060,79 & 5,72 & 4625,62 \\
\hline & & 302,35 & 91417,61 & 27640429,39 & 5,71 & 4055,69 & 0,44 & 1,77 & 0,01 & 304,65 & 92811,62 & 28275060,79 & 5,72 & 4625,62 \\
\hline & & 301,97 & 91187,54 & 27536152,75 & 5,71 & 3967,38 & 0,44 & 1,74 & 0,01 & 304,15 & 92507,22 & 28136071,72 & 5,72 & 4495,94 \\
\hline & & 302,30 & 91384,45 & 27625393,92 & 5,71 & 4042,87 & 0,43 & 1,73 & 0,01 & 303,85 & 92324,82 & 28052897,32 & 5,72 & 4419,66 \\
\hline & & 300,79 & 90474,10 & 27213626,95 & 5,71 & 3703,39 & 0,47 & 1,74 & 0,01 & 301,85 & 91113,42 & 27502586,58 & 5,71 & 3939,26 \\
\hline & & 298,73 & 89237,59 & 26657643,79 & 5,70 & 3279,80 & 0,54 & 1,76 & 0,01 & 299,65 & 89790,12 & 26905610,21 & 5,70 & 3463,91 \\
\hline & & 298,26 & 88959,81 & 26533270,96 & 5,70 & 3190,31 & 0,57 & 1,83 & 0,01 & 297,95 & 88774,20 & 26450273,63 & 5,70 & 3131,63 \\
\hline & & 297,96 & 88781,40 & 26453491,83 & 5,70 & 3133,89 & 0,60 & 1,89 & 0,01 & 296,35 & 87823,32 & 26026441,62 & 5,69 & 2844,65 \\
\hline
\end{tabular}


Experiment 1 Tab.4b Moisture balance results (03.08.03)

\begin{tabular}{|c|c|c|c|c|c|c|c|c|c|c|c|c|}
\hline HR & $\begin{array}{l}\mathrm{Pw} \\
(\mathrm{Kpa})\end{array}$ & $\begin{array}{c}\text { Wo (kg } \\
\text { ag/ka as) }\end{array}$ & $\begin{array}{l}\text { Total } \\
\text { heat } \\
\text { /hpu }\end{array}$ & $\begin{array}{c}\text { Sensible } \\
\text { Heat } \\
\text { /animal }\end{array}$ & $\begin{array}{l}\text { Latent } \\
\text { Heat } \\
\text { /animal } \\
\text { (W) }\end{array}$ & $\begin{array}{c}\text { Latent } \\
\text { Heat } \\
\text { lanimal } \\
\text { (Kg } \\
\text { water/s) }\end{array}$ & $\begin{array}{c}\text { Latent } \\
\text { Heat } / 30 \\
000 \\
\text { animal } \\
(\mathrm{Kg} \\
\text { water/s) }\end{array}$ & $\begin{array}{c}\text { AER } \\
\mathrm{Kg} \\
\text { air/s }\end{array}$ & $\begin{array}{l}\text { AER } \\
\mathrm{m} 3 / \mathrm{s}\end{array}$ & AER m3/h & $\begin{array}{c}\text { AER /hr } \\
\text { (uncorrected) }\end{array}$ & $\begin{array}{c}\text { AER } / \mathrm{hr} \\
\text { (corrected) }\end{array}$ \\
\hline 0,78 & 1,81 & 0,01 & 912,83 & 421,54 & 491,28 & 0,0002 & 0,06 & 32,73 & 27,05 & 97390,67 & 18,71 & 20,81 \\
\hline 0,77 & 1,78 & 0,01 & 904,32 & 411,59 & 492,73 & 0,0002 & 0,06 & 28,94 & 23,92 & 86108,92 & 16,54 & 15,89 \\
\hline 0,82 & 1,78 & 0,01 & 910,98 & 419,39 & 491,59 & 0,0002 & 0,06 & 34,12 & 28,19 & 101500,65 & 19,50 & 17,76 \\
\hline 0,87 & 1,77 & 0,01 & 915,68 & 424,86 & 490,82 & 0,0002 & 0,06 & 30,35 & 25,08 & 90299,19 & 17,35 & 16,52 \\
\hline 0,87 & 1,79 & 0,01 & 913,13 & 421,89 & 491,24 & 0,0002 & 0,06 & 31,14 & 25,73 & 92642,16 & 17,80 & 15,41 \\
\hline 0,90 & 1,78 & 0,01 & 915,76 & 424,95 & 490,80 & 0,0002 & 0,06 & 26,48 & 21,88 & 78769,17 & 15,13 & 14,90 \\
\hline 0,90 & 1,81 & 0,01 & 923,72 & 434,17 & 489,55 & 0,0002 & 0,06 & 31,48 & 26,02 & 93662,27 & 17,99 & 17,12 \\
\hline 0,82 & 1,96 & 0,01 & 916,26 & 425,54 & 490,72 & 0,0002 & 0,06 & 64,10 & 52,97 & 190706,55 & 36,63 & 35,41 \\
\hline 0,73 & 2,07 & 0,01 & 904,71 & 412,05 & 492,66 & 0,0002 & 0,06 & 469,20 & 387,76 & 1395953,10 & 268,14 & 50,20 \\
\hline 0,65 & 2,08 & 0,01 & 895,67 & 401,39 & 494,29 & 0,0002 & 0,06 & $-113,47$ & $-93,77$ & $-337582,41$ & $-64,84$ & 50,20 \\
\hline 0,54 & 1,95 & 0,01 & 885,02 & 388,70 & 496,32 & 0,0002 & 0,06 & $-76,35$ & $-63,10$ & $-227170,45$ & $-43,64$ & 50,20 \\
\hline 0,51 & 2,00 & 0,01 & 863,12 & 362,21 & 500,91 & 0,0002 & 0,06 & $-77,22$ & $-63,82$ & $-229737,31$ & $-44,13$ & 50,20 \\
\hline 0,46 & 1,99 & 0,01 & 840,79 & 334,64 & 506,16 & 0,0002 & 0,06 & $-85,29$ & $-70,49$ & $-253768,24$ & $-48,75$ & 50,20 \\
\hline 0,43 & 1,98 & 0,01 & 827,57 & 318,04 & 509,53 & 0,0002 & 0,06 & $-99,85$ & $-82,52$ & $-297088,02$ & $-57,07$ & 50,20 \\
\hline 0,43 & 1,93 & 0,01 & 828,73 & 319,51 & 509,22 & 0,0002 & 0,06 & $-215,54$ & $-178,14$ & $-641290,38$ & $-123,18$ & 50,20 \\
\hline 0,41 & 1,92 & 0,01 & 814,65 & 301,63 & 513,02 & 0,0002 & 0,06 & $-6754,24$ & $-5582,02$ & $-20095265,06$ & $-3860,02$ & 50,20 \\
\hline 0,39 & 1,82 & 0,01 & 814,91 & 301,97 & 512,94 & 0,0002 & 0,06 & 755,24 & 624,17 & 2246998,56 & 431,62 & 50,20 \\
\hline 0,39 & 1,80 & 0,01 & 815,93 & 303,27 & 512,66 & 0,0002 & 0,06 & $-406,01$ & $-335,55$ & $-1207969,65$ & $-232,03$ & 50,20 \\
\hline 0,38 & 1,72 & 0,01 & 823,55 & 312,95 & 510,59 & 0,0002 & 0,06 & 471,49 & 389,66 & 1402784,38 & 269,46 & 50,20 \\
\hline 0,39 & 1,73 & 0,01 & 817,03 & 304,67 & 512,36 & 0,0002 & 0,06 & 2735,33 & 2260,60 & 8138163,44 & 1563,23 & 50,20 \\
\hline 0,45 & 1,76 & 0,01 & 847,22 & 342,63 & 504,59 & 0,0002 & 0,06 & $-438,49$ & $-362,39$ & $-1304602,06$ & $-250,60$ & 50,20 \\
\hline 0,51 & 1,78 & 0,01 & 888,47 & 392,82 & 495,65 & 0,0002 & 0,06 & $-535,51$ & $-442,57$ & $-1593248,95$ & $-306,04$ & 50,20 \\
\hline 0,57 & 1,79 & 0,01 & 897,77 & 403,87 & 493,90 & 0,0002 & 0,06 & 239,54 & 197,97 & 712676,29 & 136,90 & 50,20 \\
\hline 0,63 & 1,79 & 0,01 & 903,76 & 410,93 & 492,83 & 0,0002 & 0,06 & 89,90 & 74,30 & 267465,06 & 51,38 & 48,10 \\
\hline
\end{tabular}




\section{Experiment 1 Tab.5 AER results (14.08.03)}

\begin{tabular}{|c|c|c|c|c|c|c|c|c|c|c|c|c|c|c|c|c|c|}
\hline Date & Time & $\begin{array}{c}\mathrm{CO}_{2} \\
\text { Balance } \\
\text { (corrected) }\end{array}$ & $\begin{array}{l}\mathrm{CO}_{2} \text { Balance } \\
\text { (uncorrected) }\end{array}$ & $\begin{array}{l}\mathrm{CO}_{2} \\
\mathrm{CV} \\
(\%)\end{array}$ & $\begin{array}{l}\Delta \mathrm{CO} 2 \\
(\mathrm{ppm})\end{array}$ & $\begin{array}{c}\text { Heat } \\
\text { Balance } \\
\text { (corrected) }\end{array}$ & $\begin{array}{l}\text { Heat Balance } \\
\text { (uncorrected) }\end{array}$ & $\begin{array}{c}\Delta \\
\text { Temp } \\
\left({ }^{\circ} \mathrm{C}\right)\end{array}$ & $\begin{array}{l}\text { Moisture } \\
\text { Balance } \\
\text { corrected) }\end{array}$ & $\begin{array}{c}\text { Moisture } \\
\text { Balance } \\
\text { (uncorrected) }\end{array}$ & $\begin{array}{c}\Delta \text { water } \\
\text { content } \\
(\mathbf{k g} \\
\text { water } / \mathbf{m}^{3} \\
\text { dry air }\end{array}$ & $\begin{array}{l}\text { O.Temp } \\
\left({ }^{\circ} \mathrm{C}\right)\end{array}$ & $\begin{array}{l}\text { I.Temp } \\
\left({ }^{\circ} \mathrm{C}\right)\end{array}$ & $\begin{array}{l}\text { O.Humid } \\
(\%)\end{array}$ & $\begin{array}{l}\text { I.Humid } \\
(\%)\end{array}$ & $\begin{array}{l}\text { Wind } \\
\text { speed } \\
\left(\mathrm{mS}^{-1}\right)\end{array}$ & $\begin{array}{c}\text { Wind } \\
\text { Direction } \\
\left({ }^{\circ}\right)\end{array}$ \\
\hline 14.08 .03 & $00: 00$ & 51,27 & 46,43 & 9,8 & 232,7 & 48,41 & 48,41 & 2,8 & 47,18 & 47,18 & 0,00128 & 19,7 & 22,5 & 59,6 & 62,0 & 0,9 & 270,0 \\
\hline 14.08 .03 & 01:00 & 79,52 & 112,37 & 2,9 & 87,9 & 35,20 & 35,20 & 3,9 & 34,17 & 34,17 & 0,00177 & 18,0 & 21,9 & 64,2 & 68,4 & 0,2 & 307,4 \\
\hline 14.08 .03 & 02:00 & 79,52 & 93,94 & 1,0 & 107,9 & 25,60 & 25,60 & 5,4 & 27,23 & 27,23 & 0,00222 & 16,3 & 21,7 & 67,4 & 75,4 & 0,2 & 303,7 \\
\hline 14.08 .03 & 03:00 & 79,52 & 91,21 & 0,8 & 111,6 & 20,88 & 20,88 & 6,6 & 24,14 & 24,14 & 0,00250 & 14,9 & 21,5 & 68,9 & 80,9 & 0,0 & 359,0 \\
\hline 14.08 .03 & 04:00 & 79,52 & 93,96 & 1,4 & 107,9 & 20,49 & 20,49 & 6,7 & 25,53 & 25,53 & 0,00236 & 15,0 & 21,7 & 68,7 & 82,5 & 0,0 & 352,8 \\
\hline 14.08 .03 & 05:00 & 79,52 & 94,94 & 4,4 & 106,7 & 21,61 & 21,61 & 6,3 & 25,10 & 25,10 & 0,00240 & 15,4 & 21,7 & 68,9 & 80,6 & 0,1 & 331,3 \\
\hline 14.08 .03 & 06:00 & 79,52 & 104,57 & 3,8 & 95,5 & 23,53 & 23,53 & 5,8 & 27,58 & 27,58 & 0,00219 & 16,1 & 21,9 & 68,2 & 79,0 & 0,1 & 345,0 \\
\hline 14.08 .03 & 07:00 & 79,52 & 110,95 & 1,8 & 89,2 & 28,40 & 28,40 & 4,8 & 31,30 & 31,30 & 0,00193 & 17,1 & 21,9 & 67,7 & 75,8 & 0,0 & 348,7 \\
\hline 14.08 .03 & 08:00 & 79,52 & 91,40 & 8,3 & 111,3 & 29,59 & 29,59 & 4,6 & 32,34 & 32,34 & 0,00187 & 17,5 & 22,1 & 67,3 & 74,8 & 0,2 & 335,1 \\
\hline 14.08 .03 & 09:00 & 70,97 & 62,89 & 9,5 & 168,1 & 33,55 & 33,55 & 4,0 & 34,70 & 34,70 & 0,00175 & 18,7 & 22,7 & 63,6 & 68,4 & 0,3 & 283,3 \\
\hline 14.08 .03 & $10: 00$ & 50,91 & 46,12 & 11,6 & 234,4 & 25,60 & 25,60 & 4,9 & 34,53 & 34,53 & 0,00176 & 18,7 & 23,6 & 60,2 & 68,4 & 0,8 & 290,6 \\
\hline 14.08 .03 & $11: 00$ & 35,43 & 32,65 & 13,0 & 336,8 & 37,20 & 37,20 & 3,5 & 49,92 & 49,92 & 0,00122 & 19,5 & 23,0 & 59,7 & 65,6 & 1,4 & 269,8 \\
\hline 14.08 .03 & $12: 00$ & 39,13 & 35,91 & 9,2 & 305,0 & 52,60 & 172,37 & 0,8 & 85,90 & 343,30 & 0,00018 & 22,2 & 23,0 & 55,0 & 56,6 & 2,4 & 273,9 \\
\hline 14.08 .03 & $13: 00$ & 42,26 & 38,65 & 10,4 & 282,4 & 52,60 & 166,52 & 0,8 & 85,90 & $-16131,82$ & 0,00000 & 21,7 & 22,5 & 58,2 & 61,2 & 2,9 & 278,1 \\
\hline 14.08 .03 & $14: 00$ & 67,88 & 60,36 & 7,0 & 175,8 & 52,60 & $-217,99$ & $-0,6$ & 85,90 & $-363,88$ & $-0,00017$ & 23,9 & 23,3 & 47,0 & 46,2 & 4,7 & 274,5 \\
\hline 14.08 .03 & $15: 00$ & 79,52 & 79,52 & 6,6 & 130,1 & 52,60 & $-120,49$ & $-1,1$ & 85,90 & $-251,23$ & $-0,00024$ & 24,8 & 23,7 & 33,2 & 32,3 & 5,7 & 279,1 \\
\hline 14.08 .03 & $16: 00$ & 79,52 & 74,81 & 7,9 & 139,1 & 52,60 & $-140,34$ & $-0,9$ & 85,90 & $-1979,78$ & $-0,00003$ & 24,7 & 23,8 & 31,4 & 29,8 & 5,3 & 284,1 \\
\hline 14.08 .03 & $17: 00$ & 79,52 & 78,30 & 5,1 & 132,3 & 52,60 & $-137,51$ & $-1,0$ & 85,90 & $-292,15$ & $-0,00021$ & 24,6 & 23,6 & 30,4 & 29,8 & 5,0 & 277,5 \\
\hline 14.08 .03 & $18: 00$ & 55,49 & 50,02 & 9,3 & 215,0 & 52,60 & $-240,92$ & $-0,6$ & 85,90 & $-1582,91$ & $-0,00004$ & 23,4 & 22,8 & 35,0 & 34,0 & 4,5 & 286,2 \\
\hline 14.08 .03 & $19: 00$ & 46,28 & 42,14 & 8,0 & 257,8 & 52,60 & 1057,38 & 0,1 & 85,90 & 231,02 & 0,00026 & 22,5 & 22,6 & 39,3 & 38,1 & 4,0 & 285,3 \\
\hline 14.08 .03 & $20: 00$ & 79,52 & 94,77 & 6,9 & 106,9 & 52,60 & 70,59 & 1,9 & 77,78 & 77,78 & 0,00078 & 20,8 & 22,7 & 41,1 & 41,2 & 3,5 & 283,8 \\
\hline 14.08 .03 & $21: 00$ & 79,52 & 95,13 & 5,1 & 106,4 & 30,85 & 30,85 & 4,2 & 33,27 & 33,27 & 0,00182 & 18,7 & 22,9 & 47,3 & 47,9 & 1,3 & 270,8 \\
\hline 14.08 .03 & $22: 00$ & 79,52 & 114,40 & 2,8 & 86,1 & 24,43 & 24,43 & 5,3 & 27,57 & 27,57 & 0,00220 & 17,5 & 22,8 & 52,5 & 55,5 & 1,2 & 272,3 \\
\hline 14.08 .03 & 23:00 & 79,52 & 90,35 & 4,4 & 112,8 & 20,73 & 20,73 & 6,2 & 25,38 & 25,38 & 0,00239 & 16,7 & 22,9 & 55,4 & 61,5 & 1,2 & 270,5 \\
\hline
\end{tabular}




\section{Experiment 1 Tab. $6 \mathrm{CO}_{2}$ balance results (14.08.03)}

\begin{tabular}{|c|c|c|c|c|c|c|c|c|}
\hline Date & Time & $\begin{array}{l}\text { Inside } \mathrm{CO}_{2} \\
\text { concentration }\end{array}$ & $\begin{array}{l}\text { Corrected } \\
\text { for } \\
\text { manure }\end{array}$ & $\Delta \mathrm{CO}_{2}$ & $\begin{array}{c}\mathrm{CO}_{2} \\
\text { productn } \\
/ \triangle \mathrm{CO}_{2}\end{array}$ & $\begin{array}{c}\text { Air volume } \\
\text { displacement } \\
\text { m3/h }\end{array}$ & $\mathrm{AER} / \mathrm{h}$ & $\begin{array}{c}\text { AER } \\
\text { (corrected) }\end{array}$ \\
\hline 14.08 .03 & 00:00 & 607,0 & 582,7 & 232,7 & 794,94 & 417745,92 & 51,27 & 51,27 \\
\hline 14.08 .03 & 01:00 & 456,2 & 437,9 & 87,9 & 2103,91 & 1105621,99 & 135,69 & 79,52 \\
\hline 14.08 .03 & 02:00 & 477,0 & 457,9 & 107,9 & 1713,93 & 900688,01 & 110,54 & 79,52 \\
\hline 14.08 .03 & 03:00 & 480,8 & 461,6 & 111,6 & 1657,90 & 871241,43 & 106,93 & 79,52 \\
\hline 14.08 .03 & 04:00 & 477,0 & 457,9 & 107,9 & 1714,50 & 900985,87 & 110,58 & 79,52 \\
\hline 14.08 .03 & 05:00 & 475,7 & 456,7 & 106,7 & 1734,59 & 911540,16 & 111,87 & 79,52 \\
\hline 14.08 .03 & 06:00 & 464,1 & 445,5 & 95,5 & 1936,32 & 1017552,01 & 124,88 & 79,52 \\
\hline 14.08 .03 & 07:00 & 457,5 & 439,2 & 89,2 & 2073,08 & 1089420,56 & 133,70 & 79,52 \\
\hline 14.08 .03 & 08:00 & 480,5 & 461,3 & 111,3 & 1661,90 & 873344,87 & 107,19 & 79,52 \\
\hline 14.08 .03 & 09:00 & 539,7 & 518,1 & 168,1 & 1100,38 & 578259,07 & 70,97 & 70,97 \\
\hline 14.08 .03 & $10: 00$ & 608,7 & 584,4 & 234,4 & 789,34 & 414807,67 & 50,91 & 50,91 \\
\hline 14.08 .03 & $11: 00$ & 715,4 & 686,8 & 336,8 & 549,33 & 288677,56 & 35,43 & 35,43 \\
\hline 14.08 .03 & $12: 00$ & 682,2 & 655,0 & 305,0 & 606,65 & 318797,65 & 39,13 & 39,13 \\
\hline 14.08 .03 & $13: 00$ & 658,7 & 632,4 & 282,4 & 655,19 & 344308,36 & 42,26 & 42,26 \\
\hline 14.08 .03 & $14: 00$ & 547,7 & 525,8 & 175,8 & 1052,46 & 553075,31 & 67,88 & 67,88 \\
\hline 14.08 .03 & $15: 00$ & 500,1 & 480,1 & 130,1 & 1422,52 & 747547,33 & 91,75 & 79,52 \\
\hline 14.08 .03 & $16: 00$ & 509,5 & 489,1 & 139,1 & 1329,83 & 698838,42 & 85,77 & 79,52 \\
\hline 14.08 .03 & $17: 00$ & 502,4 & 482,3 & 132,3 & 1398,48 & 734912,92 & 90,20 & 79,52 \\
\hline 14.08 .03 & 18:00 & 588,6 & 565,0 & 215,0 & 860,39 & 452144,22 & 55,49 & 55,49 \\
\hline 14.08 .03 & 19:00 & 633,1 & 607,8 & 257,8 & 717,65 & 377130,13 & 46,28 & 46,28 \\
\hline 14.08 .03 & 20:00 & 475,9 & 456,9 & 106,9 & 1731,19 & 909754,67 & 111,65 & 79,52 \\
\hline 14.08 .03 & 21:00 & 475,4 & 456,4 & 106,4 & 1738,65 & 913674,00 & 112,13 & 79,52 \\
\hline 14.08 .03 & $22: 00$ & 454,3 & 436,1 & 86,1 & 2147,96 & 1128774,72 & 138,53 & 79,52 \\
\hline 14.08 .03 & 23:00 & 482,1 & 462,8 & 112,8 & 1640,40 & 862044,79 & 105,80 & 79,52 \\
\hline
\end{tabular}




\section{Experiment 1 Tab.7 Heat balance results (14.08.03)}

\begin{tabular}{|c|c|c|c|c|c|c|c|c|c|c|}
\hline Date & Time & $\begin{array}{c}\text { Total } \\
\text { heat } \\
\text { /animal } \\
\left(20^{\circ} \mathrm{C}\right) \\
\mathrm{W} \\
\end{array}$ & $\begin{array}{l}\text { hpu/all } \\
\text { animals }\end{array}$ & $\begin{array}{c}\text { Sensible } \\
\text { heat and } \\
\text { temperature } \\
\text { factors }\end{array}$ & $\begin{array}{l}\text { Sensible } \\
\text { Heat/ all } \\
\text { animals } \\
\text { (W) }\end{array}$ & $\begin{array}{l}\text { Heat loss } \\
\text { Thought } \\
\text { Building } \\
\text { (W) }\end{array}$ & $\begin{array}{c}\text { Calculated } \\
\text { AER } \\
\left(\mathrm{m}^{3} / \mathrm{s}\right)\end{array}$ & $\begin{array}{l}\text { Calculated } \\
\text { AER }\left(\mathrm{m}^{3} / \mathrm{h}\right)\end{array}$ & $\begin{array}{c}\text { Heat balance } \\
\text { AER/h } \\
\text { (uncorrected) }\end{array}$ & $\begin{array}{c}\text { Heat } \\
\text { balance } \\
\text { AER/h } \\
\text { (corrected) }\end{array}$ \\
\hline 14.8 .2003 & 00:00 & 13,33 & 525,51 & 464,01 & 243840,30 & $-6408,02$ & 70,01 & 252021,70 & 48,41 & 48,41 \\
\hline 14.8 .2003 & 01:03 & 13,33 & 525,51 & 476,95 & 250642,22 & $-8969,27$ & 50,91 & 183270,65 & 35,20 & 35,20 \\
\hline 14.8.2003 & 02:00 & 13,33 & 525,51 & 482,27 & 253435,01 & $-12307,01$ & 37,02 & 133265,19 & 25,60 & 25,60 \\
\hline 14.8.2003 & $03: 00$ & 13,33 & 525,51 & 486,58 & 255699,87 & $-15060,63$ & 30,19 & 108678,82 & 20,88 & 20,88 \\
\hline 14.8.2003 & 04:00 & 13,33 & 525,51 & 482,93 & 253784,04 & $-15210,24$ & 29,64 & 106686,25 & 20,49 & 20,49 \\
\hline 14.8.2003 & 05:00 & 13,33 & 525,51 & 481,66 & 253114,87 & $-14427,58$ & 31,26 & 112527,17 & 21,61 & 21,61 \\
\hline 14.8.2003 & 06:00 & 13,33 & 525,51 & 477,91 & 251146,38 & $-13214,10$ & 34,02 & 122472,24 & 23,53 & 23,53 \\
\hline 14.8.2003 & 07:00 & 13,33 & 525,51 & 476,98 & 250656,84 & $-11023,93$ & 41,07 & 147853,49 & 28,40 & 28,40 \\
\hline 14.8.2003 & 08:00 & 13,33 & 525,51 & 473,05 & 248591,76 & $-10513,48$ & 42,79 & 154026,30 & 29,59 & 29,59 \\
\hline 14.8 .2003 & 09:00 & 13,33 & 525,51 & 460,34 & 241913,92 & $-9066,66$ & 48,52 & 174681,04 & 33,55 & 33,55 \\
\hline 14.8.2003 & $10: 00$ & 13,33 & 525,51 & 439,09 & 230743,99 & $-11202,74$ & 37,03 & 133294,90 & 25,60 & 25,60 \\
\hline 14.8.2003 & $11: 00$ & 13,33 & 525,51 & 452,18 & 237623,57 & $-8062,94$ & 53,79 & 193653,56 & 37,20 & 37,20 \\
\hline 14.8.2003 & $12: 00$ & 13,33 & 525,51 & 453,16 & 238139,17 & $-1791,49$ & 249,26 & 897344,62 & 172,37 & 52,60 \\
\hline 14.8.2003 & $13: 00$ & 13,33 & 525,51 & 463,42 & 243529,55 & $-1895,89$ & 240,80 & 866894,78 & 166,52 & 52,60 \\
\hline 14.8.2003 & $14: 00$ & 13,33 & 525,51 & 446,39 & 234580,72 & 1414,46 & $-315,23$ & 1134842,14 & 217,99 & 52,60 \\
\hline 14.8.2003 & $15: 00$ & 13,33 & 525,51 & 436,81 & 229548,06 & 2516,41 & $-174,24$ & 627261,93 & 120,49 & 52,60 \\
\hline 14.8.2003 & $16: 00$ & 13,33 & 525,51 & 435,43 & 228820,27 & 2150,26 & $-202,95$ & 730612,68 & 140,34 & 52,60 \\
\hline 14.8.2003 & $17: 00$ & 13,33 & 525,51 & 438,32 & 230343,09 & 2209,61 & $-198,85$ & 715859,28 & 137,51 & 52,60 \\
\hline 14.8.2003 & $18: 00$ & 13,33 & 525,51 & 456,69 & 239996,06 & 1308,62 & $-348,39$ & 1254218,32 & 240,92 & 52,60 \\
\hline 14.8 .2003 & $19: 00$ & 13,33 & 525,51 & 461,13 & 242329,37 & $-299,06$ & 1529,09 & 5504715,46 & 155,76 & 52,60 \\
\hline 14.8.2003 & $20: 00$ & 13,33 & 525,51 & 459,17 & 241297,62 & $-4384,65$ & 102,09 & 367515,34 & 70,59 & 52,60 \\
\hline 14.8.2003 & 21:00 & 13,33 & 525,51 & 454,13 & 238646,85 & $-9695,59$ & 44,62 & 160616,64 & 30,85 & 30,85 \\
\hline 14.8.2003 & 22:03 & 13,33 & 525,51 & 456,68 & 239988,62 & $-12181,09$ & 35,33 & 127204,83 & 24,43 & 24,43 \\
\hline 14.8 .2003 & 23:00 & 13,33 & 525,51 & 455,03 & 239124,27 & $-14176,20$ & 29,98 & 107930,51 & 20,73 & 20,73 \\
\hline
\end{tabular}




\section{Experiment 1 Tab.8a Moisture balance results (14.08.03)}

\begin{tabular}{|c|c|c|c|c|c|c|c|c|c|c|c|c|c|}
\hline A1 & $\begin{array}{c}- \\
5,8002206 E+03\end{array}$ & $\begin{array}{l}\text { indoor } \\
\mathrm{T}{ }^{\circ} \mathrm{K}\end{array}$ & $\mathrm{T} 2$ & T3 & LnT & Pws Pa) & HR & $\begin{array}{c}\mathrm{Pw} \\
\text { (Kpa) }\end{array}$ & $\begin{array}{c}\text { Wi } \\
(\mathbf{k g} \\
\mathbf{a g} / \mathbf{k a}\end{array}$ & $\begin{array}{l}\text { outdoor } \\
\mathrm{T}^{\circ} \mathrm{OK}\end{array}$ & T2 & T3 & LnT Pws (Pa) \\
\hline
\end{tabular}

\begin{tabular}{|c|c|c|c|c|c|c|c|c|c|c|c|c|c|c|}
\hline A2 & 1,39 & 295,65 & 87410,68 & 25843227,63 & 5,69 & 2726,99 & 0,60 & 1,63 & 0,01 & 292,85 & 85761,12 & 25115144,72 & 5,68 & 2295,69 \\
\hline A3 & $-0,05$ & 295,07 & 87068,26 & 25691518,29 & 5,69 & 2632,41 & 0,64 & 1,69 & 0,01 & 291,15 & 84768,32 & 24680297,10 & 5,67 & 2064,29 \\
\hline A4 & 0,00 & 294,83 & 86926,67 & 25628876,65 & 5,69 & 2594,09 & 0,67 & 1,75 & 0,01 & 289,45 & 83781,30 & 24250498,01 & 5,67 & 1853,59 \\
\hline A5 & 0,00 & 294,64 & 86811,42 & 25577922,74 & 5,69 & 2563,24 & 0,69 & 1,77 & 0,01 & 288,05 & 82972,80 & 23900315,76 & 5,66 & 1694,50 \\
\hline A6 & 0,00 & 294,80 & 86908,93 & 25621033,18 & 5,69 & 2589,32 & 0,69 & 1,78 & 0,01 & 288,15 & 83030,42 & 23925216,24 & 5,66 & 1705,45 \\
\hline \multirow[t]{2}{*}{ A7 } & 6,55 & 294,86 & 86942,93 & 25636067,89 & 5,69 & 2598,47 & 0,69 & 1,79 & 0,01 & 288,55 & 83261,10 & 24024991,13 & 5,66 & 1749,88 \\
\hline & & 295,03 & 87042,74 & 25680225,46 & 5,69 & 2625,47 & 0,68 & 1,79 & 0,01 & 289,25 & 83665,56 & 24200263,95 & 5,67 & 1830,09 \\
\hline patm $(\mathrm{Pa})$ & 101325,00 & 295,07 & 87067,52 & 25691190,92 & 5,69 & 2632,20 & 0,68 & 1,78 & 0,01 & 290,25 & 84245,06 & 24452129,39 & 5,67 & 1950,27 \\
\hline \multirow[t]{16}{*}{$\mathrm{Ra}$} & 287,06 & 295,25 & 87171,84 & 25737378,28 & 5,69 & 2660,73 & 0,67 & 1,79 & 0,01 & 290,65 & 84477,42 & 24553362,85 & 5,67 & 2000,25 \\
\hline & & 295,82 & 87507,05 & 25885977,52 & 5,69 & 2754,11 & 0,64 & 1,75 & 0,01 & 291,85 & 85176,42 & 24858738,91 & 5,68 & 2156,97 \\
\hline & & 296,75 & 88060,72 & 26132042,37 & 5,69 & 2914,19 & 0,60 & 1,75 & 0,01 & 291,85 & 85176,42 & 24858738,91 & 5,68 & 2156,97 \\
\hline & & 296,18 & 87720,74 & 25980852,83 & 5,69 & 2815,02 & 0,60 & 1,68 & 0,01 & 292,65 & 85644,02 & 25063723,18 & 5,68 & 2267,34 \\
\hline & & 296,13 & 87695,12 & 25969475,36 & 5,69 & 2807,66 & 0,55 & 1,54 & 0,01 & 295,35 & 87231,62 & 25763859,71 & 5,69 & 2677,19 \\
\hline & & 295,68 & 87426,24 & 25850130,19 & 5,69 & 2731,35 & 0,58 & 1,59 & 0,01 & 294,85 & 86936,52 & 25633233,66 & 5,69 & 2596,74 \\
\hline & & 296,43 & 87871,51 & 26047865,85 & 5,69 & 2858,65 & 0,47 & 1,34 & 0,01 & 297,05 & 88238,70 & 26211306,58 & 5,69 & 2967,24 \\
\hline & & 296,85 & 88119,50 & 26158208,66 & 5,69 & 2931,63 & 0,33 & 0,97 & 0,01 & 297,95 & 88774,20 & 26450273,63 & 5,70 & 3131,63 \\
\hline & & 296,91 & 88155,22 & 26174115,69 & 5,69 & 2942,26 & 0,31 & 0,92 & 0,01 & 297,85 & 88714,62 & 26423650,31 & 5,70 & 3112,98 \\
\hline & & 296,78 & 88080,43 & 26140817,72 & 5,69 & 2920,03 & 0,30 & 0,89 & 0,01 & 297,75 & 88655,06 & 26397044,86 & 5,70 & 3094,43 \\
\hline & & 295,98 & 87602,73 & 25928445,15 & 5,69 & 2781,24 & 0,35 & 0,97 & 0,01 & 296,55 & 87941,90 & 26079171,19 & 5,69 & 2879,21 \\
\hline & & 295,78 & 87486,29 & 25876765,87 & 5,69 & 2748,25 & 0,39 & 1,08 & 0,01 & 295,65 & 87408,92 & 25842447,94 & 5,69 & 2726,50 \\
\hline & & 295,87 & 87537,83 & 25899634,53 & 5,69 & 2762,81 & 0,41 & 1,14 & 0,01 & 293,95 & 86406,60 & 25399220,80 & 5,68 & 2457,25 \\
\hline & & 296,09 & 87669,89 & 25958266,03 & 5,69 & 2800,42 & 0,47 & 1,32 & 0,01 & 291,85 & 85176,42 & 24858738,91 & 5,68 & 2156,97 \\
\hline & & 295,98 & 87603,10 & 25928609,84 & 5,69 & 2781,35 & 0,52 & 1,46 & 0,01 & 290,65 & 84477,42 & 24553362,85 & 5,67 & 2000,25 \\
\hline & & 296,05 & 87646,14 & 25947719,02 & 5,69 & 2793,63 & 0,55 & 1,55 & 0,01 & 289,85 & 84013,02 & 24351174,57 & 5,67 & 1901,39 \\
\hline
\end{tabular}




\section{Experiment 1 Tab.8b Moisture balance results (14.08.03)}

\begin{tabular}{|c|c|c|c|c|c|c|c|c|c|c|c|c|c|c|}
\hline HR & $\begin{array}{c}\text { Pw } \\
(\mathrm{Kpa})\end{array}$ & $\begin{array}{c}\text { Wo (kg } \\
\text { water/kg } \\
\text { dry air) }\end{array}$ & Date & Time & $\begin{array}{l}\text { Total } \\
\text { heat } \\
\text { /hpu }\end{array}$ & $\begin{array}{c}\text { Sensible } \\
\text { Heat } \\
\text { /animal }\end{array}$ & $\begin{array}{c}\text { Latent } \\
\text { Heat } \\
\text { /animal } \\
\text { (W) }\end{array}$ & $\begin{array}{c}\text { Latent } \\
\text { Heat } \\
\text { /animal } \\
\text { (Kg } \\
\text { water/s) }\end{array}$ & $\begin{array}{c}\text { Latent } \\
\text { Heat } / 30 \\
000 \\
\text { animal } \\
(\mathrm{Kg} \\
\text { water/s) }\end{array}$ & $\begin{array}{c}\text { AER Kg } \\
\text { air/s }\end{array}$ & $\begin{array}{l}\text { AER } \\
\mathrm{m} 3 / \mathrm{s}\end{array}$ & AER m3/h & $\begin{array}{c}\text { AER /hr } \\
\text { (uncorre } \\
\text { cted) }\end{array}$ & $\begin{array}{c}\text { AER } / \mathrm{hr} \\
\text { (corrected) }\end{array}$ \\
\hline 0,62 & 1,42 & 0,01 & 14.08 .03 & $0: 00$ & 949,94 & 464,01 & 485,93 & 0,0002 & 0,11 & 82,56 & 68,23 & 245619,88 & 47,18 & 47,18 \\
\hline 0,68 & 1,41 & 0,01 & 14.08 .03 & $1: 03$ & 961,53 & 476,95 & 484,58 & 0,0002 & 0,11 & 59,78 & 49,41 & 177869,19 & 34,17 & 34,17 \\
\hline 0,75 & 1,40 & 0,01 & 14.08 .03 & $2: 00$ & 966,33 & 482,27 & 484,07 & 0,0002 & 0,11 & 47,65 & 39,38 & 141758,48 & 27,23 & 27,23 \\
\hline 0,81 & 1,37 & 0,01 & 14.08 .03 & 3:00 & 970,24 & 486,58 & 483,67 & 0,0002 & 0,11 & 42,24 & 34,91 & 125680,35 & 24,14 & 24,14 \\
\hline 0,83 & 1,41 & 0,01 & 14.08 .03 & $4: 00$ & 966,94 & 482,93 & 484,01 & 0,0002 & 0,11 & 44,68 & 36,92 & 132922,63 & 25,53 & 25,53 \\
\hline 0,81 & 1,41 & 0,01 & 14.08 .03 & $5: 00$ & 965,78 & 481,66 & 484,13 & 0,0002 & 0,11 & 43,92 & 36,30 & 130677,34 & 25,10 & 25,10 \\
\hline 0,79 & 1,45 & 0,01 & 14.08 .03 & $6: 00$ & 962,40 & 477,91 & 484,49 & 0,0002 & 0,11 & 48,26 & 39,88 & 143574,22 & 27,58 & 27,58 \\
\hline 0,76 & 1,48 & 0,01 & 14.08 .03 & $7: 00$ & 961,56 & 476,98 & 484,58 & 0,0002 & 0,11 & 54,76 & 45,26 & 162935,44 & 31,30 & 31,30 \\
\hline 0,75 & 1,50 & 0,01 & 14.08 .03 & $8: 00$ & 958,02 & 473,05 & 484,97 & 0,0002 & 0,11 & 56,59 & 46,77 & 168371,80 & 32,34 & 32,34 \\
\hline 0,68 & 1,48 & 0,01 & 14.08 .03 & 9:00 & 946,68 & 460,34 & 486,34 & 0,0002 & 0,11 & 60,72 & 50,18 & 180643,69 & 34,70 & 34,70 \\
\hline 0,68 & 1,48 & 0,01 & 14.08 .03 & $10: 00$ & 927,99 & 439,09 & 488,91 & 0,0002 & 0,11 & 60,42 & 49,93 & 179753,15 & 34,53 & 34,53 \\
\hline 0,66 & 1,49 & 0,01 & 14.08 .03 & 11:00 & 939,46 & 452,18 & 487,28 & 0,0002 & 0,11 & 87,34 & 72,18 & 259862,09 & 49,92 & 49,92 \\
\hline 0,57 & 1,52 & 0,01 & 14.08 .03 & $12: 00$ & 940,33 & 453,16 & 487,17 & 0,0002 & 0,11 & 600,70 & 496,44 & 1787194,72 & 343,30 & 85,90 \\
\hline 0,61 & 1,59 & 0,01 & 14.08 .03 & 13:00 & 949,41 & 463,42 & 486,00 & 0,0002 & 0,11 & $-28227,37$ & $-23328,41$ & $-83982267,70$ & $-16131,82$ & 85,90 \\
\hline 0,46 & 1,37 & 0,01 & 14.08 .03 & $14: 00$ & 934,37 & 446,39 & 487,99 & 0,0002 & 0,11 & $-636,71$ & $-526,21$ & $-1894346,94$ & $-363,88$ & 85,90 \\
\hline 0,32 & 1,01 & 0,01 & 14.08 .03 & $15: 00$ & 926,01 & 436,81 & 489,20 & 0,0002 & 0,11 & $-439,61$ & $-363,31$ & $-1307919,29$ & $-251,23$ & 85,90 \\
\hline 0,30 & 0,93 & 0,01 & 14.08 .03 & $16: 00$ & 924,81 & 435,43 & 489,38 & 0,0002 & 0,11 & $-3464,20$ & $-2862,98$ & $-10306717,45$ & $-1979,78$ & 85,90 \\
\hline 0,30 & 0,92 & 0,01 & 14.08 .03 & $17: 00$ & 927,33 & 438,32 & 489,01 & 0,0002 & 0,11 & $-511,21$ & $-422,49$ & $-1520957,60$ & $-292,15$ & 85,90 \\
\hline 0,34 & 0,98 & 0,01 & 14.08 .03 & $18: 00$ & 943,45 & 456,69 & 486,76 & 0,0002 & 0,11 & $-2769,76$ & $-2289,06$ & $-8240621,32$ & $-1582,91$ & 85,90 \\
\hline 0,38 & 1,04 & 0,01 & 14.08 .03 & 19:00 & 947,38 & 461,13 & 486,25 & 0,0002 & 0,11 & 404,23 & 334,07 & 1202664,33 & 231,02 & 85,90 \\
\hline 0,41 & 1,01 & 0,01 & 14.08 .03 & $20: 00$ & 945,64 & 459,17 & 486,47 & 0,0002 & 0,11 & 136,09 & 112,47 & 404905,36 & 77,78 & 77,78 \\
\hline 0,48 & 1,03 & 0,01 & 14.08 .03 & $21: 00$ & 941,18 & 454,13 & 487,05 & 0,0002 & 0,11 & 58,22 & 48,12 & 173218,75 & 33,27 & 33,27 \\
\hline 0,56 & 1,11 & 0,01 & 14.08 .03 & 22:03 & 943,44 & 456,68 & 486,76 & 0,0002 & 0,11 & 48,24 & 39,87 & 143514,50 & 27,57 & 27,57 \\
\hline 0,62 & 1,17 & 0,01 & 14.08 .03 & 23:00 & 941,98 & 455,03 & 486,95 & 0,0002 & 0,11 & 44,41 & 36,70 & 132119,46 & 25,38 & 25,38 \\
\hline
\end{tabular}


Appendix B. Experiment 2 Tab.1a AER results (07.11.03)

\begin{tabular}{|c|c|c|c|c|c|c|c|c|c|c|c|c|c|c|}
\hline Date & Time & $\begin{array}{l}\text { Tracer } \\
\text { gas } \\
\text { (AER) }\end{array}$ & $\begin{array}{l}\text { SF6 } \\
\text { (CV) }\end{array}$ & $\begin{array}{c}\text { Heat } \\
\text { Balance } \\
\text { (AER) }\end{array}$ & $\begin{array}{c}\text { Moisture } \\
\text { Balance } \\
\text { (AER) }\end{array}$ & $\begin{array}{l}\text { O.Temp } \\
\left({ }^{\circ} \mathrm{C}\right)\end{array}$ & $\begin{array}{l}\text { I.Temp } \\
\left({ }^{\circ} \mathrm{C}\right)\end{array}$ & $\begin{array}{c}\Delta \\
\text { Temp } \\
\left({ }^{\circ} \mathrm{C}\right)\end{array}$ & $\begin{array}{c}\text { O. Humid } \\
(\%)\end{array}$ & $\begin{array}{l}\text { I. Humid } \\
(\%)\end{array}$ & $\begin{array}{c}\Delta \text { water } \\
\text { content } \\
(\mathrm{kg} \\
\text { water } / \mathrm{m}^{3} \\
\text { dry air }\end{array}$ & $\begin{array}{l}\text { Wind } \\
\text { speed } \\
\left(\mathrm{mS}^{-1}\right)\end{array}$ & $\begin{array}{l}\text { Max } \\
\text { wind } \\
\text { speed } \\
(\mathrm{mS}-1)\end{array}$ & $\begin{array}{c}\text { Wind } \\
\text { Direction } \\
\left({ }^{\circ}\right)\end{array}$ \\
\hline 07.11 .03 & $17: 00$ & 1,04 & 13,87 & 2,99 & 4,55 & 6,5 & 24,1 & 17,6 & 84,4 & 58,8 & 0,00594 & 1,9 & 4,8 & 86,6 \\
\hline 07.11 .03 & $18: 00$ & 3,04 & 15,01 & 3,21 & 4,70 & 6,6 & 23,6 & 17,0 & 86 & 60,2 & 0,00576 & 2,3 & 5,4 & 78,3 \\
\hline 07.11 .03 & 19:00 & 2,13 & 17,23 & 3,16 & 5,00 & 6,6 & 23,7 & 17,1 & 85,8 & 57,8 & 0,00540 & 3,1 & 7,1 & 78,7 \\
\hline 07.11 .03 & $20: 00$ & 2,84 & 23,11 & 3,22 & 5,22 & 6,5 & 23,5 & 17,0 & 85,1 & 56,8 & 0,00518 & 3,8 & 9,4 & 83,8 \\
\hline 07.11 .03 & $21: 00$ & 1,97 & 20,67 & 3,25 & 5,22 & 6,3 & 23,3 & 17,0 & 83,8 & 56,7 & 0,00518 & 4,5 & 8,6 & 86,7 \\
\hline 07.11 .03 & $22: 00$ & 1,75 & 21,71 & 3,13 & 5,13 & 6,2 & 23,6 & 17,4 & 83,9 & 56,2 & 0,00526 & 4,2 & 7,5 & 87,3 \\
\hline 07.11 .03 & $23: 00$ & 2,22 & 27,14 & 3,12 & 5,04 & 6,3 & 23,6 & 17,3 & 84,1 & 56,7 & 0,00536 & 3,6 & 7,6 & 89,4 \\
\hline 08.11 .03 & 00:00 & 1,53 & 15,15 & 3,20 & 4,91 & 6,4 & 23,5 & 17,1 & 84,3 & 58,1 & 0,00550 & 3,3 & 6,8 & 92,1 \\
\hline 08.11 .03 & 01:00 & 2,75 & 20,92 & 3,08 & 5,12 & 6,3 & 23,7 & 17,4 & 85 & 56,2 & 0,00528 & 3,5 & 6,9 & 89,1 \\
\hline 08.11 .03 & 02:00 & 1,98 & 19,28 & 3,02 & 5,17 & 6,2 & 23,8 & 17,6 & 85,5 & 55,6 & 0,00523 & 3,7 & 7,8 & 88,0 \\
\hline 08.11 .03 & 03:00 & 2,19 & 19,52 & 3,02 & 5,17 & 6,3 & 23,9 & 17,6 & 85,1 & 55,4 & 0,00522 & 3,5 & 8,8 & 89,3 \\
\hline 08.11 .03 & 04:00 & 2,41 & 19,74 & 3,11 & 5,00 & 6,4 & 23,7 & 17,3 & 85,3 & 57,3 & 0,00540 & 3,7 & 8 & 89,3 \\
\hline 08.11 .03 & 05:00 & 3,00 & 21,84 & 3,18 & 5,32 & 6,5 & 23,6 & 17,1 & 85,1 & 56,1 & 0,00509 & 3,7 & 7,2 & 89,4 \\
\hline 08.11 .03 & 06:00 & 1,61 & 23,21 & 3,28 & 5,46 & 6,5 & 23,4 & 16,9 & 84,9 & 56,0 & 0,00495 & 4,6 & 8,8 & 87,3 \\
\hline 08.11 .03 & 07:00 & 2,18 & 19,45 & 3,38 & 5,51 & 6,5 & 23,2 & 16,7 & 84,7 & 56,4 & 0,00491 & 4,4 & 8,3 & 88,3 \\
\hline 08.11 .03 & 08:00 & 2,75 & 12,77 & 3,26 & 5,22 & 6,4 & 23,4 & 17,0 & 84,7 & 57,0 & 0,00518 & 3,7 & 7,8 & 88,5 \\
\hline 08.11 .03 & 09:00 & 2,57 & 15,01 & 3,32 & 5,05 & 6,4 & 23,2 & 16,8 & 84,6 & 58,5 & 0,00536 & 3,2 & 7,3 & 90,6 \\
\hline 08.11 .03 & $10: 00$ & 2,98 & 10,78 & 3,65 & 5,43 & 7,1 & 22,9 & 15,8 & 81,7 & 57,8 & 0,00499 & 3,9 & 7,9 & 90,6 \\
\hline 08.11 .03 & $11: 00$ & 2,98 & 12,74 & 4,16 & 5,93 & 8,1 & 22,6 & 14,5 & 77,8 & 57,3 & 0,00458 & 4,5 & 10,4 & 88,2 \\
\hline 08.11 .03 & $12: 00$ & 3,72 & 15,84 & 4,57 & 6,21 & 8,7 & 22,2 & 13,5 & 74,8 & 57,3 & 0,00438 & 5,3 & 11,2 & 87,0 \\
\hline 08.11 .03 & $13: 00$ & 2,68 & 14,25 & 4,50 & 6,63 & 9 & 22,5 & 13,5 & 73,5 & 54,8 & 0,00410 & 5,2 & 9 & 86,7 \\
\hline 08.11 .03 & $14: 00$ & 4,49 & 14,69 & 4,39 & 6,73 & 9,1 & 22,8 & 13,7 & 72,6 & 53,5 & 0,00404 & 4,8 & 11 & 85,0 \\
\hline 08.11 .03 & $15: 00$ & 3,35 & 17,03 & 4,49 & 6,64 & 9,2 & 22,7 & 13,5 & 70,8 & 53,6 & 0,00409 & 5,2 & 11,1 & 91,3 \\
\hline 08.11 .03 & $16: 00$ & 4,30 & 24,80 & 4,30 & 6,22 & 8,8 & 22,7 & 13,9 & 74 & 55,4 & 0,00436 & 4,4 & 10,8 & 91,1 \\
\hline
\end{tabular}


Appendix B. Experiment 2 Tab.1b U-value calculation for Livestock house 1

\begin{tabular}{|c|c|c|c|c|c|c|c|c|c|c|}
\hline \multirow{2}{*}{\multicolumn{2}{|c|}{$\begin{array}{c}\text { Livestock } \\
\text { house } 1 \mathrm{U} \\
\text { value } \\
\text { calculation }\end{array}$}} & \multirow{2}{*}{$\begin{array}{c}\text { Situation } \\
\text { factor } \\
\text { (Wm- } \\
2^{\circ} \text { C-1) }\end{array}$} & \multicolumn{2}{|c|}{ Brick } & \multicolumn{2}{|c|}{ Wood boarding } & \multirow[t]{2}{*}{ PVC curtain } & \multicolumn{3}{|c|}{ Metal sheeting } \\
\hline & & & $\mathrm{L}(\mathrm{m})$ & $\begin{array}{l}(\lambda ; \mathrm{Wm}- \\
\left.1^{\circ} \mathrm{C}-1\right)\end{array}$ & $\mathrm{L}(\mathrm{m})$ & $\left(\lambda ; W m-1^{\circ} \mathrm{C}-1\right)$ & & $\begin{array}{c}\left(\lambda ; \mathrm{Wm}^{-1^{\circ} \mathrm{C}-}-\right. \\
1)\end{array}$ & $\mathrm{L}(\mathrm{m})$ & $\left(\lambda ; W m-1^{\circ} \mathrm{C}-1\right)$ \\
\hline & $\begin{array}{c}\text { Top (east } \\
\text { \& west) }\end{array}$ & 0,17 & & & 0,016 & 0,14 & & & 0,0008 & 0,02 \\
\hline & & & & & & & & & 0,0008 & 0,02 \\
\hline & $\begin{array}{c}\text { bottom } \\
\text { (east \& } \\
\text { west) }\end{array}$ & 0,17 & 0,3 & 0,76 & 0,016 & 0,14 & & & 0,0008 & 0,02 \\
\hline & $\begin{array}{l}\text { Top (north } \\
\text { \& south) }\end{array}$ & 0,17 & & & 0,016 & 0,14 & & & 0,0016 & 0,02 \\
\hline External & $\begin{array}{c}\text { bottom } \\
\text { (north \& } \\
\text { south) }\end{array}$ & 0,17 & 0,3 & 0,76 & 0,016 & 0,14 & & & 0,0016 & 0,02 \\
\hline Wall & Top & 0,22 & 0,15 & 0,76 & 0,016 & 0,14 & & & & \\
\hline Curtain & $\begin{array}{l}\text { east to } \\
\text { west }\end{array}$ & 0,17 & & & & & 0,003 & 0,48 & & \\
\hline Roof & & 0,14 & & & - & - & & & 0,0008 & 0,02 \\
\hline $\begin{array}{l}\text { Roof chimne } \\
\text { Floor }\end{array}$ & baffles & 0,14 & & & 0,018 & 0,1 & & & & \\
\hline
\end{tabular}


Appendix B. Experiment 2 Tab.1c U-value calculation for Livestock house 1

\begin{tabular}{|c|c|c|c|c|c|c|c|c|c|}
\hline & Wool fiber & $\begin{array}{c}\text { AAC } \\
\text { block }\end{array}$ & & $\begin{array}{l}\text { Alloy } \\
\text { roof }\end{array}$ & & $\begin{array}{c}\text { U/element } \\
\text { (Wm-2º- } \\
1)\end{array}$ & $A(m 2)$ & $U^{*} A$ & $\mathrm{U}$ value \\
\hline $\mathrm{L}(\mathrm{m})$ & $\left(\lambda ; W m-1^{\circ} \mathrm{C}-1\right)$ & $\mathrm{L}(\mathrm{m})$ & $\begin{array}{c}\left(\lambda ; W m-1^{\circ} \mathrm{C}-\right. \\
1)\end{array}$ & $\mathrm{L}(\mathrm{m})$ & $\left(\lambda ; W m-1^{\circ} \mathrm{C}-1\right)$ & & & & \\
\hline \multirow[t]{2}{*}{0,15} & 0,038 & & & - & - & 0,234 & 174,700 & 40,898 & \\
\hline & & & & & & & & 0,000 & \\
\hline 0,075 & 0,038 & 0,015 & 0,14 & & & 0,362 & 224,000 & 81,164 & \\
\hline 0,15 & 0,038 & & & & & 0,232 & 51,200 & 11,875 & \\
\hline 0,075 & 0,038 & 0,015 & 0,14 & & & 0,362 & 96,000 & 34,785 & \\
\hline 0,1 & 0,038 & 0,026 & 0,3 & - & - & $\begin{array}{l}0,328 \\
5,674\end{array}$ & $\begin{array}{c}21,000 \\
291,200\end{array}$ & $\begin{array}{c}6,880 \\
1652,199\end{array}$ & \\
\hline 0,15 & 0,038 & & & 0,001 & 0,02 & $\begin{array}{l}0,239 \\
3,125\end{array}$ & $\begin{array}{c}1914,700 \\
15,400 \\
2772,800\end{array}$ & $\begin{array}{c}458,351 \\
48,125 \\
2286,150\end{array}$ & \\
\hline
\end{tabular}


Appendix B. Experiment 2 Tab.2 Tracer gas results (07.11.03)

\begin{tabular}{|c|c|c|c|c|c|c|c|c|c|c|c|}
\hline Date & Time & $\begin{array}{c}\text { SF6 } \\
(\mathrm{mg} / \mathrm{m} 3)\end{array}$ & Reciprocal & $\begin{array}{l}\text { Measurement } \\
\text { interval (min) }\end{array}$ & $\begin{array}{l}\text { Background } \\
\text { (mg) }\end{array}$ & $\begin{array}{c}\text { Dosage } \\
\text { (mg) }\end{array}$ & $\begin{array}{c}\text { Dosage + } \\
\text { background }\end{array}$ & $\begin{array}{c}\text { Dosage } \\
\text { (g/min) }\end{array}$ & $\begin{array}{l}\text { Supplied } \\
\text { air volume } \\
\text { m3/min }\end{array}$ & $\begin{array}{l}\text { Supplied } \\
\text { air } \\
\text { volume } \\
\text { m3/h }\end{array}$ & AER \\
\hline 07.11 .03 & $17: 00$ & 104,69 & 0,00955155 & & 853054,9 & & & & & & \\
\hline 07.11 .03 & $18: 00$ & 163,08 & 0,00613196 & 61,47 & 1328775,8 & 522842 & 1375897 & 22,4 & 137,3 & 8436,9 & 1,0 \\
\hline 07.11 .03 & $19: 00$ & 72,26 & 0,01383975 & 59,80 & 588739,2 & 463768 & 1792544 & 30,0 & 414,9 & 24808,3 & 3,0 \\
\hline 07.11 .03 & $20: 00$ & 60,10 & 0,0166394 & 59,80 & 489681,2 & 454162 & 1042901 & 17,4 & 290,2 & 17353,2 & 2,1 \\
\hline 07.11 .03 & 21:00 & 40,51 & 0,02468465 & 59,38 & 330083,6 & 446118,2 & 935799 & 15,8 & 389,0 & 23099,9 & 2,8 \\
\hline 07.11 .03 & $22: 00$ & 48,44 & 0,02064395 & 59,63 & 394691,8 & 446473,8 & 776557 & 13,0 & 268,8 & 16031,2 & 2,0 \\
\hline 07.11 .03 & $23: 00$ & 59,57 & 0,01678707 & 61,23 & 485373,6 & 456369,5 & 851061 & 13,9 & 233,3 & 14286,8 & 1,8 \\
\hline 08.11 .03 & 00:00 & 51,14 & 0,01955518 & 59,46 & 416667,0 & 439872,1 & 925246 & 15,6 & 304,3 & 18093,4 & 2,2 \\
\hline 08.11 .03 & 01:00 & 69,17 & 0,01445686 & 60,55 & 563608,0 & 444884 & 861551 & 14,2 & 205,7 & 12455,3 & 1,5 \\
\hline 08.11 .03 & 02:00 & 44,56 & 0,0224393 & 59,13 & 363112,9 & 433575,3 & 997183 & 16,9 & 378,4 & 22376,1 & 2,7 \\
\hline 08.11 .03 & 03:00 & 50,03 & 0,01998947 & 60,55 & 407614,6 & 443190 & 806303 & 13,3 & 266,2 & 16117,6 & 2,0 \\
\hline 08.11 .03 & 04:00 & 10,13 & 0,09874073 & 59,38 & 82519,1 & 137957,3 & 545572 & 9,2 & 907,2 & 53870,2 & 6,6 \\
\hline 08.11 .03 & 05:00 & 9,37 & 0,10670043 & 60,38 & 76363,3 & 101339,7 & 183859 & 3,0 & 324,9 & 19617,8 & 2,4 \\
\hline 08.11 .03 & 06:00 & 7,26 & 0,13773472 & 60,38 & 59157,2 & 101378,5 & 177742 & 2,9 & 405,5 & 24481,2 & 3,0 \\
\hline 08.11 .03 & 07:00 & 31,15 & 0,03210445 & 59,22 & 253796,6 & 348792,5 & 407950 & 6,9 & 221,2 & 13097,0 & 1,6 \\
\hline 08.11 .03 & 08:00 & 9,88 & 0,10122824 & 61,14 & 80491,4 & 259479,8 & 513276 & 8,4 & 849,8 & 51958,1 & 6,4 \\
\hline 08.11 .03 & 09:00 & 7,88 & 0,12695887 & 58,63 & 64178,3 & 96039,2 & 176531 & 3,0 & 382,3 & 22412,1 & 2,8 \\
\hline 08.11 .03 & $10: 00$ & 7,79 & 0,12830657 & 60,13 & 63504,2 & 99071,5 & 163250 & 2,7 & 348,3 & 20946,0 & 2,6 \\
\hline 08.11 .03 & $11: 00$ & 6,77 & 0,14781893 & 60,14 & 55121,5 & 100862,5 & 164367 & 2,7 & 404,0 & 24296,5 & 3,0 \\
\hline 08.11 .03 & $12: 00$ & 6,31 & 0,15856069 & 59,71 & 51387,3 & 97926,9 & 153048 & 2,6 & 406,4 & 24267,5 & 3,0 \\
\hline 08.11 .03 & $13: 00$ & 4,96 & 0,20162916 & 60,55 & 40410,8 & 99095,1 & 150482 & 2,5 & 501,1 & 30341,6 & 3,7 \\
\hline 08.11 .03 & $14: 00$ & 6,41 & 0,15603789 & 59,64 & 52218,1 & 99326,6 & 139737 & 2,3 & 365,6 & 21804,3 & 2,7 \\
\hline 08.11 .03 & $15: 00$ & 4,16 & 0,24011141 & 60,21 & 33934,2 & 100303,4 & 152521 & 2,5 & 608,2 & 36622,1 & 4,5 \\
\hline 08.11 .03 & $16: 00$ & 4,90 & 0,20427896 & 59,81 & 39886,6 & 99658 & 133592 & 2,2 & 456,3 & 27290,1 & 3,3 \\
\hline 08.11 .03 & $17: 00$ & 4,00 & 0,25014383 & 59,97 & 32573,3 & 100021 & 139908 & 2,3 & 583,6 & 34997,0 & 4,3 \\
\hline
\end{tabular}


Appendix B. Experiment 2 Tab.3 Heat balance results (07.11.03)

\begin{tabular}{|c|c|c|c|c|c|c|c|c|c|}
\hline Date & Time & $\begin{array}{l}\text { Total heat } \\
\text { /animal } \\
\left(20^{\circ} \mathrm{C}\right) \mathrm{W}\end{array}$ & $\begin{array}{l}\text { hpu/all } \\
\text { animals }\end{array}$ & $\begin{array}{c}\text { Sensible heat } \\
\text { and } \\
\text { temperature } \\
\text { factors }\end{array}$ & $\begin{array}{c}\text { Sensible } \\
\text { Heat/ all } \\
\text { animals (W) }\end{array}$ & $\begin{array}{l}\text { Heat loss } \\
\text { Thought } \\
\text { Building } \\
\text { (W) }\end{array}$ & $\begin{array}{l}\text { Calculated } \\
\operatorname{AER}\left(\mathrm{m}^{3} / \mathrm{s}\right)\end{array}$ & $\begin{array}{l}\text { Calculated } \\
\operatorname{AER}\left(\mathrm{m}^{3} / \mathrm{h}\right)\end{array}$ & $\begin{array}{c}\text { Heat balance } \\
\text { AER/h }\end{array}$ \\
\hline 7.11 .2003 & $17: 00$ & 10,01 & 400,40 & 428,69 & 171646,97 & $-40124,44$ & 6,19 & 22295,28 & 2,99 \\
\hline 7.11 .2003 & 18:00 & 10,01 & 400,40 & 439,63 & 176028,58 & $-38810,89$ & 6,68 & 24047,96 & 3,21 \\
\hline 7.11 .2003 & 19:00 & 10,01 & 400,40 & 437,02 & 174984,70 & $-39070,30$ & 6,57 & 23661,41 & 3,16 \\
\hline 7.11 .2003 & $20: 00$ & 10,01 & 400,40 & 441,14 & 176634,08 & $-38888,78$ & 6,69 & 24092,08 & 3,22 \\
\hline 7.11 .2003 & $21: 00$ & 10,01 & 400,40 & 445,56 & 178403,77 & $-38904,32$ & 6,77 & 24389,14 & 3,25 \\
\hline 7.11 .2003 & $22: 00$ & 10,01 & 400,40 & 439,95 & 176155,38 & $-39693,80$ & 6,50 & 23383,49 & 3,13 \\
\hline 7.11 .2003 & $23: 00$ & 10,01 & 400,40 & 438,42 & 175542,20 & $-39617,68$ & 6,48 & 23336,22 & 3,12 \\
\hline 8.11 .2003 & $00: 00$ & 10,01 & 400,40 & 441,18 & 176648,16 & $-39113,88$ & 6,64 & 23916,73 & 3,20 \\
\hline 8.11 .2003 & 01:00 & 10,01 & 400,40 & 436,42 & 174744,56 & $-39815,73$ & 6,40 & 23050,05 & 3,08 \\
\hline 8.11 .2003 & 02:00 & 10,01 & 400,40 & 434,23 & 173867,69 & $-40261,68$ & 6,27 & 22571,26 & 3,02 \\
\hline 8.11 .2003 & 03:00 & 10,01 & 400,40 & 432,63 & 173223,14 & $-40192,57$ & 6,25 & 22512,69 & 3,02 \\
\hline 8.11 .2003 & 04:00 & 10,01 & 400,40 & 436,78 & 174885,83 & $-39552,06$ & 6,46 & 23273,34 & 3,11 \\
\hline 8.11 .2003 & 05:00 & 10,01 & 400,40 & 439,37 & 175922,89 & $-39065,80$ & 6,62 & 23828,26 & 3,18 \\
\hline 8.11 .2003 & 06:00 & 10,01 & 400,40 & 444,48 & 177969,00 & $-38555,76$ & 6,83 & 24594,42 & 3,28 \\
\hline 8.11 .2003 & 07:00 & 10,01 & 400,40 & 449,25 & 179880,29 & $-38077,27$ & 7,04 & 25330,37 & 3,38 \\
\hline 8.11 .2003 & 08:00 & 10,01 & 400,40 & 444,55 & 177997,06 & $-38777,36$ & 6,78 & 24419,92 & 3,26 \\
\hline 8.11 .2003 & 09:00 & 10,01 & 400,40 & 447,94 & 179356,01 & $-38437,34$ & 6,93 & 24936,59 & 3,32 \\
\hline 8.11 .2003 & $10: 00$ & 10,01 & 400,40 & 454,53 & 181992,24 & $-36174,51$ & 7,62 & 27417,60 & 3,65 \\
\hline 8.11 .2003 & 11:00 & 10,01 & 400,40 & 462,93 & 185359,15 & $-33036,54$ & 8,71 & 31361,12 & 4,16 \\
\hline 8.11 .2003 & $12: 00$ & 10,01 & 400,40 & 469,81 & 188111,25 & $-30963,76$ & 9,59 & 34520,37 & 4,57 \\
\hline 8.11 .2003 & 13:00 & 10,01 & 400,40 & 463,26 & 185490,26 & $-30945,70$ & 9,44 & 33968,41 & 4,50 \\
\hline 8.11 .2003 & $14: 00$ & 10,01 & 400,40 & 458,06 & 183408,60 & $-31244,65$ & 9,20 & 33125,15 & 4,39 \\
\hline 8.11 .2003 & $15: 00$ & 10,01 & 400,40 & 460,12 & 184232,74 & $-30807,47$ & 9,41 & 33873,71 & 4,49 \\
\hline 8.11 .2003 & $16: 00$ & 10,01 & 400,40 & 458,84 & 183720,43 & $-31851,63$ & 9,01 & 32430,88 & 4,30 \\
\hline
\end{tabular}


Appendix B. Experiment 2 Tab.4a Moisture balance results (07.11.03)

\begin{tabular}{|c|c|c|c|c|c|c|c|c|c|c|c|}
\hline A1 & $\stackrel{-}{5,8002206 \mathrm{E}+03}$ & $\begin{array}{l}\text { indoor } \\
\mathrm{T} \text { oK }\end{array}$ & T2 & T3 & LnT & Pws Pa) & HR & $\begin{array}{l}\mathrm{Pw} \\
\text { (Kpa) }\end{array}$ & $\begin{array}{c}\text { Wi (kg } \\
\text { ag/ka } \\
\text { as) }\end{array}$ & $\begin{array}{l}\text { outdoor } \\
\mathrm{T} \text { 으 }\end{array}$ & T2 \\
\hline
\end{tabular}

\begin{tabular}{|c|c|c|c|c|c|c|c|c|c|c|c|c|}
\hline $\mathrm{A} 2$ & 1,39 & 297,20 & 88328,49 & 26251325,53 & 5,69 & 2994,30 & 0,59 & 1,76 & 0,01 & 279,65 & 78204,12 & 21869782,86 \\
\hline A3 & $-0,05$ & 296,73 & 88046,64 & 26125772,95 & 5,69 & 2910,03 & 0,60 & 1,75 & 0,01 & 279,75 & 78260,06 & 21893252,48 \\
\hline A4 & 0,00 & 296,84 & 88113,99 & 26155755,49 & 5,69 & 2929,99 & 0,58 & 1,69 & 0,01 & 279,75 & 78260,06 & 21893252,48 \\
\hline A5 & 0,00 & 296,66 & 88007,51 & 26108361,19 & 5,69 & 2898,49 & 0,57 & 1,65 & 0,01 & 279,65 & 78204,12 & 21869782,86 \\
\hline \multirow[t]{2}{*}{ A7 } & 6,55 & 296,71 & 88038,45 & 26122127,99 & 5,69 & 2907,61 & 0,56 & 1,63 & 0,01 & 279,35 & 78036,42 & 21799474,63 \\
\hline & & 296,78 & 88078,03 & 26139748,44 & 5,69 & 2919,32 & 0,57 & 1,66 & 0,01 & 279,45 & 78092,30 & 21822893,93 \\
\hline patm (Pa) & 101325,00 & 296,66 & 88006,60 & 26107956,36 & 5,69 & 2898,22 & 0,58 & 1,68 & 0,01 & 279,55 & 78148,20 & 21846330,01 \\
\hline \multirow[t]{15}{*}{$\mathrm{Ra}$} & 287,06 & 296,87 & 88129,46 & 26162646,60 & 5,69 & 2934,59 & 0,56 & 1,65 & 0,01 & 279,45 & 78092,30 & 21822893,93 \\
\hline & & 296,96 & 88185,91 & 26187789,18 & 5,69 & 2951,43 & 0,56 & 1,64 & 0,01 & 279,35 & 78036,42 & 21799474,63 \\
\hline & & 297,03 & 88227,36 & 26206250,83 & 5,69 & 2963,84 & 0,55 & 1,64 & 0,01 & 279,45 & 78092,30 & 21822893,93 \\
\hline & & 296,85 & 88120,36 & 26158592,86 & 5,69 & 2931,88 & 0,57 & 1,68 & 0,01 & 279,55 & 78148,20 & 21846330,01 \\
\hline & & 296,74 & 88053,46 & 26128810,68 & 5,69 & 2912,05 & 0,56 & 1,63 & 0,01 & 279,65 & 78204,12 & 21869782,86 \\
\hline & & 296,51 & 87921,11 & 26069920,79 & 5,69 & 2873,13 & 0,56 & 1,61 & 0,01 & 279,65 & 78204,12 & 21869782,86 \\
\hline & & 296,31 & 87797,03 & 26014754,09 & 5,69 & 2837,03 & 0,56 & 1,60 & 0,01 & 279,65 & 78204,12 & 21869782,86 \\
\hline & & 296,51 & 87919,29 & 26069111,93 & 5,69 & 2872,59 & 0,57 & 1,64 & 0,01 & 279,55 & 78148,20 & 21846330,01 \\
\hline & & 296,36 & 87831,11 & 26029902,02 & 5,69 & 2846,91 & 0,58 & 1,67 & 0,01 & 279,55 & 78148,20 & 21846330,01 \\
\hline & & 295,70 & 87438,92 & 25855753,86 & 5,69 & 2734,91 & 0,57 & 1,57 & 0,01 & 281,25 & 79101,56 & 22247314,45 \\
\hline & & 295,39 & 87257,65 & 25775393,45 & 5,69 & 2684,38 & 0,57 & 1,54 & 0,01 & 281,85 & 79439,42 & 22390001,23 \\
\hline & & 295,69 & 87430,31 & 25851932,97 & 5,69 & 2732,50 & 0,55 & 1,50 & 0,01 & 282,15 & 79608,62 & 22461572,84 \\
\hline & & 295,92 & 87566,83 & 25912508,22 & 5,69 & 2771,04 & 0,53 & 1,48 & 0,01 & 282,25 & 79665,06 & 22485463,89 \\
\hline & & 295,83 & 87512,84 & 25888548,57 & 5,69 & 2755,74 & 0,54 & 1,48 & 0,01 & 282,35 & 79721,52 & 22509371,88 \\
\hline & & 295,88 & 87546,41 & 25903446,11 & 5,69 & 2765,24 & 0,55 & 1,53 & 0,01 & 281,95 & 79495,80 & 22413841,51 \\
\hline
\end{tabular}


Appendix B. Experiment 2 Tab.4b Moisture balance results (07.11.03)

\begin{tabular}{|c|c|c|c|c|c|c|c|c|c|c|c|c|c|}
\hline LnT & Pws Pa) & HR & $\begin{array}{c}\text { Pw } \\
(\mathrm{Kpa})\end{array}$ & $\begin{array}{c}\text { Wo (kg } \\
\text { ag/ka } \\
\text { as) }\end{array}$ & $\begin{array}{l}\text { Total } \\
\text { heat } \\
\text { /hpu }\end{array}$ & $\begin{array}{c}\text { Sensible } \\
\text { Heat } \\
\text { /animal }\end{array}$ & $\begin{array}{l}\text { Latent } \\
\text { Heat } \\
\text { /animal } \\
\text { (W) }\end{array}$ & $\begin{array}{c}\text { Latent } \\
\text { Heat } \\
\text { lanimal } \\
\text { (Kg } \\
\text { water/s) }\end{array}$ & $\begin{array}{c}\text { Latent } \\
\text { Heat } / 40 \\
000 \\
\text { animal } \\
\text { (Kg } \\
\text { water/s) }\end{array}$ & $\begin{array}{c}\text { AER Kg } \\
\text { air/s }\end{array}$ & $\begin{array}{l}\text { AER } \\
\text { m3/s }\end{array}$ & $\begin{array}{l}\text { AER } \\
\mathrm{m} 3 / \mathrm{h}\end{array}$ & AER /hr \\
\hline 5,63 & 968,10 & 0,84 & 0,82 & 0,01 & 918,98 & 428,69 & 490,29 & 0,00 & 0,08 & 13,72 & 11,34 & 40833,83 & 4,55 \\
\hline 5,63 & 974,79 & 0,86 & 0,84 & 0,01 & 928,47 & 439,63 & 488,84 & 0,00 & 0,08 & 14,11 & 11,66 & 41983,02 & 4,70 \\
\hline 5,63 & 974,79 & 0,86 & 0,84 & 0,01 & 926,20 & 437,02 & 489,18 & 0,00 & 0,08 & 15,05 & 12,44 & 44775,72 & 5,00 \\
\hline 5,63 & 968,10 & 0,85 & 0,82 & 0,01 & 929,79 & 441,14 & 488,64 & 0,00 & 0,08 & 15,68 & 12,96 & 46655,51 & 5,22 \\
\hline 5,63 & 954,84 & 0,84 & 0,80 & 0,00 & 933,65 & 445,56 & 488,09 & 0,00 & 0,08 & 15,65 & 12,94 & 46576,04 & 5,22 \\
\hline 5,63 & 948,27 & 0,84 & 0,80 & 0,00 & 928,75 & 439,95 & 488,80 & 0,00 & 0,08 & 15,44 & 12,76 & 45925,35 & 5,13 \\
\hline 5,63 & 954,84 & 0,84 & 0,80 & 0,00 & 927,41 & 438,42 & 488,99 & 0,00 & 0,08 & 15,16 & 12,53 & 45097,67 & 5,04 \\
\hline 5,63 & 961,44 & 0,84 & 0,81 & 0,01 & 929,82 & 441,18 & 488,64 & 0,00 & 0,08 & 14,76 & 12,20 & 43924,18 & 4,91 \\
\hline 5,63 & 954,84 & 0,85 & 0,81 & 0,01 & 925,68 & 436,42 & 489,25 & 0,00 & 0,08 & 15,41 & 12,74 & 45855,74 & 5,12 \\
\hline 5,63 & 948,27 & 0,86 & 0,81 & 0,01 & 923,78 & 434,23 & 489,54 & 0,00 & 0,08 & 15,57 & 12,86 & 46311,53 & 5,17 \\
\hline 5,63 & 954,84 & 0,85 & 0,81 & 0,01 & 922,38 & 432,63 & 489,76 & 0,00 & 0,08 & 15,59 & 12,88 & 46372,64 & 5,17 \\
\hline 5,63 & 961,44 & 0,85 & 0,82 & 0,01 & 925,99 & 436,78 & 489,21 & 0,00 & 0,08 & 15,05 & 12,44 & 44783,73 & 5,00 \\
\hline 5,63 & 968,10 & 0,85 & 0,82 & 0,01 & 928,24 & 439,37 & 488,87 & 0,00 & 0,08 & 15,98 & 13,21 & 47551,82 & 5,32 \\
\hline 5,63 & 968,10 & 0,85 & 0,82 & 0,01 & 932,70 & 444,48 & 488,22 & 0,00 & 0,08 & 16,39 & 13,55 & 48776,28 & 5,46 \\
\hline 5,63 & 968,10 & 0,85 & 0,82 & 0,01 & 936,89 & 449,25 & 487,64 & 0,00 & 0,08 & 16,51 & 13,65 & 49134,59 & 5,51 \\
\hline 5,63 & 961,44 & 0,85 & 0,81 & 0,01 & 932,76 & 444,55 & 488,21 & 0,00 & 0,08 & 15,68 & 12,96 & 46651,49 & 5,22 \\
\hline 5,63 & 961,44 & 0,85 & 0,81 & 0,01 & 935,74 & 447,94 & 487,80 & 0,00 & 0,08 & 15,14 & 12,51 & 45029,80 & 5,05 \\
\hline 5,64 & 1008,86 & 0,82 & 0,82 & 0,01 & 941,53 & 454,53 & 487,01 & 0,00 & 0,08 & 16,23 & 13,42 & 48295,42 & 5,43 \\
\hline 5,64 & 1080,17 & 0,78 & 0,84 & 0,01 & 948,99 & 462,93 & 486,05 & 0,00 & 0,08 & 17,66 & 14,60 & 52542,90 & 5,93 \\
\hline 5,64 & 1125,05 & 0,75 & 0,84 & 0,01 & 955,12 & 469,81 & 485,31 & 0,00 & 0,08 & 18,42 & 15,23 & 54813,11 & 6,21 \\
\hline 5,64 & 1148,11 & 0,74 & 0,84 & 0,01 & 949,28 & 463,26 & 486,01 & 0,00 & 0,08 & 19,71 & 16,29 & 58630,08 & 6,63 \\
\hline 5,64 & 1155,89 & 0,73 & 0,84 & 0,01 & 944,66 & 458,06 & 486,60 & 0,00 & 0,08 & 20,04 & 16,56 & 59617,01 & 6,73 \\
\hline 5,64 & 1163,71 & 0,71 & 0,82 & 0,01 & 946,49 & 460,12 & 486,36 & 0,00 & 0,08 & 19,75 & 16,32 & 58749,55 & 6,64 \\
\hline 5,64 & 1132,69 & 0,74 & 0,84 & 0,01 & 945,35 & 458,84 & 486,51 & 0,00 & 0,08 & 18,53 & 15,31 & 55126,86 & 6,22 \\
\hline
\end{tabular}


Appendix B. Experiment 2 Tab.5 AER results (08.11.03)

\begin{tabular}{|c|c|c|c|c|c|c|c|c|c|c|c|c|c|c|}
\hline Date & Time & $\begin{array}{l}\text { Tracer gas } \\
\quad \text { (AER) }\end{array}$ & SF6 (CV) & $\begin{array}{c}\text { Heat } \\
\text { Balance } \\
\text { (AER) }\end{array}$ & $\begin{array}{c}\text { Moisture } \\
\text { Balance } \\
\text { (AER) }\end{array}$ & $\begin{array}{c}\text { O.Temp } \\
\left({ }^{\circ} \mathrm{C}\right)\end{array}$ & $\begin{array}{l}\text { I.Temp } \\
\left({ }^{\circ} \mathrm{C}\right)\end{array}$ & $\begin{array}{c}\Delta \text { Temp } \\
\left({ }^{\circ} \mathrm{C}\right)\end{array}$ & $\begin{array}{c}\text { O.Humid } \\
(\%)\end{array}$ & $\begin{array}{l}\text { I.Humid } \\
(\%)\end{array}$ & $\begin{array}{c}\Delta \text { water } \\
\text { content } \\
(\mathrm{kg} \\
\text { water } / \mathrm{m}^{3} \\
\text { dry air }\end{array}$ & $\begin{array}{l}\text { Wind } \\
\text { speed } \\
\left(\mathrm{mS}^{-1}\right)\end{array}$ & $\begin{array}{l}\text { Max wind } \\
\text { speed } \\
\text { (mS-1) }\end{array}$ & $\begin{array}{c}\text { Wind } \\
\text { Direction } \\
\left(^{\circ}\right)\end{array}$ \\
\hline 08.11 .03 & $12: 00$ & 3,88 & 15,75 & 4,64 & 6,28 & 8,7 & 22,6 & 13,9 & 74,8 & 57,4 & 0,00459 & 5,3 & 11,2 & 87 \\
\hline 08.11 .03 & $13: 00$ & 2,68 & 14,25 & 4,62 & 6,72 & 9 & 22,8 & 13,8 & 73,5 & 55,0 & 0,00429 & 5,2 & 9 & 86,7 \\
\hline 08.11 .03 & $14: 00$ & 4,49 & 14,69 & 4,52 & 6,80 & 9,1 & 23,0 & 13,9 & 72,6 & 53,9 & 0,00424 & 4,8 & 11 & 85 \\
\hline 08.11 .03 & $15: 00$ & 3,35 & 16,84 & 4,57 & 6,68 & 9,2 & 23,0 & 13,8 & 70,8 & 53,8 & 0,00431 & 5,2 & 11,1 & 91,3 \\
\hline 08.11 .03 & $16: 00$ & 4,28 & 24,80 & 4,47 & 6,34 & 8,8 & 22,9 & 14,1 & 74 & 55,9 & 0,00454 & 4,4 & 10,8 & 91,1 \\
\hline 08.11 .03 & $17: 00$ & 3,20 & 20,43 & 3,95 & 5,82 & 7,9 & 23,2 & 15,3 & 77,8 & 56,6 & 0,00495 & 5,1 & 12,1 & 87,5 \\
\hline 08.11 .03 & $18: 00$ & 3,94 & 16,90 & 3,81 & 5,67 & 7,2 & 23,1 & 15,9 & 79,9 & 57,2 & 0,00507 & 4,4 & 8,9 & 89,2 \\
\hline 08.11 .03 & 19:00 & 2,99 & 16,98 & 3,54 & 5,37 & 6,5 & 23,3 & 16,8 & 81,7 & 57,5 & 0,00535 & 4,8 & 10,8 & 86,4 \\
\hline 08.11 .03 & $20: 00$ & 3,09 & 10,07 & 3,37 & 5,32 & 6,1 & 23,4 & 17,3 & 82,7 & 56,8 & 0,00540 & 4,7 & 9,7 & 87 \\
\hline 08.11 .03 & $21: 00$ & 2,31 & 12,69 & 3,25 & 4,90 & 6 & 23,6 & 17,6 & 83,3 & 58,5 & 0,00586 & 3,6 & 7,9 & 90,8 \\
\hline 08.11 .03 & $22: 00$ & 0,92 & 19,07 & 3,03 & 4,89 & 5,3 & 23,8 & 18,5 & 85,5 & 57,4 & 0,00586 & 3,1 & 6,2 & 89,6 \\
\hline 08.11 .03 & $23: 00$ & 1,29 & 18,74 & 2,98 & 4,73 & 4,8 & 23,7 & 18,9 & 86,9 & 58,5 & 0,00605 & 3,3 & 7,6 & 89,4 \\
\hline 09.11 .03 & $00: 00$ & 1,66 & 12,47 & 2,88 & 4,71 & 4,5 & 23,8 & 19,3 & 87,4 & 57,9 & 0,00608 & 3,5 & 7,6 & 89,8 \\
\hline 09.11 .03 & 01:00 & 2,35 & 15,15 & 2,74 & 4,61 & 4,1 & 23,9 & 19,8 & 88,2 & 57,4 & 0,00620 & 3 & 7 & 90,5 \\
\hline 09.11 .03 & 02:00 & 3,57 & 13,28 & 2,70 & 4,81 & 4,2 & 24,1 & 19,9 & 88,2 & 55,7 & 0,00594 & 3,2 & 6,6 & 91,5 \\
\hline 09.11 .03 & 03:00 & 2,11 & 15,91 & 2,74 & 4,85 & 4,3 & 24,1 & 19,8 & 88,2 & 55,7 & 0,00589 & 3,4 & 7,1 & 90,4 \\
\hline 09.11 .03 & 04:00 & 1,67 & 10,39 & 2,65 & 4,54 & 4,3 & 24,3 & 20,0 & 88,5 & 57,1 & 0,00629 & 2,7 & 7 & 89,3 \\
\hline 09.11 .03 & 05:00 & 1,91 & 12,58 & 2,70 & 4,64 & 4,2 & 24,1 & 19,9 & 89,2 & 57,1 & 0,00615 & 2,5 & 5,4 & 89,6 \\
\hline 09.11 .03 & 06:00 & 0,96 & 18,48 & 2,76 & 4,58 & 4,3 & 24,0 & 19,7 & 89,4 & 58,2 & 0,00625 & 2,3 & 4,5 & 89,6 \\
\hline 09.11 .03 & 07:00 & 1,79 & 16,96 & 2,86 & 4,78 & 4,4 & 23,8 & 19,4 & 89,3 & 57,7 & 0,00599 & 2,5 & 5,7 & 93 \\
\hline 09.11 .03 & 08:00 & 1,52 & 10,17 & 2,91 & 4,63 & 4,3 & 23,6 & 19,3 & 89,7 & 59,3 & 0,00618 & 2,2 & 5,2 & 92,3 \\
\hline 09.11 .03 & 09:00 & 5,67 & 15,68 & 3,01 & 4,18 & 4,4 & 23,4 & 19,0 & 90,1 & 64,0 & 0,00685 & 2 & 5,1 & 96,8 \\
\hline 09.11 .03 & $10: 00$ & 1,98 & 14,65 & 3,05 & 4,51 & 4,5 & 23,3 & 18,8 & 90,2 & 61,8 & 0,00636 & 2,1 & 4,7 & 98,7 \\
\hline 09.11 .03 & $11: 00$ & 2,35 & 14,45 & 3,12 & 4,35 & 4,8 & 23,3 & 18,5 & 90 & 63,5 & 0,00658 & 2,1 & 5,4 & 102,3 \\
\hline
\end{tabular}


Appendix B. Experiment 2 Tab.6 Tracer gas results (08.11.03)

\begin{tabular}{|c|c|c|c|c|c|c|c|c|c|c|c|c|c|}
\hline Date & Time & $\begin{array}{c}\text { SF6 } \\
(\mathrm{mg} / \mathrm{m} 3)\end{array}$ & Reciprocal & $\begin{array}{l}\text { Measurement } \\
\text { interval } \\
\text { (mins) }\end{array}$ & $\begin{array}{l}\text { Background } \\
(\mathrm{mg} / \mathrm{m} 3)\end{array}$ & $\begin{array}{c}\text { Dosage } \\
(\mathrm{mg})\end{array}$ & $\begin{array}{l}\text { Dosage + } \\
\text { background } \\
(\mathrm{mg})\end{array}$ & $\begin{array}{c}\text { Total } \\
\text { dosage } \\
(\mathrm{mg})\end{array}$ & $\begin{array}{l}\text { Dosage } \\
\text { (mg/min) }\end{array}$ & $\begin{array}{l}\text { Dosage } \\
\text { (g/min) }\end{array}$ & $\begin{array}{l}\text { Supplied } \\
\text { air volume } \\
\text { m3/min }\end{array}$ & $\begin{array}{c}\text { Supplied } \\
\text { air volume } \\
\text { m3/h }\end{array}$ & AER \\
\hline 08.11 .03 & $12: 00$ & 5,99 & 0,17 & & 48814,7 & & & & & & & & \\
\hline 08.11 .03 & $13: 00$ & 4,96 & 0,20 & 60,55 & 40410,8 & 47925,00 & 107851,00 & 156666 & 2587,4 & 2,587 & 521,69 & 31588,37 & 3,88 \\
\hline 08.11 .03 & $14: 00$ & 6,41 & 0,16 & 59,64 & 52218,1 & 48340,32 & 198227,26 & 139732 & 2342,9 & 2,343 & 365,59 & 21803,5 & 2,68 \\
\hline 08.11 .03 & $15: 00$ & 4,16 & 0,24 & 60,21 & 33934,2 & 48549,80 & 200141,92 & 152394 & 2531,0 & 2,531 & 607,73 & 36591,49 & 4,49 \\
\hline 08.11 .03 & $16: 00$ & 4,90 & 0,20 & 59,81 & 39886,6 & 48806,67 & 199059,09 & 133592 & 2233,6 & 2,234 & 456,28 & 27290,08 & 3,35 \\
\hline 08.11 .03 & $17: 00$ & 4,00 & 0,25 & 59,97 & 32573,3 & 51092,90 & 196633,61 & 139347 & 2323,6 & 2,324 & 581,24 & 34856,68 & 4,28 \\
\hline 08.11 .03 & $17: 59$ & 5,06 & 0,20 & 59,64 & 41228,6 & 48192,40 & 201981,50 & 132114 & 2215,2 & 2,215 & 437,79 & 26109,61 & 3,20 \\
\hline 08.11 .03 & $18: 59$ & 4,41 & 0,23 & 59,97 & 35916,7 & 48648,50 & 199868,88 & 141391 & 2357,7 & 2,358 & 534,86 & 32075,78 & 3,94 \\
\hline 08.11 .03 & $19: 59$ & 5,58 & 0,18 & 59,80 & 45497,1 & 48467,80 & 200356,10 & 136004 & 2274,3 & 2,274 & 407,30 & 24356,81 & 2,99 \\
\hline 08.11 .03 & $20: 59$ & 5,79 & 0,17 & 59,89 & 47189,1 & 49155,00 & 200081,10 & 145881 & 2435,8 & 2,436 & 420,59 & 25188,85 & 3,09 \\
\hline 08.11 .03 & $21: 59$ & 8,13 & 0,12 & 59,88 & 66270,1 & 54206,80 & 206654,20 & 153042 & 2555,8 & 2,556 & 314,24 & 18816,73 & 2,31 \\
\hline 08.11 .03 & $23: 00$ & 57,65 & 0,02 & 61,39 & 469729,5 & 194934,90 & 594616,40 & 433942 & 7068,6 & 7,069 & 122,61 & 7527,231 & 0,92 \\
\hline 09.11 .03 & $0: 00$ & 7,60 & 0,13 & 59,46 & 61937,8 & 51479,10 & 491580,46 & 643792 & 10827,3 & 10,827 & 1424,35 & 84691,62 & 10,39 \\
\hline 09.11 .03 & $1: 00$ & 12,05 & 0,08 & 60,22 & 98202,4 & 48917,70 & 204850,60 & 163082 & 2708,1 & 2,708 & 224,70 & 13531,19 & 1,66 \\
\hline 09.11 .03 & $2: 00$ & 10,38 & 0,10 & 59,64 & 84616,4 & 51746,90 & 197795,00 & 198515 & 3328,5 & 3,329 & 320,52 & 19115,63 & 2,35 \\
\hline 09.11 .03 & $3: 00$ & 6,34 & 0,16 & 60,31 & 51674,1 & 47803,90 & 203178,80 & 184234 & 3054,8 & 3,055 & 481,68 & 29050,19 & 3,57 \\
\hline 09.11 .03 & $4: 00$ & 8,80 & 0,11 & 60,39 & 71710,5 & 52390,40 & 194964,30 & 151449 & 2507,9 & 2,508 & 284,95 & 17208,21 & 2,11 \\
\hline 09.11 .03 & $5: 00$ & 12,63 & 0,08 & 59,46 & 102936,4 & 51437,50 & 201316,90 & 171893 & 2890,9 & 2,891 & 228,83 & 13606,27 & 1,67 \\
\hline 09.11 .03 & $6: 01$ & 13,49 & 0,07 & 61,38 & 109932,8 & 54988,00 & 209816,30 & 209620 & 3415,1 & 3,415 & 253,12 & 15536,6 & 1,91 \\
\hline 09.11 .03 & 7:01 & 36,37 & 0,03 & 59,30 & 296356,3 & 126965,70 & 278319,50 & 285081 & 4807,4 & 4,807 & 132,18 & 7838,008 & 0,96 \\
\hline 09.11 .03 & 8:01 & 46,40 & 0,02 & 60,72 & 378056,3 & 189246,70 & 697088,20 & 676041 & 11133,7 & 11,134 & 239,96 & 14570,27 & 1,79 \\
\hline 09.11 .03 & 9:00 & 59,31 & 0,02 & 58,72 & 483255,2 & 178952,00 & 723101,50 & 734460 & 12507,8 & 12,508 & 210,89 & 12383,47 & 1,52 \\
\hline 09.11 .03 & $10: 01$ & 13,03 & 0,08 & 61,39 & 106184,7 & 51409,50 & 365597,90 & 602283 & 9810,8 & 9,811 & 752,82 & 46215,69 & 5,67 \\
\hline 09.11 .03 & $11: 01$ & 12,79 & 0,08 & 59,22 & 104237,4 & 51536,70 & 199749,40 & 206123 & 3480,6 & 3,481 & 272,07 & 16112,17 & 1,98 \\
\hline 09.11 .03 & $12: 00$ & 10,48 & 0,10 & 59,13 & 85409,2 & 45471,60 & 199362,50 & 200886 & 3397,4 & 3,397 & 324,11 & 19164,43 & 2,35 \\
\hline
\end{tabular}




\section{Appendix B. Experiment 2 Tab.7 Heat balance results (08.11.03)}

\begin{tabular}{|c|c|c|c|c|c|c|c|c|c|}
\hline Date & Time & $\begin{array}{l}\text { Total heat } \\
\text { /animal } \\
\left(20^{\circ} \mathrm{C}\right) \mathrm{W}\end{array}$ & $\begin{array}{c}\text { hpu/all } \\
\text { animals }\end{array}$ & $\begin{array}{c}\text { Sensible } \\
\text { heat and } \\
\text { temperature } \\
\text { factors }\end{array}$ & $\begin{array}{l}\text { Sensible } \\
\text { Heat/ all } \\
\text { animals } \\
\text { (W) }\end{array}$ & $\begin{array}{l}\text { Heat loss } \\
\text { Thought } \\
\text { Building } \\
\text { (W) }\end{array}$ & $\begin{array}{l}\text { Calculated } \\
\operatorname{AER}\left(\mathrm{m}^{3} / \mathrm{s}\right)\end{array}$ & $\begin{array}{l}\text { Calculated } \\
\operatorname{AER}\left(\mathrm{m}^{3} / \mathrm{h}\right)\end{array}$ & $\begin{array}{c}\text { Heat } \\
\text { balance } \\
\text { AER/h }\end{array}$ \\
\hline 8.11 .2003 & $12: 00$ & 10,56 & 422,40 & 462,75 & 195465,52 & $-31683,67$ & 10,49 & 37775,03 & 4,64 \\
\hline 8.11 .2003 & $13: 00$ & 10,56 & 422,40 & 457,85 & 193397,33 & $-31494,52$ & 10,44 & 37596,09 & 4,62 \\
\hline 8.11 .2003 & $14: 00$ & 10,56 & 422,40 & 453,15 & 191411,81 & $-31740,70$ & 10,23 & 36826,26 & 4,52 \\
\hline 8.11 .2003 & $15: 00$ & 10,56 & 422,40 & 453,56 & 191585,62 & $-31470,60$ & 10,34 & 37238,27 & 4,57 \\
\hline 8.11 .2003 & $16: 00$ & 10,56 & 422,40 & 455,35 & 192340,46 & $-32204,72$ & 10,11 & 36393,78 & 4,47 \\
\hline 8.11 .2003 & $17: 00$ & 10,56 & 422,40 & 447,19 & 188892,75 & $-35083,62$ & 8,94 & 32180,81 & 3,95 \\
\hline 8.11 .2003 & $18: 00$ & 10,56 & 422,40 & 450,25 & 190183,74 & $-36377,06$ & 8,62 & 31036,12 & 3,81 \\
\hline 8.11 .2003 & $19: 00$ & 10,56 & 422,40 & 446,89 & 188764,48 & $-38314,67$ & 8,02 & 28870,67 & 3,54 \\
\hline 8.11 .2003 & $20: 00$ & 10,56 & 422,40 & 443,48 & 187327,35 & $-39569,68$ & 7,64 & 27492,23 & 3,37 \\
\hline 8.11 .2003 & $21: 00$ & 10,56 & 422,40 & 438,14 & 185071,82 & $-40330,74$ & 7,35 & 26464,69 & 3,25 \\
\hline 8.11 .2003 & $22: 00$ & 10,56 & 422,40 & 434,51 & 183537,67 & $-42291,80$ & 6,85 & 24675,40 & 3,03 \\
\hline 8.11 .2003 & $23: 00$ & 10,56 & 422,40 & 437,66 & 184868,37 & $-43122,03$ & 6,74 & 24279,27 & 2,98 \\
\hline 9.11 .2003 & $00: 00$ & 10,56 & 422,40 & 435,21 & 183831,65 & $-44051,68$ & 6,52 & 23463,27 & 2,88 \\
\hline 9.11 .2003 & 01:00 & 10,56 & 422,40 & 431,03 & 182066,82 & $-45379,99$ & 6,20 & 22312,86 & 2,74 \\
\hline 9.11 .2003 & $02: 00$ & 10,56 & 422,40 & 427,32 & 180501,57 & $-45517,20$ & 6,11 & 21991,20 & 2,70 \\
\hline 9.11 .2003 & 03:00 & 10,56 & 422,40 & 428,49 & 180993,25 & $-45173,79$ & 6,19 & 22284,11 & 2,74 \\
\hline 9.11 .2003 & 04:00 & 10,56 & 422,40 & 422,99 & 178672,24 & $-45714,67$ & 6,00 & 21594,64 & 2,65 \\
\hline 9.11 .2003 & 05:00 & 10,56 & 422,40 & 427,36 & 180515,77 & $-45513,88$ & 6,11 & 21995,42 & 2,70 \\
\hline 9.11 .2003 & $06: 00$ & 10,56 & 422,40 & 430,23 & 181730,31 & $-45001,51$ & 6,25 & 22506,87 & 2,76 \\
\hline 9.11 .2003 & 07:00 & 10,56 & 422,40 & 435,36 & 183895,87 & $-44265,20$ & 6,48 & 23327,15 & 2,86 \\
\hline 9.11 .2003 & 08:00 & 10,56 & 422,40 & 439,16 & 185500,77 & $-44116,13$ & 6,58 & 23676,40 & 2,91 \\
\hline 9.11 .2003 & 09:00 & 10,56 & 422,40 & 443,96 & 187529,03 & $-43408,40$ & 6,80 & 24491,12 & 3,01 \\
\hline 9.11 .2003 & $10: 00$ & 10,56 & 422,40 & 445,52 & 188188,33 & $-43023,62$ & 6,91 & 24875,22 & 3,05 \\
\hline 9.11 .2003 & $11: 00$ & 10,56 & 422,40 & 445,88 & 188338,29 & $-42302,22$ & 7,07 & 25439,53 & 3,12 \\
\hline
\end{tabular}


Appendix B. Experiment 2 Tab.8a Moisture balance results (08.11.03)
A1

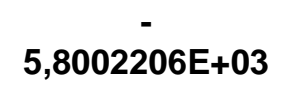
indoor $\mathrm{T}$
oK
T2
T3
LnT Pws Pa) HR

Pw
(Kpa)

\section{Wi (kg}
as)
outdoor
$\mathrm{T}$ ㅇ K
T2
T3
LnT

\begin{tabular}{|c|c|c|c|c|c|c|c|c|c|c|c|c|c|}
\hline A2 & 1,3914993 & 295,71 & 87443,793 & 25857914 & 5,6893757 & 2736,2824 & 0,57 & 1,572 & 0,0097988 & 281,85 & 79439,423 & 22390001 & 5,641375 \\
\hline A3 & $-4,86 \mathrm{E}-02$ & 295,93 & 87572,332 & 25914950 & 5,6901102 & 2772,5982 & 0,55 & 1,526 & 0,00951 & 282,15 & 79608,623 & 22461573 & 5,6424388 \\
\hline A4 & $4,18 \mathrm{E}-05$ & 296,13 & 87695,293 & 25969550 & 5,6908118 & 2807,706 & 0,54 & 1,514 & 0,0094321 & 282,25 & 79665,063 & 22485464 & 5,6427932 \\
\hline A5 & $-1,45 \mathrm{E}-08$ & 296,12 & 87684,546 & 25964777 & 5,6907505 & 2804,6232 & 0,54 & 1,510 & 0,0094107 & 282,35 & 79721,523 & 22509372 & 5,6431474 \\
\hline A6 & 0 & 296,04 & 87637,836 & 25944032 & 5,6904841 & 2791,2559 & 0,56 & 1,561 & 0,0097309 & 281,95 & 79495,803 & 22413842 & 5,6417298 \\
\hline \multirow[t]{2}{*}{ A7 } & 6,5459673 & 296,40 & 87850,684 & 26038606 & 5,6916969 & 2852,5924 & 0,57 & 1,615 & 0,0100762 & 281,05 & 78989,103 & 22199887 & 5,6385326 \\
\hline & & 296,26 & 87771,133 & 26003246 & 5,691244 & 2829,5405 & 0,57 & 1,617 & 0,0100899 & 280,35 & 78596,123 & 22034423 & 5,6360388 \\
\hline patm (Pa) & 101325 & 296,41 & 87858,579 & 26042115 & 5,6917419 & 2854,8883 & 0,57 & 1,641 & 0,0102389 & 279,65 & 78204,123 & 21869783 & 5,6335388 \\
\hline \multirow[t]{16}{*}{$\mathrm{Ra}$} & 287,055 & 296,56 & 87946,908 & 26081398 & 5,6922443 & 2880,6805 & 0,57 & 1,637 & 0,0102158 & 279,25 & 77980,563 & 21776072 & 5,6321074 \\
\hline & & 296,79 & 88085,099 & 26142894 & 5,6930293 & 2921,4142 & 0,59 & 1,710 & 0,0106754 & 279,15 & 77924,723 & 21752686 & 5,6317493 \\
\hline & & 296,95 & 88178,791 & 26184616 & 5,6935609 & 2949,2982 & 0,57 & 1,693 & 0,0105719 & 278,45 & 77534,403 & 21589454 & 5,6292385 \\
\hline & & 296,81 & 88097,538 & 26148432 & 5,6930999 & 2925,1039 & 0,58 & 1,710 & 0,0106781 & 277,95 & 77256,203 & 21473361 & 5,6274412 \\
\hline & & 296,92 & 88160,856 & 26176628 & 5,6934592 & 2943,9438 & 0,58 & 1,703 & 0,0106338 & 277,65 & 77089,523 & 21403906 & 5,6263613 \\
\hline & & 297,10 & 88268,39 & 26224536 & 5,6940687 & 2976,1669 & 0,57 & 1,709 & 0,0106685 & 277,25 & 76867,563 & 21311532 & 5,6249196 \\
\hline & & 297,26 & 88363,498 & 26266932 & 5,6946071 & 3004,906 & 0,56 & 1,672 & 0,0104379 & 277,35 & 76923,023 & 21334600 & 5,6252802 \\
\hline & & 297,21 & 88333,649 & 26253624 & 5,6944382 & 2995,8621 & 0,56 & 1,670 & 0,010421 & 277,45 & 76978,503 & 21357686 & 5,6256407 \\
\hline & & 297,45 & 88474,338 & 26316370 & 5,6952339 & 3038,6847 & 0,57 & 1,735 & 0,0108339 & 277,45 & 76978,503 & 21357686 & 5,6256407 \\
\hline & & 297,26 & 88362,636 & 26266547 & 5,6946022 & 3004,6445 & 0,57 & 1,714 & 0,0107043 & 277,35 & 76923,023 & 21334600 & 5,6252802 \\
\hline & & 297,13 & 88288,858 & 26233658 & 5,6941846 & 2982,3328 & 0,58 & 1,736 & 0,0108394 & 277,45 & 76978,503 & 21357686 & 5,6256407 \\
\hline & & 296,91 & 88156,937 & 26174882 & 5,6934369 & 2942,7748 & 0,58 & 1,699 & 0,010606 & 277,55 & 77034,003 & 21380787 & 5,6260011 \\
\hline & & 296,75 & 88058,859 & 26131214 & 5,6928804 & 2913,6438 & 0,59 & 1,728 & 0,0107886 & 277,45 & 76978,503 & 21357686 & 5,6256407 \\
\hline & & 296,54 & 87934,525 & 26075890 & 5,6921739 & 2877,0533 & 0,64 & 1,841 & 0,0115106 & 277,55 & 77034,003 & 21380787 & 5,6260011 \\
\hline & & 296,47 & 87894,016 & 26057873 & 5,6919435 & 2865,2134 & 0,62 & 1,770 & 0,0110575 & 277,65 & 77089,523 & 21403906 & 5,6263613 \\
\hline & & 296,45 & 87884,796 & 26053773 & 5,6918911 & 2862,5241 & 0,64 & 1,819 & 0,01137 & 277,95 & 77256,203 & 21473361 & 5,6274412 \\
\hline
\end{tabular}


Appendix B. Experiment 2 Tab.8b Moisture balance results (08.11.03)

\begin{tabular}{|c|c|c|c|c|c|c|c|c|c|c|c|c|}
\hline Pws Pa) & HR & $\begin{array}{c}\text { Pw } \\
(\mathrm{Kpa})\end{array}$ & $\begin{array}{c}\text { Wo (kg } \\
\text { ag/ka } \\
\text { as) }\end{array}$ & $\begin{array}{l}\text { Total } \\
\text { heat } \\
\text { /hpu }\end{array}$ & $\begin{array}{c}\text { Sensible } \\
\text { Heat } \\
\text { /animal }\end{array}$ & $\begin{array}{l}\text { Latent } \\
\text { Heat } \\
\text { /animal } \\
\text { (W) }\end{array}$ & $\begin{array}{c}\text { Latent } \\
\text { Heat } \\
\text { /animal } \\
\text { (Kg } \\
\text { water/s) }\end{array}$ & $\begin{array}{c}\text { Latent } \\
\text { Heat } / 30 \\
000 \\
\text { animal } \\
(\mathrm{Kg} \\
\text { water/s) }\end{array}$ & $\begin{array}{c}\text { AER Kg } \\
\text { air/s }\end{array}$ & $\begin{array}{l}\text { AER } \\
\mathrm{m} 3 / \mathrm{s}\end{array}$ & $\begin{array}{l}\text { AER } \\
\mathrm{m} 3 / \mathrm{h}\end{array}$ & AER $/ \mathrm{hr}$ \\
\hline 1125,0542 & 0,748 & 0,842 & 0,005209 & 948,82 & 462,7498 & 486,071 & 0,0002017 & 0,0851935 & 18,571584 & 15,348417 & 55254,3 & 6,3 \\
\hline 1148,109 & 0,735 & 0,844 & 0,0052235 & 944,48 & 457,8535 & 486,622 & 0,0002019 & 0,0852901 & 19,906815 & 16,451913 & 59226,888 & 6,7 \\
\hline 1155,8859 & 0,726 & 0,839 & 0,0051943 & 940,32 & 453,1530 & 487,169 & 0,0002021 & 0,0853859 & 20,157782 & 16,659324 & 59973,565 & 6,8 \\
\hline 1163,7093 & 0,708 & 0,824 & 0,005099 & 940,68 & 453,5645 & 487,120 & 0,0002021 & 0,0853774 & 19,810723 & 16,372498 & 58940,993 & 6,7 \\
\hline 1132,6933 & 0,74 & 0,838 & 0,0051881 & 942,26 & 455,3515 & 486,911 & 0,000202 & 0,0853407 & 18,795918 & 15,533817 & 55921,741 & 6,3 \\
\hline 1065,5587 & 0,778 & 0,829 & 0,0051308 & 935,08 & 447,1893 & 487,887 & 0,0002024 & 0,0855119 & 17,301282 & 14,29858 & 51474,888 & 5,8 \\
\hline 1015,7955 & 0,799 & 0,812 & 0,0050223 & 937,76 & 450,2456 & 487,516 & 0,0002023 & 0,0854467 & 16,871738 & 13,943585 & 50196,908 & 5,7 \\
\hline 968,09522 & 0,817 & 0,791 & 0,0048933 & 934,81 & 446,8856 & 487,925 & 0,0002025 & 0,0855184 & 16,008087 & 13,229824 & 47627,365 & 5,4 \\
\hline 941,7356 & 0,827 & 0,779 & 0,0048178 & 931,83 & 443,4833 & 488,348 & 0,0002026 & 0,0855926 & 15,866446 & 13,112765 & 47205,955 & 5,3 \\
\hline 935,2456 & 0,833 & 0,779 & 0,0048193 & 927,17 & 438,1435 & 489,030 & 0,0002029 & 0,0857121 & 14,647064 & 12,105012 & 43578,042 & 4,9 \\
\hline 890,91129 & 0,855 & 0,762 & 0,0047113 & 924,02 & 434,5115 & 489,506 & 0,0002031 & 0,0857955 & 14,649911 & 12,107365 & 43586,513 & 4,9 \\
\hline 860,39147 & 0,869 & 0,748 & 0,0046237 & 926,75 & 437,6619 & 489,092 & 0,0002029 & 0,0857231 & 14,169562 & 11,710382 & 42157,373 & 4,7 \\
\hline 842,52661 & 0,874 & 0,736 & 0,0045533 & 924,62 & 435,2075 & 489,414 & 0,0002031 & 0,0857794 & 14,117807 & 11,667609 & 42003,393 & 4,7 \\
\hline 819,21737 & 0,882 & 0,723 & 0,0044672 & 921,00 & 431,0294 & 489,971 & 0,0002033 & 0,0858771 & 13,858906 & 11,453641 & 41233,107 & 4,6 \\
\hline 824,99056 & 0,882 & 0,728 & 0,0044989 & 917,80 & 427,3238 & 490,477 & 0,0002035 & 0,0859657 & 14,485179 & 11,971223 & 43096,401 & 4,8 \\
\hline 830,7997 & 0,882 & 0,733 & 0,0045308 & 918,80 & 428,4878 & 490,317 & 0,0002035 & 0,0859377 & 14,600344 & 12,0664 & 43439,04 & 4,9 \\
\hline 830,7997 & 0,885 & 0,735 & 0,0045463 & 914,07 & 422,9930 & 491,080 & 0,0002038 & 0,0860714 & 13,700087 & 11,322386 & 40760,59 & 4,5 \\
\hline 824,99056 & 0,892 & 0,736 & 0,0045503 & 917,83 & 427,3574 & 490,472 & 0,0002035 & 0,0859649 & 13,979704 & 11,553474 & 41592,507 & 4,6 \\
\hline 830,7997 & 0,894 & 0,743 & 0,0045929 & 920,31 & 430,2327 & 490,079 & 0,0002034 & 0,085896 & 13,761936 & 11,373501 & 40944,603 & 4,6 \\
\hline 836,64499 & 0,893 & 0,747 & 0,0046203 & 924,75 & 435,3596 & 489,394 & 0,0002031 & 0,0857759 & 14,340587 & 11,851725 & 42666,21 & 4,8 \\
\hline 830,7997 & 0,897 & 0,745 & 0,0046084 & 928,06 & 439,1590 & 488,898 & 0,0002029 & 0,0856891 & 13,875949 & 11,467726 & 41283,815 & 4,6 \\
\hline 836,64499 & 0,901 & 0,754 & 0,004662 & 932,25 & 443,9608 & 488,288 & 0,0002026 & 0,0855821 & 12,507667 & 10,336915 & 37212,893 & 4,2 \\
\hline 842,52661 & 0,902 & 0,760 & 0,0047002 & 933,62 & 445,5216 & 488,093 & 0,0002025 & 0,085548 & 13,467784 & 11,1304 & 40069,44 & 4,5 \\
\hline 860,39147 & 0,9 & 0,774 & 0,0047899 & 933,93 & 445,8766 & 488,049 & 0,0002025 & 0,0855403 & 13,011316 & 10,753154 & 38711,354 & 4,4 \\
\hline
\end{tabular}


Appendix B. Experiment 2 Tab.9 AER Results (09.11.03)

\begin{tabular}{|c|c|c|c|c|c|c|c|c|c|c|c|c|}
\hline $\begin{array}{l}\text { Tracer gas } \\
\text { (AER) }\end{array}$ & SF6 (CV) & $\begin{array}{c}\text { Heat } \\
\text { Balance } \\
\text { (AER) }\end{array}$ & $\begin{array}{c}\text { Moisture } \\
\text { Balance } \\
\text { (AER) }\end{array}$ & $\begin{array}{l}\text { O.Temp } \\
\left({ }^{\circ} \mathrm{C}\right)\end{array}$ & $\begin{array}{l}\text { I.Temp } \\
\left({ }^{\circ} \mathrm{C}\right)\end{array}$ & $\begin{array}{c}\Delta \text { Temp } \\
\left({ }^{\circ} \mathrm{C}\right)\end{array}$ & $\begin{array}{l}\text { O.Humid } \\
(\%)\end{array}$ & $\begin{array}{l}\text { I.Humid } \\
(\%)\end{array}$ & $\begin{array}{c}\Delta \text { water } \\
\text { content } \\
(\mathbf{k g} \\
\text { water } / \mathbf{m}^{3} \\
\text { dry air }\end{array}$ & $\begin{array}{l}\text { Wind } \\
\text { speed } \\
\left(\mathrm{mS}^{-1}\right)\end{array}$ & $\begin{array}{l}\text { Max wind } \\
\text { speed } \\
\text { (mS-1) }\end{array}$ & $\begin{array}{c}\text { Wind } \\
\text { Direction } \\
\left({ }^{\circ}\right)\end{array}$ \\
\hline 2,57 & 10,74 & 3,43 & 4,93 & 4,9 & 23,1 & 18,2 & 62,2 & 90,0 & 0,00615 & 2,8 & 5,3 & 97,1 \\
\hline 2,01 & 12,28 & 3,49 & 4,92 & 5,2 & 23,1 & 17,9 & 62,6 & 89,6 & 0,00616 & 2,5 & 5 & 94,1 \\
\hline 2,28 & 15,85 & 3,49 & 4,85 & 5,6 & 23,3 & 17,7 & 62,7 & 88,4 & 0,00625 & 2,4 & 4,5 & 94,1 \\
\hline 1,59 & 25,33 & 3,50 & 5,09 & 5,5 & 23,2 & 17,7 & 61,3 & 89,0 & 0,00595 & 2,7 & 5,4 & 93,4 \\
\hline 2,23 & 24,14 & 3,40 & 5,06 & 5,2 & 23,3 & 18,1 & 61,1 & 90,2 & 0,00599 & 2,7 & 5,9 & 91,7 \\
\hline 2,45 & 18,29 & 3,36 & 4,95 & 4,9 & 23,2 & 18,3 & 61,8 & 91,3 & 0,00611 & 2,7 & 6,4 & 91,9 \\
\hline 4,22 & 17,03 & 3,30 & 5,29 & 4,7 & 23,3 & 18,6 & 59,7 & 93,2 & 0,00572 & 3,5 & 8 & 93,2 \\
\hline 2,66 & 19,01 & 3,34 & 5,07 & 5,1 & 23,4 & 18,3 & 61,3 & 92,9 & 0,00598 & 2,6 & 5,1 & 92,1 \\
\hline 1,96 & 11,04 & 3,57 & 5,09 & 5,7 & 23,2 & 17,5 & 62,4 & 90,5 & 0,00596 & 2,7 & 6,1 & 95,4 \\
\hline 2,34 & 12,81 & 3,60 & 4,81 & 5,5 & 23,0 & 17,5 & 64,8 & 91,1 & 0,00631 & 1,9 & 5 & 92,2 \\
\hline 2,81 & 14,60 & 3,35 & 4,91 & 5,1 & 23,4 & 18,3 & 62,3 & 92,5 & 0,00617 & 2,6 & 5,5 & 93,4 \\
\hline 1,91 & 13,92 & 3,03 & 4,98 & 4,4 & 23,8 & 19,4 & 59,7 & 94,9 & 0,00607 & 2,5 & 5,2 & 90,6 \\
\hline 2,26 & 12,06 & 2,95 & 5,11 & 4 & 23,8 & 19,8 & 58,5 & 96,8 & 0,00591 & 2,8 & 5,8 & 90,6 \\
\hline 2,46 & 14,38 & 2,92 & 5,17 & 3,9 & 23,8 & 19,9 & 58,2 & 97,7 & 0,00585 & 2,6 & 5,5 & 92,5 \\
\hline 3,15 & 12,13 & 2,89 & 5,50 & 3,8 & 23,9 & 20,1 & 56,0 & 97,8 & 0,00549 & 2,9 & 7,5 & 92,6 \\
\hline 2,40 & 15,67 & 2,78 & 5,32 & 3,6 & 24,1 & 20,5 & 56,0 & 98,1 & 0,00567 & 2,6 & 5,6 & 94,1 \\
\hline 1,90 & 16,62 & 2,80 & 5,45 & 3,4 & 23,9 & 20,5 & 55,6 & 98,3 & 0,00555 & 2,5 & 5,6 & 93,4 \\
\hline 3,13 & 18,26 & 2,77 & 5,38 & 3,4 & 24,0 & 20,6 & 55,6 & 98,4 & 0,00561 & 2,6 & 5,9 & 94 \\
\hline 2,06 & 12,31 & 2,82 & 5,63 & 3,3 & 23,8 & 20,5 & 54,8 & 98,6 & 0,00536 & 2,9 & 7 & 92 \\
\hline 3,20 & 17,54 & 2,71 & 5,56 & 2,9 & 23,9 & 21,0 & 54,2 & 98,8 & 0,00543 & 3,2 & 6,6 & 91,4 \\
\hline 2,62 & 12,50 & 2,84 & 5,14 & 2,4 & 23,3 & 20,9 & 57,8 & 99,0 & 0,00588 & 3,1 & 7,2 & 97,7 \\
\hline 2,11 & 24,71 & 2,79 & 5,23 & 2,4 & 23,4 & 21,0 & 56,8 & 99,1 & 0,00577 & 2,5 & 5,4 & 94,8 \\
\hline 1,76 & 19,87 & 2,83 & 5,22 & 2,1 & 23,2 & 21,1 & 57,2 & 98,9 & 0,00578 & 3,2 & 7,6 & 96,1 \\
\hline 3,97 & 13,86 & 2,75 & 5,21 & 2,2 & 23,4 & 21,2 & 56,2 & 98,0 & 0,00579 & 2,9 & 8,6 & 97 \\
\hline
\end{tabular}


Appendix B. Experiment 2 Tab.10 Tracer gas results (09.11.03)

\begin{tabular}{|c|c|c|c|c|c|c|c|c|c|c|c|c|c|}
\hline Date & Time & $\begin{array}{c}\text { SF6 } \\
(\mathrm{mg} / \mathrm{m} 3)\end{array}$ & Reciprocal & $\begin{array}{l}\text { Measurement } \\
\text { interval } \\
\text { (mins) }\end{array}$ & $\begin{array}{l}\text { Background } \\
(\mathrm{mg} / \mathrm{m} 3)\end{array}$ & $\begin{array}{l}\text { Dosage } \\
\text { (mg) }\end{array}$ & $\begin{array}{l}\text { Dosage + } \\
\text { background } \\
(\mathrm{mg})\end{array}$ & $\begin{array}{l}\text { Total } \\
\text { dosage } \\
\text { (mg) }\end{array}$ & $\begin{array}{l}\text { Dosage } \\
\text { (mg/min) }\end{array}$ & $\begin{array}{l}\text { Dosage } \\
\text { (g/min) }\end{array}$ & $\begin{array}{l}\text { Supplied } \\
\text { air volume } \\
\text { m3/min }\end{array}$ & $\begin{array}{l}\text { Supplied } \\
\text { air } \\
\text { volume } \\
\text { m3/h }\end{array}$ & AER \\
\hline 09.11 .03 & $12: 00$ & 11,22 & 0,089 & & 91419,7 & & & & & & & & \\
\hline 09.11 .03 & $13: 00$ & 9,24 & 0,108 & 59,71 & 75247,3 & 48909,9 & 101952,9 & 193372,6 & 3238,5303 & 3,2 & 350,7 & 20939,0 & 2,6 \\
\hline 09.11 .03 & $14: 00$ & 10,90 & 0,092 & 61,30 & 88848,5 & 51561,5 & 103461,4 & 178708,7 & 2915,3136 & 2,9 & 267,4 & 16388,8 & 2,0 \\
\hline 09.11 .03 & $15: 00$ & 10,17 & 0,098 & 59,47 & 82832,3 & 51595,8 & 100358,5 & 189207,0 & 3181,5539 & 3,2 & 313,0 & 18611,8 & 2,3 \\
\hline 09.11 .03 & $16: 00$ & 23,32 & 0,043 & 59,55 & 190030,4 & 164213,5 & 218527,7 & 301360,0 & 5060,6213 & 5,1 & 217,0 & 12921,5 & 1,6 \\
\hline 09.11 .03 & $17: 00$ & 31,22 & 0,032 & 60,64 & 254399,6 & 189621,4 & 377135,5 & 567165,9 & 9352,9993 & 9,4 & 299,6 & 18165,4 & 2,2 \\
\hline 09.11 .03 & $18: 00$ & 31,82 & 0,031 & 60,57 & 259280,2 & 190591,2 & 380159,3 & 634558,9 & 10476,455 & 10,5 & 329,2 & 19941,3 & 2,4 \\
\hline 09.11 .03 & $19: 00$ & 16,68 & 0,060 & 59,05 & 135933,1 & 128702,7 & 313693,4 & 572973,6 & 9703,1944 & 9,7 & 581,6 & 34344,8 & 4,2 \\
\hline 09.11 .03 & $20: 00$ & 10,93 & 0,092 & 59,55 & 89038,6 & 48938,7 & 100654,2 & 236587,3 & 3972,9182 & 4,0 & 363,6 & 21650,3 & 2,7 \\
\hline 09.11 .03 & $21: 00$ & 11,98 & 0,083 & 61,30 & 97640,2 & 50541,2 & 102453,3 & 191491,9 & 3123,8487 & 3,1 & 260,7 & 15979,9 & 2,0 \\
\hline 09.11 .03 & $22: 00$ & 10,37 & 0,096 & 59,30 & 84518,7 & 51848,3 & 100334,4 & 197974,6 & 3338,5261 & 3,3 & 321,8 & 19085,7 & 2,3 \\
\hline 09.11 .03 & $23: 00$ & 8,81 & 0,114 & 59,38 & 71770,0 & 65178,9 & 117414,8 & 201933,5 & 3400,6982 & 3,4 & 386,1 & 22925,4 & 2,8 \\
\hline 10.11 .03 & $0: 00$ & 11,10 & 0,090 & 59,13 & 90474,6 & 48873,5 & 100632,1 & 172402,1 & 2915,6457 & 2,9 & 262,6 & 15526,3 & 1,9 \\
\hline 10.11 .03 & $1: 00$ & 10,57 & 0,095 & 61,30 & 86108,3 & 52041,2 & 104289,2 & 194763,8 & 3177,2231 & 3,2 & 300,6 & 18429,5 & 2,3 \\
\hline 10.11 .03 & $2: 00$ & 9,40 & 0,106 & 59,80 & 76600,2 & 52785,0 & 102275,1 & 188383,4 & 3150,2247 & 3,2 & 335,1 & 20038,4 & 2,5 \\
\hline 10.11 .03 & 3:00 & 6,83 & 0,146 & 59,47 & 55688,6 & 48443,5 & 98738,6 & 175338,8 & 2948,3565 & 2,9 & 431,4 & 25654,5 & 3,1 \\
\hline 10.11 .03 & 4:00 & 8,04 & 0,124 & 60,23 & 65515,4 & 49852,1 & 101776,4 & 157465,0 & 2614,3947 & 2,6 & 325,1 & 19583,6 & 2,4 \\
\hline 10.11 .03 & 5:00 & 10,71 & 0,093 & 59,46 & 87224,6 & 49031,5 & 99903,4 & 165418,8 & 2782,0174 & 2,8 & 259,9 & 15452,4 & 1,9 \\
\hline 10.11 .03 & $6: 00$ & 7,47 & 0,134 & 60,30 & 60898,4 & 50318,7 & 103433,6 & 190658,2 & 3161,8277 & 3,2 & 423,0 & 25509,4 & 3,1 \\
\hline 10.11 .03 & 7:00 & 9,72 & 0,103 & 59,72 & 79193,1 & 50030,9 & 102439,1 & 163337,5 & 2735,0557 & 2,7 & 281,4 & 16805,4 & 2,1 \\
\hline 10.11 .03 & 8:00 & 7,08 & 0,141 & 61,46 & 57649,5 & 52875,2 & 105361,0 & 184554,1 & 3002,8332 & 3,0 & 424,4 & 26084,3 & 3,2 \\
\hline 10.11 .03 & 9:00 & 7,86 & 0,127 & 59,97 & 64065,0 & 60499,4 & 109911,0 & 167560,5 & 2794,0728 & 2,8 & 355,4 & 21310,9 & 2,6 \\
\hline 10.11 .03 & $10: 00$ & 24,77 & 0,040 & 59,05 & 201847,7 & 181470,5 & 362454,4 & 426519,4 & 7223,0213 & 7,2 & 291,6 & 17217,3 & 2,1 \\
\hline 10.11 .03 & $11: 00$ & 40,22 & 0,025 & 59,73 & 327747,9 & 190956,4 & 375311,2 & 577158,9 & 9662,7973 & 9,7 & 240,2 & 14348,5 & 1,8 \\
\hline 10.11 .03 & $12: 00$ & 19,32 & 0,052 & 60,97 & 157386,8 & 108286,5 & 297684,7 & 625432,6 & 10258,038 & 10,3 & 531,1 & 32379,0 & 4,0 \\
\hline
\end{tabular}


Appendix B. Experiment 2 Tab.11 Heat balance results (09.11.03)

\begin{tabular}{|c|c|c|c|c|c|c|c|c|c|}
\hline Date & Time & $\begin{array}{c}\text { Total } \\
\text { heat } \\
\text { /animal } \\
\left(20^{\circ} \mathrm{C}\right) \mathrm{W}\end{array}$ & $\begin{array}{l}\text { hpu/all } \\
\text { animals }\end{array}$ & $\begin{array}{c}\text { Sensible } \\
\text { heat and } \\
\text { temperature } \\
\text { factors }\end{array}$ & $\begin{array}{l}\text { Sensible } \\
\text { Heat/ all } \\
\text { animals } \\
\text { (W) }\end{array}$ & $\begin{array}{l}\text { Heat loss } \\
\text { Thought } \\
\text { Building } \\
\text { (W) }\end{array}$ & $\begin{array}{c}\text { Calculated } \\
\text { AER } \\
\left(\mathrm{m}^{3} / \mathrm{s}\right)\end{array}$ & $\begin{array}{c}\text { Calculated } \\
\text { AER } \\
\left(\mathrm{m}^{3} / \mathrm{h}\right)\end{array}$ & $\begin{array}{c}\text { Heat } \\
\text { balance } \\
\text { AER/h }\end{array}$ \\
\hline 9.11 .2003 & $12: 00$ & 11,10 & 444,00 & 450,91 & 200203,26 & $-41568,56$ & 7,21 & 25957,03 & 3,43 \\
\hline 9.11 .2003 & 13:00 & 11,10 & 444,00 & 450,30 & 199931,93 & $-40944,18$ & 7,34 & 26411,51 & 3,49 \\
\hline 9.11 .2003 & $14: 00$ & 11,10 & 444,00 & 445,62 & 197853,98 & $-40499,30$ & 7,34 & 26427,37 & 3,49 \\
\hline 9.11 .2003 & $15: 00$ & 11,10 & 444,00 & 447,27 & 198587,89 & $-40562,28$ & 7,36 & 26498,84 & 3,50 \\
\hline 9.11 .2003 & $16: 00$ & 11,10 & 444,00 & 445,57 & 197834,30 & $-41418,20$ & 7,14 & 25686,92 & 3,40 \\
\hline 9.11 .2003 & $17: 00$ & 11,10 & 444,00 & 447,23 & 198570,18 & $-41937,97$ & 7,06 & 25403,61 & 3,36 \\
\hline 9.11 .2003 & 18:00 & 11,10 & 444,00 & 446,60 & 198289,81 & $-42458,50$ & 6,93 & 24963,86 & 3,30 \\
\hline 9.11 .2003 & $19: 00$ & 11,10 & 444,00 & 443,71 & 197007,83 & $-41833,04$ & 7,01 & 25230,36 & 3,34 \\
\hline 9.11 .2003 & $20: 00$ & 11,10 & 444,00 & 448,28 & 199038,32 & $-40003,28$ & 7,51 & 27040,77 & 3,57 \\
\hline 9.11 .2003 & $21: 00$ & 11,10 & 444,00 & 451,87 & 200630,65 & $-40100,00$ & 7,56 & 27229,23 & 3,60 \\
\hline 9.11 .2003 & 22:00 & 11,10 & 444,00 & 444,13 & 197192,35 & $-41791,49$ & 7,03 & 25292,24 & 3,35 \\
\hline 9.11 .2003 & $23: 00$ & 11,10 & 444,00 & 434,67 & 192992,00 & $-44333,95$ & 6,34 & 22807,30 & 3,03 \\
\hline 10.11 .2003 & $00: 00$ & 11,10 & 444,00 & 434,50 & 192915,95 & $-45265,39$ & 6,16 & 22186,59 & 2,95 \\
\hline 10.11 .2003 & 01:00 & 11,10 & 444,00 & 433,94 & 192667,37 & $-45549,52$ & 6,10 & 21968,65 & 2,92 \\
\hline 10.11 .2003 & 02:00 & 11,10 & 444,00 & 432,99 & 192246,55 & $-45872,04$ & 6,03 & 21703,97 & 2,89 \\
\hline 10.11 .2003 & 03:00 & 11,10 & 444,00 & 428,62 & 190306,77 & $-46761,17$ & 5,80 & 20879,80 & 2,78 \\
\hline 10.11 .2003 & 04:00 & 11,10 & 444,00 & 432,38 & 191976,74 & $-46846,67$ & 5,85 & 21071,74 & 2,80 \\
\hline 10.11 .2003 & 05:00 & 11,10 & 444,00 & 430,19 & 191003,73 & $-47063,40$ & 5,78 & 20802,76 & 2,77 \\
\hline 10.11 .2003 & 06:00 & 11,10 & 444,00 & 434,58 & 192953,82 & $-46857,24$ & 5,89 & 21207,29 & 2,82 \\
\hline 10.11 .2003 & 07:00 & 11,10 & 444,00 & 432,11 & 191856,13 & $-48016,63$ & 5,66 & 20375,50 & 2,71 \\
\hline 10.11 .2003 & 08:00 & 11,10 & 444,00 & 445,92 & 197990,50 & $-47784,18$ & 5,94 & 21380,89 & 2,84 \\
\hline 10.11 .2003 & 09:00 & 11,10 & 444,00 & 442,79 & 196599,88 & $-48097,45$ & 5,83 & 21000,67 & 2,79 \\
\hline 10.11 .2003 & $10: 00$ & 11,10 & 444,00 & 449,07 & 199388,46 & $-48154,24$ & 5,93 & 21361,77 & 2,83 \\
\hline 10.11 .2003 & $11: 00$ & 11,10 & 444,00 & 442,70 & 196556,84 & $-48564,36$ & 5,76 & 20727,35 & 2,75 \\
\hline
\end{tabular}


Appendix B. Experiment 2 Tab.12a Moisture balance results (09.11.03)

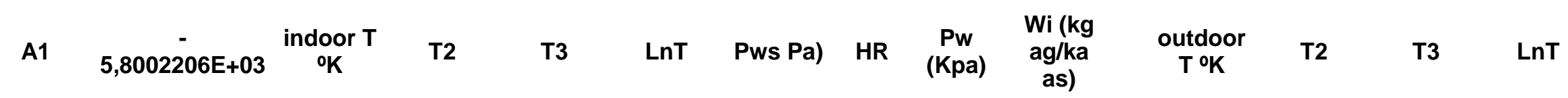

\begin{tabular}{|c|c|c|c|c|c|c|c|c|c|c|c|c|c|}
\hline A2 & 1,3914993 & 296,23 & 87753,862 & 25995571 & 5,6911456 & 2824,5559 & 0,62 & 1,757 & 0,0109745 & 278,05 & 77311,803 & 21496547 & 5,627801 \\
\hline A3 & $-4,86 \mathrm{E}-02$ & 296,26 & 87769,79 & 26002649 & 5,6912363 & 2829,1526 & 0,63 & 1,771 & 0,0110651 & 278,35 & 77478,723 & 21566202 & 5,6288793 \\
\hline A4 & 4,18E-05 & 296,47 & 87891,537 & 26056771 & 5,6919294 & 2864,4901 & 0,63 & 1,796 & 0,0112225 & 278,75 & 77701,563 & 21659311 & 5,6303153 \\
\hline A5 & $-1,45 E-08$ & 296,39 & 87848,585 & 26037672 & 5,691685 & 2851,9821 & 0,61 & 1,750 & 0,0109284 & 278,65 & 77645,823 & 21636008 & 5,6299565 \\
\hline A6 & 0 & 296,47 & 87892,689 & 26057283 & 5,691936 & 2864,826 & 0,61 & 1,749 & 0,0109267 & 278,35 & 77478,723 & 21566202 & 5,6288793 \\
\hline \multirow[t]{2}{*}{ A7 } & 6,5459673 & 296,39 & 87849,622 & 26038133 & 5,6916909 & 2852,2836 & 0,62 & 1,762 & 0,0110075 & 278,05 & 77311,803 & 21496547 & 5,627801 \\
\hline & & 296,42 & 87866,037 & 26045431 & 5,6917843 & 2857,0588 & 0,60 & 1,705 & 0,0106476 & 277,85 & 77200,623 & 21450193 & 5,6270814 \\
\hline patm $(\mathrm{Pa})$ & 101325 & 296,55 & 87940,995 & 26078767 & 5,6922107 & 2878,948 & 0,61 & 1,765 & 0,0110266 & 278,25 & 77423,063 & 21542967 & 5,62852 \\
\hline \multirow[t]{16}{*}{$\mathrm{Ra}$} & 287,055 & 296,35 & 87822,198 & 26025942 & 5,6915348 & 2844,3202 & 0,62 & 1,775 & 0,0110888 & 278,85 & 77757,323 & 21682629 & 5,630674 \\
\hline & & 296,19 & 87728,758 & 25984417 & 5,6910025 & 2817,3235 & 0,65 & 1,824 & 0,0114032 & 278,65 & 77645,823 & 21636008 & 5,6299565 \\
\hline & & 296,53 & 87930,216 & 26073973 & 5,6921494 & 2875,7918 & 0,62 & 1,792 & 0,0111958 & 278,25 & 77423,063 & 21542967 & 5,62852 \\
\hline & & 296,94 & 88174,794 & 26182836 & 5,6935382 & 2948,1041 & 0,60 & 1,759 & 0,0109861 & 277,55 & 77034,003 & 21380787 & 5,6260011 \\
\hline & & 296,95 & 88179,207 & 26184801 & 5,6935632 & 2949,4225 & 0,59 & 1,727 & 0,0107832 & 277,15 & 76812,123 & 21288480 & 5,6245589 \\
\hline & & 296,97 & 88193,628 & 26191225 & 5,693645 & 2953,7336 & 0,58 & 1,718 & 0,0107288 & 277,05 & 76756,703 & 21265444 & 5,624198 \\
\hline & & 297,02 & 88218,027 & 26202095 & 5,6937833 & 2961,0398 & 0,56 & 1,658 & 0,010346 & 276,95 & 76701,303 & 21242426 & 5,623837 \\
\hline & & 297,20 & 88330,287 & 26252125 & 5,6944192 & 2994,8449 & 0,56 & 1,678 & 0,0104717 & 276,75 & 76590,563 & 21196438 & 5,6231146 \\
\hline & & 297,04 & 88233,663 & 26209061 & 5,6938719 & 2965,7293 & 0,56 & 1,649 & 0,0102866 & 276,55 & 76479,903 & 21150517 & 5,6223916 \\
\hline & & 297,14 & 88289,992 & 26234163 & 5,694191 & 2982,6748 & 0,56 & 1,660 & 0,010358 & 276,55 & 76479,903 & 21150517 & 5,6223916 \\
\hline & & 296,95 & 88177,009 & 26183822 & 5,6935508 & 2948,7659 & 0,55 & 1,617 & 0,0100867 & 276,45 & 76424,603 & 21127581 & 5,62203 \\
\hline & & 297,05 & 88240,65 & 26212174 & 5,6939115 & 2967,8269 & 0,54 & 1,607 & 0,0100263 & 276,05 & 76203,603 & 21036004 & 5,620582 \\
\hline & & 296,45 & 87883,551 & 26053219 & 5,691884 & 2862,1611 & 0,58 & 1,655 & 0,010325 & 275,55 & 75927,803 & 20921906 & 5,6187691 \\
\hline & & 296,59 & 87964,815 & 26089364 & 5,6923461 & 2885,9326 & 0,57 & 1,638 & 0,0102203 & 275,55 & 75927,803 & 20921906 & 5,6187691 \\
\hline & & 296,31 & 87801,672 & 26016818 & 5,6914179 & 2838,3718 & 0,57 & 1,624 & 0,0101316 & 275,25 & 75762,563 & 20853645 & 5,6176798 \\
\hline & & 296,59 & 87967,327 & 26090481 & 5,6923604 & 2886,6699 & 0,56 & 1,624 & 0,0101286 & 275,35 & 75817,623 & 20876382 & 5,618043 \\
\hline
\end{tabular}


Appendix B. Experiment 2 Tab.12b Moisture balance results (09.11.03)

\begin{tabular}{|c|c|c|c|c|c|c|c|c|c|c|c|c|}
\hline Pws Pa) & HR & $\begin{array}{c}\text { Pw } \\
(\mathrm{Kpa})\end{array}$ & $\begin{array}{c}\text { Wo (kg } \\
\text { ag/ka } \\
\text { as) }\end{array}$ & $\begin{array}{l}\text { Total } \\
\text { heat } \\
\text { /hpu }\end{array}$ & $\begin{array}{c}\text { Sensible } \\
\text { Heat } \\
\text { /animal }\end{array}$ & $\begin{array}{l}\text { Latent } \\
\text { Heat } \\
\text { /animal } \\
\text { (W) }\end{array}$ & $\begin{array}{c}\text { Latent } \\
\text { Heat } \\
\text { /animal } \\
\text { (Kg } \\
\text { water/s) }\end{array}$ & $\begin{array}{c}\text { Latent } \\
\text { Heat } / 30 \\
000 \\
\text { animal } \\
\text { (Kg } \\
\text { water/s) }\end{array}$ & $\begin{array}{c}\text { AER Kg } \\
\text { air/s }\end{array}$ & $\begin{array}{l}\text { AER } \\
\text { m3/s }\end{array}$ & $\begin{array}{l}\text { AER } \\
\mathrm{m} 3 / \mathrm{h}\end{array}$ & AER /hr \\
\hline 866,4204 & 0,9 & 0,780 & 0,0048238 & 938,34 & 450,9082 & 487,436 & 0,000202 & 0,0898015 & 14,61 & 12,08 & 43471,28 & 4,9 \\
\hline 884,7319 & 0,896 & 0,793 & 0,0049045 & 937,81 & 450,2971 & 487,510 & 0,000202 & 0,089815 & 14,59 & 12,06 & 43408,23 & 4,9 \\
\hline 909,67897 & 0,884 & 0,804 & 0,0049758 & 933,70 & 445,6171 & 488,082 & 0,000203 & 0,0899204 & 14,41 & 11,91 & 42860,96 & 4,9 \\
\hline 903,38462 & 0,89 & 0,804 & 0,0049749 & 935,15 & 447,2700 & 487,878 & 0,000202 & 0,0898828 & 15,11 & 12,49 & 44950,69 & 5,1 \\
\hline 884,7319 & 0,902 & 0,798 & 0,0049376 & 933,66 & 445,5727 & 488,087 & 0,000203 & 0,0899214 & 15,03 & 12,42 & 44702,53 & 5,1 \\
\hline 866,4204 & 0,913 & 0,791 & 0,004894 & 935,11 & 447,2301 & 487,882 & 0,000202 & 0,0898837 & 14,71 & 12,16 & 43775,58 & 5,0 \\
\hline 854,39966 & 0,932 & 0,796 & 0,0049268 & 934,56 & 446,5987 & 487,960 & 0,000202 & 0,0898981 & 15,72 & 13,00 & 46784,60 & 5,3 \\
\hline 878,59042 & 0,929 & 0,816 & 0,005051 & 932,03 & 443,7113 & 488,319 & 0,000203 & 0,0899642 & 15,07 & 12,45 & 44825,27 & 5,1 \\
\hline 916,01203 & 0,905 & 0,829 & 0,0051307 & 936,04 & 448,2845 & 487,753 & 0,000202 & 0,08986 & 15,09 & 12,47 & 44905,39 & 5,1 \\
\hline 903,38462 & 0,911 & 0,823 & 0,0050932 & 939,19 & 451,8708 & 487,321 & 0,000202 & 0,0897803 & 14,24 & 11,77 & 42365,81 & 4,8 \\
\hline 878,59042 & 0,925 & 0,813 & 0,005029 & 932,39 & 444,1269 & 488,267 & 0,000203 & 0,0899546 & 14,60 & 12,06 & 43432,71 & 4,9 \\
\hline 836,64499 & 0,949 & 0,794 & 0,0049123 & 924,15 & 434,6667 & 489,485 & 0,000203 & 0,090179 & 14,86 & 12,28 & 44206,15 & 5,0 \\
\hline 813,47995 & 0,968 & 0,787 & 0,0048716 & 924,00 & 434,4954 & 489,508 & 0,000203 & 0,0901832 & 15,27 & 12,62 & 45419,30 & 5,1 \\
\hline 807,7781 & 0,977 & 0,789 & 0,0048825 & 923,52 & 433,9355 & 489,582 & 0,000203 & 0,0901969 & 15,44 & 12,76 & 45933,28 & 5,2 \\
\hline 802,11163 & 0,978 & 0,784 & 0,004853 & 922,70 & 432,9877 & 489,708 & 0,000203 & 0,0902201 & 16,43 & 13,58 & 48897,32 & 5,5 \\
\hline 790,88409 & 0,981 & 0,776 & 0,0047993 & 918,92 & 428,6189 & 490,299 & 0,000203 & 0,0903289 & 15,93 & 13,17 & 47408,97 & 5,3 \\
\hline 779,79583 & 0,983 & 0,767 & 0,0047412 & 922,17 & 432,3801 & 489,790 & 0,000203 & 0,0902351 & 16,28 & 13,46 & 48443,38 & 5,4 \\
\hline 779,79583 & 0,984 & 0,767 & 0,0047461 & 920,27 & 430,1886 & 490,085 & 0,000203 & 0,0902895 & 16,10 & 13,31 & 47898,51 & 5,4 \\
\hline 774,30347 & 0,986 & 0,763 & 0,0047221 & 924,08 & 434,5807 & 489,497 & 0,000203 & 0,0901811 & 16,82 & 13,90 & 50044,45 & 5,6 \\
\hline 752,67479 & 0,988 & 0,744 & 0,0045986 & 921,93 & 432,1084 & 489,826 & 0,000203 & 0,0902418 & 16,64 & 13,75 & 49496,02 & 5,6 \\
\hline 726,39207 & 0,99 & 0,719 & 0,0044459 & 933,97 & 445,9246 & 488,043 & 0,000203 & 0,0899134 & 15,30 & 12,65 & 45532,65 & 5,1 \\
\hline 726,39207 & 0,991 & 0,720 & 0,0044504 & 931,23 & 442,7925 & 488,435 & 0,000203 & 0,0899855 & 15,61 & 12,90 & 46430,54 & 5,2 \\
\hline 711,01551 & 0,989 & 0,703 & 0,0043467 & 936,73 & 449,0731 & 487,657 & 0,000202 & 0,0898423 & 15,54 & 12,84 & 46236,17 & 5,2 \\
\hline 716,10869 & 0,98 & 0,702 & 0,0043379 & 931,14 & 442,6956 & 488,447 & 0,000203 & 0,0899878 & 15,55 & 12,85 & 46265,03 & 5,2 \\
\hline
\end{tabular}




\section{Appendix B. Experiment 2 Tab.13 AER results (12.11.03)}

\begin{tabular}{|c|c|c|c|c|c|c|c|c|c|c|c|c|c|c|c|c|c|}
\hline Date & Time & $\begin{array}{l}\text { Tracer } \\
\text { gas } \\
\text { (AER) }\end{array}$ & $\begin{array}{l}\text { SF6 } \\
\text { (CV) }\end{array}$ & $\begin{array}{c}\text { Heat } \\
\text { Balance } \\
\text { (AER) }\end{array}$ & $\begin{array}{c}\text { Moisture } \\
\text { Balance } \\
\text { (AER) }\end{array}$ & $\begin{array}{l}\text { Bird } \\
\text { activity }\end{array}$ & $\begin{array}{c}\text { Heat } \\
\text { Balance } \\
\text { with } \\
\text { activity }\end{array}$ & $\begin{array}{c}\text { Moisture } \\
\text { Balance } \\
\text { with } \\
\text { activity }\end{array}$ & $\begin{array}{c}\text { O.Temp } \\
\left({ }^{\circ} \mathrm{C}\right)\end{array}$ & $\begin{array}{l}\text { I.Temp } \\
\left({ }^{\circ} \mathrm{C}\right)\end{array}$ & $\begin{array}{c}\Delta \text { Temp } \\
\left({ }^{\circ} \mathrm{C}\right)\end{array}$ & $\begin{array}{c}\text { O.Humid } \\
(\%)\end{array}$ & $\underset{(\%)}{\text { I.Humid }}$ & $\begin{array}{c}\Delta \text { water } \\
\text { content } \\
(\mathbf{k g} \\
\text { water } / \mathrm{m}^{3} \\
\text { dry air }\end{array}$ & $\begin{array}{l}\text { Wind } \\
\text { speed } \\
\left(\mathrm{mS}^{-1}\right)\end{array}$ & $\begin{array}{l}\text { Max wind } \\
\text { speed } \\
\text { (mS-1) }\end{array}$ & $\begin{array}{c}\text { Wind } \\
\text { Direction } \\
\left({ }^{\circ}\right)\end{array}$ \\
\hline 12.11 .03 & $0: 00$ & 3,23 & 8,52 & 3,22 & 5,47 & 1,16 & 3,75 & 6,35 & 1,9 & 23,2 & 21,3 & 87,3 & 60,1 & 0,00691 & 2,8 & 6,5 & 91,3 \\
\hline 12.11 .03 & $1: 00$ & 0,71 & 14,35 & 3,23 & 5,69 & 1,22 & 3,94 & 6,94 & 1,5 & 23,0 & 21,5 & 87,7 & 58,8 & 0,00663 & 2,9 & 5,5 & 90,2 \\
\hline 12.11 .03 & $2: 00$ & 3,22 & 7,53 & 2,88 & 5,61 & 0,84 & 2,41 & 4,70 & 1,1 & 23,8 & 22,7 & 88,4 & 56,3 & 0,00675 & 2,2 & 4,7 & 90,1 \\
\hline 12.11 .03 & 3:00 & 0,82 & 12,25 & 2,83 & 5,19 & 0,86 & 2,43 & 4,45 & 0,6 & 23,7 & 23,1 & 89,0 & 59,1 & 0,00731 & 1,3 & 3,3 & 82,5 \\
\hline 12.11 .03 & 4:00 & 3,42 & 8,91 & 2,72 & 5,22 & 0,91 & 2,47 & 4,72 & 0,2 & 23,8 & 23,6 & 89,9 & 58,1 & 0,00727 & 1,5 & 3,5 & 88,0 \\
\hline 12.11 .03 & 5:00 & 3,94 & 6,26 & 2,94 & 5,43 & 0,86 & 2,52 & 4,66 & 0,4 & 23,3 & 22,9 & 88,7 & 58,3 & 0,00696 & 2,0 & 4,6 & 85,8 \\
\hline 12.11 .03 & $6: 00$ & 2,97 & 7,78 & 2,92 & 5,99 & 0,92 & 2,68 & 5,48 & 0,6 & 23,4 & 22,8 & 87,2 & 54,2 & 0,00632 & 3,0 & 6,4 & 90,2 \\
\hline 12.11 .03 & 7:00 & 2,40 & 9,44 & 3,09 & 6,16 & 1,11 & 3,42 & 6,81 & 0,5 & 22,9 & 22,4 & 86,6 & 54,6 & 0,00613 & 3,4 & 6,3 & 91,1 \\
\hline 12.11 .03 & $8: 00$ & 3,28 & 6,16 & 3,13 & 5,84 & 1,26 & 3,95 & 7,38 & 0,2 & 22,7 & 22,5 & 87,1 & 57,0 & 0,00645 & 3,4 & 7,5 & 91,1 \\
\hline 12.11 .03 & 9:00 & 2,61 & 7,51 & 3,11 & 5,86 & 1,33 & 4,15 & 7,82 & 0,5 & 22,9 & 22,4 & 85,3 & 56,2 & 0,00643 & 3,4 & 6,0 & 93,0 \\
\hline 12.11 .03 & $10: 00$ & 2,37 & 7,96 & 3,22 & 5,72 & 1,11 & 3,58 & 6,37 & 1,6 & 23,1 & 21,5 & 81,1 & 56,9 & 0,00661 & 2,4 & 6,1 & 91,4 \\
\hline 12.11 .03 & 11:00 & 5,41 & 11,23 & 3,74 & 5,62 & 1,02 & 3,80 & 5,72 & 3,5 & 22,8 & 19,3 & 72,5 & 58,9 & 0,00671 & 2,9 & 7,3 & 98,3 \\
\hline 12.11 .03 & $12: 00$ & 3,49 & 31,55 & 4,13 & 6,07 & 1,09 & 4,52 & 6,63 & 4,8 & 22,7 & 17,9 & 66,5 & 56,6 & 0,00621 & 3,7 & 8,0 & 98,3 \\
\hline 12.11 .03 & $13: 00$ & 5,57 & 26,16 & 4,55 & 5,97 & 0,97 & 4,41 & 5,79 & 5,9 & 22,5 & 16,6 & 62,1 & 57,9 & 0,00630 & 3,0 & 6,9 & 103,3 \\
\hline 12.11 .03 & $14: 00$ & 0,90 & 30,74 & 4,54 & 6,45 & 1,13 & 5,12 & 7,29 & 6,0 & 22,6 & 16,6 & 61,0 & 54,7 & 0,00584 & 3,2 & 7,2 & 98,9 \\
\hline 12.11 .03 & $15: 00$ & 2,62 & 11,13 & 4,50 & 6,37 & 1,13 & 5,11 & 7,22 & 5,9 & 22,6 & 16,7 & 62,4 & 55,5 & 0,00591 & 2,8 & 7,2 & 99,0 \\
\hline 12.11 .03 & $16: 00$ & 1,28 & 13,92 & 4,34 & 7,27 & 1,14 & 4,96 & 8,31 & 5,0 & 22,4 & 17,4 & 66,5 & 51,9 & 0,00517 & 3,5 & 7,3 & 96,2 \\
\hline 12.11 .03 & $17: 00$ & 5,81 & 14,91 & 3,77 & 5,62 & 0,97 & 3,65 & 5,43 & 4,1 & 23,1 & 19,0 & 69,7 & 58,2 & 0,00671 & 2,5 & 5,7 & 93,3 \\
\hline 12.11 .03 & $18: 00$ & 1,57 & 5,78 & 3,47 & 4,59 & 0,85 & 2,94 & 3,89 & 2,8 & 23,1 & 20,3 & 75,2 & 66,3 & 0,00822 & 1,3 & 4,0 & 90,6 \\
\hline 12.11 .03 & 19:00 & 1,32 & 3,87 & 3,22 & 4,74 & 0,83 & 2,69 & 3,96 & 2,2 & 23,4 & 21,2 & 78,3 & 63,6 & 0,00798 & 0,7 & 2,7 & 79,1 \\
\hline 12.11 .03 & 20:00 & 1,46 & 2,68 & 3,10 & 4,45 & 0,79 & 2,46 & 3,53 & 1,4 & 23,3 & 21,9 & 81,4 & 66,3 & 0,00850 & 0,5 & 2,4 & 56,8 \\
\hline 12.11 .03 & 21:00 & 1,68 & 3,05 & 2,86 & 4,30 & 0,83 & 2,36 & 3,56 & $-0,1$ & 23,3 & 23,4 & 87,9 & 67,5 & 0,00879 & 0,7 & 2,3 & 70,0 \\
\hline 12.11 .03 & $22: 00$ & 0,43 & 8,69 & 2,65 & 4,44 & 0,85 & 2,25 & 3,76 & $-0,2$ & 23,9 & 24,1 & 87,9 & 63,8 & 0,00855 & 0,6 & 2,0 & 70,0 \\
\hline 12.11 .03 & 23:00 & 1,19 & 4,53 & 2,65 & 4,32 & 0,83 & 2,19 & 3,57 & $-1,0$ & 23,5 & 24,5 & 90,9 & 65,8 & 0,00876 & 0,8 & 2,2 & 81,3 \\
\hline
\end{tabular}


Appendix B. Experiment 2 Tab.14 Tracer gas results (12.11.03)

\begin{tabular}{|c|c|c|c|c|c|c|c|c|c|c|c|c|c|}
\hline Date & Time & $\begin{array}{c}\text { SF6 } \\
(\mathrm{mg} / \mathrm{m} 3)\end{array}$ & Reciprocal & $\begin{array}{l}\text { Measurement } \\
\text { interval } \\
\text { (mins) }\end{array}$ & $\begin{array}{c}\text { Background } \\
(\mathrm{mg} / \mathrm{m} 3)\end{array}$ & $\begin{array}{c}\text { Dosage } \\
\text { (mg) }\end{array}$ & $\begin{array}{l}\text { Dosage + } \\
\text { background } \\
(\mathrm{mg})\end{array}$ & $\begin{array}{c}\text { Total } \\
\text { dosage } \\
\text { (mg) }\end{array}$ & $\begin{array}{l}\text { Dosage } \\
\text { (mg/min) }\end{array}$ & $\begin{array}{l}\text { Dosage } \\
\text { (g/min) }\end{array}$ & $\begin{array}{l}\text { Supplied } \\
\text { air volume } \\
\text { m3/min }\end{array}$ & $\begin{array}{l}\text { Supplied } \\
\text { air } \\
\text { volume } \\
\text { m3/h }\end{array}$ & AER \\
\hline 12.11 .03 & $00: 00$ & 16,047 & 0,062 & & 130750,96 & 48792,90 & 88904,20 & 219655,16 & 4,15 & 497,75 & 26316,09 & 3,23 & \\
\hline 12.11 .03 & $1: 00$ & 8,347 & 0,120 & 52,870 & 68009,73 & 200833,80 & 281430,20 & 349439,93 & 5,93 & 97,84 & 5767,79 & 0,71 & 2,6 \\
\hline 12.11 .03 & $2: 00$ & 60,585 & 0,017 & 58,950 & 493643,87 & 56392,00 & 155704,60 & 649348,47 & 10,74 & 433,14 & 26196,08 & 3,22 & 2,0 \\
\hline 12.11 .03 & 3:00 & 24,788 & 0,040 & 60,480 & 201972,62 & 200018,80 & 391839,80 & 593812,42 & 9,81 & 110,68 & 6701,72 & 0,82 & 2,3 \\
\hline 12.11 .03 & 4:00 & 88,606 & 0,011 & 60,550 & 721961,69 & 47607,66 & 205241,26 & 927202,95 & 15,81 & 474,72 & 27842,26 & 3,42 & 1,6 \\
\hline 12.11 .03 & 5:00 & 33,302 & 0,030 & 58,650 & 271344,70 & 58350,00 & 109342,20 & 380686,90 & 5,87 & 494,94 & 32121,86 & 3,94 & 2,2 \\
\hline 12.11 .03 & $6: 00$ & 11,851 & 0,084 & 64,900 & 96564,66 & 50395,70 & 98502,00 & 195066,66 & 3,34 & 413,82 & 24167,34 & 2,97 & 2,4 \\
\hline 12.11 .03 & 7:00 & 8,072 & 0,124 & 58,400 & 65766,58 & 50977,60 & 99379,80 & 165146,38 & 2,80 & 332,11 & 19554,44 & 2,40 & 4,2 \\
\hline 12.11 .03 & $8: 00$ & 8,445 & 0,118 & 58,880 & 68813,66 & 59125,30 & 107179,10 & 175992,76 & 2,77 & 421,64 & 26765,60 & 3,28 & 2,7 \\
\hline 12.11 .03 & $9: 00$ & 6,575 & 0,152 & 63,480 & 53575,82 & 47295,60 & 98222,10 & 151797,92 & 2,61 & 365,69 & 21257,43 & 2,61 & 2,0 \\
\hline 12.11 .03 & $10: 00$ & 7,141 & 0,140 & 58,130 & 58184,32 & 76846,00 & 124550,60 & 182734,92 & 3,15 & 332,90 & 19301,56 & 2,37 & 2,3 \\
\hline 12.11 .03 & $11: 00$ & 9,467 & 0,106 & 57,980 & 77140,10 & 96503,30 & 182855,40 & 259995,50 & 4,02 & 681,49 & 44058,32 & 5,41 & 2,8 \\
\hline 12.11 .03 & $12: 00$ & 5,901 & 0,169 & 64,650 & 48082,71 & 182585,90 & 326648,60 & 374731,31 & 6,59 & 500,72 & 28475,74 & 3,49 & 1,9 \\
\hline 12.11 .03 & $13: 00$ & 13,160 & 0,076 & 56,870 & 107224,97 & 172423,00 & 358713,40 & 465938,37 & 7,94 & 773,60 & 45371,38 & 5,57 & 2,3 \\
\hline 12.11 .03 & $14: 00$ & 10,269 & 0,097 & 58,650 & 83675,34 & 218588,00 & 372951,00 & 456626,34 & 7,99 & 128,09 & 7324,26 & 0,90 & 2,5 \\
\hline 12.11 .03 & $15: 00$ & 62,344 & 0,016 & 57,180 & 507981,63 & 203072,10 & 467215,50 & 975197,13 & 15,22 & 333,08 & 21347,36 & 2,62 & 3,1 \\
\hline 12.11 .03 & $16: 00$ & 45,682 & 0,022 & 64,090 & 372219,65 & 229416,10 & 446130,80 & 818350,45 & 14,10 & 179,92 & 10444,36 & 1,28 & 2,4 \\
\hline 12.11 .03 & $17: 00$ & 78,353 & 0,013 & 58,050 & 638422,95 & 47593,10 & 162490,80 & 800913,75 & 12,39 & 732,47 & 47361,45 & 5,81 & 1,9 \\
\hline 12.11 .03 & $18: 00$ & 16,911 & 0,059 & 64,660 & 137788,11 & 46642,20 & 93826,50 & 231614,61 & 4,15 & 228,26 & 12752,94 & 1,57 & 3,1 \\
\hline 12.11 .03 & $19: 00$ & 18,162 & 0,055 & 55,870 & 147981,26 & 47622,60 & 97594,80 & 245576,06 & 4,24 & 184,98 & 10725,41 & 1,32 & 2,1 \\
\hline 12.11 .03 & $20: 00$ & 22,897 & 0,044 & 57,980 & 186562,04 & 47609,30 & 108163,50 & 294725,54 & 4,59 & 185,14 & 11876,75 & 1,46 & 3,2 \\
\hline 12.11 .03 & $21: 00$ & 24,815 & 0,040 & 64,150 & 202195,34 & 49888,10 & 96910,10 & 299105,44 & 5,21 & 238,53 & 13686,74 & 1,68 & 2,6 \\
\hline 12.11 .03 & $22: 00$ & 21,854 & 0,046 & 57,380 & 178063,68 & 148815,50 & 196083,60 & 374147,28 & 5,87 & 55,38 & 3532,36 & 0,43 & 2,1 \\
\hline 12.11 .03 & $23: 00$ & 105,920 & 0,009 & 63,780 & 863036,15 & 176552,80 & 372184,70 & 1235220,85 & 22,22 & 174,24 & 9684,46 & 1,19 & 1,8 \\
\hline
\end{tabular}


Appendix B. Experiment 2 Tab.15 Heat balance results (12.11.03)

\begin{tabular}{|c|c|c|c|c|c|c|c|c|c|}
\hline Date & Time & $\begin{array}{l}\text { Total heat } \\
\text { /animal } \\
\left(20^{\circ} \mathrm{C}\right) \mathrm{W}\end{array}$ & $\begin{array}{l}\text { hpu/all } \\
\text { animals }\end{array}$ & $\begin{array}{c}\text { Sensible } \\
\text { heat and } \\
\text { temperature } \\
\text { factors }\end{array}$ & $\begin{array}{c}\text { Sensible } \\
\text { Heat/ all } \\
\text { animals (W) }\end{array}$ & $\begin{array}{l}\text { Heat loss } \\
\text { Thought } \\
\text { Building } \\
\text { (W) }\end{array}$ & $\begin{array}{l}\text { Calculated } \\
\text { AER }\left(\mathrm{m}^{3} / \mathrm{s}\right)\end{array}$ & $\begin{array}{l}\text { Calculated } \\
\operatorname{AER}\left(\mathrm{m}^{3} / \mathrm{h}\right)\end{array}$ & $\begin{array}{c}\text { Heat } \\
\text { balance } \\
\text { AER/h }\end{array}$ \\
\hline 12.11 .2003 & $00: 00$ & 12,77 & 510,80 & 447,42 & 228542,32 & $-48777,34$ & 7,30 & 26270,22 & 3,22 \\
\hline 12.11 .2003 & 01:00 & 12,77 & 510,80 & 452,40 & 231083,55 & $-49191,77$ & 7,32 & 26342,97 & 3,23 \\
\hline 12.11 .2003 & 02:00 & 12,77 & 510,80 & 434,56 & 221974,75 & $-51888,53$ & 6,51 & 23426,35 & 2,88 \\
\hline 12.11 .2003 & 03:00 & 12,77 & 510,80 & 437,11 & 223277,83 & $-52778,32$ & 6,41 & 23084,67 & 2,83 \\
\hline 12.11 .2003 & 04:00 & 12,77 & 510,80 & 433,92 & 221644,81 & $-54010,10$ & 6,17 & 22197,41 & 2,72 \\
\hline 12.11 .2003 & 05:00 & 12,77 & 510,80 & 446,30 & 227967,76 & $-52319,32$ & 6,65 & 23956,58 & 2,94 \\
\hline 12.11 .2003 & 06:00 & 12,77 & 510,80 & 443,07 & 226319,36 & $-52184,96$ & 6,62 & 23820,92 & 2,92 \\
\hline 12.11 .2003 & 07:00 & 12,77 & 510,80 & 454,73 & 232277,33 & $-51242,26$ & 6,99 & 25175,13 & 3,09 \\
\hline 12.11 .2003 & 08:00 & 12,77 & 510,80 & 460,48 & 235215,14 & $-51346,08$ & 7,08 & 25499,64 & 3,13 \\
\hline 12.11 .2003 & 09:00 & 12,77 & 510,80 & 456,02 & 232934,50 & $-51112,33$ & 7,04 & 25343,87 & 3,11 \\
\hline 12.11 .2003 & $10: 00$ & 12,77 & 510,80 & 450,27 & 229999,81 & $-49176,67$ & 7,28 & 26203,26 & 3,22 \\
\hline 12.11 .2003 & $11: 00$ & 12,77 & 510,80 & 456,75 & 233308,85 & $-44179,80$ & 8,46 & 30445,68 & 3,74 \\
\hline 12.11 .2003 & $12: 00$ & 12,77 & 510,80 & 459,71 & 234818,84 & $-40908,48$ & 9,35 & 33675,30 & 4,13 \\
\hline 12.11 .2003 & $13: 00$ & 12,77 & 510,80 & 463,25 & 236627,80 & $-38034,09$ & 10,29 & 37057,82 & 4,55 \\
\hline 12.11 .2003 & $14: 00$ & 12,77 & 510,80 & 461,49 & 235729,58 & $-37984,18$ & 10,27 & 36954,60 & 4,54 \\
\hline 12.11 .2003 & $15: 00$ & 12,77 & 510,80 & 461,55 & 235761,05 & $-38206,54$ & 10,20 & 36705,54 & 4,50 \\
\hline 12.11 .2003 & $16: 00$ & 12,77 & 510,80 & 466,08 & 238075,59 & $-39802,96$ & 9,82 & 35356,07 & 4,34 \\
\hline 12.11 .2003 & $17: 00$ & 12,77 & 510,80 & 451,51 & 230628,83 & $-43337,42$ & 8,54 & 30749,05 & 3,77 \\
\hline 12.11 .2003 & $18: 00$ & 12,77 & 510,80 & 451,32 & 230535,07 & $-46327,89$ & 7,86 & 28311,38 & 3,47 \\
\hline 12.11 .2003 & $19: 00$ & 12,77 & 510,80 & 444,05 & 226821,75 & $-48428,81$ & 7,30 & 26266,58 & 3,22 \\
\hline 12.11 .2003 & $20: 00$ & 12,77 & 510,80 & 445,22 & 227419,37 & $-50140,68$ & 7,01 & 25218,65 & 3,10 \\
\hline 12.11 .2003 & $21: 00$ & 12,77 & 510,80 & 446,20 & 227919,97 & $-53471,77$ & 6,47 & 23287,58 & 2,86 \\
\hline 12.11 .2003 & $22: 00$ & 12,77 & 510,80 & 432,88 & 221117,11 & $-55026,92$ & 6,00 & 21596,32 & 2,65 \\
\hline 12.11 .2003 & $23: 00$ & 12,77 & 510,80 & 440,74 & 225130,36 & $-56075,12$ & 5,99 & 21552,27 & 2,65 \\
\hline
\end{tabular}


Appendix B. Experiment 2 Tab.16a Moisture balance results (12.11.03)

\begin{tabular}{|c|c|c|c|c|c|c|c|c|c|c|c|}
\hline A1 & $5,8002206 \mathrm{E}+03$ & $\begin{array}{c}\text { indoor } T \\
\text { oK }\end{array}$ & T2 & T3 & LnT & Pws Pa) & HR & $\begin{array}{c}\mathrm{Pw} \\
(\mathrm{Kpa})\end{array}$ & $\begin{array}{c}\text { Wi (kg } \\
\text { ag/ka } \\
\text { as) }\end{array}$ & $\begin{array}{l}\text { outdoor } \\
T{ }^{\circ} \mathrm{K}\end{array}$ & T2 \\
\hline
\end{tabular}

\begin{tabular}{|c|c|c|c|c|c|c|c|c|c|c|c|c|}
\hline A2 & 1,3914993 & 296,39 & 87844,676 & 26035934 & 5,6916627 & 2850,846 & 0,60 & 1,712 & 0,0106893 & 275,05 & 75652,503 & 20808221 \\
\hline A3 & $-4,86 \mathrm{E}-02$ & 296,17 & 87715,071 & 25978336 & 5,6909245 & 2813,3868 & 0,59 & 1,654 & 0,0103206 & 274,65 & 75432,623 & 20717570 \\
\hline A4 & $4,18 \mathrm{E}-05$ & 296,95 & 88177,466 & 26184026 & 5,6935534 & 2948,9024 & 0,56 & 1,661 & 0,0103646 & 274,25 & 75213,063 & 20627182 \\
\hline A5 & $-1,45 \mathrm{E}-08$ & 296,84 & 88111,682 & 26154730 & 5,6931802 & 2929,3037 & 0,59 & 1,732 & 0,010814 & 273,75 & 74939,063 & 20514568 \\
\hline A6 & 0 & 296,97 & 88194,104 & 26191437 & 5,6936477 & 2953,8762 & 0,58 & 1,715 & 0,0107091 & 273,35 & 74720,223 & 20424773 \\
\hline \multirow[t]{2}{*}{ A7 } & 6,5459673 & 296,44 & 87873,913 & 26048934 & 5,6918291 & 2859,3525 & 0,58 & 1,667 & 0,010404 & 273,55 & 74829,603 & 20469638 \\
\hline & & 296,58 & 87957,663 & 26086182 & 5,6923054 & 2883,8341 & 0,54 & 1,564 & 0,0097533 & 273,75 & 74939,063 & 20514568 \\
\hline patm $(\mathrm{Pa})$ & 101325 & 296,06 & 87654,024 & 25951220 & 5,6905764 & 2795,8824 & 0,55 & 1,526 & 0,0095127 & 273,65 & 74884,323 & 20492095 \\
\hline \multirow[t]{16}{*}{$\mathrm{Ra}$} & 287,055 & 295,81 & 87503,339 & 25884331 & 5,6897161 & 2753,0571 & 0,57 & 1,569 & 0,0097818 & 273,35 & 74720,223 & 20424773 \\
\hline & & 296,01 & 87620,373 & 25936277 & 5,6903844 & 2786,2717 & 0,56 & 1,566 & 0,009765 & 273,65 & 74884,323 & 20492095 \\
\hline & & 296,26 & 87770,401 & 26002920 & 5,6912398 & 2829,329 & 0,57 & 1,610 & 0,0100399 & 274,75 & 75487,563 & 20740208 \\
\hline & & 295,97 & 87601,189 & 25927760 & 5,6902749 & 2780,805 & 0,59 & 1,639 & 0,0102262 & 276,65 & 76535,223 & 21173469 \\
\hline & & 295,84 & 87523,704 & 25893367 & 5,6898325 & 2758,8132 & 0,57 & 1,562 & 0,0097404 & 277,95 & 77256,203 & 21473361 \\
\hline & & 295,69 & 87430,651 & 25852085 & 5,6893006 & 2732,5914 & 0,58 & 1,581 & 0,0098602 & 279,05 & 77868,903 & 21729317 \\
\hline & & 295,76 & 87476,886 & 25872594 & 5,6895649 & 2745,5946 & 0,55 & 1,502 & 0,0093603 & 279,15 & 77924,723 & 21752686 \\
\hline & & 295,76 & 87475,267 & 25871876 & 5,6895557 & 2745,1386 & 0,55 & 1,523 & 0,0094911 & 279,05 & 77868,903 & 21729317 \\
\hline & & 295,56 & 87355,998 & 25818981 & 5,6888735 & 2711,7022 & 0,52 & 1,406 & 0,0087541 & 278,15 & 77367,423 & 21519749 \\
\hline & & 296,21 & 87738,297 & 25988655 & 5,6910569 & 2820,07 & 0,58 & 1,641 & 0,0102365 & 277,25 & 76867,563 & 21311532 \\
\hline & & 296,21 & 87743,084 & 25990782 & 5,6910842 & 2821,449 & 0,66 & 1,869 & 0,0116909 & 275,95 & 76148,403 & 21013152 \\
\hline & & 296,53 & 87932,159 & 26074837 & 5,6921604 & 2876,3608 & 0,64 & 1,830 & 0,0114413 & 275,35 & 75817,623 & 20876382 \\
\hline & & 296,48 & 87901,797 & 26061333 & 5,6919878 & 2867,4845 & 0,66 & 1,902 & 0,0119017 & 274,55 & 75377,703 & 20694948 \\
\hline & & 296,44 & 87876,344 & 26050015 & 5,691843 & 2860,0607 & 0,67 & 1,930 & 0,012079 & 273,05 & 74556,303 & 20357598 \\
\hline & & 297,02 & 88220,699 & 26203285 & 5,6937984 & 2961,8406 & 0,64 & 1,889 & 0,0118136 & 272,95 & 74501,703 & 20335240 \\
\hline & & 296,68 & 88017,951 & 26113007 & 5,692648 & 2901,5631 & 0,66 & 1,910 & 0,0119514 & 272,15 & 74065,623 & 20156959 \\
\hline
\end{tabular}


Appendix B. Experiment 2 Tab.16b Moisture balance results (12.11.03)

\begin{tabular}{|c|c|c|c|c|c|c|c|c|c|c|c|c|c|}
\hline LnT & Pws Pa) & HR & $\begin{array}{c}\text { Pw } \\
(\mathrm{Kpa})\end{array}$ & $\begin{array}{c}\text { Wo (kg } \\
\text { ag/ka } \\
\text { as) }\end{array}$ & $\begin{array}{c}\text { Total } \\
\text { heat } \\
\text { /hpu } \\
\text { (eqn. } \\
26)\end{array}$ & $\begin{array}{c}\text { Sensible } \\
\text { Heat } \\
\text { /animal }\end{array}$ & $\begin{array}{l}\text { Latent } \\
\text { Heat } \\
\text { /animal } \\
\text { (W) }\end{array}$ & $\begin{array}{c}\text { Latent } \\
\text { Heat } \\
\text { /animal } \\
\text { (Kg } \\
\text { water/s) }\end{array}$ & $\begin{array}{c}\text { Latent } \\
\text { Heat } / 30 \\
000 \\
\text { animal } \\
(\mathrm{Kg} \\
\text { water/s) }\end{array}$ & $\begin{array}{c}\text { AER } \\
\mathrm{Kg} \\
\text { air/s }\end{array}$ & $\begin{array}{c}\text { AER } \\
\text { m3/s }\end{array}$ & $\begin{array}{c}\text { AER } \\
\text { m3/h }\end{array}$ & AER $/ \mathrm{hr}$ \\
\hline 5,6169529 & 700,92531 & 0,873 & 0,612 & 0,003779 & 935,28 & 447,4204 & 487,859 & 0,0002024 & 0,1034018 & 14,97 & 12,38 & 44551,02 & 5,5 \\
\hline 5,6154976 & 681,12464 & 0,877 & 0,597 & 0,0036885 & 939,65 & 452,3954 & 487,259 & 0,0002022 & 0,1032746 & 15,58 & 12,88 & 46360,65 & 5,7 \\
\hline 5,6140401 & 661,82117 & 0,884 & 0,585 & 0,0036122 & 924,06 & 434,5629 & 489,499 & 0,0002031 & 0,1037494 & 15,38 & 12,71 & 45744,27 & 5,6 \\
\hline 5,6122153 & 638,37459 & 0,89 & 0,568 & 0,0035073 & 926,28 & 437,1140 & 489,164 & 0,000203 & 0,1036783 & 14,20 & 11,74 & 42248,52 & 5,2 \\
\hline 5,610753 & 620,15064 & 0,899 & 0,558 & 0,0034412 & 923,50 & 433,9170 & 489,585 & 0,0002031 & 0,1037675 & 14,29 & 11,81 & 42510,43 & 5,2 \\
\hline 5,6114844 & 629,20412 & 0,887 & 0,558 & 0,0034449 & 934,29 & 446,2955 & 487,998 & 0,0002025 & 0,1034312 & 14,87 & 12,29 & 44250,43 & 5,4 \\
\hline 5,6122153 & 638,37459 & 0,872 & 0,557 & 0,0034359 & 931,47 & 443,0684 & 488,400 & 0,0002027 & 0,1035165 & 16,40 & 13,55 & 48781,00 & 6,0 \\
\hline 5,6118499 & 633,77465 & 0,866 & 0,549 & 0,0033874 & 941,72 & 454,7324 & 486,983 & 0,0002021 & 0,1032162 & 16,86 & 13,93 & 50163,05 & 6,2 \\
\hline 5,610753 & 620,15064 & 0,871 & 0,540 & 0,0033335 & 946,81 & 460,4838 & 486,324 & 0,0002018 & 0,1030764 & 15,99 & 13,22 & 47587,55 & 5,8 \\
\hline 5,6118499 & 633,77465 & 0,853 & 0,541 & 0,0033363 & 942,85 & 456,0190 & 486,833 & 0,000202 & 0,1031844 & 16,06 & 13,27 & 47783,06 & 5,9 \\
\hline 5,6158616 & 686,02777 & 0,811 & 0,556 & 0,0034341 & 937,79 & 450,2737 & 487,512 & 0,0002023 & 0,1033283 & 15,65 & 12,94 & 46568,13 & 5,7 \\
\hline 5,6227532 & 785,32265 & 0,725 & 0,569 & 0,0035147 & 943,50 & 456,7519 & 486,749 & 0,000202 & 0,1031665 & 15,38 & 12,71 & 45764,35 & 5,6 \\
\hline 5,6274412 & 860,39147 & 0,665 & 0,572 & 0,0035321 & 946,12 & 459,7080 & 486,411 & 0,0002018 & 0,1030949 & 16,62 & 13,73 & 49435,62 & 6,1 \\
\hline 5,631391 & 928,79514 & 0,621 & 0,577 & 0,0035608 & 949,27 & 463,2494 & 486,016 & 0,0002017 & 0,1030111 & 16,36 & 13,52 & 48681,55 & 6,0 \\
\hline 5,6317493 & 935,2456 & 0,61 & 0,570 & 0,0035218 & 947,70 & 461,4910 & 486,211 & 0,0002017 & 0,1030525 & 17,66 & 14,59 & 52541,71 & 6,4 \\
\hline 5,631391 & 928,79514 & 0,624 & 0,580 & 0,0035781 & 947,76 & 461,5526 & 486,204 & 0,0002017 & 0,103051 & 17,44 & 14,41 & 51880,01 & 6,4 \\
\hline 5,6281605 & 872,48665 & 0,665 & 0,580 & 0,0035821 & 951,79 & 466,0838 & 485,707 & 0,0002015 & 0,1029456 & 19,91 & 16,46 & 59246,00 & 7,3 \\
\hline 5,6249196 & 819,21737 & 0,697 & 0,571 & 0,0035249 & 938,87 & 451,5051 & 487,365 & 0,0002022 & 0,103297 & 15,40 & 12,73 & 45821,28 & 5,6 \\
\hline 5,6202197 & 747,3519 & 0,752 & 0,562 & 0,0034691 & 938,71 & 451,3216 & 487,387 & 0,0002022 & 0,1033017 & 12,58 & 10,39 & 37416,56 & 4,6 \\
\hline 5,618043 & 716,10869 & 0,783 & 0,561 & 0,0034611 & 932,33 & 444,0520 & 488,277 & 0,0002026 & 0,1034903 & 12,98 & 10,73 & 38617,40 & 4,7 \\
\hline 5,6151334 & 676,25258 & 0,814 & 0,550 & 0,0033975 & 933,35 & 445,2220 & 488,131 & 0,0002025 & 0,1034594 & 12,18 & 10,06 & 36230,95 & 4,4 \\
\hline 5,6096549 & 606,78697 & 0,879 & 0,533 & 0,0032914 & 934,21 & 446,2020 & 488,009 & 0,0002025 & 0,1034336 & 11,78 & 9,74 & 35055,20 & 4,3 \\
\hline 5,6092886 & 602,38952 & 0,879 & 0,530 & 0,0032674 & 922,61 & 432,8839 & 489,722 & 0,0002032 & 0,1037967 & 12,16 & 10,05 & 36169,89 & 4,4 \\
\hline 5,6063534 & 568,21525 & 0,909 & 0,517 & 0,0031868 & 929,44 & 440,7407 & 488,695 & 0,0002028 & 0,1035791 & 11,83 & 9,78 & 35196,12 & 4,3 \\
\hline
\end{tabular}


Appendix B. Experiment 2 Tab.17 AER results (13.11.03)

\begin{tabular}{|c|c|c|c|c|c|c|c|c|c|c|c|c|c|c|c|c|c|}
\hline Date & Time & $\begin{array}{l}\text { Tracer } \\
\text { gas } \\
\text { (AER) }\end{array}$ & $\begin{array}{l}\text { SF6 } \\
\text { (CV) }\end{array}$ & $\begin{array}{c}\text { Heat } \\
\text { Balance } \\
\text { (AER) }\end{array}$ & $\begin{array}{c}\text { Moisture } \\
\text { Balance } \\
\text { (AER) }\end{array}$ & $\begin{array}{c}\text { Bird } \\
\text { activity }\end{array}$ & $\begin{array}{c}\text { Heat } \\
\text { Balance } \\
\text { with } \\
\text { activity }\end{array}$ & $\begin{array}{c}\text { Moisture } \\
\text { Balance } \\
\text { with } \\
\text { activity }\end{array}$ & $\begin{array}{c}\text { O.Temp } \\
\left({ }^{\circ} \mathrm{C}\right)\end{array}$ & $\begin{array}{l}\text { I.Temp } \\
\left({ }^{\circ} \mathrm{C}\right)\end{array}$ & $\begin{array}{c}\Delta \\
\text { Temp } \\
\left({ }^{\circ} \mathrm{C}\right)\end{array}$ & $\begin{array}{l}\text { O. Humid } \\
(\%)\end{array}$ & $\begin{array}{c}\text { I. Humid } \\
(\%)\end{array}$ & $\begin{array}{c}\Delta \text { water } \\
\text { content } \\
(\mathrm{kg} \\
\text { water } / \mathrm{m}^{3} \\
\text { dry air }\end{array}$ & $\begin{array}{l}\text { Wind } \\
\text { speed } \\
\left(\mathrm{mS}^{-1}\right)\end{array}$ & $\begin{array}{c}\text { Max } \\
\text { wind } \\
\text { speed } \\
(\mathrm{mS}-1)\end{array}$ & $\begin{array}{c}\text { Wind } \\
\text { Direction } \\
\left({ }^{\circ}\right)\end{array}$ \\
\hline 13.11 .03 & $12: 00$ & 1,71 & 8,62 & 3,00 & 3,98 & 1,08 & 3,24 & 4,29 & 3,0 & 24,8 & 21,8 & 87,6 & 69,5 & 0,00950 & 0,2 & 1,7 & 6,3 \\
\hline 13.11 .03 & $13: 00$ & 0,80 & 5,26 & 3,00 & 3,95 & 1,05 & 3,15 & 4,14 & 3,4 & 24,9 & 21,5 & 87,6 & 69,7 & 0,00959 & 0,3 & 1,7 & 29,5 \\
\hline 13.11 .03 & $14: 00$ & 0,67 & 4,04 & 2,96 & 3,89 & 1,02 & 3,02 & 3,96 & 3,2 & 24,9 & 21,7 & 89,9 & 70,7 & 0,00974 & 0,4 & 2,2 & 46 \\
\hline 13.11 .03 & $15: 00$ & 0,29 & 1,51 & 3,01 & 3,83 & 1,00 & 3,00 & 3,82 & 3,1 & 24,8 & 21,7 & 92,6 & 72,6 & 0,00988 & 0,1 & 0,7 & 355,6 \\
\hline 13.11 .03 & $16: 00$ & 0,29 & 1,72 & 2,90 & 3,78 & 1,08 & 3,13 & 4,08 & 3,0 & 25,0 & 22,0 & 95,1 & 72,7 & 0,01001 & 0,2 & 1,2 & 31 \\
\hline 13.11 .03 & $17: 00$ & 0,30 & 1,34 & 2,92 & 3,65 & 1,07 & 3,12 & 3,90 & 3,0 & 25,0 & 22,0 & 96,9 & 75,1 & 0,01037 & 0 & 0,5 & 4,1 \\
\hline 13.11 .03 & $18: 00$ & 0,56 & 1,01 & 2,93 & 3,61 & 1,04 & 3,05 & 3,75 & 3,0 & 24,9 & 21,9 & 97,7 & 75,9 & 0,01049 & 0 & 0,8 & 3 \\
\hline 13.11 .03 & 19:00 & 0,62 & 0,93 & 3,00 & 3,62 & 1,04 & 3,11 & 3,75 & 3,2 & 24,8 & 21,6 & 98,2 & 76,7 & 0,01047 & 0 & 0,6 & 359 \\
\hline 13.11 .03 & $20: 00$ & 0,62 & 0,89 & 3,03 & 3,74 & 1,05 & 3,19 & 3,94 & 3,5 & 24,9 & 21,4 & 98,5 & 75,3 & 0,01012 & 0 & 1 & 2,1 \\
\hline 13.11 .03 & $21: 00$ & 0,67 & 0,70 & 3,01 & 3,65 & 1,04 & 3,13 & 3,79 & 3,5 & 25,0 & 21,5 & 98,7 & 76,3 & 0,01038 & 0 & 0 & 0 \\
\hline 13.11 .03 & 22:00 & 0,69 & 1,05 & 2,96 & 3,61 & 1,03 & 3,06 & 3,73 & 3,7 & 25,2 & 21,5 & 98,8 & 76,3 & 0,01050 & 0 & 0,1 & 359 \\
\hline 13.11 .03 & 23:00 & 0,66 & 1,11 & 2,88 & 3,63 & 1,07 & 3,07 & 3,88 & 3,8 & 25,4 & 21,6 & 98,9 & 75,0 & 0,01044 & 0,1 & 0,8 & 6,3 \\
\hline 14.11 .03 & 00:00 & 0,73 & 1,16 & 2,97 & 3,75 & 1,06 & 3,15 & 3,97 & 4,0 & 25,3 & 21,3 & 99,0 & 74,5 & 0,01011 & 0 & 0,4 & 1 \\
\hline 14.11 .03 & 01:00 & 0,90 & 1,55 & 3,01 & 3,85 & 1,02 & 3,08 & 3,95 & 4,1 & 25,2 & 21,1 & 99,1 & 73,6 & 0,00984 & 0,1 & 0,5 & 14 \\
\hline 14.11 .03 & 02:00 & 0,80 & 2,95 & 3,18 & 4,31 & 0,87 & 2,78 & 3,76 & 4,4 & 24,9 & 20,5 & 99,2 & 70,2 & 0,00879 & 0,5 & 2,2 & 54,5 \\
\hline 14.11 .03 & 03:00 & 0,62 & 2,53 & 2,89 & 4,90 & 0,89 & 2,56 & 4,34 & 4,4 & 25,7 & 21,3 & 99,2 & 62,4 & 0,00774 & 1,3 & 2,8 & 90 \\
\hline 14.11 .03 & 04:00 & 0,82 & 1,70 & 3,05 & 4,30 & 0,87 & 2,66 & 3,75 & 4,3 & 25,2 & 20,9 & 99,3 & 69,1 & 0,00882 & 0,5 & 1,6 & 70 \\
\hline 14.11 .03 & 05:00 & 0,85 & 2,57 & 3,20 & 4,35 & 0,85 & 2,74 & 3,72 & 4,3 & 24,9 & 20,6 & 99,4 & 70,1 & 0,00870 & 0,5 & 1,7 & 70 \\
\hline 14.11 .03 & 06:00 & 0,89 & 2,54 & 3,28 & 4,36 & 0,86 & 2,81 & 3,73 & 4,4 & 24,7 & 20,3 & 99,5 & 70,7 & 0,00867 & 0,3 & 1,3 & 58,6 \\
\hline 14.11 .03 & 07:00 & 1,39 & 4,06 & 3,46 & 4,61 & 0,86 & 2,99 & 3,98 & 4,5 & 24,4 & 19,9 & 99,6 & 70,0 & 0,00820 & 0,5 & 1,7 & 69,3 \\
\hline 14.11 .03 & 08:00 & 1,28 & 11,53 & 3,15 & 4,13 & 1,05 & 3,32 & 4,35 & 4,5 & 25,1 & 20,6 & 99,6 & 72,0 & 0,00918 & 0,6 & 1,8 & 74,5 \\
\hline 14.11 .03 & 09:00 & 2,77 & 8,34 & 3,25 & 4,32 & 1,10 & 3,57 & 4,74 & 4,6 & 24,9 & 20,3 & 99,7 & 70,9 & 0,00877 & 1 & 3,2 & 87,1 \\
\hline
\end{tabular}


Appendix B. Experiment 2 Tab.18 Tracer gas results (13.11.03)

\begin{tabular}{|c|c|c|c|c|c|c|c|c|c|c|c|c|c|}
\hline Date & Time & $\begin{array}{c}\text { SF6 } \\
(\mathrm{mg} / \mathrm{m} 3)\end{array}$ & Reciprocal & $\begin{array}{l}\text { Measurement } \\
\text { interval } \\
\text { (mins) }\end{array}$ & $\begin{array}{l}\text { Background } \\
\text { (mg/m3) }\end{array}$ & $\begin{array}{c}\text { Dosage } \\
\text { (mg) }\end{array}$ & $\begin{array}{c}\text { Dosage + } \\
\text { background } \\
(\mathrm{mg})\end{array}$ & $\begin{array}{c}\text { Total } \\
\text { dosage } \\
\text { (mg) }\end{array}$ & $\begin{array}{l}\text { Dosage } \\
\text { (mg/min) }\end{array}$ & $\begin{array}{l}\text { Dosage } \\
\text { (g/min) }\end{array}$ & $\begin{array}{l}\text { Supplied } \\
\text { air volume } \\
\text { m3/min }\end{array}$ & $\begin{array}{c}\text { Supplied } \\
\text { air } \\
\text { volume } \\
\text { m3/h }\end{array}$ & AER \\
\hline 13.11 .03 & $11: 00$ & 20,37 & 0,05 & & 29408,24 & 192402,70 & & 219310 & 7317,6 & 7,318 & 359,20 & 10765,1785 & \\
\hline 13.11 .03 & $12: 00$ & 28,42 & 0,04 & 59,74 & 41032,14 & 175806,00 & 368208,70 & 395116 & 6613,9 & 6,614 & 232,68 & 13900,5686 & 1,71 \\
\hline 13.11 .03 & $13: 00$ & 76,44 & 0,01 & 60,32 & 110347,84 & 224469,50 & 455442,60 & 496475 & 8230,7 & 8,231 & 107,67 & 6494,80046 & 0,80 \\
\hline 13.11 .03 & $14: 00$ & 94,99 & 0,01 & 60,15 & 137125,74 & 200932,30 & 411312,90 & 521661 & 8672,7 & 8,673 & 91,30 & 5491,63508 & 0,67 \\
\hline 13.11 .03 & $15: 00$ & 102,71 & 0,01 & 59,48 & 148268,08 & 52135,80 & 102485,70 & 239611 & 4028,4 & 4,028 & 39,22 & 2332,87988 & 0,29 \\
\hline 13.11 .03 & $16: 00$ & 105,90 & 0,01 & 60,24 & 152874,56 & 52433,40 & 104071,00 & 252339 & 4188,9 & 4,189 & 39,55 & 2382,76824 & 0,29 \\
\hline 13.11 .03 & $17: 00$ & 105,94 & 0,01 & 59,97 & 152922,87 & 52042,00 & 104269,00 & 257144 & 4287,9 & 4,288 & 40,48 & 2427,36845 & 0,30 \\
\hline 13.11 .03 & $18: 00$ & 103,50 & 0,01 & 60,21 & 149405,45 & 176019,30 & 318420,80 & 471344 & 7828,3 & 7,828 & 75,64 & 4554,11241 & 0,56 \\
\hline 13.11 .03 & 19:00 & 96,66 & 0,01 & 59,78 & 139537,48 & 170041,70 & 336042,60 & 485448 & 8120,6 & 8,121 & 84,01 & 5022,0885 & 0,62 \\
\hline 13.11 .03 & $20: 00$ & 89,63 & 0,01 & 58,74 & 129384,39 & 156441,20 & 315130,80 & 454668 & 7740,4 & 7,740 & 86,36 & 5072,77106 & 0,62 \\
\hline 13.11 .03 & $21: 00$ & 82,87 & 0,01 & 61,03 & 119622,57 & 157866,80 & 325729,10 & 455113 & 7457,2 & 7,457 & 89,99 & 5492,10825 & 0,67 \\
\hline 13.11 .03 & $22: 00$ & 77,01 & 0,01 & 60,00 & 111173,14 & 154748,30 & 314169,50 & 433792 & 7229,9 & 7,230 & 93,88 & 5632,66895 & 0,69 \\
\hline 13.11 .03 & $23: 00$ & 77,89 & 0,01 & 60,06 & 112442,77 & 150745,30 & 308130,50 & 419304 & 6981,4 & 6,981 & 89,63 & 5383,06453 & 0,66 \\
\hline 14.11 .03 & 00:00 & 71,63 & 0,01 & 60,31 & 103400,11 & 157084,80 & 311635,20 & 424078 & 7031,6 & 7,032 & 98,17 & 5920,48372 & 0,73 \\
\hline 14.11 .03 & 01:00 & 55,46 & 0,02 & 60,00 & 80065,19 & 146837,00 & 302216,90 & 405617 & 6760,3 & 6,760 & 121,89 & 7313,15744 & 0,90 \\
\hline 14.11 .03 & 02:00 & 50,88 & 0,02 & 59,98 & 73453,29 & 149358,00 & 250987,80 & 331053 & 5519,4 & 5,519 & 108,47 & 6506,07069 & 0,80 \\
\hline 14.11 .03 & 03:00 & 63,83 & 0,02 & 60,15 & 92148,47 & 152555,10 & 250121,00 & 323574 & 5379,5 & 5,379 & 84,27 & 5068,95402 & 0,62 \\
\hline 14.11 .03 & 04:00 & 58,89 & 0,02 & 59,90 & 85009,07 & 149133,40 & 299314,40 & 391463 & 6535,3 & 6,535 & 110,98 & 6647,49177 & 0,82 \\
\hline 14.11 .03 & 05:00 & 54,65 & 0,02 & 59,65 & 78892,98 & 145302,00 & 294724,60 & 379734 & 6366,0 & 6,366 & 116,48 & 6948,21474 & 0,85 \\
\hline 14.11 .03 & 06:00 & 51,29 & 0,02 & 60,23 & 74033,06 & 146841,80 & 293926,10 & 372819 & 6189,9 & 6,190 & 120,70 & 7269,5066 & 0,89 \\
\hline 14.11 .03 & 07:00 & 33,77 & 0,03 & 59,88 & 48749,73 & 161274,20 & 307199,10 & 381232 & 6366,6 & 6,367 & 188,52 & 11288,8532 & 1,39 \\
\hline 14.11 .03 & 08:00 & 31,91 & 0,03 & 60,07 & 46067,90 & 141139,90 & 284918,60 & 333668 & 5554,7 & 5,555 & 174,06 & 10455,6027 & 1,28 \\
\hline 14.11 .03 & 09:00 & 19,71 & 0,05 & 60,31 & 28445,92 & 216916,30 & 398333,10 & 444401 & 7368,6 & 7,369 & 373,94 & 22552,1269 & 2,77 \\
\hline
\end{tabular}


Appendix B. Experiment 2 Tab.19 Heat balance results (13.11.03)

\begin{tabular}{|c|c|c|c|c|c|c|c|c|c|}
\hline Date & Time & $\begin{array}{c}\text { Total } \\
\text { heat } \\
\text { /animal } \\
\left(20^{\circ} \mathrm{C}\right) \\
\mathrm{W} \\
\end{array}$ & $\begin{array}{l}\text { hpu/all } \\
\text { animals }\end{array}$ & $\begin{array}{c}\text { Sensible } \\
\text { heat and } \\
\text { temperature } \\
\text { factors }\end{array}$ & $\begin{array}{l}\text { Sensible } \\
\text { Heat/ all } \\
\text { animals } \\
\text { (W) }\end{array}$ & $\begin{array}{l}\text { Heat loss } \\
\text { Thought } \\
\text { Building } \\
\text { (W) }\end{array}$ & $\begin{array}{c}\text { Calculated } \\
\text { AER } \\
\left(\mathrm{m}^{3} / \mathrm{s}\right)\end{array}$ & $\begin{array}{c}\text { Calculated } \\
\text { AER } \\
\left(\mathrm{m}^{3} / \mathrm{h}\right)\end{array}$ & $\begin{array}{l}\text { Heat } \\
\text { balance } \\
\text { AER/h }\end{array}$ \\
\hline 13.11 .2003 & $12: 00$ & 13,33 & 533,20 & 412,35 & 219866,69 & $-49726,93$ & 6,79 & 24452,01 & 3,24 \\
\hline 13.11 .2003 & $13: 00$ & 13,33 & 533,20 & 408,12 & 217608,60 & $-49223,97$ & 6,79 & 24459,32 & 3,15 \\
\hline 13.11 .2003 & $14: 00$ & 13,33 & 533,20 & 407,84 & 217461,97 & $-49707,88$ & 6,70 & 24134,93 & 3,02 \\
\hline 13.11 .2003 & $15: 00$ & 13,33 & 533,20 & 411,71 & 219522,21 & $-49561,18$ & 6,81 & 24509,25 & 3,00 \\
\hline 13.11 .2003 & $16: 00$ & 13,33 & 533,20 & 406,32 & 216647,92 & $-50313,07$ & 6,57 & 23652,76 & 3,13 \\
\hline 13.11 .2003 & $17: 00$ & 13,33 & 533,20 & 407,65 & 217360,70 & $-50183,52$ & 6,62 & 23827,99 & 3,12 \\
\hline 13.11 .2003 & $18: 00$ & 13,33 & 533,20 & 407,84 & 217458,48 & $-50165,74$ & 6,63 & 23852,10 & 3,05 \\
\hline 13.11 .2003 & $19: 00$ & 13,33 & 533,20 & 410,16 & 218696,81 & $-49483,07$ & 6,79 & 24445,22 & 3,11 \\
\hline 13.11 .2003 & $20: 00$ & 13,33 & 533,20 & 408,76 & 217953,46 & $-48932,61$ & 6,86 & 24693,40 & 3,19 \\
\hline 13.11 .2003 & 21:00 & 13,33 & 533,20 & 407,27 & 217154,64 & $-49077,91$ & 6,80 & 24489,44 & 3,13 \\
\hline 13.11 .2003 & $22: 00$ & 13,33 & 533,20 & 402,48 & 214603,09 & $-49083,63$ & 6,70 & 24132,22 & 3,06 \\
\hline 13.11 .2003 & $23: 00$ & 13,33 & 533,20 & 396,26 & 211287,74 & $-49453,86$ & 6,51 & 23444,65 & 3,07 \\
\hline 14.11 .2003 & $00: 00$ & 13,33 & 533,20 & 399,89 & 213223,43 & $-48647,36$ & 6,73 & 24216,74 & 3,15 \\
\hline 14.11 .2003 & 01:00 & 13,33 & 533,20 & 400,81 & 213711,73 & $-48330,47$ & 6,80 & 24488,83 & 3,08 \\
\hline 14.11 .2003 & 02:00 & 13,33 & 533,20 & 407,74 & 217409,59 & $-46974,02$ & 7,20 & 25927,84 & 2,78 \\
\hline 14.11 .2003 & 03:00 & 13,33 & 533,20 & 390,90 & 208430,20 & $-48595,92$ & 6,55 & 23578,68 & 2,56 \\
\hline 14.11 .2003 & 04:00 & 13,33 & 533,20 & 401,11 & 213869,74 & $-47844,66$ & 6,90 & 24829,02 & 2,66 \\
\hline 14.11 .2003 & 05:00 & 13,33 & 533,20 & 410,02 & 218623,62 & $-46981,64$ & 7,25 & 26098,30 & 2,74 \\
\hline 14.11 .2003 & 06:00 & 13,33 & 533,20 & 413,34 & 220395,22 & $-46429,79$ & 7,43 & 26748,87 & 2,81 \\
\hline 14.11 .2003 & 07:00 & 13,33 & 533,20 & 421,69 & 224846,11 & $-45385,15$ & 7,83 & 28188,16 & 2,99 \\
\hline 14.11 .2003 & 08:00 & 13,33 & 533,20 & 404,99 & 215941,36 & $-47012,12$ & 7,14 & 25688,89 & 3,32 \\
\hline 14.11 .2003 & 09:00 & 13,33 & 533,20 & 409,49 & 218341,25 & $-46347,24$ & 7,36 & 26507,20 & 3,57 \\
\hline
\end{tabular}


Appendix B. Experiment 2 Tab.20a Moisture balance results (13.11.03)

\begin{tabular}{|c|c|c|c|c|c|c|c|c|c|c|c|c|}
\hline A1 & $\begin{array}{l}- \\
5,8002206 E+03\end{array}$ & $\begin{array}{l}\text { indoor } \mathrm{T} \\
\text { oK }\end{array}$ & T2 & T3 & LnT & Pws Pa) & HR & $\begin{array}{c}\text { Pw } \\
(\mathrm{Kpa})\end{array}$ & $\begin{array}{c}\text { Wi (kg } \\
\text { ag/ka } \\
\text { as) }\end{array}$ & $\begin{array}{l}\text { outdoor } \\
\mathrm{T} \text { ㅇ K }\end{array}$ & T2 & T3 \\
\hline $\mathrm{A} 2$ & 1,3914993 & 297,90 & 88745,238 & 26437330 & 5,6967625 & 3122,5486 & 0,69 & 2,169 & 0,0136075 & 276,15 & 76258,823 & 21058874 \\
\hline A3 & $-4,86 \mathrm{E}-02$ & 298,08 & 88852,514 & 26485281 & 5,6973666 & 3156,2768 & 0,70 & 2,201 & 0,0138131 & 276,55 & 76479,903 & 21150517 \\
\hline A4 & $4,18 \mathrm{E}-05$ & 298,09 & 88859,47 & 26488391 & 5,6974057 & 3158,4738 & 0,71 & 2,232 & 0,0140114 & 276,35 & 76369,323 & 21104662 \\
\hline A5 & $-1,45 \mathrm{E}-08$ & 297,93 & 88761,623 & 26444652 & 5,6968548 & 3127,6811 & 0,73 & 2,270 & 0,0142532 & 276,25 & 76314,063 & 21081760 \\
\hline $\mathrm{A} 6$ & 0 & 298,16 & 88898,06 & 26505648 & 5,6976228 & 3170,6862 & 0,73 & 2,304 & 0,0144691 & 276,15 & 76258,823 & 21058874 \\
\hline \multirow[t]{2}{*}{ A7 } & 6,5459673 & 298,10 & 88864,272 & 26490538 & 5,6974327 & 3159,9916 & 0,75 & 2,373 & 0,0149127 & 276,15 & 76258,823 & 21058874 \\
\hline & & 298,09 & 88859,635 & 26488465 & 5,6974066 & 3158,5261 & 0,76 & 2,396 & 0,0150664 & 276,15 & 76258,823 & 21058874 \\
\hline patm $(\mathrm{Pa})$ & 101325 & 297,99 & 88800,854 & 26462186 & 5,6970758 & 3139,9979 & 0,77 & 2,408 & 0,0151387 & 276,35 & 76369,323 & 21104662 \\
\hline \multirow[t]{14}{*}{$\mathrm{Ra}$} & 287,055 & 298,05 & 88836,151 & 26477965 & 5,6972745 & 3151,1129 & 0,75 & 2,371 & 0,0149053 & 276,65 & 76535,223 & 21173469 \\
\hline & & 298,12 & 88874,044 & 26494908 & 5,6974877 & 3163,0814 & 0,76 & 2,414 & 0,0151777 & 276,65 & 76535,223 & 21173469 \\
\hline & & 298,32 & 88994,822 & 26548935 & 5,6981667 & 3201,4771 & 0,76 & 2,444 & 0,0153711 & 276,85 & 76645,923 & 21219424 \\
\hline & & 298,58 & 89151,178 & 26618932 & 5,6990444 & 3251,7466 & 0,75 & 2,440 & 0,0153502 & 276,95 & 76701,303 & 21242426 \\
\hline & & 298,43 & 89059,968 & 26578092 & 5,6985326 & 3222,3441 & 0,75 & 2,401 & 0,0150942 & 277,15 & 76812,123 & 21288480 \\
\hline & & 298,39 & 89036,924 & 26567777 & 5,6984032 & 3214,9502 & 0,74 & 2,365 & 0,0148648 & 277,25 & 76867,563 & 21311532 \\
\hline & & 298,10 & 88861,954 & 26489502 & 5,6974197 & 3159,2588 & 0,70 & 2,219 & 0,0139278 & 277,55 & 77034,003 & 21380787 \\
\hline & & 298,81 & 89285,424 & 26679080 & 5,6997968 & 3295,42 & 0,62 & 2,055 & 0,0128751 & 277,55 & 77034,003 & 21380787 \\
\hline & & 298,38 & 89029,464 & 26564438 & 5,6983613 & 3212,5596 & 0,69 & 2,218 & 0,0139226 & 277,45 & 76978,503 & 21357686 \\
\hline & & 298,00 & 88804,331 & 26463740 & 5,6970954 & 3141,0913 & 0,70 & 2,201 & 0,0138101 & 277,45 & 76978,503 & 21357686 \\
\hline & & 297,86 & 88720,083 & 26426090 & 5,6966208 & 3114,6828 & 0,71 & 2,204 & 0,0138269 & 277,55 & 77034,003 & 21380787 \\
\hline & & 297,50 & 88507,572 & 26331199 & 5,6954217 & 3048,8732 & 0,70 & 2,135 & 0,0133904 & 277,65 & 77089,523 & 21403906 \\
\hline & & 298,21 & 88931,524 & 26520615 & 5,697811 & 3181,3071 & 0,72 & 2,289 & 0,014376 & 277,65 & 77089,523 & 21403906 \\
\hline & & 298,02 & 88817,742 & 26469735 & 5,6971709 & 3145,3117 & 0,71 & 2,231 & 0,0140034 & 277,75 & 77145,063 & 21427041 \\
\hline
\end{tabular}


Appendix B. Experiment 2 Tab.20b Moisture balance results (13.11.03)

\begin{tabular}{|c|c|c|c|c|c|c|c|c|c|c|c|c|c|}
\hline LnT & Pws Pa) & HR & $\begin{array}{c}\text { Pw } \\
\text { (Kpa) }\end{array}$ & $\begin{array}{c}\text { Wo (kg } \\
\text { ag/ka } \\
\text { as) }\end{array}$ & $\begin{array}{l}\text { Total } \\
\text { heat } \\
\text { /hpu }\end{array}$ & $\begin{array}{c}\text { Sensible } \\
\text { Heat } \\
\text { lanimal }\end{array}$ & $\begin{array}{l}\text { Latent } \\
\text { Heat } \\
\text { /animal } \\
\text { (W) }\end{array}$ & $\begin{array}{c}\text { Latent } \\
\text { Heat } \\
\text { /animal } \\
(\mathrm{Kg} \\
\text { water/s) }\end{array}$ & $\begin{array}{c}\text { Latent } \\
\text { Heat } / 30 \\
000 \\
\text { animal } \\
(\mathrm{Kg} \\
\text { water/s) }\end{array}$ & $\begin{array}{c}\text { AER Kg } \\
\text { air/s }\end{array}$ & $\begin{array}{c}\text { AER } \\
\text { m3/s }\end{array}$ & $\begin{array}{l}\text { AER } \\
\mathrm{m} 3 / \mathrm{h}\end{array}$ & AER /hr \\
\hline 5,6209442 & 758,03121 & 0,876 & 0,664 & 0,004103 & 904,97 & 412,3531 & 492,619 & 0,0002044 & 0,1089894 & 11,480839 & 9,4882971 & 34157,869 & 4,0 \\
\hline 5,6223916 & 779,79583 & 0,876 & 0,683 & 0,0042217 & 901,37 & 408,1181 & 493,254 & 0,0002047 & 0,1091299 & 11,391662 & 9,414597 & 33892,549 & 3,9 \\
\hline 5,6213063 & 763,42134 & 0,926 & 0,707 & 0,0043699 & 904,42 & 411,7071 & 492,715 & 0,0002044 & 0,1090107 & 11,044079 & 9,1273377 & 32858,416 & 3,8 \\
\hline 5,6209442 & 758,03121 & 0,951 & 0,721 & 0,0044569 & 899,84 & 406,3164 & 493,528 & 0,0002048 & 0,1091905 & 10,920124 & 9,024896 & 32489,626 & 3,8 \\
\hline 5,6209442 & 758,03121 & 0,969 & 0,735 & 0,0045418 & 900,98 & 407,6532 & 493,325 & 0,0002047 & 0,1091455 & 10,539133 & 8,7100272 & 31356,098 & 3,6 \\
\hline 5,6209442 & 758,03121 & 0,977 & 0,741 & 0,0045796 & 901,13 & 407,8366 & 493,297 & 0,0002047 & 0,1091393 & 10,422389 & 8,6135444 & 31008,76 & 3,6 \\
\hline 5,6216682 & 768,84536 & 0,982 & 0,755 & 0,0046694 & 903,11 & 410,1591 & 492,946 & 0,0002045 & 0,1090619 & 10,432417 & 8,6218325 & 31038,597 & 3,6 \\
\hline 5,6227532 & 785,32265 & 0,985 & 0,774 & 0,0047849 & 901,92 & 408,7649 & 493,156 & 0,0002046 & 0,1091083 & 10,795879 & 8,9222144 & 32119,972 & 3,7 \\
\hline 5,6227532 & 785,32265 & 0,987 & 0,775 & 0,0047947 & 900,65 & 407,2668 & 493,383 & 0,0002047 & 0,1091585 & 10,528342 & 8,7011094 & 31323,994 & 3,6 \\
\hline 5,6234758 & 796,48036 & 0,988 & 0,787 & 0,0048683 & 896,60 & 402,4814 & 494,119 & 0,000205 & 0,1093212 & 10,424153 & 8,6150028 & 31014,01 & 3,6 \\
\hline 5,6245589 & 813,47995 & 0,99 & 0,805 & 0,0049832 & 894,42 & 399,8939 & 494,523 & 0,0002052 & 0,1094106 & 10,836047 & 8,9554104 & 32239,477 & 3,7 \\
\hline 5,6249196 & 819,21737 & 0,991 & 0,812 & 0,0050237 & 895,19 & 400,8097 & 494,379 & 0,0002051 & 0,1093788 & 11,129386 & 9,1978401 & 33112,224 & 3,9 \\
\hline 5,6260011 & 836,64499 & 0,992 & 0,830 & 0,0051367 & 901,06 & 407,7449 & 493,311 & 0,0002047 & 0,1091424 & 12,429003 & 10,271903 & 36978,85 & 4,3 \\
\hline 5,6260011 & 836,64499 & 0,992 & 0,830 & 0,0051367 & 886,87 & 390,9044 & 495,962 & 0,0002058 & 0,1097291 & 14,192643 & 11,729457 & 42226,044 & 4,9 \\
\hline 5,6256407 & 830,7997 & 0,993 & 0,825 & 0,0051057 & 895,44 & 401,1060 & 494,333 & 0,0002051 & 0,1093686 & 12,418359 & 10,263107 & 36947,185 & 4,3 \\
\hline 5,6256407 & 830,7997 & 0,994 & 0,826 & 0,0051109 & 902,99 & 410,0218 & 492,967 & 0,0002046 & 0,1090664 & 12,551355 & 10,373021 & 37342,875 & 4,4 \\
\hline 5,6260011 & 836,64499 & 0,995 & 0,832 & 0,0051524 & 905,82 & 413,3444 & 492,472 & 0,0002043 & 0,1089569 & 12,574373 & 10,392044 & 37411,358 & 4,4 \\
\hline 5,6263613 & 842,52661 & 0,996 & 0,839 & 0,0051942 & 912,96 & 421,6919 & 491,264 & 0,0002038 & 0,1086895 & 13,274335 & 10,970524 & 39493,888 & 4,6 \\
\hline 5,6263613 & 842,52661 & 0,996 & 0,839 & 0,0051942 & 898,72 & 404,9913 & 493,731 & 0,0002049 & 0,1092354 & 11,911247 & 9,8440059 & 35438,421 & 4,1 \\
\hline 5,6267214 & 848,44477 & 0,997 & 0,846 & 0,0052362 & 902,54 & 409,4922 & 493,047 & 0,0002046 & 0,109084 & 12,456287 & 10,294452 & 37060,029 & 4,3 \\
\hline
\end{tabular}


Appendix C. Experiment 3 Tab. 1a AER results (14.07.04)

\begin{tabular}{|c|c|c|c|c|c|c|c|c|c|c|c|c|c|c|c|}
\hline Date & Time & $\begin{array}{l}\text { Tracer gas } \\
\text { (AER) }\end{array}$ & $\begin{array}{c}\text { SF6 } \\
\text { (CV) } \\
\text { ch's 1-4 }\end{array}$ & $\begin{array}{c}\text { SF6 } \\
\text { (CV) } \\
\text { ch's 1-6 }\end{array}$ & $\begin{array}{c}\text { Heat } \\
\text { Balance } \\
\text { (AER) }\end{array}$ & $\begin{array}{c}\text { Moisture } \\
\text { Balance } \\
\text { (AER) }\end{array}$ & $\begin{array}{c}\mathrm{CO2} \\
\text { Balance } \\
\text { (AER) }\end{array}$ & $\begin{array}{l}\text { O.Temp } \\
\left({ }^{\circ} \mathrm{C}\right)\end{array}$ & $\begin{array}{l}\text { I.Temp } \\
\left({ }^{\circ} \mathrm{C}\right)\end{array}$ & $\underset{\left({ }^{\circ} \mathrm{C}\right)}{\Delta \text { Temp }}$ & $\begin{array}{c}\text { CV } \\
\text { I.Temp } \\
\left({ }^{\circ} \mathrm{C}\right)\end{array}$ & $\begin{array}{l}\text { O.Humid } \\
(\%)\end{array}$ & $\begin{array}{c}\text { I. Humid } \\
(\%)\end{array}$ & $\underset{\substack{\text { I.Humid } \\
\text { I\%) }}}{\text { CV }}$ & 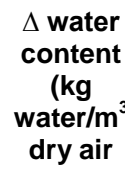 \\
\hline 14.07 .04 & $16: 00$ & 2,41 & 12,4 & 63,3 & 13,5 & 13,4 & 17,1 & 22,06 & 15,7 & 6,36 & 5,13 & 88,5 & 75,92 & 5,5 & 0,00277 \\
\hline 14.07 .04 & $17: 00$ & 2,22 & 13,5 & 63,6 & 13,2 & 13,2 & 16,3 & 21,41 & 14,7 & 6,71 & 5,64 & 85,9 & 73,64 & 6,0 & 0,00280 \\
\hline 14.07 .04 & $18: 00$ & 2,28 & 14,7 & 59,0 & 12,3 & 13,0 & 14,9 & 21,14 & 13,9 & 7,24 & 6,19 & 90,4 & 75,16 & 6,2 & 0,00286 \\
\hline 14.07 .04 & $19: 00$ & 2,42 & 14,6 & 63,0 & 12,2 & 13,1 & 15,9 & 21,20 & 13,9 & 7,30 & 6,07 & 92,7 & 76,15 & 6,1 & 0,00283 \\
\hline 14.07 .04 & $20: 00$ & 2,50 & 13,3 & 60,3 & 12,1 & 12,9 & 16,1 & 21,46 & 14,2 & 7,26 & 6,10 & 93,3 & 76,75 & 6,4 & 0,00288 \\
\hline 14.07 .04 & $21: 00$ & 2,30 & 13,2 & 58,8 & 11,9 & 12,7 & 16,5 & 21,88 & 14,6 & 7,28 & 6,16 & 94,4 & 77,22 & 6,4 & 0,00292 \\
\hline 14.07 .04 & $22: 00$ & 2,71 & 13,2 & 58,9 & 13,1 & 13,4 & 17,1 & 21,89 & 15,3 & 6,59 & 6,41 & 94,7 & 79,24 & 7,4 & 0,00277 \\
\hline 14.07 .04 & $23: 00$ & 2,34 & 12,2 & 61,2 & 13,9 & 14,8 & 17,2 & 21,91 & 15,7 & 6,21 & 6,39 & 93,5 & 78,38 & 8,2 & 0,00250 \\
\hline 15.07 .04 & 0:00 & 2,51 & 12,1 & 62,3 & 13,7 & 14,4 & 17,0 & 21,90 & 15,6 & 6,30 & 6,70 & 92,3 & 77,65 & 8,9 & 0,00258 \\
\hline 15.07 .04 & $1: 00$ & 2,66 & 12,9 & 61,8 & 13,7 & 14,7 & 18,7 & 21,92 & 15,6 & 6,32 & 6,75 & 92 & 77,04 & 8,8 & 0,00252 \\
\hline 15.07 .04 & $2: 00$ & 2,59 & 12,9 & 63,6 & 14,3 & 15,5 & 19,4 & 21,81 & 15,7 & 6,11 & 6,69 & 91,8 & 77,10 & 8,8 & 0,00240 \\
\hline 15.07 .04 & $3: 00$ & 2,67 & 13,3 & 62,2 & 13,7 & 15,2 & 19,5 & 21,75 & 15,4 & 6,35 & 6,72 & 92,3 & 76,76 & 8,4 & 0,00244 \\
\hline 15.07 .04 & $5: 00$ & 2,72 & 13,3 & 58,4 & 11,4 & 11,9 & 16,8 & 21,97 & 14,4 & 7,57 & 7,06 & 93,5 & 76,71 & 8,3 & 0,00312 \\
\hline 15.07 .04 & $6: 00$ & 2,45 & 12,9 & 58,2 & 11,1 & 11,3 & 16,3 & 21,78 & 14 & 7,78 & 6,14 & 94,8 & 77,96 & 6,8 & 0,00330 \\
\hline 15.07 .04 & $7: 00$ & 2,58 & 13,5 & 62,6 & 11,7 & 12,0 & 16,7 & 21,95 & 14,6 & 7,35 & 5,64 & 95,2 & 78,52 & 6,8 & 0,00311 \\
\hline 15.07 .04 & $8: 00$ & 2,62 & 14,5 & 66,4 & 12,6 & 13,7 & 17,7 & 22,46 & 15,8 & 6,66 & 5,07 & 91,9 & 76,41 & 6,4 & 0,00272 \\
\hline 15.07 .04 & 9:00 & 2,53 & 14,6 & 68,3 & 14,9 & 15,7 & 20,2 & 23,10 & 17,6 & 5,50 & 4,67 & 82,5 & 71,95 & 5,7 & 0,00238 \\
\hline 15.07 .04 & $10: 00$ & 1,64 & 14,6 & 74,4 & 16,2 & 16,4 & 23,7 & 23,63 & 18,7 & 4,93 & 3,93 & 76,4 & 68,77 & 5,8 & 0,00229 \\
\hline 15.07 .04 & $11: 00$ & 2,27 & 14,5 & 70,8 & 18,6 & 18,7 & 28,4 & 23,92 & 19,7 & 4,22 & 3,79 & 71,7 & 66,06 & 5,1 & 0,00201 \\
\hline 15.07 .04 & $12: 00$ & 1,98 & 14,3 & 76,1 & 18,0 & 18,0 & 27,4 & 24,20 & 19,9 & 4,30 & 3,74 & 69,1 & 64,01 & 4,9 & 0,00209 \\
\hline 15.07 .04 & $13: 00$ & 2,11 & 15,0 & 72,1 & 17,1 & 18,4 & 26,2 & 24,14 & 19,6 & 4,54 & 3,68 & 68,1 & 62,28 & 4,6 & 0,00204 \\
\hline 15.07 .04 & $14: 00$ & 1,96 & 15,2 & 73,5 & 17,2 & 17,8 & 25,3 & 23,88 & 19,3 & 4,58 & 3,82 & 68,2 & 62,74 & 4,9 & 0,00210 \\
\hline 15.07.04 & $15: 00$ & 1,74 & 15,2 & 70,2 & 14,7 & 16,9 & 22,5 & 23,92 & 18,6 & 5,32 & 4,04 & 72 & 63,74 & 5,4 & 0,00223 \\
\hline
\end{tabular}


Appendix C. Experiment 3 Tab. 1b U-value calculation for Livestock house 2

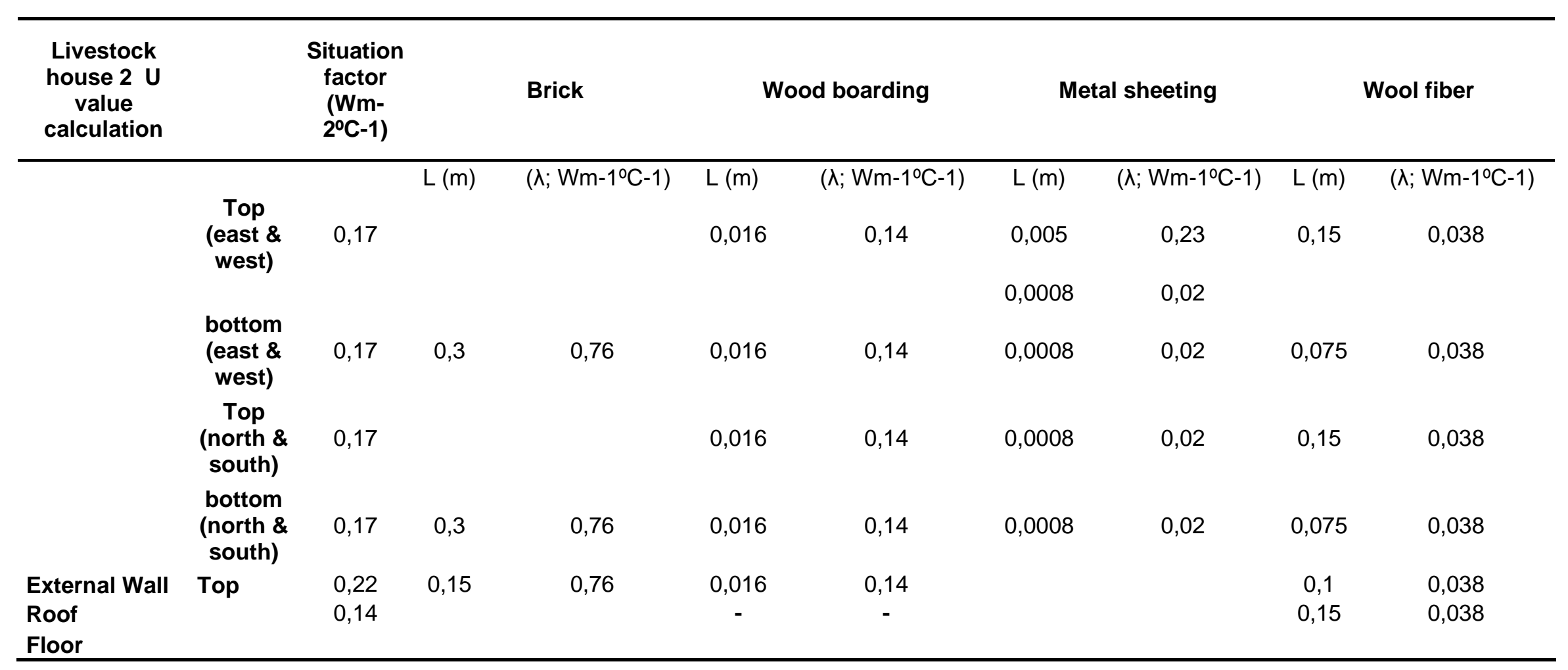


Appendix C. Experiment 3 Tab. 1c U-value calculation for Livestock house 2

\begin{tabular}{|c|c|c|c|c|c|c|c|}
\hline $\begin{array}{l}\text { AAC } \\
\text { block }\end{array}$ & & $\begin{array}{l}\text { Alloy } \\
\text { roof }\end{array}$ & & $\begin{array}{c}\text { U/element } \\
\text { (Wm-2 }{ }^{\circ} \mathrm{C}- \\
1)\end{array}$ & $A(m 2)$ & $U^{*} A$ & $\mathrm{U}$ value \\
\hline $\mathrm{L}(\mathrm{m})$ & $\begin{array}{c}\left(\lambda ; \mathrm{Wm}^{-1^{\circ} \mathrm{C}-}-\right. \\
1)\end{array}$ & $L(m)$ & $\begin{array}{c}\left(\lambda ; W m-1^{\circ} \mathrm{C}-\right. \\
1)\end{array}$ & & & & \\
\hline \multirow[t]{2}{*}{0,015} & 0,14 & - & - & 0,227 & 351,600 & 79,89936 & \\
\hline & & & & & & 0 & \\
\hline 0,015 & 0,14 & & & 0,362 & 105,000 & 38,04555 & \\
\hline 0,015 & 0,14 & & & 0,228 & 99,700 & 22,76881 & \\
\hline 0,015 & 0,14 & & & 0,362 & 23,600 & 8,551191 & \\
\hline \multirow[t]{2}{*}{0,026} & 0,3 & - & - & 0,328 & 21,000 & 6,879536 & \\
\hline & & 0,002 & 0,02 & 0,239 & 1311 & 313,0845 & \\
\hline
\end{tabular}


Appendix C. Experiment 3 Tab. 2 Tracer calculation results (14.07.04)

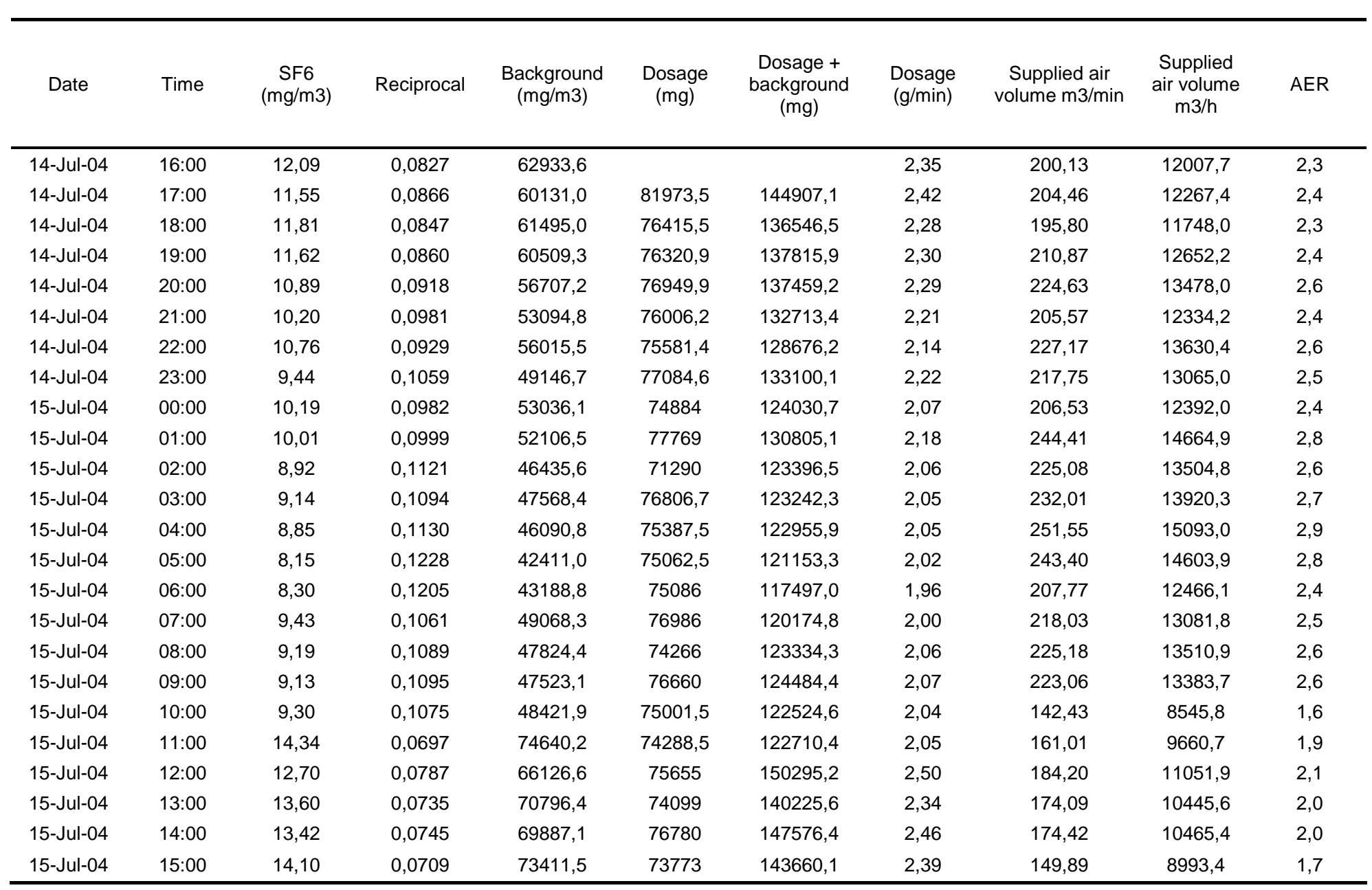


Appendix C. Experiment $3 \mathrm{Tab} .3 \mathrm{CO}_{2}$ balance results (14.07.04)

\begin{tabular}{cccccccc}
\hline Date & Time & $\begin{array}{c}\text { Inside } \mathrm{CO}_{2} \\
\text { concentration }\end{array}$ & $\begin{array}{c}\text { Corrected } \\
\text { for } \\
\text { manure }\end{array}$ & $\Delta \mathrm{CO}_{2}$ & $\begin{array}{c}\mathrm{CO}_{2} \\
\text { productn } \\
/ \Delta \mathrm{CO}_{2}\end{array}$ & $\begin{array}{c}\text { Air volume } \\
\text { displacement } \\
\text { m3/h }\end{array}$ & AER /h \\
\hline 14.07 .04 & $16: 00$ & 1065,0 & 1022,4 & 672,4 & 275,12 & 88974,86 & 17,09 \\
14.07 .04 & $17: 00$ & 1100,3 & 1056,2 & 706,2 & 261,95 & 84714,55 & 16,27 \\
14.07 .04 & $18: 00$ & 1167,1 & 1120,5 & 770,5 & 240,12 & 77653,65 & 14,92 \\
14.07 .04 & $19: 00$ & 1115,5 & 1070,9 & 720,9 & 256,63 & 82995,60 & 15,94 \\
14.07 .04 & $20: 00$ & 1106,8 & 1062,5 & 712,5 & 259,64 & 83966,70 & 16,13 \\
14.07 .04 & $21: 00$ & 1088,9 & 1045,4 & 695,4 & 266,05 & 86039,55 & 16,53 \\
14.07 .04 & $22: 00$ & 1063,7 & 1021,1 & 671,1 & 275,65 & 89145,43 & 17,12 \\
14.07 .04 & $23: 00$ & 1059,4 & 1017,1 & 667,1 & 277,34 & 89691,09 & 17,23 \\
15.07 .04 & $0: 00$ & 1069,5 & 1026,7 & 676,7 & 273,37 & 88408,35 & 16,98 \\
15.07 .04 & $1: 00$ & 1003,4 & 963,3 & 613,3 & 301,65 & 97554,61 & 18,74 \\
15.07 .04 & $2: 00$ & 980,1 & 940,9 & 590,9 & 313,07 & 101247,05 & 19,45 \\
15.07 .04 & $3: 00$ & 979,8 & 940,6 & 590,6 & 313,26 & 101308,77 & 19,46 \\
15.07 .04 & $4: 00$ & 1044,1 & 1002,3 & 652,3 & 283,61 & 91718,71 & 17,62 \\
15.07 .04 & $5: 00$ & 1079,1 & 1036,0 & 686,0 & 269,69 & 87216,72 & 16,75 \\
15.07 .04 & $6: 00$ & 1098,2 & 1054,3 & 704,3 & 262,68 & 84949,23 & 16,32 \\
15.07 .04 & $7: 00$ & 1081,8 & 1038,6 & 688,6 & 268,67 & 86889,05 & 16,69 \\
15.07 .04 & $8: 00$ & 1042,5 & 1000,8 & 650,8 & 284,25 & 91927,51 & 17,66 \\
15.07 .04 & $9: 00$ & 957,6 & 919,3 & 569,3 & 324,96 & 105093,24 & 20,19 \\
15.07 .04 & $10: 00$ & 870,4 & 835,6 & 485,6 & 380,98 & 123208,88 & 23,67 \\
15.07 .04 & $11: 00$ & 785,8 & 754,4 & 404,4 & 457,51 & 147958,28 & 28,42 \\
15.07 .04 & $12: 00$ & 801,6 & 769,6 & 419,6 & 440,94 & 142598,43 & 27,39 \\
15.07 .04 & $13: 00$ & 820,7 & 787,9 & 437,9 & 422,51 & 136638,53 & 26,25 \\
15.07 .04 & $14: 00$ & 838,6 & 805,0 & 455,0 & 406,57 & 131484,31 & 25,26 \\
15.07 .04 & $15: 00$ & 896,1 & 860,3 & 510,3 & 362,56 & 117253,40 & 22,52 \\
\hline
\end{tabular}


Appendix C. Experiment 3 Tab. 4 Heat balance results (14.07.04)

\begin{tabular}{|c|c|c|c|c|c|c|c|c|c|}
\hline Date & Time & $\begin{array}{c}\text { Total } \\
\text { heat } \\
\text { /animal } \\
\left(20^{\circ} \mathrm{C}\right) \\
\mathrm{W} \\
\end{array}$ & $\begin{array}{l}\text { hpu/all } \\
\text { animals }\end{array}$ & $\begin{array}{c}\text { Sensible } \\
\text { heat and } \\
\text { temperature } \\
\text { factors }\end{array}$ & $\begin{array}{l}\text { Sensible } \\
\text { Heat/ all } \\
\text { animals } \\
\text { (W) }\end{array}$ & $\begin{array}{c}\text { Heat } \\
\text { loss } \\
\text { Thought } \\
\text { Building } \\
\text { (W) }\end{array}$ & $\begin{array}{c}\text { Calculated } \\
\text { AER } \\
\left(\mathrm{m}^{3} / \mathrm{s}\right)\end{array}$ & $\begin{array}{c}\text { Calculated } \\
\text { AER } \\
\left(\mathrm{m}^{3} / \mathrm{h}\right)\end{array}$ & $\begin{array}{l}\text { Heat } \\
\text { balance } \\
\text { AER/h }\end{array}$ \\
\hline 14.07.04 & $16: 00: 00$ & 10,78 & 323,40 & 474,00 & 153290,54 & $-2982,54$ & 19,54 & 70355,54 & 13,51 \\
\hline 14.07.04 & 17:00:00 & 10,78 & 323,40 & 488,34 & 157929,29 & $-3147,35$ & 19,07 & 68655,72 & 13,19 \\
\hline 14.07.04 & 18:00:00 & 10,78 & 323,40 & 494,17 & 159815,09 & $-3397,80$ & 17,85 & 64267,05 & 12,34 \\
\hline 14.07 .04 & $19: 00: 00$ & 10,78 & 323,40 & 492,83 & 159382,20 & $-3426,54$ & 17,65 & 63539,92 & 12,21 \\
\hline 14.07.04 & 20:00:00 & 10,78 & 323,40 & 487,10 & 157529,55 & $-3408,36$ & 17,54 & 63127,50 & 12,13 \\
\hline 14.07.04 & 21:00:00 & 10,78 & 323,40 & 477,83 & 154530,02 & $-3417,75$ & 17,15 & 61725,11 & 11,86 \\
\hline 14.07.04 & 22:00:00 & 10,78 & 323,40 & 477,80 & 154521,06 & $-3089,87$ & 19,01 & 68418,99 & 13,14 \\
\hline 14.07 .04 & 23:00:00 & 10,78 & 323,40 & 477,33 & 154368,60 & $-2912,15$ & 20,17 & 72606,52 & 13,95 \\
\hline 15.07.04 & 00:00:00 & 10,78 & 323,40 & 477,44 & 154404,48 & $-2956,73$ & 19,86 & 71507,77 & 13,74 \\
\hline 15.07.04 & 01:00:00 & 10,78 & 323,40 & 477,14 & 154305,81 & $-2963,18$ & 19,81 & 71302,55 & 13,70 \\
\hline 15.07.04 & 02:00:00 & 10,78 & 323,40 & 479,57 & 155094,42 & $-2864,64$ & 20,61 & 74187,56 & 14,25 \\
\hline 15.07.04 & 03:00:00 & 10,78 & 323,40 & 480,90 & 155523,81 & $-2977,26$ & 19,87 & 71529,95 & 13,74 \\
\hline 15.07.04 & 04:00:00 & 10,78 & 323,40 & 482,17 & 155934,82 & $-3231,81$ & 18,32 & 65963,41 & 12,67 \\
\hline 15.07 .04 & 05:00:00 & 10,78 & 323,40 & 475,91 & 153910,83 & $-3552,06$ & 16,42 & 59094,90 & 11,35 \\
\hline 15.07.04 & 06:00:00 & 10,78 & 323,40 & 480,05 & 155246,56 & $-3652,36$ & 16,10 & 57944,31 & 11,13 \\
\hline 15.07.04 & 07:00:00 & 10,78 & 323,40 & 476,28 & 154027,58 & $-3450,59$ & 16,92 & 60920,98 & 11,70 \\
\hline 15.07.04 & 08:00:00 & 10,78 & 323,40 & 465,09 & 150408,57 & $-3122,72$ & 18,29 & 65846,10 & 12,65 \\
\hline 15.07.04 & 09:00:00 & 10,78 & 323,40 & 450,43 & 145669,60 & $-2582,52$ & 21,49 & 77349,74 & 14,86 \\
\hline 15.07.04 & 10:00:00 & 10,78 & 323,40 & 438,52 & 141817,02 & $-2310,95$ & 23,41 & 84276,02 & 16,19 \\
\hline 15.07.04 & 11:00:00 & 10,78 & 323,40 & 431,66 & 139600,23 & $-1981,32$ & 26,94 & 96967,36 & 18,63 \\
\hline 15.07.04 & 12:00:00 & 10,78 & 323,40 & 425,15 & 137492,52 & $-2019,44$ & 26,01 & 93653,30 & 17,99 \\
\hline 15.07.04 & 13:00:00 & 10,78 & 323,40 & 426,57 & 137952,53 & $-2131,47$ & 24,71 & 88958,88 & 17,09 \\
\hline 15.07.04 & 14:00:00 & 10,78 & 323,40 & 432,76 & 139955,05 & $-2146,72$ & 24,89 & 89619,29 & 17,21 \\
\hline 15.07 .04 & 15:00:00 & 10,78 & 323,40 & 431,64 & 139590,89 & $-2498,06$ & 21,28 & 76615,07 & 14,72 \\
\hline
\end{tabular}


Appendix C. Experiment 3 Tab. 5a Moisture balance results (14.07.04)

\begin{tabular}{|c|c|c|c|c|c|c|c|c|c|c|c|c|}
\hline A1 & $\stackrel{-}{5,8002206 E+03}$ & $\begin{array}{l}\text { indoor } \mathbf{T} \\
\text { oK }\end{array}$ & T2 & T3 & LnT & Pws Pa) & HR & $\begin{array}{c}\text { Pw } \\
(\mathrm{Kpa})\end{array}$ & $\begin{array}{c}\text { Wi (kg } \\
\text { ag/ka } \\
\text { as) }\end{array}$ & $\begin{array}{l}\text { outdoor } \\
\mathrm{T} \text { oK }\end{array}$ & T2 & T3 \\
\hline $\mathrm{A} 2$ & 1,3914993 & 295,21 & 87146,73 & 25726259 & 5,688 & 2653,841 & 0,76 & 2,015 & 0,0126193 & 288,85 & 83434,323 & 24100004 \\
\hline A3 & $-4,86 \mathrm{E}-02$ & 294,56 & 86764,121 & 25557023 & 5,685 & 2550,666 & 0,74 & 1,878 & 0,0117483 & 287,85 & 82857,623 & 23850567 \\
\hline A4 & $4,18 \mathrm{E}-05$ & 294,29 & 86607,34 & 25487782 & 5,685 & 2509,348 & 0,75 & 1,886 & 0,0117975 & 287,05 & 82397,703 & 23652261 \\
\hline A5 & $-1,45 E-08$ & 294,35 & 86643,394 & 25503700 & 5,685 & 2518,801 & 0,76 & 1,918 & 0,012001 & 287,05 & 82397,703 & 23652261 \\
\hline A6 & 0 & 294,61 & 86797,262 & 25571667 & 5,686 & 2559,471 & 0,77 & 1,964 & 0,0122972 & 287,35 & 82570,023 & 23726496 \\
\hline \multirow[t]{2}{*}{ A7 } & 6,5459673 & 295,03 & 87044,914 & 25681187 & 5,687 & 2626,057 & 0,77 & 2,028 & 0,012702 & 287,75 & 82800,063 & 23825718 \\
\hline & & 295,04 & 87045,651 & 25681514 & 5,687 & 2626,258 & 0,79 & 2,081 & 0,0130429 & 288,45 & 83203,403 & 24000021 \\
\hline oatm (Pa) & 101325 & 295,06 & 87058,191 & 25687063 & 5,687 & 2629,667 & 0,78 & 2,061 & 0,0129145 & 288,85 & 83434,323 & 24100004 \\
\hline \multirow[t]{16}{*}{$\mathrm{Ra}$} & 287,055 & 295,05 & 87055,24 & 25685757 & 5,687 & 2628,864 & 0,78 & 2,041 & 0,0127882 & 288,75 & 83376,563 & 24074982 \\
\hline & & 295,07 & 87063,354 & 25689349 & 5,687 & 2631,072 & 0,77 & 2,027 & 0,0126965 & 288,75 & 83376,563 & 24074982 \\
\hline & & 294,96 & 86998,452 & 25660628 & 5,687 & 2613,458 & 0,77 & 2,015 & 0,0126204 & 288,85 & 83434,323 & 24100004 \\
\hline & & 294,90 & 86963,061 & 25644972 & 5,687 & 2603,894 & 0,77 & 1,999 & 0,0125161 & 288,55 & 83261,103 & 24024991 \\
\hline & & 294,84 & 86929,151 & 25629974 & 5,686 & 2594,758 & 0,76 & 1,974 & 0,0123556 & 287,95 & 82915,203 & 23875433 \\
\hline & & 295,12 & 87095,814 & 25703717 & 5,687 & 2639,917 & 0,77 & 2,025 & 0,0126846 & 287,55 & 82685,003 & 23776072 \\
\hline & & 294,93 & 86985,917 & 25655083 & 5,687 & 2610,068 & 0,78 & 2,035 & 0,012747 & 287,15 & 82455,123 & 23676988 \\
\hline & & 295,10 & 87086,223 & 25699471 & 5,687 & 2637,301 & 0,79 & 2,071 & 0,0129774 & 287,75 & 82800,063 & 23825718 \\
\hline & & 295,61 & 87382,316 & 25830650 & 5,689 & 2719,052 & 0,76 & 2,078 & 0,01302 & 288,95 & 83492,103 & 24125043 \\
\hline & & 296,25 & 87766,284 & 26001091 & 5,691 & 2828,140 & 0,72 & 2,035 & 0,0127466 & 290,75 & 84535,563 & 24578715 \\
\hline & & 296,78 & 88075,401 & 26138577 & 5,693 & 2918,540 & 0,69 & 2,007 & 0,0125687 & 291,85 & 85176,423 & 24858739 \\
\hline & & 297,07 & 88252,07 & 26217263 & 5,694 & 2971,258 & 0,66 & 1,963 & 0,0122857 & 292,85 & 85761,123 & 25115145 \\
\hline & & 297,35 & 88419,253 & 26291796 & 5,695 & 3021,859 & 0,64 & 1,934 & 0,0121044 & 293,05 & 85878,303 & 25166637 \\
\hline & & 297,29 & 88382,831 & 26275553 & 5,695 & 3010,776 & 0,62 & 1,875 & 0,0117278 & 292,75 & 85702,563 & 25089425 \\
\hline & & 297,03 & 88223,851 & 26204689 & 5,694 & 2962,786 & 0,63 & 1,859 & 0,011623 & 292,45 & 85527,003 & 25012372 \\
\hline & & 297,07 & 88252,813 & 26217594 & 5,694 & 2971,481 & 0,64 & 1,894 & 0,0118486 & 291,75 & 85118,063 & 24833195 \\
\hline
\end{tabular}


Appendix C. Experiment 3 Tab. 5b Moisture balance results (14.07.04)

\begin{tabular}{|c|c|c|c|c|c|c|c|c|c|c|c|c|c|}
\hline LnT & Pws Pa) & HR & $\begin{array}{c}P w \\
\text { (Kpa) }\end{array}$ & $\begin{array}{c}\text { Wo (kg } \\
\text { ag/ka } \\
\text { as) }\end{array}$ & $\begin{array}{l}\text { Total } \\
\text { heat } \\
\text { /hpu } \\
\text { (eqn. } \\
26)\end{array}$ & $\begin{array}{c}\text { Sensible } \\
\text { Heat } \\
\text { /animal }\end{array}$ & $\begin{array}{l}\text { Latent } \\
\text { Heat } \\
\text { /animal } \\
\text { (W) }\end{array}$ & $\begin{array}{c}\text { Latent } \\
\text { Heat } \\
\text { /animal } \\
\text { (Kg } \\
\text { water/s) }\end{array}$ & $\begin{array}{c}\text { Latent } \\
\text { Heat } / 30 \\
000 \\
\text { animal } \\
(\mathrm{Kg} \\
\text { water/s) }\end{array}$ & $\begin{array}{c}\text { AER } \\
\mathrm{Kg} \\
\text { air/s }\end{array}$ & $\begin{array}{c}\text { AER } \\
\text { m3/s }\end{array}$ & $\begin{array}{c}\text { AER } \\
\mathrm{m} 3 / \mathrm{h}\end{array}$ & $\begin{array}{c}\text { AER } \\
/ \mathrm{hr}\end{array}$ \\
\hline 5,6659075 & 1783,8718 & 0,885 & 1,579 & 0,0098443 & 958,88 & 474,00 & 484,88 & 0,0002 & 0,0651 & 23,46 & 19,39 & 69798,89 & 13,41 \\
\hline 5,6624395 & 1672,7754 & 0,859 & 1,437 & 0,0089473 & 971,85 & 488,34 & 483,51 & 0,0002 & 0,0649 & 23,18 & 19,15 & 68953,01 & 13,24 \\
\hline 5,6596564 & 1588,3217 & 0,904 & 1,436 & 0,0089406 & 977,18 & 494,17 & 483,00 & 0,0002 & 0,0648 & 22,70 & 18,76 & 67533,22 & 12,97 \\
\hline 5,6596564 & 1588,3217 & 0,927 & 1,472 & 0,0091714 & 975,95 & 492,83 & 483,12 & 0,0002 & 0,0648 & 22,92 & 18,95 & 68202,17 & 13,10 \\
\hline 5,660701 & 1619,5421 & 0,933 & 1,511 & 0,0094158 & 970,73 & 487,10 & 483,62 & 0,0002 & 0,0649 & 22,54 & 18,62 & 67048,46 & 12,88 \\
\hline 5,662092 & 1662,0074 & 0,944 & 1,569 & 0,0097823 & 962,33 & 477,83 & 484,50 & 0,0002 & 0,0650 & 22,28 & 18,41 & 66288,24 & 12,73 \\
\hline 5,6645218 & 1738,6793 & 0,947 & 1,647 & 0,0102741 & 962,30 & 477,80 & 484,50 & 0,0002 & 0,0650 & 23,49 & 19,42 & 69900,44 & 13,43 \\
\hline 5,6659075 & 1783,8718 & 0,935 & 1,668 & 0,0104098 & 961,88 & 477,33 & 484,54 & 0,0002 & 0,0650 & 25,97 & 21,47 & 77275,45 & 14,84 \\
\hline 5,6655613 & 1772,4781 & 0,923 & 1,636 & 0,0102073 & 961,98 & 477,44 & 484,53 & 0,0002 & 0,0650 & 25,21 & 20,83 & 74993,39 & 14,41 \\
\hline 5,6655613 & 1772,4781 & 0,92 & 1,631 & 0,0101736 & 961,70 & 477,14 & 484,56 & 0,0002 & 0,0650 & 25,79 & 21,31 & 76718,71 & 14,74 \\
\hline 5,6659075 & 1783,8718 & 0,918 & 1,638 & 0,0102174 & 963,90 & 479,57 & 484,33 & 0,0002 & 0,0650 & 27,06 & 22,36 & 80505,56 & 15,46 \\
\hline 5,6648684 & 1749,8821 & 0,923 & 1,615 & 0,0100751 & 965,10 & 480,90 & 484,20 & 0,0002 & 0,0650 & 26,63 & 22,01 & 79229,74 & 15,22 \\
\hline 5,6627869 & 1683,6046 & 0,926 & 1,559 & 0,0097195 & 966,25 & 482,17 & 484,08 & 0,0002 & 0,0650 & 24,65 & 20,38 & 73353,25 & 14,09 \\
\hline 5,6613968 & 1640,654 & 0,935 & 1,534 & 0,0095612 & 960,60 & 475,91 & 484,69 & 0,0002 & 0,0650 & 20,84 & 17,22 & 61992,57 & 11,91 \\
\hline 5,6600047 & 1598,6692 & 0,948 & 1,516 & 0,0094443 & 964,33 & 480,05 & 484,28 & 0,0002 & 0,0650 & 19,69 & 16,27 & 58580,70 & 11,25 \\
\hline 5,662092 & 1662,0074 & 0,952 & 1,582 & 0,0098665 & 960,93 & 476,28 & 484,65 & 0,0002 & 0,0650 & 20,92 & 17,29 & 62237,52 & 11,95 \\
\hline 5,6662537 & 1795,3297 & 0,919 & 1,650 & 0,0102955 & 950,90 & 465,09 & 485,81 & 0,0002 & 0,0652 & 23,94 & 19,79 & 71231,18 & 13,68 \\
\hline 5,6724638 & 2012,9137 & 0,825 & 1,661 & 0,0103637 & 937,93 & 450,43 & 487,49 & 0,0002 & 0,0654 & 27,47 & 22,70 & 81716,30 & 15,70 \\
\hline 5,67624 & 2156,9729 & 0,764 & 1,648 & 0,010283 & 927,50 & 438,52 & 488,98 & 0,0002 & 0,0656 & 28,72 & 23,74 & 85448,73 & 16,41 \\
\hline 5,6796605 & 2295,6929 & 0,717 & 1,646 & 0,0102708 & 921,55 & 431,66 & 489,89 & 0,0002 & 0,0657 & 32,64 & 26,97 & 97106,33 & 18,65 \\
\hline 5,6803432 & 2324,3554 & 0,691 & 1,606 & 0,010018 & 915,93 & 425,15 & 490,78 & 0,0002 & 0,0659 & 31,58 & 26,10 & 93947,08 & 18,05 \\
\hline 5,679319 & 2281,4781 & 0,681 & 1,554 & 0,0096858 & 917,15 & 426,57 & 490,58 & 0,0002 & 0,0658 & 32,25 & 26,65 & 95949,90 & 18,43 \\
\hline 5,6782937 & 2239,295 & 0,682 & 1,527 & 0,0095181 & 922,50 & 432,76 & 489,74 & 0,0002 & 0,0657 & 31,23 & 25,81 & 92924,87 & 17,85 \\
\hline 5,6758973 & 2143,5135 & 0,72 & 1,543 & 0,0096202 & 921,53 & 431,64 & 489,89 & 0,0002 & 0,0657 & 29,51 & 24,39 & 87806,62 & 16,87 \\
\hline
\end{tabular}


Appendix C. Experiment 3 Tab. 6 AER results (28.07.04)

\begin{tabular}{|c|c|c|c|c|c|c|c|c|c|c|c|c|c|c|c|}
\hline Date & Time & $\begin{array}{l}\text { Tracer } \\
\text { gas } \\
\text { (AER) }\end{array}$ & $\begin{array}{c}\text { SF6 } \\
\text { (CV) } \\
\text { ch's 1-4 }\end{array}$ & $\begin{array}{c}\text { SF6 } \\
\text { (CV) } \\
\text { ch's 1-6 }\end{array}$ & $\begin{array}{c}\text { Heat } \\
\text { Balance } \\
\text { (AER) }\end{array}$ & $\begin{array}{c}\text { Moisture } \\
\text { Balance } \\
\text { (AER) }\end{array}$ & $\begin{array}{c}\mathrm{CO2} \\
\text { Balance } \\
\text { (AER) }\end{array}$ & $\begin{array}{l}\text { O.Temp } \\
\left({ }^{\circ} \mathrm{C}\right)\end{array}$ & $\begin{array}{l}\text { I.Temp } \\
\left({ }^{\circ} \mathrm{C}\right)\end{array}$ & $\underset{\left({ }^{\circ} \mathrm{C}\right)}{\Delta \underset{\text { Temp }}{ }}$ & $\begin{array}{c}\text { CV } \\
\text { I.Temp } \\
\left({ }^{\circ} \mathrm{C}\right)\end{array}$ & $\begin{array}{c}\text { O.Humid } \\
(\%)\end{array}$ & $\begin{array}{l}\text { I. Humid } \\
(\%)\end{array}$ & $\begin{array}{c}\text { CV } \\
\text { I.Humid } \\
(\%)\end{array}$ & 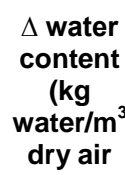 \\
\hline 28.07 .04 & $12: 00$ & 2,23 & 19,84 & 38,77 & 32,47 & 31,63 & 34,42 & 18,6 & 21,8 & 3,2 & 2,3 & 65,4 & 62,1 & 4,46 & 0,00138 \\
\hline 28.07 .04 & $13: 00$ & 1,30 & 7,30 & 44,50 & 34,05 & 32,21 & 35,41 & 18,8 & 21,8 & 3,0 & 2,2 & 66,0 & 62,9 & 4,54 & 0,00135 \\
\hline 28.07 .04 & $14: 00$ & 1,40 & 13,64 & 48,05 & 38,46 & 36,21 & 34,07 & 19,8 & 22,4 & 2,6 & 2,0 & 63,0 & 60,7 & 4,24 & 0,00121 \\
\hline 28.07 .04 & $15: 00$ & 2,27 & 7,08 & 44,33 & 37,98 & 34,39 & 36,70 & 20,4 & 23,0 & 2,6 & 2,0 & 60,7 & 59,0 & 3,77 & 0,00127 \\
\hline 28.07 .04 & $16: 00$ & 2,47 & 11,08 & 49,77 & 34,69 & 31,77 & 36,06 & 20,8 & 23,5 & 2,7 & 1,8 & 59,3 & 57,7 & 4,02 & 0,00138 \\
\hline 28.07 .04 & $17: 00$ & 1,98 & 8,86 & 50,19 & 33,67 & 34,88 & 35,50 & 20,5 & 23,3 & 2,8 & 1,7 & 59,3 & 57,8 & 4,27 & 0,00126 \\
\hline 28.07 .04 & $18: 00$ & 1,54 & 11,41 & 49,48 & 34,41 & 43,97 & 35,99 & 20,2 & 23,0 & 2,8 & 1,5 & 61,8 & 57,6 & 3,32 & 0,00100 \\
\hline 28.07 .04 & $19: 00$ & 2,08 & 11,63 & 44,55 & 30,34 & 42,25 & 35,28 & 19,2 & 22,5 & 3,3 & 1,7 & 67,8 & 61,4 & 4,25 & 0,00103 \\
\hline 28.07 .04 & $20: 00$ & 1,72 & 12,83 & 43,76 & 28,77 & 36,80 & 33,04 & 18,0 & 21,6 & 3,6 & 2,2 & 72,7 & 65,3 & 5,25 & 0,00118 \\
\hline 28.07 .04 & $21: 00$ & 1,69 & 12,21 & 40,46 & 21,18 & 24,80 & 28,40 & 16,0 & 21,0 & 5,0 & 3,3 & 80,6 & 69,9 & 7,42 & 0,00175 \\
\hline 28.07 .04 & $22: 00$ & 1,86 & 11,48 & 39,91 & 17,67 & 19,42 & 25,35 & 14,5 & 20,6 & 6,1 & 3,8 & 86,4 & 73,3 & 8,37 & 0,00223 \\
\hline 28.07 .04 & $23: 00$ & 1,76 & 12,91 & 37,34 & 17,87 & 17,70 & 21,71 & 13,8 & 20,0 & 6,2 & 3,4 & 90,5 & 77,6 & 8,48 & 0,00244 \\
\hline 29.07 .04 & $0: 00$ & 1,87 & 11,84 & 37,25 & 17,85 & 16,49 & 21,15 & 13,4 & 19,7 & 6,3 & 3,1 & 92,5 & 80,0 & 7,62 & 0,00262 \\
\hline 29.07 .04 & $1: 00$ & 1,77 & 12,08 & 36,93 & 17,37 & 14,50 & 20,98 & 13,3 & 19,7 & 6,4 & 3,1 & 94,6 & 83,2 & 8,14 & 0,00298 \\
\hline 29.07 .04 & $2: 00$ & 1,78 & 12,28 & 36,19 & 17,27 & 14,30 & 20,36 & 13,1 & 19,6 & 6,5 & 3,3 & 95,4 & 83,9 & 7,95 & 0,00302 \\
\hline 29.07 .04 & $3: 00$ & 1,79 & 11,61 & 37,13 & 15,51 & 12,50 & 20,46 & 12,6 & 19,8 & 7,2 & 3,8 & 96,0 & 84,3 & 8,26 & 0,00346 \\
\hline 29.07 .04 & $4: 00$ & 1,90 & 10,60 & 37,98 & 14,41 & 11,86 & 19,02 & 12,3 & 20,0 & 7,7 & 4,9 & 96,3 & 83,7 & 8,31 & 0,00365 \\
\hline 29.07 .04 & $5: 00$ & 1,73 & 9,54 & 38,92 & 13,30 & 11,59 & 17,76 & 11,7 & 20,0 & 8,3 & 4,8 & 96,6 & 82,1 & 8,65 & 0,00373 \\
\hline 29.07 .04 & $6: 00$ & 1,80 & 11,27 & 38,62 & 13,11 & 11,15 & 20,46 & 12,3 & 20,5 & 8,2 & 4,8 & 96,0 & 82,2 & 8,43 & 0,00389 \\
\hline 29.07 .04 & $7: 00$ & 1,58 & 10,65 & 39,80 & 18,53 & 16,61 & 24,97 & 14,7 & 20,5 & 5,8 & 3,3 & 86,3 & 76,7 & 8,66 & 0,00261 \\
\hline 29.07 .04 & $8: 00$ & 2,00 & 13,26 & 40,87 & 24,20 & 21,01 & 30,21 & 17,0 & 21,3 & 4,3 & 3,1 & 79,9 & 73,8 & 8,87 & 0,00207 \\
\hline 29.07 .04 & 9:00 & 2,05 & 7,87 & 49,59 & 35,02 & 22,97 & 36,76 & 19,9 & 22,7 & 2,8 & 2,6 & 68,5 & 68,5 & 6,89 & 0,00190 \\
\hline 29.07 .04 & $10: 00$ & 2,04 & 8,94 & 50,61 & 45,30 & 22,74 & 36,15 & 22,4 & 24,2 & 1,8 & 2,4 & 57,7 & 62,0 & 6,13 & 0,00194 \\
\hline 29.07 .04 & $11: 00$ & 2,76 & 11,86 & 47,41 & 41,40 & 21,57 & 36,36 & 23,9 & 25,2 & 1,3 & 2,2 & 50,5 & 57,0 & 5,58 & 0,00206 \\
\hline
\end{tabular}


Appendix C. Experiment 3 Tab. 7 Tracer gas results (28.07.04)

\begin{tabular}{|c|c|c|c|c|c|c|c|c|}
\hline Date & Time & $\begin{array}{c}\text { SF6 } \\
(\mathrm{mg} / \mathrm{m} 3)\end{array}$ & Reciprocal & $\begin{array}{c}\text { Background } \\
(\mathrm{mg} / \mathrm{m} 3)\end{array}$ & $\begin{array}{l}\text { Dosage + } \\
\text { background } \\
(\mathrm{mg})\end{array}$ & $\begin{array}{l}\text { Dosage } \\
(\mathrm{g} / \mathrm{min})\end{array}$ & $\begin{array}{l}\text { Supplied } \\
\text { air volume } \\
\text { m3/h }\end{array}$ & AER \\
\hline & & 9,66 & 0,1035 & 50297,09 & & & & \\
\hline 28-Jul-04 & $12: 00$ & 9,17 & 0,1091 & 47725,20 & 56326,5 & 1,8 & 11630,80 & 2,2 \\
\hline 28-Jul-04 & 13:00 & 15,10 & 0,0662 & 78586,59 & 54800,5 & 1,7 & 6791,86 & 1,3 \\
\hline 28-Jul-04 & $14: 00$ & 15,44 & 0,0648 & 80361,87 & 34024,5 & 1,9 & 7295,17 & 1,4 \\
\hline 28-Jul-04 & $15: 00$ & 13,36 & 0,0748 & 69553,98 & 77723,5 & 2,6 & 11832,43 & 2,3 \\
\hline 28-Jul-04 & $16: 00$ & 11,39 & 0,0878 & 59316,87 & 76948 & 2,4 & 12857,88 & 2,5 \\
\hline 28-Jul-04 & $17: 00$ & 13,45 & 0,0743 & 70037,97 & 79543,2 & 2,3 & 10321,62 & 2,0 \\
\hline 28-Jul-04 & 18:00 & 15,04 & 0,0665 & 78289,74 & 50189,8 & 2,0 & 7994,74 & 1,5 \\
\hline 28-Jul-04 & 19:00 & 14,12 & 0,0708 & 73494,94 & 74231 & 2,5 & 10803,78 & 2,1 \\
\hline 28-Jul-04 & $20: 00$ & 17,07 & 0,0586 & 88872,00 & 79433,3 & 2,5 & 8958,33 & 1,7 \\
\hline 28-Jul-04 & $21: 00$ & 18,64 & 0,0536 & 97055,46 & 75188,7 & 2,7 & 8800,12 & 1,7 \\
\hline 28-Jul-04 & 22:00 & 18,19 & 0,0550 & 94689,29 & 78791,2 & 2,9 & 9668,02 & 1,9 \\
\hline 28-Jul-04 & $23: 00$ & 18,70 & 0,0535 & 97364,34 & 76577 & 2,9 & 9157,48 & 1,8 \\
\hline 29-Jul-04 & 00:00 & 17,79 & 0,0562 & 92611,85 & 75526,8 & 2,9 & 9718,75 & 1,9 \\
\hline 29-Jul-04 & 01:00 & 18,39 & 0,0544 & 95730,34 & 77305,2 & 2,8 & 9240,42 & 1,8 \\
\hline 29-Jul-04 & 02:00 & 18,74 & 0,0534 & 97542,02 & 77629,8 & 2,9 & 9252,55 & 1,8 \\
\hline 29-Jul-04 & 03:00 & 18,54 & 0,0539 & 96502,46 & 75007,4 & 2,9 & 9308,49 & 1,8 \\
\hline 29-Jul-04 & 04:00 & 17,51 & 0,0571 & 91144,91 & 77075,6 & 2,9 & 9914,40 & 1,9 \\
\hline 29-Jul-04 & 05:00 & 18,65 & 0,0536 & 97073,53 & 76613,2 & 2,8 & 8996,78 & 1,7 \\
\hline 29-Jul-04 & 06:00 & 18,47 & 0,0541 & 96168,70 & 75792,8 & 2,9 & 9357,95 & 1,8 \\
\hline 29-Jul-04 & 07:00 & 19,47 & 0,0514 & 101348,01 & 64170 & 2,7 & 8236,21 & 1,6 \\
\hline 29-Jul-04 & 08:00 & 15,97 & 0,0626 & 83159,28 & 64591,8 & 2,8 & 10388,29 & 2,0 \\
\hline 29-Jul-04 & 09:00 & 15,23 & 0,0656 & 79299,81 & 79201,2 & 2,7 & 10658,90 & 2,0 \\
\hline 29-Jul-04 & $10: 00$ & 14,34 & 0,0697 & 74671,39 & 72847 & 2,5 & 10607,49 & 2,0 \\
\hline 29-Jul-04 & $11: 00$ & 10,65 & 0,0939 & 55454,59 & 78559,3 & 2,6 & 14385,08 & 2,8 \\
\hline
\end{tabular}


Appendix C. Experiment 3 Tab. $8 \mathrm{CO}_{2}$ mass balance results (28.07.04)

\begin{tabular}{|c|c|c|c|c|c|c|c|}
\hline Date & Time & $\begin{array}{c}\text { Inside } \mathrm{CO}_{2} \\
\text { concentration }\end{array}$ & $\begin{array}{c}\text { Corrected } \\
\text { for manure }\end{array}$ & $\Delta \mathrm{CO}_{2}$ & $\begin{array}{c}\mathrm{CO}_{2} \\
\text { productn / } \\
\Delta \mathrm{CO}_{2}\end{array}$ & $\begin{array}{c}\text { Air volume } \\
\text { displacement } \\
\mathrm{m} 3 / \mathrm{h}\end{array}$ & $\mathrm{AER} / \mathrm{h}$ \\
\hline 28-Jul-04 & $12: 00$ & 772,0 & 741,1 & 391,1 & 472,99 & 179215,20 & 34,42 \\
\hline 28-Jul-04 & $13: 00$ & 760,7 & 730,3 & 380,3 & 486,48 & 184326,02 & 35,41 \\
\hline 28-Jul-04 & $14: 00$ & 776,3 & 745,2 & 395,2 & 468,12 & 177369,61 & 34,07 \\
\hline 28-Jul-04 & $15: 00$ & 746,7 & 716,9 & 366,9 & 504,27 & 191068,79 & 36,70 \\
\hline 28-Jul-04 & $16: 00$ & 753,5 & 723,4 & 373,4 & 495,45 & 187727,47 & 36,06 \\
\hline 28-Jul-04 & $17: 00$ & 759,7 & 729,3 & 379,3 & 487,71 & 184792,08 & 35,50 \\
\hline 28-Jul-04 & $18: 00$ & 754,3 & 724,1 & 374,1 & 494,53 & 187377,04 & 35,99 \\
\hline 28-Jul-04 & $19: 00$ & 762,1 & 731,6 & 381,6 & 484,79 & 183685,71 & 35,28 \\
\hline 28-Jul-04 & $20: 00$ & 789,1 & 757,5 & 407,5 & 453,95 & 172001,66 & 33,04 \\
\hline 28-Jul-04 & $21: 00$ & 858,5 & 824,1 & 474,1 & 390,20 & 147845,41 & 28,40 \\
\hline 28-Jul-04 & $22: 00$ & 917,9 & 881,2 & 531,2 & 348,28 & 131964,77 & 25,35 \\
\hline 28-Jul-04 & $23: 00$ & 1010,5 & 970,1 & 620,1 & 298,34 & 113042,25 & 21,71 \\
\hline 29-Jul-04 & $00: 00$ & 1027,7 & 986,6 & 636,6 & 290,61 & 110111,54 & 21,15 \\
\hline 29-Jul-04 & 01:00 & 1033,2 & 991,9 & 641,9 & 288,21 & 109204,62 & 20,98 \\
\hline 29-Jul-04 & 02:00 & 1053,5 & 1011,3 & 661,3 & 279,75 & 105995,93 & 20,36 \\
\hline 29-Jul-04 & 03:00 & 1049,9 & 1007,9 & 657,9 & 281,18 & 106537,88 & 20,46 \\
\hline 29-Jul-04 & 04:00 & 1102,1 & 1058,0 & 708,0 & 261,28 & 99000,81 & 19,02 \\
\hline 29-Jul-04 & 05:00 & 1154,4 & 1108,3 & 758,3 & 243,98 & 92444,35 & 17,76 \\
\hline 29-Jul-04 & 06:00 & 1049,9 & 1007,9 & 657,9 & 281,18 & 106537,73 & 20,46 \\
\hline 29-Jul-04 & 07:00 & 926,3 & 889,2 & 539,2 & 343,10 & 129998,98 & 24,97 \\
\hline 29-Jul-04 & 08:00 & 828,8 & 795,7 & 445,7 & 415,10 & 157281,91 & 30,21 \\
\hline 29-Jul-04 & 09:00 & 746,1 & 716,3 & 366,3 & 505,06 & 191365,90 & 36,76 \\
\hline 29-Jul-04 & $10: 00$ & 752,6 & 722,5 & 372,5 & 496,70 & 188199,66 & 36,15 \\
\hline 29-Jul-04 & $11: 00$ & 750,4 & 720,3 & 370,3 & 499,53 & 189271,77 & 36,36 \\
\hline
\end{tabular}


Appendix C. Experiment 3 Tab. 9 Heat balance results (28.07.04)

\begin{tabular}{|c|c|c|c|c|c|c|c|c|c|}
\hline Date & Time & $\begin{array}{c}\text { Total } \\
\text { heat } \\
\text { /animal } \\
\left(20^{\circ} \mathrm{C}\right) \mathrm{W}\end{array}$ & $\begin{array}{l}\text { hpu/all } \\
\text { animals }\end{array}$ & $\begin{array}{c}\text { Sensible } \\
\text { heat and } \\
\text { temperature } \\
\text { factors }\end{array}$ & $\begin{array}{l}\text { Sensible } \\
\text { Heat/ all } \\
\text { animals } \\
\text { (W) }\end{array}$ & $\begin{array}{c}\text { Heat } \\
\text { loss } \\
\text { Thought } \\
\text { Building } \\
\text { (W) }\end{array}$ & $\begin{array}{l}\text { Calculated } \\
\operatorname{AER}\left(\mathrm{m}^{3} / \mathrm{s}\right)\end{array}$ & $\begin{array}{c}\text { Calculated } \\
\text { AER } \\
\left(\mathrm{m}^{3} / \mathrm{h}\right)\end{array}$ & $\begin{array}{c}\text { Heat balance } \\
\text { AER/h }\end{array}$ \\
\hline 28.7.2004 & $12: 00$ & 12,63 & 378,90 & 480,21 & 181951,95 & $-1490,39$ & 46,96 & 169039,09 & 32,47 \\
\hline 28.7.2004 & $13: 00$ & 12,63 & 378,90 & 479,16 & 181553,46 & $-1418,83$ & 49,23 & 177242,74 & 34,05 \\
\hline 28.7.2004 & $14: 00$ & 12,63 & 378,90 & 466,18 & 176635,08 & $-1222,93$ & 55,62 & 200244,56 & 38,46 \\
\hline 28.7.2004 & 15:00 & 12,63 & 378,90 & 453,53 & 171840,67 & $-1204,75$ & 54,93 & 197732,08 & 37,98 \\
\hline 28.7.2004 & 16:00 & 12,63 & 378,90 & 440,70 & 166980,97 & $-1280,99$ & 50,16 & 180583,03 & 34,69 \\
\hline 28.7.2004 & $17: 00$ & 12,63 & 378,90 & 445,05 & 168628,58 & $-1332,61$ & 48,68 & 175260,59 & 33,67 \\
\hline 28.7.2004 & $18: 00$ & 12,63 & 378,90 & 452,25 & 171357,16 & $-1324,99$ & 49,76 & 179152,14 & 34,41 \\
\hline 28.7.2004 & 19:00 & 12,63 & 378,90 & 464,41 & 175965,65 & $-1541,42$ & 43,88 & 157975,08 & 30,34 \\
\hline 28.7.2004 & 20:00 & 12,63 & 378,90 & 483,91 & 183354,02 & $-1693,33$ & 41,60 & 149768,78 & 28,77 \\
\hline 28.7.2004 & $21: 00$ & 12,63 & 378,90 & 496,90 & 188274,68 & $-2353,77$ & 30,63 & 110272,24 & 21,18 \\
\hline 28.7.2004 & 22:00 & 12,63 & 378,90 & 505,82 & 191654,42 & $-2864,64$ & 25,56 & 92004,68 & 17,67 \\
\hline 28.7.2004 & 23:00 & 12,63 & 378,90 & 518,93 & 196623,81 & $-2906,29$ & 25,85 & 93053,42 & 17,87 \\
\hline 29.7.2004 & 00:00 & 12,63 & 378,90 & 525,55 & 199129,42 & $-2947,93$ & 25,81 & 92905,77 & 17,85 \\
\hline 29.7.2004 & 01:00 & 12,63 & 378,90 & 524,41 & 198697,92 & $-3020,07$ & 25,13 & 90453,61 & 17,37 \\
\hline 29.7.2004 & 02:00 & 12,63 & 378,90 & 527,11 & 199720,67 & $-3054,09$ & 24,97 & 89898,01 & 17,27 \\
\hline 29.7.2004 & 03:00 & 12,63 & 378,90 & 523,43 & 198326,23 & $-3370,24$ & 22,43 & 80756,61 & 15,51 \\
\hline 29.7.2004 & 04:00 & 12,63 & 378,90 & 519,57 & 196866,04 & $-3596,05$ & 20,84 & 75030,91 & 14,41 \\
\hline 29.7.2004 & 05:00 & 12,63 & 378,90 & 519,15 & 196704,57 & $-3886,97$ & 19,24 & 69252,71 & 13,30 \\
\hline 29.7.2004 & 06:00 & 12,63 & 378,90 & 507,68 & 192359,53 & $-3856,48$ & 18,96 & 68238,55 & 13,11 \\
\hline 29.7.2004 & 07:00 & 12,63 & 378,90 & 507,19 & 192175,71 & $-2740,88$ & 26,80 & 96487,53 & 18,53 \\
\hline 29.7.2004 & 08:00 & 12,63 & 378,90 & 489,93 & 185635,03 & $-2034,11$ & 35,00 & 126009,38 & 24,20 \\
\hline 29.7.2004 & 09:00 & 12,63 & 378,90 & 459,18 & 173982,99 & $-1322,05$ & 50,65 & 182325,45 & 35,02 \\
\hline 29.7.2004 & 10:00 & 12,63 & 378,90 & 420,58 & 159356,97 & $-938,46$ & 65,46 & 235663,91 & 45,27 \\
\hline 29.7.2004 & 11:00 & 12,63 & 378,90 & 385,08 & 145905,04 & $-938,46$ & 59,90 & 215652,77 & 41,42 \\
\hline
\end{tabular}


Appendix C. Experiment 3 Tab. 10a Moisture balance results (28.07.04)

\begin{tabular}{|c|c|c|c|c|c|c|c|c|c|c|c|c|}
\hline A1 & $-5,8002206 E+03$ & $\begin{array}{c}\text { indoor } \mathbf{T} \\
\text { oK }\end{array}$ & T2 & T3 & LnT & Pws Pa) & HR & $\begin{array}{c}\text { Pw } \\
(\mathrm{Kpa})\end{array}$ & $\begin{array}{c}\text { Wi (kg } \\
\text { ag/ka } \\
\text { as) }\end{array}$ & $\begin{array}{c}\text { outdoor } \\
\text { T } \text { oK }\end{array}$ & T2 & T3 \\
\hline $\mathrm{A} 2$ & 1,3914993 & 294,93 & 86981,493 & 25653126 & 5,6867253 & 2608,8718 & 0,62 & 1,619 & 0,010102 & 291,75 & 85118,063 & 24833195 \\
\hline A3 & $-4,86 \mathrm{E}-02$ & 294,97 & 87009,513 & 25665522 & 5,6868864 & 2616,4533 & 0,63 & 1,646 & 0,0102712 & 291,95 & 85234,803 & 24884301 \\
\hline A4 & $4,18 \mathrm{E}-05$ & 295,56 & 87353,497 & 25817872 & 5,6888592 & 2711,0048 & 0,61 & 1,646 & 0,0102689 & 292,95 & 85819,703 & 25140882 \\
\hline A5 & $-1,45 \mathrm{E}-08$ & 296,12 & 87685,574 & 25965233 & 5,6907563 & 2804,9178 & 0,59 & 1,656 & 0,010336 & 293,55 & 86171,603 & 25295674 \\
\hline A6 & 0 & 296,68 & 88019,022 & 26113484 & 5,6926541 & 2901,879 & 0,58 & 1,675 & 0,0104574 & 293,95 & 86406,603 & 25399221 \\
\hline \multirow[t]{2}{*}{ A7 } & 6,5459673 & 296,49 & 87906,32 & 26063345 & 5,6920135 & 2868,8053 & 0,58 & 1,659 & 0,0103547 & 293,65 & 86230,323 & 25321534 \\
\hline & & 296,17 & 87718,89 & 25980033 & 5,6909463 & 2814,4848 & 0,58 & 1,621 & 0,0101105 & 293,35 & 86054,223 & 25244006 \\
\hline patm $(\mathrm{Pa})$ & 101325 & 295,64 & 87400,053 & 25838515 & 5,6891256 & 2724,0138 & 0,61 & 1,672 & 0,0104352 & 292,35 & 85468,523 & 24986723 \\
\hline \multirow[t]{16}{*}{$\mathrm{Ra}$} & 287,055 & 294,76 & 86882,721 & 25609442 & 5,6861572 & 2582,2901 & 0,65 & 1,687 & 0,0105324 & 291,15 & 84768,323 & 24680297 \\
\hline & & 294,17 & 86533,783 & 25455318 & 5,6841451 & 2490,153 & 0,70 & 1,742 & 0,0108786 & 289,15 & 83607,723 & 24175173 \\
\hline & & 293,76 & 86292 & 25348706 & 5,6827461 & 2427,9042 & 0,73 & 1,779 & 0,0111136 & 287,65 & 82742,523 & 23800887 \\
\hline & & 293,14 & 85933,258 & 25190798 & 5,6806631 & 2337,8984 & 0,78 & 1,814 & 0,0113351 & 286,95 & 82340,303 & 23627550 \\
\hline & & 292,83 & 85750,873 & 25110643 & 5,6796008 & 2293,1998 & 0,80 & 1,835 & 0,0114742 & 286,55 & 82110,903 & 23528879 \\
\hline & & 292,89 & 85782,355 & 25124472 & 5,6797843 & 2300,8649 & 0,83 & 1,915 & 0,0119795 & 286,45 & 82053,603 & 23504254 \\
\hline & & 292,76 & 85707,686 & 25091675 & 5,6793489 & 2282,7188 & 0,84 & 1,914 & 0,0119771 & 286,25 & 81939,063 & 23455057 \\
\hline & & 292,93 & 85809,45 & 25136377 & 5,6799422 & 2307,4785 & 0,84 & 1,946 & 0,0121778 & 285,75 & 81653,063 & 23332363 \\
\hline & & 293,11 & 85915,67 & 25183064 & 5,6805608 & 2333,5571 & 0,84 & 1,952 & 0,0122194 & 285,45 & 81481,703 & 23258952 \\
\hline & & 293,13 & 85927,395 & 25188220 & 5,680629 & 2336,4505 & 0,82 & 1,917 & 0,0119957 & 284,85 & 81139,523 & 23112593 \\
\hline & & 293,67 & 86241,335 & 25326385 & 5,6824524 & 2415,0231 & 0,82 & 1,986 & 0,0124335 & 285,45 & 81481,703 & 23258952 \\
\hline & & 293,69 & 86254,55 & 25332207 & 5,682529 & 2418,3776 & 0,77 & 1,855 & 0,0115972 & 287,85 & 82857,623 & 23850567 \\
\hline & & 294,49 & 86721,415 & 25538156 & 5,6852281 & 2539,3565 & 0,74 & 1,874 & 0,0117198 & 290,15 & 84187,023 & 24426865 \\
\hline & & 295,87 & 87537,578 & 25899524 & 5,6899117 & 2762,7404 & 0,68 & 1,892 & 0,0118328 & 293,05 & 85878,303 & 25166637 \\
\hline & & 297,31 & 88391,75 & 26279530 & 5,694767 & 3013,4866 & 0,62 & 1,869 & 0,0116884 & 295,55 & 87349,803 & 25816234 \\
\hline & & 298,30 & 88982,89 & 26543596 & 5,6980997 & 3197,6669 & 0,57 & 1,823 & 0,0113952 & 297,05 & 88238,703 & 26211307 \\
\hline
\end{tabular}


Appendix C. Experiment 3 Tab. 10b Moisture balance results (28.07.04)

\begin{tabular}{|c|c|c|c|c|c|c|c|c|c|c|c|c|c|}
\hline LnT & Pws Pa) & HR & $\begin{array}{c}\text { Pw } \\
(\mathrm{Kpa})\end{array}$ & $\begin{array}{c}\text { Wo (kg } \\
\text { ag/ka } \\
\text { as) }\end{array}$ & $\begin{array}{l}\text { Total } \\
\text { heat } \\
\text { /hpu } \\
\text { (eqn. } \\
26)\end{array}$ & $\begin{array}{c}\text { Sensible } \\
\text { Heat } \\
\text { /animal }\end{array}$ & $\begin{array}{l}\text { Latent } \\
\text { Heat } \\
\text { /animal } \\
\text { (W) }\end{array}$ & $\begin{array}{l}\text { Latent } \\
\text { Heat } \\
\text { /animal } \\
\text { (Kg } \\
\text { water/s) }\end{array}$ & $\begin{array}{c}\text { Latent } \\
\text { Heat } / 30 \\
000 \\
\text { animal } \\
(\mathrm{Kg} \\
\text { water/s) }\end{array}$ & $\begin{array}{c}\text { AER Kg } \\
\text { air/s }\end{array}$ & $\begin{array}{l}\text { AER } \\
\text { m3/s }\end{array}$ & $\begin{array}{l}\text { AER } \\
\mathrm{m} 3 / \mathrm{h}\end{array}$ & AER /hr \\
\hline 5,6758973 & 2143,5135 & 0,654 & 1,402 & 0,008726 & 964,48 & 480,2110 & 484,264 & 0,0002009 & 0,0761359 & 55,339888 & 45,735445 & 164647,6 & 31,6 \\
\hline 5,6765826 & 2170,5063 & 0,66 & 1,433 & 0,0089197 & 963,53 & 479,1593 & 484,366 & 0,000201 & 0,0761519 & 56,35613 & 46,575314 & 167671,13 & 32,2 \\
\hline 5,6800019 & 2309,9852 & 0,63 & 1,455 & 0,0090634 & 951,88 & 466,1786 & 485,696 & 0,0002015 & 0,0763611 & 63,354847 & 52,359378 & 188493,76 & 36,2 \\
\hline 5,682048 & 2397,3861 & 0,607 & 1,455 & 0,0090629 & 940,65 & 453,5251 & 487,125 & 0,0002021 & 0,0765857 & 60,170413 & 49,727614 & 179019,41 & 34,4 \\
\hline 5,6834097 & 2457,2485 & 0,593 & 1,457 & 0,0090752 & 929,40 & 440,6993 & 488,701 & 0,0002028 & 0,0768335 & 55,595907 & 45,94703 & 165409,31 & 31,8 \\
\hline 5,6823886 & 2412,2308 & 0,6055 & 1,461 & 0,009097 & 933,20 & 445,0477 & 488,152 & 0,0002026 & 0,0767473 & 61,031621 & 50,439356 & 181581,68 & 34,9 \\
\hline 5,6813664 & 2367,9364 & 0,618 & 1,463 & 0,0091146 & 939,53 & 452,2490 & 487,276 & 0,0002022 & 0,0766095 & 76,931719 & 63,579933 & 228887,76 & 44,0 \\
\hline 5,6779517 & 2225,3865 & 0,678 & 1,509 & 0,0094018 & 950,30 & 464,4118 & 485,888 & 0,0002016 & 0,0763913 & 73,93491 & 61,103232 & 219971,63 & 42,3 \\
\hline 5,6738386 & 2064,2916 & 0,727 & 1,501 & 0,0093507 & 967,83 & 483,9114 & 483,914 & 0,0002008 & 0,0760809 & 64,393886 & 53,218087 & 191585,11 & 36,8 \\
\hline 5,6669456 & 1818,4396 & 0,806 & 1,466 & 0,009129 & 979,68 & 496,8981 & 482,777 & 0,0002003 & 0,0759021 & 43,393124 & 35,862086 & 129103,51 & 24,8 \\
\hline 5,6617445 & 1651,3004 & 0,864 & 1,427 & 0,008883 & 987,90 & 505,8179 & 482,082 & 0,0002 & 0,0757929 & 33,989154 & 28,09021 & 101124,76 & 19,4 \\
\hline 5,659308 & 1578,0331 & 0,905 & 1,428 & 0,0088918 & 1000,13 & 518,9332 & 481,192 & 0,0001997 & 0,0756529 & 30,975251 & 25,599381 & 92157,77 & 17,7 \\
\hline 5,657913 & 1537,462 & 0,925 & 1,422 & 0,0088541 & 1006,35 & 525,5461 & 480,804 & 0,0001995 & 0,0755919 & 28,862038 & 23,852924 & 85870,526 & 16,5 \\
\hline 5,657564 & 1527,4637 & 0,946 & 1,445 & 0,0089983 & 1005,28 & 524,4073 & 480,868 & 0,0001995 & 0,075602 & 25,371027 & 20,967791 & 75484,048 & 14,5 \\
\hline 5,6568656 & 1507,6384 & 0,954 & 1,438 & 0,008956 & 1007,83 & 527,1065 & 480,718 & 0,0001995 & 0,0755785 & 25,029263 & 20,685341 & 74467,228 & 14,3 \\
\hline 5,6551173 & 1459,0617 & 0,96 & 1,401 & 0,0087187 & 1004,35 & 523,4263 & 480,924 & 0,0001996 & 0,0756108 & 21,870303 & 18,074631 & 65068,671 & 12,5 \\
\hline 5,6540669 & 1430,5813 & 0,963 & 1,378 & 0,0085732 & 1000,73 & 519,5726 & 481,152 & 0,0001996 & 0,0756467 & 20,759264 & 17,156417 & 61763,1 & 11,9 \\
\hline 5,6519627 & 1375,084 & 0,966 & 1,328 & 0,0082622 & 1000,33 & 519,1464 & 481,179 & 0,0001997 & 0,0756509 & 20,274888 & 16,756106 & 60321,982 & 11,6 \\
\hline 5,6540669 & 1430,5813 & 0,96 & 1,373 & 0,0085461 & 989,63 & 507,6789 & 481,946 & 0,0002 & 0,0757715 & 19,504357 & 16,119303 & 58029,492 & 11,1 \\
\hline 5,6624395 & 1672,7754 & 0,863 & 1,444 & 0,0089896 & 989,18 & 507,1938 & 481,981 & 0,0002 & 0,0757771 & 29,071086 & 24,025691 & 86492,488 & 16,6 \\
\hline 5,670398 & 1937,9488 & 0,799 & 1,548 & 0,0096524 & 973,30 & 489,9315 & 483,369 & 0,0002006 & 0,0759952 & 36,771288 & 30,389494 & 109402,18 & 21,0 \\
\hline 5,6803432 & 2324,3554 & 0,685 & 1,592 & 0,0099296 & 945,65 & 459,1792 & 486,471 & 0,0002019 & 0,0764829 & 40,198917 & 33,222245 & 119600,08 & 23,0 \\
\hline 5,688838 & 2709,9746 & 0,577 & 1,564 & 0,0097489 & 916,85 & 426,2212 & 490,629 & 0,0002036 & 0,0771366 & 39,78309 & 32,878587 & 118362,91 & 22,7 \\
\hline 5,6939005 & 2967,2422 & 0,505 & 1,498 & 0,0093363 & 897,00 & 402,9549 & 494,045 & 0,000205 & 0,0776737 & 37,736854 & 31,187483 & 112274,94 & 21,6 \\
\hline
\end{tabular}




\section{Appendix C. Experiment 3 Tab. 11 AER results (18.08.04)}

\begin{tabular}{|c|c|c|c|c|c|c|c|c|c|c|c|c|c|c|c|c|c|c|c|c|}
\hline Date & Time & $\begin{array}{l}\text { True } \\
\text { AER }\end{array}$ & $\begin{array}{l}\text { Tracer } \\
\text { gas } \\
\text { (AER) }\end{array}$ & $\begin{array}{c}\text { SF6 } \\
\text { (CV) } \\
\text { ch's 1- } \\
\quad 4\end{array}$ & $\begin{array}{c}\text { SF6 } \\
\text { (CV) } \\
\text { ch's 1-6 }\end{array}$ & $\begin{array}{c}\text { Heat } \\
\text { Balance } \\
\text { (AER) }\end{array}$ & $\begin{array}{c}\text { Moisture } \\
\text { Balance } \\
\text { (AER) }\end{array}$ & $\begin{array}{c}\mathrm{CO} 2 \\
\text { Balance } \\
\text { (AER) }\end{array}$ & $\begin{array}{l}\text { Bird } \\
\text { activity }\end{array}$ & $\begin{array}{c}\text { Heat } \\
\text { Balance } \\
\text { with } \\
\text { activity }\end{array}$ & $\begin{array}{c}\text { Moisture } \\
\text { Balance } \\
\text { with } \\
\text { activity }\end{array}$ & $\begin{array}{c}\mathrm{CO} 2 \\
\text { Balance } \\
\text { with } \\
\text { activity }\end{array}$ & $\begin{array}{l}\text { O.Temp } \\
\quad\left({ }^{\circ} \mathrm{C}\right)\end{array}$ & $\begin{array}{l}\text { I.Temp } \\
\left({ }^{\circ} \mathrm{C}\right)\end{array}$ & $\begin{array}{c}\Delta \\
\text { Temp } \\
\left({ }^{\circ} \mathrm{C}\right)\end{array}$ & $\begin{array}{l}\text { CV } \\
\text { I.Temp } \\
\left({ }^{\circ} \mathrm{C}\right)\end{array}$ & $\begin{array}{l}\text { O.Humid } \\
(\%)\end{array}$ & $\underset{(\%)}{\text { I. Humid }}$ & $\begin{array}{c}\text { CV } \\
\text { I.Humid } \\
(\%)\end{array}$ & $\begin{array}{c}\Delta \text { water } \\
\text { content }(\mathrm{kg} \\
\text { water } / \mathrm{m}^{3} \\
\text { dry air }\end{array}$ \\
\hline 18.08 .04 & $12: 00$ & 9,82 & 1,78 & 6,32 & 59,59 & 9,4 & 9,5 & 17,9 & 1,12 & 10,5 & 10,7 & 20,1 & 22,5 & 25,9 & 3,4 & 5,19 & 72,2 & 77,9 & 9,53 & 0,00183 \\
\hline 18.08 .04 & $13: 00$ & 9,82 & 2,01 & 6,39 & 54,49 & 13,3 & 10,4 & 19,1 & 1,16 & 15,4 & 12,1 & 22,3 & 24,0 & 26,3 & 2,3 & 4,02 & 68,8 & 70,3 & 7,28 & 0,00169 \\
\hline 18.08 .04 & $14: 00$ & 9,82 & 1,98 & 8,00 & 55,79 & 14,7 & 13,0 & 19,1 & 0,92 & 13,6 & 12,0 & 17,6 & 24,3 & 26,4 & 2,1 & 3,66 & 64,7 & 66,4 & 6,49 & 0,00135 \\
\hline 18.08 .04 & $15: 00$ & 9,82 & 1,99 & 9,25 & 54,14 & 14,6 & 11,8 & 19,1 & 0,95 & 15,8 & 11,2 & 18,2 & 25,3 & 27,1 & 1,8 & 3,02 & 62,0 & 61,7 & 5,88 & 0,00150 \\
\hline 18.08 .04 & $16: 00$ & 9,95 & 1,93 & 9,93 & 56,30 & 14,2 & 10,0 & 17,9 & 1,04 & 16,6 & 10,4 & 18,6 & 25,7 & 27,5 & 1,8 & 2,74 & 59,8 & 58,1 & 4,92 & 0,00178 \\
\hline 18.08 .04 & $17: 00$ & 10,13 & 2,04 & 10,82 & 57,66 & 14,0 & 11,0 & 21,4 & 1,04 & 17,8 & 11,5 & 22,2 & 25,9 & 27,6 & 1,7 & 2,72 & 58,1 & 56,6 & 4,70 & 0,00161 \\
\hline 18.08 .04 & $18: 00$ & 10,02 & 1,88 & 9,59 & 55,15 & 13,9 & 12,0 & 21,4 & 0,93 & 18,7 & 11,1 & 19,9 & 26,0 & 27,4 & 1,4 & 2,71 & 58,4 & 56,7 & 5,25 & 0,00148 \\
\hline 18.08 .04 & 19:00 & 9,82 & 1,95 & 8,59 & 54,20 & 12,6 & 9,2 & 16,0 & 1,13 & 14,2 & 10,3 & 18,0 & 24,2 & 26,6 & 2,4 & 2,89 & 64,3 & 64,3 & 6,34 & 0,00192 \\
\hline 18.08 .04 & $20: 00$ & 8,84 & 1,87 & 7,02 & 52,41 & 7,8 & 9,2 & 15,1 & 1,35 & 10,5 & 12,3 & 20,3 & 22,8 & 26,7 & 3,9 & 3,77 & 62,8 & 68,3 & 7,73 & 0,00192 \\
\hline 18.08 .04 & $21: 00$ & 9,82 & 1,95 & 6,48 & 53,00 & 6,4 & 10,6 & 15,6 & 1,15 & 7,4 & 12,2 & 18,0 & 22,2 & 26,8 & 4,6 & 5,06 & 59,9 & 69,2 & 8,91 & 0,00166 \\
\hline 18.08 .04 & $22: 00$ & 9,82 & 1,95 & 6,71 & 52,40 & 6,7 & 10,3 & 14,9 & 1,02 & 6,8 & 10,5 & 15,2 & 22,4 & 26,8 & 4,4 & 5,55 & 59,8 & 68 & 9,06 & 0,00172 \\
\hline 18.08 .04 & 23:00 & 9,82 & 1,89 & 8,20 & 56,44 & 5,7 & 10,9 & 14,7 & 0,90 & 5,1 & 9,8 & 13,2 & 21,2 & 26,5 & 5,3 & 7,14 & 61,4 & 74,2 & 11,94 & 0,00161 \\
\hline 19.08 .04 & $0: 00$ & 9,82 & 1,85 & 6,23 & 51,61 & 3,2 & 8,7 & 12,5 & 0,76 & 2,4 & 6,6 & 9,5 & 18,3 & 27,1 & 8,8 & 10,12 & 59,4 & 86,3 & 15,62 & 0,00202 \\
\hline 19.08 .04 & $1: 00$ & 9,82 & 1,88 & 6,23 & 51,72 & 2,9 & 10,2 & 12,7 & 0,76 & 2,2 & 7,7 & 9,6 & 18,3 & 27,5 & 9,2 & 11,29 & 58,2 & 88,7 & 17,61 & 0,00175 \\
\hline 19.08 .04 & $2: 00$ & 9,82 & 1,93 & 6,03 & 52,02 & 2,9 & 10,3 & 13,1 & 0,76 & 2,2 & 7,8 & 9,9 & 18,6 & 27,8 & 9,2 & 11,70 & 57,1 & 86,8 & 17,98 & 0,00172 \\
\hline 19.08 .04 & 3:00 & 9,82 & 1,90 & 6,13 & 51,73 & 2,9 & 10,6 & 12,7 & 0,76 & 2,2 & 8,0 & 9,7 & 18,7 & 27,7 & 9,0 & 11,67 & 57,3 & 86,6 & 18,25 & 0,00168 \\
\hline 19.08 .04 & $4: 00$ & 9,82 & 1,89 & 6,05 & 54,25 & 3,0 & 11,6 & 12,9 & 0,76 & 2,2 & 8,8 & 9,7 & 18,6 & 27,6 & 9,0 & 11,86 & 56,4 & 86,1 & 18,39 & 0,00153 \\
\hline 19.08 .04 & 5:00 & 9,82 & 2,02 & 6,48 & 54,92 & 3,0 & 10,2 & 12,8 & 0,91 & 2,7 & 9,3 & 11,6 & 18,4 & 27,5 & 9,1 & 12,03 & 56,0 & 84,3 & 18,52 & 0,00174 \\
\hline 19.08 .04 & $6: 00$ & 9,82 & 1,87 & 6,82 & 54,03 & 3,0 & 9,2 & 11,4 & 1,04 & 3,1 & 9,6 & 11,9 & 18,0 & 27,3 & 9,3 & 11,81 & 56,9 & 85,3 & 17,94 & 0,00191 \\
\hline 19.08 .04 & 7:00 & 9,82 & 1,88 & 6,81 & 53,98 & 3,1 & 9,3 & 11,6 & 1,08 & 3,3 & 10,0 & 12,5 & 18,4 & 27,3 & 8,9 & 11,25 & 57,8 & 84,9 & 16,68 & 0,00191 \\
\hline 19.08 .04 & $8: 00$ & 9,82 & 1,94 & 6,10 & 55,46 & 3,5 & 10,2 & 12,7 & 1,20 & 4,2 & 12,2 & 15,1 & 19,2 & 27,1 & 7,9 & 10,12 & 58,3 & 81,8 & 14,64 & 0,00173 \\
\hline 19.08 .04 & 9:00 & 9,82 & 2,02 & 7,29 & 55,62 & 4,0 & 9,6 & 12,7 & 1,20 & 4,8 & 11,5 & 15,2 & 19,5 & 26,7 & 7,2 & 9,50 & 58,0 & 77 & 13,73 & 0,00184 \\
\hline 19.08 .04 & $10: 00$ & 9,13 & 1,94 & 7,41 & 58,80 & 4,9 & 9,2 & 12,0 & 1,00 & 4,9 & 9,2 & 12,0 & 20,5 & 26,5 & 6,0 & 8,82 & 57,2 & 69,9 & 12,25 & 0,00192 \\
\hline 19.08 .04 & 11:00 & 6,83 & 1,96 & 8,79 & 59,36 & 6,2 & 7,2 & 9,4 & 1,07 & 6,7 & 7,8 & 10,1 & 20,9 & 25,9 & 5,0 & 6,26 & 60,0 & 65,9 & 8,30 & 0,00241 \\
\hline
\end{tabular}


Appendix C. Experiment 3 Tab. 12 Tracer gas results (18.08.04)

\begin{tabular}{|c|c|c|c|c|c|c|c|c|c|}
\hline Date & Time & $\begin{array}{c}\text { SF6 } \\
(\mathrm{mg} / \mathrm{m} 3)\end{array}$ & Reciprocal & $\begin{array}{c}\text { Background } \\
(\mathrm{mg} / \mathrm{m} 3)\end{array}$ & $\begin{array}{l}\text { Dosage } \\
\text { (mg) }\end{array}$ & $\begin{array}{l}\text { Dosage }+ \\
\text { background } \\
\text { (g) }\end{array}$ & $\begin{array}{l}\text { Dosage } \\
(\mathrm{g} / \mathrm{min})\end{array}$ & $\begin{array}{l}\text { Supplied } \\
\text { air } \\
\text { volume } \\
\text { m3/min }\end{array}$ & AER \\
\hline 18.8 .04 & $12: 00$ & 15,531 & 0,064 & 80851,783 & 78216,000 & 2705,234 & 2,705 & 158,030 & 1,785 \\
\hline 18.8 .04 & $13: 00$ & 17,118 & 0,058 & 89118,910 & 77944,000 & 2841,206 & 2,841 & 178,263 & 2,013 \\
\hline 18.8 .04 & $14: 00$ & 15,938 & 0,063 & 82974,530 & 78010,000 & 2737,832 & 2,738 & 175,643 & 1,984 \\
\hline 18.8 .04 & $15: 00$ & 15,588 & 0,064 & 81148,525 & 77642,000 & 2704,198 & 2,704 & 176,676 & 1,993 \\
\hline 18.8 .04 & $16: 00$ & 15,306 & 0,065 & 79683,035 & 77411,000 & 2675,307 & 2,675 & 171,148 & 1,930 \\
\hline 18.8 .04 & $17: 00$ & 15,632 & 0,064 & 81377,589 & 77105,000 & 2703,097 & 2,703 & 181,243 & 2,041 \\
\hline 18.8 .04 & $18: 00$ & 14,914 & 0,067 & 77643,325 & 77068,000 & 2631,145 & 2,631 & 166,758 & 1,883 \\
\hline 18.8 .04 & $19: 00$ & 15,778 & 0,063 & 82141,568 & 87178,500 & 2814,964 & 2,815 & 168,490 & 1,947 \\
\hline 18.8 .04 & $20: 00$ & 16,707 & 0,060 & 86976,641 & 78198,900 & 2812,935 & 2,813 & 165,469 & 1,866 \\
\hline 18.8 .04 & $21: 00$ & 17,000 & 0,059 & 88500,699 & 81560,900 & 2833,652 & 2,834 & 169,060 & 1,949 \\
\hline 18.8 .04 & $22: 00$ & 16,761 & 0,060 & 87259,068 & 84077,700 & 2852,760 & 2,853 & 169,173 & 1,952 \\
\hline 18.8 .04 & $23: 00$ & 16,863 & 0,059 & 87788,779 & 77589,000 & 2816,379 & 2,816 & 167,199 & 1,886 \\
\hline 19.8.04 & $0: 00$ & 16,845 & 0,059 & 87692,467 & 77595,000 & 2815,800 & 2,816 & 164,215 & 1,852 \\
\hline 19.8 .04 & $1: 00$ & 17,147 & 0,058 & 89267,282 & 77112,000 & 2828,618 & 2,829 & 166,357 & 1,880 \\
\hline 19.8 .04 & $2: 00$ & 17,003 & 0,059 & 88518,922 & 76998,000 & 2815,871 & 2,816 & 170,778 & 1,928 \\
\hline 19.8 .04 & $3: 00$ & 16,489 & 0,061 & 85839,132 & 76952,000 & 2767,615 & 2,768 & 168,380 & 1,902 \\
\hline 19.8 .04 & 4:00 & 16,437 & 0,061 & 85569,721 & 76714,000 & 2767,930 & 2,768 & 167,700 & 1,889 \\
\hline 19.8 .04 & 5:00 & 16,505 & 0,061 & 85926,332 & 89683,100 & 2920,011 & 2,920 & 174,775 & 2,019 \\
\hline 19.8 .04 & $6: 00$ & 16,707 & 0,060 & 86977,944 & 76935,500 & 2787,644 & 2,788 & 165,395 & 1,868 \\
\hline 19.8.04 & 7:00 & 16,855 & 0,059 & 87744,530 & 76804,600 & 2802,267 & 2,802 & 166,787 & 1,881 \\
\hline 19.8 .04 & 8:00 & 16,801 & 0,060 & 87468,606 & 76800,500 & 2797,498 & 2,797 & 171,573 & 1,935 \\
\hline 19.8 .04 & 9:00 & 16,305 & 0,061 & 84883,830 & 83435,300 & 2802,516 & 2,803 & 175,475 & 2,024 \\
\hline 19.8 .04 & $10: 00$ & 15,971 & 0,063 & 83145,027 & 77093,000 & 2728,849 & 2,729 & 172,371 & 1,944 \\
\hline 19.8 .04 & $11: 00$ & 15,831 & 0,063 & 82417,488 & 77049,000 & 2715,248 & 2,715 & 173,412 & 1,956 \\
\hline
\end{tabular}


Appendix C. Experiment 3 Tab. $13 \mathrm{CO}_{2}$ balance results (18.08.04)

\begin{tabular}{|c|c|c|c|c|c|c|c|c|c|}
\hline Date & Time & $\begin{array}{c}\text { Inside } \mathrm{CO}_{2} \\
\text { concentration }\end{array}$ & $\begin{array}{c}\text { Corrected } \\
\text { for } \\
\text { manure }\end{array}$ & $\Delta \mathrm{CO}_{2}$ & $\begin{array}{l}\text { Animal } \\
\text { activity }\end{array}$ & $\begin{array}{c}\mathrm{CO}_{2} \\
\text { productn } \\
/ \Delta \mathrm{CO}_{2}\end{array}$ & $\begin{array}{c}\text { Air volume } \\
\text { displacement } \\
\text { m3/h }\end{array}$ & $\mathrm{AER} / \mathrm{h}$ & $\begin{array}{l}\text { AER /h } \\
\text { with } \\
\text { activity }\end{array}$ \\
\hline 18.08 .04 & $12: 00$ & 670,6 & 643,8 & 293,8 & 1,120 & 629,75 & 93329,00 & 17,93 & 20,07 \\
\hline 18.08 .04 & $13: 00$ & 651,5 & 625,4 & 275,4 & 1,165 & 671,72 & 99549,18 & 19,12 & 22,25 \\
\hline 18.08 .04 & $14: 00$ & 652,3 & 626,2 & 276,2 & 0,923 & 669,72 & 99252,76 & 19,07 & 17,58 \\
\hline 18.08 .04 & $15: 00$ & 651,7 & 625,7 & 275,7 & 0,954 & 671,13 & 99462,06 & 19,11 & 18,21 \\
\hline 18.08 .04 & $16: 00$ & 671,0 & 644,1 & 294,1 & 1,040 & 628,99 & 93215,80 & 17,91 & 18,60 \\
\hline 18.08 .04 & $17: 00$ & 621,3 & 596,4 & 246,4 & 1,040 & 750,73 & 111258,60 & 21,37 & 22,20 \\
\hline 18.08 .04 & 18:00 & 620,4 & 595,6 & 245,6 & 0,927 & 753,26 & 111632,72 & 21,44 & 19,86 \\
\hline 18.08 .04 & 19:00 & 707,4 & 679,1 & 329,1 & 1,126 & 562,06 & 83296,66 & 16,00 & 18,00 \\
\hline 18.08 .04 & $20: 00$ & 728,2 & 699,1 & 349,1 & 1,346 & 529,96 & 78540,16 & 15,09 & 20,29 \\
\hline 18.08 .04 & 21:00 & 716,0 & 687,3 & 337,3 & 1,151 & 548,41 & 81274,18 & 15,61 & 17,96 \\
\hline 18.08 .04 & 22:00 & 732,1 & 702,8 & 352,8 & 1,018 & 524,41 & 77718,02 & 14,93 & 15,19 \\
\hline 18.08 .04 & 23:00 & 737,9 & 708,4 & 358,4 & 0,897 & 516,19 & 76499,46 & 14,69 & 13,17 \\
\hline 19.08 .04 & 00:00 & 803,6 & 771,5 & 421,5 & 0,758 & 438,94 & 65050,87 & 12,50 & 9,46 \\
\hline 19.08 .04 & 01:00 & 796,8 & 765,0 & 415,0 & 0,759 & 445,81 & 66069,25 & 12,69 & 9,62 \\
\hline 19.08 .04 & 02:00 & 784,4 & 753,0 & 403,0 & 0,759 & 459,03 & 68027,82 & 13,07 & 9,91 \\
\hline 19.08 .04 & 03:00 & 795,4 & 763,6 & 413,6 & 0,760 & 447,35 & 66296,60 & 12,73 & 9,67 \\
\hline 19.08 .04 & 04:00 & 789,7 & 758,1 & 408,1 & 0,756 & 453,31 & 67180,25 & 12,90 & 9,75 \\
\hline 19.08.04 & 05:00 & 793,9 & 762,2 & 412,2 & 0,912 & 448,86 & 66521,29 & 12,78 & 11,64 \\
\hline 19.08.04 & 06:00 & 845,5 & 811,7 & 461,7 & 1,041 & 400,73 & 59387,48 & 11,41 & 11,87 \\
\hline 19.08 .04 & 07:00 & 836,8 & 803,4 & 453,4 & 1,076 & 408,07 & 60475,51 & 11,62 & 12,49 \\
\hline 19.08 .04 & 08:00 & 797,3 & 765,4 & 415,4 & 1,196 & 445,33 & 65997,58 & 12,68 & 15,15 \\
\hline 19.08 .04 & 09:00 & 798,1 & 766,2 & 416,2 & 1,198 & 444,49 & 65874,12 & 12,65 & 15,15 \\
\hline 19.08.04 & 10:00 & 822,4 & 789,5 & 439,5 & 1,002 & 420,90 & 62377,41 & 11,98 & 12,00 \\
\hline 19.08 .04 & $11: 00$ & 949,5 & 911,5 & 561,5 & 1,075 & 329,49 & 48830,35 & 9,38 & 10,07 \\
\hline
\end{tabular}


Appendix C. Experiment 3 Tab. 14 Heat balance results (18.08.04)

\begin{tabular}{|c|c|c|c|c|c|c|c|c|c|}
\hline Date & Time & $\begin{array}{l}\text { Total heat } \\
\text { /animal } \\
\left(20^{\circ} \mathrm{C}\right) \mathrm{W}\end{array}$ & $\begin{array}{c}\text { hpu/all } \\
\text { animals }\end{array}$ & $\begin{array}{c}\text { Sensible } \\
\text { heat and } \\
\text { temperature } \\
\text { factors }\end{array}$ & $\begin{array}{c}\text { Sensible } \\
\text { Heat/ all } \\
\text { animals } \\
\text { (W) }\end{array}$ & $\begin{array}{c}\text { Heat loss } \\
\text { Thought } \\
\text { Building } \\
\text { (W) }\end{array}$ & $\begin{array}{c}\text { Calculated } \\
\text { AER } \\
\left(\mathrm{m}^{3} / \mathrm{s}\right)\end{array}$ & $\begin{array}{c}\text { Calculated } \\
\text { AER } \\
\left(\mathrm{m}^{3} / \mathrm{h}\right)\end{array}$ & $\begin{array}{c}\text { Heat } \\
\text { balance } \\
\text { AER/h }\end{array}$ \\
\hline 18.09 .04 & 12:00:00 & 4,94 & 148,20 & 385,68 & 57157,10 & $-1583,65$ & 13,61 & 48990,37 & 9,41 \\
\hline 18.09 .04 & 13:00:00 & 4,94 & 148,20 & 374,38 & 55482,49 & $-1099,76$ & 19,18 & 69034,62 & 13,26 \\
\hline 18.09 .04 & 14:00:00 & 4,94 & 148,20 & 372,86 & 55258,09 & $-988,31$ & 21,29 & 76659,37 & 14,73 \\
\hline 18.09 .04 & $15: 00: 00$ & 4,94 & 148,20 & 351,01 & 52020,26 & $-938,46$ & 21,11 & 75989,45 & 14,60 \\
\hline 18.09 .04 & $16: 00: 00$ & 4,94 & 148,20 & 341,12 & 50553,67 & $-938,46$ & 20,50 & 73807,75 & 14,18 \\
\hline 18.09 .04 & 17:00:00 & 4,94 & 148,20 & 336,14 & 49816,32 & $-938,46$ & 20,20 & 72710,87 & 13,97 \\
\hline 18.09 .04 & 18:00:00 & 4,94 & 148,20 & 333,65 & 49446,63 & $-938,46$ & 20,04 & 72160,92 & 13,86 \\
\hline 18.09 .04 & 19:00:00 & 4,94 & 148,20 & 367,70 & 54493,15 & $-1134,95$ & 18,23 & 65633,77 & 12,61 \\
\hline 18.09 .04 & $20: 00: 00$ & 4,94 & 148,20 & 366,73 & 54348,82 & $-1810,64$ & 11,25 & 40508,44 & 7,78 \\
\hline 18.09 .04 & 21:00:00 & 4,94 & 148,20 & 363,34 & 53847,33 & $-2157,28$ & 9,29 & 33450,48 & 6,43 \\
\hline 18.09 .04 & 22:00:00 & 4,94 & 148,20 & 362,98 & 53793,04 & $-2070,47$ & 9,69 & 34874,86 & 6,70 \\
\hline 18.09 .04 & 23:00:00 & 4,94 & 148,20 & 371,53 & 55060,40 & $-2468,73$ & 8,26 & 29740,29 & 5,71 \\
\hline 19.09 .04 & 00:00:00 & 4,94 & 148,20 & 355,84 & 52735,85 & $-4130,97$ & 4,56 & 16425,90 & 3,16 \\
\hline 19.09 .04 & 01:00:00 & 4,94 & 148,20 & 345,49 & 51201,22 & $-4328,05$ & 4,20 & 15119,38 & 2,90 \\
\hline 19.09.04 & 02:00:00 & 4,94 & 148,20 & 339,63 & 50332,75 & $-4298,14$ & 4,15 & 14952,24 & 2,87 \\
\hline 19.09 .04 & 03:00:00 & 4,94 & 148,20 & 340,81 & 50507,66 & $-4228,93$ & 4,24 & 15277,54 & 2,93 \\
\hline 19.09 .04 & 04:00:00 & 4,94 & 148,20 & 343,29 & 50875,41 & $-4228,93$ & 4,28 & 15398,94 & 2,96 \\
\hline 19.09.04 & 05:00:00 & 4,94 & 148,20 & 346,42 & 51338,72 & $-4263,53$ & 4,28 & 15414,33 & 2,96 \\
\hline 19.09.04 & 06:00:00 & 4,94 & 148,20 & 352,21 & 52198,26 & $-4340,95$ & 4,28 & 15390,93 & 2,96 \\
\hline 19.09 .04 & 07:00:00 & 4,94 & 148,20 & 351,26 & 52056,78 & $-4171,44$ & 4,45 & 16025,73 & 3,08 \\
\hline 19.09 .04 & 08:00:00 & 4,94 & 148,20 & 355,66 & 52708,55 & $-3712,19$ & 5,12 & 18426,20 & 3,54 \\
\hline 19.09 .04 & 09:00:00 & 4,94 & 148,20 & 365,60 & 54181,80 & $-3380,79$ & 5,83 & 20977,58 & 4,03 \\
\hline 19.09.04 & 10:00:00 & 4,94 & 148,20 & 369,43 & 54749,97 & $-2837,66$ & 7,09 & 25539,45 & 4,91 \\
\hline 19.09 .04 & 11:00:00 & 4,94 & 148,20 & 384,35 & 56961,38 & $-2360,22$ & 8,97 & 32296,17 & 6,20 \\
\hline
\end{tabular}


Appendix C. Experiment 3 Tab. 15a Moisture balance results (18.08.04)

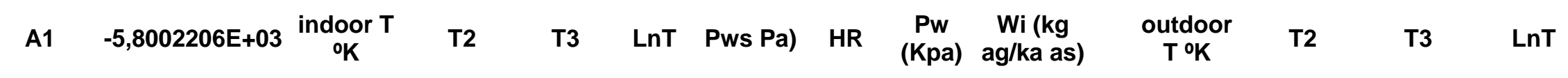

\begin{tabular}{|c|c|c|c|c|c|c|c|c|c|c|c|c|c|}
\hline A2 & 1,3914993 & 299,03 & 89415,951 & $2,7 \mathrm{E}+07$ & 5,701 & 3338,341 & 0,72 & 2,409 & 0,0151487 & 295,65 & 87408,923 & 25842448 & 5,6891763 \\
\hline A3 & $-4,86 \mathrm{E}-02$ & 299,49 & 89696,506 & $2,7 \mathrm{E}+07$ & 5,702 & 3432,139 & 0,69 & 2,362 & 0,0148437 & 297,15 & 88298,123 & 26237787 & 5,6942371 \\
\hline A4 & $4,18 \mathrm{E}-05$ & 299,56 & 89733,947 & $2,7 \mathrm{E}+07$ & 5,702 & 3444,817 & 0,65 & 2,229 & 0,0139899 & 297,45 & 88476,503 & 26317336 & 5,6952461 \\
\hline A5 & $-1,45 \mathrm{E}-08$ & 300,25 & 90147,06 & $2,7 \mathrm{E}+07$ & 5,705 & 3587,259 & 0,62 & 2,225 & 0,0139627 & 298,45 & 89072,403 & 26583659 & 5,6986024 \\
\hline A6 & 0 & 300,65 & 90391,926 & $2,7 \mathrm{E}+07$ & 5,706 & 3673,928 & 0,60 & 2,197 & 0,0137866 & 298,85 & 89311,323 & 26690689 & 5,6999418 \\
\hline \multirow[t]{2}{*}{ A7 } & 6,5459673 & 300,73 & 90438,533 & $2,7 \mathrm{E}+07$ & 5,706 & 3690,616 & 0,58 & 2,144 & 0,0134422 & 299,05 & 89430,903 & 26744311 & 5,7006108 \\
\hline & & 300,59 & 90354,348 & $2,7 \mathrm{E}+07$ & 5,706 & 3660,518 & 0,58 & 2,138 & 0,0134091 & 299,15 & 89490,723 & 26771150 & 5,7009451 \\
\hline patm $(\mathrm{Pa})$ & 101325 & 299,77 & 89861,303 & $2,7 \mathrm{E}+07$ & 5,703 & 3488,229 & 0,64 & 2,242 & 0,0140742 & 297,35 & 88417,023 & 26290802 & 5,6949099 \\
\hline \multirow[t]{16}{*}{$\mathrm{Ra}$} & 287,055 & 299,81 & 89885,287 & $2,7 \mathrm{E}+07$ & 5,703 & 3496,454 & 0,63 & 2,197 & 0,013782 & 295,95 & 87586,403 & 25921196 & 5,6901905 \\
\hline & & 299,95 & 89968,503 & $2,7 \mathrm{E}+07$ & 5,704 & 3525,115 & 0,60 & 2,112 & 0,0132429 & 295,35 & 87231,623 & 25763860 & 5,6881611 \\
\hline & & 299,96 & 89977,501 & $2,7 \mathrm{E}+07$ & 5,704 & 3528,226 & 0,60 & 2,111 & 0,0132367 & 295,55 & 87349,803 & 25816234 & 5,688838 \\
\hline & & 299,61 & 89766,901 & $2,7 \mathrm{E}+07$ & 5,702 & 3456,008 & 0,61 & 2,121 & 0,0132969 & 294,35 & 86641,923 & 25503050 & 5,6847695 \\
\hline & & 300,25 & 90152,314 & $2,7 \mathrm{E}+07$ & 5,705 & 3589,101 & 0,59 & 2,132 & 0,013366 & 291,45 & 84943,103 & 24756667 & 5,6748685 \\
\hline & & 300,67 & 90404,704 & $2,7 \mathrm{E}+07$ & 5,706 & 3678,497 & 0,58 & 2,139 & 0,0134136 & 291,45 & 84943,103 & 24756667 & 5,6748685 \\
\hline & & 300,91 & 90546,828 & $2,7 \mathrm{E}+07$ & 5,707 & 3729,630 & 0,57 & 2,130 & 0,0133556 & 291,75 & 85118,063 & 24833195 & 5,6758973 \\
\hline & & 300,86 & 90518,244 & $2,7 \mathrm{E}+07$ & 5,707 & 3719,300 & 0,57 & 2,131 & 0,0133625 & 291,85 & 85176,423 & 24858739 & 5,67624 \\
\hline & & 300,76 & 90458,081 & $2,7 \mathrm{E}+07$ & 5,706 & 3697,634 & 0,56 & 2,085 & 0,0130706 & 291,75 & 85118,063 & 24833195 & 5,6758973 \\
\hline & & 300,64 & 90382,155 & $2,7 \mathrm{E}+07$ & 5,706 & 3670,438 & 0,56 & 2,057 & 0,0128882 & 291,55 & 85001,403 & 24782159 & 5,6752115 \\
\hline & & 300,40 & 90240,911 & $2,7 \mathrm{E}+07$ & 5,705 & 3620,278 & 0,57 & 2,061 & 0,0129125 & 291,15 & 84768,323 & 24680297 & 5,6738386 \\
\hline & & 300,44 & 90264,194 & $2,7 \mathrm{E}+07$ & 5,705 & 3628,508 & 0,58 & 2,096 & 0,0131386 & 291,55 & 85001,403 & 24782159 & 5,6752115 \\
\hline & & 300,26 & 90156,818 & $2,7 \mathrm{E}+07$ & 5,705 & 3590,681 & 0,58 & 2,092 & 0,0131097 & 292,35 & 85468,523 & 24986723 & 5,6779517 \\
\hline & & 299,86 & 89913,021 & $2,7 \mathrm{E}+07$ & 5,703 & 3505,985 & 0,58 & 2,035 & 0,0127456 & 292,65 & 85644,023 & 25063723 & 5,6789774 \\
\hline & & 299,70 & 89818,592 & $2,7 \mathrm{E}+07$ & 5,703 & 3473,621 & 0,57 & 1,988 & 0,012445 & 293,65 & 86230,323 & 25321534 & 5,6823886 \\
\hline & & 299,08 & 89448,846 & $2,7 \mathrm{E}+07$ & 5,701 & 3349,229 & 0,60 & 2,009 & 0,0125787 & 294,05 & 86465,403 & 25425152 & 5,6837498 \\
\hline
\end{tabular}


Appendix C. Experiment 3 Tab. 15b Moisture balance results (18.08.04)

\begin{tabular}{|c|c|c|c|c|c|c|c|c|c|c|c|c|c|c|}
\hline Pws Pa) & HR & Pw (Kpa) & $\begin{array}{c}\text { Wo (kg } \\
\text { ag/ka as) }\end{array}$ & Total He & at/ animal & $\begin{array}{l}\text { Total heat } \\
\text { /hpu (eqn. } \\
\text { 26) }\end{array}$ & $\begin{array}{c}\text { Sensible } \\
\text { Heat } \\
\text { /animal }\end{array}$ & $\begin{array}{l}\text { Latent } \\
\text { Heat } \\
\text { /animal } \\
\text { (W) }\end{array}$ & $\begin{array}{c}\text { Latent } \\
\text { Heat } \\
\text { lanimal } \\
\text { (Kg } \\
\text { water/s) }\end{array}$ & $\begin{array}{c}\text { Latent } \\
\text { Heat } / 30 \\
000 \\
\text { animal } \\
(\mathrm{Kg} \\
\text { water/s) }\end{array}$ & $\begin{array}{c}\text { AER } \\
\mathrm{Kg} \\
\text { air/s }\end{array}$ & AER $\mathrm{m} 3 / \mathrm{s}$ & $\begin{array}{l}\text { AER } \\
\mathrm{m} 3 / \mathrm{h}\end{array}$ & $\begin{array}{c}\text { AER } \\
/ \mathrm{hr}\end{array}$ \\
\hline 2726,4979 & 0,779 & 2,124 & 0,0133169 & 4,94 & 1000,00 & 882,50 & 385,6754 & 496,825 & 0,0002062 & 0,0305516 & 16,69 & 13,80 & 49666,64 & 9,54 \\
\hline 2985,1271 & 0,703 & 2,099 & 0,0131543 & 4,94 & 1000,00 & 873,13 & 374,3758 & 498,749 & 0,0002069 & 0,03067 & 18,17 & 15,02 & 54055,91 & 10,38 \\
\hline 3039,3475 & 0,664 & 2,018 & 0,01264 & 4,94 & 1000,00 & 871,88 & 372,8616 & 499,013 & 0,0002071 & 0,0306862 & 22,74 & 18,80 & 67670,83 & 13,00 \\
\hline 3226,3399 & 0,617 & 1,991 & 0,0124644 & 4,94 & 1000,00 & 858,10 & 356,0573 & 502,043 & 0,0002083 & 0,0308725 & 20,62 & 17,04 & 61346,48 & 11,78 \\
\hline 3303,9001 & 0,581 & 1,920 & 0,0120107 & 4,94 & 1000,00 & 849,95 & 346,0131 & 503,937 & 0,0002091 & 0,030989 & 17,46 & 14,43 & 51957,29 & 9,98 \\
\hline 3343,2863 & 0,566 & 1,892 & 0,0118369 & 4,94 & 1000,00 & 848,40 & 344,0943 & 504,306 & 0,0002093 & 0,0310117 & 19,33 & 15,98 & 57514,10 & 11,05 \\
\hline 3363,1324 & 0,567 & 1,907 & 0,0119299 & 4,94 & 1000,00 & 851,20 & 347,5586 & 503,641 & 0,000209 & 0,0309708 & 20,95 & 17,32 & 62335,06 & 11,97 \\
\hline 3021,1793 & 0,643 & 1,943 & 0,0121578 & 4,94 & 1000,00 & 867,63 & 367,7001 & 499,925 & 0,0002074 & 0,0307423 & 16,06 & 13,27 & 47768,07 & 9,18 \\
\hline 2776,5973 & 0,683 & 1,896 & 0,0118631 & 4,94 & 1000,00 & 866,83 & 366,7262 & 500,099 & 0,0002075 & 0,030753 & 16,04 & 13,26 & 47722,99 & 9,17 \\
\hline 2677,1903 & 0,692 & 1,853 & 0,011584 & 4,94 & 1000,00 & 864,05 & 363,3423 & 500,708 & 0,0002078 & 0,0307904 & 18,57 & 15,35 & 55263,36 & 10,62 \\
\hline 2709,9746 & 0,68 & 1,843 & 0,0115214 & 4,94 & 1000,00 & 863,75 & 362,9760 & 500,774 & 0,0002078 & 0,0307945 & 17,97 & 14,85 & 53451,91 & 10,27 \\
\hline 2518,4145 & 0,742 & 1,869 & 0,0116862 & 4,94 & 1000,00 & 870,78 & 371,5277 & 499,247 & 0,0002072 & 0,0307006 & 19,07 & 15,76 & 56749,50 & 10,90 \\
\hline 2103,5758 & 0,863 & 1,815 & 0,011347 & 4,94 & 1000,00 & 857,93 & 355,8424 & 502,083 & 0,0002083 & 0,030875 & 15,31 & 12,65 & 45536,52 & 8,75 \\
\hline 2103,5758 & 0,887 & 1,866 & 0,0116685 & 4,94 & 1000,00 & 849,53 & 345,4873 & 504,038 & 0,0002091 & 0,0309952 & 17,77 & 14,69 & 52881,13 & 10,16 \\
\hline 2143,5135 & 0,868 & 1,861 & 0,0116347 & 4,94 & 1000,00 & 844,80 & 339,6272 & 505,173 & 0,0002096 & 0,031065 & 18,06 & 14,93 & 53745,36 & 10,32 \\
\hline 2156,9729 & 0,866 & 1,868 & 0,0116816 & 4,94 & 1000,00 & 845,75 & 340,8075 & 504,943 & 0,0002095 & 0,0310508 & 18,49 & 15,28 & 55000,41 & 10,56 \\
\hline 2143,5135 & 0,861 & 1,846 & 0,0115391 & 4,94 & 1000,00 & 847,75 & 343,2889 & 504,461 & 0,0002093 & 0,0310212 & 20,27 & 16,75 & 60304,56 & 11,58 \\
\hline 2116,8153 & 0,843 & 1,784 & 0,0111503 & 4,94 & 1000,00 & 850,28 & 346,4151 & 503,860 & 0,0002091 & 0,0309842 & 17,84 & 14,75 & 53082,03 & 10,20 \\
\hline 2064,2916 & 0,853 & 1,761 & 0,011 & 4,94 & 1000,00 & 854,98 & 352,2150 & 502,760 & 0,0002086 & 0,0309166 & 16,18 & 13,37 & 48135,41 & 9,25 \\
\hline 2116,8153 & 0,849 & 1,797 & 0,0112311 & 4,94 & 1000,00 & 854,20 & 351,2603 & 502,940 & 0,0002087 & 0,0309277 & 16,23 & 13,41 & 48277,82 & 9,27 \\
\hline 2225,3865 & 0,818 & 1,820 & 0,0113787 & 4,94 & 1000,00 & 857,78 & 355,6582 & 502,117 & 0,0002083 & 0,0308771 & 17,85 & 14,75 & 53110,70 & 10,20 \\
\hline 2267,3404 & 0,77 & 1,746 & 0,0109047 & 4,94 & 1000,00 & 865,90 & 365,5992 & 500,301 & 0,0002076 & 0,0307654 & 16,73 & 13,82 & 49761,32 & 9,56 \\
\hline 2412,2308 & 0,699 & 1,686 & 0,0105255 & 4,94 & 1000,00 & 869,05 & 369,4330 & 499,617 & 0,0002073 & 0,0307233 & 16,02 & 13,24 & 47659,21 & 9,15 \\
\hline 2472,4169 & 0,659 & 1,629 & 0,010165 & 4,94 & 1000,00 & 881,40 & 384,3548 & 497,045 & 0,0002062 & 0,0305652 & 12,68 & 10,48 & 37713,77 & 7,24 \\
\hline
\end{tabular}


Appendix C. Experiment 3 Tab. 16 AER results (25.08.04)

\begin{tabular}{|c|c|c|c|c|c|c|c|c|c|c|c|c|c|c|c|c|}
\hline Date & Time & $\begin{array}{l}\text { True } \\
\text { AER }\end{array}$ & $\begin{array}{l}\text { Tracer gas } \\
\text { (AER) }\end{array}$ & $\begin{array}{l}\text { SF6 (CV) } \\
\text { ch's 1-4 }\end{array}$ & $\begin{array}{l}\text { SF6 (CV) } \\
\text { ch's 1-6 }\end{array}$ & $\begin{array}{c}\text { Heat } \\
\text { Balance } \\
\text { (AER) }\end{array}$ & $\begin{array}{c}\text { Moisture } \\
\text { Balance } \\
\text { (AER) }\end{array}$ & $\begin{array}{c}\mathrm{CO2} \\
\text { Balance } \\
\text { (AER) }\end{array}$ & $\begin{array}{l}\text { O.Temp } \\
\left({ }^{\circ} \mathrm{C}\right)\end{array}$ & $\begin{array}{l}\text { I.Temp } \\
\left({ }^{\circ} \mathrm{C}\right)\end{array}$ & $\underset{\left({ }^{\circ} \mathrm{C}\right)}{\Delta \text { Temp }}$ & $\begin{array}{c}\text { CV } \\
\text { I.Temp } \\
(\%)\end{array}$ & $\underset{(\%)}{\text { O.Humid }}$ & $\begin{array}{l}\text { I. Humid } \\
(\%)\end{array}$ & $\begin{array}{c}\text { CV } \\
\text { I.Humid } \\
(\%)\end{array}$ & $\begin{array}{c}\Delta \text { water } \\
\text { content } \\
(\mathbf{k g} \\
\text { water } / \mathrm{m}^{3} \\
\text { dry air }\end{array}$ \\
\hline 08.25 .04 & $15: 00$ & 9,82 & 4,42 & 3,5 & 40,7 & 6,2 & 6,6 & 14,3 & 18,7 & 24,6 & 5,9 & 2,84 & 72,2 & 62,6 & 7,07 & 0,00295 \\
\hline 08.25 .04 & $16: 00$ & 9,39 & 4,28 & 4,8 & 36,3 & 6,1 & 5,5 & 14,8 & 17,5 & 24,3 & 6,8 & 3,95 & 77,8 & 65,7 & 6,62 & 0,00353 \\
\hline 08.25 .04 & $17: 00$ & 8,83 & 4,27 & 5,3 & 36,7 & 5,6 & 4,3 & 12,2 & 16,9 & 24,3 & 7,4 & 4,09 & 83,4 & 69,2 & 7,49 & 0,00456 \\
\hline 08.25 .04 & $18: 00$ & 8,33 & 4,18 & 5,7 & 33,5 & 5,6 & 4,3 & 12,4 & 17,2 & 24,3 & 7,1 & 3,81 & 83,7 & 69,3 & 7,83 & 0,00454 \\
\hline 08.25 .04 & 19:00 & 8,33 & 4,10 & 5,9 & 34,1 & 6,1 & 4,4 & 11,9 & 16,2 & 24,2 & 8,0 & 4,40 & 88,5 & 70,5 & 8,17 & 0,00438 \\
\hline 08.25 .04 & $20: 00$ & 8,33 & 4,11 & 4,7 & 33,8 & 6,0 & 3,9 & 11,5 & 15,9 & 24,0 & 8,1 & 5,02 & 90,2 & 72,7 & 9,15 & 0,00492 \\
\hline 08.25 .04 & $21: 00$ & 8,27 & 4,15 & 6,2 & 34,0 & 5,8 & 4,1 & 11,5 & 15,5 & 23,8 & 8,3 & 5,17 & 91,4 & 72,5 & 9,12 & 0,00470 \\
\hline 08.25 .04 & $22: 00$ & 6,45 & 3,92 & 5,6 & 33,7 & 5,9 & 4,5 & 10,9 & 15,2 & 23,8 & 8,6 & 6,04 & 90,7 & 70,5 & 8,80 & 0,00429 \\
\hline 08.25 .04 & 23:00 & 6,45 & 3,99 & 5,3 & 32,1 & 5,8 & 4,7 & 11,2 & 14,8 & 23,9 & 9,1 & 6,11 & 92,4 & 68,8 & 9,35 & 0,00409 \\
\hline 08.26 .04 & 00:00 & 6,45 & 3,84 & 5,6 & 31,9 & 6,0 & 5,1 & 11,0 & 14,4 & 23,8 & 9,4 & 6,33 & 93,3 & 68,5 & 9,65 & 0,00381 \\
\hline 08.26 .04 & 01:00 & 6,45 & 4,01 & 5,5 & 31,0 & 6,0 & 5,3 & 11,2 & 14,2 & 23,7 & 9,5 & 6,39 & 93,8 & 68,0 & 9,79 & 0,00363 \\
\hline 08.26 .04 & 02:00 & 6,45 & 3,85 & 4,1 & 30,8 & 6,3 & 5,7 & 11,7 & 14,4 & 23,6 & 9,2 & 6,19 & 93,3 & 68,1 & 9,76 & 0,00339 \\
\hline 08.26 .04 & 03:00 & 6,45 & 4,84 & 5,4 & 31,5 & 6,5 & 6,0 & 12,3 & 14,4 & 23,4 & 9,0 & 6,09 & 92,9 & 68,6 & 9,94 & 0,00325 \\
\hline 08.26 .04 & 04:00 & 6,45 & 3,88 & 5,9 & 30,8 & 6,5 & 5,9 & 12,8 & 14,5 & 23,5 & 9,0 & 6,19 & 93,5 & 69,0 & 10,11 & 0,00328 \\
\hline 08.26 .04 & 05:00 & 6,45 & 4,00 & 6,6 & 31,4 & 6,3 & 5,4 & 12,1 & 14,2 & 23,7 & 9,5 & 5,90 & 93,7 & 70,0 & 9,87 & 0,00361 \\
\hline 08.26 .04 & 06:00 & 7,83 & 4,25 & 5,6 & 31,7 & 6,5 & 4,9 & 10,5 & 14,4 & 23,4 & 9,0 & 4,54 & 94,3 & 72,9 & 10,85 & 0,00396 \\
\hline 08.26 .04 & 07:00 & 8,33 & 4,12 & 6,1 & 33,4 & 7,0 & 5,5 & 11,7 & 14,6 & 23,3 & 8,7 & 6,12 & 94,1 & 72,8 & 10,17 & 0,00350 \\
\hline 08.26 .04 & 08:00 & 9,37 & 4,44 & 26,4 & 34,9 & 7,4 & 5,7 & 12,4 & 16 & 23,7 & 7,7 & 4,83 & 91,2 & 73,1 & 9,56 & 0,00338 \\
\hline 08.26 .04 & 09:00 & 9,82 & 3,25 & 57,0 & 43,2 & 7,6 & 4,4 & 14,0 & 17,2 & 24,1 & 6,9 & 3,64 & 87,5 & 73,3 & 8,88 & 0,00440 \\
\hline 08.26 .04 & $10: 00$ & 9,89 & 2,76 & 3,8 & 44,0 & 9,9 & 4,1 & 15,0 & 17,5 & 23,9 & 6,4 & 3,78 & 86,5 & 72,8 & 8,58 & 0,00471 \\
\hline 08.26 .04 & $11: 00$ & 9,92 & 3,96 & 6,1 & 43,3 & 9,1 & 3,9 & 14,9 & 17,4 & 24,0 & 6,6 & 4,15 & 86,8 & 74,0 & 8,74 & 0,00493 \\
\hline 08.26 .04 & $12: 00$ & 9,96 & 4,26 & 5,4 & 37,2 & 9,9 & 6,4 & 14,8 & 17,9 & 24,2 & 6,3 & 3,82 & 85,2 & 73,6 & 8,90 & 0,00306 \\
\hline 08.26 .04 & $13: 00$ & 9,67 & 3,98 & 4,9 & 37,9 & 10,1 & 7,1 & 16,3 & 18,2 & 24,3 & 6,1 & 3,33 & 82,2 & 70,6 & 8,64 & 0,00275 \\
\hline 08.26 .04 & $14: 00$ & 10,68 & 3,98 & 4,0 & 39,7 & 13,5 & 9,3 & 15,0 & 19,7 & 24,3 & 4,6 & 4,90 & 72,3 & 65,3 & 8,8 & 0,00210 \\
\hline
\end{tabular}


Appendix C. Experiment 3 Tab. 17 Tracer gas results (25.08.04)

\begin{tabular}{|c|c|c|c|c|c|c|c|c|c|c|}
\hline Date & Time & $\begin{array}{c}\mathrm{SF6} \\
(\mathrm{mg} / \mathrm{m} 3)\end{array}$ & Reciprocal & $\begin{array}{c}\text { Background } \\
(\mathrm{mg} / \mathrm{m} 3)\end{array}$ & $\begin{array}{c}\text { Dosage } \\
\text { (mg) }\end{array}$ & $\begin{array}{l}\text { Dosage + } \\
\text { background } \\
\text { (mg) }\end{array}$ & $\begin{array}{l}\text { Dosage } \\
(\mathrm{g} / \mathrm{min})\end{array}$ & $\begin{array}{c}\text { Supplied } \\
\text { air } \\
\text { volume } \\
\text { m3/min }\end{array}$ & $\begin{array}{c}\text { Supplied } \\
\text { air } \\
\text { volume } \\
\text { m3/h }\end{array}$ & AER \\
\hline 25.08 .04 & 15:00 & 20,32 & 0,0492 & 105774,21 & & & & & & \\
\hline 25.08 .04 & $16: 00$ & 21,12 & 0,0473 & 109975,01 & 194021,30 & 379872,80 & 8,09 & 373,53 & 22411,72 & 4,30 \\
\hline 25.08 .04 & $17: 00$ & 21,67 & 0,0461 & 112810,55 & 194013,00 & 373010,10 & 8,05 & 371,48 & 22288,88 & 4,28 \\
\hline 25.08 .04 & $18: 00$ & 22,56 & 0,0443 & 117423,93 & 193823,00 & 388185,00 & 8,35 & 370,19 & 22211,68 & 4,27 \\
\hline 25.08 .04 & 19:00 & 22,52 & 0,0444 & 117239,12 & 178903,40 & 372705,40 & 8,17 & 362,74 & 21764,18 & 4,18 \\
\hline 25.08 .04 & $20: 00$ & 23,29 & 0,0429 & 121273,77 & 185678,70 & 379995,60 & 8,29 & 355,75 & 21345,13 & 4,10 \\
\hline 25.08 .04 & $21: 00$ & 23,34 & 0,0428 & 121495,89 & 184926,20 & 378489,70 & 8,33 & 356,91 & 21414,46 & 4,11 \\
\hline 25.08 .04 & $22: 00$ & 22,85 & 0,0438 & 118951,89 & 178669,60 & 372711,30 & 8,24 & 360,49 & 21629,27 & 4,15 \\
\hline 25.08 .04 & 23:00 & 24,89 & 0,0402 & 129598,16 & 194808,00 & 389146,00 & 8,47 & 340,17 & 20410,46 & 3,92 \\
\hline 26.08 .04 & $0: 00$ & 24,93 & 0,0401 & 129794,26 & 194500,00 & 388910,00 & 8,64 & 346,62 & 20797,17 & 3,99 \\
\hline 26.08 .04 & $1: 00$ & 25,21 & 0,0397 & 131231,11 & 179630,70 & 374191,70 & 8,40 & 333,22 & 19993,36 & 3,84 \\
\hline 26.08 .04 & $2: 00$ & 24,88 & 0,0402 & 129546,11 & 194230,90 & 387828,50 & 8,65 & 347,65 & 20859,17 & 4,01 \\
\hline 26.08 .04 & 3:00 & 25,46 & 0,0393 & 132529,14 & 194107,10 & 380065,90 & 8,49 & 333,64 & 20018,54 & 3,85 \\
\hline 26.08 .04 & 4:00 & 26,10 & 0,0383 & 135859,24 & 339501,00 & 525453,90 & 10,97 & 420,22 & 25213,30 & 4,84 \\
\hline 26.08 .04 & $5: 00$ & 25,22 & 0,0397 & 131276,23 & 194561,00 & 373003,00 & 8,48 & 336,33 & 20179,87 & 3,88 \\
\hline 26.08 .04 & $6: 00$ & 24,98 & 0,0400 & 130030,26 & 194514,00 & 389441,00 & 8,68 & 347,46 & 20847,87 & 4,00 \\
\hline 26.08 .04 & 7:00 & 23,46 & 0,0426 & 122120,62 & 194322,00 & 388744,00 & 8,65 & 368,59 & 22115,34 & 4,25 \\
\hline 26.08 .04 & $8: 00$ & 23,21 & 0,0431 & 120822,58 & 196077,90 & 375797,60 & 8,30 & 357,57 & 21454,29 & 4,12 \\
\hline 26.08 .04 & 9:00 & 12,48 & 0,0801 & 64955,44 & 39140,30 & 167622,40 & 4,81 & 385,30 & 23118,07 & 4,44 \\
\hline 26.08 .04 & $10: 00$ & 23,80 & 0,0420 & 123927,09 & 150030,20 & 337598,80 & 6,71 & 281,85 & 16910,73 & 3,25 \\
\hline 26.08 .04 & $11: 00$ & 23,94 & 0,0418 & 124636,84 & 146360,40 & 220663,80 & 5,74 & 239,89 & 14393,34 & 2,76 \\
\hline 26.08 .04 & $12: 00$ & 24,07 & 0,0416 & 125294,54 & 192794,50 & 371576,50 & 8,27 & 343,63 & 20617,71 & 3,96 \\
\hline 26.08 .04 & $13: 00$ & 23,01 & 0,0435 & 119769,23 & 192236,20 & 384930,50 & 8,50 & 369,63 & 22177,91 & 4,26 \\
\hline 26.08 .04 & $14: 00$ & 23,58 & 0,0424 & 122741,86 & 192427,20 & 369335,20 & 8,15 & 345,75 & 20744,98 & 3,98 \\
\hline
\end{tabular}


Appendix C. Experiment 3 Tab. $18 \mathrm{CO}_{2}$ balance results (25.08.04)

\begin{tabular}{cccccccc}
\hline Date & Time & $\begin{array}{c}\text { Inside } \mathrm{CO}_{2} \\
\text { concentration }\end{array}$ & $\begin{array}{c}\text { Corrected } \\
\text { for manure }\end{array}$ & $\Delta \mathrm{CO}_{2}$ & $\begin{array}{c}\mathrm{CO}_{2} \\
\text { productn } / \\
\Delta \mathrm{CO}_{2}\end{array}$ & $\begin{array}{c}\text { Air volume } \\
\text { displacement } \\
\mathrm{m} 3 / \mathrm{h}\end{array}$ & $\mathrm{AER} / \mathrm{h}$ \\
\hline 25.8 .2004 & $15: 00$ & 1047,97 & 1006,05 & 656,05 & 282,0 & 74529,873 & 14,3 \\
25.8 .2004 & $16: 00$ & 1027,27 & 986,18 & 636,18 & 290,8 & 76857,783 & 14,8 \\
25.8 .2004 & $17: 00$ & 1165,11 & 1118,50 & 768,50 & 240,7 & 63624,335 & 12,2 \\
25.8 .2004 & $18: 00$ & 1150,67 & 1104,64 & 754,64 & 245,2 & 64793,186 & 12,4 \\
25.8 .2004 & $19: 00$ & 1184,11 & 1136,74 & 786,74 & 235,1 & 62149,142 & 11,9 \\
25.8 .2004 & $20: 00$ & 1212,56 & 1164,06 & 814,06 & 227,3 & 60064,031 & 11,5 \\
25.8 .2004 & $21: 00$ & 1218,50 & 1169,76 & 819,76 & 225,7 & 59645,842 & 11,5 \\
25.8 .2004 & $22: 00$ & 1260,39 & 1209,97 & 859,97 & 215,1 & 56857,043 & 10,9 \\
25.8 .2004 & $23: 00$ & 1234,98 & 1185,58 & 835,58 & 221,4 & 58516,786 & 11,2 \\
26.8 .2004 & $00: 00$ & 1255,60 & 1205,38 & 855,38 & 216,3 & 57162,275 & 11,0 \\
26.8 .2004 & $01: 00$ & 1241,40 & 1191,75 & 841,75 & 219,8 & 58088,208 & 11,2 \\
26.8 .2004 & $02: 00$ & 1202,31 & 1154,22 & 804,22 & 230,0 & 60798,557 & 11,7 \\
26.8 .2004 & $03: 00$ & 1158,87 & 1112,52 & 762,52 & 242,6 & 64123,928 & 12,3 \\
26.8 .2004 & $04: 00$ & 1130,43 & 1085,21 & 735,21 & 251,6 & 66505,651 & 12,8 \\
26.8 .2004 & $05: 00$ & 1170,43 & 1123,61 & 773,61 & 239,1 & 63204,155 & 12,1 \\
26.8 .2004 & $06: 00$ & 1294,67 & 1242,89 & 892,89 & 207,2 & 54761,202 & 10,5 \\
26.8 .2004 & $07: 00$ & 1202,00 & 1153,92 & 803,92 & 230,1 & 60821,181 & 11,7 \\
26.8 .2004 & $08: 00$ & 1152,27 & 1106,18 & 756,18 & 244,6 & 64660,875 & 12,4 \\
26.8 .2004 & $09: 00$ & 1063,91 & 1021,36 & 671,36 & 275,6 & 72830,883 & 14,0 \\
26.8 .2004 & $10: 00$ & 1014,73 & 974,14 & 624,14 & 296,4 & 78340,928 & 15,0 \\
26.8 .2004 & $11: 00$ & 1021,09 & 980,25 & 630,25 & 293,5 & 77581,483 & 14,9 \\
26.8 .2004 & $12: 00$ & 1027,76 & 986,64 & 636,64 & 290,6 & 76801,849 & 14,8 \\
26.8 .2004 & $13: 00$ & 964,24 & 925,67 & 575,67 & 321,4 & 84936,75 & 16,3 \\
26.8 .2004 & $14: 00$ & 1018,61 & 977,86 & 627,86 & 294,7 & 77876,041 & 15,0 \\
\hline & & & & & & &
\end{tabular}


Appendix C. Experiment 3 Tab. 19 Heat balance results (25.08.04)

\begin{tabular}{|c|c|c|c|c|c|c|c|c|c|}
\hline Date & Time & $\begin{array}{l}\text { Total heat } \\
\text { /animal } \\
\left(20^{\circ} \mathrm{C}\right) \mathrm{W}\end{array}$ & $\begin{array}{l}\text { hpu/all } \\
\text { animals }\end{array}$ & $\begin{array}{c}\text { Sensible } \\
\text { heat and } \\
\text { temperature } \\
\text { factors }\end{array}$ & $\begin{array}{c}\text { Sensible } \\
\text { Heat/ all } \\
\text { animals (W) }\end{array}$ & $\begin{array}{c}\text { Heat loss } \\
\text { Thought } \\
\text { Building } \\
\text { (W) }\end{array}$ & $\begin{array}{l}\text { Calculated } \\
\text { AER (m3/s) }\end{array}$ & $\begin{array}{l}\text { Calculated } \\
\text { AER }(\mathrm{m} 3 / \mathrm{h})\end{array}$ & $\begin{array}{c}\text { Heat } \\
\text { balance } \\
\text { AER/h }\end{array}$ \\
\hline 25.08 .04 & $15: 00: 00$ & 8,81 & 264,30 & 448,24 & 118470,17 & $-3425,37$ & 13,02 & 46887,95 & 6,18 \\
\hline 25.08 .04 & $16: 00: 00$ & 8,81 & 264,30 & 443,16 & 117127,62 & $-3529,77$ & 12,48 & 44928,82 & 6,09 \\
\hline 25.08 .04 & 17:00:00 & 8,81 & 264,30 & 417,10 & 110240,34 & $-4152,09$ & 9,91 & 35669,95 & 5,62 \\
\hline 25.08 .04 & 18:00:00 & 8,81 & 264,30 & 415,26 & 109753,05 & $-4564,42$ & 8,94 & 32172,49 & 5,61 \\
\hline 25.08 .04 & 19:00:00 & 8,81 & 264,30 & 423,66 & 111974,57 & $-4723,96$ & 8,80 & 31695,33 & 6,11 \\
\hline 25.08 .04 & 20:00:00 & 8,81 & 264,30 & 422,24 & 111597,71 & $-5081,16$ & 8,13 & 29265,49 & 5,97 \\
\hline 25.08 .04 & 21:00:00 & 8,81 & 264,30 & 423,34 & 111890,01 & $-5105,80$ & 8,11 & 29197,48 & 5,83 \\
\hline 25.08 .04 & $22: 00: 00$ & 8,81 & 264,30 & 425,73 & 112519,84 & $-4729,24$ & 8,84 & 31819,35 & 5,89 \\
\hline 25.08 .04 & 23:00:00 & 8,81 & 264,30 & 429,64 & 113553,99 & $-4884,67$ & 8,63 & 31057,99 & 5,78 \\
\hline 26.08 .04 & 00:00:00 & 8,81 & 264,30 & 433,68 & 114622,83 & $-5037,17$ & 8,44 & 30371,68 & 5,97 \\
\hline 26.08 .04 & 01:00:00 & 8,81 & 264,30 & 435,10 & 114996,05 & $-5008,43$ & 8,52 & 30658,00 & 6,04 \\
\hline 26.08 .04 & 02:00:00 & 8,81 & 264,30 & 432,39 & 114279,68 & $-5063,57$ & 8,36 & 30111,48 & 6,27 \\
\hline 26.08 .04 & 03:00:00 & 8,81 & 264,30 & 434,17 & 114752,36 & $-4933,36$ & 8,63 & 31076,85 & 6,52 \\
\hline 26.08 .04 & 04:00:00 & 8,81 & 264,30 & 437,43 & 115612,01 & $-4914,00$ & 8,74 & 31448,98 & 6,53 \\
\hline 26.08 .04 & 05:00:00 & 8,81 & 264,30 & 438,49 & 115892,97 & $-4751,53$ & 9,07 & 32654,61 & 6,28 \\
\hline 26.08 .04 & 06:00:00 & 8,81 & 264,30 & 442,62 & 116983,96 & $-4620,15$ & 9,43 & 33952,58 & 6,48 \\
\hline 26.08 .04 & 07:00:00 & 8,81 & 264,30 & 441,36 & 116651,01 & $-4599,03$ & 9,45 & 34013,80 & 6,98 \\
\hline 26.08 .04 & 08:00:00 & 8,81 & 264,30 & 437,20 & 115551,23 & $-4731,00$ & 9,08 & 32701,52 & 7,42 \\
\hline 26.08 .04 & 09:00:00 & 8,81 & 264,30 & 443,16 & 117127,62 & $-4655,92$ & 9,37 & 33724,01 & 7,60 \\
\hline 26.08 .04 & 10:00:00 & 8,81 & 264,30 & 446,16 & 117920,29 & $-4359,72$ & 10,10 & 36363,91 & 9,92 \\
\hline 26.08 .04 & $11: 00: 00$ & 8,81 & 264,30 & 437,08 & 115520,83 & $-4029,50$ & 10,73 & 38627,04 & 9,14 \\
\hline 26.08 .04 & $12: 00: 00$ & 8,81 & 264,30 & 427,47 & 112979,89 & $-3849,44$ & 10,99 & 39577,71 & 9,86 \\
\hline 26.08 .04 & 13:00:00 & 8,81 & 264,30 & 432,04 & 114188,10 & $-3006,00$ & 14,34 & 51635,47 & 10,12 \\
\hline 26.08 .04 & 14:00:00 & 8,81 & 264,30 & 429,87 & 113615,17 & $-3237,68$ & 13,22 & 47593,60 & 13,45 \\
\hline
\end{tabular}


Appendix C. Experiment 3 Tab. 20a Moisture balance results (25.08.04)

\begin{tabular}{|c|c|c|c|c|c|c|c|c|c|c|c|c|}
\hline A1 & $\begin{array}{c}- \\
5,8002206 E+03\end{array}$ & $\begin{array}{l}\text { indoor } \mathrm{T} \\
\text { oK }\end{array}$ & T2 & T3 & LnT & Pws Pa) & HR & $\begin{array}{c}\text { Pw } \\
\text { (Kpa) }\end{array}$ & $\begin{array}{c}\text { Wi (kg } \\
\text { ag/ka } \\
\text { as) }\end{array}$ & $\begin{array}{l}\text { outdoor } \\
\text { T ․ K }\end{array}$ & T2 & T3 \\
\hline $\mathrm{A} 2$ & 1,3914993 & 296,35 & 87823,323 & 26026442 & 5,6915412 & 2844,6464 & 0,73 & 2,069 & 0,0129628 & 289,05 & 83549,903 & 24150099 \\
\hline A3 & $-4,86 \mathrm{E}-02$ & 296,57 & 87955,248 & 26085108 & 5,6922917 & 2883,1256 & 0,69 & 1,997 & 0,0125038 & 289,05 & 83549,903 & 24150099 \\
\hline A4 & $4,18 \mathrm{E}-05$ & 297,70 & 88624,546 & 26383416 & 5,6960821 & 3084,9551 & 0,63 & 1,952 & 0,0122206 & 288,85 & 83434,323 & 24100004 \\
\hline A5 & $-1,45 \mathrm{E}-08$ & 297,78 & 88671,44 & 26404360 & 5,6963466 & 3099,5176 & 0,63 & 1,941 & 0,0121497 & 288,05 & 82972,803 & 23900316 \\
\hline \multirow[t]{2}{*}{ A7 } & 6,5459673 & 297,48 & 88493,607 & 26324968 & 5,6953428 & 3044,5885 & 0,69 & 2,107 & 0,0132055 & 286,65 & 82168,223 & 23553521 \\
\hline & & 297,43 & 88465,348 & 26312359 & 5,6951831 & 3035,9337 & 0,69 & 2,102 & 0,0131793 & 286,55 & 82110,903 & 23528879 \\
\hline patm $(\mathrm{Pa})$ & 101325 & 297,33 & 88404,386 & 26285165 & 5,6948384 & 3017,3308 & 0,71 & 2,127 & 0,0133381 & 287,25 & 82512,563 & 23701734 \\
\hline \multirow[t]{18}{*}{$\mathrm{Ra}$} & 287,055 & 297,16 & 88304,066 & 26240436 & 5,6942707 & 2986,9207 & 0,73 & 2,171 & 0,0136213 & 286,75 & 82225,563 & 23578180 \\
\hline & & 296,99 & 88200,09 & 26194104 & 5,6936816 & 2955,6673 & 0,72 & 2,143 & 0,0134366 & 286,25 & 81939,063 & 23455057 \\
\hline & & 296,92 & 88163,713 & 26177900 & 5,6934754 & 2944,7962 & 0,70 & 2,075 & 0,0130018 & 286,25 & 81939,063 & 23455057 \\
\hline & & 297,04 & 88233,504 & 26208990 & 5,693871 & 2965,6817 & 0,69 & 2,039 & 0,0127747 & 286,25 & 81939,063 & 23455057 \\
\hline & & 296,96 & 88187,469 & 26188481 & 5,6936101 & 2951,8917 & 0,68 & 2,022 & 0,0126638 & 286,45 & 82053,603 & 23504254 \\
\hline & & 296,78 & 88076,143 & 26138907 & 5,6929785 & 2918,7601 & 0,68 & 1,988 & 0,0124501 & 286,65 & 82168,223 & 23553521 \\
\hline & & 296,60 & 87969,336 & 26091375 & 5,6923718 & 2887,2596 & 0,69 & 1,980 & 0,0123958 & 286,75 & 82225,563 & 23578180 \\
\hline & & 296,65 & 88001,964 & 26105893 & 5,6925572 & 2896,8531 & 0,69 & 1,999 & 0,0125167 & 286,85 & 82282,923 & 23602856 \\
\hline & & 296,83 & 88109,533 & 26153773 & 5,693168 & 2928,6653 & 0,70 & 2,050 & 0,0128446 & 286,75 & 82225,563 & 23578180 \\
\hline & & 296,57 & 87955,248 & 26085108 & 5,6922917 & 2883,1256 & 0,73 & 2,103 & 0,0131809 & 286,65 & 82168,223 & 23553521 \\
\hline & & 296,44 & 87877,415 & 26050491 & 5,6918491 & 2860,3726 & 0,73 & 2,082 & 0,0130472 & 287,15 & 82455,123 & 23676988 \\
\hline & & 296,84 & 88112,501 & 26155095 & 5,6931849 & 2929,5472 & 0,73 & 2,142 & 0,0134331 & 288,25 & 83088,063 & 23950134 \\
\hline & & 297,25 & 88359,792 & 26265279 & 5,6945862 & 3003,782 & 0,73 & 2,201 & 0,0138138 & 289,05 & 83549,903 & 24150099 \\
\hline & & 297,06 & 88242,416 & 26212961 & 5,6939215 & 2968,3573 & 0,73 & 2,162 & 0,0135629 & 290,65 & 84477,423 & 24553363 \\
\hline & & 297,15 & 88298,123 & 26237787 & 5,6942371 & 2985,1271 & 0,74 & 2,210 & 0,0138699 & 290,25 & 84245,063 & 24452129 \\
\hline & & 297,38 & 88434,121 & 26298428 & 5,6950066 & 3026,3929 & 0,74 & 2,226 & 0,0139733 & 291,05 & 84710,103 & 24654875 \\
\hline & & 297,49 & 88498,813 & 26327291 & 5,6953722 & 3046,1851 & 0,71 & 2,150 & 0,013484 & 291,35 & 84884,823 & 24731193 \\
\hline & & 297,49 & 88502,531 & 26328950 & 5,6953932 & 3047,326 & 0,65 & 1,990 & 0,0124577 & 292,85 & 85761,123 & 25115145 \\
\hline
\end{tabular}


Appendix C. Experiment 3 Tab. 20b Moisture balance results (25.08.04)

\begin{tabular}{|c|c|c|c|c|c|c|c|c|c|c|c|c|c|}
\hline LnT & Pws Pa) & HR & $\begin{array}{c}\mathrm{Pw} \\
\text { (Kpa) }\end{array}$ & $\begin{array}{c}\text { Wo (kg } \\
\text { ag/ka } \\
\text { as) }\end{array}$ & $\begin{array}{l}\text { Total } \\
\text { heat } \\
\text { /hpu } \\
\text { (eqn. } \\
26)\end{array}$ & $\begin{array}{c}\text { Sensible } \\
\text { Heat } \\
\text { /animal }\end{array}$ & $\begin{array}{l}\text { Latent } \\
\text { Heat } \\
\text { /animal } \\
\text { (W) }\end{array}$ & $\begin{array}{l}\text { Latent } \\
\text { Heat } \\
\text { lanimal } \\
\text { (Kg } \\
\text { water/s) }\end{array}$ & $\begin{array}{c}\text { Latent } \\
\text { Heat } / 30 \\
000 \\
\text { animal } \\
(\mathrm{Kg} \\
\text { water/s) }\end{array}$ & $\begin{array}{c}\text { AER } \\
\mathrm{Kg} \\
\text { air/s }\end{array}$ & $\begin{array}{c}\text { AER } \\
\text { m3/s }\end{array}$ & $\begin{array}{c}\text { AER } \\
\text { m3/h }\end{array}$ & AER /hr \\
\hline 5,6665997 & 1806,8522 & 0,771 & 1,393 & 0,0086706 & 936,00 & 448,2413 & 487,759 & 0,0002024 & 0,0337586 & 7,88 & 6,51 & 23438,64 & 4,50 \\
\hline 5,6665997 & 1806,8522 & 0,781 & 1,411 & 0,0087846 & 931,55 & 443,1616 & 488,388 & 0,0002027 & 0,0338022 & 9,10 & 7,52 & 27077,86 & 5,20 \\
\hline 5,6631341 & 1694,4953 & 0,872 & 1,478 & 0,0092044 & 907,45 & 415,2594 & 492,191 & 0,0002042 & 0,0340653 & 11,58 & 9,57 & 34448,13 & 6,62 \\
\hline 5,660701 & 1619,5421 & 0,887 & 1,437 & 0,0089449 & 914,65 & 423,6647 & 490,985 & 0,0002037 & 0,0339819 & 9,64 & 7,96 & 28673,05 & 5,51 \\
\hline 5,658262 & 1547,5178 & 0,898 & 1,390 & 0,0086491 & 913,43 & 422,2388 & 491,186 & 0,0002038 & 0,0339958 & 7,47 & 6,18 & 22237,32 & 4,27 \\
\hline 5,657913 & 1537,462 & 0,903 & 1,388 & 0,0086406 & 914,38 & 423,3447 & 491,030 & 0,0002037 & 0,033985 & 7,50 & 6,20 & 22316,80 & 4,29 \\
\hline 5,6603529 & 1609,0759 & 0,894 & 1,439 & 0,0089574 & 916,43 & 425,7277 & 490,697 & 0,0002036 & 0,033962 & 7,77 & 6,42 & 23105,49 & 4,44 \\
\hline 5,6586108 & 1557,6314 & 0,897 & 1,397 & 0,0086966 & 919,80 & 429,6405 & 490,159 & 0,0002034 & 0,0339247 & 6,90 & 5,70 & 20535,58 & 3,94 \\
\hline 5,6568656 & 1507,6384 & 0,931 & 1,404 & 0,0087371 & 923,30 & 433,6846 & 489,615 & 0,0002032 & 0,0338871 & 7,22 & 5,97 & 21493,15 & 4,13 \\
\hline 5,6568656 & 1507,6384 & 0,928 & 1,399 & 0,0087085 & 924,53 & 435,0967 & 489,428 & 0,0002031 & 0,0338741 & 7,90 & 6,53 & 23512,98 & 4,52 \\
\hline 5,657564 & 1527,4637 & 0,931 & 1,422 & 0,0088536 & 923,73 & 434,1747 & 489,550 & 0,0002031 & 0,0338826 & 8,91 & 7,36 & 26494,67 & 5,09 \\
\hline 5,6572148 & 1517,5226 & 0,936 & 1,420 & 0,008843 & 926,55 & 437,4272 & 489,123 & 0,000203 & 0,033853 & 9,35 & 7,73 & 27820,55 & 5,34 \\
\hline 5,658262 & 1547,5178 & 0,94 & 1,455 & 0,0090595 & 927,48 & 438,4902 & 488,985 & 0,0002029 & 0,0338434 & 9,99 & 8,26 & 29734,25 & 5,71 \\
\hline 5,6586108 & 1557,6314 & 0,943 & 1,469 & 0,0091491 & 931,08 & 442,6181 & 488,457 & 0,0002027 & 0,0338069 & 10,43 & 8,62 & 31016,95 & 5,96 \\
\hline 5,6589594 & 1567,8031 & 0,946 & 1,483 & 0,0092395 & 929,98 & 441,3584 & 488,617 & 0,0002027 & 0,0338179 & 10,33 & 8,54 & 30738,88 & 5,90 \\
\hline 5,6586108 & 1557,6314 & 0,952 & 1,483 & 0,0092377 & 926,35 & 437,1972 & 489,153 & 0,000203 & 0,0338551 & 9,40 & 7,77 & 27964,17 & 5,37 \\
\hline 5,658262 & 1547,5178 & 0,957 & 1,481 & 0,0092258 & 931,55 & 443,1616 & 488,388 & 0,0002027 & 0,0338022 & 8,56 & 7,07 & 25466,59 & 4,89 \\
\hline 5,6600047 & 1598,6692 & 0,958 & 1,532 & 0,0095455 & 934,18 & 446,1608 & 488,014 & 0,0002025 & 0,0337763 & 9,66 & 7,98 & 28736,51 & 5,52 \\
\hline 5,6638282 & 1716,4624 & 0,939 & 1,612 & 0,0100536 & 926,25 & 437,0822 & 489,168 & 0,000203 & 0,0338561 & 10,03 & 8,29 & 29846,20 & 5,73 \\
\hline 5,6665997 & 1806,8522 & 0,836 & 1,511 & 0,0094126 & 917,93 & 427,4684 & 490,457 & 0,0002035 & 0,0339453 & 7,73 & 6,39 & 22988,40 & 4,42 \\
\hline 5,6721198 & 2000,2458 & 0,711 & 1,422 & 0,0088542 & 921,88 & 432,0397 & 489,835 & 0,0002033 & 0,0339023 & 7,21 & 5,96 & 21461,97 & 4,12 \\
\hline 5,6707426 & 1950,2702 & 0,736 & 1,435 & 0,0089378 & 920,00 & 429,8720 & 490,128 & 0,0002034 & 0,0339226 & 6,89 & 5,70 & 20504,15 & 3,94 \\
\hline 5,6734951 & 2051,3406 & 0,852 & 1,748 & 0,0109168 & 915,43 & 424,566 & 490,859 & 0,0002037 & 0,0339732 & 11,13 & 9,20 & 33111,10 & 6,36 \\
\hline 5,6745253 & 2090,4089 & 0,822 & 1,718 & 0,0107298 & 913,25 & 422,035 & 491,215 & 0,0002038 & 0,0339978 & 12,36 & 10,21 & 36765,28 & 7,06 \\
\hline 5,6796605 & 2295,6929 & 0,723 & 1,660 & 0,0103582 & 913,13 & 421,889 & 491,236 & 0,0002038 & 0,0339992 & 16,21 & 13,39 & 48217,72 & 9,26 \\
\hline
\end{tabular}


Appendix C. Experiment 3 Tab. 21 AER results (08.09.04)

\begin{tabular}{|c|c|c|c|c|c|c|c|c|c|c|c|c|c|c|c|c|c|}
\hline Date & Time & $\begin{array}{l}\text { True } \\
\text { AER }\end{array}$ & $\begin{array}{c}\text { Heat } \\
\text { Balance } \\
\text { (AER) }\end{array}$ & $\begin{array}{c}\text { Moisture } \\
\text { Balance } \\
\text { (AER) }\end{array}$ & $\begin{array}{c}\mathrm{CO} 2 \\
\text { Balance } \\
\text { (AER) }\end{array}$ & $\begin{array}{l}\text { Bird } \\
\text { activity }\end{array}$ & $\begin{array}{c}\text { Heat } \\
\text { Balance } \\
\text { with } \\
\text { activity }\end{array}$ & $\begin{array}{c}\text { Moisture } \\
\text { Balance } \\
\text { with } \\
\text { activity }\end{array}$ & $\begin{array}{c}\text { CO2 } \\
\text { Balance } \\
\text { with } \\
\text { activity }\end{array}$ & $\begin{array}{l}\text { O.Temp } \\
\left({ }^{\circ} \mathrm{C}\right)\end{array}$ & $\begin{array}{c}\text { I.Temp } \\
\left({ }^{\circ} \mathrm{C}\right)\end{array}$ & $\begin{array}{c}\Delta \\
\text { Temp } \\
\left({ }^{\circ} \mathrm{C}\right)\end{array}$ & $\begin{array}{l}\text { CV } \\
\text { I.Temp } \\
\left({ }^{\circ} \mathrm{C}\right)\end{array}$ & $\underset{(\%)}{\text { O.Humid }}$ & $\begin{array}{l}\text { I. Humid } \\
(\%)\end{array}$ & 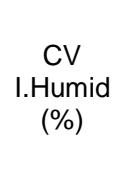 & $\begin{array}{c}\Delta \text { water } \\
\text { content } \\
(\mathrm{kg} \\
\text { water } / \mathrm{m}^{3} \\
\text { dry air }\end{array}$ \\
\hline 08.09 .04 & $14: 00$ & 25,8 & 28,6 & 30,4 & 29,1 & 1,046 & 28,4 & 30,2 & 30,5 & 20,8 & 24,09 & 3,29 & 2,36 & 56,8 & 54,34 & 5,07 & 0,00149 \\
\hline 08.09 .04 & $15: 00$ & 25,9 & 25,7 & 28,3 & 32,1 & 0,988 & 25,4 & 27,9 & 31,7 & 20,9 & 24,48 & 3,58 & 2,58 & 55,5 & 52,91 & 4,78 & 0,00160 \\
\hline 08.09 .04 & $16: 00$ & 25,8 & 24,6 & 25,9 & 25,9 & 0,982 & 25,0 & 26,2 & 25,4 & 20,7 & 24,44 & 3,74 & 2,87 & 50 & 48,89 & 5,63 & 0,00175 \\
\hline 08.09 .04 & $17: 00$ & 25,8 & 24,0 & 27,6 & 18,2 & 1,010 & 25,0 & 28,8 & 18,4 & 19,9 & 23,86 & 3,96 & 3,24 & 49,7 & 47,78 & 7,01 & 0,00163 \\
\hline 08.09 .04 & $18: 00$ & 23,9 & 22,6 & 26,9 & 16,9 & 1,037 & 24,1 & 28,7 & 17,5 & 18,9 & 23,24 & 4,34 & 3,58 & 56,1 & 52,25 & 6,88 & 0,00167 \\
\hline 08.09 .04 & $19: 00$ & 17,9 & 18,0 & 21,2 & 15,8 & 1,059 & 19,2 & 22,6 & 16,8 & 17 & 22,61 & 5,61 & 4,56 & 67,9 & 60,10 & 8,68 & 0,00211 \\
\hline 08.09 .04 & $20: 00$ & 12,0 & 14,5 & 16,0 & 13,5 & 1,061 & 15,7 & 17,4 & 14,3 & 14,5 & 21,74 & 7,24 & 6,97 & 78,6 & 66,81 & 9,36 & 0,00279 \\
\hline 08.09 .04 & $21: 00$ & 10,4 & 14,4 & 15,5 & 18,8 & 1,080 & 14,3 & 15,4 & 20,3 & 13,6 & 21,09 & 7,49 & 7,98 & 84,7 & 70,84 & 8,91 & 0,00286 \\
\hline 08.09 .04 & $22: 00$ & 10,4 & 13,8 & 13,8 & 27,9 & 0,986 & 12,2 & 12,1 & 27,5 & 13,1 & 20,94 & 7,84 & 8,77 & 89,3 & 74,88 & 9,49 & 0,00323 \\
\hline 08.09 .04 & $23: 00$ & 10,0 & 12,7 & 12,8 & 27,2 & 0,875 & 10,9 & 11,0 & 23,7 & 11,8 & 20,50 & 8,70 & 9,21 & 92,2 & 75,63 & 9,91 & 0,00347 \\
\hline 09.09 .04 & $0: 00$ & 9,6 & 13,2 & 13,4 & 20,7 & 0,855 & 11,3 & 11,4 & 17,7 & 12 & 20,38 & 8,38 & 8,73 & 94,7 & 77,30 & 9,09 & 0,00331 \\
\hline 09.09 .04 & $1: 00$ & 9,4 & 14,3 & 14,4 & 18,1 & 0,851 & 12,1 & 12,2 & 15,4 & 12,1 & 20,00 & 7,90 & 8,56 & 90,1 & 75,12 & 9,31 & 0,00307 \\
\hline 09.09 .04 & $2: 00$ & 10,0 & 13,3 & 13,5 & 17,8 & 0,840 & 11,3 & 11,4 & 15,0 & 11,2 & 19,77 & 8,57 & 9,07 & 91,2 & 75,16 & 8,45 & 0,00328 \\
\hline 09.09 .04 & 3:00 & 9,5 & 13,2 & 14,3 & 14,9 & 0,845 & 11,1 & 12,0 & 12,6 & 10,7 & 19,42 & 8,72 & 8,96 & 92,1 & 74,28 & 8,36 & 0,00310 \\
\hline 09.09 .04 & 4:00 & 9,5 & 13,5 & 15,3 & 17,8 & 0,835 & 11,4 & 13,0 & 14,9 & 10,3 & 18,99 & 8,69 & 9,16 & 91,8 & 73,21 & 9,60 & 0,00289 \\
\hline 09.09 .04 & 5:00 & 9,8 & 11,3 & 10,7 & 27,7 & 0,844 & 11,1 & 10,6 & 23,4 & 9,5 & 19,63 & 10,13 & 8,91 & 93,7 & 77,26 & 10,16 & 0,00412 \\
\hline 09.09 .04 & $6: 00$ & 9,5 & 10,6 & 10,8 & 29,1 & 0,984 & 11,7 & 11,9 & 28,7 & 8,7 & 19,52 & 10,82 & 9,44 & 94,3 & 75,34 & 9,31 & 0,00410 \\
\hline 09.09 .04 & 7:00 & 9,9 & 10,8 & 11,0 & 31,2 & 1,095 & 12,0 & 12,2 & 34,1 & 9,3 & 19,81 & 10,51 & 9,00 & 91,8 & 74,20 & 8,73 & 0,00404 \\
\hline 09.09 .04 & 8:00 & 10,0 & 13,3 & 12,2 & 28,4 & 1,102 & 14,5 & 13,3 & 31,3 & 12,6 & 20,79 & 8,19 & 7,65 & 81,8 & 71,99 & 9,48 & 0,00363 \\
\hline 09.09 .04 & $9: 00$ & 11,2 & 16,8 & 14,0 & 21,0 & 1,080 & 18,3 & 15,3 & 22,7 & 15,6 & 21,83 & 6,23 & 5,36 & 69,3 & 66,15 & 8,42 & 0,00318 \\
\hline 09.09 .04 & $10: 00$ & 16,6 & 23,3 & 17,6 & 19,0 & 1,085 & 26,7 & 20,2 & 20,6 & 17,4 & 21,89 & 4,49 & 5,06 & 61,5 & 61,80 & 5,98 & 0,00253 \\
\hline 09.09 .04 & $11: 00$ & 21,5 & 30,0 & 20,7 & 18,1 & 1,140 & 32,7 & 22,6 & 20,6 & 18,8 & 22,25 & 3,45 & 4,00 & 51,4 & 54,31 & 4,98 & 0,00216 \\
\hline 09.09 .04 & $12: 00$ & 25,3 & 32,3 & 20,9 & 19,9 & 1,084 & 33,7 & 21,8 & 21,5 & 19,8 & 22,90 & 3,10 & 3,46 & 45,5 & 49,81 & 4,37 & 0,00214 \\
\hline 09.09 .04 & $13: 00$ & 25,7 & 33,9 & 21,2 & 26,2 & 1,038 & 37,9 & 23,7 & 27,2 & 20,7 & 23,56 & 2,86 & 3,7 & 41,8 & 46,71 & 4,7 & 0,00212 \\
\hline
\end{tabular}


Appendix C. Experiment $3 \mathrm{Tab} .22 \mathrm{CO}_{2}$ mass balance results (08.09.04)

\begin{tabular}{|c|c|c|c|c|c|c|c|c|c|}
\hline Date & Time & $\begin{array}{l}\text { Inside } \mathrm{CO}_{2} \\
\text { concentration }\end{array}$ & $\begin{array}{l}\text { Corrected for } \\
\text { manure }\end{array}$ & $\Delta \mathrm{CO}_{2}$ & $\begin{array}{l}\text { Animal } \\
\text { activity }\end{array}$ & $\begin{array}{c}\mathrm{CO}_{2} \\
\text { productn / } \\
\Delta \mathrm{CO}_{2}\end{array}$ & $\begin{array}{c}\text { Air volume } \\
\text { displacement } \\
\text { m3/h }\end{array}$ & $\mathrm{AER} / \mathrm{h}$ & $\begin{array}{l}\text { AER /h with } \\
\text { activity }\end{array}$ \\
\hline 09.08 .04 & $14: 00$ & 857,42 & 823,12 & 473,12 & 1,05 & 391,02 & 158720,55 & 29,13 & 30,49 \\
\hline 09.08.04 & $15: 00$ & 812,23 & 779,74 & 429,74 & 0,99 & 430,49 & 165024,49 & 32,07 & 31,70 \\
\hline 09.08 .04 & $16: 00$ & 919,72 & 882,94 & 532,94 & 0,98 & 347,13 & 132292,96 & 25,86 & 25,41 \\
\hline 09.08 .04 & $17: 00$ & 1154,35 & 1108,18 & 758,18 & 1,01 & 244,01 & 95552,09 & 18,18 & 18,35 \\
\hline 09.08 .04 & $18: 00$ & 1213,39 & 1164,86 & 814,86 & 1,04 & 227,03 & 91312,15 & 16,92 & 17,54 \\
\hline 09.08 .04 & 19:00 & 1271,38 & 1220,52 & 870,52 & 1,06 & 212,52 & 87281,70 & 15,83 & 16,77 \\
\hline 09.08 .04 & $20: 00$ & 1431,88 & 1374,61 & 1024,61 & 1,06 & 180,56 & 74321,63 & 13,45 & 14,28 \\
\hline 09.08 .04 & $21: 00$ & 1126,78 & 1081,71 & 731,71 & 1,08 & 252,83 & 105914,14 & 18,84 & 20,34 \\
\hline 09.08 .04 & $22: 00$ & 878,60 & 843,46 & 493,46 & 0,99 & 374,90 & 143353,70 & 27,93 & 27,54 \\
\hline 09.08 .04 & 23:00 & 893,37 & 857,64 & 507,64 & 0,87 & 364,43 & 123620,91 & 27,15 & 23,75 \\
\hline 09.09.04 & $0: 00$ & 1059,26 & 1016,89 & 666,89 & 0,86 & 277,41 & 92051,04 & 20,67 & 17,68 \\
\hline 09.09 .04 & $1: 00$ & 1155,84 & 1109,61 & 759,61 & 0,85 & 243,55 & 80405,17 & 18,15 & 15,44 \\
\hline 09.09 .04 & $2: 00$ & 1170,31 & 1123,50 & 773,50 & 0,84 & 239,17 & 77961,92 & 17,82 & 14,98 \\
\hline 09.09 .04 & $3: 00$ & 1327,21 & 1274,12 & 924,12 & 0,84 & 200,19 & 65581,48 & 14,92 & 12,60 \\
\hline 09.09 .04 & 4:00 & 1170,16 & 1123,35 & 773,35 & 0,84 & 239,22 & 77525,92 & 17,82 & 14,89 \\
\hline 09.09 .04 & 5:00 & 882,13 & 846,85 & 496,85 & 0,84 & 372,35 & 121827,40 & 27,74 & 23,40 \\
\hline 09.09.04 & $6: 00$ & 857,28 & 822,99 & 472,99 & 0,98 & 391,13 & 149338,17 & 29,14 & 28,69 \\
\hline 09.09 .04 & 7:00 & 825,01 & 792,01 & 442,01 & 1,09 & 418,54 & 177698,26 & 31,18 & 34,13 \\
\hline 09.09 .04 & 8:00 & 869,61 & 834,83 & 484,83 & 1,10 & 381,58 & 163113,76 & 28,43 & 31,33 \\
\hline 09.09.04 & 9:00 & 1047,05 & 1005,17 & 655,17 & 1,08 & 282,37 & 118302,12 & 21,04 & 22,72 \\
\hline 09.09 .04 & $10: 00$ & 1119,47 & 1074,69 & 724,69 & 1,09 & 255,28 & 107460,38 & 19,02 & 20,64 \\
\hline 09.09 .04 & $11: 00$ & 1159,24 & 1112,88 & 762,88 & 1,14 & 242,50 & 107246,94 & 18,07 & 20,60 \\
\hline 09.09 .04 & $12: 00$ & 1087,00 & 1043,52 & 693,52 & 1,08 & 266,75 & 112112,97 & 19,88 & 21,54 \\
\hline 09.09 .04 & $13: 00$ & 913,28 & 876,75 & 526,75 & 1,04 & 351,21 & 141417,10 & 26,17 & 27,16 \\
\hline 09.09.04 & $14: 00$ & 919,00 & 882,24 & 532,24 & 1,11 & 347,59 & 149700,11 & 25,90 & 28,76 \\
\hline
\end{tabular}


Appendix C. Experiment 3 Tab. 23 Heat balance results (08.09.04)

\begin{tabular}{|c|c|c|c|c|c|c|c|c|c|}
\hline Date & Time & $\begin{array}{l}\text { Total heat } \\
\text { /animal } \\
\left(20^{\circ} \mathrm{C}\right) \mathrm{W}\end{array}$ & $\begin{array}{l}\mathrm{hpu} / \mathrm{all} \\
\text { animals }\end{array}$ & $\begin{array}{c}\text { Sensible } \\
\text { heat and } \\
\text { temperature } \\
\text { factors }\end{array}$ & $\begin{array}{l}\text { Sensible Heat/ } \\
\text { all animals (W) }\end{array}$ & $\begin{array}{c}\text { Heat loss } \\
\text { Thought } \\
\text { Building (W) }\end{array}$ & $\begin{array}{l}\text { Calculated } \\
\text { AER }(\mathrm{m} 3 / \mathrm{s})\end{array}$ & $\begin{array}{l}\text { Calculated } \\
\text { AER }(m 3 / h)\end{array}$ & $\begin{array}{c}\text { Heat } \\
\text { balance } \\
\text { AER/h }\end{array}$ \\
\hline 08.09 .04 & $14: 00$ & 12,93 & 387,90 & 427,82 & 165949,89 & $-1543,18$ & 41,31 & 148732,48 & 28,57 \\
\hline 08.09 .04 & $15: 00$ & 12,93 & 387,90 & 418,77 & 162440,40 & $-1678,67$ & 37,14 & 133696,54 & 25,68 \\
\hline 08.09 .04 & $16: 00$ & 12,93 & 387,90 & 419,70 & 162802,74 & $-1753,74$ & 35,61 & 128201,75 & 24,63 \\
\hline 08.09 .04 & $17: 00$ & 12,93 & 387,90 & 433,05 & 167980,09 & $-1859,32$ & 34,65 & 124730,25 & 23,96 \\
\hline 08.09 .04 & $18: 00$ & 12,93 & 387,90 & 447,44 & 173563,42 & $-2034,11$ & 32,70 & 117724,37 & 22,61 \\
\hline 08.09 .04 & $19: 00$ & 12,93 & 387,90 & 461,60 & 179055,28 & $-2632,37$ & 25,99 & 93564,10 & 17,97 \\
\hline 08.09 .04 & $20: 00$ & 12,93 & 387,90 & 480,96 & 186563,46 & $-3398,39$ & 20,90 & 75243,90 & 14,45 \\
\hline 08.09 .04 & $21: 00$ & 12,93 & 387,90 & 495,37 & 192154,85 & $-3512,76$ & 20,83 & 74970,67 & 14,40 \\
\hline 08.09 .04 & $22: 00$ & 12,93 & 387,90 & 498,58 & 193401,09 & $-3678,17$ & 20,00 & 72009,55 & 13,83 \\
\hline 08.09 .04 & $23: 00$ & 12,93 & 387,90 & 508,06 & 197074,95 & $-4082,88$ & 18,33 & 65989,52 & 12,68 \\
\hline 09.09 .04 & 00:00 & 12,93 & 387,90 & 510,72 & 198107,98 & $-3930,97$ & 19,16 & 68960,52 & 13,25 \\
\hline 09.09 .04 & 01:00 & 12,93 & 387,90 & 518,77 & 201232,18 & $-3707,49$ & 20,66 & 74377,69 & 14,29 \\
\hline 09.09 .04 & 02:00 & 12,93 & 387,90 & 523,80 & 203181,09 & $-4018,95$ & 19,22 & 69182,55 & 13,29 \\
\hline 09.09 .04 & 03:00 & 12,93 & 387,90 & 531,04 & 205988,97 & $-4092,85$ & 19,13 & 68865,88 & 13,23 \\
\hline 09.09 .04 & 04:00 & 12,93 & 387,90 & 540,18 & 209535,37 & $-4075,84$ & 19,55 & 70373,82 & 13,52 \\
\hline 09.09 .04 & 05:00 & 12,93 & 387,90 & 526,74 & 204321,09 & $-4751,53$ & 16,29 & 58635,79 & 11,26 \\
\hline 09.09 .04 & 06:00 & 12,93 & 387,90 & 529,01 & 205201,99 & $-5076,47$ & 15,29 & 55035,45 & 10,57 \\
\hline 09.09 .04 & 07:00 & 12,93 & 387,90 & 522,76 & 202779,74 & $-4933,36$ & 15,55 & 55987,05 & 10,75 \\
\hline 09.09 .04 & 08:00 & 12,93 & 387,90 & 501,81 & 194654,00 & $-3842,98$ & 19,25 & 69316,51 & 13,31 \\
\hline 09.09 .04 & 09:00 & 12,93 & 387,90 & 479,02 & 185812,19 & $-2923,30$ & 24,26 & 87340,65 & 16,78 \\
\hline 09.09 .04 & $10: 00$ & 12,93 & 387,90 & 477,64 & 185274,73 & $-2108,01$ & 33,70 & 121304,14 & 23,30 \\
\hline 09.09 .04 & $11: 00$ & 12,93 & 387,90 & 469,79 & 182230,56 & $-1616,49$ & 43,33 & 155983,79 & 29,96 \\
\hline 09.09 .04 & $12: 00$ & 12,93 & 387,90 & 455,05 & 176515,65 & $-1454,61$ & 46,67 & 168013,79 & 32,27 \\
\hline 09.09 .04 & $13: 00$ & 12,93 & 387,90 & 440,10 & 170713,72 & $-1340,24$ & 49,01 & 176427,53 & 33,89 \\
\hline 09.09 .04 & $14: 00$ & 12,93 & 387,90 & 431,26 & 167285,68 & $-1191,84$ & 54,04 & 194552,56 & 37,37 \\
\hline
\end{tabular}


Appendix C. Experiment 3 Tab. 24a Moisture balance results (08.09.04)

\begin{tabular}{|c|c|c|c|c|c|c|c|c|c|c|c|}
\hline A1 & $\begin{array}{l}- \\
5,8002206 E+03\end{array}$ & $\begin{array}{c}\text { indoor } \mathbf{T} \\
\text { oKK }\end{array}$ & T2 & T3 & LnT & Pws Pa) & HR & $\begin{array}{c}\mathrm{Pw} \\
(\mathrm{Kpa})\end{array}$ & $\begin{array}{c}\text { Wi (kg } \\
\text { ag/ka } \\
\text { as) }\end{array}$ & $\begin{array}{l}\text { outdoor } \\
\mathrm{T}{ }^{\circ} \mathrm{K}\end{array}$ & T2 \\
\hline
\end{tabular}

\begin{tabular}{|c|c|c|c|c|c|c|c|c|c|c|c|c|}
\hline A2 & 1,3914993 & 297,24 & 88350,875 & 26261303 & 5,6945357 & 3001,0786 & 0,54 & 1,631 & 0,0101738 & 293,95 & 86406,603 & 25399221 \\
\hline A3 & $-4,86 \mathrm{E}-02$ & 297,63 & 88582,129 & 26364478 & 5,6958427 & 3071,831 & 0,53 & 1,625 & 0,010139 & 294,05 & 86465,403 & 25425152 \\
\hline A4 & $4,18 \mathrm{E}-05$ & 297,59 & 88558,32 & 26353849 & 5,6957083 & 3064,4845 & 0,49 & 1,498 & 0,0093351 & 293,85 & 86347,823 & 25373308 \\
\hline A5 & $-1,45 \mathrm{E}-08$ & 297,01 & 88216,425 & 26201381 & 5,6937742 & 2960,5595 & 0,48 & 1,415 & 0,0088064 & 293,05 & 85878,303 & 25166637 \\
\hline \multirow[t]{2}{*}{ A7 } & 6,5459673 & 295,76 & 87473,978 & 25871304 & 5,6895483 & 2744,7752 & 0,60 & 1,649 & 0,0102928 & 290,15 & 84187,023 & 24426865 \\
\hline & & 294,89 & 86961,587 & 25644320 & 5,6866109 & 2603,4966 & 0,67 & 1,739 & 0,0108631 & 287,65 & 82742,523 & 23800887 \\
\hline patm $(\mathrm{Pa})$ & 101325 & 294,24 & 86574,971 & 25473495 & 5,684383 & 2500,8864 & 0,71 & 1,772 & 0,0110692 & 286,75 & 82225,563 & 23578180 \\
\hline \multirow[t]{16}{*}{$\mathrm{Ra}$} & 287,055 & 294,09 & 86488,193 & 25435205 & 5,6838816 & 2478,3166 & 0,75 & 1,856 & 0,0116033 & 286,25 & 81939,063 & 23455057 \\
\hline & & 293,65 & 86231,057 & 25321858 & 5,6823928 & 2412,4169 & 0,76 & 1,824 & 0,0114049 & 284,95 & 81196,503 & 23136943 \\
\hline & & 293,53 & 86158,393 & 25289858 & 5,6819713 & 2394,0571 & 0,77 & 1,851 & 0,011571 & 285,15 & 81310,523 & 23185695 \\
\hline & & 293,15 & 85937,655 & 25192731 & 5,6806887 & 2338,9848 & 0,75 & 1,757 & 0,0109757 & 285,25 & 81367,563 & 23210097 \\
\hline & & 292,92 & 85799,197 & 25131872 & 5,6798825 & 2304,9741 & 0,75 & 1,732 & 0,010819 & 284,35 & 80854,923 & 22991097 \\
\hline & & 292,57 & 85598,668 & 25043816 & 5,6787125 & 2256,4365 & 0,74 & 1,676 & 0,010462 & 283,85 & 80570,823 & 22870028 \\
\hline & & 292,14 & 85343,589 & 24931956 & 5,6772203 & 2195,9106 & 0,73 & 1,608 & 0,0100269 & 283,45 & 80343,903 & 22773479 \\
\hline & & 292,78 & 85717,933 & 25096175 & 5,6794087 & 2285,202 & 0,77 & 1,766 & 0,0110298 & 282,65 & 79891,023 & 22581198 \\
\hline & & 292,67 & 85654,997 & 25068541 & 5,6790414 & 2269,9854 & 0,75 & 1,710 & 0,0106779 & 281,85 & 79439,423 & 22390001 \\
\hline & & 293,94 & 86400,724 & 25396629 & 5,6833757 & 2455,7362 & 0,72 & 1,768 & 0,0110452 & 285,75 & 81653,063 & 23332363 \\
\hline & & 294,98 & 87013,2 & 25667154 & 5,6869076 & 2617,4523 & 0,66 & 1,731 & 0,0108132 & 288,75 & 83376,563 & 24074982 \\
\hline & & 295,04 & 87050,077 & 25683472 & 5,6871194 & 2627,4606 & 0,62 & 1,624 & 0,0101294 & 290,55 & 84419,303 & 24528028 \\
\hline & & 295,40 & 87258,206 & 25775638 & 5,6883134 & 2684,5364 & 0,54 & 1,458 & 0,009081 & 291,95 & 85234,803 & 24884301 \\
\hline & & 296,05 & 87645,603 & 25947481 & 5,6905284 & 2793,4748 & 0,50 & 1,392 & 0,0086608 & 292,95 & 85819,703 & 25140882 \\
\hline & & 296,71 & 88034,599 & 26120416 & 5,6927426 & 2906,4744 & 0,47 & 1,358 & 0,0084471 & 293,85 & 86347,823 & 25373308 \\
\hline & & 297,09 & 88262,468 & 26221897 & 5,6940351 & 2974,3849 & 0,45 & 1,350 & 0,0083965 & 294,55 & 86759,703 & 25555070 \\
\hline
\end{tabular}


Appendix C. Experiment 3 Tab. 24b Moisture balance results (08.09.04)

\begin{tabular}{|c|c|c|c|c|c|c|c|c|c|c|c|c|c|}
\hline LnT & Pws Pa) & HR & $\begin{array}{c}\mathrm{Pw} \\
\text { (Kpa) }\end{array}$ & $\begin{array}{c}\text { Wo (kg } \\
\text { ag/ka } \\
\text { as) }\end{array}$ & $\begin{array}{c}\text { Total } \\
\text { heat } \\
\text { /hpu } \\
\text { (eqn. } \\
26)\end{array}$ & $\begin{array}{c}\text { Sensible } \\
\text { Heat } \\
\text { /animal }\end{array}$ & $\begin{array}{l}\text { Latent } \\
\text { Heat } \\
\text { lanimal } \\
\text { (W) }\end{array}$ & $\begin{array}{l}\text { Latent } \\
\text { Heat } \\
\text { lanimal } \\
\text { (Kg } \\
\text { water/s) }\end{array}$ & $\begin{array}{c}\text { Latent } \\
\text { Heat } / 30 \\
000 \\
\text { animal } \\
\text { (Kg } \\
\text { water/s) }\end{array}$ & $\begin{array}{c}\text { AER Kg } \\
\text { air/s }\end{array}$ & $\begin{array}{l}\text { AER } \\
\mathrm{m} 3 / \mathrm{s}\end{array}$ & $\begin{array}{l}\text { AER } \\
\mathrm{m} 3 / \mathrm{h}\end{array}$ & AER /hr \\
\hline 5,6834097 & 2457,2485 & 0,568 & 1,396 & 0,0086872 & 918,23 & 427,8162 & 490,409 & 0,0002035 & 0,0789334 & 53,107712 & 43,890671 & 158006,42 & 30,4 \\
\hline 5,6837498 & 2472,4169 & 0,555 & 1,372 & 0,0085388 & 910,45 & 418,7688 & 491,681 & 0,000204 & 0,0791382 & 49,463685 & 40,879079 & 147164,68 & 28,3 \\
\hline 5,6830694 & 2442,1616 & 0,5 & 1,221 & 0,007587 & 911,25 & 419,7029 & 491,547 & 0,000204 & 0,0791167 & 45,268316 & 37,411832 & 134682,59 & 25,9 \\
\hline 5,6803432 & 2324,3554 & 0,497 & 1,155 & 0,007173 & 922,75 & 433,0500 & 489,700 & 0,0002032 & 0,0788194 & 48,263316 & 39,887038 & 143593,34 & 27,6 \\
\hline 5,676925 & 2184,114 & 0,561 & 1,225 & 0,0076135 & 935,30 & 447,4437 & 487,856 & 0,0002024 & 0,0785226 & 47,134096 & 38,953799 & 140233,67 & 26,9 \\
\hline 5,670398 & 1937,9488 & 0,679 & 1,316 & 0,0081837 & 947,80 & 461,6016 & 486,198 & 0,0002017 & 0,0782557 & 37,114084 & 30,672797 & 110422,07 & 21,2 \\
\hline 5,6617445 & 1651,3004 & 0,786 & 1,298 & 0,0080706 & 965,15 & 480,9576 & 484,192 & 0,0002009 & 0,0779329 & 27,91915 & 23,073678 & 83065,241 & 16,0 \\
\hline 5,6586108 & 1557,6314 & 0,847 & 1,319 & 0,0082054 & 978,28 & 495,3721 & 482,903 & 0,0002004 & 0,0777253 & 27,151676 & 22,439402 & 80781,846 & 15,5 \\
\hline 5,6568656 & 1507,6384 & 0,893 & 1,346 & 0,0083756 & 981,23 & 498,5849 & 482,640 & 0,0002003 & 0,077683 & 24,079622 & 19,900514 & 71641,852 & 13,8 \\
\hline 5,6523137 & 1384,1999 & 0,922 & 1,276 & 0,007934 & 989,98 & 508,0561 & 481,919 & 0,0002 & 0,077567 & 22,359647 & 18,479047 & 66524,57 & 12,8 \\
\hline 5,6530154 & 1402,5912 & 0,947 & 1,328 & 0,0082617 & 992,45 & 510,7192 & 481,731 & 0,0001999 & 0,0775367 & 23,441598 & 19,373222 & 69743,598 & 13,4 \\
\hline 5,653366 & 1411,8672 & 0,901 & 1,272 & 0,007908 & 999,98 & 518,7733 & 481,202 & 0,0001997 & 0,0774515 & 25,258148 & 20,874502 & 75148,208 & 14,4 \\
\hline 5,6502059 & 1330,2929 & 0,912 & 1,213 & 0,0075376 & 1004,70 & 523,7976 & 480,902 & 0,0001995 & 0,0774033 & 23,599289 & 19,503545 & 70212,76 & 13,5 \\
\hline 5,6484459 & 1286,7914 & 0,921 & 1,185 & 0,007361 & 1011,55 & 531,0363 & 480,514 & 0,0001994 & 0,0773408 & 24,951303 & 20,620912 & 74235,282 & 14,3 \\
\hline 5,6470357 & 1252,8973 & 0,918 & 1,150 & 0,0071413 & 1020,28 & 540,1788 & 480,096 & 0,0001992 & 0,0772736 & 26,788555 & 22,139302 & 79701,487 & 15,3 \\
\hline 5,6442094 & 1187,4601 & 0,937 & 1,113 & 0,0069058 & 1007,48 & 526,7365 & 480,738 & 0,0001995 & 0,077377 & 18,773795 & 15,515533 & 55855,918 & 10,7 \\
\hline 5,641375 & 1125,0542 & 0,943 & 1,061 & 0,0065814 & 1009,63 & 529,0074 & 480,618 & 0,0001994 & 0,0773575 & 18,894248 & 15,615081 & 56214,293 & 10,8 \\
\hline 5,6435015 & 1171,5792 & 0,918 & 1,076 & 0,0066728 & 1003,73 & 522,7629 & 480,962 & 0,0001996 & 0,0774129 & 19,180116 & 15,851335 & 57064,807 & 11,0 \\
\hline 5,6551173 & 1459,0617 & 0,818 & 1,194 & 0,0074137 & 984,20 & 501,8149 & 482,385 & 0,0002002 & 0,077642 & 21,390992 & 17,678506 & 63642,622 & 12,2 \\
\hline 5,6655613 & 1772,4781 & 0,693 & 1,228 & 0,0076326 & 963,40 & 479,0209 & 484,379 & 0,000201 & 0,0779629 & 24,522698 & 20,266692 & 72960,093 & 14,0 \\
\hline 5,6717757 & 1987,6478 & 0,615 & 1,222 & 0,0075953 & 962,15 & 477,6353 & 484,515 & 0,000201 & 0,0779848 & 30,784696 & 25,441897 & 91590,83 & 17,6 \\
\hline 5,6765826 & 2170,5063 & 0,514 & 1,116 & 0,0069246 & 955,10 & 469,7875 & 485,313 & 0,0002014 & 0,0781132 & 36,232267 & 29,944022 & 107798,48 & 20,7 \\
\hline 5,6800019 & 2309,9852 & 0,455 & 1,051 & 0,0065194 & 942,00 & 455,0545 & 486,945 & 0,0002021 & 0,078376 & 36,608835 & 30,255236 & 108918,85 & 20,9 \\
\hline 5,6830694 & 2442,1616 & 0,418 & 1,021 & 0,0063301 & 928,88 & 440,0973 & 488,778 & 0,0002028 & 0,0786709 & 37,169795 & 30,718839 & 110587,82 & 21,2 \\
\hline 5,6854488 & 2549,4938 & 0,408 & 1,040 & 0,0064514 & 921,20 & 431,2598 & 489,940 & 0,0002033 & 0,078858 & 40,551164 & 33,513359 & 120648,09 & 23,2 \\
\hline
\end{tabular}


Appendix C. Experiment 3 Tab. 25 AER results (14.09.04)

\begin{tabular}{|c|c|c|c|c|c|c|c|c|c|c|c|c|c|c|c|c|c|}
\hline Date & Time & $\begin{array}{l}\text { True } \\
\text { AER }\end{array}$ & $\begin{array}{c}\text { Heat } \\
\text { Balance } \\
\text { (AER) }\end{array}$ & $\begin{array}{c}\text { Moisture } \\
\text { Balance } \\
\text { (AER) }\end{array}$ & $\begin{array}{c}\mathrm{CO} 2 \\
\text { Balance } \\
\text { (AER) }\end{array}$ & $\begin{array}{l}\text { Bird } \\
\text { activity }\end{array}$ & $\begin{array}{c}\text { Heat } \\
\text { Balance } \\
\text { with } \\
\text { activity }\end{array}$ & $\begin{array}{l}\text { Moisture } \\
\text { Balance } \\
\text { with } \\
\text { activity }\end{array}$ & $\begin{array}{c}\mathrm{CO} 2 \\
\text { Balance } \\
\text { with } \\
\text { activity }\end{array}$ & $\begin{array}{l}\text { O.Temp } \\
\left({ }^{\circ} \mathrm{C}\right)\end{array}$ & $\begin{array}{l}\text { I.Temp } \\
\left({ }^{\circ} \mathrm{C}\right)\end{array}$ & $\begin{array}{c}\Delta \\
\text { Temp } \\
\left({ }^{\circ} \mathrm{C}\right)\end{array}$ & $\begin{array}{l}\text { CV } \\
\text { I.Temp } \\
\left({ }^{\circ} \mathrm{C}\right)\end{array}$ & $\underset{(\%)}{\text { O. Humid }}$ & $\underset{(\%)}{\text { I. Humid }}$ & $\begin{array}{c}\text { CV } \\
\text { I.Humid } \\
(\%)\end{array}$ & $\begin{array}{c}\Delta \text { water } \\
\text { content } \\
(\mathrm{kg} \\
\text { water } / \mathrm{m}^{3} \\
\text { dry air }\end{array}$ \\
\hline 14.09 .04 & $18: 00$ & 22,0 & 45,1 & 38,5 & 35,5 & 1,047 & 47,3 & 40,4 & 37,2 & 18 & 21,0 & 3,0 & 4,83 & 58,9 & 57,9 & 1,60 & 0,00144 \\
\hline 14.09 .04 & $19: 00$ & 12,2 & 28,5 & 32,2 & 29,4 & 1,066 & 30,5 & 34,4 & 31,4 & 14,2 & 19,3 & 5,1 & 7,78 & 75,1 & 66,3 & 4,51 & 0,00171 \\
\hline 14.09 .04 & $20: 00$ & 11,3 & 26,8 & 28,8 & 25,3 & 1,086 & 29,1 & 31,3 & 27,5 & 13,4 & 18,9 & 5,5 & 8,96 & 77,4 & 68,2 & 4,88 & 0,00192 \\
\hline 14.09 .04 & $21: 00$ & 11,7 & 35,9 & 35,0 & 30,7 & 0,955 & 34,3 & 33,4 & 29,3 & 14,6 & 18,8 & 4,2 & 8,11 & 69,4 & 64,8 & 3,91 & 0,00158 \\
\hline 14.09 .04 & $22: 00$ & 10,5 & 33,5 & 31,0 & 27,7 & 0,863 & 28,9 & 26,8 & 23,9 & 14,3 & 18,8 & 4,5 & 6,73 & 71,7 & 67,0 & 3,19 & 0,00178 \\
\hline 14.09 .04 & $23: 00$ & 10,7 & 31,1 & 31,4 & 27,3 & 0,845 & 26,3 & 26,6 & 23,1 & 14,1 & 18,9 & 4,8 & 6,98 & 74,1 & 67,4 & 3,43 & 0,00176 \\
\hline 15.09 .04 & $00: 00$ & 10,9 & 30,7 & 30,5 & 29,0 & 0,849 & 26,1 & 25,9 & 24,6 & 13,8 & 18,7 & 4,9 & 7,16 & 78,2 & 70,6 & 3,59 & 0,00181 \\
\hline 15.09 .04 & 01:00 & 10,1 & 29,4 & 30,8 & 29,2 & 0,850 & 25,0 & 26,2 & 24,8 & 13,2 & 18,4 & 5,2 & 7,00 & 81,6 & 72,1 & 4,53 & 0,00179 \\
\hline 15.09 .04 & 02:00 & 10,1 & 30,0 & 31,7 & 29,2 & 0,841 & 25,3 & 26,7 & 24,5 & 13,1 & 18,2 & 5,1 & 6,91 & 82,6 & 72,8 & 4,52 & 0,00174 \\
\hline 15.09 .04 & 03:00 & 10,5 & 29,8 & 32,9 & 30,0 & 0,837 & 25,0 & 27,6 & 25,1 & 12,9 & 18,1 & 5,2 & 6,39 & 83,7 & 72,9 & 4,30 & 0,00168 \\
\hline 15.09 .04 & 04:00 & 10,6 & 29,5 & 31,9 & 30,8 & 0,834 & 24,6 & 26,6 & 25,7 & 12,6 & 17,9 & 5,3 & 6,71 & 84,2 & 73,5 & 4,27 & 0,00173 \\
\hline 15.09 .04 & 05:00 & 11,0 & 26,0 & 27,1 & 29,4 & 1,075 & 28,0 & 29,2 & 31,6 & 12,2 & 18,1 & 5,9 & 7,77 & 85,5 & 74,1 & 5,04 & 0,00203 \\
\hline 15.09 .04 & $06: 00$ & 11,0 & 27,0 & 28,6 & 27,1 & 1,118 & 30,3 & 32,1 & 30,3 & 12,1 & 17,8 & 5,7 & 9,78 & 87,0 & 75,1 & 5,29 & 0,00193 \\
\hline 15.09 .04 & 07:00 & 10,7 & 28,0 & 29,9 & 25,4 & 1,119 & 31,4 & 33,5 & 28,4 & 12,4 & 17,9 & 5,5 & 9,33 & 86,5 & 74,9 & 4,87 & 0,00184 \\
\hline 15.09 .04 & 08:00 & 11,5 & 27,1 & 28,1 & 27,2 & 1,157 & 31,5 & 32,6 & 31,5 & 13,1 & 18,6 & 5,5 & 6,57 & 84,7 & 73,9 & 4,67 & 0,00196 \\
\hline 15.09 .04 & 09:00 & 12,6 & 30,7 & 31,9 & 29,9 & 1,122 & 34,5 & 35,9 & 33,5 & 14,1 & 18,9 & 4,8 & 5,90 & 81,0 & 72,0 & 4,32 & 0,00173 \\
\hline 15.09 .04 & $10: 00$ & 13,3 & 32,8 & 32,8 & 31,1 & 1,059 & 34,8 & 34,8 & 32,9 & 14,4 & 18,9 & 4,5 & 6,17 & 79,8 & 72,0 & 4,40 & 0,00168 \\
\hline 15.09 .04 & $11: 00$ & 19,1 & 37,4 & 34,4 & 33,7 & 1,053 & 39,4 & 36,3 & 35,4 & 16,2 & 20,0 & 3,8 & 3,73 & 72,7 & 68,1 & 2,51 & 0,00161 \\
\hline 15.09 .04 & $12: 00$ & 15,5 & 35,0 & 32,3 & 33,4 & 1,085 & 37,0 & 34,2 & 36,2 & 15,3 & 19,5 & 4,2 & 5,45 & 77,5 & 71,5 & 3,23 & 0,00171 \\
\hline 15.09 .04 & $13: 00$ & 15,2 & 34,4 & 32,0 & 33,5 & 1,069 & 36,3 & 33,7 & 35,8 & 15,1 & 19,4 & 4,3 & 4,20 & 80,0 & 73,3 & 4,83 & 0,00173 \\
\hline 15.09 .04 & $14: 00$ & 20,9 & 35,3 & 34,9 & 34,6 & 1,047 & 37,0 & 36,6 & 36,3 & 16,2 & 20,2 & 4,0 & 4,87 & 70,7 & 65,6 & 3,16 & 0,00159 \\
\hline 15.09 .04 & $15: 00$ & 21,5 & 35,2 & 37,0 & 35,1 & 1,063 & 37,5 & 39,4 & 37,3 & 16,5 & 20,5 & 4,0 & 4,78 & 62,4 & 58,5 & 1,36 & 0,00150 \\
\hline 15.09 .04 & $16: 00$ & 22,9 & 34,1 & 35,8 & 34,2 & 1,031 & 35,3 & 37,0 & 35,3 & 16,6 & 20,7 & 4,1 & 4,41 & 62,7 & 58,7 & 1,48 & 0,00155 \\
\hline 15.09 .04 & $17: 00$ & 19,7 & 34,6 & 22,9 & 33,3 & 0,930 & 32,3 & 21,4 & 31,0 & 16 & 20,2 & 4,2 & 6,10 & 64,8 & 59,3 & 1,65 & 0,00241 \\
\hline
\end{tabular}


Appendix C. Experiment 3 Tab. $26 \mathrm{CO}_{2}$ balance results (14.09.04)

\begin{tabular}{|c|c|c|c|c|c|c|c|c|c|}
\hline Date & Time & $\begin{array}{c}\text { Inside } \mathrm{CO}_{2} \\
\text { concentration }\end{array}$ & $\begin{array}{l}\text { Corrected } \\
\text { for manure }\end{array}$ & $\Delta \mathrm{CO}_{2}$ & $\begin{array}{l}\text { Animal } \\
\text { activity }\end{array}$ & $\begin{array}{c}\mathrm{CO}_{2} \\
\text { productn / } \\
\Delta \mathrm{CO}_{2}\end{array}$ & $\begin{array}{c}\text { Air volume } \\
\text { displacement } \\
\mathrm{m} 3 / \mathrm{h}\end{array}$ & $\mathrm{AER} / \mathrm{h}$ & $\begin{array}{l}\mathrm{AER} / \mathrm{h} \\
\text { with } \\
\text { activity }\end{array}$ \\
\hline 14.09 .04 & $18: 00$ & 869,86 & 835,06 & 485,06 & 1,05 & 381,39 & 193530,08 & 35,52 & 37,17 \\
\hline 14.09 .04 & 19:00 & 974,55 & 935,57 & 585,57 & 1,07 & 315,93 & 163234,95 & 29,42 & 31,36 \\
\hline 14.09 .04 & $20: 00$ & 1074,75 & 1031,76 & 681,76 & 1,09 & 271,36 & 142911,43 & 25,27 & 27,45 \\
\hline 14.09 .04 & 21:00 & 950,05 & 912,05 & 562,05 & 0,95 & 329,15 & 152318,02 & 30,65 & 29,26 \\
\hline 14.09 .04 & 22:00 & 1011,44 & 970,98 & 620,98 & 0,86 & 297,92 & 124611,20 & 27,74 & 23,94 \\
\hline 14.09 .04 & 23:00 & 1022,05 & 981,17 & 631,17 & 0,85 & 293,11 & 120110,51 & 27,30 & 23,07 \\
\hline 15.09 .04 & $0: 00$ & 983,16 & 943,84 & 593,84 & 0,85 & 311,53 & 128171,46 & 29,01 & 24,62 \\
\hline 15.09 .04 & $1: 00$ & 979,54 & 940,36 & 590,36 & 0,85 & 313,37 & 129153,67 & 29,18 & 24,81 \\
\hline 15.09 .04 & $2: 00$ & 979,95 & 940,75 & 590,75 & 0,84 & 313,16 & 127719,92 & 29,16 & 24,53 \\
\hline 15.09 .04 & 3:00 & 962,28 & 923,79 & 573,79 & 0,84 & 322,42 & 130869,63 & 30,02 & 25,14 \\
\hline 15.09 .04 & 4:00 & 946,29 & 908,44 & 558,44 & 0,83 & 331,28 & 133943,38 & 30,85 & 25,73 \\
\hline 15.09 .04 & $5: 00$ & 975,70 & 936,67 & 586,67 & 1,07 & 315,34 & 164295,07 & 29,37 & 31,56 \\
\hline 15.09 .04 & $6: 00$ & 1027,88 & 986,77 & 636,77 & 1,12 & 290,53 & 157538,96 & 27,06 & 30,26 \\
\hline 15.09 .04 & 7:00 & 1072,43 & 1029,53 & 679,53 & 1,12 & 272,25 & 147741,46 & 25,35 & 28,38 \\
\hline 15.09 .04 & 8:00 & 1024,46 & 983,48 & 633,48 & 1,16 & 292,04 & 163833,44 & 27,20 & 31,47 \\
\hline 15.09 .04 & $9: 00$ & 964,89 & 926,29 & 576,29 & 1,12 & 321,02 & 174637,04 & 29,89 & 33,55 \\
\hline 15.09 .04 & 10:00 & 941,84 & 904,17 & 554,17 & 1,06 & 333,83 & 171338,34 & 31,09 & 32,91 \\
\hline 15.09 .04 & 11:00 & 897,75 & 861,84 & 511,84 & 1,05 & 361,44 & 184455,04 & 33,66 & 35,43 \\
\hline 15.09 .04 & $12: 00$ & 902,03 & 865,95 & 515,95 & 1,08 & 358,56 & 188520,25 & 33,39 & 36,21 \\
\hline 15.09 .04 & $13: 00$ & 899,89 & 863,89 & 513,89 & 1,07 & 360,00 & 186495,78 & 33,52 & 35,82 \\
\hline 15.09 .04 & $14: 00$ & 882,50 & 847,20 & 497,20 & 1,05 & 372,09 & 188893,55 & 34,65 & 36,28 \\
\hline 15.09 .04 & 15:00 & 876,16 & 841,11 & 491,11 & 1,06 & 376,70 & 194137,84 & 35,08 & 37,29 \\
\hline 15.09 .04 & $16: 00$ & 888,84 & 853,28 & 503,28 & 1,03 & 367,59 & 183776,13 & 34,23 & 35,30 \\
\hline 15.09 .04 & $17: 00$ & 903,35 & 867,22 & 517,22 & 0,93 & 357,68 & 161200,49 & 33,31 & 30,96 \\
\hline
\end{tabular}


Appendix C. Experiment 3 Tab. 27 Heat balance results (14.09.04)

\begin{tabular}{|c|c|c|c|c|c|c|c|c|c|}
\hline Date & Time & $\begin{array}{l}\text { Total heat } \\
\text { /animal } \\
\left(20^{\circ} \mathrm{C}\right) \mathrm{W}\end{array}$ & $\begin{array}{l}\text { hpu/all } \\
\text { animals }\end{array}$ & $\begin{array}{c}\text { Sensible } \\
\text { heat and } \\
\text { temperature } \\
\text { factors }\end{array}$ & $\begin{array}{c}\text { Sensible } \\
\text { Heat/ all } \\
\text { animals (W) }\end{array}$ & $\begin{array}{l}\text { Heat loss } \\
\text { Thought } \\
\text { Building } \\
\text { (W) }\end{array}$ & $\begin{array}{c}\text { Calculated } \\
\text { AER }(\mathrm{m} 3 / \mathrm{s})\end{array}$ & $\begin{array}{c}\text { Calculated } \\
\text { AER (m3/h) }\end{array}$ & $\begin{array}{c}\text { Heat balance } \\
\text { AER/h }\end{array}$ \\
\hline 14.9 .2004 & $18: 00$ & 16,16 & 484,80 & 496,54 & 240724,55 & $-1422,94$ & 65,22 & 234780,46 & 45,10 \\
\hline 14.9 .2004 & 19:00 & 16,16 & 484,80 & 533,01 & 258402,43 & $-2406,56$ & 41,25 & 148504,14 & 28,53 \\
\hline 14.9 .2004 & $20: 00$ & 16,16 & 484,80 & 541,01 & 262283,00 & $-2602,46$ & 38,69 & 139301,92 & 26,76 \\
\hline 14.9 .2004 & $21: 00$ & 16,16 & 484,80 & 544,55 & 263997,31 & $-1959,62$ & 51,86 & 186678,55 & 35,86 \\
\hline 14.9 .2004 & 22:00 & 16,16 & 484,80 & 544,60 & 264022,47 & $-2099,21$ & 48,39 & 174188,50 & 33,46 \\
\hline 14.9 .2004 & $23: 00$ & 16,16 & 484,80 & 542,18 & 262850,94 & $-2247,61$ & 44,96 & 161868,22 & 31,09 \\
\hline 15.9 .2004 & $00: 00$ & 16,16 & 484,80 & 546,31 & 264852,07 & $-2295,12$ & 44,36 & 159705,84 & 30,68 \\
\hline 15.9 .2004 & $01: 00$ & 16,16 & 484,80 & 553,13 & 268155,41 & $-2421,81$ & 42,55 & 153182,35 & 29,42 \\
\hline 15.9 .2004 & 02:00 & 16,16 & 484,80 & 556,54 & 269810,48 & $-2390,72$ & 43,38 & 156158,79 & 30,00 \\
\hline 15.9 .2004 & 03:00 & 16,16 & 484,80 & 559,38 & 271187,10 & $-2419,46$ & 43,08 & 155081,55 & 29,79 \\
\hline 15.9 .2004 & 04:00 & 16,16 & 484,80 & 563,53 & 273200,90 & $-2464,62$ & 42,60 & 153354,85 & 29,46 \\
\hline 15.9 .2004 & 05:00 & 16,16 & 484,80 & 558,77 & 270889,81 & $-2762,00$ & 37,65 & 135525,27 & 26,03 \\
\hline 15.9 .2004 & 06:00 & 16,16 & 484,80 & 564,02 & 273435,05 & $-2688,10$ & 39,06 & 140611,50 & 27,01 \\
\hline 15.9 .2004 & 07:00 & 16,16 & 484,80 & 562,29 & 272596,49 & $-2587,21$ & 40,47 & 145696,38 & 27,99 \\
\hline 15.9 .2004 & 08:00 & 16,16 & 484,80 & 547,50 & 265429,38 & $-2596,60$ & 39,25 & 141311,38 & 27,14 \\
\hline 15.9 .2004 & $09: 00$ & 16,16 & 484,80 & 541,01 & 262283,00 & $-2274,00$ & 44,34 & 159624,55 & 30,66 \\
\hline 15.9.2004 & $10: 00$ & 16,16 & 484,80 & 541,33 & 262434,52 & $-2126,19$ & 47,48 & 170917,75 & 32,83 \\
\hline 15.9 .2004 & $11: 00$ & 16,16 & 484,80 & 518,45 & 251346,25 & $-1790,69$ & 54,04 & 194557,31 & 37,37 \\
\hline 15.9 .2004 & $12: 00$ & 16,16 & 484,80 & 530,06 & 256974,01 & $-1956,10$ & 50,56 & 182004,43 & 34,96 \\
\hline 15.9 .2004 & $13: 00$ & 16,16 & 484,80 & 532,54 & 258173,16 & $-1994,81$ & 49,80 & 179284,57 & 34,44 \\
\hline 15.9 .2004 & $14: 00$ & 16,16 & 484,80 & 514,29 & 249325,84 & $-1882,19$ & 50,98 & 183532,81 & 35,25 \\
\hline 15.9 .2004 & 15:00 & 16,16 & 484,80 & 508,57 & 246553,63 & $-1866,36$ & 50,84 & 183028,33 & 35,16 \\
\hline 15.9 .2004 & $16: 00$ & 16,16 & 484,80 & 504,52 & 244591,96 & $-1907,42$ & 49,34 & 177622,80 & 34,12 \\
\hline 15.9 .2004 & $17: 00$ & 16,16 & 484,80 & 514,45 & 249403,70 & 232,85 & $-415,74$ & $-1496665,68$ & $-287,49$ \\
\hline
\end{tabular}


Appendix C. Experiment 3 Tab. 28a Moisture balance results (14.09.04)

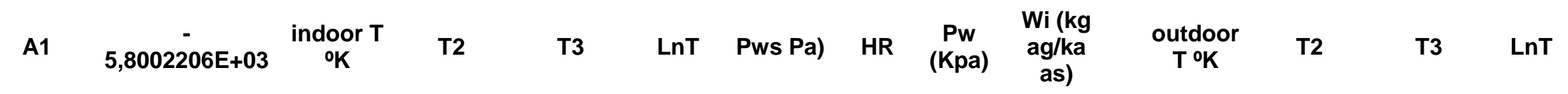

\begin{tabular}{|c|c|c|c|c|c|c|c|c|c|c|c|c|c|}
\hline A2 & 1,39 & 294,18 & 86543,34 & 25459537,09 & 5,68 & 2492,64 & 0,58 & 1,44 & 0,01 & 291,15 & 84768,32 & 24680297,10 & 5,67 \\
\hline A3 & $-0,05$ & 292,48 & 85543,82 & 25019749,31 & 5,68 & 2243,31 & 0,66 & 1,49 & 0,01 & 287,35 & 82570,02 & 23726495,97 & 5,66 \\
\hline A4 & 0,00 & 292,10 & 85320,22 & 24921716,10 & 5,68 & 2190,43 & 0,68 & 1,49 & 0,01 & 286,55 & 82110,90 & 23528879,11 & 5,66 \\
\hline A5 & 0,00 & 291,93 & 85220,94 & 24878228,10 & 5,68 & 2167,29 & 0,65 & 1,40 & 0,01 & 287,75 & 82800,06 & 23825717,98 & 5,66 \\
\hline A6 & 0,00 & 291,92 & 85219,48 & 24877588,95 & 5,68 & 2166,95 & 0,67 & 1,45 & 0,01 & 287,45 & 82627,50 & 23751275,59 & 5,66 \\
\hline \multirow[t]{2}{*}{ A7 } & 6,55 & 292,04 & 85287,36 & 24907321,08 & 5,68 & 2182,75 & 0,67 & 1,47 & 0,01 & 287,25 & 82512,56 & 23701733,58 & 5,66 \\
\hline & & 291,84 & 85171,32 & 24856503,09 & 5,68 & 2155,79 & 0,71 & 1,52 & 0,01 & 286,95 & 82340,30 & 23627549,80 & 5,66 \\
\hline patm $(\mathrm{Pa})$ & 101325,00 & 291,51 & 84978,81 & 24772278,80 & 5,68 & 2111,68 & 0,72 & 1,52 & 0,01 & 286,35 & 81996,32 & 23479646,95 & 5,66 \\
\hline \multirow[t]{16}{*}{$\mathrm{Ra}$} & 287,06 & 291,35 & 84881,91 & 24729919,78 & 5,67 & 2089,75 & 0,73 & 1,52 & 0,01 & 286,25 & 81939,06 & 23455056,64 & 5,66 \\
\hline & & 291,21 & 84801,08 & 24694604,51 & 5,67 & 2071,61 & 0,73 & 1,51 & 0,01 & 286,05 & 81824,60 & 23405927,55 & 5,66 \\
\hline & & 291,00 & 84682,46 & 24642806,11 & 5,67 & 2045,21 & 0,73 & 1,50 & 0,01 & 285,75 & 81653,06 & 23332362,61 & 5,66 \\
\hline & & 291,24 & 84818,55 & 24702237,40 & 5,67 & 2075,52 & 0,74 & 1,54 & 0,01 & 285,35 & 81424,62 & 23234516,03 & 5,65 \\
\hline & & 290,98 & 84668,63 & 24636772,98 & 5,67 & 2042,16 & 0,75 & 1,53 & 0,01 & 285,25 & 81367,56 & 23210097,20 & 5,65 \\
\hline & & 291,06 & 84718,11 & 24658369,79 & 5,67 & 2053,12 & 0,75 & 1,54 & 0,01 & 285,55 & 81538,80 & 23283405,05 & 5,65 \\
\hline & & 291,78 & 85137,76 & 24841813,94 & 5,68 & 2148,05 & 0,74 & 1,59 & 0,01 & 286,25 & 81939,06 & 23455056,64 & 5,66 \\
\hline & & 292,10 & 85320,22 & 24921716,10 & 5,68 & 2190,43 & 0,72 & 1,58 & 0,01 & 287,25 & 82512,56 & 23701733,58 & 5,66 \\
\hline & & 292,08 & 85311,46 & 24917876,88 & 5,68 & 2188,38 & 0,72 & 1,58 & 0,01 & 287,55 & 82685,00 & 23776072,47 & 5,66 \\
\hline & & 293,17 & 85946,45 & 25196598,49 & 5,68 & 2341,16 & 0,68 & 1,59 & 0,01 & 289,35 & 83723,42 & 24225372,30 & 5,67 \\
\hline & & 292,62 & 85625,73 & 25055694,91 & 5,68 & 2262,94 & 0,72 & 1,62 & 0,01 & 288,45 & 83203,40 & 24000021,45 & 5,66 \\
\hline & & 292,50 & 85556,98 & 25025523,96 & 5,68 & 2246,45 & 0,73 & 1,65 & 0,01 & 288,25 & 83088,06 & 23950134,02 & 5,66 \\
\hline & & 293,36 & 86060,82 & 25246910,61 & 5,68 & 2369,58 & 0,66 & 1,55 & 0,01 & 289,35 & 83723,42 & 24225372,30 & 5,67 \\
\hline & & 293,63 & 86217,11 & 25315714,10 & 5,68 & 2408,88 & 0,59 & 1,41 & 0,01 & 289,65 & 83897,12 & 24300801,53 & 5,67 \\
\hline & & 293,82 & 86327,25 & 25364242,20 & 5,68 & 2436,90 & 0,59 & 1,43 & 0,01 & 289,75 & 83955,06 & 24325979,36 & 5,67 \\
\hline & & 293,35 & 86056,42 & 25244974,29 & 5,68 & 2368,49 & 0,59 & 1,40 & 0,01 & 293,85 & 86347,82 & 25373307,64 & 5,68 \\
\hline
\end{tabular}


Appendix C. Experiment 3 Tab. 28b Moisture balance results (14.09.04)

\begin{tabular}{|c|c|c|c|c|c|c|c|c|c|c|c|c|}
\hline $\begin{array}{c}\text { Pws } \\
\text { Pa) }\end{array}$ & HR & $\begin{array}{c}\mathrm{Pw} \\
(\mathrm{Kpa})\end{array}$ & $\begin{array}{c}\text { Wo (kg } \\
\text { ag/ka as) }\end{array}$ & $\begin{array}{c}\text { Total } \\
\text { heat } \\
\text { /hpu } \\
\text { (eqn. 26) }\end{array}$ & $\begin{array}{c}\text { Sensible } \\
\text { Heat } \\
\text { /animal }\end{array}$ & $\begin{array}{l}\text { Latent } \\
\text { Heat } \\
\text { /animal } \\
\text { (W) }\end{array}$ & $\begin{array}{c}\text { Latent } \\
\text { Heat } \\
\text { /animal } \\
\text { (Kg } \\
\text { water/s) }\end{array}$ & $\begin{array}{c}\text { Latent } \\
\text { Heat } / 30 \\
000 \\
\text { animal } \\
(\mathrm{Kg} \\
\text { water/s) }\end{array}$ & $\begin{array}{c}\text { AER Kg } \\
\text { air/s }\end{array}$ & $\begin{array}{l}\text { AER } \\
\mathrm{m} 3 / \mathrm{s}\end{array}$ & $\begin{array}{l}\text { AER } \\
\mathrm{m} 3 / \mathrm{h}\end{array}$ & AER /hr \\
\hline 2064,29 & 0,59 & 1,22 & 0,01 & 979,35 & 496,54 & 482,81 & 0,00 & 0,10 & 67,44 & 55,73 & 200642,42 & 38,54 \\
\hline 1619,54 & 0,75 & 1,22 & 0,01 & 1013,43 & 533,01 & 480,42 & 0,00 & 0,10 & 56,38 & 46,60 & 167744,24 & 32,22 \\
\hline 1537,46 & 0,77 & 1,19 & 0,01 & 1021,08 & 541,01 & 480,06 & 0,00 & 0,10 & 50,31 & 41,58 & 149691,15 & 28,75 \\
\hline 1662,01 & 0,69 & 1,15 & 0,01 & 1024,48 & 544,55 & 479,93 & 0,00 & 0,10 & 61,16 & 50,54 & 181954,90 & 34,95 \\
\hline 1630,07 & 0,72 & 1,17 & 0,01 & 1024,53 & 544,60 & 479,92 & 0,00 & 0,10 & 54,23 & 44,81 & 161330,89 & 30,99 \\
\hline 1609,08 & 0,74 & 1,19 & 0,01 & 1022,20 & 542,18 & 480,02 & 0,00 & 0,10 & 54,95 & 45,42 & 163498,16 & 31,41 \\
\hline 1578,03 & 0,78 & 1,23 & 0,01 & 1026,18 & 546,31 & 479,86 & 0,00 & 0,10 & 53,32 & 44,06 & 158631,00 & 30,47 \\
\hline 1517,52 & 0,82 & 1,24 & 0,01 & 1032,78 & 553,13 & 479,65 & 0,00 & 0,10 & 53,90 & 44,55 & 160369,08 & 30,80 \\
\hline 1507,64 & 0,83 & 1,25 & 0,01 & 1036,10 & 556,54 & 479,56 & 0,00 & 0,10 & 55,44 & 45,82 & 164949,98 & 31,68 \\
\hline 1488,04 & 0,84 & 1,25 & 0,01 & 1038,88 & 559,38 & 479,50 & 0,00 & 0,10 & 57,55 & 47,56 & 171227,88 & 32,89 \\
\hline 1459,06 & 0,84 & 1,23 & 0,01 & 1042,95 & 563,53 & 479,42 & 0,00 & 0,10 & 55,73 & 46,06 & 165815,23 & 31,85 \\
\hline 1421,20 & 0,86 & 1,22 & 0,01 & 1038,28 & 558,77 & 479,51 & 0,00 & 0,10 & 47,44 & 39,20 & 141129,69 & 27,11 \\
\hline 1411,87 & 0,87 & 1,23 & 0,01 & 1043,43 & 564,02 & 479,41 & 0,00 & 0,10 & 50,03 & 41,35 & 148856,19 & 28,59 \\
\hline 1440,02 & 0,87 & 1,25 & 0,01 & 1041,73 & 562,29 & 479,44 & 0,00 & 0,10 & 52,32 & 43,24 & 155671,14 & 29,90 \\
\hline 1507,64 & 0,85 & 1,28 & 0,01 & 1027,33 & 547,50 & 479,82 & 0,00 & 0,10 & 49,16 & 40,63 & 146269,16 & 28,10 \\
\hline 1609,08 & 0,81 & 1,30 & 0,01 & 1021,08 & 541,01 & 480,06 & 0,00 & 0,10 & 55,85 & 46,16 & 166177,09 & 31,92 \\
\hline 1640,65 & 0,80 & 1,31 & 0,01 & 1021,38 & 541,33 & 480,05 & 0,00 & 0,10 & 57,39 & 47,43 & 170742,41 & 32,80 \\
\hline 1841,81 & 0,73 & 1,34 & 0,01 & 999,68 & 518,45 & 481,22 & 0,00 & 0,10 & 60,19 & 49,74 & 179079,70 & 34,40 \\
\hline 1738,68 & 0,78 & 1,35 & 0,01 & 1010,63 & 530,06 & 480,56 & 0,00 & 0,10 & 56,50 & 46,69 & 168091,71 & 32,29 \\
\hline 1716,46 & 0,80 & 1,37 & 0,01 & 1012,98 & 532,54 & 480,44 & 0,00 & 0,10 & 55,99 & 46,28 & 166590,34 & 32,00 \\
\hline 1841,81 & 0,71 & 1,30 & 0,01 & 995,78 & 514,29 & 481,49 & 0,00 & 0,10 & 61,06 & 50,46 & 181666,37 & 34,90 \\
\hline 1877,36 & 0,62 & 1,17 & 0,01 & 990,45 & 508,57 & 481,88 & 0,00 & 0,10 & 64,69 & 53,46 & 192466,62 & 36,97 \\
\hline 1889,34 & 0,63 & 1,18 & 0,01 & 986,70 & 504,52 & 482,18 & 0,00 & 0,10 & 62,67 & 51,79 & 186444,37 & 35,81 \\
\hline 2442,16 & 0,42 & 1,02 & 0,01 & 995,93 & 514,45 & 481,48 & 0,00 & 0,10 & 40,14 & 33,17 & 119417,46 & 22,94 \\
\hline
\end{tabular}




\section{Ehenwörtliche Erklärung}

Ich erkläre ehenwörtlich, dass ich die der Fakultät für Agrarwissenschaften der GeorgAugust-Universität Göttingen zur Promotion eingereichte Arbeit mit dem Titel "Calculating air exchange rates from broiler livestock houses " am Institut für Tierhygiene, Tierschutz und Nutztierethologie der Tierärztlichen Hochschule unter der Leitung von Prof. Hartung ohne sonstige Hilfe selbst durchgefüht und bei der Abfassung der Arbeit keine anderen als die in der Dissertation angegebenen Hilfsmittel benutzt habe. Ich habe bislang an keiner anderen in- oder ausländischen Fakultät für Agrarwissenschaften ein Gesuch um Zulassung zur Promotion, noch die vorliegende oder eine andere Arbeit als Dissertation eingereicht.

Hannover, den 